Portland State University

PDXScholar

Summer 8-13-2015

\title{
A Queer Liberation Movement? A Qualitative Content Analysis of Queer Liberation Organizations, Investigating Whether They are Building a Separate Social Movement
}

Joseph Nicholas DeFilippis

Portland State University

Follow this and additional works at: https://pdxscholar.library.pdx.edu/open_access_etds

Part of the Civil Rights and Discrimination Commons, Lesbian, Gay, Bisexual, and Transgender Studies Commons, and the Social Work Commons

Let us know how access to this document benefits you.

\section{Recommended Citation}

DeFilippis, Joseph Nicholas, "A Queer Liberation Movement? A Qualitative Content Analysis of Queer Liberation Organizations, Investigating Whether They are Building a Separate Social Movement" (2015). Dissertations and Theses. Paper 2466.

https://doi.org/10.15760/etd.2464

This Dissertation is brought to you for free and open access. It has been accepted for inclusion in Dissertations and Theses by an authorized administrator of PDXScholar. Please contact us if we can make this document more accessible: pdxscholar@pdx.edu. 


\section{A Queer Liberation Movement?}

\section{A Qualitative Content Analysis of Queer Liberation Organizations,}

Investigating Whether They are Building a Separate Social Movement

by

Joseph Nicholas DeFilippis

A dissertation submitted in partial fulfillment of the requirements for the degree of

Doctor of Philosophy

in

Social Work and Social Research

Dissertation Committee:

Ben Anderson-Nathe, Chair

Laura Nissen

Stephanie Wahab

Sally McWilliams

Portland State University

2015 
(C) 2015 Joseph Nicholas DeFilippis 


\begin{abstract}
In the last forty years, U.S. national and statewide LGBT organizations, in pursuit of "equality" through a limited and focused agenda, have made remarkably swift progress moving that agenda forward. However, their agenda has been frequently criticized as prioritizing the interests of White, middle-class gay men and lesbians and ignoring the needs of other LGBT people. In their shadows have emerged numerous grassroots organizations led by queer people of color, transgender people, and low-income LGBT people. These "queer liberation" groups have often been viewed as the left wing of the GRM, but have not been extensively studied. My research investigated how these grassroots liberation organizations can be understood in relation to the equality movement, and whether they actually comprise a separate movement operating alongside, but in tension with, the mainstream gay rights movement.

This research used a qualitative content analysis, grounded in black feminism's framework of intersectionality, queer theory, and social movement theories, to examine eight queer liberation organizations. Data streams included interviews with staff at each organization, organizational videos from each group, and the organizations' mission statements. The study used deductive content analysis, informed by a predetermined categorization matrix drawn from social movement theories, and also featured inductive analysis to expand those categories throughout the analysis.

This study's findings indicate that a new social movement - distinct from the mainstream equality organizations - does exist. Using criteria informed by leading social movement theories, findings demonstrate that these organizations cannot be understood
\end{abstract}


as part of the mainstream equality movement but must be considered a separate social movement. This "queer liberation movement" has constituents, goals, strategies, and structures that differ sharply from the mainstream equality organizations. This new movement prioritizes queer people in multiple subordinated identity categories, is concerned with rebuilding institutions and structures, rather than with achieving access to them, and is grounded more in "liberation" or "justice" frameworks than "equality." This new movement does not share the equality organizations' priorities (e.g., marriage) and, instead, pursues a different agenda, include challenging the criminal justice and immigration systems, and strengthening the social safety net.

Additionally, the study found that this new movement complicates existing social movement theory. For decades, social movement scholars have documented how the redistributive agenda of the early 20th century class-based social movements has been replaced by the demands for access and recognition put forward by the identity-based movements of the 1960s New Left. While the mainstream equality movement can clearly be characterized as an identity-based social movement, the same is not true of the groups in this study. This queer liberation movement, although centered on identity claims, has goals that are redistributive as well as recognition-based.

While the emergence of this distinct social movement is significant on its own, of equal significance is the fact that it represents a new post-structuralist model of social movement. This study presents a "four-domain" framework to explain how this movement exists simultaneously inside and outside of other social movements, as a bridge between them, and as its own movement. Implications for research, practice, and policy in social work and allied fields are presented. 


\section{Dedication}

For my parents, Dr. Daisy Cocco DeFilippis and Nunzio DeFilippis, who have always shown me the importance of thinking critically but giving generously,

and for Jay Toole, whose life and work changed mine forever. 


\section{Acknowledgements}

I am deeply grateful for the many people who went on this journey with me. This project is the product of the activism, thinking, support, guidance, love, and scholarship of many people.

I want to acknowledge all of the activists that generously donated their time for this project. My research focused on the work of eight amazing organizations: Affinity Community Services, allgo, the Audre Lorde Project, Center for Artistic Revolution, the National Queer Asian Pacific Islander Alliance, Queers for Economic Justice, Southerners on New Ground, and Sylvia Rivera Law Project. For years, the activists at these organizations have been doing some of the most inspiring work in the country. My interviews with staff members Ben deGuzman, Kenyon Farrow, Reina Gossett, Paulina Helm-Hernandez, Kim L. Hunt, Cara Page, Rose Pulliam, and Randi Romo provided the foundation of this project and taught me so much. My interviews with Katherine Acey, Terry Boggis, Bishop Tonyia Rawls, and Lisa Emina Weiner-Mahfuz informed my thinking a great deal even though much of those interviews ended up not fitting into the parameters of this project. In addition, I drew heavily from the words of other activists at these organizations, notably Caitlin Breedlove, Trishala Deb, Amber Hollibaugh, and Dean Spade. The wisdom and insights I gained from these sixteen activists during this research was invaluable, and it has been a gift to be able to spend the past year thinking about their words. It is not hyperbole to say that the world is a much better place because of them.

Thank you to my dissertation committee: Dr. Ben Anderson-Nathe, Dr. Laura Nissen, Dr. Stephanie Wahab, and Dr. Sally McWilliams. Their feedback and guidance 
made this work much better than it would otherwise have been, and their curiousity and excitement often kept me going, even when they did not necessarily know I needed that motivation. I started this doctoral program with an attitude towards research that was, at best, skeptical and, at worst, disdainful. It is because of this committee that I can imagine myself as a researcher. My committee chair, Ben, in particular, deserves special thanks for the countless versions of each chapter he read and for which he provided feedback. In addition, he has spent hundreds of hours in meetings with me over the past several years, offering suggestions and guidance, and letting me fight with him about each of them. I will be eternally grateful for his patience and generousity.

I am grateful to the CSWE Minority Fellows Program for providing me with tremendous financial support and professional development. I must also thank Portland State University's School of Social Work for its financial support and for providing me with the opportunity to teach hundreds of interesting, dedicated, and irrepressible students.

I am blessed to have a Portland community to whom I am endebted forever: the Anderson-Nathe family (Ben, Margaret, Michael, and Sophie), Abby Bandurraga, Kevin Cherry, the Cunningham family (Greg, Josh, Kim, Merrit, and Miranda), Thuan Duong (and her wonderful children Pippin \& Gus Houser), T.J. Ford, Roberta Hunte, Sandy Leotti, and Gitarani Mehrotra. They are my Portland family and they have fed me emotionally and intellectually. (And they have also fed me literally - providing me with countless homemade dinners, take-out meals, drinks, and pies.) I am so very grateful for how they opened their homes and hearts to me these past five years, and how supportive they have been about my dissertation, providing me with ideas, feedback, advice, 
transcription, editing, logistical support, encouragement, and forgiveness when I disappeared for months at a time. I love them all.

I am also grateful to my QEJ family. Queers for Economic Justice was a magical organization, and the hundreds of brilliant people who worked there over the years as staff, board members, volunteers, consultants, and interns have indelibly shaped my politics and my life. From them I learned how to pursue a long-term vision of radical transformation even while engaging in short-term reform. I am also grateful to them for demonstrating to me how to disagree with colleagues respectfully, and how not to give up on people when they make mistakes. These traits are often lacking in activism, but the people at QEJ forgave me my mistakes over and over again. In particular, I want to thank Ricky Blum, Terry Boggis, Ann Cammett, Aine Duggan, Kenyon Farrow, Mary Guyton, Monroe France, Félix Eduardo Gardón, Reina Gossett, Amber Hollibaugh, Richard Kim, Maureen Lane, Ola Osaze, Ignacio G. Rivera, Jessica Stern, and Jay Toole. With them I did the most important work of my life.

I have had the great privilege to work with five scholar-activists whose work has deeply influenced my thinking over the years, and who have shown me how, if done right, life in the academy can be a form of activism: Dr. Mimi Abramovitz, Dr. John D'Emilio, Dr. Martin Duberman, Dr. Lisa Duggan, and Professor Nancy Polikoff. In addition, four people have served as mentors to me at different points in my life and have influenced my career: Tom Hill, Maria Mottola, Dr. Hiram Perez, and Achebe Powell. I am fortunate to have been guided by them during the periods when I needed it most. 
I am grateful to have been supported for many years by dear old friends outside of my work life who I will always love and who, no matter how much time passes between visits, always replenish me: Rachel Baum, Rodrigo Brandão, Kerri Green Cesene, Kate Chittenden, Sunder Ganglani, Greg Kravitz, Kara Post-Kennedy, and Karen Wexler. And finally, my deepest gratitude and love to my family: Daisy Cocco DeFilippis, Alexa DeFilippis, James DeFilippis, Marley DeFilippis, Nunzio DeFilippis, Sr., Nunzio Andrew DeFilippis, Jennifer Koteles, David Koteles, Marv Lazar, Norma Lazar, Allison Lucas, C.J. Trentacosta, Joe Trentacosta, Lilly Trentacosta, and Christina Weir. Their kind hearts, keen minds, and unconditional love lift me up. "Thank you" is an insufficient phrase for acknowledging all they have given me. 


\section{Table of Contents}

$\begin{array}{lr}\text { Abstract } & \text { i } \\ \text { Dedication } & \text { iii } \\ \text { Acknowledgements } & \text { iv } \\ \text { List of Tables } & \text { x } \\ \text { List of Figures } & \text { xi }\end{array}$

Chapter 1: Introduction $\quad 1$

Background 1

Reasons for this Study $\quad 5$

Overview of this Dissertation $\quad 7$

Some Preliminary Explanatory Notes $\quad 12$

$\begin{array}{ll}\text { Chapter 2: } \text { Theoretical Frameworks } & 15\end{array}$

Critical Theories and Frameworks $\quad 15$

Social Movement Theories $\quad 26$

$\begin{array}{ll}\text { Conclusion } & 51\end{array}$

Chapter 3: A Brief History of the Gay Rights Movement In the United States 54

Before The Gay Rights Movement $\quad 55$

$\begin{array}{lr}\text { The Start of A Movement } & 67\end{array}$

$\begin{array}{lr}\text { Conclusion } & 109\end{array}$

Chapter 4: The Twenty-First Century $\quad 111$

Continued Progress for the Mainstream Gay Rights Agenda 111

Needs and Obstacles not Addressed by the Gay Agenda 113

$\begin{array}{ll}\text { A Fractured Movement } & 141\end{array}$

A New Social Movement? 165

$\begin{array}{ll}\text { Conclusion } & 173\end{array}$

Chapter 5: Methods and Methodology $\quad 174$

$\begin{array}{ll}\text { Overview } & 174\end{array}$

$\begin{array}{ll}\text { Epistemological Stance } & 174\end{array}$

$\begin{array}{ll}\text { Methodology } & 176\end{array}$

$\begin{array}{ll}\text { Methods } & 178\end{array}$

$\begin{array}{ll}\text { Evaluation of Trustworthiness } & 210\end{array}$

$\begin{array}{ll}\text { Ethical Considerations } & 221\end{array}$

Chapter 6: Research Question One $\quad 224$

$\begin{array}{ll}\text { Introduction and Overview } & 224\end{array}$

$\begin{array}{ll}\text { Targets of Mobilization and Targets of Benefits } & 227\end{array}$

$\begin{array}{ll}\text { Targets of Influence } & 247\end{array}$ 
Chapter 7: Research Question Two $\quad 303$

$\begin{array}{ll}\text { Introduction and Overview } & 303\end{array}$

Common Purposes and Collective Identity $\quad 304$

Conclusion: Common Purposes and Collective Identity 342

Collective Action and Organization $\quad 342$

Discussion 361

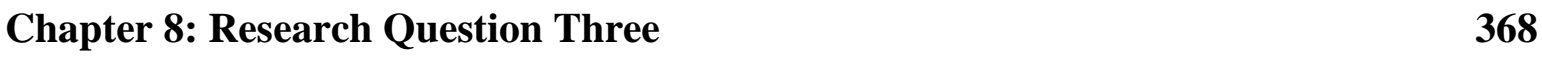

Introduction and Overview 368

Significant Existing Social Movement Theories $\quad 369$

$\begin{array}{ll}\text { Another Politics } & 389\end{array}$

$\begin{array}{ll}\text { Conclusion } & 440\end{array}$

Chapter 9: Deconstructing and Reconstructing Identity Categories 443

Introduction $\quad 443$

Reliance on Identity $\quad 445$

Deconstructing Identity 455

Chapter 10: Desconstructing and Reconstructing Social Movement Models 481

Introduction $\quad 481$

Domain 1: Existing Outside Other Social Movements 486

Domain 2: Existing Inside, Between, and Among Other Social Movements 488

Domain 3: Existing as a Bridge yhat Connects Multiple Social Movements 495

Domain 4: Existing as Its Own Social Movement 499

Conclusion $\quad 500$

Chapter 11: Contributions, Limitations, and Further Research 502

Limitations and Future Research $\quad 502$

Other Future Research $\quad 510$

Contributions and Scholarship from this Dissertation 513

Implications for Social Work $\quad 519$

$\begin{array}{ll}\text { References } & 526\end{array}$

Appendices $\quad \mathbf{5 7 0}$

Appendix A: Defining a Social Movement $\quad 570$

Appendix B: My Working Definition of a Social Movement 572

Appendix C: Major Social Movement Theories $\quad 573$

Appendix D: Intersectional Organizations Doing Multi-Issue Work $\quad 575$

Appendix E: Organizations that Were Asked to Participate in this Study $\quad 578$

Appendix F: Targets of the Mainstream Gay Rights Movement 581

Appendix G: Categorization Matrix $\quad 582$

Appendix H: Interview Questions $\quad 583$ 


\section{List of Tables}

Table 5.1: List of Organizations Included in Study 183

Table 5.2: Data Sources for Each Organization 185

Table 5.3: Categorization Matrix for Research Question $1 \quad 196$

Table 5.4: Targets of the Mainstream Gay Rights Movement 197

Table 5.5: Categorization Matrix for Research Question $2 \quad 200$

Table 5.6: Categorization Matrix for Research Question $3 \quad 202$

Table 5.7: Full Categorization Matrix for All Three Research Questions 203

Table 6.1: Targets of the GRM 226

Table 6.2: Overview of Each Organization's Targets of Benefits and Mobilization 230

Table 6.3: Comparison of Targets of Influence 249

Table 6.4: Values and Goals $\quad 251$

Table 6.5: Targets of Influence $\quad 252$

Table 6.6: Overview of Comparison of All Targets 283

Table 8.1: The four "antis" of the QLM's politics, as delineated using Dixon (2014) 394

Table 8.2: QLM's Targets of Influence, Delineated using Dixon and Fraser 408

Table 10.1: Coalitions/Alliances Across Movements In Which the QLM Participates 496 


\section{List of Figures}

Figure 5.1: Relationships Among Theoretical Frameworks and Research Design

194

Figure 5.2: Answering Question 1

207

Figure 5.3: Analysis for Question 1

208

Figure 10.1: Four domains of the Queer Liberation Movement 


\section{Chapter 1: Introduction}

\section{Background}

In the last forty years, the gay rights movement in the United States has employed a laser-sharp focus on a limited set of agenda items and has made remarkably swift progress in moving that agenda forward. During this period, however, there have also been numerous critiques of the gay rights movement (Applied Research Center, 2012; Cohen, 1999; D’Emilio, 2012; Duggan, 2003; Gore, Jones, Kang, 2001; Hutchinson, 1999; McMichael \& Wallace, 1999; Richardson, 1999; Vaid, 2012). For the past twenty years, the national LGBT organizations and the statewide equality organizations have been frequently characterized as having an agenda set by White, middle-class gay men and lesbians and ignoring the needs of other LGBT people (Arkles, Gehi, \& Redfield, 2010; Auchmuty, 2004; Bailey, Kandaswamy, \& Richardson, 2004; Burns, 2012; Carter, 1999; Cha' vez, 2010; Cohen, 1997, 1999; Conrad, 2010; D’Emilio, 2012; DasGupta, 2012; DeFilippis, 2012; Duggan, 2003; Duggan, 2012; Eng, D. 2010; Farrow, 2012; Farrow, 2005; Hutchinson, 1999; Kandaswamy, 2008; Kohn, 2001; Mananzala \& Spade, 2008; McMichael \& Wallace, 1999; Mecca, 2004; Mogul, Ritchie, \& Whitlock, 2011; Nair, 2008, 2009, 2013; Nero, 2007; Richardson, 1999; Robson, 1997; Rosenblum, 1994;

Schulman, 2012; Seidman, 1993; Shepard, 2002; Smith, B. 1993; Vaid, 2012; Warner, 1993; Weiner-Mahfuz, 2010; Whitlock \& Kamel, 2001).

The primary strategies of these organizations have been political lobbying, judicial challenges, and media representation (D'Emilio, 2009, 2012; Vaid, 1995, 2012). Their agenda has been primarily focused on achieving equal rights under the law and 
obtaining access to American social institutions and legal structures. Except for the issue of inclusion and access, these organizations do not question the fairness, goals, effectiveness or social impact of these institutions and structures. These organizations are not interested in dismantling or even changing these institutions and structures - they merely seek LGBT admission into them. For the rest of this dissertation, I will refer to these organizations as the "mainstream gay rights movement" (or GRM). The GRM has been extremely successful in communicating its goals to the general public. The average American correctly understands that in recent decades the GRM has, under the framework of equality, made its major priorities the achievement of marriage equality, access to the military, hate crime legislation, anti-discrimination laws, and protecting LGBT youth.

The critiques cited above, coming from activists and scholars alike, have led to increased demands for an intersectional analysis and multi-issue organizing that incorporates issues of race, class, and economics with gender and sexual orientation. The mainstream gay rights movement has largely ignored these demands.

In response, numerous grassroots organizations have sprung up across the country, engaging in intersectional, multi-issue work (Applied Research Center, 2010; Applied Research Center, 2012; Funders for Lesbian and Gay Issues, 2005; HoSang, 2006; McMichael \& Wallace, 1999) and led by queer people of color (DasGupta, 2012; Gore, Jones, Kang, 2001; Mananzala, 2012; Pulliam \& Mott, 2010; Shepard, 2004; Vaid, 2012), transgender people (Currah, 2008; Donahue, 2011; Gossett, 2011; Mananzala \& Spade, 2008; Stern, 2012), and low-income LGBT people (Billies, Johnson, Murungi, \& Pugh, 2009; Duberman, 2009; Jones-Yelvington, 2008; Queers for Economic Justice, 2008). 
Throughout this paper, I borrow from the language of Southerners On New Ground (2012), and refer to these organizations as queer liberation groups.

These queer liberation groups have constituents, goals, strategies, and structures that are very different from the national gay rights organizations or the statewide equality organizations. Their primary strategies are coalition building, leadership development, legal advocacy, and community organizing. They view American social institutions and legal structures through a critical lens and are more concerned with rebuilding these institutions and structures than with achieving access to them. While the gay rights movement is grounded in the value of "equality," these queer liberation groups are rooted in "liberation" or "justice" frameworks (Jones-Yelvington, 2008; Mahfuz \& Farrow, 2012; Wyllie de Echeverria, n.d.). They appear to embrace politics of redistribution, rather than the gay rights movement's identity politics of recognition. These other organizations are largely unknown to the general public.

This research project was not primarily concerned with documenting whether there are differences between the "equality" organizations and the "liberation" organizations, or how those groups have functioned in the past in relation to each other. The question of whether there are differences has been answered many times (including in the research cited above). The question of how they function together has also been explored in numerous places (D’Emilio, 2012; Duggan, 2003; Egan \& Sherrill, 2005; Harris, 2006; McMichael \& Wallace, 1999; Smith, 1999; Vaid, 2012; and many others). Within activist communities, the gay media, funders' circles, and academia, there is a long-standing understanding of the different roles of the equality organizations and the 
liberation organizations. The liberation organizations have usually been viewed as the left wing of the GRM. This is well established already.

My research investigated whether these grassroots liberation organizations actually comprise a separate movement (a "queer liberation movement") operating alongside, but in tension with, the mainstream gay rights movement, and if they do not, is the current understanding ("the left-wing of the mainstream LGBT movement") accurate, or is there some other way to understand them?

Comparisons can be made to other social movements, such as the tensions between the mainstream Civil Rights movement and the Black Power movement. Many view the Black Power movement as a separate movement from the Civil Rights movement (Van Deburg, 1992). Others view it as a part of the Civil Rights movement the radical part, standing in stark contrast to groups like the NAACP which were the more conservative mainstream part of the movement (Blumberg, 2009; McAdam, 1982). Where there is agreement is on the fact that due to the Black Power movement's differing goals and tactics, the Civil Rights movement was forced to confront challenges to the way it was operating.

Among social movements, this dynamic is not uncommon. Any social movement is subject to disagreement (over values and strategies), conflict, fracture, and competition for resources (Mansbridge, 2009; Snow \& Soule, 2010). Whether these conflicts lead to permanent splits or to reintegration into a multi-faceted movement is the larger question that provides context for my research. "Threats to integrity, focus, and diversity have to be negotiated/navigated along the way. Do movements begin, develop, fracture into parts, resist 'single voices,' etc. and then rejoin?" (Laura Nissen, Personal Communication, 
August 30, 2013). As I investigated these queer liberation organizations, I considered whether these groups are the left-wing of the gay rights movement, or if they have split off to become a separate movement, or some combination of those two frameworks, or something else altogether.

While activists, funders, scholars and the gay media have arrived at their understanding (the "left-wing of the movement" framework) to date, there has been no systematic analysis of this issue in research. I set out to explore how social movement theory can help understand these liberation organizations. Most social movement theorists have focused on the equality organizations and I wanted to know how their theories applied to the liberation organizations.

In order to understand these issues, I studied eight of those queer liberation organizations, nationally recognized for their movement-building work. For each of these organizations I investigated three specific questions: (1) What does analyzing these organizations through social movement (SM) theories reveal about the claim held by many that these organizations are the left-wing of the GR Movement? (2) What does analyzing these organizations through SM theories reveal about their relationship to one another? (3) What does a social movement analysis reveal about these organizations, collectively and individually?

\section{Reasons for this Study}

Many of the major policy issues prioritized by the mainstream gay rights movement have already been achieved. The movement has been very successful in its efforts regarding gays in the military, hate crime legislation and, now, gay marriage. As I will document later, the mainstream gay rights organizations have received millions of 
dollars of foundation support to pursue those goals. I fear that once this limited agenda has been accomplished, foundations that have supported this work will cease or decrease their funding of LGBT issues. Yet, as I discuss in Chapter 4, there are many other issues, besides marriage, the military, hate crime laws, and safe schools for queer youth, which impact other LGBT people. Queer people who are low-income, people of color, seniors, and/or transgender have identified a wide range of racial justice and economic justice issues as being their highest priorities. These include finances (job discrimination, job training, higher wages, access to welfare), housing (affordable apartments, senior centers, homeless shelters and homelessness), health (healthcare access, medical discrimination, HIV), legal services, and violence and harassment (Battle, Cohen, Warren, Gergerson, \& Audam, 2002; Billies, Johnson, Murungi \& Pugh, 2009; Kenagy, 2005; Kenagy \& Hsieh, 2005; Ramsey, Hill \& Kellam, 2010; Vaid, 2012). These issues are being addressed by queer liberation organizations in desperate need of resources and financial support. I hope that my work contributes to philanthropic organizations' understanding of other LGBT funding options and helps catalyze philanthropic support to these other organizations. The redirection of foundation dollars to social service organizations that work with those LGBT communities who are most marginalized (seniors, transgender people, low-income queers, LGBT people of color, etc.) can support the important work of social workers employed in those settings.

In addition, I am interested in situating the results of this study in the existing frameworks offered by social movement theory. In the 1960s, a variety of new social movements developed and are often referred to now as the New Left. Many of these organizations were constructed around shared identities (the Black Power movement, 
Gay Rights, Women's Lib, etc.). These movements have been studied extensively by social movement scholars who developed new theoretical frameworks for them (see Chapter 2). Theorists and historians frequently explain that these new identity-based social movements of the New Left were focused on access and recognition, whereas previous class-based social movements organized around the redistribution of resources (Bernstein \& Taylor, 2005; Polletta \& Jasper, 2001; Taylor \& Whittier, 1999). This is widely accepted by most social movement theorists. However, I was interested in studying these queer liberation organizations to determine if they might complicate this binary.

The LGBT organizations that have been studied by social movement theorists have been the national organizations and statewide equality organizations that comprise the GRM, and they have been clearly categorized as identity-based movement focused on recognition and access (Armstrong, 2002; Chesters and Welsh, 2011; Engel, 2001; Rimmerman, 2002). However, the queer liberation organizations that have emerged in recent decades have not been included in these analyses. I believed that if these queer liberation organizations are part of the GRM, this might complicate the movement's categorization as identity-based. Or if they comprise a separate social movement, I wanted to explore how they could be understood by existing social movement theories.

\section{Overview of this Dissertation}

In chapter Two, “Theoretical Frameworks," I discuss some of the theories that have shaped my thinking and which inform this research. In the first half of the chapter, I address the critical theories and frameworks that are relevant to my work. I begin by examining how homophobia has been used to explain oppression against LGBT people, 
and the limitations of this explanation. I then turn to Black feminism's use of intersectionality and explain how this framework has been more useful to me in understanding the lives of LGBT people and its application to my research. I then draw connections to queer theory, looking specifically at how its call for the destabilization of social identity categories has implications for the gay rights movement.

In the second half of Chapter Two, I turn my focus to social movement theories. Because my research investigated whether certain groups comprise a separate social movement, I begin this section by focusing on academic definitions of social movements. I then present a review of the classical theories, focused on psychological, economic, and political explanations of social movements, which are considered foundational to the study of social movements. I do this because I used these theories to inform my analysis of the data. For the same reason, I then present an overview of modern social movement theory, focused on cultural explanations of social movements. Finally, I examine those social movement theories that have been developed which focus specifically on the gay rights movement.

In Chapter Three, “A Brief History of the Gay Rights Movement,” I provide an overview of the creation and growth of the gay rights movement. I begin the chapter by providing a summary of LGBT experiences throughout American history, showing how the conception of a gay or lesbian identity was developed, how subsequently underground LGBT communities were formed, and how this eventually led to community organizing, institution building, and the creation of a social movement. I examine the tensions that have always existed within the movement, with regards to strategies and goals, and informed by race, class, and political ideology. This chapter 
serves to contextualize the current tensions that exist in LGBT communities. Additionally, when I began this project I believed that if my research should find that a separate social movement is developing, it would be important to understand how long-standing fractures in the movement may have contributed to its creation.

Chapter Four, "The $21^{\text {st }}$ Century," is focused on understanding the current state of LGBT communities and social movement activity. It examines the progress made towards the agenda of the mainstream gay rights movement as well as the myriad of issues and obstacles that remain unaddressed. It details those issues and obstacles, as well as the critiques made of the gay rights movement for failing to address those problems. I then turn my focus to the queer liberation organizations that have emerged to tackle those issues. Finally, I examine the substantial splits in the movement that exist today. In doing so, I set the stage for my research project.

Chapter Five, "Methodology and Methods" explains how I conducted this research. I begin by locating my epistemological stance, explaining how this framed my research. I then explain my choice of qualitative content analysis as the methodology I used. I provide a theoretical overview of qualitative content analysis methodology, explaining how it applied to my project. I then explain the specifics of my research, detailing my choice of sample, methods, and analysis. I also address how my project addressed issues of trustworthiness. Finally, I address ethical considerations involved in this research, and locate myself and the role my positionality played in the project.

Chapter Six presents my findings and analysis for Research Question 1: "What does analyzing these organizations through social movement (SM) theories reveal about the claim held by many that these organizations are the left-wing of the GR Movement?". 
Using a measure I developed based upon Gamson (1990)'s framework of three targets (Targets of Influence, Targets of Benefits, and Targets of Mobilization), I compared the targets of GRM to the targets of these queer liberation organizations. I determined that seven of the organizations are not part of the GRM, and one of them is.

Chapter Seven explains my findings and analysis for Research Question 2: "What does analyzing these organizations through SM theories reveal about their relationship to one another?" Using foundational social movement theories to develop a working definition of a social movement, I examined whether the seven organizations not part of the GRM have built their own social movement, or if they are just a coalition, or if they are autonomous organizations. I found that they do rise to the standards determined by social movement theorists for qualifying as a social movement. I refer to this as the Queer Liberation Movement (QLM).

Chapter Eight presents my findings and analysis for Research Question 3: "What does a social movement analysis reveal about these organizations, collectively and individually?" First I examined the QLM through the lens of several of the most significant social movement theories. Although I found that they could all be applied to this queer liberation movement, the application of these theories was not complete, and did not expand knowledge in any significant way. Consequently, I developed a framework, based upon the "Another Politics" construction developed by Dixon (2014), for understanding this new social movement.

Chapter Nine, "Discussion: Deconstructing and Reconstructing Identity Categories," deals with questions and ideas about collective identity in the QLM that emerged during my analysis. It presents a discussion about my findings from the entire 
study, addressing theoretical issues of identity that emerged inductively from the data. Throughout this chapter, I draw from a variety of theoretical traditions, including social movement theories (collective identity and identity deployment), feminisms (Black feminism and U.S. Third World feminism) and post-structuralist theories (postcolonialism and queer theory), to explore questions of collective identity in the queer liberation movement.

In Chapter Ten, “Discussion: Desconstructing and Reconstructing Social Movement Models," I explore how, because of the QLM's complicated relationship to identity, it has created a unique social movement. By representing communities that are part of so many identity groups, and working on the corresponding multiplicity of issues that impact them, the QLM is inside of and outside of many different social movements. I present a theoretical "four domain" framework to understand the QLM, which builds off Chapter Nine's discussions of identity. I label the QLM a “post-structuralist social movement" that deconstructs social movements while also reconstructing them, existing in four domains simultaneously: (1) outside multiple social movements; (2) inside, between, and among those same social movements; (3) as a bridge connecting multiple movements; and (4) as its own movement. This four-domain structure of the QLM is a new social movement form that defies dominant models of identity-based social movements.

Finally, Chapter Eleven, “Contributions, Limitations, and Further Research” describes the limitations of this study, areas for future research, and the contributions this study makes to both social movement literature and queer studies. It also examines implications for social work practice and for LGBT organizing and funding. 


\section{Some Preliminary Explanatory Notes}

Throughout this dissertation, I use language deliberately. In order to facilitate clarity and transparency, I should explain some of those choices.

I am intentional about my word choices when I use language that indicates identity. When I say "gay” or "lesbian" or "bisexual” or "transgender," I am referring only to whatever community I have named, and nothing more. Others may use the word "gay" (or gay and lesbian) as shorthand to refer to all sexual minorities, but here I do not. When I am talking about all sexual and gender minorities (gay, lesbian, bisexual, transgender, Two Spirit, gender-nonconforming, questioning, etc.) I will use the acronym LGBT, for the sake of convenience.

I am also deliberate with my use of the word "queer." When I do so, I am using it to describe things (people, organizations or actions) that challenge hegemonic notions (Warner, 1993). Thus, in this paper, queer people are those LGBT people who are most contesting social norms, and queer groups are those LGBT groups whose politics deliberately deviate from the assimilationist agenda of the mainstream gay rights organizations.

I use the term "mainstream gay rights movement" (or GRM) to refer to the national LGBT organizations (GLAAD, Human Rights Campaign, Lambda Legal, the National Gay and Lesbian Task Force, etc.) and the statewide equality organizations (Basic Rights Oregon, Equality California, Empire State Pride Agenda, etc.). They share certain similar goals, structures and constituents that will be explored throughout this paper, and for that reason I group them together. In keeping with my deliberate use of 
identity-related language, my choice to call these organizations the "gay" rights movement reflects my political bias about the limits of their political agendas.

On the other hand, I write differently about the groups I researched. Although these groups, and others like them, are often considered part of the same movement as the national LGBT organizations and the statewide equality organizations, my research investigates whether this is, in fact, so. Because they approach their work so differently than the national LGBT organizations and the statewide equality organizations, I deliberately frame these other groups as queer liberation organizations. I used Southerners On New Ground's term "liberation" rather than the category of "social justice" organizations, because both types of organizations would identify with doing "social justice" work, but I do not believe that the national LGBT organizations and the statewide equality organizations would situate themselves in a "liberation" framework.

It is also worth briefly discussing my sources. I draw heavily from various branches of academic scholarship throughout this paper, including social work, American history, sociology, feminist theory, queer theory, social movement theory, and social movement history. However, because so much of what I am writing about is taking place in real time, the scholarly literature has not kept up with all relevant developments. Indeed, some of the most useful information about this topic may never come from the academy but may, instead, come from activist communities themselves. To address this shortage of academic literature, I also pull from the relevant grey literature (literature produced by nonprofits, government, scholars, and activists that is not published by commercial publishers). The result is a dissertation that engages thoroughly with scholarly journal articles and books, while also leaning heavily upon newspaper articles, 
reports from non-profit and government agencies, blogs, and websites. Placing the academic literature and the grey literature in conversation with each other helped me paint a fuller picture of the issues I explored.

Finally, a note about two of the authors whose work I reference. William Gamson is the author of The Strategy of Social Protest (1990). This book is highly influential in the social movement literature (it has 2,988 citations on Google Scholar as of this writing) and I used it to develop a "targets" framework that is central to my analysis. This is the only work that I use by William Gamson, but I reference it repeatedly. His son is Joshua Gamson, also a sociologist, who has written extensively about LGBT activism, queer theory, and social movement theory. I use several of his articles in my analysis. All references in this dissertation to the "targets" framework is based on William Gamson's work. All other references to Gamson are about Joshua Gamson. 


\section{Chapter 2: Theoretical Frameworks}

In this chapter, I begin by addressing some of the critical theories and frameworks that have informed my thinking and shaped my research agenda. I then describe some of the social movement theories used in my analysis.

\section{Critical Theories and Frameworks}

In this section, I explore the critical theories and frameworks relevant to my work. I start by describing how homophobia has been used to explain oppression against LGBT people and I explore the limitations of this explanation. Next, I turn to Black feminism's use of intersectionality as a framework for understanding the way that multiple social identities impact the lives of Black women. I explain how intersectionality has been useful to me in understanding the lives of LGBT people and how it has informed my research. Finally, I examine queer theory, with particular emphasis on the implications its call for the destabilization of social identity categories holds for the gay rights movement.

\section{Limitations of Homophobia as a Framework.}

In the last four decades, scholars have been putting forth theories that explain the behavior and psychological profiles of homophobes, and frame oppression against gays as based in homophobia (see Herek, 1984; Hudson \& Ricketts, 1980; Kimmel, 1994; Morin \& Garfinkle, 1978; Smith, 1971). Homophobia is commonly understood to encompass a variety of negative feelings (contempt, fear, aversion) towards people

perceived to be homosexual. It can have many forms: interpersonal homophobia, institutionalized homophobia (enacted by government agencies or religious organizations), and internalized homophobia (Herek, 1984; ILGA, 2007). 
Social disparities among gay men (and, later, lesbians, bisexuals, and transgender people) were explained as the result of discrimination, exclusion, and/or violence based in homophobia. These theorists documented and explained the ways in which the dominant heterosexual society's attitudes impacted gay people.

Although different theorists approached the issue from numerous disciplines and perspectives, their ideas shared the assumption that homophobia is the primary (or sole) source of oppression in the life of the gay person (Cohen, 1999). Implicit in this assumption is a construction of gay identity as White and middle-class.

A construction of LGBT identity that allowed for the possibility of an LGBT person of color or a low-income LGBT person (or an LGBT immigrant, or an LGBT prisoner, or an LGBT religious minority, etc.) would also have to allow for the possibility that homophobia might not be the sole (or even the primary) source of discrimination and oppression in that person's life. When it is assumed only White middle-class people embody homosexuality, issues such as racism and classism are ignored. When these scholars effectively erase other possible identities from the equation, defaulting to an assumption of Whiteness and financial stability, their concern for LGBT people's oppression becomes limited to a focus on homophobia. This framework lacks an explanation for other issues facing LGBT communities, such as poverty, because there is no acknowledgement of LGBT poverty. Only by complicating the issue of identity beyond assumptions of Whiteness, middle-class status and gender-conformity, is it possible to examine the range of issues facing LGBT people. This construction of homosexuality as the domain of White, middle-class people has allowed single-issue theories of homophobia to drive the current LGBT agenda. 
Political scientist and activist Cathy J. Cohen (1999) argued that this agenda was set years ago to address the needs of White, middle-class gays and lesbians. She explained that low-income people and people of color (POC) have not been included in the work of the LGBT movement, and their issues (i.e., poverty) have been ignored. She called for doing away with the narrow focus of theories of homophobia and embracing, instead, more intersectional understandings of LGBT lives. In the last fifteen years, countless others have offered similar critiques of the gay rights movement's lack of an intersectional analysis (Bailey, Kandaswamy \& Richardson, 2004; Conrad, 2010; DasGupta, 2012; D’Emilio, 2012; Duberman, 2009; Duggan, 2003; Grundy \& Smith, 2007; Hutchinson, 1999; McMichael \& Wallace, 1999; Nair, 2013; Richardson, 1999). These critiques are not limited to the academy. Similar intersectional arguments have come from seasoned POC LGBT activists such as Mandy Carter (1999), Kenyon Farrow (2012) and Urvashi Vaid (1995; 2012) who have held national leadership positions within

the LGBT movement and have been frustrated by the movement's narrow construction of LGBT identity as de-facto White and middle-class.

\section{Intersectionality.}

Intersectionality is one of the most important theories to come out of feminist studies and has become the "gold standard multi-disciplinary approach for analyzing ... identity and oppression', among women (Nash, 2008, p. 2). Samuels and Ross-Sheriff (2008) explained that "intersectionality theory avoids essentializing a single analytical category of identity by attending to other interlocking categories" (p. 5), and they argued that issues such as gender, race, class, and migration must all be examined simultaneously in order to understand women's experiences. Black feminist activists 
developed this framework before it entered the academy. The Combahee River Collective (1981) was one of the earliest groups to explain their work and vision by using a framework of what would later be called intersectionality theory. Legal scholar and critical race theorist Kimberlé Crenshaw (1989) built upon the Combahee River Collective and upon numerous other earlier works by black feminists who critiqued feminist studies for its centering of White, middle-class women as the de-facto definition of "women." Crenshaw (1991) claimed, "the problem with identity politics is... that it frequently conflates or ignores intragroup differences" (1991, p. 1242). Crenshaw explored the various ways race and gender intersect to shape "structural, political and representational" aspects of the lives of women of color, and made the connections between identity and institutional power. She is given credit for coining the term "intersectionality" to "understand the diversity and multiplicity of the experiences of women of color in terms of identity, social location, and structural barriers that are based on multiple forms of oppression" (Mehrotra, 2010, p. 420). In the twenty years since Crenshaw introduced intersectionality into the academic literature, this lens has been embraced by some scholars writing about the LGBT community who are critical of the limitations of a focus on homophobia.

Cohen (1999) was clear about how the construction of a White middle-class gay agenda is the result of the lack of an intersectional lens. She argued "too many of our organizations seem to be buying inclusion at any cost... because some believe in the society as it is presently constituted except for that minor problem of their own personal experiences with exclusion" (p. 113). She did not use the words "intersectionality theory," but she invoked its main principles while explaining, "as a community, we are confronted 
with multiple identities, differentiated locations within oppressive systems, and the reality that all queers don't suffer equally the process of marginalization" (p. 113).

Eventually, the actual language and formal concepts of Black feminism's intersectionality framework were finally introduced explicitly into LGBT politics. Legal scholar Darren Rosenblum (1994) claimed, "queer identity is intersectional, since most queers face multiple aspects of discrimination, as women, as people of color, as poor people, as cross-gendered [sic] people, and as sexual subversives" (p. 89) and he stated clearly "the multiplicity of the discrimination that queers face is thus greater than antilesbian and anti-gay discrimination" (p. 89). Twenty years later, this is no less true. The narrow focus on homophobia will continue to fail most LGBT poor people and, instead, a variety of structural barriers must be combated. Rosenblum (1994) explained:

Just as feminist and antiracist agendas fail Black women by centering on femaleness or Blackness, so the liberal lesbian and gay position fails by identifying the community solely on same-sex partner choice, ignoring the class, race, ethnicity, sexual and gender identity diversity of the queer community. (p. 89)

When describing LGBT legal advocacy strategies, Rosenblum (1994) explained that focusing on the intersectionality of LGBT identity can allow advocates to focus on legal strategies that tackle LGBT issues while also dealing with the distinct ways that women, people of color, poor people, transgender people, and others face anti-LGBT discrimination. He argued that "attention to these intersectionalities may help provide the largely White, middle-class lesbian and gay legal community with the perspective to litigate for a far broader sense of community" (p. 90). This same intersectional analysis can be applied to non-legal interventions as well, on both the policy and micro social services levels. 
I have used an intersectional lens throughout my practice work. This has resulted in a research agenda that is focused on understanding how identity categories of race, class, gender, and sexuality intersect to shape social movement work.

\section{U.S. Third World feminism.}

Beginning in the late 1970s, U.S. feminists of color critiqued White second-wave feminists for ignoring the multiple oppressions faced by women of color (Combahee River Collective 1981; hooks, 1981; Lorde 1984; Moraga \& Anzaldúa, 1981). Chandra Mohanty (1991) famously critiqued White feminists for constructing a reductionist notion of "woman" that inaccurately assumed that women were "a cross-culturally singular, homogeneous group with the same interests, perspectives, goals and similar experiences" (p. 33). Feminists of color complicated this essentialist construction and forged alliances across race, class, sexuality, and culture, to develop a U.S. Third World feminism built, in part, on their recognition of their shared marginality in U.S. power structures (Herr, 2014; Moraga \& Anzaldúa, 1981; Sandoval, 2000). Chicana scholars Gloria Anzaldúa and Cherríe Moraga described this feminism as a radical vision that required "the colored, the queer, the poor, the female, the physically challenged," and other groups "on the bottom" with which they have connections, to work together (Moraga \& Anzaldúa, 1981, p. 196). Because they built bridges across so many different subordinated identities, U.S. Third World feminists not only engaged in struggles with patriarchy, but understood that they had to equally struggle against racism, capitalism, homophobia, imperialism, and other forms of oppression (Combahee River Collective, 1981; Sandoval, 2000). 


\section{bell hooks' margin to center.}

Originally published in 1984, bell hooks' theory of "margin to center" (hooks, 2000) is a highly influential work of Black feminism. One of hooks' central themes was her claim that feminism should not merely seek equality between sexes, but should work to end the "ideology of domination" which undergirds sexist oppression. She contended that feminism has the potential to challenge not only patriarchy, but also racism, capitalism, and other oppressive systems. Consequently, she was frustrated with second wave feminism's limited agenda, claiming that, "Feminism has so far been a bourgeois ideology" focused on "liberal individualism" (p. 9). She critiqued second wave feminism for its acceptance of small victories, benefitting primarily White women, rather than fighting for broader social change. She maintained that "society is more responsive to those 'feminist' demands that are not threatening, that may even help maintain the status quo" and insists that feminist reforms often reinforce "capitalist, materialist values (illustrating the flexibility of capitalism) without truly liberating women economically" (p. 23). These historical critiques of second wave feminism informed contemporary liberal feminism, which echoes hooks' critique of second wave feminism, and are almost identical to the critiques that were later offered by QLM groups of the GRM. The tensions that exist between the GRM and the QLM parallel the tensions that existed between second wave White and Black feminists.

In addition, hooks (2000) claimed that White women and Black men can be both the exploited and the exploiter, by virtue of simultaneously experiencing privilege and oppression based upon race and gender. hooks argued that both groups have sought equality with White men, promoting their own interests in ways that perpetuate the 
exploitation and oppression of others. Black women, on the other hand, have the lowest social status (experiencing both racism and sexism) and work in the lowest paying jobs, thus preventing them, as a group, from functioning as "exploiter/oppressor," because there is no one lower than them to exploit. Because of this, Black women share a lived experience that inherently challenges all oppressive social structures (racism, sexism, classism). From this position on the margins, Black women possess a unique perspective that allows them to develop both individual and organized strategies of resistance, and to understand and critique hegemonic structures and ideas, creating a counter-hegemony.

U.S. Third World feminism has informed both my years of practice and my research agenda. The groups I am interested in engage in the praxis of ideas developed by U.S. Third World feminism, including hooks' concept of margin to center. I use these ideas throughout my analysis.

\section{Queer Theory.}

Finally, I use queer theory to frame my work. Queer theory, developed in the early 1990s, is a critical theory based in a post-structuralist framework. It includes both "queer readings" of texts as well as theorizing about "queerness" itself. Queer theory challenges the notion that gender or sexuality is part of an essential self. Instead, it depicts gender, sexual behavior, and sexual identity as social constructs. It also explores the idea that certain behavior and identities fall into "normative" and/or "deviant" categories, and that sexual power is embodied in different levels of the social life and is expressed through boundaries and binary divides (homosexual/heterosexual). Finally, queer theory, like other poststructuralist theories, contends that discourse helps to confer and maintain power. 


\section{Origins.}

Queer theory has some antecedents in the concept of compulsory heterosexuality that developed during $2^{\text {nd }}$ wave feminism. Lesbian feminists and gay liberationists in the late 1960s and early 1970s developed the idea of compulsory heterosexuality (Seidman, 2009). This theory posits that one's sexuality is not chosen but is, instead, imposed by society. Because heterosexuality is integral to the way that society has been structured, it is assumed the default sexuality, and most people accept their heterosexuality unquestioningly. Feminist poet Adrienne Rich popularized this concept in a widely read essay (Rich, 1980), where she argued that heterosexuality is a social construct and a political institution that requires deconstruction before women can become fully empowered. Compulsory heterosexuality is a significant framework because it shifted the focus from individual acts of discrimination to "the institutional enforcement of normative heterosexuality and its consequences for nonheterosexuals" (Seidman, 2009, p. 1). In doing so, it allowed for the creation of a structural sociology of sexuality.

\section{Judith Butler.}

Years after this destabilization of the concept of sexuality, philosopher and gender theorist Judith Butler destabilized the concept of gender. Butler (1990) argued that many feminist theorists were misguided in their examination of the "essential" notion of females, or of sex and gender. Butler took apart the entire category of woman (and gender more broadly) and examined masculinity and femininity as social performances. In addition, Butler (1993) explored the ways in which the assumption of a lesbian identity can serve not only to affirm but also to limit and regulate one's identity. She maintained that the only things lesbians may have in common with each other are experiences with 
homophobia and sexism. Consequently, Butler argued for subverting and destabilizing sexual and gender identity categorizing. Instead, Butler prescribed deploying a multitude of sexual, racial, class and gender differences in our politics, essentially calling for the adoption of Crenshaw's intersectional lens. Any challenge to an essentialized conception of homosexuality is going to be relevant to my work. Butler's call for the queer community to examine multiple differences (of race, class, gender, etc) was a good theoretic platform for my research and supported its intersectional approach.

\section{Michael Warner.}

Literary critic and social theorist Michael Warner (1993) built upon Rich's concept of compulsory heterosexuality, as well as the sex/gender system put forward by Gayle Rubin (2009), to popularize the idea of heteronormativity. Warner argued that society has built genders and gender roles that assert heterosexuality as the default sexual orientation. In this heteronormative system, biological sex, sexual orientation and gender roles align to support heterosexual society and institutions.

Warner advocated deconstructing notions of lesbian and gay identities. He used queer theory to explain how queer people are used to define non-queer people as normal. Taking that idea further, he explored how the word queer can be used to complicate anything that falls outside of hegemonic notions of normal. Yet because he conceived of gays and lesbians as sharing the experience of having been shaped by a homophobic culture and state, he constructed a shared identity of queerness that seems to be at odds with his deconstruction of an essentialized gay/lesbian identity. This was a useful complication for me to consider as I examined organizations whose work defies the normal construction of identity-based activism, but still organize around an identity. 


\section{Deconstructing sexual categories.}

Queer theorists Eng, Halberstam, and Muñoz (2005) take Butler's critique of gender and sexual identity categories and use it to oppose the sexual categories of gay and lesbian politics and Lesbian and Gay Studies. They take Michael Warner's description of how queer people are used to define non-queer people as the normal ones and expand it, insisting that this normalization process is not limited to sexuality. They claimed that queer theory must be brought to the topics of gender, race, and nationality to intervene in the normal/abnormal distinctions being created there. They argued that a queer epistemology needs to be brought to the study of the world at large, rather than just limited to the study of White gay male sexuality. My analysis drew from queer theory to unsettle concepts of normality with regards to race, gender, nationality, and sexuality. Eng, Halberstam, and Muñoz's critique of queer studies as too often focused on White gay male sexuality is similar to the critiques I address which have been made about the mainstream gay rights movement.

Sociologist Mariam Fraser (1999) used Butler's theory of performativity to examine the reappropriation of public signifiers of difference, which is often central to queer theory and activism. She argued that such signifiers are impacted by subjectivities informed by race, gender and class. She claimed that struggles that are linked to issues of visibility are problematic in the context of class subjectivities. By virtue of their class (or race, or gender), some people are excluded from representation in queer activism and queer studies and/or may choose to exclude themselves from public recognition and representation. 


\section{Homonormativity.}

My work also evolves from the concept of homonormativity. Although there have been earlier, different understandings of the term homonormativity (Halberstam, 1998; Rosenfeld, 2009; Stryker, 2008), currently the most frequently used meaning of homonormativity comes from the work of Lisa Duggan. Duggan described a new homonormativity "that does not challenge heterosexist institutions and values, but rather upholds, sustains, and seeks inclusion within them," (2003, p. 50) "while promising the possibility of a demobilized gay constituency and a privatized, depoliticized gay culture anchored in domesticity and consumption" (2002, p. 179). She argued that this new homonormativity represented the sexual politics of neoliberalism, and privileges domesticity, privacy and consumption over engaging in radical social change or even critiquing heteronormativity. Viera (2013) claimed that Duggan's arguments describe the results of the swift liberalization of legal and social attitudes towards homosexuality since the 1990s (described in chapter 3). During this period, lesbian and gay advocacy organizations "have moved to the right - their calls for 'equality' no longer offer even a pretense of addressing broader issues of social and economic justice" (Viera, 2013, para 1). Duggan's theory of homonormativity has been embraced and expanded by numerous queer theorists (for examples see Decena, 2008; Puar, 2006; Rosenfeld, 2009; and Viera 2013), and is central to the critiques of the equality organizations offered by the queer liberation organizations I studied.

\section{Social Movement Theories}

In this section, I turn my focus to social movement theories. My research investigated whether certain groups comprise a separate social movement. Consequently, 
I begin this section by focusing on theoretical definitions of a social movement. I used these definitions to determine if the queer liberation organizations meet the theoretical definition of a queer liberation movement.

Once I determined that they do comprise a movement, I then used social movement theories to understand what kind of movement they comprise. I present a review of the classical theories, which are largely focused on psychological, economic, and political explanations of social movements. These theories are considered foundational to the study of social movements. I then present an overview of modern social movement theory, focused on cultural explanations of social movements. I present the foundational and modern social movement theories because I used them to inform my analysis (e.g., in the creation of codes) for my data. Finally, I examine those social movement theories that have focused specifically on the gay rights movement and consider how they may apply to my study.

\section{Definitions of a Social Movement.}

Researching multi-issue queer liberation organizations raised many questions that I answered using definitions provided by social movement theory. Are these organizations the left wing of the LGBT movement, as they are often characterized? Alternatively, are these queer liberation groups something separate? If so, what? Are they individual groups, engaged in social justice work but isolated from any movement? Are they a countermovement, seeking to undo the work of the LGBT movement? Are they a separate social movement (what I am calling a queer liberation movement)? In order to answer these questions, it was necessary to explore some basic social movement definitions. 
The first question I needed to answer is whether the organizations I studied might comprise a countermovement to the mainstream movement, rather than an alternative movement. This appeared to me to be the easiest question to answer. Countermovements are a significant aspect of social movement theory (Meyer \& Staggenborg, 1996). It is a concept used to explain mass responses to the progress made by social movements. Political scientist Roberta Johnson (1999) defined countermovements as movements "seeking to undermine the changes achieved by social movements. Countermovements seek to protect their constituents' socioeconomic positions which have been threatened by social movements seeking greater access to resources, status and power for their constituencies" (p. 241). The organizations I investigated are not trying to undo the greater access achieved by White middle-class gays and lesbians, but are instead trying to extend those gains to other LGBT people. Consequently, using Johnson's definition, it was clear that the organizations I was researching are not a countermovement to the gay rights movement. In order to understand if they are a separate social movement, I explored definitions of a social movement, as conceived of by some of the major social movement theorists. These definitions have been summarized in Appendix A.

Sociologist William Gamson (1990)'s definition of a social movement is simple: Challenging groups capable of taking action together. Yet this definition alone is not useful in providing criteria for answering the question "of which social movement are they a part?" However, Gamson also provides a way of identifying "challenging groups" (those groups capable of taking action) by creating three distinct concepts of targets for challenging groups: (1) the target of influence; (2) the target of mobilization; and (3) the target of benefits. Using this framework, I investigated whether the queer liberation 
groups I researched share the same targets as the GRM. I designed my project so that if my research found that they do share the same targets as the organizations that are part of the GRM, I could argue that they are part of the same movement. Similarly, I knew that if I determined that their targets are substantially different from the GRM, then I would explore whether they are a separate movement, or just engaged in coalition work, or merely individual challenging groups acting independently.

One way to distinguish between a social movement and independent challenging groups is to work with existing definitions of a social movement, as determined by social movement theorists. Political scientist Sidney Tarrow (1998) offered a precise definition of a social movement: "Collective challenges, based on common purposes and social solidarities, in sustained interaction with elites, opponents and authorities" (p. 4). This simple definition is embraced and expanded upon by sociologists Snow and Soule (2010). They defined social movements as: (1) challengers to (or defenders of) structures or systems of authority; (2) collective actors; (3) extra-institutional challengers; (4) engaged in organized activities; and (5) existing with temporal continuity. They also explained that all social movements are collectivities acting with some degree of organization and continuity, partly outside institutional or organizational channels, for the purpose of challenging extant systems of authority, or resisting change in such systems, in the organization, society, culture or world system in which they are embedded.

McAdam, Tarrow and Tilly (2001) argued that, in order to comprise a social movement, challenging groups must have a "classical social movement agenda." This agenda always includes four components. The first component is "political opportunities" for challenging groups to partake in successful collective action. The second component 
is "forms of organization" which allow them structure to engage in mobilization efforts. Next is the "framing of grievances" which legitimizes their claims, connects them to other claims, and forms a collective identity among the claimants. The last part of a social movement agenda is "repertoires of contention" or the means by which people engage in collective action.

When defining social movements, the influential Spanish sociologist Manuel Castells differed from other scholars in his explicit determination to avoid generalizing and over-theorizing (Castells, 2010). Instead, he argued it is important to focus on the specifics of any individual movement. He maintained that social movements must be understood on their own terms and that they are simply whatever they claim to be. His caution against over-theorizing is helpful in that it complicates any one approach to social movement analysis. Castells defined social movements simply as "a certain type of organization of social practices, the logic of whose development contradicts the institutionally dominant social logic" (Castells, 1972, p. 93). This broad definition, from such an authoritative source, provided me with much room to investigate my research question.

Just because organizations are working together does not necessarily mean they are social movement. They may be merely involved in coalition work. Once my first research indicated the need to distinguish between a queer liberation coalition and a queer liberation social movement, then I used the work of Italian Sociologists Mario Diani and Ivano Bison (2004) whose research defined distinctions between coalitions and social movements. They posit that a social movement is different from a coalition, where collective action is organized by each specific organizations rather created by "broader, 
looser networks" (p. 281) and they claim that a social movement process is not in place until "collective identities develop that go beyond specific campaigns and initiatives" (p. 284). They maintain that another important distinction between a coalition and a social movement is the issue of collective identity. They claim a coalition is where "alliances to achieve specific goals are not backed by significant identity links" (p. 281), whereas a social movement requires a collective identity. This collective identity involves creating and recognizing a connectedness, and brings "a sense of common purpose and shared commitment to a cause, which enables single activists and organizations to regard themselves as inextricably linked to other actors, not necessarily identical but surely compatible, in a broader collective mobilization" (p. 284). Once I determined that the queer liberation organizations are not part of the GRM, I used Diani and Bison's definitions to help determine if these organizations comprise a separate social movement or merely constitute a coalition.

As I considered the multi-issue organizations that are the focus of my research, the above definitions (compiled and summarized in Appendix A) provided answers to some of my questions and informed the way I asked other questions. Initially, the social movement literature answered, to my satisfaction, the question of whether these organizations constitute a countermovement (they do not). Therefore, my research was focused on determining on whether these organizations are merely independent challenging groups, isolated from any social movement, or whether they are part of a social movement. Based on the above literature, I used the following as my working definition of a social movement: A social movement is a group of people engaged in collective work, consisting of structured activities and organizations, with common 
goals, grievances, values and purposes. (See Appendix B for details.)

\section{Foundational social movement theories.}

As I investigated these queer liberation organizations, I wanted to situate these organizations in social movement theory. In order to explain and categorize these organizations, I wanted to understand how they do or do not fit within existing theoretical frameworks. Towards that end, it is important to provide a brief overview of foundational social movement theories, including "collective behavior," "resource mobilization," "political process" theories, and cultural explanations. These theories have been summarized in Appendix C.

\section{The classical social movement theories.}

“Collective behavior" theory (Kornhauser, 1959) was developed from the "mass society" ideas of the early-1900s. It posited that large societies breed social movements, because in big cities people feel isolated and insignificant (McAdam, 1982). People who are not fully integrated into society join social movements to end the alienation and anxiety and provide a sense of empowerment and belonging. This theory views social movements as responses to societal strain, and random occurrences of individuals trying to emotionally react to situations outside their control (Gamson, 1990). Collective behavior differs from everyday organizational and institutional behavior in that it arises in response to unusual situations, such as urbanization, industrialization, or other rapid social change (Morris, 1984). According to this theory, social movements are psychological, rather than political, responses to these societal changes. These theories view the act of joining social movements as an irrational, extreme behavior that is a mark of an unhealthy person. Because contemporary social movement scholars reject the idea 
that the joining social movements is an irrational act, collective behavior theory has largely been discredited (Gamson, 1990; McAdam, 1982; Morris, 1984). Nevertheless collective behavior and its precursor, mass society theory, are important early social movement theories, which influenced the field tremendously.

\section{Modern social movement theories.}

By the 1970s, those theories were largely replaced by "resource mobilization" theory. When explaining their highly influential theory of resource mobilization, sociologists McCarthy and Zald (1977) took social movement theory away from its heavy emphasis upon the psychology of social movement participants and began integrating a structural analysis. As opposed to previous theories that viewed social movements as irrational, resource mobilization theory regards social movements as rational social institutions, created with the goal of political action. This theory describes social movement participants as rational actors engaged in instrumental action through formal organization to secure resources and foster mobilization (Buechler, 1995). It emphasizes the ability of movement participants to build institutions, obtain resources and to mobilize constituents towards the goals of the movement (Morris, 1984). This theory can be applied to the mainstream gay rights movement, which (as detailed in Chapter 3) has engaged in institution-building as one of its foremost strategies.

Resource mobilization theory also explains that elite third parties have important impacts on social protest because the oppressed group, on its own, rarely possesses the power and resources necessary to organize and sustain movements. They must leverage elite third parties (government officials, philanthropic organizations, affluent liberal leaders, etc.) to move their agenda forward and to gain acceptance for their ideas. Finally, 
resource mobilization theory downplays issues such as culture, identity, or charisma, and focuses instead on measurable factors such as organization and money.

Eventually, resource mobilization held sway as the dominant theoretical framework of social movement scholars. It however received criticism on several fronts. Sociologist McAdam (1982) observed that resource mobilization proponents failed to examine the ways in which the involvement of elite third parties might contribute to the demise of a movement (e.g. through cooption), rather than to its success. Additionally, Piven and Cloward (1979) maintain that elite third parties are not needed because oppressed groups have sufficient power on their own. They argue that social movements have demonstrated the ability to engage in "negative inducements" - that is the withdrawal of the provision of necessary services or the refusal to produce needed goods. Piven and Cloward maintained that because oppressed groups have the ability to withdraw services or goods, elite third parties are not a requirement for a successful social movement.

In response to the dominant resource mobilization theory, social movement scholars Piven and Cloward (1979) put forth their own highly influential arguments about how social movements operate, known as their "disruptive power" framework. They argued that government acceptance (a marker of success according to resource mobilization) is not necessarily an indication of a social movement's success. They believed that acceptance often leads to the institutionalizing of issues, rather than to continued disruption and cooption. For them, acceptance actually brings the demise of social movements, because it changes the political climate and the social movement. They argued that building institutions that represent the people is a mistake, because 
elites do not react to organizations. Rather, elites react to rebellion and disruption, and social movements must focus on that. In fact, they argue that the building of institutions actually undermines success, because these organizations cannot succeed, and they distract energy and resources away from engaging in activities that actually can succeed. Piven and Cloward fault organizers for failing to try to do what they actually can do (engage in disruptive mass protests), when they instead try to do what they can't do.

According to Piven and Cloward, only in very unusual circumstances (such as the Great Depression in the 1930s or the rapid economic changes and migration of the 1960s) is success possible for challenging groups. It is breaks in political stability and institutional stability that provide the right historical moments for social movements to succeed. In their disruptive power framework, success means obtaining as many new benefits as the political circumstance allows. They believe that the challenging group cannot be judged by whether they achieved all of their goals, but rather, if they achieved everything that the historical moment allowed. When they say that organizers and leaders "can only win whatever can be won while it can be won" (Piven \& Cloward, 1979, p37). Their critique of institution building that takes place at the expense of mass disruption predates the full development of the gay rights movement, but easily applies to it.

The "political process" model was developed by sociologist Doug McAdam (1982) among others, and represents an alternative to both the classical and resource mobilization perspectives. This model describes insurgency as a product of both factors internal or external to the movement. It claims that the creation of a social movement requires certain political opportunities, indigenous organizational strength, and shared understandings of the problem (McAdam, 1982). The political process model is 
concerned with how political, economic, and social contexts create political opportunities that can be exploited by social movements (Haber, 1996). It states that social movements are created when increased political opportunities are taken advantage of by groups of dissatisfied people, formally or informally organized, who are confident that they can rectify their grievances (Goodwin \& Jasper, 1999). As in the disruptive power framework, the political process model claims that there are particular historical moments that must be seized by insurgents in order to achieve success. In order to take advantage of these political opportunities, social movement must have strong and efficient leadership and the necessary resources. In this regard, it is similar to resource mobilization theory.

\section{Cultural theories.}

After the previous decades' focus on economics and politics, by the late 1980s, social movement theorists were studying the cultural side of social movements. This occurred because existing theories did not explain the shift that occurred in the 1960s and 1970s as the social movements of the New Left moved away from redistributive politics to identity politics. In the first half of the $20^{\text {th }}$ Century, most social movements were class-based and engaged in what theorists refer to as redistributive politics and activities (Armstrong, 2002). Movements that embrace redistributive political logics see the problem as being one of structural inequality, and their goal is to transform society. Their organizations are usually short-lived and engage in strategies involving large actions (boycotts, strikes, etc.) and mass demonstrations (Piven \& Cloward, 1979). However, by the 1980s, social movement theorists recognized that existing frameworks did not explain the development of social movements that had arisen in the decades immediately prior, and cultural theories began to emerge. These new theories focused on the ways that social 
movements created public symbols as well as cultural solidarity among members, often in pursuit of access and recognition of their social identities (Goodwin \& Jasper, 2009).

\section{Framing.}

One cultural theory that gained prominence during this period is the "framing" theory. Framing argues that activists sometimes make certain claims that resonate with the public, including media, elites, sympathetic allies, and potential recruits (Benford \& Snow, 2000). In making these claims, social movements transmit beliefs, values, and ideologies to the public. Framing their issues in certain ways will draw more recruits to their cause (Goodwin \& Jasper, 2009). Snow and Benford (1988) classify three essential framing-tasks, and contend that the degree to which framers attend to these tasks will impact constituent mobilization. These three tasks are (1) diagnostic framing (which identifies a problem and assigns blame), (2) prognostic framing (which offers problemsolving solutions, and tactics), and (3) motivational framing (which inspires people to take action).

Framing theory argues that social movement participants are actively involved in the production and maintenance of meaning for their constituents, antagonists, and observers. Along with media and government, they engage in the politics of signification (Benford \& Snow, 2000). Framing is often a strategic process in that they are "deliberative, utilitarian, and goal directed" (Benford \& Snow, 2000, p. 624). Frames are deployed with the deliberate goals of recruiting new members, mobilizing existing constituents, persuading the public, and increasing resources.

\section{Collective identity.}

Another cultural theory that developed was the idea of "collective identity" which 
organizers use, or create, to build solidarity and support around an idea (Goodwin \& Jasper, 2009). The idea of collective identity has been used widely by social movement scholars to theorize about how social movements generate and maintain commitment and unity between activists over time. Collective identities are formed with pre-existing membership in a group based on identity (e.g. the civil rights movement or the disability rights movement) or by creating an actual membership (e.g. the Communist Party). This theory has been utilized by scholars who felt that dominant theories such as resource mobilization theory or political process models were too rationalistic and goal-driven and failed to incorporate significant cultural, social-psychological, and emotional influences on social movements.

Social movement scholar Elizabeth Armstrong (2002) categorized many movements centered on a collective identity as "interest group" movements. Interest group movements are based on the idea that change occurs when organizations represent large, united, and homogeneous groups of people to successfully influence public policy. They do so by engaging in lobbying for political change through legislative channels. They do this work to create reform, or increase rights, because of an understanding that discrimination is the problem. Their organizations are large and bureaucratic.

\section{The redistribution/recognition divide.}

In the first half of the $20^{\text {th }}$ Century, most social movements were class-based and engaged in what theorists refer to as redistributive politics and activities (Armstrong, 2002). Movements that embrace redistributive political logics see the problem as being one of structural inequality, and their goal is to transform society. In the mid-twentieth century, an important social movement development began to take place. The New Left 
of the 1960s saw the creation of many interest group movements (organized around status-based categories such as gender, race/ethnicity, and sexuality). These new groups are often analyzed through a lens of collective identity theory and referred to as identity politics movements. These identity-based movements are often discussed as seeking forms of "recognition" (Fraser, 1995; Hobson, 2003). The creation of these new types of movements caused a shift from the agenda of the early $20^{\text {th }}$ century class-based social movements, which called for the redistribution of resources, to the demands for access and recognition put forward by the identity-based movements of the 1960s New Left (Bernstein \& Taylor, 2005; Polletta \& Jasper, 2001; Taylor \& Whittier, 1999).

The LGBT organizations that have been studied by social movement theorists have been the national organizations and statewide equality organizations that comprise the GRM, and they have been clearly categorized as identity-based movement focused on recognition and access (Armstrong, 2002; Chesters and Welsh, 2011; Engel, 2001; Rimmerman, 2002). However, the queer liberation organizations that have emerged in recent decades have not been included in these analyses.

Some leftists and social movement theorists view identity-based movements as exclusionary and focused on access and recognition for individual groups, rather than broader societal change (Bernstein \& Taylor, 2005; Tarrow, 1998). They see economic issues as affecting everyone, thus being of greater importance than narrow identity-based issues, which impact fewer people, and argue that focusing on identity diverts focus from class and economic issues. Others claim that racism, sexism, and heterosexism are outgrowths of capitalism, and that the way to liberate people of color, women, and queers is to concentrate on economic issues. In response, others argue that 
these "isms" existed before capitalism (often perpetuated through other societal forces such as religion) and can be fund in numerous economic and political systems. They contend that without actively addressing these identity-based issues, there is no reason to assume that they would not persist in a non-neoliberal, post-capitalist world (Highleyman, 2002).

This issue has been widely and angrily debated in the social movement literature, causing activist Rinku Sen (2003) to state that "identity politics has been soundly attacked by white self-named leftists who bemoan the loss of the universal politics they believe lead to mass movements" (p. 1xi). For instance, Gitlin (1995) framed identitybased movements as part of the trend of "political correctness" that helped flame the culture wars of the 1980s and 90s. He claimed that since the late 1960s, while the right was organizing to build power, the left was more concerned with inclusive representation of different identities, famously arguing, "While the right has been busy taking the White House, the left has been marching on the English department." His highly influential work argued that the left should be working together on class-based claims of economic exploitation, which are universal issues. He critiqued what he saw as a splintering that was caused by race and gender divisions and which was destroying the left, claiming that if we only have "peoples" but no "people," then there is no left. Similarly, Tomasky (1996) condemned the left's turn away from economic issues and taking up causes that do not resonate with the white middle class. Lemisch (1997) describes similar and frequent entreaties (from white leftists) for the left to confront and reject identity politics because they are too splintering.

Other scholars agree that the left has been splintered but argue that the reason for 
the splintering is not because of identity politics groups, but rather because the traditional class-based left has dismissed, rather than integrated, identity politics. They claim that the failure to take identity politics seriously is because these heterosexual, white men do not experience identity-based oppression (Hardisty, 1999; Kelley, 1997). Some scholars take that argument further and contend that the denigration of identity politics is an expression of homophobia (Libretti, 2004; Bernstein, 2002). Kelley (1997) has argued that those who dismiss identity-based movements, and position class-based claims as more universal, do not understand the ways that class is lived through race and gender.

There is no universal class identity just as there is no universal racial or sexual identity. The idea that and race, gender and sexuality are particular, whereas class is universal not only presumes that class struggle is some sort of race- and gender-neutral terrain, but takes for granted that movements focused on race, gender, or sexuality necessarily undermine class unity, and by definition cannot be emancipatory for the whole (Kelley, 1997, pp. 86-86).

Libretti (2004) contends that Kelley's analysis situates identity-based movements as having the potential to center the same Marxist politics as the class-based movements of the early $20^{\text {th }}$ century, because Marxist constructions of the proletariat as the agent of revolutionary change were actually their own form of identity politics.

Surprisingly, the social movement literature offers very few examples that question the binary conceptualization of social movements as either concerned with redistribution efforts or with recognition claims. Debates abound about the merits of recognition-based movements versus redistributive movements, but very few scholars challenge the need for such a distinction to exist in the first place. Consequently, Fraser's theory of "perspectival dualism" is significant. 


\section{Fraser's challenge to the redistribution/recognition binary.}

As mentioned previously, there is not a wealth of social movement literature documenting the emergence in the $21^{\text {st }}$ century of social movements that embrace both redistributive and recognition-based frameworks. Critical theorist Nancy Fraser (1995; 2003 ) is one of the few social movement scholars to challenge this binary. She theorizes about the potential of social movements to be both redistribution-based and recognitionbased, calling for "transformational" goals (rather than "affirmational" goals). She argues that these transformational goals must be focused on redistribution (socialism) and recognition (deconstruction). She also explores how movements that are focused on recognition can still potentially support (as well as potentially undermine) a politics of redistribution. Fraser challenges the standard notion of redistributive movements as being necessarily separate and oppositional from recognition movements (Smith, 2001) and proposes "a 'two-dimensional' conception of justice that encompasses claims of both types without reducing either type to the other" (Fraser \& Honneth, 2003, p. 3). This framework of "perspectival dualism" integrates both the recognition perspective and the distribution perspective in its analysis of current American society's class inequity and status hierarchy.

Fraser's framework remains largely theoretical, unconnected to an in-depth analysis of any specific social movement. She does not apply her theory to the queer liberation organizations. In fact, because she uses the national equality organizations to define the movement (Fraser, 1995), she heuristically categorizes the GRM as specifically focused on recognition-based goals, arguing that her model does not apply to them. This is because she uses an essentialist definition of gayness (which she somewhat 
acknowledges), and she does not address the LGBT movement work that is pursuing both economic and identity-based agendas. Because I use a more intersectional understanding of queerness than Fraser did, her theory actually applies to the queer organizing I researched. My analysis incorporates her theory, builds upon her ideas and, by focusing on a particular movement, expands Fraser's theory into practical application.

\section{Theorizing the Gay Rights Movement.}

Social movement theory is a vast field of which I have merely scratched the surface. In addition, there is also an abundance of scholarly literature explaining the history of the gay rights movement (much of which I draw from in Chapter 3). However, there is little academic literature that develops social movement theory specifically around the events of the gay rights movement. This is particularly surprising given how other social movements (e.g. the civil rights movement in the 1960s, or the labor movement in the 1920s and 1930s) prompted the creation of numerous theoretical frameworks to explain them. Those few scholars that have attempted to build theory around the gay rights movement warrant special mention here, as their work informed mine.

Bernstein (1997) introduced the concept of "identity deployment" as a way of explaining how gay rights advocates frame their identities in different ways at different times. Identity deployment describes the ways many activists frequently choose to strategically suppress their differences from the dominant society, in order to highlight similarities to the majority of Americans who identify as heterosexual. Bernstein provided examples of how and when gay activists have chosen to highlight these similarities, and argued that this theory might also have applications to other social 
movements. This raised the question: similarities to which heterosexual people? It appears from her examples that she is referring to White, middle-class gay people highlighting their similarities to White, middle-class heterosexual people. Bernstein's reliance on essentialized identities feels troubling to me, but, unfortunately, not inaccurate. A decade later, she and Taylor addressed this very issue directly (Bernstein \& Taylor, 2005). They argued that the mobilization of essentialized identities happens because the dominant culture places greater value on these essentialized identities and devalues other identities. Consequently, they claim that organizing around an essentialized identity (White and middle class) may have been deliberate and strategic on the part of the gay rights movement. Bernstein and Taylor present this strategy without critique. However, it was a useful framework for contextualizing and supporting the numerous critiques (described in Chapter 4) that have been made about the gay rights movement by queer activists of color.

Armstrong $(2002 ; 2002 b)$ is another of the few scholars to have developed a theoretical framework specifically to explain the gay rights social movement. She recognized the importance of previous social movement theories, particularly resource mobilization and political process theories, but argued that these theories downplayed unique cultural dynamics. She used as her starting place the cultural frame institutional perspective, which posits that the creation of social movement organizations and institutions serves to legitimize the theory and values that underpin the organization (Rao, 1998). Armstrong expanded this theory by arguing that the emergence of new organizational forms requires a "cultural context that facilitates cultural and organizational creativity" (Armstrong, 2002b, p. 362). She believed that the emergence of 
the New Left movements in the 1960s presented exactly such a cultural context. Subsequently, the 1970s San Francisco gay movement developed what Armstrong terms the "Gay+1" model of institutions (2002). A Gay+1 group combines gay identity with another interest (e.g. gay doctors, gay parents or gay athletes, etc.) to create a new institutional form that spread across the country. Many organizers in the San Francisco gay rights organizations of the 1970s described the creation of this wide array of groups, focused on many different interests but united in their gay identity, as "unity in diversity." Armstrong embraced that term and used it to explain the success of the gay rights movement over the subsequent decades. Armstrong's "unity in diversity" theory is unique to the gay rights movement, and has been accepted into the social movement literature as a new theoretical framework (Clemens \& Minkoff, 2004).

\section{Postmodern understandings of LGBT identities.}

Postmodern thinkers have posed a challenge to social movement theorists, particularly about the question of collective identity. Political scientist Shane Phelan (1997) characterized this challenge as "a profound confrontation with identities, both of persons and of communities. This confrontation is by no means a simple rejection of identity, but is a questioning, a challenge to the ontological and political status of sexuality, race, and gender" (p. 2). In order to situate my analysis of the QLM in a larger theoretical context, I turn my attention now to how postmodern scholars have understood activism driven by LGBT collective identity.

There has been much debate among social movement theorists and others about the rise over the last fifty years of identity-based politics. Marxists and others decry how these recognition-based groups focus on cultural goals rather than on redistributive goals. 
However, postmodern theorists are equally critical of collective identity groups. Through postmodern understandings of power, identity politics do not sufficiently address the cultural bases of power. Whereas Marxist understandings of power depict identity politics as too focused on culture, postmodernist analyses view identity politics as not cultural enough (Bernstein, 2005; Vaid 1995).

In postmodernist conceptualizations of power, the use of identity categories is a form of regulation (Bernstein, 2005; Warner, 1993, 2000). Consequently, social movements constructed around those identity categories will not remedy inequality. Instead, by reifying those categories, these social movements will intensify the use of the very categories that regulate and dominate subordinate groups within those identity categories (Butler, 1990). In this view, identity politics strengthen rather than redefine differences in identity categories upon which inequality is based. Postmodernists argue that identity politics not only fail to contest power, but they also ignore the intersection of multiple identities (forcing people with multiple identities to privilege some features of their own identity over others), fail to recognize other diversity within groups (imposing a homogenous identity upon heterogeneous groups), and thus essentialize a group's identity (Ryan 1997, Humphrey 1999, Phelan 1989, Alexander 1999). For these reasons, postmodernists celebrated the rise of queer politics as an antidote to identity politics.

\section{The unrealized potential of queer politics.}

Queer politics emerged in the late 1980s and early 1990s in short-lived groups such as Queer Nation and Sex Panic!. In response to the dominance of middle-class white gay men in the GRM, and that movement's focus on single-issue politics, these groups claimed to build a multi-gendered movement of disparate people with diverse sexualities 
(Bernstein, 2005, Valocchi, 1999). These groups reappropriated the word "queer," redefining it to mean anything that challenges dominant social norms and, in doing so, enacted a queer politics that represented postmodernist and poststructural theories (Bernstein, 2005; Epstein 1998; Seidman 1993). They deliberately contested the identity categories around which the GRM organized, thus embodying an important element of queer theory, and reviving a politics that had antecedents in the similarly short-lived Gay Power groups of the 1970s, which also worked to abolish sexual identity categories (Armstrong, 2002). Much of the identity-based activism critiqued by queer politics had been very successful, leading to apprehension about whether queer politics could similarly succeed by employing such dissimilar tactics (Gamson, 1995; Ryan 2009). These observers questioned whether groups organized around the deconstruction of group identity would be able to avoid implosion. And indeed, the queer politics groups did not last long.

Nevertheless, these queer politics presented a profound challenge to identity politics. Queer politics, by critiquing the gender and sexuality categories of gay and lesbian politics, destabilized the categories around which those politics organized. In addition, queer politics was often more inclusive of bisexual and transgender people, thus loosening (as well as critiquing) rigid constructions of sexual orientation and gender identity (Ryan, 2009). Queer politics had the potential to completely deconstruct identitybased categories; queerness is a denunciation of identity itself (Gamson, 1995).

Ryan (2009) contends that although groups like Queer Nation were short-lived, these queer deconstructivist politics still exist alongside GRM activism. As the GRM has utilized identity politics to successfully create access to institutions, queer politics have 
led to cultural changes, such as the creation of lesbian "femme" communities or transgender politics. In this way, queer cultural politics “contribute cultural challenges as the mainstream movement creates institutional challenges" (p. 47). She draws on Gamson (1995) who maintained that both deconstructivist and identity politics were necessary for LGBT activism, explaining that deconstructivist queer politics can contribute changes that cannot be achieved by the ethnic/essentialist identity politics of the GRM, while the GRM's ethnic/essentialist identity politics obtain victories deconstructivist queer politics cannot.

However, at the turn of the century, political scientist Cathy Cohen (1997) memorably offered a damning condemnation of queer politics. She claimed that it had failed to materialize truly radical or transformative politics, despite its potential. She claimed that despite a discourse that purports to destabilize or deconstruct identity categories, queer politics has merely served to reinforce dichotomies between heterosexuality and everything queer. This binary mode of thinking constructs all heterosexual subjects as dominant, and all queers subjects as marginalized and invisible, failing to recognize how some heterosexuals are subordinated while some gays and lesbians hold power. In this way, queer politics have obscured the operations of power, echoing much of hooks' (2000) critique of White feminism. Cohen critiqued the disconnect in queer politics between its hypothetical commitment to breaking down static categories of sexuality and the political practices of queer politics that reify binary ideas of sexuality and power. She called for an examination of how power informs and constitutes privileged and marginalized subjects on both sides of the heterosexual/queer dichotomy. She said that truly transformative queer politics must employ an 
intersectional analysis and interrogate the role of race, gender, and class, arguing, "It is the multiplicity and interconnectedness of our identities which provide the most promising avenue for the destabilization and radical politicalization" of identity categories (pp. 459-60). Such politics would position some queer people, invested with privilege by virtue of their whiteness, gender conformity, and financial affluence, as more aligned with the dominant, while other queers have more in common with heterosexuals subordinated by virtue of their race, class, and gender:

I'm talking about a politics where the nonnormative and marginal position of punks, bulldaggers, and welfare queens, for example, is the basis for progressive transformative coalition work. Thus, if there is any truly radical potential to be found in the idea of queerness and the practice of queer politics, it would seem to be located in its ability to create a space in opposition to dominant norms, a space where transformational political work can begin (p. 438).

Cohen suggested a new political direction for LGBT activism that does not prioritize obtaining access to dominant structures "but instead seeks to transform the basic fabric and hierarchies that allow systems of oppression to persist and operate efficiently" (p. 480). She argued that to do so, movement building must be constructed not around identity, but around shared marginal status within the dominant power systems.

Cohen is not alone in her dismay about how allegedly "radical" queer politics have failed to live up to the potential power of queer theory. Eng, Halberstam, and Muñoz (2005), Gamson (1995; 2009), Perez (2005), and Seidman (1993) share many of Cohen's critiques, employing poststructuralist lenses to argue that queer theory is often utilized in ways that fail to challenge binaries and destabilize identity categories. For instance, Gamson $(1995 ; 2009)$ interrogated the deployment of identity categories (e.g., gay or lesbian) as a basis for organizing given queer theory's destabilization of identity 
categories. Additionally, Seidman (1993) utilized an intersectional framework to critique the one-dimensional assumptions of identity (e.g., white, middle-class citizens) in the gay rights movement. The analyses offered by Gamson and Seidmant implicitly critique Armstrong and Bernstein.

When writing about the gay rights movement, Gamson (1995; 2009) addressed the issue of essentialized identities. He centralized the question of queer and other sexual identities in social movements. Gamson (1995) examined the implications of queer theory on social movement theory. He raised questions about the usefulness of identity categories (such as gay or lesbian) in social movements when queer theory is simultaneously deconstructing those very identities. Again employing queer theory, Gamson (2009) later debated whether social movements should use fixed categories (i.e. gay, lesbian) or whether to emphasize the subversion of categories (queer).

Seidman (1993) combined social movement theory and history with queer theory to examine the state of LGBT politics. Like Gamson, he examined the relationship between poststructuralism and constructs of identity and what this said about the relationship between postmodernism and the new social movements. He documented how this is related to the difference between identity politics as solidarity versus identity politics as politics of difference. His examination of how queer theory deconstructs rigid sexual identity categories led him to embrace a Black feminist intersectional analysis and call for less essentialized (by race and class) notions of gayness. He then used this analysis to examine recent identity based social movements, with particular emphasis on the gay rights movement. His integration of queer theory, intersectional frameworks and social movement theory is relevant to my work and was useful in my analysis of my data. 
As with Cohen, the work by Gamson and Seidman focused on and aptly described the equality organizations. However, they did not look at the types of organizations centered in my study; they merely theorized about and critiqued existing models. The queer liberation organizations are largely exempt from those critiques, and in many ways they embody exactly the organizing frameworks for which they, and other poststructuralists, advocate.

\section{Conclusion}

The theories and frameworks presented in this chapter are central to my research investigating queer liberation organizations. From Black Feminism, I employ an intersectional understanding of LGBT communities, issues and organizations. This framework is central to my view of the world and informed my choice of research topics. Queer theory posits that there is no single authoritative account of experience. Critical theories critique the hegemonic positions of dominant discourses, and in doing so destabilize static understandings of identity constructions, and develop counter narratives (Anderson-Nathe, Hansen \& Rotman forthcoming; Mehrotra, 2010). This lens shaped my work contesting the dominant discourse about LGBT people.

Social movement scholars have developed foundational theories (collective behavior, resource mobilization, political process, etc.) that continue to be applied today. These theories were complicated in recent decades by frameworks created to explain the identity/recognition-based social movements of the New Left. Fraser's challenge to the redistribution/recognition binary brings these new theories into direct conversation with the foundational theories, and informed my questions. Additionally, social movement 
theory developed to explain the LGBT movement provides an important context for my work.

My analysis, including my coding system, was informed by all of these social movement theories that I have reviewed. To answer my first research question ("What does analyzing these organizations through social movement theories reveal about the claim held by many that these organizations are the left-wing of the GR Movement?'), I used a working definition of a social movement that has been based on the literature summarized in this chapter. This working definition is "A social movement is a group of people engaged in collective work, consisting of structured activities and organizations, with common goals, grievances, values and purposes." See Appendix B for an explanation of how I integrated the many definitions presented in this chapter into this working definition.

For my second research question ("What does analyzing these organizations through social movement theories reveal about these organizations' autonomy, relationship to one another, and/or composition as a distinct social movement?") and my third research question ("What does a social movement analysis reveal about these organizations, collectively and individually?") I used the major social movement theories to inform my analysis. In this way, I situated my findings within the context of the major theoretical frameworks. See Appendix C for a summary of the social movement theories I used in my analysis.

In closing, the critical theories and social movement theories presented in this chapter have shaped my thinking throughout the development of this research. It is 
through the various lenses offered by these different theories that my research topic must be viewed. I turn now to providing some historical background for that topic. 


\section{Chapter 3: A Brief History of the Gay Rights Movement in the United States}

In this chapter, I provide an overview of the formation and growth of the gay rights movement in the United States. I look at how homosexuality has been viewed by society throughout American history, examine the ways in which public opinion, public policy, and the law have impacted LGBT people, and explore the ways in which LGBT people have responded and organized.

I begin by providing a summary of LGBT experiences throughout American history. I show how homosexual behavior was originally treated and then explain how the conception of a gay or lesbian identity was developed in this country. Next, I explore how underground LGBT communities were first formed, and how this eventually led to community organizing, institution building and the creation of a social movement. I address some of the government policies that have affected LGBT communities as well as how the social work profession has responded to LGBT people. I focus extensively on the tensions over goals and strategies that have existed within the movement since its inception. I analyze how these tensions were informed by race, class, and political ideology.

This chapter provides historical context for the tensions that can be found in LGBT communities currently. Should my research determine that a separate social movement exists, this background may help explain how long-standing fractures in the gay rights movement have contributed to its creation. 


\section{Before The Gay Rights Movement \\ The Colonial Period.}

It is generally understood that homosexual behavior has existed in most civilizations throughout history, and colonial America was no exception. New England court records and transcripts of church sermons provide evidence that public officials were aware that homosexual behavior took place in $17^{\text {th }}$ century colonial America (Katz, 1992; Oaks, 1978; Spencer, 1995). Homosexual behavior, however, is different from homosexual identity. As historian John D’Emilio explained, “There was, quite simply, no 'social space' in the colonial system of production that allowed men and women to be gay. Survival was structured around participation in a nuclear family" (1992, p. 7). People engaged in certain same-sex acts (generally referred to as 'sodomy' among men, 'lewdness' among women), but colonial America did not even have a category of homosexual or lesbian. D'Emilio suggests that some people may have been primarily attracted to people of their own sex (and cites colonial court cases which prosecute men who persisted in their 'unnatural' attractions throughout their lives), but "one could not fashion out of that preference a way of life. Colonial Massachusetts even had laws prohibiting unmarried adults from living outside family units" (D’Emilio, 1992, p. 7).

In 1607, at Jamestown, the very first English settlement, the law called for the death penalty for sodomy (which usually referred to same-sex behavior), adultery and rape (Spencer, 1995). These laws generally only applied to men - female same-sex sexual behavior did not fall under the category of sodomy. Eventually, sodomy and buggery were punishable by the death penalty in all of the New England colonies (Oaks, 1978). Homosexual activity had been a capital crime in England since the beginning of 
the $16^{\text {th }}$ century, "but the Puritan colonies, where laws regulating moral behavior were often severe, patterned their laws not on the English statutes, but on the Old Testament" (Oaks, 1978, p. 268). Consequently, homosexual acts were seen as a moral issue first, and a criminal issue secondarily. Religion was the guiding force behind society's response to homosexual acts for over two hundred years, even when it treated the issue as a criminal issue (Katz, 1992; Oaks, 1978).

The colonists frequently and openly discussed sodomy in their sermons, and in the journals and court transcripts, as a deviation from the laws of God (Fone, 1995). In America, in the $17^{\text {th }}$ and $18^{\text {th }}$ centuries, sodomy "was not a secret, not unspoken, not unnamed. Sodomy was raised to a relatively high degree of public consciousness... sodomy was publicly named as one of the major crimes against the state, one of the few infractions meriting death" (Katz, 1992, p. 40).

Sometimes the Puritan leaders refused to follow the anti-sodomy laws. They often chose to take a forgiveness ("remission") approach to these and other sex crimes. Oaks (1978) suggested that the reason for this might have been because labor was needed, and they could not afford to lose the men from the workforce, or because they feared that the crimes were so common that they could not justify killing so many people. Whatever the reason, Oaks argued that the Puritans did not appear to regard homosexual acts as being particularly worse than other sex crimes. Adultery, like sodomy, was a capital offense, but the death penalty was not frequently applied to those convicted of that crime either. As the $17^{\text {th }}$ century proceeded, it grew increasingly uncommon to punish most illegal sexual activity — which was most sexual activity outside of marriage (Oaks, 1978). Lesbian behavior, in particular, was not punished. There were no laws that specifically 
addressed sex between two women, and in fact there is only one recorded case in New England legal records (Oaks, 1978).

It is also important to note how local colonial governments dealt with same-sex behavior among the indigenous communities they encountered. In over 130 different Indigenous tribes, colonists found sexual practices and gender roles that did not conform with White, European Christian norms (Miller, 1995; Morgensen, 2011; Williams, 1992). The European colonists were appalled, and (perhaps, in part, because these behaviors were neither secretive nor policed) the colonists did not extend their own remission policies to Indigenous tribes. From the beginning, the colonists were interested in ending tribal customs that they saw as sins against their god, and eradicating those who practiced them (Miller, 1995). Morgensen (2010) argued that the terrorism embedded in the sexual colonization of Indigenous people is a historical root of the biopolitics of contemporary sexuality in the United States.

Shortly after the United States declared its independence from the British Empire, its new leaders were publicly addressing the issue of same-sex behavior. The public response to same-sex behavior shifted away from laws which openly cited religious scripture as a justification for death (Katz, 1992). Instead, these sexual acts became treated as criminal matters. These changes in the social conceptions of sodomy began in the late $18^{\text {th }}$ century. Religious sermons of deviant sexual behavior began to wane, as the subject matter was now viewed as too disgusting to discuss (Katz, 1992). As the new century began, sodomy was shifting from being viewed as a sin to a crime, and an increasingly unspeakable aberrant behavior (Fone, 1995; Miller, 1995; Spencer, 1995). 


\section{The Nineteenth Century.}

The nineteenth century was a period when romantic friendships between men, and between women, were common (Miller, 1995). Sodomy, although still illegal, was now rarely prosecuted. It was viewed as so terrible and so "unnatural" that it was not considered to have any connection with tender, affectionate relationships between men or between women. A single person might share their bed for years with an intimate friend of the same sex, and it would not occur to others that there might be a sexual component to their relationship. These often intense — and occasionally sexual—same-sex relationships were widely accepted as normal during youth. For men, these relationships were understood as "rehearsals for marriage," and after getting married it was assumed that such friendships would end. This was not the case for women, where lifelong romantic friendships were common. Only toward the end of the $19^{\text {th }}$ century did such relationships begin to be considered deviant (Miller, 1995).

Seidman (2003) explored the impact of capitalism upon sexuality during this period. In the nineteenth century market economies, a sexual culture developed that equated sex with marriage and children. Capitalism required workers who repressed their sexual selves during the day in order to function as labor. Sexuality was reserved for nonworking hours with the family, and its goal there was to reproduce more workers. "Only genital-centered, procreation-orientated sex in marriage was acceptable. Sex oriented to pleasure, sex outside marriage, autoerotic sex, sex in public, nonheterosexual sex, and nongenital sex were unacceptable and deviant" (Seidman, 2003, p. 15). Those alternate expressions of sexuality conflicted with capitalism's need for disciplined, focused, and productive workers. 
In the Great Plains and the American West, the United States tried to assimilate the Indigenous tribes into White culture, by forcing them to cut their hair, and wear men's clothing (Miller, 1995). The government attempted to impose, by force, the norms of heterosexual White European male behavior. When these attempts failed, federal agents attempted to exterminate those who did not comply with these norms.

There are numerous documented stories of same-sex behavior in the west in the 1800 s, although there were fewer laws to govern this behavior on the frontier. Williams (1992) suggested that migration to the frontier might have been a common pattern for men who were attracted to other men. Such men might have been drawn to the frontier because it was a virtually all-male society and because stories about Indigenous communities had led to the colonists to have an association between the Indians and sodomy. Williams did not suggest that most men deliberately went west with these conscious notions, but he argued that any historian who did not consider this motivation ignored an important facet of frontier life.

\section{The Progressive Era.}

As the $19^{\text {th }}$ century ended, the medical and psychiatric communities began taking sexuality seriously as a field of study. The historical construction of "sodomy" as a sinful and illegal behavior changed into "homosexuality," constructed as a medical category (Miller, 1995). The biomedical conceptualization of sexuality consistently classified people by their sexual inclinations_- "the heterosexual and the homosexual; the fetishist, the sadist, the masochist" (Miller, 1995, p. xxiii). This new understanding of homosexuality stigmatized it, characterized it as fundamentally different from "normal" sexuality, and depicted it as a medical condition or a symptom of degeneracy. More 
importantly, it started the re-conceptualization of homosexuality from a behavior to an identity (Engel, 2001).

This stigmatizing medical view was a new paradigm wherein homosexuals were degenerates constituting a third sex, where men had female traits, and women had male traits. Treatments that were recommended (and used) included hypnosis, castration and (later) electric shock treatment. Foucault (1990) summarized the important historical transition that transpired during this time:

As defined by the ancient civil or canonical codes, sodomy was a category of forbidden acts; their perpetrator was nothing more than the juridical subject of them. The nineteenth-century homosexual became a personage, a past, a case history, and a childhood, in addition to being a type of life, a life form, and a morphology, with an indiscreet anatomy and possibly a mysterious physiology.... The sodomite had been a temporary aberration; the homosexual was now a species (p. 43).

Social work, as a profession, responded to homosexuality, for the first time, in this context. Social workers only dealt with the issue in the context of psychology, where psychiatric social workers might assist a psychiatrist in his treatment of a homosexual (Levy, 1927). There is not documentation of the profession's further involvement, beyond this limited role.

During this period, a parallel set of changes was taking place that would equally impact the formation of homosexuality as a social identity and lead to the development of gay and lesbian identities and communities.

D'Emilio (1992) argued that the formation of a gay or lesbian identity could only take place because of changes in American capitalism. He explained that White colonists in $17^{\text {th }}$ century New England established villages structured around a household economy, comprised of family units who each contributed to the family's livelihood. Men owned 
the land and worked on it, while women processed raw farm products into food, clothing, soap and candles. The survival of each member depended on the cooperation of all and each family was an independent economic system. By the nineteenth century, this system of household production was in decline. As merchant capitalists invested in the production of goods, wage labor outside the house became more common. For White women in the $19^{\text {th }}$ century, working for wages rarely lasted beyond marriage, but for men it became a permanent condition. No longer was the family an independent unit of production.

During this period, a racialized ideology of "Separate Spheres" emerged as a byproduct of the industrial revolution. It mandated that men belong in the public sphere (paid labor, government, law, economics, etc.) and women belonged in the private sphere (raising children, maintaining home, religious and moral education), and used biological differences and the will of God to justify the distinctions in these realms (Kuersten, 2003). Although the notion of gender-distinct realms has existed since the ancient Greeks, the industrial revolution elevated this ideology by requiring men to leave the home for work during most of their days to earn money (for households being run by their wives). The ideology of separate spheres presumes that the separate realms are natural because men and women are inherently different.

Urbanization not only pushed men into work outside of the home, but it also sent people off the farm and into large anonymous cities. Once there, people attracted to others of the same sex could find others like themselves (Miller, 1995). D’Emilio explained "only when individuals began to make their living through wage labor, instead of as parts of an interdependent family unit, was it possible for homosexual desire to 
coalesce into a personal identity" $(1992$, p. 8). This identity could be built outside the traditional family unit, and include a sexual and romantic life with people of the same sex. Rodriguez (2012) and Sinfield (1998) argued that this break from the family was true for white people, but people of color were more interconnected with their family and kin, and so they did not follow the same trajectory. The queer communities that they built were less separate from their families, and they maintained presences in multiple kinships simultaneously. Consequently, the gay communities that developed in urban centers were predominantly white.

The shift in capitalism to industrialized wage labor also had impacts on heterosexual relationships. In colonial New England, families needed the labor of children, and sex was tied to procreation. However, as the use of wage labor increased, sexuality was separated from the imperative to procreate, and couples began having fewer children (D’Emilio, 1992). Seidman (2003) described how this period of industrialization created a new consumer economy that weakened Victorian culture's emphasis on privacy and self-control. The new consumer economy relied upon advertising to sell products, which used sexual imagery and brought sexuality into commerce and public life. Ideologically, heterosexual sexual behavior became a way of experiencing intimacy and pleasure.

In doing these two things (divesting the household of its economic independence, and allowing for sexuality to be separated from procreation), capitalism created conditions that allowed some people to organize a personal life around their emotional and sexual attraction to people of their own gender, for the first time in history. "It was now possible to live outside of marriage, outside of the family structure. The homosexual 
was a distinct being and, in many cases, began to develop a distinct social world as well" (Miller, 1995, p. xxii). These changes in capitalism allowed for the creation of urban communities of lesbians and gay men and, later, a politics based on sexual identity. For instance, by the end of the $19^{\text {th }}$ century, New York City already had a thriving gay scene (Chauncey, 1994). Although it was common for police to raid these establishments of "perversion," these clubs, and the communities of gay men that formed there, continued to thrive in New York (and in other cities) into the $20^{\text {th }}$ century through World War II.

Shifting gender roles also contributed to the creation of these communities. Women, too, began to form communities around their lesbian identities. First wave feminism in the latter decades of the $19^{\text {th }}$ century brought with it the advent of the "New Woman" - educated and financially independent, either from inheritance or employment (Smith-Rosenberg, 1989). The emergence of the New Woman in the United States saw an increasing number of unmarried women living together in long-term relationships, now dubbed "Boston Marriages" (Faderman, 1981).

While more affluent women were engaged in the relatively genteel existence of their Boston Marriages, some less privileged women were engaged in their own forms of defiance against cultural norms. During the nineteenth century and before, individual working class women passed as men by dressing and acting like them for a variety of economic, sexual, and adventure-seeking reasons (Freedman, 1996; Newton, 1984; San Francisco Lesbian and Gay History Project, 1983). In addition, they now sometimes married other women while dressed as men (Freedman, 1996). By the end of the century, some single working-class women pooled resources and lived as couples in urban, furnished-room districts (Freedman, 1996). 
Social workers were impacted by these changes. The settlement houses were often home to many women who volunteered there. A number of these women formed close, lasting relationships with one another while living and working there (Matzner, 2008). Many of them were actively rejecting the social expectations that they would become wives and mothers, and settlement houses gave women opportunities to explore both short and long term emotional and physical relationships with other women. Many leaders in the social work movement had romantic friendships or Boston Marriages of their own. Jane Adams, founder of Hull House, the first settlement house in 1889 in Chicago, lived with Ellen Gates Starr for years (Faderman, 1981, Martinac, 2002). After they "grew apart," she shared her life and (by her own account) her bed for the next 40 years with Mary Rozet Smith, one of the many women who came to Hull-House soon after graduating from college for on-the-job training in social work (Faderman, 1981, Martinac, 2002). Nevertheless, social work, as a profession, still had very little to say about same-sex behavior during this period.

In cities across the country, people found ways of meeting one another and created institutions to build a sense of community and identity. For the most part hidden from view because of social hostility, an urban gay subculture had come into existence by the 1920s and 1930s (Chauncey Jr., 1982; Garraty \& Foner, 1981).

These new communities frequently came under attack from authorities. For example, in 1919, officers at the Newport Naval Training Station sent a group of young military men into some Rhode Island communities to investigate the "immoral conditions" that were developing there (Chauncey, 1989). These men acted as 'bait', seeking out suspected 'sexual perverts', and then had sex with, gathering as much evidence as they 
could about homosexual activity in Rhode Island. Based on their research, Navy officials and local governments ended up arresting 16 civilians (most of them working class men) and over 20 sailors (also primarily working class), as well as a prominent Episcopal clergyman. The ensuing controversy received much attention, in part because of the battle that followed between the Navy, the local government and the Episcopal Church, over what constituted deviant "sexual" behavior, who should be prosecuted, and for what. Throughout this very public battle between public and religious institutions about the behavioral control of society (in particular, low-income men), the social work profession remained conspicuously silent.

Because thousands of Blacks migrated to northern urban areas at the beginning of the $20^{\text {th }}$ century, Black gay subcultures began to take shape, particularly in New York's Harlem (Garber, 1983; Johnson, 2010; Vogel, 2009). For Black women, the Harlem Renaissance (1920 to 1935) fostered a sexually experimental subculture that offered a measure of tolerance for lesbian relationships (Garber, 1983). Throughout the Harlem Renaissance, Black lesbians and gay men built friendship networks, socialized in cabarets, drag balls and rent parties, and built religious communities, creating their own language, social structures, and a complex network of institutions (Garber, 1989). This community attracted White gays as regular visitors (Garber, 1989; Mumford, 1996), creating friendships between people of different races and building alliances that could become the foundation of future social change (Garber, 1989).

By the end of the Progressive Era, lesbian and gay people had clearly started to be recognized as a distinct social identity, and as medically and criminally defined social problem. There was still, however, little involvement by social workers. 


\section{World War II.}

World War II was an important demarcation in the history of American queerness. Many gay men and lesbians left their families and small towns to join the (sexsegregated) military, or moved to bigger cities for employment during the war (Berube, 1990). In the military, and in the cities, they often found others like them for the first time. During World War II, women's work force and military participation intensified a process of homosexual community formation (Freedman, 1996). Upon returning from the war, many men and women did not return to their hometowns, but rather, went to large urban areas where gay and lesbian communities were forming (Miller, 1995). Gay bars, which were not uncommon in very large cities before the war, began to also show up in smaller cities after the war (Engel, 2001). In the 1940s, many cities saw the formation of large gay subcultures, which revolved around bars, social clubs, restaurants, cafes, bathhouses, motorcycle clubs, and friendship networks (Armstrong, 2002; D'Emilio, 1983).

This new visibility provoked a backlash. Firings from government jobs and purges from the military intensified in the 1950s. Dominant medical and therapeutic ideas were the underpinnings of these policy actions. Politicians used the pathologizing language and frameworks of psychology as they engaged in partisan campaigns to weed out "sexual perverts" from working from the government (D’Emilio, 1983, p, 41). President Dwight D. Eisenhower issued an executive order in 1953 barring gay men and lesbians from all federal jobs. Many state and local governments and private corporations followed suit. The FBI began a surveillance program against homosexuals, and police departments kept lists of known homosexuals, their friends and their hangouts (D'Emilio, 1983; Garraty \& Foner, 1981). Under the leadership of Senator Joseph McCarthy, 
homosexuals (and many others) were under attack, and the accusation of homosexuality was one of the ways used as means of silencing those on the left, regardless of their actual sexual orientation or behavior (Miller, 1995).

These federal policies trickled down to local police forces across the country, which increased their harassment of gays and lesbians. Vice officers regularly raided gay bars, sometimes arresting dozens of men and women on a single night, and publishing their names in newspapers the next day. Cities performed "sweeps" to rid neighborhoods, parks, bars, and beaches of gays. They outlawed the wearing of "opposite gender" clothes, and universities expelled instructors suspected of being homosexual (Adam, 1987). Countless gays and lesbians were physically harassed or beaten, publicly humiliated, fired from their jobs, imprisoned, or institutionalized in mental hospitals. Many lived double lives, keeping their private lives secret from their professional ones.

\section{The Start of a Movement}

\section{The 1950s.}

As the previous sections explained, by the middle of the $20^{\text {th }}$ century, in the United States gays and lesbians were living in very different conditions than at any other previous point in history. It was under these conditions that some gays began to organize politically for the first time.

In Los Angeles, the Knights of the Clock formed in 1949 as one of the first gay

rights organizations in the country. Its goal was to combat both homophobia and racism, addressing social problems that affected interracial gay and lesbian couples, including employment counseling and locating integrated housing for same-sex couples (Licata, 1981). This short-lived group demonstrates that from its very beginnings the gay rights 
movements had members who saw gay liberation as intertwined with other social justice issues.

In November 1950 in Los Angeles, a small group of men led by Harry Hay and Chuck Rowland met to form what would become the Mattachine Society (D'Emilio, 1983; Gallo 2012). Hay and some of his colleagues were members of the Communist Party and tensions began immediately between those who wanted to focus on acceptance and equal rights and those who had more expansive, revolutionary agendas (Gallo, 2012). Hay ended up leaving the organization, and it quickly narrowed its focus to acceptance and assimilation.

The Mattachine Society was mostly male in membership and it was joined in 1955 by a lesbian organization in San Francisco, the Daughters of Bilitis (DOB), founded by Del Martin and Phyllis Lyon. DOB's engaged in socializing as well as social action. They held gatherings in members' homes and large public meetings, and produced local and national publications. Some of its leaders went on to participate in other social justice movements in the late 1960s and 1970s, in particular, women's liberation and lesbian feminism (Gallo, 2012).

In the 1950s the Mattachine Society and the Daughters of Bilitis remained small, but they published magazines that were a beacon of hope to the readers (D'Emilio, 1983; Gallo, 2006). By the middle of the decade, membership in the Mattachine Society increased, and chapters opened in New York, San Francisco, and Chicago (Engel, 2001), and by the end of the decade Daughters of Bilitis had additional chapters in New York City, Los Angeles, Chicago, and Rhode Island (Gallo, 2006). 
These early groups generally referred to themselves as the "Homophile movement" (Armstrong, 2002; D'Emilio, 1983; Duberman, 1994; Gallo, 2006). The Homophile movement made the argument that homosexuals were a minority group that deserved rights like other minority groups, including the right to privacy. They structured their organization in emulation of the established organizations (ACLU, NAACP, Rotary Club, etc.) of the political times (Armstrong, 2002). They can best be described by collective identity or interest group social movement theories which argue that organizers create identity to build solidarity and support around a group identity, and build organizations to represent those groups (Goodwin \& Jasper, 2009; Armstrong, 2002). These Homophile organizations argued that gay people could be assimilated into society, and although they challenged police harassment (Gossett, Gossett, \& Lewis, 2012) they favored nonconfrontational education. They placed a high priority on privacy for gay people, and sought to understand why people are gay so that a cure could be found (Engel, 2001). Armstrong (2002) argued that the Homophile movement utilized the political logic of Interest Group politics. Their organizations were large and bureaucratic, their goal was homosexual rights, and their main strategies involved lobbying, influencing elite groups and electoral politics. Initially the gay movement had a limited ability to engage in interest group politics, because the gay community was not yet unified or visible enough, or a large enough political constituency, to affect politics and public policy. The creation of Homophile groups made it possible for gay people to locate each other, and start to organize.

This activism led to small shifts in public recognition. Gay and lesbian characters began occasionally appearing in movies and, despite generally being portrayed as 
tormented or sick, the appearance in popular culture marked the beginning of public discussion of the issue (Engel, 2001).

Between 1953 and 1968, San Francisco saw the creation of 15 new Homophile organizations (Armstrong, 2002). By as early as the late-1950s, these groups had become established enough that San Francisco mayoral candidate Russell Wolden attacked Mayor Christopher with the accusation that he had allowed San Francisco to become the national headquarters of organized homosexuals. In response, Christopher led a campaign against gay bars that, in turn, led to an increase in gay organizing (Armstrong, 2002). By the next decade, these groups had spread across country to the east coast.

\section{0s and The New Left.}

In the 1960s, influenced by the model of the Black civil rights movement, the Homophile movement became more visible. By 1969, perhaps fifty Homophile organizations existed in the United States, with memberships of a few thousand (Gallo, 2006; Garraty \& Foner, 1981).

While members of the Homophile movement were focused on assimilating into mainstream culture, other queer people were not interested in conforming. They challenged gender expectations with their dress and mannerisms, and lived on the outskirts of the developing gay and lesbian communities. Today we would call some of them cross-dressers and, others, transgender. Their expressions of identity complicated the clear narrative being put forth by the Mattachine Society and the Daughters of Bilitis, which argued homosexuals and lesbians were respectable, normal people (Duberman, 1994; Stryker, 2008). These Homophile groups were not initially antagonistic to transgender issues, but they saw them as separate from their own. They viewed 
transgender issues as a parallel, rather than intersecting, movement (Stryker, 2008). They also viewed class and race as unrelated to their concerns, and avoided engagement in social activism relating to those issues (Stryker, 2008). This was in marked contrast to the earlier organizations that had deliberately attended to those concerns.

The political and cultural environment of the 1960s changed the direction of the gay movement created by the Homophile organizations. The political upheaval of the Civil Rights Movement, the rise of the counterculture, protests against the Vietnam war, the Women's Lib movement, and the beginnings of other social justice movements led to many Americans challenging rules, authority, and social norms (Armstrong, 2002).

In the 1960s, the assimilationist goals and tactics of the Homophile movement were beginning to face criticism from within. In 1964, the Mattachine Society of NY held a convention during which they were strongly criticized by Frank Kameny, the leader of the Washington, DC branch (Engel, 2001). Kameny argued that they did not need to find a cure for homosexuality because it was not an illness. He insisted that it was, instead, "a characteristic marking a particular group of people" (Engel, 2001, p.34) and made explicit comparisons to the Black civil rights movement. This comparison, and this cultural frame, would later be adopted by many gay rights organizations.

In the 1960 s, the social work profession began addressing same-sex behavior. It primarily treated homosexuality as deviant behavior that could be treated compassionately (Brown \& Lynn, 1966, Druss, 1967; Kitsuse, 1961; Simon \& Gagnon, 1967). Meanwhile, police harassment of gay, lesbian and transgender communities continued throughout the decade.

Resistance increased to these attempts to regulate, change or punish same-sex 
behaviors and identities. Gay and transgender people staged a small riot in Los Angeles in 1959 in response to police harassment (Faderman \& Timmons, 2006) and in 1966, transgender people and sex workers fought back against police arrests in a larger riot in Compton's Cafeteria in San Francisco (Stryker, 2008). The Compton's Cafeteria riot is now regarded as a case of anti-transgender discrimination (rather than an act of discrimination against sexual orientation) and marked the beginning of transgender activism in San Francisco (Stryker, 2008).

During this same period, queer street youth in San Francisco's Tenderloin area founded a group called Vanguard in 1966 (Rohrer, 2013). This group was notably different from the assimilationist goals and tactics of the homophile movement. They protested police harassment, held same-sex dances in church halls, and picketed discriminatory businesses. They also produced a magazine that spoke openly about queer politics, poverty, drug use, sex work, isolation, the arts, and religion.

Then, on June 27, 1969, the New York City police raided a Greenwich Village gay bar, the Stonewall Inn, resulting legendary riots. These Stonewall riots were a series of spontaneous, violent demonstrations by Stonewall patrons against police harassment. The rioters were a mix of races (Caucasian, Black, and Latino), genders (gay men, lesbians and transgender people) and ages (Duberman, 1993). The riots went on for three days. Stonewall is now frequently depicted as having been conducted by fed-up White gay men, erasing the central roles that gender nonconforming Blacks and Latinos played (Roque Ramirez, 2006).

Despite the previously noted activism, the Stonewall Riots exist in the public imagination (insofar as it exists at all) as the first instance in American history when 
people in the homosexual community fought back against a government-sponsored system that persecuted sexual minorities. It has come to be considered the defining event that started the modern gay rights movement in the United States and around the world (Duberman, 1994; Garraty \& Foner, 1981). It did inspire other LGBT people to become more active in the years that immediately followed.

Exposure to the New Left movements had a profound impact on gay organizers. The identity politics developing in other social movements influenced gay activists to challenge the Homophile organizations' commitment to honoring the rights of privacy. Secrecy about sexuality was no longer considered a fundamental assumption of gay organizing. In its commitment to "authenticity," its rejection of alienation from self in American society, and its celebration of identity, the New Left influenced the gay movement to come out. In doing so, it moved away from Homophile organizations and towards a new model of organization, called gay liberation groups (Armstrong, 2002).

Throughout the Sixties, LGBT people played critical roles in local and national student movements. Moreover, following the Stonewall riots, the gay liberation movement's sweeping vision of democratic social transformation and ardent espousal of 'coming out' derived directly from its members' experiences in the New Left. (Lekus, 2006, p. 33)

The New Left also saw an increase in grassroots political organizing (as opposed to large structured bureaucracies), which inspired the gay liberation groups to engage in their own "challenging acts" - usually focused on publicly coming out. The New Left also influenced the gay movement by inspiring a politics of redistribution, which prioritized economic, gender and racial justice alongside sexual liberation (Armstrong, 2002). The gay liberation movement was an example of redistributive politics combined with identity politics. It was connected with the politics of the New Left, and it viewed 
gay liberation as inextricably linked with structural societal transformation (but also embraced identity politics values of pride and visibility), and pursued these goals with smaller, ephemeral groups, such as the Gay Liberation Front.

The new gay radicals, then, often came out of other New Left movements (such as black, women's, and anti-war groups) and brought those principles, which they applied to issues of gender and sexuality (Adam, 1987). They brought some of those militant messages to LGBT people. These messages included a call to reject establishments that they viewed as essentially unequal and dishonest, and instead argued for a participatory democracy whereby all the most oppressed could gain power.

Civil rights had become passe: why petition to be let into a social system so deeply riven by racism, sexism, militarism, and heterosexism? The goal that radical women and gay men shared with the counterculture was 'to construct community institutions based on democratic participation': free universities, an underground press, communes, a society of cooperative and non exploitative relations (Adam, 1987, p.76).

Gay liberationists did not identify as a part of a civil rights movement for a specific minority. Rather, they viewed their work as a revolutionary struggle to sexually liberate everyone. They challenged the conventional arrangements that limited sexuality to monogamous heterosexual families. "For gay liberation there was not 'normal' or 'perverse' sexuality, only a world of sexual possibilities ranged against a repressive order of marriage, oedipal families, and compulsory heterosexuality" (Adam, 1987, p. 78).

Formed shortly after the Stonewall Riots, the Gay Liberation Front (GLF) was the first gay organization to openly use "gay" in its name (Duberman, 1993), and it soon had branches in multiple cities. The GLF aligned themselves with and borrowed tactics from radical Black and antiwar demonstrators, and sought to restructure American society 
(Duberman, 1993). The focus of the work shifted away from fighting for the right to privacy towards public visibility, publicity, and battles about the meaning of public space (Duggan, 2003). The GLF organizations took on causes of women's rights groups and radical New Left causes. For instance, they looked to the Black Panther Party when calling for the end of the "racist police force," and arguing that the police and the prison system were intrinsically oppressive of racial, sexual, and gender minorities alike (Gossett, Gossett, \& Lewis, 2012). On the one-year anniversary of the Stonewall riots, gay liberation activists marched in front of New York City’s Women's House of Detention (near the Stonewall Bar), where Black Panther members were incarcerated, shouting, "Free Our Sisters! Free Ourselves!” (Kunzel, 2008).

These multi-issue politics were at odds with the single-issue politics held by others since the Homophile movement. This led to factions in gay liberation, as groups split over disagreements about goals and strategy (Armstrong, 2002) and led to some members leaving to form groups that were more focused on "gay-specific" issues (Carter, 2004) and others to engage in more coalition-based politics. Between 1969 and 1971, half of the new organizations that sprung up were focused on gay rights (specifically and narrowly) and half of them built connections to other New Left movements, identifying as Gay Power organizations (Armstrong, 2002). This clearly marked a turning away from the limited interest group politics (and valuing of privacy) of the Homophile movement, and a turn towards either identity politics or redistributive politics.

Those who ascribed to the idea of Gay Power identified first as revolutionaries, and second as gay. This identity was informed by the socialist ideals of the New Left. Gay Power activists argued that gay freedom was inextricably linked to freedom for 
workers, women and Blacks. They aligned with revolutionary projects of the left, and aspired to replace capitalism with a liberated society (Armstrong, 2002). They also sought to get rid of sexual identity categories and, in keeping with those values, they wanted to abolish segregated spaces (bars and bathhouses), which were often under the control of organized crime.

\section{The 1970s.}

The radical queer politics of the late 1960s continued briefly into the next decade. For example, in the early 1970s a radical group of drag queens (including Sylvia Rivera) formed in the aftermath of Stonewall and called themselves STAR: Street Transvestite Action Revolutionaries (Shepard, 2004). STAR organized around the issues facing people that today would be called trans women. It was comprised largely of transgender women of color who were involved in the sex industry. They organized against police violence and anti-trans street violence, and for access to housing. Additionally, later in the decade socialist groups such as the Lavender \& Red Union and the Magnus Collective were formed, identifying as "flaming faggots" who advocated for a socialist revolution (Lavender \& Red Union, 1976; Magnus Collective, 1976).

LGBT groups like STAR, the Lavender \& Red Union, and the Magnus Collective made questions of economic justice, sexual liberation and sexual pleasure central to their activism, even while those same questions became increasingly irrelevant to most other organizations that developed throughout the decade (Gallo, 2012; Shepard, 2012). For instance, within the first few years of the decade, the Gay Liberation Front (and most gay power groups) had folded. What remained were groups more narrowly focused on gay pride and a gay rights agenda, whose goals were the reform of laws and public policies so 
that gays and lesbians had equal access to them (D'Emilio, 2000). Rather than revolutionary tactics, these groups were more focused on building institutions (Armstrong, 2002).

During this same period, gays and lesbians increasingly began to present themselves as a legitimate minority group, having a quasi-“ethnic" status, and deserving of the same rights and protections as other minority groups (Epstein, 1998). In this way, gays and lesbians began to understand themselves as similar to Blacks, Italians, or Jews, and publicly present themselves in essentialist terms that made generalizations about the unique and inherent traits that comprise sexual orientation. These essentialist notions were reflected in the types of single-identity organizations that developed throughout the decade.

Armstrong (2002) argued that Gay Power movement collapsed because of the demise of the New Left politics, and that groups focused on gay pride and gay rights survived because they were more viable in the new, more conservative context. The rapid decline of the New Left diminished the credibility of the redistributive political logic, without undermining the viability of interest group politics and identity politics. Armstrong argues that this "ideological pruning" of gay power actually strengthened the gay movement, because it reduced internal conflict (2002, p. 96). In addition, the "gay pride" movement utilized some of the tactics of "gay power," such as confrontation. The marriage of "gay power" tactics to "gay pride" politics proved to be a successful combination. The two remaining political logics, gay rights and gay pride, formed a successful partnership. Armstrong gives credit for the unification of these two frameworks to an identity logic that prioritized self-expression. It put forth the idea that 
significant social change was possible even if differences in gay strategies or interests were unresolved. The gay identity movement did something new - it highlighted the individualistic side of the identity logic. In essence, what it did was use both meanings of the word "identity" - the sameness and the individuality. Armstrong asserted that this model of "unity through diversity" allowed the two remaining political logics (gay pride and gay rights) to become a coherent political movement, rather than causing factions in the movement. Once this model was "locked in" (routinized and regularized) it guided all future strategies utilized by the gay movement. Armstrong argued that there was an important change from interest-group organizations (focused on obtaining rights for gays) and gay power organizations (focused on challenging cultural heteronormativity) toward a merger of the cultural and political (Armstrong, 2002). This change, from a political field to a cultural-political field, was what she calls the crystallization of Gay Identity politics. In the following two decades (between 1972 and 1994), as the country became more conservative, only 11 new Gay Liberation groups were created, but an astonishing 859 new Gay Identity groups were formed (Armstrong, 2002). An example can be seen in the 1971 formation of the Gay Activist Alliance (GAA). When GAA was created, the agenda was redefined to emphasize the extension of institutional protection to Gays by working within the framework of conventional political activity and social appearance. The GAA's agenda did not exclude direct action or a concern for Blacks and women. Nevertheless, GAA developed early on a pronounced preference for legislative and electoral reform and a distaste for unconventional manner and appearance. This formula was successful in attracting a new cadre of activistsprofessional, middle-class, Gay, White males (Boozer, 2013. p.2).

Queer activist Reina Gossett described the difference between the goals of the GAA and those of Sylvia Rivera and the radical drag queens at STAR: 
The Gay Activist Alliance imagined that the way to secure equality and freedom for gay people would be a non-discrimination bill that would stop mostly middle class people from being fired from their jobs. Who isn't covered in the non discrimination bill are people who are doing sex work, people who are systematically denied access to those jobs so it does not matter if there is a non discrimination bill, they can't get that job anyway. They can't get the job because of discrimination. They can't get the job because they are in prison. They can't get the job because they are supporting each other and navigating incredible amounts of violence. So a non-discrimination bill was really not what a lot of the people who made Stonewall happen needed. They didn't need a non-discrimination bill. They needed organizing to stop the violences that were affecting their lives. And that's what Sylvia Rivera was saying. (R. Gossett, personal communication, July 27, 2014).

Sylvia Rivera and other queer activists of color felt shoved out of this new movement. The expansive agenda of gay power politics of the late 1960s had been replaced by a White gay political movement in the 1970s that framed "gay issues" in very narrowly constructed conceptions of gay identity politics, and that identity was presumed to be White, gender-conforming, and middle class. Valocchi (1999) offers an illustration:

Established in 1973, The National Gay Task Force, for example, subscribed to the notion of gay people as a minority group and defined the agenda narrowly as the struggle for the civil rights of gay people, with little or no reference to issues that had proven so central (and so tumultuous) for the (earlier) gay liberationists: race; class; power; sexual style; or gender performance. The founders of the organization, Bruce Voeller and Ron Gold, were middle class white men who were frustrated with the disorganization and posturing of liberationist politics and thought that the focus on issues of class, race, and sexual style was partly responsible for the disorganization and lack of success of gay liberation. A more narrow focus on issues of discrimination and prejudice, they thought, would be a more productive strategy for the movement and would facilitate the resource gathering necessary for a national organization. The consequence, of course, was that this strategy reinforced the middle class nature of the movement... (p. 218)

Valocchi explained that these class-inflected influences on the emergence of a collective gay identity affected their recruitment strategies leading to a White, middle-class identity 
constituency.

These new organizations not only angered people of color by abandoning any focus on race and class, they also faced criticisms from lesbians who claimed the leadership and agenda was too focused on men and their issues. In 1970, at the North Conference of Homophile Organizations seven women (including legendary lesbian activist Del Martin) challenged conference participants, asking them how the gay rights movement benefited lesbians. The delegates passed a resolution supporting women's liberation. Nevertheless, Del Martin felt this was insufficient, and publicly criticized gay rights organizations as sexist (Blasius \& Phelan, 1997; Dececco \& Bullough, 2014).

These types of critiques were being made across the country. In 1972, an organization called the Lesbian Feminist Liberation (LFL) was started in response to charges of sexism in the Gay Activist Alliance. The LFL centered the concerns of lesbian women.

At the same time, lesbian separatism was becoming popular among lesbians who felt that American society, including the gay rights movement, had nothing to offer them. Taking a page from radical feminism and black separatism, these lesbians worked to create lesbian communities that were completely autonomous. For instance, in the summer of 1971, a group of twelve white women calling themselves "The Furies" formed a commune open to lesbians only. The Furies published a monthly newspaper, lived together, and shared chores and finances. They also ran classes to teach women about auto and home repair so they did not need to rely on men (Clendinen \& Nagourney, 2001). By the late 1970s, there were similar groups across the country, including the C.L.I.T. Collective (in New York City), the Gorgons (in Seattle), the Gutter Dykes (in 
Berkeley), the Radicalesbians (in New York City), the Separatists Enraged Proud and Strong (in San Francisco), and the Van Dykes (a nomadic group of van-driving vegans who lived on the highways of North America), and these groups were comprised of thousands of women (Levy, 2009).

Different groups defined separatism differently; some refused to associate with men, others also refused to associate with straight women, and some also refused to associate with lesbians who were not separatists (Levy, 2009). Separatists aspired to complete autonomy, and they built separatists publishing houses, food co-ops, and credit unions.

It was in this context that women's music festivals emerged in the early 1970s. These festivals (originally in California, Massachusetts, Illinois, and Missouri) presented feminist and lesbian artists to women-only audiences (Levy, 2009). The festivals were a rare safe public place for lesbians to be able to socialize openly. The Michigan Womyn's Music Festival (MWMF), founded in 1976, has been active for four decades, and remains an important cultural institution today, despite criticisms from transgender activists who protest the festival's current "cisgender women only" policy.

The current tensions between MWMF and transgender activists have their roots in the 1970s. When lesbian activists broke off from the GAA and formed Lesbian Feminist Liberation, their ire was not, however, limited to the men in the GAA. They were opposed to what they saw as the denigration of women by drag queens. These tensions came to a head at a 1973 gay liberation rally where Bette Midler was performing. STAR's Sylvia Rivera fought her way on to the stage and chastised the gay activism led by groups like GAA for being a white middle class movement and forgetting about 
people in prison. After her speech, LFL's Jean O'Leary gave a speech and said that the people enacting the most sexism were female impersonators who are doing that work for profit (Clendinen \& Nagourney, 2001; Gossett, 2012-2013; Shepard, 2004). This incident is significant because it illustrates tensions that existed between transgender people of color and white gay men, between lesbians and transgender people, and between lesbians and gay men. Similar tensions continued in the subsequent decades.

"Coming out" became a central tactic of 1970s organizing across the country. Having been used as an organizing tactic during the 1960s in San Francisco, it became widely used across the country in the 1970s (Armstrong, 2002). It turned the personal act of being honest about one's sexuality into a political act, and it was a tactic that was embraced by many activists and organizations. This tactic was consistent with those of the New Left, particularly second wave feminism's rallying cry of "the personal is political." This motto, originating from women's consciousness-raising groups that examined women's personal relationships (in marriage and parenting) to make links to larger structural issues, exemplified the New Left's use of personal experience as a catalyst for broader social change (Hanisch, 1970). Coming out took the same philosophy and made it specific to gay and lesbian people.

The dominant cultural norms and political structures were hostile to homosexuals, and consequently lesbian and gay people involved in the Homophile movement in the 1950s and 1960s had been required to be discrete about their sexuality in order to keep their jobs and their families. Consequently, it had been difficult to move forward a political agenda to gain gay rights, when there was no known political constituency. Instead, the widespread images of gay and lesbian people constructed them as deviants, 
child molesters, sinners, and monsters. It was not going to be possible to gain rights for deviants, child molesters, sinners, and monsters, so the first step towards gaining rights had to be changing public opinion (Armstrong, 2002). Activists decided that the best way to change public opinion was to make sure that the members of the public each knew a gay man or lesbian woman personally. Putting a face to a label would help humanize the label. Moreover, it would humanize the label even more if that face were the face of someone that was known and cared about by the "audience." Current social movement theorists describe this as an example of framing (Benford \& Snow, 2000). It was grassroots street logic then, and activists did not frame this tactic in theoretical terms, but their actions provide a good test for intergroup contact theory. Intergroup contact theory claims that stereotyping decreases if people of differing races, religions or ethnicities interact ("make contact") with each other on equal level (Pettigrew, 1998). Today, studies continue to demonstrate that people are much more likely to support gay rights if they actually know someone who is gay (Dolan \& Garrison, 2013), providing support for both the theory and the gay rights activists' tactic.

This coming out strategy signaled a major shift from the thinking of Homophile groups twenty years earlier. They had felt, with good reason, that the threats of violence, abandonment, arrest, and loss of employment were too serious to risk coming out and posed greater threats than the psychological trauma of secrecy and lies. Gay liberation argued the opposite: that lying about one's self (and not being "authentic"') caused too much damage (to self-esteem and identity integration) to be worthwhile.

Coming out also allowed for visible gay men and lesbians to serve as models and inspire other people to come out (Armstrong, 2002). By making public disclosure of 
one's sexuality deeply meaningful, gay activists persuaded masses of people to come out. Visible gay men and lesbians served as magnets that attracted other gay men and women, which helped mobilization efforts. Identity politics and the tactic of coming out allowed the gay community to create a collective public identity large enough to engage in interest group politics.

Having made the choice to come out of the closet and publicly proclaim their identity, gays and lesbians then engaged in community organizing and political advocacy, ushering in a social change movement that grew substantially. In 1969, prior to the Stonewall riots, there were 50 Homophile organizations in the country. By 1973 there were over 800 gay and lesbian groups; by the end of the decade there were thousands (Engel, 2001).

Adopting coming out as the central strategy of the early movement (instead of just one of many strategies deployed equally) helped to ensure a White middle-class constituency would develop. Coming out still comes with risks today, and those risks were even greater 40 years ago. People with class privilege had greater resources to manage those risks, and to handle the potential consequences of coming out. For gays and lesbians who could financially afford to be disowned by their families or fired from their jobs, coming out was a risk that could more easily be taken. Fraser (1999) convincingly used queer theory to explore how a movement built upon "coming out" as a central strategy would end up excluding low-income people and become a de facto middle-class movement. Queer activists of color have also raised similar concerns about the centrality of these tactics (Boykin, 2000). Perez (2005) argued that the metaphor of "coming out of the closet" created a cultural narrative about gay and lesbian identity "that violently 
excludes or includes the subjects it names according to their access to specific kinds of privacy, property, and mobility” (p. 178).

Others have critiqued the role that coming out has played in assimilating lesbians and gays into the mainstream. Sex radicals were not welcomed as the public face of gays and lesbians since this campaign to change the public image and humanize gays and lesbians required appearing "just like you." In a country where sexual behavior has been regulated to support heteronormative reproductive goals, "just like you" was presumed to be not only White, gender-conforming, and middle-class, but also distinctly vanilla in sexual practices. Additionally, Gender Studies scholar Carlos Ulises Decena writes,

One enters the hegemonic space of gayness through coming out. Once a first step towards personal and collective transformation, coming out ... has come to be associated with a regime in which the sexual subject must disclose himself (the choice of pronoun is deliberate) for regulation by the state. A regime of compulsory disclosure is one in which subjects who avoid coming out become a threat to mainstream US society because they refuse regulation (Decena, 2008, p.405).

As Valocchi (1999) argued, using coming out as a recruitment tactic not only led to the solidification of a White, middle-class constituency, but also, in turn, led to the creation of a White, middle-class identity politic. This political agenda was focused on inclusion in existing societal institutions, rather than changing or dismantling those institutions, or addressing issues that what were "non-gay" (in their conception), such as poverty or racism. Cohen (1999) argued that this process of inclusion into existing institutions of privilege requires that group members must meet "the normative standards of a dominant White, heterosexual, capitalist class. The consequence of accepting this social contract is to exclude large segments of LGBTTSQ communities” (p. 115). The people who became involved in the LGBT organizations that formed in the 1970 s were 
generally those gays and lesbians whose race, income and gender presentation were within the normative standards that Cohen described. Those people of color who did want to join these organizations were frequently met with racism and did not remain (Armstrong, 2002; Gallo, 2006).

Mostly LGBT people of color continued to engage in community building (with social clubs, restaurants, bars and friendship circles). Some, however, formed their own political organizations. These included groups such as Salsa Soul Sisters (the first black lesbian organization), Black and White Gay Men Together (BWMT), Dykes Against Racism Everywhere (DARE), the National Coalition of Black Lesbians, and Gays (Gossett, Gossett, \& Lewis, 2012). They engaged in a variety of projects, and sometimes worked together. For example, BWMT, DARE, and Salsa Soul Sisters collectively organized activists in response to a police raid on Blue's Bar, a predominantly black gay bar in New York City. Their work involved a critique of police violence that situated anti-gay police violence as connected to all state violence against people of color.

LGBT Latino organizations developed as well. One of these organizations was the Gay Latino Alliance (GALA) in California. Active from 1975 to 1983, GALA combined political activism and socializing as it simultaneously addressed homophobia and racism. In addition, some lesbian Latinas and gay Latinos worked in multiracial coalitions (e.g., San Francisco's Third World Gay Caucus) or in lesbian and feminist organizations (Roque Ramírez, 2003; Roque Ramírez, 2005).

An important people of color group was The Combahee River Collective (CRC), a group of Black socialist lesbian feminists active in Boston from 1973 to 1980. These women formed the collective in response to a feminist movement that was predominantly 
White and to a Black Nationalist movement that was led by men (Harris, 2009; Smith, 1999). Their "Combahee River Collective Statement" articulated an understanding of gender, race, class and sexuality as a series of interlocked structural systems of oppression that created the conditions of their lives (Combahee River Collective, 1977). They were committed to combating sexism, racism, and capitalism just as fully as they were committed to combating homophobia (Smith, 1999). Members of the collective, including renowned lesbian activist Barbara Smith, went on to continue their activism across the country, and influenced many subsequent queer organizations over the years (Harris, 2009; Smith, 1999).

These few organizations struggled with getting the resources needed to sustain them (Brinkley, 2009). By the end of the 1970s, only eleven organizations across the country existed specifically for lesbian and gay people of color (Armstrong, 2002). Organizations like these were, however, dwarfed in number by the thousands of White gay and lesbian groups created throughout the decade. Two White national organizations founded in 1973 still thrive today and are among the most influential in the movement's history. Lambda Legal Defense and Education Fund, created as a sort of gay ACLU, employs litigation to make legal changes. The National Gay Task Force (now the National Gay and Lesbian Task Force) was created to work on electoral politics and to mobilize local activists and organizations in campaigns (D’Emilio, 2000).

All of these new organizations made an almost immediate impact. In 1973, the American Psychiatric Association declassified homosexuality as a mental disorder. This, and other signs of progress, led to an anti-gay backlash and countermovement, exemplified by Anita Bryant's “Save Our Children” campaign (Engel, 2001). 
Nevertheless, LGBT organizing continued. In 1977, Harvey Milk became the first openly gay man to be elected to public office when he won a seat on the San Francisco Board of Supervisors. Milk was a pro-union organizer who engaged in coalition-building between labor organizations and gay rights groups. His focus on economic justice was shared by other activists in the late 1970s, such as in the 1977 Coors beer boycott organized by lesbian/gay businesses in partnership with the AFL-CIO boycott of Coors, and in queer alliances with the United Farm Workers. Milk served 11 months in office and passed a landmark gay rights ordinance for the city. In 1978, Milk was assassinated, prompting vigils and protests. Despite his short career in politics, Milk became an icon in San Francisco and a martyr for gay rights (Shilts, 1988).

Social work practice was moving away from "fixing” LGBT people, and began to take early steps towards serving these communities (Gochros, 1972). This included the start of work focused on specific subpopulations, such as work with lesbians (Chafetz, Sampson, Beck, \& West, 1974; Hall, 1978), youth (DeCrescenzo, 1979) and "transsexuals" (Wicks, 1977). Social work began not merely providing direct services for LGBT people, but also started engaging in advocacy (Berger, 1977), as well as beginning to incorporate LGBT issues into social work education curriculum (Matek, 1977). By no means did the entire profession serve LGBT people, but the 1970s saw a clear preliminary turn in that direction.

The decade ended with a historic 1979 march on Washington. It was organized entirely by grassroots activists because the existing burgeoning national organizations were afraid it would attract publicity and right-wing reaction (Vaid, 1995). Because of pressure from LGBT activists of color, challenging racism was a "central plank" at the 
march (Vaid, 1995, p. 71). Two hundred thousand people came to Washington DC to demand equal rights, in the largest gathering of openly lesbian and gay people in history.

The 1980s.

Among the historic events of the 1979 national lesbian and gay march on Washington, was a National Conference of Third World Lesbians and Gays convened by lesbian and gay people of color. Subsequently, queer communities of color spent the 1980s expanding their coalitions and work across the country (Armstrong, 2002; Brinkley, 2009). They organized with gay leftists to protest at the 1981 demonstration against the war in El Salvador (Vaid, 1995, 71-72). The National Coalition of Black Lesbians and Gays was founded in 1979 and over the next several years it built branches in 11 cities across the country (Brinkley, 2009). It was not supported by the White national organizations (e.g. - it was excluded from a historic White House meeting). After almost a decade, the Coalition folded due to burnout caused by lack of resources, even as the 1980s saw a major growth in White, gay and lesbian organizations (Brinkley, 2009).

The onset of the AIDS epidemic in the 1980s, although it intensified the antigay rhetoric of the New Right, also stimulated further organizing within the gay community. Following discovery of the first HIV/AIDS cases in 1981, it soon became clear that a national health crisis was developing, and it was disproportionately affecting gay men. The response of the federal government to AIDS consisted of either apathy (President Reagan did not even utter the word AIDS for the first six years of the epidemic) or hostility (Reagan's communications director Pat Buchanan argued that AIDS was "nature's revenge on gay men"). The government's response to AIDS made political mobilization a matter of life and death (Shilts, 2000; White, 2004). By the time President 
Reagan finally addressed the issue of AIDS in 1987, near the end of his second term, 36,058 Americans had been diagnosed with AIDS and 20,849 had died. The disease had spread to 113 countries, with more than 50,000 cases (White, 2004).

During those six years of government silence, the gay community had already created a number of AIDS social service organizations, starting in 1982 in San Francisco and New York City. Existing side by side with these service organizations were direct action groups, fighting to pressure the government to take action. ACT UP, in particular, merits special mention. The AIDS Coalition To Unleash Power (ACT UP) was created in March 1987 in New York City, and grew to have thousands of members in chapters in more than 140 cities in the U.S., with more worldwide.

ACT UP is regarded as having been very media savvy, resulting in many successes as an activist organization (Crimp \& Rolston, 1990; DeLuca, 1999; Edwards, 2000). It is famous for its street theatre actions and non-violent direct action, including their die-ins, in which they dramatically appeared in public with their "dead" bodies in order to make visible the way that HIV was ravaging their communities (DeLuca, 1999).

ACT-UP utilized the "disruptive power" strategies advocated by Piven and Cloward (1979). In marked contrast to the advocacy and social service organizations that had been created with hierarchical structures that mirrored the for-profit sector and represented Resource Mobilization social movement theory (McCarthy \& Zald, 1977), ACT UP groups ran democratically, with most branches operating with a consensusbased decision making model. In her analysis of ACT UP, Haldi (1999) discussed the differences between social movements that are instrumental (having external goals) or expressive (participation itself provides motivation), and explains how this lines up with 
the difference between resource mobilization (instrumental) and new social movement theories (expressive). Halcli illustrated how ACT UP blended both instrumental and expressive goals and tactics, and how this was not a weakness but rather "a rich source of innovation and diversity" within a single social justice group (p. 137). The group was very successful in achieving many of its goals, but there was internal tension in many branches, as some people wanted to focus specifically on HIV/AIDS treatment, while others wanted to focus on the health care system overall (Haldi, 1999; Morgan, 2002; Shepard, B \& Schulman; 2002).

Throughout the decade, numerous Latina/Latino organizations were created, often as a response to the AIDS crisis (Roque Ramírez, 2005). They developed in cities across the country: Denver (Ambiente Latino and Las Mujeres Alegres), Houston (Gay Hispanic Caucus), Los Angeles (Gay and Lesbian Latinos Unidos), New York (Las Buenas Amigas) and San Francisco (Mujerío). Some of them organized transnationally with LGBT activists in Latin America. The AIDS epidemic also prompted Black gay men across the country to organize in formal and informal activism groups (Beam, 1991; Roberts, 1986).

The creation of these new formal groups during the AIDS crisis was sometimes precipitated by the fracturing of pre-existing informal ones. Often parents did not know about their sons' sexuality until after they were diagnosed, at which point they evicted them from their homes. Countless families were split by this dynamic. This led to the creation of family-like arrangements by gay men and lesbians, who were caregivers to thousands of HIV+ gay men, whose families and the government had abandoned them (Shepard \& Hayduk, 2002; Shilts, 2000). The participants of these caregiving 
configurations often grew increasingly angry about the lack of government support. This anger frequently politicized them and led many to join in advocacy organizations.

For many young Black gay men and gender-nonconforming people, alternative family structures took the form of the ballroom community (sometimes called ball culture or the house system). This underground subculture had its roots in the Harlem Renaissance drag performances (Garber, 1983; Garber, 1989). The members of the community belonged to "Houses" where they often lived, and they would compete at events know as balls, where they would "walk" in drag. The houses to which they belonged would provide care and support to many young people of color whose biological families had rejected them (Arnold \& Bailey, 2009). The HIV/AIDS epidemic led to an increase in the number of young men of color becoming infected and consequently disowned by their families. Consequently, although this subculture had existed for about 50 years, House participation increased in the 1980s and 1990s. The White HIV/AIDS organizations rarely reached out to these communities, contributing to the racial divide in the gay rights movement - a divide that would continue to grow deeper in subsequent decades.

The American public's fear of AIDS increased homophobia in the media, resulting in new anti-gay initiatives at the national, state, and local levels (Crimp \& Rolston, 1990; Schulman, 1994). As a result of theses new laws, the AIDS crisis, the government's refusal to do anything about it, and a 1986 Supreme Court Decision (Bowers V. Hardwick) maintaining the criminalization of private sexual relations between members of the same sex, a second gay and lesbian March on Washington was 
held in 1987. Thousands of people went to Washington, DC to demand civil rights, often engaging in civil disobedience on Capital Hill (Ryan, 2009).

Social movement scholar Sydney Tarrow (1994) explained that the organizers of this march faced a dilemma: "how to put forward a set of unsettling demands for unconventional people in ways that will not make enemies of potential allies" (p. 10). Their solution was to downplay in the media the traits that made gays and lesbians different from heterosexuals, while simultaneously celebrating those differences in public. Bernstein (1997) characterized this as "identity deployment" (the strategic use of identity). However, in doing so, these activists chose to portray themselves as "just like" straight America, presenting an essentialized notion of gayness that was formulated to be just like White, middle-class America. The mobilization of essentialized identities happens because the dominant culture places greater value on these essentialized identities and devalues other identities. Consequently, organizing around an essentialized identity (White and middle class) may have been deliberate and strategic on the part of the gay rights movement (Bernstein \& Taylor, 2005).

Throughout the decade, the social work profession expanded its services for the LGBT community - particularly for lesbians and gay men (Bohn, 1984; Dulaney \& Kelly, 1982; Gramick, 1983; Hidalgo, Peterson, \& Woodman, 1985; Potter \& Darty, 1981). The profession began to develop an intersectional understanding of gay and lesbian lives, factoring in how sexual orientation was impacted by other identity markers such as race (Icard, 1986; Loiacano, 1989) and age (Berger, 1984; Hunter \& Schaecher, 1987). As might be expected, social work responded to AIDS and often used that crisis as its way into working with gay men (Dunkel \& Hatfield, 1986; Furstenberg \& Meltzer Olson, 
1984; Gambe \& Getzel, 1989). Social work education also saw a substantial expansion in the presence of gay and lesbian issues covered in the curriculum (Humphreys, 1983; Newman, 1989).

Local and national gay civil rights groups also grew in size and number, as the community sought to increase funding for research and education and to win protection against discrimination. Previously, most organizations had been focused on local activism and politics, but in the 1980s, with the AIDS epidemic out of control and the rise of the Republican politics threatening previous accomplishments, many organizations turned their focus to the federal government (D’Emilio, 2000). The Human Rights Campaign Fund (later called the Human Rights Campaign, or HRC) became the first gay PAC (political action committee) at the national level (Vaid, 1995). HRC's main activities consisted of lobbying federal officials and donating to the campaigns of gay-friendly candidates, regardless of their political parties (D'Emilio, 2000). In deciding that "gay friendly" was the only relevant criteria for supporting politicians, HRC was far removed from the redistributive politics and revolutionary goals of the Gay Power or gay liberation organizations of the 1960s.

One of the strategies used to force politicians to pay attention to the gay and lesbian community and to HIV/AIDS was to tout the community's economic strength. Marketing surveys of the readerships of gay newspapers and magazines like the Advocate demonstrated that their readers had high incomes and lacked children on which to spend them (Badgett, 1997). Gay and lesbian leaders, eager to flex their community's political muscles, circulated these statistics widely in order to argue that the community was 
affluent, with financial resources that could be leveraged to support gay-friendly politicians.

The predominantly White, affluent gay men who subscribe to the Advocate, however, were and remain only one small subsection of the queer community. Subscribers of any magazine are wealthier than the average American, and data generated about the readerships of gay magazines could never represent the entire community (Badgett, 1997; Badgett, 1998). Nevertheless, the data was used as a political weapon for years.

The tactic worked in many ways - elected officials paid attention. So did Wall Street. Excited at the opportunity to win brand-loyalty among a new affluent nichemarket, corporate America started chasing gay and lesbian consumers (Chasen, 2000; McDermott, 2014). With LGBT people being targeted in the media, the community started becoming legitimized in the popular culture. Throughout the 1980s, gay and lesbian characters increasingly turned up in movies and television. This helped fuel social and political acceptance.

By the end of the decade, gays and lesbians had built many social service and political organizations. In addition, they were also firmly ensconced in the national imagination as a powerful constituency, albeit one that was still stigmatized. A tragedy of massive proportions, HIV/AIDS (and the lack of a social policy response) ironically strengthened the political arm of the gay movement (Garraty \& Foner, 1981).

\section{The 1990s.}

In the 1990 s, sexuality became central to American political life. The religious right, empowered in the national political arena during the Reagan administration, spent 
the 1990s recruiting members by stoking fears of homosexual power, as well as attacking abortion rights and welfare recipients (Phelan, 1997). Though there was in increase in homosexuality among the general public, battle lines during the "culture wars" calcified.

During this decade, the gay and lesbian movement focused less on HIV/AIDS, while AIDS activists directed their work toward the treatment of people living with AIDS, regardless of their sexual orientation (Edwards, 2000; Schulman, 1994). Ryan (2009) argues that this was a move toward social respectability and reflected increased conservatism. The gay and lesbian movement, having built its institutional and political power as a result of the HIV epidemic, now sought to maintain and increase its power by distancing itself from that same issue.

The 1990s saw several mainstream reformist organizations embracing this power and solidifying their role in directing the movement and shaping the public dialogue about gay issues. The five organizations most recognized nationally were Human Rights Campaign (HRC), the National Gay and Lesbian Task Force (NGLTF), Lambda Legal Defense Fund, the Gay and Lesbian Alliance Against Defamation and the Gay and Lesbian Victory Fund (Boykin, 2000). Each was a national organization with tremendous power over the direction of the movement because of their resources, and their willingness to use those resources to frame the issues in American society. NGLTF often used a more intersectional lens in its work than did the other groups. Nevertheless, the concerns that all five of these organizations framed as gay issues were primarily limited to hate crime legislation, anti-discrimination laws, adoption rights, access to the military, and (by the end of the decade) "marriage equality." 
It is important to note that these were almost entirely White middle-class organizations. By the time the $21^{\text {st }}$ century rolled in, none had ever been led by an Black, and only one (NGLTF) had ever been led (briefly) by a person of color (Boykin, 2000). All their leaders were college-educated, most had graduate degrees, and none were transgender. This was in stark contrast with the Stonewall Riots (still touted as the birthplace of the movement and employed as a rallying cry), which had been led by lowincome, gender-nonconforming people of color.

By 1996, HRC was the largest and most influential national gay political organization (D'Emilio, 2000). It was also the most hierarchical, with no branches providing local leadership and with an executive board that made all decisions for the organization (D'Emilio, 2000). While pursuing an agenda focused exclusively on standalone gay rights issues, it sought to cultivate access to politicians and, consequently, it took a "safe, middle-of-the-road approach" to political change (Vaid, 1995, p. 92).

This political approach alienated the most powerful gay group in the country from many smaller organizations. In 1998, HRC provided support to Al D'Amato for reelection as Senator from New York, despite the fact that local New York LGBT groups were working against his re-election (Gamson, 2001). Local gay organizations were angry that their decisions were being overlooked and undermined by a national organization that claimed to represent gay America (Vasquez, 1998; Walsh, 1998). Additionally, progressive activists were angry that D'Amato's anti-immigrant, antireproductive choice, and anti-welfare positions were disregarded by HRC simply because he was "gay-friendly" (Cohen, 1999; Hutchinson, 2000; Vazquez, 1998). Carmen Vasquez (1998) argued that those who question whether these "other" progressive issues 
were "gay" issues should ask the thousands of gays and lesbians receiving welfare, for whom D'Amato's budget cuts mean the difference between low-income housing and homelessness (Shepard, 2001). Vasquez (1998) claimed that split between groups like HRC and groups with a broader agenda represented "a rift between those who want to be normal at any cost and those of us who believe gay liberation (and therefore reproductive rights) is a central and inviolable tenet of our struggle for freedom" (p. 1). For many others too, HRC's endorsement vividly illustrated a significant divide that already existed between local groups with progressive politics and large national organizations that were focused only on narrowly defined gay issues (Gamson, 2001; Hutchinson, 2000; Walsh, 1998).

This focus on narrowly defined gay issues was evident throughout the decade. The major events of the country were largely unremarked upon by the national gay and lesbian organizations, starting in 1990 with the Gulf War, which only NGLTF opposed, all the way through the 1999 WTO protests in Seattle, which involved many individual LGBT activists but no LGBT organizations (Highleyman, 2002).

This was apparent in 1995-96, when the Clinton administration dismantled large parts of the social safety net under the guise of welfare reform. Many elements of welfare reform - abstinence-only sex education, marriage promotion, fatherhood initiatives and charitable choice programs - had significant implications for queer people, and especially for low-income queers (DeFilippis, 2012b; Kandaswamy, 2008; Richardson, 1999; Smith, 2001). However, the national LGBT organizations had not a single word to say on the subject at the time (DeFilippis, 2012b; Richardson, 1999). The fallout, however, was far more sweeping than ignoring the needs of just low-income queer people. LGBT people of 
all economic classes should have been concerned about a sweeping piece of national legislation that was more concerned with ending "illegitimate families" than with ending poverty, as was the expressed purpose of welfare reform legislation. The national LGBT organizations failed to see how queer families might be lumped into the category of the "illegitimate" by both the political right wing and liberals determined to regulate the sexuality of poor people, women, and queers (DeFilippis, 2012b; Kandaswamy, 2008; Smith, 2001).

The national organizations even ignored those racial justice issues with more obvious connections to "gay rights." For years, gay rights organizations had been trying to bring attention and remedy to the issue of hate crimes. Yet in the spring of 1998 when James Byrd, Jr., a Black man from Texas, was viciously murdered in a hate crime by White supremacists, gay rights organizations were largely silent about it. Months later when Matthew Shepard, a young gay White man in Wyoming was murdered in a hate crime, gay rights organizations across the country organized protests and vigils and turned Matthew Shepard into a household name - a symbol and martyr for the movement. No connection to the recent Byrd case was made, much to the resentment of queer activists of color (Carter, 1999). They could not understand the failure of the movement to see how hate crimes against gay people are related to hate crimes against people of color.

In addition, national gay and lesbian organizations, such as the Human Rights Campaign and the National Gay and Lesbian Taskforce advocated for "hate crimes legislation," despite the objections of people of color activists (this tension is addressed in the next chapter). The position of the national organizations has been traced back to the 
pro-police positions taken in the 1980s by Queer Nation, contradicting the critiques of the police advocated by gay liberationists and other New Left groups (Gossett, Gossett, \& Lewis, 2012).

During the 1990s, the social work profession increased their support for LGBT communities. Lesbian, gay and bisexual social workers challenged the pervasiveness of homophobia and heterosexism in the scholarly literature and in the profession (Reisch \& Andres, 2002). “Although most gay and lesbian social workers were not politically radical, perhaps because of their predominantly White, middle-class backgrounds, the intellectual and cultural forces unleashed by their efforts transformed and often complicated" the social work profession (Reisch \& Andres, 2002, p. 181). Consequently, the decade brought the creation of an LGBT-focused social work journal (The Journal of Gay and Lesbian Social Services) and the Council for Social Work Education created a committee to address LGBT concerns.

Locally, the decade saw statewide equality organizations, moderate-to-liberal in their political goals, developing across the country. These organizations were successful in raising public dollars for LGBT social services, and in many of their political and legislative goals. These statewide organizations were modeled on the national organizations, such as HRC, both in structure and in goals. They were hierarchical and corporate in the ways they operated, and they sought inclusion into existing legal institutions and social structures, which they otherwise did not question. They pursued these goals primarily through electoral politics, and rarely engaged in direct action (Vaid, 1995). 
In addition, local queer communities continued to develop across the country, often segregated by race. Gentrified White "gay ghettos" thrived in major cities, while queer people of color communities were also developing. For instance, The Mission District in San Francisco had emerged as a queer latino community, filled with bars, stores, and community events (Rodriguez, 2012).

The myth of gay affluence continued to be perpetuated by gay and lesbian political leaders, in their sustained efforts to be taken seriously by politicians. These inaccurate economic statistics also came with a backlash, however. The data was used against the LGBT community by conservative foes, who depicted the LGBT community as privileged White gay men who do not need additional "special rights" (Hardisty \& Gluckman, 1997; Hutchinson, 1999). This rhetoric has moved from the media into important political and legal battles to legislate against the LGBT community. For example, in 1996, the Colorado Amendment 2 case went before the U.S. Supreme Court and Justice Antonin Scalia wrote that "high disposable income" gave gay people "disproportionate political power," so Colorado voters should be permitted to rein in that power by banning anti-discrimination protections for lesbian, gay, and bisexual residents (McDermott, 2014; National Gay and Lesbian Task Force, 2000). Nevertheless, the national gay rights organizations and statewide equality groups did little to challenge this myth of gay affluence (DeFilippis, 2012a; Hutchinson, 1999).

Attempts to obtain gay marriage, in states like Hawaii and Vermont, were successful enough to prompt a backlash. In 1996, in response to the local marriage work being conducted by statewide equality organizations, congress passed the Defense of 
Marriage Act (DOMA) which barred same-sex married couples from being recognized as "spouses" for purposes of federal laws, or receiving federal marriage benefits.

Some grassroots organizations created during the 1990s used tactics that were very different from those employed by statewide equality groups. Queer Nation was started in New York City in 1990 by several ACT UP activists who were concerned about anti-gay and lesbian violence and by negative depictions of queer people in the media. Direct action by groups like ACT UP had never had public support and their provocative tactics were losing support among gay men (Vaid, 1995). Yet Queer Nation embraced these strategies, engaged in confrontational tactics, and was controversial for its practice of outing closeted public figures (Engel, 2001; Gray, 2009; Slagle, 1995).

Queer Nation (and subsequent groups such Sex Panic!, and the Lesbian Avengers) reframed the discourse around sexual orientation to contest the same categories of identity around which previous groups organized (Bernstein, 2005). These new groups attempted to form a movement of people with multiple genders and sexualities, and did so by reappropriating the word "queer" and redefining it to signify anything that challenges dominant cultural norms (Epstein 1998; Seidman 1993). As such, Queer Nation is noted for initiating "queer politics" in the 1980s and embodying emerging postmodernist and poststructuralist theories (Bernstein, 2005). Scholars theorized queer politics as a politics with which to destabilize group categories and to bring diverse groups of marginalized people together under one umbrella (Epstein 1998; Gamson 1995; Valocchi 1999; Warner 2000).

Others contend that, while its tactics may have been radical, Queer Nation's political goals were frequently similar to those of the mainstream organizations (Gossett, 
Gossett \& Lewis, 2012). For example, it did not see antigay violence as coming from the state, but from individual perpetrators. It looked to the police as potential allies, and in doing so, provided support to the neoliberal state, rather than challenging it, as previous activists had done (Hanhardt, 2013).

In this sense, Queer Nation and its spin-offs - in particular the Safe Street Patrol and the Pink Panthers — embodied a significant shift away from the critiques of state- and police-perpetrated violence espoused by gay liberationists and their allies in the New Left and carried forward by antiracist queer activists in the 1980s and 1990s (Gossett, Gossett, \& Lewis, 2012, p. 1).

Sharing similar tactics but pursuing much more radical goals was Sex Panic!. Founded in 1997 in New York City, Sex Panic! was a "pro-queer, pro-feminist, antiracist direct action group" that fought to maintain sexual freedom in a world that had, because of AIDS, been stigmatizing sex (Pendleton \& Goldschmidt, 1998, p. 33). Specifically, it battled government efforts to regulate sex and limit public sex venues. Sex Panic! and other sex radicals also opposed the mainstream gay rights movement in its efforts to hide sexual expression and promote same-sex marriage (Shepard, 2002).

Feminists and lesbians also engaged in direct action. Confrontational groups such as the Women's Action Coalition (WAC), the Women's Health Action Mobilization (WHAM) and the Lesbian Avengers were created out of frustration with having their issues ignored by both the women's movement and the gay rights movement (Shepard \& Schulman, 2002; Vaid, 1995).

Ryan (2009) argued the gay and lesbian movement's deemphasize of AIDS activism and the rise of groups like Queer Nation and the Lesbian Avengers delineates the break between mainstream gay and lesbian politics and a queer politics. Although 
most of these groups do not exist today, "their radical critique still exists in the ethics of queer politics today" (p. 245).

Direct action groups like Lesbian Avengers, Queer Nation, Sex Panic!, WAC, and WHAM responded (to varying degrees) to the public's fear of queer sex by celebrating queer sex, and engaged in direct actions focused on bringing visibility to queer sexuality (Schulman, 1994; Warner, 2000). However there was tremendous disagreement in LGBT communities about these strategies, and the result was a heated political conflict about the role of public sexuality (Ryan, 2009). Debates about these issues (e.g., whether gay bathhouses should be closed) often invoked rhetoric similar to those that took place during the famous feminist sex wars of the 1980s (Hollibaugh, 1996). According to Ryan (2009) and Warner (2000), the battles around sexual representation following the AIDS epidemic marked the start of a political divide between mainstream gay and lesbian reformists attempting to 'sanitize' the movement by desexualizing it, and those queers who hailed the potential liberatory power of the representation of queer sexuality.

While these types of battles were taking place between the mainstream movement, represented by large institutions such as HRC, Lambda Legal and GLAAD (which were predominantly White), and infamous grassroots organizations such as Queer Nation and Lesbian Avengers (which were also predominantly White), queer people of color were building their own organizations. Many of them were social service organizations, but others had more overt political agendas. Some of these organizations shared the intersectional vision of the Combahee River Collective and the redistributive politics of gay liberation groups of the 1960s. These new organizations included the Esperanza Peace and Justice Center (founded in San Antonio in 1988), Southerners on New Ground 
(North Carolina, 1993), and the Audre Lorde Project (NYC, 1994). In 1995, these organizations began convening gatherings for queer people of color at the annual Creating Change conference (Weiner-Mahfuz \& Farrow, 2012). These annual all-day meetings (the People of Color Organizing Institute) provided a space for POC LGBT activists from across the country to strategize, build relationships and coalitions, and bring visibility to underserved communities. These meetings marked the beginning of a network of POC organizations that continues today.

These smaller people of color organizations lived alongside the statewide equality groups and national organizations in a constant state of tension. This tension continued the decades-long debate about whether the gay and lesbian movement should pursue narrow, rights-based goals using traditional legal strategies and lobbying, or embrace a radical, liberationist strategy to pursue larger social justice goals. This disagreement was reflected by Andrew Sullivan and Urvashi Vaid, two of the highest-profile LGBT advocates, when they published important books within months of each other. Their books, with remarkably similar names but vastly different prescriptions, clearly illustrated how these tensions continued to plague the movement. Virtually Normal (Sullivan, 1995) called for the more narrow and conservative approach, while Virtual Equality (Vaid, 1995) advocated for a broader vision of social justice.

As the century ended, nothing illustrated the divisions that existed quite so starkly as the Millennium March on Washington. In 1998, leaders at HRC and the Metropolitan Community Church announced plans for a third national march to be held in April 2000. There had been three previous national marches that were organized by grassroots organizations from across the country, but for the first time a national march was 
organized by just two organizations. Indeed the march was initially planned by five staff people at these two organizations, who decided on a theme of "faith and family" and then informed most of the rest of the movement in a press release after it was planned (Boykin, 2000; Carter, 1999). Lisa Duggan (2003) noted that the Millennium March was a definitive change from previous marches. "Brought to you by corporate sponsors corralled by a corporate-style board of directions w1ith little outside input, the Millennium March was more of a public relations media campaign than a grassroots action" (p. 45).

Within days, anger erupted across the country. Soon an official opposition group formed (the Ad Hoc Committee for an Open Process), comprised of grassroots activists from across the country. They were concerned about how undemocratic the planning had been, its conservative themes, its corporate sponsors and profit-making events (Duggan, 2003), and the fact that it was organized without input from grassroots activists or any community discussion Gamson, 2000). Longtime Black lesbian activist Mandy Carter (1999) said, “It isn’t even a march. It is a rally without specific political demands, without democratic representation or community accountability" (p. 63). The battles continued, very publicly, for the entire two years of planning for the event (Boykin, 2000; Gamson, 2000).

Many criticized the planning committee's exclusion of people of color (Boykin, 2000; Carter, 1999). They voiced concern that the march exemplified how Whitedominated organizations had long been selecting the LGBT community's priorities and then asking for input after the fact (Boykin, 2000). Carter wrote, "It wasn't a coincidence that five white people met via HRC and MCC and selected themselves to plan a national 
march... without once questioning who wasn't sitting at the table" (Carter, 1999, p .64).

Carter argued that this was directly connected to the bigger question of how people with

the most money and resources believe they can set the national agenda for the movement.

Many others agreed that the march itself was not the only concern and were more

concerned about the larger implications of what it represented. Social movement scholar

Joshua Gamson observed,

The Millennium March is the kind of diagnostic event that X-rays a movement at a particular historical moment, and what it shows isn't all that pretty. It's a picture of a deeply divided movement burdened by its own growth, tripping on the very changes it has built, its resources increasingly consolidated in a few organizational hands. Partly, the march shows off the tremendous growth over the nineties of one organization, the Human Rights Campaign, whose "organizational culture," as University of Illinois, Chicago, historian John D'Emilio puts it, "has always been a culture of arrogance." The Millennium March has come to symbolize, for its opponents, a movement increasingly run by what is essentially a national, corporate, business-as-usual political lobby, which collects funds while local and state groups struggle against attack...But this bitter fight isn't just about the HRC. The march and its attendant controversy also provide revealing snapshots of a movement that has institutionalized itself at all levels--a movement that has institutionalized pretty much everything except accountability--and is only now starting to come to grips with what that means (Gamson, 2000, p. 1)

The movement had indeed changed substantially over the past two decades. Not too much earlier in time there were no national organizations, and so accusations of topdown elitism and hierarchy were unimaginable. In the previous 15 years, however, the movement had become completely institutionalized - not just on the national level but also locally via individual statewide equality groups (Duggan, 2003). The types of unaffiliated grassroots organizers who had organized the previous marches were no longer in the loop, and decisions were being made entirely by non-profits. The LGBT 
movement has shifted from one of loosely affiliated activists to one of organizations (Gamson, 2000).

In addition to concerns about the structure, power and decision-making in the movement, the march also highlighted a difference in goals. It flared up the ongoing tensions between queer activists who sought to link the GLBT movement with broader social justice issues, and other more single-issue gay assimilationist organizations concerned about accessing existing institutions.

Queers who envisioned their movement as a critique of social, sexual, and economic "regimes of the normal" rejected the Millennium March, while mainstream gay groups who sought to portray the gay community as "just like everyone else" turned to corporate sponsorship for the event. (Shepard, 2001, p. 50)

After two years of very public fighting, the march was boycotted by many organizations and although over 300,000 people attended, the turnout for the event did not meet the organizers' expectations. Criticisms of the march continued after it was over. Even those who praised the march in other ways observed that the crowd was predominantly White and the event lacked focus, anger or energy (see Engel, 2001). Gamson (2000) said that the march employed some of the most clueless organizing in American history. He described "a movement dominated by arrogant, corporate-style, money-driven organizations geared toward assimilation through the marketing of acceptable gayness" and explained how "as the HRC grew and presumptuousness morphed into power, it began to look a bit monstrous, like it was sucking up the movement and spitting it out in its own image" (Gamson, 2000, p. 2). Similar critiques were echoed by activists across the country (see Boykin, 2000; Duggan, 2003, etc.), in articles with titles like “The Emperor's New Clothes, Or How Not To Run A Movement” 
(Carter, 1999). Nevertheless, HRC continued to gain support. This support frequently came from non-activists who wanted to feel a little bit connected to the movement, so they wrote checks to the only gay organization whose name they had heard of, or attended apolitical gala dinners (Vaid, 1995).

Duggan (2003) charged that by the end of the century, "no longer representative of a broad-based progressive movement, many of the dominant national lesbian and gay civil rights organizations have become the lobbying, legal and public relations firms for an increasingly narrow gay, moneyed elite" (p. 45). The largest gay and lesbian organizations had become successful through the "marketing of a particular kind of gayness--for the most part, unsurprisingly, the white kind with money" (Gamson, 2000, p. 2). As more privileged White gays and lesbians became accepted by the media and the culture, "less marketable gay people--poorer or darker or older or more radical in their gender and sexual practices--remain mostly invisible" (Gamson, 2000, p. 2). The national gay and lesbian organizations had built up a donor base and, to a lesser degree, a constituency of affluent White gays and lesbians who were politically moderate. As the $21^{\text {st }}$ century began, it was this base that was represented by the mainstream gay rights movement.

\section{Conclusion}

For centuries, there was no conceptualization of LGBT as an identity. Same-sex relations were viewed initially by the American Puritan colonists as morally deviant sexual behavior, which evolved into a framework of criminalizing deviant sexual behavior. During the Progressive Era, the changes in capitalism and in gender roles worked in tandem with the medical community to lead to the creation of lesbian and gay 
identity. This identity was stigmatized by the helping professions (and ignored by the social work profession) and considered a social problem yet, nevertheless, led to the formation of gay and lesbian communities across the country.

During the course of the $20^{\text {th }}$ century, America's conception of homosexuality changed from a behavior to an identity. Communities formed around this identity, activism was sparked and institutions were built. A political agenda was developed, revised, debated, and advanced. However, White gays and lesbians have disproportionately felt the advancements made by the gay rights agenda. Other queer people built their own organizations that were ignored or overshadowed by the numerous organizations run by affluent White, gays and lesbians. By the end of the century, longstanding disagreements about goals and strategies were exacerbated by increased claims by people of color, low-income people, transgender people, and sex radicals, who did not seem themselves reflected in the mainstream gay rights agenda. The turn of the century found the movement at its most powerful yet fraught with increasingly insurmountable divisions. 


\section{Chapter 4: The Twenty-First Century}

This chapter focuses on the current state of LGBT communities and social movement activity. I begin by examining the progress made towards the existing agenda of the mainstream gay rights movement. I then turn my attention to the myriad needs and obstacles that remain unaddressed by the agenda of this movement. Following that, I present an overview of the numerous critiques, made by activists and scholars, of the gay rights movement. These critiques express frustration with the limitations of the gay rights movement, in part because of its failure to address the needs and obstacles I describe, and in part because of its corporate, assimilationist agenda.

Each of those sections implicitly examines the mainstream gay rights movement's targets of influence, targets of mobilization and targets of benefits. This information is then made explicit and used to analyze the GRM with the framework developed by Gamson (1990), for identifying and categorizing challenging groups, which was described in chapter 2 .

I then turn my focus to the queer liberation organizations that have emerged in order to tackle those needs and obstacles that have been unaddressed by the GRM. I use Fraser $(1995 ; 2003)$ to situate these organizations in a theoretical context. Finally, I examine the substantial splits in the movement today. In doing so, I set the stage for my research project questioning whether two distinct movements exist.

\section{Continued Progress for the Mainstream Gay Rights Agenda}

Fifteen years into the new century, the movement has sustained its institutionalization, and LGBT organizations continue to grow. The 40 largest LGBT organizations report combined 2012 budgets of $\$ 158.4$ million (an 11\% increase from the 
previous year) and employ 925 people, of whom 800 are full-time and 125 are part-time (Movement Advancement Project, 2012). Most of these organizations have annual budgets over $\$ 1$ million.

Public support for these institutions continues to grow each year. One measure of this can be found in the dramatic increase in philanthropic support that has been provided to the movement. In the 40 years between 1970 and 2010, hundreds of foundations have invested more than $\$ 771$ million in LGBT issues, 86\% of which (\$663 million) were awarded from 2000 to 2010 (Funders for LGBTQ Issues, 2012). This is an astonishing increase in a very short time. However, for LGBT people of color, funding is more difficult. In 2010, despite being $25 \%$ of the community, LGBT people of color received only 14 percent of the overall annual philanthropic support that went to LGBT issues (Funders for LGBTQ Issues, 2012).

The $21^{\text {st }}$ century has seen remarkable progress made on the political issues of greatest concern to the national gay rights organizations. In 2009, President Obama signed the Matthew Shepard and James Byrd, Jr. Hate Crimes Prevention Act. This law expanded federal hate crime law to apply to crimes motivated by a victim's actual or perceived sexual orientation, gender, gender identity, or disability. In 2011, a federal appeals court, congress, and President Obama approved various measures to end the 18year "Don't Ask, Don't Tell” policy that barred lesbian and gay people from openly serving in the military. Recently, in June 2013, the U.S. Supreme Court issued a 5-4 decision declaring sections of the Defense of Marriage Act unconstitutional. Lastly, the Employee Non-Discrimination Act has not yet passed, but it too seems probable. These four issues have been at the top of the national organizations' political agenda for two 
decades, and the majority of their resources have been dispatched in pursuit of these goals.

The mainstream gay rights movement has seen tremendously accelerated growth in the $21^{\text {st }}$ century. The GRM's increased resources and its clear and narrow focus on a limited, single-issue political agenda has resulted in incredibly swift progress on the issues that were prioritized.

\section{Needs and Obstacles Not Addressed by the Gay Agenda}

The GRM's crystal sharp focus on a limited agenda may have resulted in rapid progress on that agenda, but it has also meant that a huge array of issues have gone unaddressed. Most of these issues are of concern to communities of color, low-income people, transgender people and other subpopulations of the LGBT community. As the following section will demonstrate, these subpopulations face a host of obstacles and have a large variety of needs that are not present on the agenda of the mainstream gay rights movement.

The following section will show how the existing literature consistently debunks the myth of gay affluence and repeatedly documents economic hardship, disproportionate poverty rates, and multiple social service needs among LGBT communities. Whether looking at LGBT people overall or breaking it down into specific groupings of LGBT people by gender (e.g., queer women and transgender populations), race (e.g., Blacks, Latinos, Asian Americans, immigrants), or other categories (e.g., senior citizens, people with HIV/AIDS), the research is clear. Aggregated or divided into those subpopulations, the following studies will show that LGBT people experience lower incomes and higher 
poverty rates than the average American and have articulated health and social service needs that remain unaddressed.

\section{Income of LGBT people.}

The myth of gay affluence continues today in pop culture (McDermott, 2014), supported by new marketing surveys making the same claims about wealthy gay and lesbian consumers (Fetto, 2012). There is increasing research, however, that proves that this is not true.

The research does demonstrate that gay White men tend to be better off financially than other segments of the LGBT community (Albelda, Badgett, Schneebaum \& Gates, 2009). Yet their affluence too has been overstated in the popular imagination. Over the past twenty years, study after study has shown that gay men earn less than heterosexual men (Allegretto \& Arthur, 2001; Badgett, 1997; Badgett, 1998; Black, Gates, Sanders, \& Taylor, 2000; Elmslie \& Tebaldi, 2007; Gates, 2003; Gates, 2014). Even one study that claimed gay and lesbian couples are doing better than cohabitating heterosexuals conceded that same-sex couples bring in less income than heterosexual married couples (Prokos \& Keene, 2010). These studies contradict the public perception of the queer community as affluent, White gays and lesbians. An intersectional analysis requires that we complicate such essentialized constructs, and integrate issues of income, wealth and class into our understanding of LGBT lives (Samuels \& Ross-Sheriff, 2008).

In 29 states, employers are legally allowed to fire someone for their sexual orientation (McDermott, 2014). The Center for American Progress reported that "a root cause of lower incomes and poverty among adult gay and transgender Americans is the high rate of workplace discrimination they face" (Krehely \& Hunt, 2011, p. 8). Their 
research described unequal pay, barriers to health insurance, unfair hiring and promotion practices, and verbal and sexual harassment that created hostile and unsafe working environments. Their report found that gay men earn 10\%-32\% less income than their heterosexual male counterparts who are similarly qualified. Other studies come to similar conclusions (Badgett, Lau, Sears \& Ho, 2007; Elmslie \& Tebaldi, 2007), and found companies were less likely to hire an openly gay man than they are to hire a similarly qualified heterosexual man (Tilcsik, 2011). LGBT people in the states without protections are more likely to report household incomes below $\$ 24,000$ than those living in the states where workers are protected (Hasenbush, Flores, Kastanis, Sears, \& Gates, 2014).

The Williams Institute (Albelda, Badgett, Schneebaum \& Gates, 2009) undertook the first comprehensive analysis of the income of lesbian, gay, and bisexual people (they did not address transgender communities). Their report offered a comprehensive examination of poverty in LGB communities, with data specific to race, gender, age, and region. It found that gay men and bisexual men had poverty rates (15\%) that were slightly higher than those of heterosexual men (13\%). The report also found disproportionally high rates of poverty among lesbian couples and children in same-sex households.

Subsequent studies report similar trends. In an anonymous survey of Americans ages $18-44$, gay men were found to have a poverty rate of 20.5 percent; the rate for heterosexual men was 15.3 percent (Badgett, Durso, \& Schneebaum, 2013). Additionally, a 2014 report found that $29 \%$ of LGBT adults, approximately 2.4 million people, experienced a time in the last year when they did not have enough money to feed themselves or their family, and that same-sex couples are 1.7 times more likely than 
different-sex couples to receive food stamps (Gates, 2014). In fact, 21\% of LGB adults aged 18-44 (approximately 1.1 million people) and 43\% of LGB adults who were raising children (approximately 650,000 people), participated in the SNAP program through receipt of food stamps in the past year (Gates, 2014).

There is evidence that poverty rates are higher for same-sex couples living in rural areas. The Williams Institute report (Albelda, Badgett, Schneebaum \& Gates, 2009) found the official poverty rates for people in same-sex couples who lived in rural areas were twice as high as same-sex couples who live in large metropolitan areas, and they were also poorer than people in different-sex married couples who lived in rural areas. Another study reported that lesbian couples who live in rural areas are more than three times more likely to be poor than coupled lesbians in large cities (Badgett, Durso \& Schneebaum, 2013). Poverty gaps are at their highest in the Midwest and Mountain states, where LGBT individuals are almost 1.5 times more likely to have incomes below \$24,000 than non-LGBT people (Hasenbush, Flores, Kastanis, Sears, \& Gates, 2014).

\section{Homelessness.}

Homelessness has been documented as a problem facing LGBT adults. A recent report out of San Francisco found that one third of their homeless are gay (Allday, 2013). A survey of 165 self-identified low-income LGBT adults in New York (The Welfare Warriors Research Collaborative, 2010) found that the vast majority (70\%) had been homeless at some point in their lives. The majority of respondents were still not in permanent housing: $35 \%$ reported living in homeless shelters, $7 \%$ on the street/subways, $3 \%$ in SROs (Single Room Occupancies), and $26 \%$ with friends/relatives or in temporary living situations. Large cities, magnets for LGBT people, are just beginning to document 
this problem. In New York City, on any given night, thousands of LGBT people live in the homeless adult shelters (Duggan, 2012).

Incidents of discrimination are commonplace for lesbian, gay, bisexual and transgender homeless people throughout many cities' shelter systems. Information in shelters about support services or resources for homeless LGBT people, as well as structured training on LGBT issues for shelter personnel, are non-existent and LGBT relationships are not validated in recovery groups and other therapeutic programs (Duggan, 2012). LGBT homeless people have reported that in the shelters they regularly face harassment, threats of violence, or actual violence from security personnel, medical staff, administrative staff and other residents (Billies, Johnson, Murungi \& Pugh, 2009; Welfare Warriors Research Collaborative, 2010). In most municipalities, domestic partnerships are not given equal weight to marriage licenses, so gay and lesbian couples cannot access "family shelters" (Polikoff, 2008). As a result, they are often forced to choose between being sheltered but separated in the "single adult" shelters, or remaining together on the streets.

In a study of low-income LGBT people, they identified housing and homelessness, violence and discrimination as being of great importance (Billies, Johnson, Murungi \& Pugh, 2009). Interestingly, respondents never identified gay marriage (the top priority of the mainstream gay rights movement) as a concern to them.

\section{Poverty among lesbian and bisexual women.}

Utilizing the intersectional framework developed by Black feminists requires that we centralize the experiences of women and examine the role that gender plays in the economic lives of LGBT people, while simultaneously considering their sexual 
orientation (The Combahee River Collective, 1981; Crenshaw, 1989). In a country where women earn only $81 \%$ of the income earned by men, it should come as no surprise that the Williams Institute found that lesbian couples have much higher poverty rates than either different-sex couples or gay male couples (Albelda, Badgett, Schneebaum \& Gates, 2009). That study reported that same-sex couples and their children were significantly more likely to be poor than heterosexual married families, primarily because lesbian couples and their families were much more likely to be poor than heterosexual couples and their families. The researchers found that $24 \%$ of lesbians and bisexual women were poor, compared with only $19 \%$ of heterosexual women. Lesbian and bisexual women are more likely to receive food stamps and public assistance than were heterosexual women (Albelda, et al., 2009). Another study found that Latina and White lesbian and bisexual women in Jamaica Plain were about twice as likely to be without health insurance as their heterosexual female neighbors (Bowen, et al., 2004). And race is an economic factor among lesbian and bisexual women - Black female same-sex couples reported a median income of \$21,000 less than White female same-sex couples (Dang \& Frazer, 2005), and women of color who have sex with women are disproportionately affected by homelessness and poverty (Arend, 2005).

\section{Economic issues facing transgender people.}

When discussing intersectionality, Crenshaw (1997) addressed the question of which differences matter. She argued that this question causes power struggles that determine whether, and which, intersectional differences will be addressed in policy formulation. This is evident in the struggles within LGBT communities, which have seen those gay men with the most power pursuing public policy goals that exclude transgender 
people and their concerns (TransGriot, 2007). Yet an intersectional understanding of the LGBT community requires centralizing oppression rooted in gender, and against transgender identity, alongside questions of homophobia and sexual orientation (Monro \& Richardson, 2010). Doing so, and consequently acknowledging the following research, complicates and debunks the notion that all queer people are affluent White gay men.

It is abundantly clear that poverty rates among transgender people are much higher than in the general population or in the rest of the LGBT community. One study estimated that $65 \%$ were living in poverty (Badgett, Lau, Sears, \& Ho, 2007). Another report (San Francisco Bay Guardian \& the Transgender Law Center, 2006) found that while the official unemployment rate in San Francisco stood at 4.7 percent, more than $35 \%$ of the transgender community in the city was unemployed, and $60 \%$ were living in poverty. Forty percent did not have a bank account of any kind. Only $25 \%$ were working full-time. Sixteen percent were working part-time, and nearly nine percent had no source of income. Over 57\% reported experiencing employment discrimination. In 2011, the largest study ever conducted on the transgender community found that transgender people were twice as likely to be unemployed as the population as a whole and are nearly four times more likely to live in extreme poverty, with household income of less than $\$ 10,000$ (Grant, Mottet \& Tanis, 2011). In the years following welfare reform, unemployed transgender people seeking public assistance reported being so severely harassed at welfare work sites that they dropped out and turned to sex work on the streets, where they felt safer (Blum, DeFilippis \& Perrina, 2000). Reports from community organizations indicate that this harassment continued at welfare offices for years (Arkles, Gehi, \& Redfield, 2010; Audre Lorde Project, 2010). 
Black transgender people are particularly vulnerable to economic instability. One study found that Black transgender respondents had an extremely high unemployment rate at $26 \%$, two times the rate of the overall transgender sample and four times the rate of the general population (National Black Justice Coalition, the National Gay and Lesbian Task Force, and the National Center for Transgender Equality, 2011). Black transgender people lived in extreme poverty with $34 \%$ reporting a household income of less than $\$ 10,000$ per year. This is more than twice the rate for transgender people of all races $(15 \%)$, four times the general Black population rate $(9 \%)$, and eight times the general U.S. population rate of 4\% (National Black Justice Coalition, et al, 2011).

The existing data indicates that HIV has affected Black transgender people in devastating numbers. In a 2001 study of San Francisco, (Clements-Nolle, Guzman \& Katz, 2001) $63 \%$ of Black male-to-female transgender participants were living with HIV. A national study of Black transgender people, conducted a decade later, reported that more than one-fifth $(20.23 \%)$ of respondents were living with HIV (National Black Justice Coalition, the National Gay and Lesbian Task Force, and the National Center for Transgender Equality, 2011). This rate was lower than those found in the 2001 study, but still much higher than the general population.

One report (Grant, Mottet, \& Tanis, 2011) found that American Indian and Alaskan Native transgender and gender nonconforming people had a high unemployment rate $(18 \%)$ and often live in extreme poverty, with $23 \%$ earning less than $\$ 10,000$ per year. This is about three times the extreme poverty rate of the general American Indian and Alaskan Native population (8 percent), and nearly six times the general U.S. population rate (4 percent). 
In the past decade, research has documented the problem of transgender homelessness. Although there is no comprehensive data about the number of homeless transgender people, existing studies find consistent results. Three different studies found that approximately $20 \%$ of transgender people were homeless (Grant, Mottet, \& Tanis, 2011; National Center for Lesbian Rights, et al., 2003; Risser \& Shelton, 2002) - a rate that is wildly disproportionate with other populations, and which suggests that the problem is of crisis proportions. For Blacks, the situation is even worse; one study found that $41 \%$ of Black transgender people reported experiencing homelessness at some point in their lives, more than five times the rate of the general U.S. population (National Black Justice Coalition, the National Gay and Lesbian Task Force, and the National Center for Transgender Equality, 2011).

When transgender people seek shelter, they are frequently met with apathy or hostility (Duggan, 2012; Motta, 2011; Smith, 2003). In most cities, transgender homeless shelter residents do not have the option of choosing to be in the men or women's system and are forced to reside in whichever system matches their birth sex (Duggan, 2012; Motta, 2011). Transgender women residing in male shelters must contend daily with the risk of violence, rape and murder. Transgender homeless people often leave the shelter system because they are afraid for their safety and return to the streets (Duggan, 2012; Motta, 2011; Mottet \& Ohle, 2003).

In needs assessment surveys, when asked about their most pressing concerns, transgender people have prioritized job discrimination, job training, legal services, housing, welfare benefits, HIV/AIDS, hate violence, and barriers to health-care access 
(Battle, Cohen, Warren, Gergerson, \& Audam, 2002; Kenagy, 2005; Kenagy \& Hsieh, 2005).

\section{Poverty among people of color.}

Numerous authors have claimed that the national gay rights organizations ignore the issues facing LGBT people of color (see Carter, 1999; Cohen, 1999; Conrad, 2010; Farrow, 2012; Grundy \& Smith, 2007; Vaid, 2012). They have advocated using a framework that goes beyond just the narrow focus on homophobia and utilizing intersectional understandings of LGBT lives that addresses the experiences of people of color. To do so would immediately shed light on the issue of vast economic inequalities that shatter the myth of gay affluence.

The Williams Institute analysis of US Census data suggests that at least $25 \%$ of the LGB community consists of people of color, comprised in roughly the same proportion as in the larger society (Albelda, Badgett, Schneebaum \& Gates, 2009). LGBT people of color, like their heterosexual counterparts, generally make less money than White men and women (Dunn \& Moodie-Mills, 2012). White gay men in same-sex couples have poverty rates of $2.7 \%$, compared to $4.5 \%$ of Asian or Pacific Islander, $14.4 \%$ of Black, and $19.1 \%$ of Native American gay men (Albelda, et al., 2009). Disparity in the income, employment, education attainment, and home ownership of persons in same-sex couples is strongly associated with race and ethnicity (Sears, Gates \& Lau, 2006). One study (Human Rights Campaign, 2009) found that $21 \%$ of LGBT people of color reported being denied a job or fired because of being an LGBT person, and $27 \%$ reported being denied a job or fired because of race or ethnicity. A study of Black and Latino men who have sex with men found that over a third of the participants 
had an annual income under $\$ 5000$ (Bond, et al., 2009). In addition, the healthcare needs of LGBT people of color have gone unmet (Charles \& Conron, 2002). Because the term "people of color" encompasses many different communities, there have also been studies that examine specific racial groups separately.

Black LGBT people are more likely to experience poverty than their White or heterosexual counterparts. Four separate studies found that same-sex Black couples experience significantly higher poverty rates than Black heterosexual couples - with one of the studies finding the poverty rate to be twice as high for Black same-sex couples (Albelda, et al., 2009; Badgett, et al., 2013; Dang \& Frazer, 2005; Ramos. \& Gates, 2008). These same studies also found that same-sex Black couples also had significantly higher poverty rates than those of White same-sex couples - with one study finding that they had poverty rates that were three times higher than those of White same-sex couples (Albelda, et al., 2009). One study broke down the White-Black comparison by gender, and found that Black male same-sex couples reported a median income of $\$ 23,000$ less than White male same-sex couples, and that Black lesbian couples reported a median income of \$21,000 less than White female lesbian couples (Dang \& Frazer, 2005). Another study found that Black gay and bisexual men had household incomes that were 44\% lower than heterosexual peers (Gates \& Ramos, 2008). Consequently, Black LGBT families are struggling financially. When compared to opposite-sex Black families, gay families had far lower incomes (Gates \& Ramos, 2008). Black children in gay male households have the highest poverty rate $(52.3 \%)$ of any children in any household type in America (Badgett, et al., 2013). Families headed by Black same-sex couples are more likely to raise their children in poverty and Black lesbians are more likely to suffer from 
chronic diseases (Moodie-Mills, 2012). Home ownership rate of Black individuals in same-sex couples raising children has been reported at $20 \%$, compared to $63 \%$ of those in different-sex marriages raising children (Gates \& Ramos, 2008). This disparity is not a new phenomenon. In 1990, a household headed by a Black lesbian was twice as likely as a household headed by a White lesbian to earn less than $\$ 10,000$ per year (Ettelbrick, Bradford \& Ellis, 2001). A decade later, in a survey of participants at "Black Pride" events, $12 \%$ of respondents had a household income of less than $\$ 15,000$ (Battle, Cohen, Warren, Gergerson \& Audam, 2002). The findings from these studies indicate that the problem of poverty among Black LGBT people has persisted for decades, despite remaining largely invisible.

Various studies have examined the concerns and priorities of Black LGBT people. The findings from these studies show that Black LGBT people were concerned about issues such as jobs and financial security, health care access and education before civil rights issues like marriage and partner protection (see Battle, Cohen, Warren, Gergerson, \& Audam, 2002; Ramsey, Hill \& Kellam, 2010; Vaid, 2012; Victoria \& Belcher, 2010). One study found that the top two issues that LGBT people of color prioritized as most important to them were affordable health care and jobs/the economy (Human Rights Campaign, 2009).

LGBT Latinos are not faring much better economically. Hispanic lesbian couples have encountered poverty rates three times those of non-Hispanic lesbian couples (Albelda, et al., 2009). In a three-city study of gay and bisexual Latino men, the majority had run out of money for necessities in the prior 12 months (Diaz, Ayala, Bein, Henne \& Marin, 2001). When comparing heterosexuals against lesbian, gay, and bisexual people, 
and broken down by race, the Center for American Progress found that LGB Latino adults were the group least likely to have health insurance, while White heterosexuals were the group most likely to (Kreheley, 2009).

LGBT Asian-Americans are doing better financially than other LGBT racial minority groups, but are still struggling to get by. A survey of three cities (Asian American Federation of New York, 2004), found that in Los Angeles and New York, $17 \%$ of Asian same-sex households earned less than $\$ 25,000$ and in San Francisco about $10 \%$ of Asian same-sex households earned less than $\$ 25,000$. Asian lesbian households had substantially lower household incomes than Asian gay households. Another study (Dang \& Hu, 2004) of LGBT Asian-Americans found that $40 \%$ earned less than $\$ 40,000$ a year, and almost half of those people earned less than $\$ 12,000$ a year.

In a study by NGLTF (Dang \& Hu, 2004), LGBT Asian Pacific Americans indicated that the three most important issues facing LGBT APA people were immigration, hate violence/harassment, and media representation.

There is not a lot of research about the needs of Two Spirit or LGBT Native Americans. Research by The Williams Institute in 2009 (Albelda, et al., 2009) found that Native American men in same-sex couples had poverty rates of $19.1 \%$ (compared with 2.7\% of White men in same-sex couples). However, their 2013 research (Badgett, Durso, \& Schneebaum, 2013) found that the poverty rate of Native American men in same-sex couples was only at $8.1 \%$. That 2013 research also found that Native American women in same-sex couples had a poverty rate of 18.4 , which is much higher than white female couples (5.8\%), white different sex couples (4.8\%), or Native American different-sex couples $(12.6 \%)$. 
HRC conducted a survey of 727 LGBT POC, and convened nine focus groups in 2007 and 2008 to research the priorities and experiences of LGBT POC who were interacting with the LGBT movement. The overall issues that LGBT POC prioritized as most important to them were, in order: affordable health care (89\%), jobs and the economy (84\%), equality for people of all races and ethnicities (83\%), prevention and treatment of HIV (80\%), and equality for LGBT people (79\%). When the survey asked about prioritizing existing LGBT issues, violence and job discrimination were ranked most important (80\%); civil unions ranked third at 70\%; adoption was fourth at $66 \%$ and marriage and military inclusion were cited by $60 \%$ of respondents as very important (Human Rights Campaign, 2009).

\section{Issues facing immigrants.}

Mehrotra (2010) proposes a continuum of intersectionality, incorporating a range of perspectives "that goes beyond the usual triumvirate of U.S. racial, class, and genderbased oppressions" (p. 418) to include, among other things, nation and migration. Immigration laws in the United States are, for the most part, centered around two constructs: "merit" and the reunification of "families." Immigration discussions of family define it as the heterosexual nuclear family, which means that LGBT relationships are mostly outside the scope of immigration law. Consequently, most immigrant groups operate on the assumption that the people they serve live in heterosexual relationships. As a whole, more complex family structures -- such as those of bi-national same-sex couples and extended families -- are completely absent from the larger struggle for immigration reform. The immigrant advocacy movement places undue emphasis on heteronormative relationships and conceptions of normality in an effort to gain basic citizenship rights. 
Meanwhile, the mainstream LGBT rights movement tends to focus on those immigrants who are partners of US citizens (Nair, 2008). This leaves out the predicament of, for instance, single people and/or those who do not define themselves within conventional relationships like marriage or conjugality. The result is that LGBT immigrants are mostly marginalized within the immigrant rights movement (because of the hetero-normative nature of immigration policies), and the LGBT movement. They lack support as they contend with homophobia and transphobia within their communities of origin, and xenophobia and racism within the LGBT movement. This coupled with immigration restrictions upon accessing public benefits has contributed to heightened poverty within LGBT immigrant communities, and therefore LGBT immigrant communities are left to fend for themselves. At this time, most organizations do not assist queer immigrants who are already in the country and struggling to make a living.

There is a dearth of data about LGBT immigrants in this country. This is despite the fact that existing research demonstrates that it is not a small population. For instance, in a survey of three cities, most Asian gays and lesbians living with their partners were recent immigrants (Asian American Federation of New York, 2004). The Williams Institute at UCLA estimates that at least 904,000 LGBT immigrants live in the United States, almost a third of who are undocumented (Gates, 2013). And because LGBT undocumented people find themselves at the intersection of two already marginalized groups - the LGBT population and the undocumented population - they are among society's most vulnerable individuals. The Williams Institute report found that noncitizens in same-sex couples earn about half the income of naturalized citizens (Gates, 2013). A survey by the New York City government found that almost one out of three 
lesbian, gay, and bisexual (LGB) immigrants in New York City had experienced food insecurity in the 30 days prior to the survey (NYC Department of Health and Mental Hygiene, 2006). The same study also found that LGB immigrants were more than twice as likely to lack health insurance than either U.S. born LGB people or U.S. born heterosexuals. In addition, more than $20 \%$ of the LGB foreign-born population in that study reported that, because of the costs, they had not received health treatment that they needed (NYC Department of Health and Mental Hygiene, 2006). For those immigrants who came here seeking asylum, we know that many are struggling after settling in this country. LGBT asylum-seekers likely have experienced significant trauma, often have few financial resources, and face linguistic, cultural, and racial oppression as members of targeted groups (Potocki-Tripodi, 2003).

In 2007, a vision statement, outlining the needs and political priorities of LGBT immigrants, was signed by 50 organizations (DasGupta, 2012). The needs and issues about which they expressed concern were varied. They included the policing of the border, the HIV ban, the process of applying for asylum, the guest worker program, the provisions for harboring, an end of immigrant detentions, eliminating the high income requirements for immigrant sponsors, an end to the one-year deadline for asylum application, broader definitions of family (beyond marriage) and kinship patterns for sponsorship. The issue of bi-national couples (the sole focus of the national gay rights organizations) was included but was not one of the higher priorities. The 50 organizations that signed the document represented a coalition of immigrant rights organizations, LGBT organizations and the handful of LGBT immigrant organizations that exist in the country. Most of the LGBT groups who signed on were small, local organizations - the 
majority of the national LGBT organizations refused to sign on or address these issues in their work (DasGupta, 2012).

\section{Economic issues related to age.}

It is now commonly understood by both social work practitioners and gay rights organizations that LGBT youth face discrimination that results in economic struggles and social service needs. Relative to other LGBT populations, more resources have been directed at studying and supporting LGBT youth. Numerous studies have documented how they are disproportionately homeless (Krehely \& Hunt, 2011; Ray, 2006; Reck, 2009), lack health insurance (National Youth Advocacy Coalition, n.d.), and are overrepresented in the foster care, juvenile justice, and shelter systems, and are more likely to turn to sex work in order to survive (Covenant House Institute, 2009; Lambda Legal Defense and Education Fund, 2001). The mainstream gay rights movement recognizes that LGBT youth face these obstacles and has devoted more resources towards this population than it has to any of the other groups described in this section, so I turn my focus to the other end of the age spectrum.

An examination of LGBT lives grounded in an intersectional lens must also examine the question of aging (Cronin \& King, 2010). While LGBT elders are an enhanced and significantly more at-risk senior population than their comparable heterosexual seniors in the United States, they remain unrecognized and underserved within the diverse aging demographics and communities where they reside. These are elders who, when younger, have commonly wrestled with issues of poverty, job discrimination, substance abuse, HIV/AIDS, incarceration, and homelessness. Often they are members of communities of color, rural, transgender, disabled, single, immigrant or 
very old people, or some combination of the above. These at-risk LGBT elders are underserved by the LGBT advocacy, service and political organizations and the broader senior support structures, organizations and providers in this country (Hollibaugh, 2012).

Existing data about LGBT seniors indicates that they live in economic hardship. Lesbian couples over 65 are twice as likely to live in poverty as heterosexual married couples (Albeda, et al., 2009; Fitzgerald, 2013). In one of the few studies asking this population about their needs, lesbian seniors identified economic insecurity as one of their greatest concerns (Beeler, Rawls, Herdt \& Cohler, 1999). Although this study is from 1999, there is not more current information about their stated needs, and other research gives us no reason to believe that their priorities would be different now. For instance, a study in Chicago found that $20 \%$ of LGBT seniors survived on less than $\$ 20,000$ a year (Beauchamp, Skinner \& Wiggins, 2003). Another study of older LGBT people found that $65 \%$ had incomes of less than $\$ 45,000$ a year (and almost $20 \%$ lived on less than $\$ 15,000$ a year) and were struggling to obtain the legal and mental health services that they needed (Smith, McCaslin, Chang, Martinez \& McGrew, 2010). Because of homophobia, LGBT people are often forced to move to urban centers in order to live openly, and because of their class status, many struggle to live in these more expensive municipalities (Hollibaugh, 2012). LGBT seniors cannot count on family members to supplement their meager incomes. A 2004 study of 341 LGBT elders found that $62 \%$ lived alone and only $22 \%$ had children to help support them as they aged $(\mathrm{Hu}$, 2005). Five years later another study found that LGBT seniors are more likely to live without the financial support of any family member (Movement Advancement Project \& Services and Advocacy for GLTB Elders, 2010). 
Consequently, LGBT elders are especially dependent on public/private services for seniors. Many federal programs designed for seniors, however, are inaccessible, ineffective, or irrelevant to LGBT elders. Legal and policy frameworks often exclude LGBT elders from essential financial resources (Hu, 2005; Movement Advancement Project \& SAGE, 2010). Many LGBT older people have fewer retirement resources such as Social Security or traditional pension plans because transphobia and homophobia had forced them to spend their lives working in restaurants, bars, the sex industry or other aspects of the underground economy (Hollibaugh, 2012). Transgender elders and partners may/may not be able to access Social Security spousal, survivor, or disability benefits because different states may/may not recognize gender transition, and preliminary evidence suggests that transphobia in senior services is pervasive (Hu, 2005).

LGBT seniors face a variety of health issues. They are twice as likely to selfidentify as being in poor or fair health than younger people. In one study, elders said that the most pressing problem they dealt with was "chronic illness" - including hypertension, ALS, various cancer, heart disease, Alzheimer's disease, and HIV/AIDS (Beauchamp, Skinner \&Wiggins, 2003). Studies have found that limited financial resources and the cost of medical care were frequently cited by LGBT seniors as their major concerns, and their other priorities are social interactions and accessible places to live (Beeler, Rawls, Herdt, \& Cohler, 1999; Gabbay \& Wahler, 2002; Smith, McCaslin, Chang, Martinez, \& McGrew, 2010).

\section{Lack of access to health insurance.}

As explained earlier, LGBT families struggle with poverty. Consequently, they are frequently forced to choose between health care and other necessities (Redman, 2010). 
Because of employment discrimination, LGBT people have less chance to benefit from employer-based health insurance. LGB adults are less likely to have jobs that provide insurance coverage than are non-LGB adults (Krehely, 2009). According to one study, nearly one in four gay and lesbian adults lack health insurance and are nearly twice as likely as their heterosexual counterparts to have no health insurance coverage (Harris Interactive Poll, 2008). Even in places with higher rates of health insurance coverage, we see this has been true. For instance, in 2004 , while $7 \%$ of the total population of Minnesota was without any health insurance, one study found that $22 \%$ of LGBT Minnesotans did not have any insurance (The Rainbow Health Initiative, 2004).

Those LGB people who do have insurance can rarely cover their partners. A 2011 report by the United States Department of Labor found that only $25 \%$ of workplaces provide healthcare benefits that include coverage of their employees' domestic partners (Solis, 2011). In addition, when employers do provide same-sex benefits, LGB recipients are taxed at different rates than their heterosexual counterparts. Employment benefits provided to an employee's domestic partner is counted as taxable income, whereas it is not taxed for a heterosexual employee's spouse. Consequently, same-sex couples pay thousands of dollars more for health care coverage than similarly situated heterosexual couples (Seigel-Bernard \& Lieber, 2011).

With these barriers to employer-provided insurance, many LGB people have had to consider buying their own coverage. Because of the high cost of obtaining private health insurance, many LGB people go without insurance (Fitzgerald, 2013). Without health insurance, preventive care may be inaccessible and many LGB people decline treatment until their health concerns become unmanageable (Fitzgerald, 2013). 
This issue is even more pronounced among transgender communities. High rates of joblessness and poverty in transgender populations, especially those of color and trans youth, frequently result in a lack of health insurance or underinsurance. One study found that $47 \%$ of predominately Black transgender people in a Washington D.C. study are without health insurance (Xavier, 2000). This figure matches a transgender needs assessment that found that nearly one half of survey respondents lacked any kind of health insurance coverage (Grant, Mottet, \& Tanis, 2011). This is more than double the percentage of people in California who lacked health insurance in 2000 (National Center for Lesbian Rights and the Transgender Law Center, 2003). And this statistic does not measure the percentage of respondents who had insurance, but who still had to pay out of pocket for transition related procedures or procedures that are tangentially related to or exacerbated by transition (National Center for Lesbian Rights, et al., 2003). Nearly all U.S. health care insurers exclude trans health services such as hormonal therapy and sex reassignment surgery, and there is anecdotal evidence suggesting that even post-operative transsexuals may be unable to keep or obtain health insurance if their transsexual status is revealed to their insurers (Human Rights Campaign, 2013; National Coalition for LGBT Health, 2004). In addition, care is sometimes also denied to transgender people seeking medical care related to their sex assigned at birth. For instance, transgender men are often deprived of gynecological services after informing the insurance company of their gender transition (Transgender Law Center, 2013). 


\section{Obstacles to creating families.}

Gay marriage and coupling are not the only ways in which LGBT people create families. Numerous other family forms have been created, both inside and outside of existing legal frameworks.

Many LGBT people are parents. It is difficult to locate gay and lesbian parents due to fears that they would lose custody and/or visitation rights by disclosing their sexual orientation. Regardless, some broad estimates exist of the numbers of gay and lesbian parents in the United States.

Nationally, the number of lesbian mothers has been estimated to be anywhere from one to five million, and those for gay fathers from one to three million (Lambert, 2005). The number of children being raised by gay and lesbian parents is estimated to be between four to fourteen million (Lambert, 2005). Some of are foster children. An estimated 500,000 children live in foster care, $3 \%$ of whom are being raised by gay and lesbian parents (Gates, Badgett \& Chambers, 2007). Many other children of LGBT parents have been adopted. In fact, gay and lesbian couples are raising $4 \%$ of all adopted children in the US, and are adopting at a higher rate than single heterosexuals. (Gates, Badgett, Macomber, Chambers, 2007). Yet, a survey of 307 adoption agencies nationwide in 1999 and 2000 found that more than a third would reject a gay or lesbian applicant (Evan Donaldson Adoption Institute, 2003).

Not surprisingly, many queer parents have not adopted. Terry Boggis, an activist who has worked for over 20 years advocating for the rights of queer families, explained that LGBT parents also create families in a variety of other ways (Boggis, 2012). These include: gay couples and lesbian couples generating a baby together and co-parenting, as 
four parents; lesbian couples using known sperm donors or inseminating with sperm donated by a friend or family member; using "adopted" embryos and then co-parenting with the heterosexual couple that generated the embryo; and gay men hiring surrogates who remain in the child's life long-term. Many of these families remain complicated and large, often with multiple parents or parental figures (gay and lesbian couples coparenting, sperm donors or surrogates remaining in the child's life after birth, etc). Boggis argues that rather than being confusing, it has been helpful for queer families. She refers to it as a framework of "abundance" - an abundance of love, an abundance of support - for the children conceived in such complicated ways (T. Boggis, personal communication, July 27, 2014).

Parenting rates among LGBT people of color are higher than among White LGBT people. More than half of all GLB Black, API, and Latino couples between 25 and 55 were raising kids $(43 \%, 45 \%$ and $62 \%$, respectively) versus $18 \%$ of White same gender couples (Wilson, 2007). One out of every five children under 18 years old living in a same-sex couple family is poor, compared to almost one in ten children in different-sex married couple (Albelda, Badgett, Schneebaum \& Gates, 2009). Same-sex couples and their children are significantly more likely to be poor than heterosexual married families, largely because lesbian couples and their families are much more likely to be poor than heterosexual couples and their families.

When looking at families with children, $22 \%$ of same-sex female couples are low income compared to $20.9 \%$ of those in different-sex married couple families and $14.2 \%$ in same-sex male couple families (Albelda, et al., 2009). Same-sex female couples with children are more likely to be classified as low income (200\% of the federal poverty line) 
than different-sex married couple families (Albelda, et al., 2009). There is very little research about the economic status of queer single parents.

In addition to parenting and marriage, LGBT people frequently create families in other ways. Boggis calls these different configurations "caregiving communities" (T. Boggis, personal communication, July 27, 2014). These constructions of families are varied and complicated. Increasingly, LGBT senior citizens create "Golden Girls" arrangements, living together and/or making legal contracts to care for each other (Boggis, 2012; Queers for Economic Justice, 2006a). Young queer people of color still create family structures in the different Houses of the ballroom scene (Arnold \& Bailey, 2009). Some LGBT adults create long-term, committed polyamorous relationships (Boggis, 2012; Queers for Economic Justice, 2006a). LGBT people are also more likely than their heterosexual siblings to be responsible for taking in an aging parent to care for them $(\mathrm{Hu}, 2005)$. There are no existing legal frameworks for these relationships, and they remain unprotected in court and unsupported by government programs.

\section{HIV/AIDS.}

Although HIV/AIDS is by no means a crisis faced exclusively by LGBT people, it remains a serious problem in LGBT communities. The rate of new HIV diagnoses among men who have sex with men (MSM) in the United States is more than 44 times that of other men (Centers for Disease Control and Prevention, 2012). MSM account for nearly half of the approximately 1.2 million people living with HIV in the United States and comprise $61 \%$ of new infections (Prejean, et al., 2011; Centers for Disease Control and Prevention, 2012). A seven-city survey indicates that new HIV infection is substantially higher for young Black gay and bisexual men than for their White or Latino counterparts 
(Centers for Disease Control and Prevention, 2001). HIV has affected Black transgender people in devastating numbers. In one study, more than one-fifth $(20.23 \%)$ of respondents were living with HIV (National Black Justice Coalition, the National Gay and Lesbian Task Force, and the National Center for Transgender Equality, 2011), and in a San Francisco study, 63\% of Black male-to-female transgender participants were living with HIV (Clements-Nolle, Guzman \& Katz, 2001). HIV/AIDS has become a disease of poverty, disproportionately impacting low-income people (Kelland, 2010). In fiscal year 2006, Medicaid accounted for $51 \%$ of domestic federal spending on HIV/AIDS care (Medicare accounted for $26 \%$ of federal HIV/AIDS spending) and now $57 \%$ of all people with HIV/AIDS using public benefits in order to pay for drugs and health care (Kaiser Family Foundation, 2009). A study of Black and Latino MSM found that over a third of the participants had an annual income under $\$ 5000$ (Bond, et al., 2009).

Yet, according to the Community HIV/AIDS Mobilization Project (CHAMP), of the gay and bisexual men surveyed in 15 cities, $85-92 \%$ percent of all MSM at risk for HIV do not encounter prevention intervention services (Davids, 2011). The conventional focus on changing individual behaviors, as well as the narrow range of HIV prevention programs, does not address the structural factors that exacerbate the AIDS epidemic. CHAMP argues that effective prevention is also about systemic change, and believes that the AIDS epidemic cannot be ended without universal health care; housing; drug sentencing reform and economic reforms, among other expansive measures (Davids, 2011).

However, the $21^{\text {st }}$ century has seen the reduction, rather than the expansion, of the gay rights movement's fight against HIV/AIDS (Andriote, 2013). Urvashi Vaid (2012) 
argues that gay men, particularly those with good insurance and access to drugs, decided that AIDS was no longer a crisis, and stopped donating to, and volunteering at, HIV/AIDS organizations. Since government support only existed because of constituency pressure, once that pressure decreased, so did the government support. "Fourteen years later, the epidemic still continues and spreads, uncontrollable and far from over for the poor, the disempowered and the weakest among us" (Vaid, 2012, p. 62).

\section{Criminal justice.}

Police harassment of the LGBT community remains rampant. Queer people of color, youth and transgender people are particularly targeted by law enforcement, and regularly face police brutality (Cammett, 2009, Donahue, 2011; Kohn, 2001; Mogul, Ritchie, \& Whitlock, 2011; Stern, 2012). Racial profiling combined with homophobia leads to queer people of color facing disproportionate arrest rates (Gore, Jones, \& Kang, 2001). Once on trial, LGBT people frequently find that their sexual orientation or gender identity is used to bias juries. Lesbians are portrayed by prosecutors as being hard (read: manly) and gay men are portrayed as deviant (read: child molesters), and these characterizations contribute to higher conviction rates (Kohn, 2001). Indeed, they face problems with the criminal justice as a whole. It has "a toxic effect on queer communities at every conceivable level: the marginalization and subsequent criminalization of queer youth; bias in the judicial system; trauma during incarceration in prisons and jails; and in disproportionate sentencing, particularly death penalty cases" (Cammett, 2009, p. 11).

Transgender people are particularly impacted. One study found that 14 percent of the transgender respondents reported serving time in prison or jail at some point in their lives (National Center for Lesbian Rights and the Transgender Law Center, 2002). This 
was double the national average incarceration rate of people in the country as a whole.

Once in prison, transgender people continue to be targeted. They are subject to excessive punishment and overuse of segregation, and must contend with transphobic healthcare, including denial of hormones and discrimination in even routine medical attention (Rosenblum, 1999). They are housed in men's or women's prisons based on their genitalia, regardless of how they may identify (National Center for Lesbian Rights, 2006) and once there they face rampant physical and sexual abuse (Jenness, Maxson, Matsuda, \& Sumner, 2007).

LGBT people have been engaged for decades in activism about the criminal justice system (Gossett, Gossett, \& Lewis, 2012), and currently there are small queer organizations that have devoted most (or all) of their attention to this issue (Gore, Jones, \& Kang, 2001; Gossett, 2011; Gossett, Gossett, \& Lewis, 2012; Stern, 2012). Yet these campaigns are overlooked by the mainstream press and the gay press, and these organizations are underfunded by gay (and non-gay) foundations.

\section{Social Work.}

Despite this growing body of research, the profession of social work has yet to recognize queer poverty as a social problem. In the last decades of the $20^{\text {th }}$ century, social work began serving LGBT people in various arenas, but the concept of queer poverty has not yet entered the profession in any substantial way. The dozens of research articles that I have summarized on the last 20 pages is almost entirely from outside of the Social Work literature. The profession has utterly failed to recognize LGBT poverty as a social problem. In February, 2014 I conducted Google Scholar searches of twelve Social Work journals: Affilia, Child \& Family Social Work, Clinical Social Work Journal, Critical 
Social Work, Journal of Family Social Work, Journal of Gay \& Lesbian Social Services, Journal of Social Work, Journal of Social Work Education, Journal of Social Work Values and Ethics, Qualitative Social Work, Social Work \& Society, and Social Work Today. These searches failed to turn up even a single article that was focused on LGBT poverty. Although poverty was, on occasion, addressed as a side issue in some Social Work articles about various LGBT subpopulations (e.g. transgender youth), I found no articles that focused on LGBT poverty as a fundamental crisis in the lives of multiple LGBT communities.

On those occasions when poverty issues are at least mentioned, it is frequently brought up in the context of relationship recognition by scholars who, for example, use access to poverty-reducing Social Security benefits as part of an argument about the importance of marriage equality (e.g., Hughes, Harold, \& Boyer, 2011). In this way, Social Work has taken a page from the playbook of the mainstream gay rights movement, which positions marriage as an anti-poverty strategy (having taken their own page from the compulsory marriage efforts spearheaded by conservatives).

Social work must address LGBT poverty in all aspects of its practice. The research documented in this chapter demonstrate that the profession must start to incorporate the impact of poverty, racism, ageism, immigration status, criminalization, and other issues into its micro-level work with LGBT adults and their families. Similarly, macro-level practitioners must address structural issues (capitalism, institutional racism, immigration policies, the criminal justice system, etc.) as they simultaneously pursue their existing civil rights agenda. 
For example, social workers must be trained about the impact of poverty on their LGBT clients. Poverty among LGBT people consistently manifests in ways that are both similar to and different from those experienced by other poor people, and low-income LGBT people have been uniquely impacted by the dismantling of welfare and the public safety net (Audre Lorde Project, 2010; Blum, DeFilippis, \& Perrina, 2000; Cahill \& Jones, 2001; DeFilippis, 2001; DeFilippis, 2012b; Krehely \& Hunt, 2011; Welfare Warriors Research Collaborative, 2010). Therefore, it is important that social work students be trained about LGBT families when taking classes about welfare policies. One participant-led research project (Billies, Johnson, Murungi \& Pugh, 2009; The Welfare Warriors Research Collaborative, 2010) sought to better understand the challenges that face gay and transgender individuals who have low incomes. Among their findings was the fact that need-based public benefits (food stamps, public assistance, and housing assistance) and health-related public benefits (Medicaid, Social Security Disability, and HIV/AIDS Service Administration benefits) had been used by $80 \%$ of respondents, but they had numerous obstacles accessing them - including consistent discrimination from welfare case managers. Social workers regularly interact with these public benefits systems and need to understand the ways in which they impact LGBT people. This is just one example of how the profession of social work can address LGBT poverty issues in its practice. I examine other examples in the final chapter of this dissertation.

\section{A Fractured Movement}

\section{The race and class divide.}

The research presented earlier in this chapter illustrates that LGBT communities face many life-and-death issues. Yet, Social Work is not the only field that has failed to 
address those issues. At the same time that more money is raised and spent on the battle for gay marriage, the mainstream gay rights movement maintains a stony silence about these other issues. Tens of millions of dollars have been poured into the fight for marriage equality across the country at the expense of addressing issues that are more urgent for so many LGBT people. Economic justice and racial justice are still not generally considered "gay issues" by LGBT national organizations, elected officials, funders, statewide organizations, and media. Urvashi Vaid, a longtime leader in the gay rights movement, summarized it in this way:

Few LGBT organizations are engaged in articulating a new urban policy, seeking a more effective response to homelessness and poverty, or using their clout in the service of universal health care. Today's mainstream LGBT movement is strangely silent on the broader social-justice challenges facing the world, oddly complacent in its acceptance of racial, gender, and economic inequalities, and vocal only in its challenge to the conditions facing a white, middle-class conception of the "status queer." (Vaid, 2012b, para 9)

Numerous activists have claimed that these issues are ignored because the leadership of the GRM does not reflect the diversity of the communities they claim to represent (Carter, 1999; Cohen, 1999; D’Emilio, 2012; Vaid, 2012). With few exceptions, the Directors of the national LGBT organizations have been White and middle class. In a 2011 survey of the 40 largest national LGBT advocacy organizations, only two were led by people of color and both of those were POC-specific organizations (Vaid, 2012). "Gay issues" are, for the most part, determined by those people for whom the inability to get married is the only real form of discrimination they face on a daily basis. While certainly some social movements have had leaders who have advocated for people unlike themselves, this does not appear to be the case in the current gay rights movement. For 
GRM leaders, what constitutes a "gay issue" is limited by and to the concerns of White, gender-conforming, financially secure American citizens like themselves.

Cohen (1999) voiced concern about leadership of "those individuals who consistently activate only one characteristic of their identity, or a single perspective of consciousness, to organize their politics, rejecting any recognition of the multiple and intersecting systems of power that largely dictate our life chances" (1997, p. 440). Leadership of this kind, she argued, fails to address the multiplicity of issues that face many queer people who are not White, middle-class men. Hutchinson (2001) made a similar argument, explaining that the racial, class, and gender privileges of the leaders of LGBT organizations are the reason most gay political agendas are more interested in "formal" equality under the law than they are with changing structural barriers (such as poverty and institutionalized racism and sexism) to essential society resources.

As these White-led national LGBT organizations become largely supported by middle-class, White memberships, they pursue the agendas that are of concern to middleclass White people. They set the political agenda and then, after the fact, they may hire people of color to "do outreach" to sell that agenda to minority communities (DeFilippis, 2012a). More often than not, this outreach fails, as people of color and poor communities do not see themselves reflected in the mainstream gay agenda, which remains de facto White and middle-class (Vaid, 2012).

Consequently, in the last twenty years, activists of color have increased their demands for an intersectional analysis and multi-issue organizing that incorporates issues of race, class, economics, gender, and sexual orientation (Applied Research Center, 2012; Cohen, 1999; D’Emilio, 2012; Duggan, 2003; Gore, Jones, \& Kang, 2001; Hutchinson, 
1999; McMichael \& Wallace, 1999; Richardson, 1999; Vaid, 2012). The national LGBT organizations (and statewide equality organizations) have responded to these demands by insisting that they have no choice but to concentrate on issues that are "exclusively gay" (Birch, 1999; Farrow, 2012). They argue that the exclusive problems faced by LGBT people are difficult enough, and that our organizations simply do not have the resources to address broader concerns even if they wanted to. To imagine otherwise is deemed "unrealistic" (Birch, 1999, DeFilippis, 2012a).

Yet examples of queer multi-issue work abound (see, for examples, Applied Research Center, 2010; Applied Research Center, 2012; Billies, Johnson, Murungi, \& Pugh, 2009; Currah, 2008; DasGupta, 2012; Donahue, 2011; Duberman, 2009; Funders for Lesbian and Gay Issues, 2005; Gore, Jones, Kang, 2001; Gossett, 2011; HoSang, 2006; Jones-Yelvington, 2008; Mananzala, 2012; Mananzala \& Spade, 2008; McMichael \& Wallace, 1999; Pulliam \& Mott, 2010; Queers for Economic Justice, 2008; Shepard, 2004; Stern, 2012; Taylor, 2012, Vaid, 2012). This multi-issue work, however, is not happening in the national LGBT organizations or the statewide equality organizations. It is happening in grassroots queer organizations across the country. However, the largest LGBT organizations refuse to value it (Farrow, 2012).

Instead, the largest LGBT advocacy organizations in the USA have been spending the majority of their labor and finances on a limited set of legislative goals (gay marriage, anti-discrimination laws, "Don't Ask, Don't Tell" in the military, the creation of hate crime legislation, and safe schools for LGBT youth) because they claim that these are the issues that most LGBT people care about. Groups like the Human Rights Campaign, Lambda Legal and the National Gay and Lesbian Task Force justify their efforts by citing 
research that finds that LGBT people rank marriage rights and these other single-issue goals as their greatest concern (Egan \& Sherrill, 2005; Cahill \& Kim-Butler, 2006). Yet, these surveys have been conducted at events that are not representative of the community as a whole, such as gay pride parades that have been criticized as being corporate, heavily policed, and assimilationist, thus disproportionately attracting White people (Caterine, 2014; Long, 2014; Talley, 2014). Other research, cited in the previous section, indicates that large segments of the community have prioritized a set of issues and concerns that is very different from those expressed by the mainstream gay rights movement. Taken together, these lists of priorities from these studies suggest an agenda that is very different from the dominant gay rights agenda - they suggest an agenda inclusive of, and dominated by, economic justice, and racial justice issues.

Despite these facts, little work is being done by mainstream LGBT organizations on racial and economic justice issues. In 2010, the Movement Advancement Project surveyed 16 LBGT organizations across the country, and found that although several groups named "Issues Affecting People of Color" as part of their program priorities, the actual content of these efforts only involved "outreach" to include or diversify the membership of the organizations themselves. These national groups reported little substantive or programmatic work on racial or economic justice issues (Movement Advancement Project, 2010).

The White, middle-class leadership does not merely fail to consider issues of race or class, but also chooses to actively ignore these issues when they are presented to them (Hutchinson, 2001). For example, over the last twenty years, the Human Rights Campaign (HRC) has been accused of ignoring the needs of LGBT people of color 
(Carter, 1999; Cohen, 1999; Conrad, 2010; Duggan, 2003; Hermosillo, 2013, Hutchinson, 2001). One cannot defend HRC by saying they have been unaware of these needs. This paper has already presented information collected by HRC itself (Human Rights Campaign, 2009), which describes the discrimination experienced by LGBT people of color. HRC's own report found that the issues that LGBT people of color prioritized as most important to them were affordable health care and jobs and the economy. Yet HRC has done little to address any of those issues (Movement Advancement Project, 2010).

Hutchinson provided another example of how the national gay rights

organizations ignore certain needs, even when they know better:

The pursuit of same-sex marriage, a formal equality goal, has created similar conflicts within the gay rights community. As I have previously observed, lesbian-feminists have voiced their strong opposition to or skepticism of the pursuit of same-sex marriage because marriage has historically facilitated the domination of women by men. Racial critics have also challenged the primacy given to marriage in gay and lesbian politics because the marriage movement lends credibility to a harmful discourse that stigmatizes the non-nuclear family arrangements in poor communities of color. Furthermore, extensive sociological data have demonstrated that marriage supplies very little, if any, economic benefits to extremely poor individuals. Due to these economic and cultural patterns, heterosexuals of color marry in lower rates than whites. By decreeing legal marriage "the most important" goal for gay and lesbian politics, scholars and activists obscure racial, class, and gender distinctions among gays, lesbians, bisexuals, and transgender people, construct gay and lesbian political agendas upon gender, class, and racial hierarchies, and create conflict among antiracist, feminist, anti-heterosexist, and antipoverty activists and scholars. (Hutchinson, 2001, p. 3)

\section{The gay marriage split.}

In truth, the gay marriage movement has been subject to many other criticisms from queer activists and scholars. These critiques come from numerous perspectives (Conrad, 2010). I think it is important to explore these critiques in some depth because 
the issue of gay marriage has become emblematic of the larger divisions within the movement.

\section{Marriage is a flawed marker of cultural acceptance.}

Some supporters of gay marriage claim it is a mistake to believe that marriage victories are markers of full cultural or legal acceptance. Gilligan (2011) pointed to examples from the women's rights movement and the civil rights movement to illustrate the ways in which communities can be left behind by focusing only on specific legal victories, and argued while gay marriage is a step in the right direction, additional work must be done to address broader inequalities.

\section{Using up all our resources.}

Numerous activists have complained about the resources that have been spent on gay marriage, and how they have been diverted away from other issues (Conrad, 2009;

DeFilippis, 2012a; Farrow, 2012; Nair, 2013). I spent 24 pages of this chapter describing what some of those other issues are. All of those issues are severely underfunded. Consequently, it is worth spending a little time here describing how well funded is the marriage movement.

In 2008, gay rights organizations fighting against California’s anti-gay

Proposition 8 spent $\$ 45$ million on that campaign, and still lost (Wildermuth, 2009).

When that is added to that the amount spent by those who were opposed to gay marriage, the California battle cost a total of $\$ 85,000,000$, making it "the most money ever raised for a social-issue campaign in the nation" (Wildermuth, 2009, para. 1).

Although the Proposition 8 battle was more expensive than most, the pursuit of gay marriage continues to be the biggest financial investment made by the mainstream 
gay rights movement. From 1970 to 2010 , philanthropic organizations gave $\$ 72.5$ million in grants that were spent specifically on "marriage equality" work - which is more than what was spent during that period on HIV/AIDS, education/safe schools, or labor/employment issues (Funders for LGBTQ Issues, 2012). That number only represents money from foundations, and does not even include additional money raised from individual donors or special events. Comprehensive data does not yet exist, but there is reason to believe that the amount of money spent annually in the pursuit of gay marriage has increased since 2010. For instance, almost $\$ 34,000,000$ was spent on the gay marriage battles in four states (almost \$5 million in Maine, \$6 million in Maryland, \$8 million in Minnesota, and \$15 million in Washington) in 2012 alone (Andrew, 2012; Eilperin 2013; Lavers, 2012; Tomkins, 2013). Because of the 2013 Supreme Court decision, groups are gearing up for further battles about this issue on the state level. Groups such as HRC and the American Civil Liberties Union have already mapped out plans to raise and spend millions on the gay marriage issue between now and the end of 2016 (Eilperin, 2013). For example, the gay rights organization Freedom to Marry has announced that they will be spending at least $\$ 20$ million on marriage equality campaigns over the next three years.

The focus on marriage has not just soaked up financial resources and energy; it has also limited the public imagination. In the words of one transgender activist:

I often encounter the liberal perspective of "while gay marriage may be an incomplete approach, it will still confer limited gains to some, and it's probably a step towards broader change. At worst, it won't hurt the people it doesn't directly help." But in real life, gay marriage efforts over the last decade have actively discouraged strategies that aspired to broader change, diverted millions of dollars and immeasurable other resources away from the neediest LGBT communities, rendered unintelligible a host of other 
social concerns, and helped build increasingly narrow cultural and legal parameters of family, intimacy, and human worth. The problem isn't that gay marriage has passively ignored "other issues," it's that it helped shape them into their present incarnations and contributed to the hardiness of much social inequality today (AJ Lewis, Personal Communication, March 26, 2013).

\section{Stigmatizing other families.}

Some scholars (e.g. Smith, 2001) have argued that 1996's simultaneous marriage campaigns (the fight by the religious right against same-sex marriage and welfare reform's marriage promotion programs targeted at poor single women) contribute to a reactionary politicization of marriage and sexual regulation. However, others have argued that gay activists' pursuit of gay marriage has been just as reactionary as the government's denial of it. Duggan (2004) and Kandaswamy (2008) critiqued some gay marriage groups for using conservative rhetoric that demeans unmarried people "while promoting marriage in much the same terms as the welfare reformers use to stigmatize single-parent households, divorce and 'out of wedlock' births” (Duggan, 2004, p. 6). These arguments frequently contribute to the pathologizing of Black families who frequently build families outside of the nuclear family structure (Farrow, 2005; Hutchinson, 2001). Nopper (2012) challenged the assumption that the government's only repressive role in marriage is preventing people from getting married, and uses examples from American slavery through welfare reform to illustrate how marriage is used as a form of social control.

\section{Leaving other family structures unprotected, or actually hurting them.}

Ryan (2009) argued that the 1990s debates about sexual representation resulted in a clear division that can still be seen today in the marriage campaigns. Marriage 
advocates have been frequently criticized for the ways they continue to desexualize gay identity (Warner, 2000; Goldstein, 2003). Warner (2000) contends that the GRM's focus on access to existing institutions has led them to disassociate from queer sex, so that they will be believed when they claim to be "just like everyone else."

Many have argued (Ambrogi, 2013; Sycamore, 2008; Gaia, 2011; etc.) that queer people who do not comply with dominant notions of normality (e.g. those who do not live just like heterosexual couples) will be left out of any gay marriage victories. Kaufman and Miles (2009) agreed, arguing that access for same-sex couples into an unfair system does nothing to change the essential unfairness of the situation. Instead of framing the issue in terms of the right to form a family and share household resources inside and outside marriage, marriage equality activists chose to focus exclusively on the right of gay and lesbian couples to marry. In doing so, many have argued that we will end up with a two-tiered system of social acceptance: the "good gays" who get married and the "bad gays" whose relationships are considered illegitimate or deviant (Sycamore, 2010; Essig, 2000; Clark-Flory, 2011).

Many activists have documented the creative ways in which queer people have historically formed families, both inside and outside of legally recognized structures, and illustrated the numerous family formations that would remain unprotected by a successful marriage equality strategy (Anderson-Nathe, 2015; Audre Lorde Project, 2000; Boggis, 2012; DeFilippis, 2015; Kaufman \& Miles, 2009; Queers for Economic Justice, 2006). In order to support these various family formations, many people have argued that marriage should not be the means through which benefits and rights are disbursed. Boggis claims that marriages frequently end, and in recognition of that, many queer people, even those 
who marry, choose not their spouse, but a close friend or sibling as the person they want to make medical or legal decisions for them should they become incapacitated (T. Boggis, personal communication, July 26, 2014). Polikoff (2008) has argued that the gay rights movement is solving the right problem with the wrong solution, and that all families and households need the rights and benefits that are currently only extended only to married couples. Duggan recommended, "abolishing state endorsement of the sanctified religious wedding" and advocated that, instead, weddings remain private, religious ceremonies disassociated from legal rights and benefits (2004, p. 6).

Numerous voices have called for de-centering and de-institutionalizing marriage and seeking to create multiple options of legal protections for multiple family structures, instead of proposing the couple-form as a one-size-fits-all solution (D'Emilio, 2006; Duggan, 2012; Polikoff, 2008; Queers for Economic Justice, 2006). Not only does the gay marriage movement fail to create multiple options of legal recognitions for families, it actually has reduced the number of existing options. John D’Emilio (2006) argued that the struggle to achieve gay marriage rights has failed in many states and actually resulted in more anti-gay sentiment and legislation in those places than there was before the marriage battle. In addition, even when gay marriage has won in other states, we still lose. D'Emilio (2006) and Polikoff (2013) have demonstrated how the expansion of marriage equality in some states has led to the elimination of other options for family protection (such as domestic partnerships, civil unions or reciprocal beneficiaries), consequently limiting options for families, rather than expanding them. Thus, Boggis reports that many activists are upset that the marriage campaigns have resulted in policies that "protect 
fewer people, rather than more people" (T. Boggis, personal communication, July 27, 2014).

Polikoff (2009) provided examples of how, for some activists, marriage equality is not a first step in the right direction - it is the only step. Upon achieving marriage equality, these organizations discontinue doing work on any other family protections.

Fighting for benefits that may no longer come with marriage.

Others have questioned whether, in a post-welfare reform, neoliberal country, marriage will actually provide the benefits that gay activists are fighting for, and if so, to whom? These critics argued that marriage does allow greater access to certain important institutions (such as custody, health insurance, immigration, etc.) but also documented how racial inequities are structurally embedded in those institutions (Bailey, Kandaswamy \& Richardson, 2004; Farrow, 2005; Kandaswamy, 2008). They maintain that the specific benefits that gay and lesbian activists are fighting to get through marriage equality are better understood as privileges of a racially stratified welfare state. Consequently, while gay marriage may be helpful to White middle-class gays and lesbians, it does not address the needs of other LGBT people.

In 2006, hundreds of LGBT activists and scholars from across the country signed the Beyond Marriage document (QEJ, 2006), which offered a strong rebuke to the marriage equality organizations. Among the critiques was an explanation of how the LGBT organizations that have been singularly focused on fighting for the rights and benefits that come with marriage have neglected to fight Right-wing attacks on the programs that offer those very rights and benefits. 
Same-sex marriage advocates promote marriage equality as a way for same-sex couples and their families to secure Social Security survivor and other marriage-related benefits. Yet, the Right has mounted a long-term strategic battle to dismantle all public service and benefit programs and civic values that were established beginning in the 1930s, initially as a response to widening poverty and the Great Depression. The push to privatize Social Security and many other human needs benefits, programs, and resources that serve as lifelines for many, married or not, is at the center of this attack. In fact, all but the most privileged households and families are in jeopardy as a result of a wholesale right-wing assault on funding for human needs, including Medicare, Medicaid, welfare, HIVAIDS research and treatment, public education, affordable housing, and more...Winning marriage equality in order to access our partners' benefits makes little sense if the benefits that we seek are being shredded. (QEJ, 2006, para 16)

\section{Marriage as a tool of neoliberalism.}

Others have seen gay marriage as a step in the wrong direction. They have argued that it is being used to help move forward a neo-liberal agenda (DeFilippis, AndersonNathe, Panichelli, 2015). Dobbs (2012), Farrow (2011b) and Nair (2013b) made the argument that gay marriage is actually a conservative issue, which benefits Republican goals. They argue that Republicans are now supporting the cause, and they are doing so because they understand, better than do liberals, the ways in which strengthening the institution of marriage serves a right-wing agenda. Similarly, the Beyond Marriage document claimed that the Right wants to "slash to the bone governmental funding for a wide array of family programs, including childcare, healthcare and reproductive services, and nutrition, and transfer responsibility for financial survival to families themselves" (QEJ, 2006, para 13).

This supports the broader argument about the problems with "equality" goals put forth by others. For example, Lisa Duggan (2003) argued that by framing the work around "equality," the movement has lost its explicit progressive values and agenda, and 
allowed conservatives and libertarians equal access to the movement to advocate for their versions of equality. The equality framework supports a neoliberal system that is fundamentally opposed to the redistributive and progressive values of earlier incarnations of the movement. A decade later, when critiquing the marriage equality movement, she explained how marriage serves to support a neoliberal system of privatization, when she writes how it:

aims to privatize social services by shifting the costs of support for the ill, young, elderly and dependent away from the social safety net and onto private households. Women are encouraged to marry to gain access to higher men's wages and benefits, while taking up the slack for lost social services with unpaid labor at home (Duggan, 2012, p. 1).

Similarly, Harris (2006) explained how neoliberalism has led to the absorption of emancipatory claims (towards economic, political, and social revolution) into, instead, a "structural liberalism" that actually supports neoliberalism. Consequently, American law has made gay civil rights claims possible while simultaneously limiting their scope. She argued that a gay marriage agenda (and any agenda that is dependent upon approval by and absorption into neoliberal government) means that gay rights can easily be used to support the damage caused by neoliberalism.

\section{The non-profit industrial complex.}

One of the ways that GRM may function in service of neoliberal policies is by its transition from the grassroots organizations of the 1960s and 1970s into the incorporated structures that developed in the 1980s and 1990s. Social movement scholars McCarthy, Britt, and Wolfson (1991) claimed that non-profit organizations (what they call 'channeling mechanisms') 'may now far outweigh the effect of direct social control by states in explaining the structural isomorphism, orthodox tactics, and moderate goals of 
much collective action in modern America' (p. 48). They contend that the advent of social movements led by non-profits has led to a country where it is less common than it was in the past for the state to engage in direct, overtly tyrannical forms of state repression of activism. Instead, by monitoring and regulating these non-profits, we have created more subtle forms of state control of social movements (McCarthy, Britt, \& Wolfson, 1991).

The activist organization INCITE! Women of Color (2007) has voiced similar concerns about the way informal and volunteer social justice work has been co-opted and replaced by the non-profit structure that employees professional workers. Funding for non-profits come from the government (not willing to fund organizing against the government) and from private foundations (run by rich people not willing to fund socialist efforts). Organizations apply for these funds and have to build their work around grant cycles and the priorities of funders. In addition, non-profits are based on a model that mirrors dominant corporate structures, uses paid staff, in hierarchical structure, and is overseen by Boards of Directors (often chosen for their financial resources). They argue that the structure of non-profits limits who can participate in social change work while also limiting the scope of that work (its political agenda).

That is, the overall bureaucratic formality and hierarchical (frequently elitist) structuring of the NPIC has institutionalized more than just a series of hoops through which aspiring social change activists must jump - these institutional characteristics, in fact, dictate the political vistas of NPIC organizations themselves. The form of the US Left is inseparable from its political content. The most obvious element of this kinder, gentler, industrialized repression is its bureaucratic incorporation of social change organizations into a 'tangle of incentives' - such as postal privileges, taxexempt status, and quick access to philanthropic funding apparatuses made possible by state bestowal of not-for-profit status (Rodriguez, 2007, p. 29). 
Similarly, Kivel (2007) argued that the result is that non-profits often focus on service provision rather than social change. He contends that non-profits are structured in a way that results in the provision of human services while maintaining and often strengthening social inequality.

Multiple social movements are now run by non-profits, and in the above critiques, Kivel (2007), Rodriguez (2007) and McCarthy, Britt, and Wolfson (1991) were discussing social movements in general; they were not referring specifically to the GRM. However, those critiques provide a larger context for understanding the concerns that have been raised about the GRM specifically.

A movement that began as completely grassroots is now represented almost entirely by 501(c)3 corporations. There is tremendous concern about the lack of community accountability that accompanies such structures in the GRM (Gamson, 2000; Halperin \& Traub, 2009; Mananzala \& Spade, 2008). Many feel that these institutions, more so than grassroots groups, foster (or, essentially, require) college-educated, middleclass leadership (Hussain, 1997; Mananzala \& Spade, 2008). Additionally, community members have complained about LGBT organizations being in bed with corporations and wealthy donors, arguing that corporate sponsorships limit and control the scope of work that can be done and are antithetical to progressive activism (Caterine, 2014; Chasin, 2000; Cohen, 1999; Sender, 2004, Nair, 2013, Vaid, 1995). At the turn of the century, "Gay Shame" events took place across the country protesting gay organizations and gay pride events and offering these critiques (Avicolli Mecca, 2002; Boyer, 2009; Halperin \& Traub, 2009; Sanchez, 2002). 
Numerous queer activists have raised a distinct but related concern about the community organizing strategies employed by the non-profits in the GRM (Mahfuz \& Farrow, 2012; Southerners On New Ground, 2012). They critique the way that organizations like the National Gay and Lesbian Task Force or HRC frequently send organizers into a state where there is a ballot initiative and spend a month knocking on doors to garner support. Then once the election has passed, the organizers move on to another state. Concerns have been raised repeatedly that these organizations use up precious resources and leave behind no infrastructure and no social movement (Mahfuz \& Farrow, 2012; Southerners On New Ground, 2012). This difference between a nonprofit running a campaign versus grassroots movement building frustrates some activists of color. They also believe that this makes it harder to for them to do their work, because it leads to an environment where long-term organizing and movement building is invalidated.

The focus on short-term legislative campaigns, often led by larger groups, creates a dynamic where these ways of (long-term) organizing are seen as overly complicated, not results-orientated, and lacking in large-scale impact. Many grassroots LGBT people of color organizations believe that we have to do long-term movement building in order to meet the needs of the full breadth and depth of the LGBT community, particularly communities whose primary concerns do not fit a single-issue frame (Mahfuz \& Farrow, 2012, p. 1).

\section{Other divisions in the movement.}

The internal battles about gay marriage within the movement have been the loudest, but there have also been critiques of the other major goals of the agenda of the national gay rights organizations. The ability of gay and lesbian people to serve openly in the military was a major issue in the first decade of this century, but this cause has not 
enjoyed unanimous support in the movement. The queer left who have engaged in antiwar struggles have been critical of the movement choosing to fight for access into a system that they would rather disempower. During the early years of the $21^{\text {st }}$ century, as the "War on Terror" was getting underway, there was criticism from many small grassroots organizations of organizations in the GRM that were not publicly taking antiwar positions (American Friends Service Committee and the National Youth Advocacy Coalition, 2003; Audre Lorde Project, 2003; Feinberg, 2002; Gluckman, 2003; Goodman, 2001; Kiritsy, 2001; Krisberg, 2001; Lesbians and Gays Against Intervention, 1992; Osborne, 2002; Out Against the War Coalition, 2002; Shepard, 2001; Thayer, 2002). Implicit (and often explicit) in these anti-war positions was a critique of the efforts to gain access to serve in the military. Debate about the issue, and criticism of the GRM, resurfaced publicly when "Don't Ask, Don't Tell” was considered (and overturned) by the Supreme Court in 2011 (Conrad, 2012; Farrow, 2011c; Lady Bunny, 2010; Long, 2013; Nair, 2010; Nopper, 2010; Thrasher, 2013; Whitman-Bradley, Lazare, \& WhitmanBradley, 2011).

Many other battles have been fought over the GRM's agenda. The fight for protections against employment discrimination has frequently been criticized for being too limited in scope and too focused on white-collar jobs (Blum, 2012). Battles for LGBT adoption rights have been condemned by queer people of color for not examining the complications involved when White people adopt children of color (Raible, 2010). Activists working on the HIV/AIDS epidemic have voiced frustration about how the gay rights movement has decreased work on this issue (Andriote, 2013; Vaid, 2012). 
In order to get the mainstream gay rights movement to address transgender issues, numerous internal battles were necessary (Juro, 2004; TransGriot, 2007). These battles include some very public fights with HRC, who have wanted to remove transgender people from protections offered by employment nondiscrimination bills (Juro, 2004; TransGriot, 2007).

All of the above agenda items have been determined by White middle-class gay and lesbian leaders, and have been consistently and loudly criticized by queer activists of color, transgender activists, and queer leftists. However, second after the issue of gay marriage, perhaps the agenda item that has been most divisive has been the pursuit of hate crime laws.

The rate of hate crimes against LGBT people has been and continues to be a very real problem (Herek, Berrill, \& Berrill, 1992; Federal Bureau of Investigation, 2012). There is widespread agreement that it deserves the attention that has been paid to it. Many believe, however, that the solutions embraced by the national organizations and the statewide equality groups have been misguided. Hate crimes legislation, with extended sentencing for those convicted of committing a hate crime, has been criticized for the past two decades. Progressive activists argue that enhanced prison sentences that send convicted assaulters into the most homophobic institutions in the country will do nothing to solve the problem of anti-gay violence (Kohn, 2001; Whitlock \& Kamel, 2001). These activists have explained how White gays and lesbians may feel comfortable calling the police, but transgender people and queers of color have been given reason to not trust them (Farrow, 2011b; Gossett, 2011; Gossett, Gossett \& Lewis, 2012). Activists of color and their allies are concerned about the racist nature of the criminal justice system and do 
not want to turn for solutions to an institution that has structural racism embedded into every aspect of it (Farrow, 2011b; Gossett, 2011; Hammond, 2013; Kohn, 2001; Mogul, Ritchie, \& Whitlock, 2011; Sylvia Rivera Law Project, 2009; Whitlock \& Kamel, 2001). They are concerned that the national organizations chose to embrace conservative "lock them up" values and tactics during the exact period in history when other social justice movements were working to reform or dismantle the criminal justice system (DeFilippis, 2012a; Sylvia Rivera Law Project, 2009).

These critiques have created tensions for those groups who stand in opposition to hate crime legislation. For example, in 2009, five LGBT groups in New York City (Audre Lorde Project, FIERCE, Peter Cicchino Youth Project, Queers for Economic Justice, and Sylvia Rivera Law Project) who work closely with and for transgender communities were publicly against a bill that amends state hate crime law to include gender identity. Their opposition was grounded in the belief that turning to a racist criminal justice system was not the solution (Sylvia Rivera Law Project, 2009). These organizations were criticized by White transgender leaders for being trans-phobic, despite the fact that some of the groups were led by transgender people of color.

\section{Contextualizing the critiques.}

Describing the aforementioned tensions and battles, Cohen (1997) explained that they began because of the demands of LGBT people of color "as well as others who did not see themselves or their numerous communities in the more narrowly constructed politics of white gays and lesbians" (p. 448). These battles "took shape over who and what type of issues would be represented in lesbian and gay politics and in larger community discourse" (p. 448). Seidman (1993) explained that, consequently, gay and 
lesbian identity and politics is being rethought because of "the reaction by people of color, third-world identified gays, poor and working class gays, and sex rebels to the ethnic/essentialist model of identity and community that achieved dominance in the lesbian and gay cultures of the 1970s" (p. 106). These "reactions" have led to much internal conflict in the LGBT movement about political priorities and a schism has developed between those who have been leading the work in this single-issue framework and those calling for a more intersectional approach. Hutchinson (2001), while describing the battles within the LGBT political movement, positioned this battle as emblematic of a larger ongoing fight about the future of identity politics. She explained, "whether essentialist and single-issue commitments should continue to dominate social equality movements or whether these movements must begin to embrace a more multidimensional understanding of subordination and discrimination" (p. 2).

Duggan (2002), Ryan (2009), and Ward (2008) argue that the GRM has become part of the establishment, existing in service of neoliberal policies, and seeking inclusion into neoliberal institutions. Ward (2008) contended that, as a result, GRM organizations are willing to abandon race and class diversity, as well as queer perspectives, in order to succeed. Ward said:

Lesbian and gay activists embrace racial, gender, socioeconomic, and sexual differences when they see them as predictable, profitable, rational, or respectable, and yet suppress these very same differences when they are unpredictable, unprofessional, messy, or defiant With the rise of potential profit (or success in a capitalist society), the gay and lesbian movement has become even less diverse than its origins (Ward, 2008, p. 2).

Armstrong (2002) theorized that the LGBT community utilizes an 'ethnic' status, albeit one that is different from other ethnicities determined by race, culture, or nation. Because 
LGBT people do not share a typical ethnicity, the GRM has addressed this by claiming to 'celebrity diversity' within its movement, and calls on the rest of society to do the same about LGBT people. Numerous critics claim that in reality, the GRM has failed to celebrate diversity, and Ryan (2009) argued that creating the appearance of a unified gay community has been a political strategy on the part of the GRM. In doing so, she builds on the theory put forward by Bernstein (1997) claiming that sometimes identity-based movements highlight how they are different from the dominant group (in celebration of difference) and other times when it is strategic to highlight their similarities with the dominant group (in suppression of difference). Drawing from Gamson (1995), Ryan (2009) contends that the current political strategy of the GRM is to suppress any gay and lesbian difference:

It is produced to disassociate "gay" from "strange" or "abnormal," and, more specifically to dissociate "gay" from "queer"; this particular strategy has meant a gay and lesbian disassociation from bisexual, transgender, and queer people in the social and political spheres (p. 249).

The GRM seeks to approach normality by making the claim that the only difference between gay or lesbian people and (presumably white, middle-class) heterosexuals is the slight matter of sexual orientation and that they should therefore be entitled to privileges of the state (Cohen, 1997; Ryan, 2009; Warner, 2000).

In addition to representing the tensions between essentialist versus intersectional theories of identity, these battles also reflect tensions between redistributive politics and the politics of recognition. As discussed in chapter 2, the class-based redistributive goals of the social movements of the first half of $20^{\text {th }}$ century sometimes shifted to demands for access and recognition put forward by newer identity-based movements (Bernstein \& 
Taylor, 2005; Polletta \& Jasper, 2001; Taylor \& Whittier, 1999). This development has been a contentious one (Bernstein \& Taylor, 2005). It is within this larger theoretical context that I situate the above-described battles among LGBT organizations. Many of these battles are a direct result of some LGBT activists and organizations operating from identity-based politics of recognition while others operate from a more redistributive agenda.

\section{Applying Gamson's framework to the GRM.}

By using the information presented thus far, I can analyze the mainstream gay rights movement utilizing the framework developed by Gamson (1990) for "Identifying Challenging Groups.” As I explained in Chapter 2, Gamson posited "challenging groups" (those groups capable of taking action) can be identified by creating three distinct concepts of targets for challenging groups: (1) the target of influence; (2) the target of mobilization; and (3) the target of benefits. Using the research presented in this chapter (and the preceding chapter), I can identify the targets of the national gay rights organizations and statewide equality organizations.

Gamson's first category is "target of influence." The GRM has primarily focused on two targets of influence. These have been elected officials, via lobbying, (D'Emilio, 2000; Farrow, 2012; Gamson, 2001; Movement Advancement Project, 2012; Vaid, 2012; Walsh, 1998), and the judicial system, via litigation, (Carpenter, 2014; Farrow, 2012; Rosenblum, 1994; Vaid, 2012). They have not targeted all of those players - just the ones that are well positioned to affect policies relevant to the GRM's limited agenda of singleissue campaigns. These campaigns have been focused on access to family protections (e.g., marriage and adoption), inclusion of sexual orientation in hate crime and civil 
rights/anti-discrimination laws (e.g., employment protection and access to the military), and support for youth/education (e.g., safe schools, GSAs). The majority of their resources have been spent on those issues (Bowen, 2012; Funders for LGBTQ Issues, 2012; Movement Advancement Project, 2007).

Gamson's second category is "target of mobilization." The GRM has had three targets of mobilization. The first target of mobilization has been their leadership, which has been almost entirely White, with a majority of their leaders male, and mostly from the professional class (Boykin, 2000; Carter, 1999; Cohen, 1999; D’Emilio, 2000; Vaid, 2012). The second target of mobilization has been their constituency, which has been all LGBT people, but predominantly white and middle-class cisgendered gays and lesbians. (Carter, 1999; Movement Advancement Project, 2010; TransGriot, 2007; Vaid, 1995; Vaid, 2012). Thirdly, the issues that the GRM has targeted to mobilize around have been single-issue campaigns (Cohen, 1999; Jones-Yelvington, 2008b; Mahfuz \& Farrow, 2012; McMichael \& Wallace, 1999; Shepard, 2001; Southerners On New Ground, 2012).

Gamson's third category is "target of benefits." The GRM has focused almost exclusively on one group as the target of their benefits: White middle-class and wealthy gay and lesbian American citizens (Carter, 1999; Conrad, 2010; Duggan, 2003; Hermosillo, 2013, Hutchinson, 2001; Movement Advancement Project, 2010; TransGriot, 2007; Vaid, 2012; etc.).

A summary of the above analysis using Gamson's framework can be found in Appendix F. Because the national gay rights organizations and the statewide equality organizations shared the same Targets of Influence, Mobilization and Benefits, I have categorized them as a distinct social movement that I have referred to as the mainstream 
Gay Rights Movement (GRM). As evidenced by the history documented in this chapter and the previous one, many groups have not fit easily or perfectly into the GRM framework, and have often been at odds with the leading organizations in the GRM. In my research, I compared the targets of some of those groups to the above-named targets of groups exemplifying the GRM. Using Gamson's framework, my first research question ("What does analyzing these organizations through SM theories reveal about the claim held by many that these organizations are the left-wing of the GR Movement?') explored whether the queer liberation groups in my study share these same targets as the GRM.

\section{A New Social Movement?}

\section{From critiques to alternative activism.}

These battles have changed the landscape of the LGBT movement. Increasingly, some small LGBT organizations around the country are working on racial and economic justice issues (Applied Research Center, 2012; Funders for Lesbian and Gay Issues; 2005; Weiner-Mahfuz, 2010). These organizations are doing work with different goals (justice, rather than equality), different tactics (community organizing, leadership development and coalition-building, rather than lobbying and litigation) and for different constituents (LGBT people who are people of color, low-income, transgender, incarcerated, homeless and/or immigrant, rather than middle-class white gays and lesbians).

Although numerous scholarly articles describe the aforementioned critiques of the gay rights movement, little academic literature documents the work that has developed in response to these critiques. Most of the information that follows is drawn from my years 
of practice experience or from grey literature. One of the reasons I want to do this research for my dissertation is to contribute to the scholarly literature about this work.

In my work over the past twenty years, I have witnessed the development, below the radar, of dozens of organizations doing multi-issue work. One such organization is Queers for Economic Justice (QEJ), of which I was the Founding Director. QEJ works with low-income and homeless LGBT people on issues related to their basic survival. QEJ was built with the goal of working on issues that are the highest priorities to the LGBT communities who are the most disenfranchised. QEJ deliberately executes its work in a way that makes connections with other social justice movements.

QEJ is not alone. Starting in the late 1980s and early 1990s, small local groups have been working for years on the issues facing the less-financially privileged segments of the LGBT community, and using the intersectional framework first advocated by the Combahee River Collective (CRC). As mentioned in the previous chapter, some of the first queer organizations that shared, or were built upon, CRC's ideas included the Esperanza Peace and Justice Center, Southerners on New Ground, and the Audre Lorde Project. A second wave of organizations, including QEJ, founded in 2002, and cohort organizations such as FIERCE and the Sylvia Rivera Law Project, or the Transgender, Gender Variant and Intersex Justice Project were indisputably shaped by the radical queer politics embraced by the intersectional, multi-issue organizations that came prior to them. Subsequent waves of organizations developed in the wake of the founding of these two waves of organizations. All these queer liberation organizations have used this same multi-issue, intersectional lens to guide their work. They focus on the intersections of class, gender, race, and sexual orientation and make central the issues and agendas of 
low-income queers and LGBT people of color (Applied Research Center, 2012). They center those intersections in how the organizations are structured and run, as well as in the programmatic issues on which they choose to focus. Most are led by people of color (Gore, Jones \& Kang, 2001), low-income people (Billies, Johnson, Murungi, \& Pugh, 2009), or transgender people (Currah, 2008). Their political agendas are a hybrid of the redistributive politics advocated by the class-based movements of the first half of the $20^{\text {th }}$ century, and the identity-based politics of the New Left. As opposed to the prominent LGBT national organizations, the queer liberation organizations are all small, grassroots, and forthright about their progressive political leanings. These queer liberation organizations also do not receive funding that is in any way comparable to the mainstream gay rights organizations (Applied Research Center, 2012; Funders for Lesbian and Gay Issues; 2005). Appendix D provides a list of 65 organizations that, based upon these criteria, I have classified as examples of these queer liberation organizations.

These queer liberation organizations work on a wide range of issues impacting LGBT communities. These issues range from healthcare to immigration (Pulliam \& Mott, 2010), from police brutality to prison abolition (Donahue, 2011; Gore, Jones \& Kang, 2001; Gossett, 2011), from welfare rights to living wages (Jones-Yelvington, 2008; Queers for Economic Justice, 2008), from reproductive justice to gentrification (Mananzala, 2012; Shepard, 2004), from anti-discrimination to anti-violence (Billies, Johnson, Murungi, \& Pugh, 2009; Currah, 2008). Moreover, they work on these issues while also locating themselves in identity-based organizations. They do so through grassroots community organizing, leadership development, legal advocacy, and/or public 
education. Each does its work through an intersectional understanding of LGBT identities. They believe that for queer people who are poor (or people of color, women, transgender people, immigrants, indigenous people, sex workers, homeless people, incarcerated people, old people, youth, disabled people, people with HIV, working class people, etc), a "gay agenda" cannot be limited only to marriage, hate crimes, and anti-discrimination laws. These queer liberation organizations argue that race and class and gender and citizenship and health cannot be removed when talking about sexual orientation and gender identity (Kelley, 2012).

Most of these organizations are clearly built around their LGBT identity, even though they focus on multi-issue campaigns. These organizations may represent examples of a theory put forward by Fraser (1995; 2003). As described in chapter 2, Fraser is one of the few social movement scholars to challenge the redistribution/recognition binary. Fraser disputes the prevailing notion of recognition movements as being inevitably disconnected and oppositional from redistributive movements (Smith, 2001), and believes it is possible for a social movement to encompasses claims of both types without conflating them (Fraser \& Honneth, 2003). She does not, however, specifically offer these queer liberation organizations as examples of her theory ("perspectival dualism”), nor to my knowledge has anyone else since.

In addition to all of the identity-based organizations doing multi-issue work, some of their partner organizations are not exclusively LGBT in their memberships or their programmatic work. Rather, they see LGBT issues as intrinsically related to their work on gender, racial or economic issues, and they center LGBT people along with other marginalized communities in their organizing. Groups that fall in to this category would 
include BreakOUT! (New Orleans, Louisiana); CAAAV: Organizing Asian Communities (New York, NY); Catalyst Project (San Francisco, CA); Freedom Center for Social Justice (Charlotte, North Carolina); Highlander Center (New Market TN); Generation Five (San Francisco, CA); INCITE! Women of Color Against Violence (Chicago, IL); SisterSong Women of Color Reproductive Health Collective (Atlanta, GA); SOUL: School of Unity and Liberation (Oakland, CA); and SPARK, Reproductive Justice NOW, (Atlanta, GA). In addition, despite the persistent stereotype that people of color are more homophobic than White people, there are numerous non-gay racial justice organizations across the country engaged in LGBT advocacy (Applied Research Center, 2010). These organizations contradict the idea that LGBT organizing and racial justice organizing are mutually exclusive.

\section{Queer liberation coalition work.}

The scholarly literature that does exist about queer liberation organizations usually presents them as individual organizations, not as a movement (see Billies, et al., 2009; Donahue, 2011; HoSang, 2006; Pulliam \& Mott, 2010; Shepard, 2004). Yet, the grey literature paints a different picture. Many of these organizations work together. In particular, the queer people of color organizations frequently collaborate (Applied Research Center, 2010). Additionally, although they do not all use the term "queer liberation," there is an abundance of grey literature that makes an argument for not only the need for a queer liberation movement, but also for the notion that such a movement may be already burgeoning (Applied Research Center, 2012; Astraea Foundation, 2010; Funders for Lesbian and Gay Issues; 2005; Mahfuz \& Farrow, 2012; Queers for Economic Justice, 2010; Sen \& Keleher, 2013: Wang, 2013; Weiner-Mahfuz, 2010; 
Wyllie de Echeverria, n/d). This section will explore the coalition work that has been taking place between many of these organizations. This coalition work is what led me to my research questions. This information is included to illustrate the clues that initially informed my interest in this research project.

Various combinations of these groups have been working together on specific campaigns and in ongoing coalitions for the past 15 years (Applied Research Center, 2010; Weiner-Mahfuz, 2010). They regularly present together at conferences. Some of these groups worked together in 2007 in a coalition to address the role of desire and sexuality in social justice work (Hollibaugh, Jakobsen, \& Sameh, 2010). That same year, in a separate project, Queers for Economic Justice (QEJ) and Southerners On New Ground (SONG) worked together to convene 45 organizations from 18 states gathered in Atlanta, Georgia during the U.S. Social forum to talk about collaborating on an ongoing basis (Gumbs, 2007). Out of that convening, QEJ launched its "Building a Queer Left" project which brought together many of these organizations on a regular basis for conference calls to plan strategies, exchange technical assistance and build coalition (Queers for Economic Justice, 2010b; Queers for Economic Justice, 2010c). The project folded after two years due to lack of funding. Three years after the first U.S. Social Forum gathering, QEJ and SONG again convened organizations for an all-day meeting in Detroit, MI at the 2010 U.S. Social Forum (Astraea Foundation, 2010; Queers for Economic Justice, 2010).

During these years, groups continued to partner in smaller coalitions. For instance, Critical Resistance, the Sylvia Rivera Law Project, the Transgender, Gender Variant and Intersex Justice Project and others worked together for years in the Transforming Justice 
coalition, an effort focused on prison abolition work (Critical Resistance, 2008; Gossett, 2011; Sylvia Rivera Law Project, 2011). Some geographically close organizations work together more frequently. For instance, in New York City, four grassroots organizations (Audre Lorde Project, FIERCE, Queers for Economic Justice and the Sylvia Rivera Law Project) have been working together for years (Moorehead, 2013) and recently moved into one building together, creating a progressive queer social justice center for the city (Wang, 2013). In cities where there are fewer organizations, groups have still found ways to work in coalition with like-minded organizations in neighboring cities. For instance, BreakOUT! (New Orleans), Center for Artistic Revolution (Little Rock), Freedom Center for Social Justice (Charlotte), Southerners on New Ground (Atlanta) and SPARK, Reproductive Justice NOW (Atlanta) collaborate regularly in the American south (Sen \& Keleher, 2013). Indeed, in 2012, Applied Research Center and Southerners on New Ground worked together to convene eleven organizations, spanning ten southern states, and spent a year doing research and strengthening their organizational relationships (Sen \& Keleher, 2013).

Some of the groups most active in the coalitions mentioned have been singled out by the Astraea Lesbian Foundation for Justice. In 2006, Astraea initiated a multi-year grant-making program called "U.S. Movement Building” Grants. This program awarded grants to groups that "demonstrate significant movement, leadership and creative community organization strategies for social change within and beyond LGBTI communities" (Astraea Lesbian Foundation for Justice; n.d., para. 1). In the first four years of the program, Astraea awarded $\$ 150,000$ each to 12 organizations to support their movement building work (Jiménez, 2010). These organizations were 
1. Affinity Community Services (Chicago, IL) www.affinity95.org

2. allgo (Austin, TX) www.allgo.org

3. Audre Lorde Project (Brooklyn, NY) www.alp.org

4. Center for Artistic Revolution (Little Rock, AR) www.artisticrevolution.org

5. Esperanza Peace and Justice Center (San Antonio, TX) www.esperanzacenter.org

6. FIERCE (New York, NY) www.fiercenyc.org

7. National Queer Asian Pacific Islander Alliance (Washington, DC) www.nqapia.org

8. Queer Women of Color Media Arts Project (San Francisco, CA) www.qwocmap.org

9. Queers for Economic Justice (New York, NY) www.q4ej.org

10. SONG: Southerners on New Ground (Durham, NC) www.southernersonnewground.org

11. Sylvia Rivera Law Project (New York, NY) www.srlp.org

12. Transgender, Gender Variant and Intersex Justice Project (Oakland, CA) www.tgijp.org

In addition to receiving the $\$ 150,000$, each organization participated in Astraea convenings intended to be strategic retreats where grantees could "share experiences, strategies and build skills to forward their organizational and movement efforts" (Astraea Lesbian Foundation for Justice; n.d., para. 1). Most also attended the convening at the 2010 U.S. Social Forum gathering, after which they decided to form the Roots Coalition (Mahfuz \& Farrow, 2012; Wyllie de Echeverria, n/d).

I was interested in exploring the question of whether some of the 65 organizations I have mentioned have the potential to become, or have already become, a different LGBT movement — a progressive queer liberation movement, as opposed to the current mainstream gay rights movement. I was particularly interested in those twelve organizations nationally recognized as leaders in progressive queer organizing (i.e., the Astraea grantees). I wanted to understand exactly which movement it is that they were funded to build. My dissertation focuses on this question. 


\section{Conclusion}

This chapter described some of the progress that has been made by the mainstream gay rights movement in building their infrastructures as well as succeeding in their limited political agenda. It then articulated many of the economic obstacles and social service needs that exist among LGBT communities, which are not being addressed by the GRM. I then explained how these unaddressed obstacles and needs have led to criticism of the GRM, and explored the nature of those critiques. I illustrated how this has resulted in a serious fracture in the movement - one that has been building for decades. Finally, I introduced some of the queer liberation organizations that have been created in the past two decades, and articulated some of the reasons why I started to wonder if they actually comprise a separate social movement.

The information presented in this chapter raises some issues that are connected to larger theoretical issues. The split in the LGBT movement reflects the well-documented tension between class-based movements focused on redistributive politics (as exemplified by the queer liberation organizations) and identity-based movements built upon politics of recognition (as seen in the national gay rights organizations and statewide equality organizations). In my research, I use social movement theories to examine the results of this split. 


\section{Chapter 5: Methods and Methodology}

\section{Overview}

This study investigated the possibility that a separate queer liberation movement exists in the shadow of the mainstream gay rights movement. To do this, I studied eight organizations awarded Movement Building grants by the Astraea Foundation. For each, I investigated three specific questions: (1) What does analyzing these organizations through SM theories reveal about the claim held by many that these organizations are the left-wing of the GR Movement? (2) What does analyzing these organizations through SM theories reveal about their relationship to one another? and (3) What does a social movement analysis reveal about these organizations, collectively and individually?

This research project utilized deductive qualitative content analysis (incorporating elements of inductive qualitative analysis). For each organization, I analyzed the mission statement, the transcript of an interview I conducted with the executive director, and the transcript of a public audio-visual document about the organization. I drew from social movement theories to create coding categories in advance, which I then employed in a deductive analysis of the text, engaging in thematic analysis within these categories.

\section{Epistemological Stance}

In my work, I find myself returning repeatedly to critical race theory, queer theory, Marxism, critical third wave feminism, and other social identity theories. These critical theories inform my understanding of knowledge and of the world. They help me know the things I know. They have directly led me to my research questions. Consequently, I situate myself in an epistemological stance of critical inquiry. Critical inquiry uses the framework of critical theories as a way of understanding knowledge and as a guide for 
research. Although critical theories are often regarded as paradigms or theoretical frameworks, many embrace them as epistemologies. For instance, Hesse-Biber and Leavy (2004) and Padgett (2008) have compared critical inquiry to other epistemological perspectives such as positivism, post-positivism, and postmodern epistemologies (Staller, 2012).

Moosa-Mitha (2005) stated that critical theories hold an epistemological assumption that knowledge is historically situated and contextualized. She explained that, for example, social identity theories and intersectionality contend "knowledge is understood as situated by one's social location as a result of privileges and oppression that one has experienced" (Moosa-Mitha, 2005, p. 66). Critical inquiry assumes that most knowledge is socially constructed by the dominant in society, and in their interests (Lather, 1991). Hesse-Biber (2011) argued that critical theory attends to the role of power in creating hegemonic knowledge and claimed "critical theorists seek to expose dominant power relationships and knowledge that oppress" (p.11). Critical inquiry seeks to create oppositional knowledge, critique the status quo and engage in social change (Lather, 1991).

I have always embraced a critical theory paradigm, even before I knew I did. I have always viewed the world through the lens of power and oppression, and have used various critical theories to make sense of what I observe and study. I have used feminist theories, Marxism, queer theory and critical race theories to understand the world, and have never felt that subscribing to all of them was in any way contradictory. For these reasons, I locate myself in the epistemology of critical inquiry. 


\section{Methodology}

For my research project, I engaged in qualitative content analysis. Used for the subjective interpretation of data by means of a systematic classification process of coding and identifying themes or patterns (Hsieh \& Shannon, 2005), qualitative content analysis involves the use of valid and reliable methods for making conclusions about the major themes of a text (Krippendorff, 1969). It does so by following content analytical rules and systematic models, but without reducing complicated ideas into quantified numbers or embracing quantitative frameworks (Mayring, 2000). This methodology does not merely count words but rather examines language in order to classify large amounts of text into a manageable number of categories that convey similar meanings (Weber, 1990). It focuses on meanings, intentions, consequences, and context (Downe-Wamboldt, 1992). With qualitative content analysis, different levels of content can be analyzed: the primary content and the latent content. Mayring (2000) defined the primary content as the main ideas of the text and the themes. The latent content is contextual information such as silence, posture, nervousness, sighs, laughter, etc. (Catanzaro 1988; Elo \& Kynga, 2007).

This methodology is in keeping with an epistemological stance of critical inquiry, which maintains that knowledge is historically situated and contextualized because qualitative content analysis centralizes the exploration of context. Critical inquiry also assumes that knowledge is socially constructed by those with power, and qualitative content analysis can be utilized to understand how knowledge is created, or understood, by those without power (See Nadal, et al., 2011; Noël, 2006).

Qualitative content analysis was developed in communication science with the intention of using the advantages of quantitative content analysis for qualitative purposes. 
Mayring (2000) maintained that certain strengths of quantitative research, such as use of theory, replicable models, clearly identified categories, and criteria of validity and reliability were important to use in qualitative research. Kaid (1989) argued that any type of qualitative content analysis must engage the same seven steps of the analytical process: (1) designing the research questions; (2) selecting the sample to be analyzed; (3) defining the categories that will be applied; (4) outlining the coding process; (5) implementing the coding process; (6) determining trustworthiness; and (7) analyzing the results of the coding process. These were the steps that I followed.

Although deductive analysis requires starting with pre-existing theories, which I drew from social movement theories, my goal was to avoid simply reproducing hegemonic knowledge. Throughout the analysis, I remained open to the possibility that my findings might require the development of new social movement theories or categories, rather than forcing these queer liberation organizations to fit into predetermined theoretical frameworks. And indeed, this did happen. I hoped to accomplish this by approaching my methodology from a critical inquiry epistemology, which recognizes how knowledge is usually constructed by those in power and seeks to create oppositional knowledge. Existing theory or research is used in order to focus the research questions, and can "provide predictions about the variables of interest or about the relationships among variables, thus helping to determine the initial coding scheme or relationships between codes" (Hsieh \& Shannon, 2005, p.1281).

A research project using deductive content analysis will produce findings that provide supporting and/or nonsupporting evidence for whether a theory applies to a new example. This evidence is usually offered by explaining the codes that were used, 
providing exemplars, examining counter examples, and by offering descriptive evidence (Hsieh \& Shannon, 2005). As with an inductive analysis, a deductive analysis proceeds in three main phases: preparation, organizing, and reporting (Elo \& Kynga, 2007).

\section{Methods}

\section{Selection of participants.}

I focused on eight organizations from across the country. Miles and Huberman (1994) explained that looking at a range of cases adds confidence to the findings. Since generalizability is not the goal of qualitative research, the participants did not need to be a representative sample (Marshall, 1996). In selecting multiple cases, participants were chosen on conceptual, not representative, grounds (Miles \& Huberman, 1994).

My study focused on organizations from across the country (see Appendix E) that received the Movement Building grants from the Astraea Lesbian Foundation for Justice (aka Astraea). From my years of experience in the field, I knew that these organizations are recognized throughout the country as leading movement-building queer organizations engaged in multi-issue work. What I did not know, however, is what movement they are actually building.

I did not use Astraea's definition of a social movement to answer my second research question, where I explored if the organizations in this study might constitute a social movement. Rather, I developed my own definition of a social movement, which I used as the benchmark. As explained in Chapter Two, based upon a review of social movement literature (summarized in Appendix B), I defined a social movement as "a group of people engaged in collective work, consisting of activities and organizations, with common purposes and a collective identity." I used social movement theories, rather 
than Astraea, to develop my criteria for a social movement because I wanted to situate my analysis in that theoretical context. My interest was in exploring these organizations through the lens of established social movement theories. In fact, it did not even occur to me to investigate Astraea's definition of a social movement until members of my dissertation committee asked me if I was using that definition to guide my research. At my dissertation proposal defense, the committee members asked me to explore Astraea's definition of a social movement and how it may have shaped or influenced the sample and the results. Accordingly, I want to address that now.

Astraea does not have one definition of movement building that it used consistently for their funding. When groups applied to Astraea for the Movement Building Grant, they were not provided with a definition of movement building. Rather, they were asked to define movement building themselves, and this definition was one of many criteria that Astraea used in making its grant selections (Personal Communication with Mai Kiang, Astraea Associate Director of Grantmaking, May 20, 2008).

However, despite not having one consistant definition of movement building, on numerous occassions Astraea made clear that there are certain elements of movement building that they value, and certain types of organizations that they were looking to fund. For instance, they once stated that they created their Movement Building Inititiative to "build collective power for LGBTQI people of color-led organizations and to spur collective action that includes the voices of those most seldom heard" (Astraea Foundation, 2011a). They have used similar language on other occasions (Astraea Foundation, 2011b, IHRFG, 2010). 
I recently called Katherine Acey, who served as Astraea's Executive Director for over twenty years until she left three years ago. I asked her to describe to me how Astraea was defining "movement building" when they made their funding decisions about this initiative. Her current response is consistent with Astraea's other messaging:

One of the criteria was the groups had to be people of color or predominately people of color. We were using a social justice/feminist/instersectional lens, in terms of who the groups were. We were always looking at groups who sought social justice as their goal and were using different collective action approaches, whether that was organizing or public education and/or advocacy... So we really looked at groups who were trying to make change. (And) in terms of who they reached out to, what their analysis was around intersectionality, how they looked at race, class, gender, sexual orientation, gender identification, so that they had some idea about how those systems of oppression and power work together.

These descriptions share a key similarity to the definition that I am working with. Astraea prioritized groups that engage in "collective action" to "build collective power" (rather than, say, groups who provide direct services or prioritize lobbying). Astraea's focus on "collective action" is consistent with most definitions put forward by social movement theorists (Gamson, 1990; Snow \& Soule, 2010; Tarrow, 1998). However, Astraea's definition does not explicitly address the other criteria (structured activities and organizations, common purposes) employed by social movement theorists, which I incorporated into my working definition. Consequently, my definition of a social movement held these organizations to a different, more multi-faceted, set of criteria than did Astraea. Although Astraea's imposed definition of a social movement pre-exists within my sample, there was no reason to assume that this meant that the organizations would automatically meet the different definition that I had established. 
Because Astraea prioritized certain characteristics, the groups that they funded which are included in this study are presumably not representative of all LGBT organizations. This sample was undeniably shaped by Astraea, and is reflective of its values and priorities. This was not of concern to me because I am focusing on a particular set of groups, whose work I was already familiar with. It was their work that initially raised my research questions. Consequently, participants were chosen on conceptual, not representative, grounds. (I am not attempting to generalize my findings to claim that they are representative of all groups in the GRM.) I am interested, specifically, in understanding the groups who received Astraea's movement-building grant.

However, Astraea's criteria for selection in this funding initiative did make me inclined to assume certain things about the groups in my study. Astraea's focus on community organizing and collective action predisposed me to believe that Astraea's grantees were going to prioritize community organizing over lobbying or direct services, putting them in marked contrast to the equality groups in the GRM (which have prioritized lobbying). Additionally, Astraea's focus in this initiative on "LGBTQI people of color-led organizations" and their desire to highlight "the voices of those most seldom heard" strongly implies that the groups they funded are going to be comprised of leaders and members that are very different from the white, middle-class gays and lesbians who have been the leadership, beneficiaries, and constituents of the GRM. This predisposed me to believe that the Astraea grantees in my study would have targets of benefits and mobilization (as defined by Gamson, 1990) that are different from those of the GRM and, thus, would likely not be part of the GRM. 
These assumptions required attention because they have complicated implications for my analysis. One the one hand, I see nothing wrong with starting out with certain assumptions. After all, I decided to undertake this study precisely because I had a suspicion that these groups were not part of the GRM, and I wanted to investigate this suspicion. On the other hand, I had to be diligent about not letting those assumptions prejudice my findings and analysis. Later in this chapter, I discuss how I worked to achieve trustworthiness.

I included eight of the Astraea organizations in this study. Marshall (1996) stated that the appropriate number of participants for a qualitative study is simply "one that adequately answers the research question" (p.523). Studying eight organizations provided me with a number small enough to be manageable, but large enough for different themes to emerge. Eight organizations allowed me to examine in detail where patterns among the groups converge or diverge. I began with a list all twelve Astraea grantees, and emailed all of them an invitation to participate. I chose to study the first eight organizations that responded affirmatively. Table 5.1 lists the eight organizations included in the study. 
Table 5.1

List of Organizations Included in Study

\begin{tabular}{|c|c|c|}
\hline $\begin{array}{c}\text { Name (and } \\
\text { website/location) }\end{array}$ & $\begin{array}{c}\text { Description } \\
\text { (from organizational websites) }\end{array}$ & Funding Info ${ }^{1}$ \\
\hline $\begin{array}{l}\text { Affinity Community } \\
\text { Services } \\
\text { www.affinity95.org } \\
\text { Chicago, Illinois }\end{array}$ & $\begin{array}{l}\text { Affinity works with and on behalf of } \\
\text { Black LGBTQ communities, queer } \\
\text { youth, and allies to identify emergent } \\
\text { needs, create safe spaces, develop } \\
\text { leaders, and bridge communities } \\
\text { through collective analysis and action } \\
\text { for social justice, freedom, \& human } \\
\text { rights. }\end{array}$ & $\begin{array}{l}\text { One staff person } \\
\text { Budget: } \$ 220,205 \text { (2014) } \\
65 \% \text { Foundation \& corporate } \\
16 \% \text { Individuals } \\
10 \% \text { Earned income } \\
9 \% \text { Other }\end{array}$ \\
\hline $\begin{array}{l}\text { allgo } \\
\text { www.allgo.org } \\
\text { Austin, Texas }\end{array}$ & $\begin{array}{l}\text { allgo is a statewide people of color } \\
\text { organization. allgo works toward its } \\
\text { vision through cultural arts, health and } \\
\text { advocacy programming. }\end{array}$ & Two staff (2014) \\
\hline $\begin{array}{l}\text { The Audre Lorde } \\
\text { Project (ALP) } \\
\text { www.alp.org } \\
\text { New York, New York }\end{array}$ & $\begin{array}{l}\text { ALP is a Lesbian, Gay, Bisexual, Two } \\
\text { Spirit, Trans and Gender- } \\
\text { Nonconforming People of Color center } \\
\text { for community organizing, focused on } \\
\text { mobilization, education and capacity- } \\
\text { building. }\end{array}$ & $\begin{array}{l}\text { Eight staff members (2015) } \\
\text { Budget: \$600,000 } \\
\text { \$250,000 NY Dept. of Health; } \\
\text { and HIV AIDS Institute } \\
\text { \$75K: Major Donors } \\
\text { \$275K: Foundations (Arcus } \\
\text { Foundation; Astraea Lesbian } \\
\text { Justice Foundation; North Star } \\
\text { Fund; Tides Found.; Urgent } \\
\text { Action) }\end{array}$ \\
\hline $\begin{array}{l}\text { Center for Artistic } \\
\text { Revolution (CAR) } \\
\text { www.artisticrevolution } \\
\text {.org } \\
\text { Little Rock, Arkansas }\end{array}$ & $\begin{array}{l}\text { CAR is a statewide, grassroots } \\
\text { community based organization. It } \\
\text { engages in progressive education, } \\
\text { organizing skills, advocacy, and } \\
\text { creative/cultural work and they } \\
\text { currently have programs advocating for } \\
\text { non-traditional families, queer youth, } \\
\text { and transgender people. }\end{array}$ & One staff (2015) \\
\hline $\begin{array}{l}\text { National Queer } \\
\text { Asian Pacific } \\
\text { Islander Alliance } \\
\text { (NQAPIA) } \\
\text { www.nqapia.org } \\
\text { Washington, DC }\end{array}$ & $\begin{array}{l}\text { NQAPIA is a federation of LGBTQ } \\
\text { Asian American, South Asian, } \\
\text { Southeast Asian and Pacific Islander } \\
\text { organizations. It seeks to build the } \\
\text { capacity of local LGBT AAPI } \\
\text { organizations, invigorate grassroots } \\
\text { organizing, develop leadership, and }\end{array}$ & $\begin{array}{l}\text { Two staff members (2014) } \\
\text { Budget: } \$ 300,000 \\
\text { No government money. } \\
\text { (Arcus Foundation; Astraea } \\
\text { Lesbian Foundation; Asian } \\
\text { Americans/Pacific Islanders in } \\
\text { Philanthropy; Ford Foundation; }\end{array}$ \\
\hline
\end{tabular}

${ }^{1}$ The fiscal information is not organized in a uniform manner because complete and up-to-date data was not available for all the organizations. Rather than presenting a comprehensive report on their finances, I have tried to present a general overview of the organizations' staff size, budget, and funding sources, compiled from the most recent information I could obtain for each group. 


\begin{tabular}{|c|c|c|}
\hline & $\begin{array}{l}\text { challenge homophobia, racism, and } \\
\text { anti-immigrant bias. }\end{array}$ & $\begin{array}{l}\text { Four Freedoms Fund; Open } \\
\text { Society; Public Interest } \\
\text { Projects; Walter and Evelyn } \\
\text { Haas Fund; Verison; Caesars } \\
\text { Entertainment; Hawaiian } \\
\text { Airlines; National Gay \& } \\
\text { Lesbian Task Force) }\end{array}$ \\
\hline $\begin{array}{l}\text { Queers for Economic } \\
\text { Justice }^{2} \\
\text { (QEJ) } \\
\text { www.Q4EJ.org } \\
\text { New York, New York }\end{array}$ & $\begin{array}{l}\text { QEJ was a multi-racial, multi-class } \\
\text { organization. They engaged in local } \\
\text { community organizing and advocacy } \\
\text { with low-income and homeless LGBT } \\
\text { people. They also conducted public } \\
\text { education campaigns nationally and } \\
\text { built coalitions across the country on } \\
\text { economic issues impacting LGBT } \\
\text { people. }\end{array}$ & $\begin{array}{l}\text { Five staff (2008) } \\
\text { One (2014) } \\
\text { Budget: \$400,000 (2008) / } \\
\$ 80,000(2014) \\
\text { No government grants } \\
\text { (Abelard Foundation; Arcus } \\
\text { Foundation; Astraea Lesbian } \\
\text { Foundation; Calamus; North } \\
\text { Star Fund; NY Foundation; NY } \\
\text { Womens' Foundation; } \\
\text { Rappaport Foundation; } \\
\text { Rainbow Endowment; } \\
\text { Rockefeller Philanthropy } \\
\text { Advisors; Stonewall } \\
\text { Community Foundation) }\end{array}$ \\
\hline $\begin{array}{l}\text { Southerners on New } \\
\text { Ground (SONG) } \\
\text { www.southernersonne } \\
\text { wground.org } \\
\text { Atlanta, Georgia }\end{array}$ & $\begin{array}{l}\text { SONG works in multiple states as a } \\
\text { multi-issue southern justice movement } \\
\text { organization in which poor and working } \\
\text { class, immigrant, people of color, rural } \\
\text { LGBTQ people take leadership. SONG } \\
\text { builds this movement through } \\
\text { leadership development, intersectional } \\
\text { analysis, and organizing. }\end{array}$ & $\begin{array}{l}\text { Ten staff (in 2013) } \\
\text { Budget: } \$ 655,000 \\
\text { (Arcus Foundation; Dolphin } \\
\text { Foundation; Ford Foundation; } \\
\text { Fund for Democratic } \\
\text { Communities; Open Society } \\
\text { Foundation) }\end{array}$ \\
\hline $\begin{array}{l}\text { The Sylvia Rivera } \\
\text { Law Project (SRLP) } \\
\text { www.srlp.org } \\
\text { New York, New York }\end{array}$ & $\begin{array}{l}\text { SRLP provides legal services for } \\
\text { transgender, intersex or gender } \\
\text { nonconforming people. It also engages } \\
\text { in coalition building, public education } \\
\text { and high impact litigation. It is a non- } \\
\text { hierarchal collective. }\end{array}$ & $\begin{array}{l}\text { Eight staff members (2015) } \\
\$ 615,000 \text { (in 2013) } \\
\$ 465,500 \text { from foundations } \\
\text { (Arcus Foundation; ARIA } \\
\text { Foundation; Astraea Lesbian } \\
\text { Foundation; Calamus } \\
\text { Foundation; Equal Justice } \\
\text { Works; Open Society; Gill } \\
\text { Foundation; Tides Foundation; } \\
\text { Miller-Wehrle Foundation; }\end{array}$ \\
\hline
\end{tabular}

${ }^{2}$ At the time this study was being designed, QEJ had recently announced that it was closing. However, for several months after the announcement, they continued to wrap up some of their work. Given that staff, volunteers and board were still doing QEJ-related work, and given QEJ's relationships to these other organizations, I included QEJ in my study despite the fact that they had shut down for good by the fall of 2014. For their budget, I included two sets of information: one from 2014, at the time of my study, when they were about to close, and one from 2008, when they were more fully functional. 


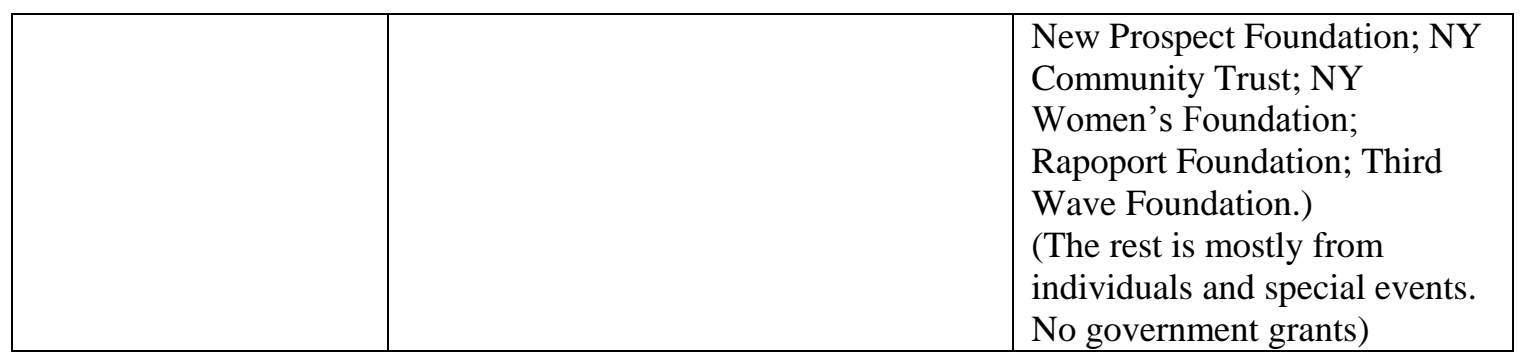

Data sources.

I analyzed three pieces of text from each organization. Qualitative content analysis can be used for any recorded communication, regardless of whether they have been recorded in writing or video (Mayring, 2000). For each organization, I (1) obtained their mission statement; (2) conducted one semi-structured interview; and (3) transcribed one videotape about the organization posted online. Each data source was analyzed for each participating organization, resulting in 24 texts included in this study (see Table 5.2).

Table 5.2

Data Sources for Each Organization

\begin{tabular}{|l|l|l|l|}
\hline Name & $\begin{array}{l}1^{\text {st }} \text { Data } \\
\text { Source }\end{array}$ & $2^{\text {nd }}$ Data Source & $3^{\text {rd }}$ Data Source \\
\hline $\begin{array}{l}\text { Affinity } \\
\text { Community }\end{array}$ & $\begin{array}{l}\text { Mission } \\
\text { Statement }\end{array}$ & $\begin{array}{l}\text { Transcript of interview with } \\
\text { Kim L. Hunt, Executive } \\
\text { Director }\end{array}$ & $\begin{array}{l}\text { Transcript of online video of } \\
\text { Affinity's public access } \\
\text { program, featuring 2013 } \\
\text { interview with Myles Brady } \\
\text { a volunteer leader }\end{array}$ \\
\hline allgo & $\begin{array}{l}\text { Mission } \\
\text { Statement }\end{array}$ & $\begin{array}{l}\text { Transcript of interview with } \\
\text { Rose Pulliam, Co-Director }\end{array}$ & $\begin{array}{l}\text { Transcript of online 2014 } \\
\text { video describing the origins } \\
\text { of allgo }\end{array}$ \\
\hline $\begin{array}{l}\text { Lhe Audre } \\
\text { (ALP) }\end{array}$ & $\begin{array}{l}\text { Mission } \\
\text { Statement }\end{array}$ & $\begin{array}{l}\text { Transcript of interview with } \\
\text { Cara Page, Executive } \\
\text { Director }\end{array}$ & $\begin{array}{l}\text { Transcript of online video } \\
\text { of 2007 speech given by } \\
\text { Trishala Deb, former ALP } \\
\text { Program Coordinator }\end{array}$ \\
\hline $\begin{array}{l}\text { Center for } \\
\text { Artistic } \\
\text { Revolution } \\
\text { (CAR) }\end{array}$ & $\begin{array}{l}\text { Mission } \\
\text { Statement }\end{array}$ & $\begin{array}{l}\text { Transcript of interview with } \\
\text { Randi Romo, Director }\end{array}$ & $\begin{array}{l}\text { Transcript of online } \\
\text { promotional video of 2009 } \\
\text { CAR community event }\end{array}$ \\
\hline $\begin{array}{l}\text { National Queer } \\
\text { Asian Pacific } \\
\begin{array}{l}\text { Islander } \\
\text { Alliance }\end{array}\end{array}$ & $\begin{array}{l}\text { Mission } \\
\text { Statement }\end{array}$ & $\begin{array}{l}\text { Transcript of interview with } \\
\text { Ben de Guzman, Co-Director }\end{array}$ & $\begin{array}{l}\text { Transcript of two-part online } \\
\text { promotional video about } \\
\text { NQAPIA's 2009 National } \\
\text { Conference }\end{array}$ \\
\hline
\end{tabular}




\begin{tabular}{|l|l|l|l|}
\hline $\begin{array}{l}\text { Queers for } \\
\text { Economic } \\
\text { Justice } \\
\text { (QEJ) }\end{array}$ & $\begin{array}{l}\text { Mission } \\
\text { Statement }\end{array}$ & $\begin{array}{l}\text { Transcript of interview with } \\
\text { Kenyon Farrow, former } \\
\text { Executive Director }\end{array}$ & $\begin{array}{l}\text { Transcript of online video of } \\
\text { 2012 interview with } \\
\text { Executive Director Amber } \\
\text { Hollibaugh on "GRITtv" }\end{array}$ \\
\hline $\begin{array}{l}\text { Southerners on } \\
\text { New Ground } \\
\text { (SONG) }\end{array}$ & $\begin{array}{l}\text { Mission } \\
\text { Statement }\end{array}$ & $\begin{array}{l}\text { Transcript of interview with } \\
\text { Paulina Helm-Hernandez, Co- } \\
\text { Director }\end{array}$ & $\begin{array}{l}\text { Transcript of seven-part } \\
\text { online video of Caitlin } \\
\text { Breedlove, Co-Director } \\
\text { presenting at a 2009 } \\
\text { conference }\end{array}$ \\
\hline $\begin{array}{l}\text { The Sylvia } \\
\text { Rivera Law } \\
\text { Project (SRLP) }\end{array}$ & $\begin{array}{l}\text { Mission } \\
\text { Statement }\end{array}$ & $\begin{array}{l}\text { Transcript of interview with } \\
\text { Reina Gossett, Director of } \\
\text { Membership }\end{array}$ & $\begin{array}{l}\text { Transcript of two-part online } \\
\text { video of 2012 interview with } \\
\text { SRLP Founding Director } \\
\text { Dean Spade on "GRITtv" }\end{array}$ \\
\hline
\end{tabular}

\section{Focus on leadership.}

Because I wanted to hear from more than one voice per organization, I

deliberately avoided using online videos that featured the same leaders I interviewed. By using the mission statements, speeches, and interviews, I heard from three different sets of leaders from each organization.

It is worth noting that SRLP has a collective leadership structure, so there is no Executive Director there. Rather, they have six Directors who each run a specific component of their work and share leadership of the organization. According to their website, they do this because it aims to redistribute power, modeling the world they want to see, and maximizes community involvement, which supports the sustainability of organization. In addition, for related reasons, several of the other organizations (allgo, NQAPIA, and SONG) have Co-Director models, each employing two directors who work together, rather than a single Executive Director. These leadership models have tremendous impact on the work of these organizations, which I explore in Chapter Eight. In addition, it complicates my focus on leaders, expanding the definition of leadership. 
All the texts were generated by leaders of these organizations, rather than by their constituents. I am aware that by focusing on leadership, and specifically by choosing to interview leaders of these organizations, I run the risk of perpetuating a hierarchical framework of knowledge production that values the role of those in power over those below them. To do so would contradict my epistemological stance of critical inquiry, which requires critiquing how power shapes the creation of hegemonic knowledge.

Yet, in order to engage with the social movement literature, I must examine leadership because so much of social movement theory centralizes the role of leaders (e.g., Blumer, 1951; Goldstone, 2001; Robnett, 1997; Wilson, 1973; Zald \& McCarthy, 1987). Leadership is an important element of social movements, regardless of whether the theoretical lens utilized is collective behavior, resource mobilization, political opportunity, or cultural frames (Chesters \& Welsh, 2010). Leaders of social movement organizations engage in numerous tasks (e.g., organizing meetings and events, building coalitions, raising funds) to move forward the agenda of their social movement. Morris and Staggenborg (2007) argue that the significance of movement leadership cannot be underestimated and they state, "leaders are critical to social movements: they inspire commitment, mobilize resources, devise strategies, frame demands, and influence outcomes" (p. 171). They maintain that leadership must be studied in order to understand a social movement. For these reasons, I decided to focus on organization leadership. In order to put these organizations in a theoretical context, the perspectives of their leaders must be understood.

Although the choice to focus on leadership is justified by my research questions, one could argue that my choice of research questions contradict my claim to be engaging 
in critical inquiry. Because of this epistemological conundrum, it is important to look at who these specific leaders are. While it is true that they hold leadership positions at their organizations, they are not typical of those in power. Leaders of social movements tend to come from the educated middle and upper classes and are disproportionately male (Morris \& Staggenborg, 2007). In the GRM, leadership has also been overwhelmingly white (Boykin, 2000, Vaid, 2012). However, these generalizations about social movement leaders do not apply to the people I interviewed. While most did have college educations (thus reflecting typical social movement leadership), the majority of the interviewees came from working class or impoverished backgrounds (which is not true of most social movement organizations, and is particularly untrue of the GRM). Of the eight leaders I interviewed, six identified as women (one of whom is transgender), and only two as men. Seven out of the eight leaders I interviewed were people of color. This is in stark contrast to the leadership of the GRM, where recently White people lead 38 out of the 40 largest national LGBT advocacy organizations (Vaid, 2012). When I expand my focus beyond just the interview participants, and also include the leaders featured in the online videos, the majority of my data comes from people who are either transgender, immigrants, low-income, or formerly incarcerated. These identities are significant to my decision to focus on leaders, and are related to the issue of critical inquiry.

Knowledge creation reflects the social, cultural, and racial contexts of, as well as the political, and economic interests of, researchers and theorists (Banks, 2002, MoosaMitha, 2005). Patricia Hill Collins (2000) argued that elite White men regulate what constitutes knowledge and their interests "pervade the themes, paradigms, and epistemologies of traditional scholarship" (p. 269). Members of marginalized 
communities can create knowledge that challenges dominant paradigms and theories, and which advocates for fundamental transformations of both social structures and knowledge production (Banks, 2002, Moosa-Mitha, 2005). However knowledge created in marginalized communities is regularly disregarded, and, as Collins (2000) put it "routinely distorted within or excluded from what counts as knowledge" (p. 269). For this reason, it is important to me to prioritize building knowledge from subordinated communities.

Collins (1990) argues, “placing Black women's experiences at the center of analysis offers fresh insights on the prevailing concepts, paradigms, and epistemologies" (para. 2). She believes that marginalized groups can be empowered by providing them with new knowledge about their lives, but "revealing new ways of knowing that allow subordinate groups to define their own reality has far greater implications" (1990, para. 3). Similarly, feminist scholar Sandra Harding contends that conducting research from an explicitly social location (based upon the lived experiences of subordinated people who have been excluded from knowledge production) produces a more useful body of knowledge (Harding, 2002; Hirsh, Olson, \& Harding, 1995).

However, many are critical of the idea of knowledge production based upon the experiences of marginalized people. They contend that centering stories of lived experience risks creating essentialized identity categories; taking ideologically and culturally shaped experiences and naturalizing them (Haraway, 1985; Stone-Mediatore, 1998). For instance, historian Joan Wallach Scott (1991) claims that personal narratives, and histories that are based on the experiences of subordinated people, serve to strengthen generalizations and assumptions about identities and differences. Despite these critiques, 
influential feminists of color (e.g. Gloria Anzaldúa, bell hooks) continue to write texts based upon their experiences because these writings are an important means of highlighting oppression (Stone-Mediatore, 1998).

Mohanty (1991) recognizes the contributions to knowledge production that can be made by women of color, but argues that in order for subordinated people to constitute a useful basis of knowledge production, they must center their common context for struggle, rather than merely focusing on their racial identities. She suggests defining third world women, with different histories and social locations, by their legacy of struggle, not by their race or location.

I am suggesting, then, an 'imagined community' of third world oppositional struggles. 'Imagined' not because it is not 'real' but because it suggests potential alliances and collaborations across divisive boundaries, and 'community'... (I)t is not color or sex which constructs the ground for these struggles. Rather, it is the way we think about race, class, and gender - the political links we choose to make among and between struggles (Mohanty, 1991, p. 4).

Mohanty (1991) invokes the phrase "communities of resistance" when she advocates for alliances based on political affinities rooted in common struggles, rather than merely biological or cultural affinities. Philosopher Shari Stone-Mediatore (1998) claims that Mohanty's ideas allow narratives based on the experiences of marginalized people to be understood as important interventions and challenges. She claims, "we can avoid naturalizing experience and yet still productively read, teach, and defend stories of marginalized experience" (Stone-Mediatore, 1998, p. 117).

The participants in my study can clearly be considered members of such "communities of resistance." Though they come from diverse marginalized identity groups, they share a commitment to oppositional struggles. Subordination based upon 
their racial, sexual, gender, immigration, and/or class identities has informed their activism and resistance. By gathering information from people who are not typically utilized as the sources of knowledge production and who are engaged in oppositional struggles against oppressive systems, I engaged in one of the goals of critical inquiry: the creation of oppositional knowledge (Lather, 1991).

I recognize that this study's focus on leadership still remains problematic in some ways, but nevertheless I contend that it does not merely reproduce hegemonic knowledge. The specific leaders of these organizations complicate such a one-dimensional assessment.

\section{Selection of texts.}

The first text I included for each organization was its mission statement. The mission statements have been written by the founding members of the organization, many of whom often become board members whose vision provides leadership to the organization. According to Rangan (2004), most non-profits stay loyal to their mission statements and base most of their program decisions on them. A mission statement is usually written and/or approved by more than one founder and represents what inspired the founders to create the organization. "It draws board members, staff, donors, and volunteers to become involved. What's more, the founders often deliberately ensure that their original vision is embraced by the next generation of leaders" (Rangan, 2004, p.2). Content analysis of mission statements is a useful way to understand how an organization presents its primary reasons for existence (Stemler \& Bebell, 1998). Because a mission statement plays such a central role in articulating the values of an organization and guiding its work, I analyzed the text of each organization's mission statement. 
The second data source for each organization was a semi-structured interview. I conducted interviews with the executive directors (or people in comparable positions, such as Co-Directors). Most directors of non-profit organizations are involved in activities that focus on securing and expanding "cognitive, symbolic or material resources" that move forward the organization's work (Chesters \& Welsh, 2010, p.109). For this reason, it was important to me to interview them about how they see the work of their organization.

For my third data source from each group, I initially intended to include online videotapes of speeches been given by a different staff person (or a volunteer authorized to represent the organization). I did not want to include speeches given by executive directors because multiple voices describing the work of each organization may produce data that is more complicated and rich. However, after beginning my research, this proved to be impossible. Not all of the groups had such videos online. After engaging in both peer debriefing and consultation with my dissertation committee, I expanded this third category. I still required that the video feature staff/key volunteers other than the Executive Director, but I decided not to limit the options to videotaped speeches. Instead, the final source of data I used was any public audio/visual document found online that describes the work of the organization. For the eight organizations, I ended up using two filmed conference presentations/speeches, three television interviews, and three organizational promotional videos. Despite these different formats, the videos shared important commonalities. They were all audiovisual documents that publicly present staff and volunteers discussing the work of their organizations. That similarity was significant enough to justify their inclusion. 


\section{Preparing for the data analysis.}

In qualitative content analysis, the material must be analyzed systematically using analytical units or categories (Mayring, 2000). The development of these coding categories is central to qualitative content analysis, and its purpose is to organize large quantities of text into much fewer content categories (Weber, 1990). This can be done deductively, inductively, or in some combination. When analyzing the text, the researcher must use theory and the text itself to develop category definitions, exemplar text passages, and rules for distinguishing different categories. These are completed systematically and are then revised, in feedback loops, throughout the process of analysis (Mayring, 2000). The development of a good coding scheme is central to trustworthiness in research using content analysis (Hsieh \& Shannon, 2005).

I focused my analysis on the manifest content of the text, rather than the latent content (e.g., silence, sighs, laughter, and posture), because I was interested in how the text explains their work. Mission statements and public speeches employ carefully crafted words, where latent content is less relevant. Although the interviews I conducted could have been analyzed for latent content, focusing only on the manifest content allowed greater consistency with my analysis of mission statements and public statements.

For deductive content analysis, researchers begin by using existing theory or prior research to identify key concepts or categories, which become the basis for initial coding categories (Hsieh \& Shannon, 2005). Operational definitions for each category are then determined (also based upon existing theory and research) by developing explicit definitions, examples and coding rules for each deductive category, determining in advance when a text passage can be coded with a category (Mayring, 2000). My 
qualitative content analysis was informed by social movement theories and by the information about LGBT organizations I researched for the dissertation proposal. I engaged in deductive analysis and used constructs from the social movement literature (described broadly in Chapter Two, and more specifically in Appendixes A, B, C, F, and G) to inform the categories and themes I explored in my analysis. Diagram 5.3 illustrates how different theoretical frameworks (described in Chapter Two) informed my research design. The boxes are numbered, representing the sequence in which they were developed.

Figure 5.1

Relationships Among Theoretical Frameworks and Research Design

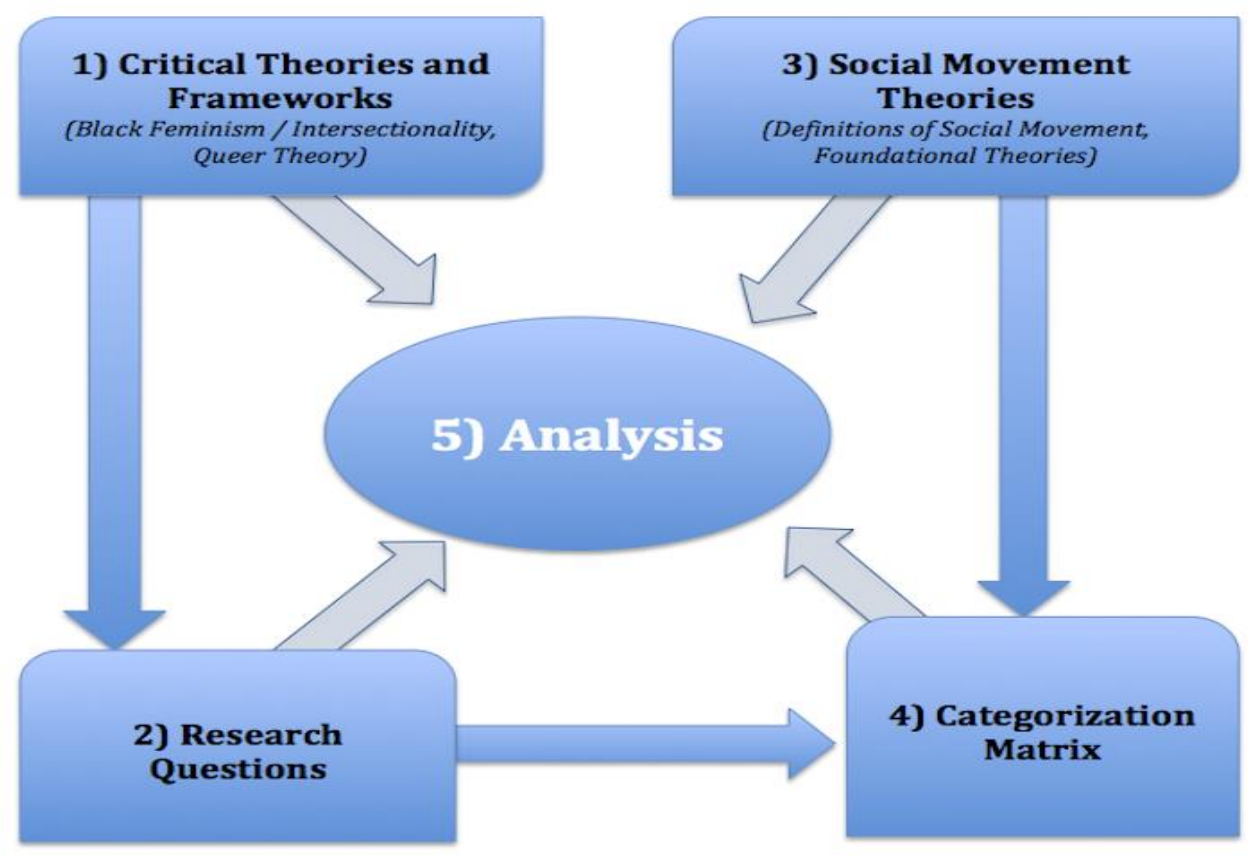

The diagram provides an illustration of how my (1) critical theories and frameworks informed my choice of (2) research questions. I then brought those research questions into conversation with (3) social movement theories to shape (4) the categorization matrix's deductive codes, which were developed in advance of collecting 
data. My analysis was then informed by these theoretical frameworks (both critical theories and social movement theories), as well as by the research questions and categorization matrix.

\section{Categorization matrix.}

To answer my three research questions using deductive content analysis, I developed a categorization matrix before I began my analysis. This matrix identified the themes I investigated in the analysis and provided preliminary categories and codes with which to later analyze the text (Elo \& Kynga, 2007). Researchers can use either a structured or unconstrained matrix of analysis. I chose an unconstrained matrix, and when I began my analysis it required me to borrow from inductive (thematic) content analysis to create additional categories and subcategories within the matrix. I began with initial categories, but I remained open to new concepts emerging from these organizations. Even in a deductive framework, qualitative content analysis often produces themes that emerge from the analysis (Hsieh \& Shannon, 2005; Krippendorff, 1969; Mayring, 2000), and my categorization matrix gave me a starting place for considering themes that surfaced. I used social movement theories to develop 11 initial coding categories in my matrix.

To answer my first question (Q1) - "What does analyzing these organizations through SM theories reveal about the claim held by many that these organizations are the left-wing of the GR Movement?” - I used a framework developed by Gamson (1990), which maintained that challenging groups involved in social movement work could be categorized by three criteria: (1) the target of influence; (2) the target of mobilization; and (3) the target of benefits. Based upon this framework, I developed coding categories to 
investigate whether the queer liberation groups in my study share the same targets as the GRM.

I began my coding with these three pre-determined codes for Q1. Table 5.3 is an excerpt from my categorization matrix. It illustrates the codes determined in advance to answer the first research question.

Table 5.3

Categorization Matrix for Research Question 1

Q1 - What does analyzing these organizations through social movement theories reveal about the claim held by many that these organizations are the left wing of the GR Movement?

\begin{tabular}{|c|c|c|}
\hline Target of Influence & Target of Mobilization & Target of Benefits \\
\hline $\begin{array}{c}\text { Quotes from all 24 data } \\
\text { sources that identified who } \\
\text { the organization is trying to } \\
\text { influence or change. }\end{array}$ & $\begin{array}{c}\text { Quotes from all 24 data sources that } \\
\text { identified the constituency being } \\
\text { organized, members joining the } \\
\text { group, and leadership of the group. }\end{array}$ & $\begin{array}{c}\text { Quotes from all 24 } \\
\text { data sources that } \\
\text { identified whose } \\
\text { lives are being } \\
\text { improved by the } \\
\text { organization. }\end{array}$ \\
\hline
\end{tabular}

In order to compare the targets of the queer liberation organizations to the GRM, I first needed to be clear about the GRM's targets, drawn from my literature review. Table 5.4 (also found in Appendix F) summarizes this information and identifies the mainstream LGBT movement's targets, against which I measured the targets of the groups in my study. 
Table 5.4

Targets of the Mainstream Gay Rights Movement

\begin{tabular}{|c|l|l|}
\hline \multicolumn{2}{|c|}{ MAINSTREAM GAY RIGHTS MOVEMENT } \\
Analyzed Using Framework Developed by Gamson (1990) for “Identifying Challenging \\
Groups"
\end{tabular}

I analyzed the mission statements, interviews, and audiovideo transcripts, and used the criteria found in this table to determine whether the queer liberation groups share the same targets, which according to the framework I developed based upon Gamson (1990), indicates whether they are part of the same movement. While this first research question is binary, its answer required elaboration as I engaged with the implications. My 
other two research questions were open-ended, intended to explore the meanings and implications of the answer to the first.

I explored my second research question (Q2) - "What does analyzing these organizations through SM theories reveal about their relationship to one another?" - in light of the answer to Q1. The first question determined whether or not the groups were part of the GRM, and Q2 explored the relationships among those groups I found to be part of the GRM. In addition, Q2 explored whether the groups I found to be outside the GRM are unaffiliated with any movement, work in coalition, or comprise a different social movement.

As explained previously, I defined a social movement as a group of people engaged in collective work, consisting of structured activities and organizations, with common purposes and collective identity. I looked for three criteria to determine if these organizations meet this definition of a social movement.

The first criterion was the question of whether they are engaged in organizing people to work collectively (as opposed to lobbyists or litigants working individually). Collective action, such as a mass protest or boycott, has been articulated as hallmark of social movements by social movement theorists (Gamson 1990; Snow \& Soule, 2010; Tarrow, 1998). Consequently, one of the categories in my categorization matrix was "Collective Action." The second criterion I used is whether these groups and their collective actions have structure and organization. Social movement theorists (Snow \& Soule, 2010; McAdam, et al., 2001) maintain that social movements are engaged in organized activities. These activities can be varied (coordinated protests, the creation of an organization, networking of different groups) but they must be deliberately planned 
and organized. Because of this, I included "Structure and Organization" as one of the categories in my matrix. The third criterion I looked for was "Common Purposes and Collective Identity." Tarrow (1998) argued that the collective action of a social movement is based upon similar goals and social solidarities, and McAdam, et al. (2001) made the same point when talking about how all movements engage in the "framing of grievances" which legitimizes their claims, connects them to other claims, and forms a collective identity among the claimants. For this reason, my categorization matrix contained a category for "Common Purposes and Collective Identity" where I investigated whether or not the queer liberation organizations share similar values, social solidarities, grievances and/or goals.

Once I began coding the data for Q2, I quickly realized I needed to create additional codes. The deductively created codes in the categorization matrix had focused on determining whether these groups comprise a social movement. However, the possibility that they might be unaffiliated organizations or coalitions (as defined by Diani and Bison, 2004) required the creation of codes that I could use as I explored the data for those themes.

In total, I began my coding with five pre-determined codes for Q2. Table 5.5 illustrates the codes determined in advance to answer the second research question. 
Table 5.5

Categorization Matrix for Research Question 2

\begin{tabular}{|c|c|c|c|c|}
\hline \multicolumn{5}{|c|}{ Q2 - What does analyzing these organizations through social movement theories reveal } \\
about their relationship to one another?
\end{tabular}

At a certain point in my analysis, I came to the understanding that although my working definition of a social movement was very useful, it did not completely explain everything I was finding, which indicated that these groups shared most but not all of the characteristics of a social movement. I decided to refine my analytic tools by including more nuanced definitions of social movements. I ended up bringing in two additional social movement theorists (Hopper, 1950, and Freeman, 1999) to help explain the findings.

Consequently, in Question 2, I refer to two frameworks developed by social movement theorists for understanding how new social movements develop: one by Hopper (1950) and one by Freeman (1999). Doing so helped me to distinguish between "emerging," "coalescing," "formalizing" and "declining" social movements. In both of these frameworks, the early stage of, "coalescence" is not a precursor to a potential social movement; it is a (early) stage of an existing social movement. I used this distinction to help determine that these organizations comprise a coalescing social movement.

Finally, my third research question (Q3) was "What does a social movement 
analysis reveal about these organizations, collectively and individually?" I set out to explore this question regardless of the answers to my first two research questions.

I knew that regardless of whether, based on my first two research questions, I determined that these organizations are a separate social movement, I would still want to explore what social movement theories say about them. These groups are clearly different from the equality organizations in the GRM that have been analyzed by previous social movement theorists. I created codes in the categorization matrix to help me understand how these queer liberation organizations (largely ignored by theorists) might (or might not) fit into existing social movement theory frameworks. Whether they were part of the GRM, unaffiliated organizations, a coalition, or a new social movement, I set out to explore if they fit into one of the existing social movement theoretical frameworks (described in Chapter Two). I considered: resource mobilization theory (McCarthy \& Zald, 1977); Piven and Cloward's (1979) disruptive power framework; the political process model (McAdam, 1982); framing theory (Benford \& Snow, 2000), collective identity (Goodwin \& Jasper, 2009), unity in diversity (Armstrong, 2002) and perspectival dualism (Fraser, 1995; Fraser \& Honneth, 2003). I also planned to consider whether multiple theories can be simultaneously employed to provide theoretical understanding (McAdam, McCarthy, \& Zald, 1996).

To explore these theoretical frameworks, I included six coding categories for Q3 in my categorization matrix: (1) Disruption; (2) Framing; (3) Identity; (4) Politics; (5) Resources; and (6) Redistribution/Recognition. I chose these categories because each represented a theme central to one or more of the major social movement theories informing the study. These categories were used throughout my coding, to help determine 
which frameworks applied to these queer liberation organizations, and how. I began my

coding with six pre-determined codes for Q3. Table 5.6 illustrates the codes determined

in advance to answer Q3.

Table 5.6

Categorization Matrix for Research Question 3

\begin{tabular}{|c|l|l|}
\hline \multicolumn{2}{|c|}{ Q3-What does a social movement analysis reveal about these organizations, } \\
collectively \& individually?
\end{tabular}

Tables 5.4 (for Q1), 5.5 (for Q2), and 5.6 (for Q3) are each pieces of my full categorization matrix. The coding categories found in each of those tables can be brought 
together to see the entire matrix. Table 5.7 (also found in Appendix G) presents the full categorization matrix for all three of my research questions. It shows all 14 initial deductive coding categories.

Table 5.7

Full Categorization Matrix for All Three Research Questions

\begin{tabular}{|c|c|c|c|c|c|c|}
\hline \multicolumn{7}{|c|}{$\begin{array}{l}\text { Q1 - What does analyzing these or } \\
\text { the claim held by many that the }\end{array}$} \\
\hline \multicolumn{2}{|c|}{ Target of Influence } & \multicolumn{3}{|c|}{ Target of Mobilization } & \multicolumn{2}{|c|}{ Target of Benefits } \\
\hline \multicolumn{2}{|c|}{$\begin{array}{l}\text { Quotes from all } 24 \\
\text { data sources that } \\
\text { identified who the } \\
\text { organization is trying } \\
\text { to influence or change. }\end{array}$} & \multicolumn{3}{|c|}{$\begin{array}{l}\text { Quotes from all } 24 \text { data sources tha } \\
\text { identified the constituency being } \\
\text { organized, members joining the } \\
\text { group, and leadership of the group. }\end{array}$} & \multicolumn{2}{|c|}{$\begin{array}{l}\text { Quotes from all } 24 \text { data } \\
\text { sources that identified whose } \\
\text { lives are being improved by } \\
\text { the organization. }\end{array}$} \\
\hline \multicolumn{7}{|c|}{$\begin{array}{r}\text { Q2- What does analyzing these organizatio } \\
\text { their relation }\end{array}$} \\
\hline $\begin{array}{l}\text { Collective } \\
\text { Action }\end{array}$ & \multicolumn{2}{|c|}{$\begin{array}{c}\text { Structure } \\
\text { and Organization }\end{array}$} & \multicolumn{2}{|c|}{$\begin{array}{l}\text { Common Purposes } \\
\text { / Collective Identity }\end{array}$} & Cos & Unaffiliated \\
\hline $\begin{array}{l}\text { Quotes that } \\
\text { addressed } \\
\text { collective } \\
\text { action } \\
\text { organized by } \\
\text { the groups. }\end{array}$ & \multicolumn{2}{|c|}{$\begin{array}{c}\text { Quotes that } \\
\text { addressed } \\
\text { deliberately planned } \\
\text { and structured } \\
\text { activities. }\end{array}$} & \multicolumn{2}{|c|}{$\begin{array}{l}\text { Quotes that } \\
\text { addressed their } \\
\text { values, goals, } \\
\text { grievances, or } \\
\text { identities. }\end{array}$} & $\begin{array}{l}\text { Qu } \\
\text { addres } \\
\text { coalitio } \\
\text { group } \\
\text { why tl } \\
\text { coalitio }\end{array}$ & $\begin{array}{l}\text { indicated if the } \\
\text { organizations } \\
\text { primarily } \\
\text { worked alone. }\end{array}$ \\
\hline \multicolumn{7}{|c|}{ Q3 - What does a social movement analys } \\
\hline $\begin{array}{l}\text { Disrupti } \\
\text { on }\end{array}$ & $\lg$ & Iden & & ics & $\mathrm{Re}$ & \\
\hline $\begin{array}{l}\text { Quotes } \\
\text { related } \\
\text { to } \\
\text { disruptiv } \\
\text { e power } \\
\text { theory } \\
\text { by Piven } \\
\& \\
\text { Cloward } \\
(1979) .\end{array}$ & $\begin{array}{l}\text { Quotes } \\
\text { related to } \\
\text { Framing } \\
\text { theory } \\
\text { (Benford \& } \\
\text { Snow, } \\
\text { 2000). }\end{array}$ & $\begin{array}{r}\text { Quote } \\
\text { to Co } \\
\text { Ide } \\
\text { (Goo } \\
\text { Jasper, } \\
\text { Interes } \\
\text { (Arm } \\
20\end{array}$ & or & $\begin{array}{c}\text { Quotes } \\
\text { related to } \\
\text { Political } \\
\text { Process } \\
\text { theory } \\
\text { (McAdam, } \\
\text { Tarrow \& } \\
\text { Tilly, 2001). }\end{array}$ & $\begin{array}{l}\text { Quote } \\
\text { to R } \\
\text { Mob } \\
\text { th } \\
\text { (McC } \\
\text { Zald }\end{array}$ & $\begin{array}{l}\text { Quotes related } \\
\text { to the } \\
\text { question of } \\
\text { whether this } \\
\text { social } \\
\text { movement is } \\
\text { focused on } \\
\text { recognition or } \\
\text { on } \\
\text { redistribution } \\
\text { or both. }\end{array}$ \\
\hline
\end{tabular}

\section{Data collection and analysis.}

After designing this categorization matrix, and upon receiving IRB approval, my 
next step was data collection. I began by gathering the various mission statements and analyzing them. I also hired a transcriber to transcribe the videos I selected. The transcriptions took place as the interviews were being conducted. As per Hsieh and Shannon (2005), my semi-structured interview questions were open-ended, followed by targeted questions about the predetermined categories. Appendix $\mathrm{H}$ presents my interview questions, each followed by the targeted questions designed as prompts. I conducted four interviews in person, and four were conducted by telephone.

I used Atlas.ti to do my coding. I downloaded all the documents into Atlas.ti and programmed my pre-existing categorization matrix codes in the program. I reviewed all the data for content and coded for correspondence with the identified categories (Elo \& Kynga, 2007). Sequentially, for each research question, I began by reading the transcript and highlighting all text that on first impression appeared relevant (Hsieh and Shannon, 2005). I did this for the data on an ongoing basis, as the different types of data were obtained. The next step was to code the text that corresponded with the various predetermined codes.

I engaged in this cycle of coding three times with each of the 24 data sources. First I coded (and recoded, and recoded again) each of the 24 data sources using the codes established for Q1 in the categorization matrix. Then I coded (and recoded) each of the 24 data sources using the codes created for Q2. Then I repeated this process with the 24 data sources using the categorization matrix's codes established for Q3. In the end, I coded 72 documents.

In qualitative content analysis, as the analysis proceeds, additional codes are developed, and the initial coding scheme is revised and refined (Hsieh \& Shannon, 2005). 
Using the categorization matrix, it was possible to choose text that did or did not fit the categories I developed in advance. In this way, I borrowed from the principles of inductive content analysis and used text that did not fit the existing categories to create new categories (Elo \& Kynga, 2007). Any text that could not be categorized with the initial coding scheme was read and reread as I inductively determined what content should be used to create new categories and what those categories might be (Hsieh \& Shannon, 2005). I created many new codes inductively; some sub-codes were created to focus in on specific aspects of existing codes, and other new codes were developed to create categories for unanticipated findings.

For Q1, I created new codes to break down the three initial deductive codes (targets of benefits, mobilization, and influence) into sub-codes with more specific categories. As examples, I created more precise codes to categorize targets of benefits by different demographic traits (race, gender, etc.) and developed specific codes to classify different targets of influence (marriage, immigration, etc.). These more narrowly defined sub-codes were later reintegrated back into the higher order categories when I analyzed the data. I engaged in a similar process for Q2.

For Q3, I inductively created new codes to explore categories that emerged from the data, however most of these new codes remained separate categories in my analysis. They could not be reintegrated into higher order categories because they were unrelated to the categories I developed deductively in my categorization matrix. Examples of this include codes called "Non-profit Structure," "Margin to Center," and "Another Politics." I explore each of these themes separately in my analysis of Q3. 


\section{Analysis of three different types of data.}

Because I engaged in deductive analysis and worked with pre-existing social movement theories, I applied these coding categories to all three types of data (mission statements, interviews, videos) to see how they fit the categories I had previously identified or whether they generated new themes. I did content coding and thematic analysis; one does not preclude the other. I used the same type of analysis for the live interviews as I did for the mission statements and speeches. Consequently, I viewed the interviews as similar data as mission statements and audiovideo documents because in all three cases I looked to see if the content fits with pre-existing theoretical frameworks.

The analysis process was different for each of my three research questions. Each question could stand on its own as a separate research project, and each required its own analysis procedure. For the first research question, I analyzed data for each organization separately from the other organizations, considering the group's mission statement, interview transcript, and online video. I explored each organization as a separate case, to determine its congruence with the GRM. Figure 5.2 illustrates this process I undertook eight times, to make decisions about all eight organizations 
Figure 5.2

Answering Question 1
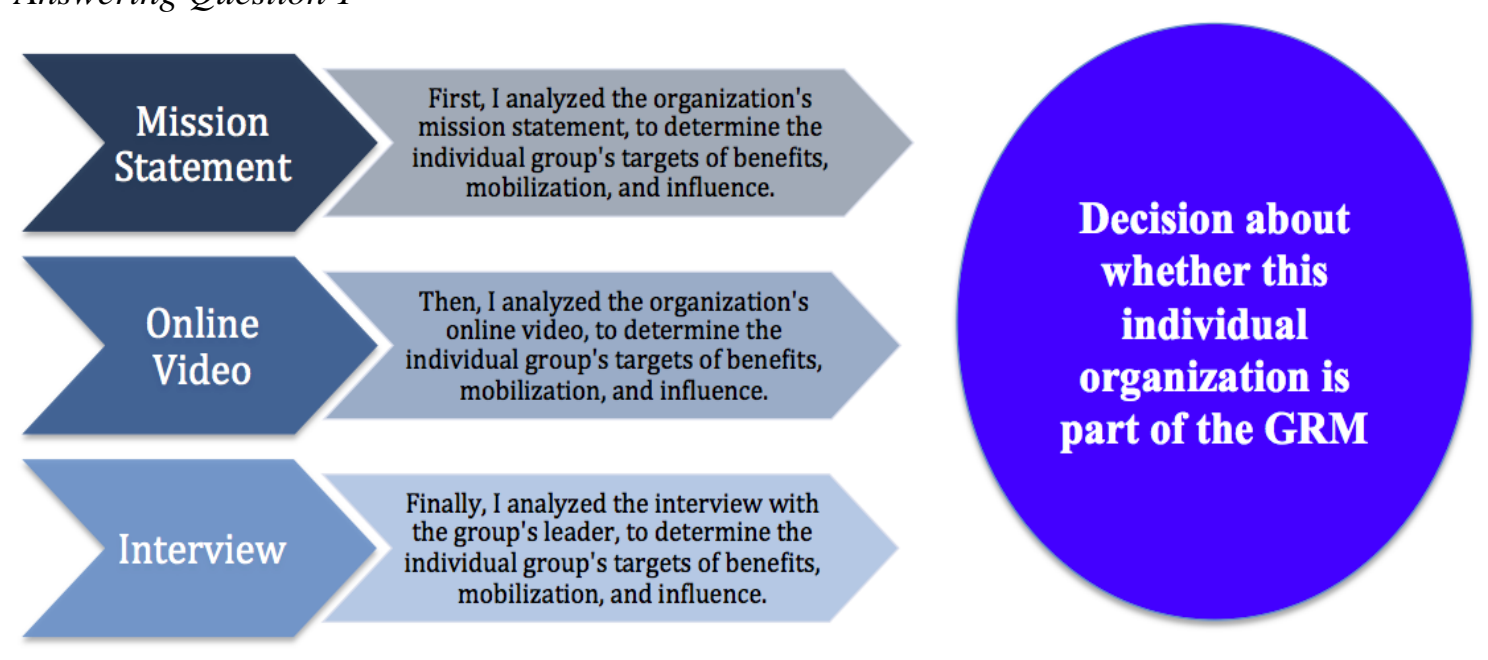

I made eight individual assessments, determining that seven organizations are not part of the GRM, while one is.

In addition to making decisions about which groups were part of the GRM, I also explored the data to look for emergent themes by analyzing the organizations collectively. I brought together all the data from each organization in order to explore common threads that emerged from multiple groups. I also looked at differences between them. Figure 5.3 illustrates the how the data informed my analysis of Q1. 
Figure 5.3

Analysis for Question 1

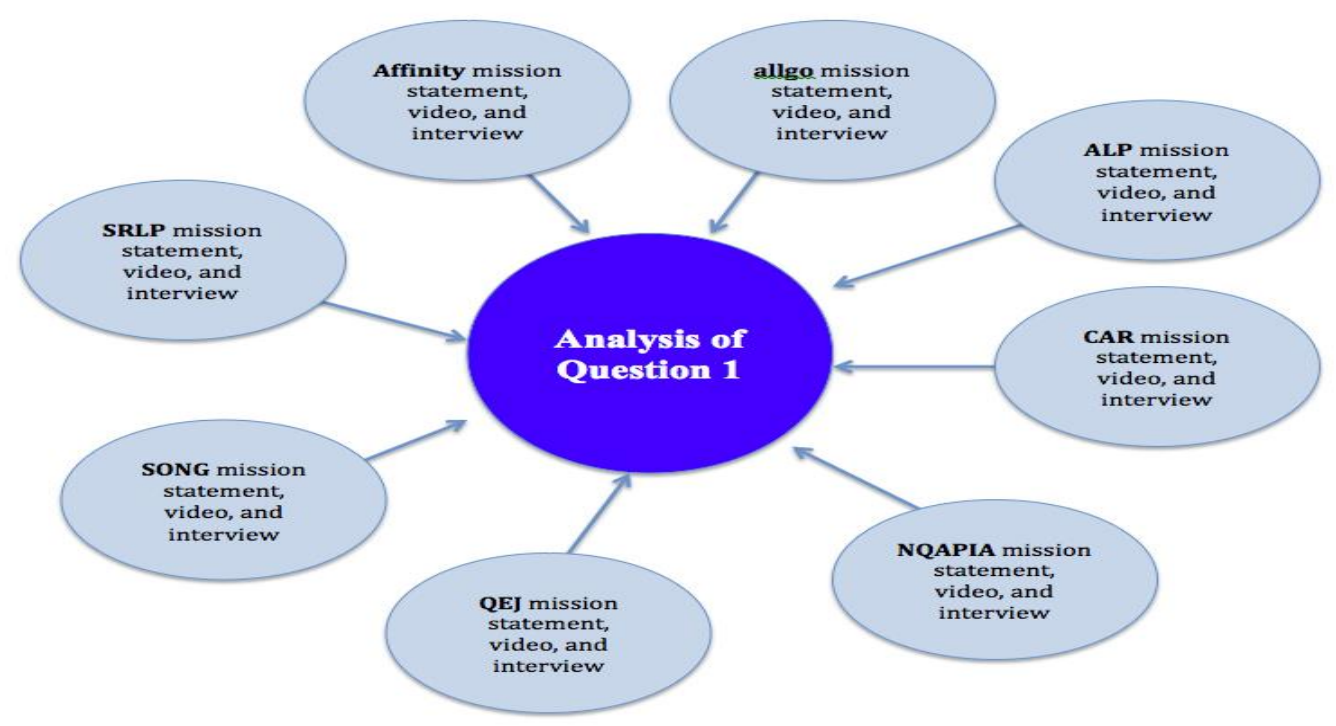

For the Q2 analysis, I began by looking at Center for Artistic Revolution (CAR),

the one organization I determined to be part of the GRM. In this case, I explored all three pieces of CAR's data (mission statement, interview, video) to understand how it worked in relationship to the GRM, as well as its relationship to the other seven organizations. After my analysis of CAR, I turned to the other seven organizations, which I had found were not in the GRM. To analyze these groups, I engaged in a process similar to the one I used for Q1.

First, I looked at the organizations individually, investigating whether each possessed the characteristics of an organization in a social movement. I investigated whether the first organization engaged in collective action, explored whether it had structured activities and formal organization, and analyzed its values and goals. I then 
repeated this same process (investigating collective action, structure and organization, and values) for each of the other organizations.

Next, I analyzed the seven organizations collectively. I looked at whether they had collectively built structure between their seven organizations, engaged together in interagency collective action, and/or shared collective values and identities.

Throughout my analysis of all three questions, I engaged in both inductive and deductive thematic analyses. However, the way in which I incorporated both forms of analysis for Q3 requires an explanation. Deductive qualitative content analysis takes previous knowledge and existing theoretical frameworks and uses them to analyze text (Mayring, 2000). Deductive analysis is used when the analysis is operationalized based upon previous knowledge and the goal of the research is to test theories in order to validate or extend them (Elo \& Kynga, 2007; Hsieh \& Shannon, 2005). For the third research question, I explored the data in light of several theoretical frameworks I had identified in advance. These include Black feminism's intersectionality framework, queer theory, and certain social movement theories. For example, I planned on applying Nancy's Fraser's (1995) theorizing about "perspectival dualism," where she challenges the redistribution/recognition binary of most social movement theories. After answering the first two research questions with a determination that there are two distinct social movements, I investigated whether the queer liberation movement is an example of Fraser's "perspectival dualism" theoretical framework.

Based upon my findings, I also inductively expanded the analysis to include other theories I had not planned in advance to incorporate. For instance, when I found that one of the activists described their work as "trickle-up social justice," I created an inductive 
code for it and examined that code's resonance with the other organizations. As I analyzed the data categorized with this code, I realized that the "trickle-up social justice" framework was essentially a real world application of bell hooks' "Margin to Center" theoretical construct. Consequently, I brought hooks into my analysis of Q3. I engaged in other similarly inductive analytic processes for Q3.

In fact, in my analysis of Q3, I developed an inductive theoretical framework for understanding this new social movement. This framework is situated in a larger framework (“Another Politics") developed by Dixon (2014) for understanding certain $21^{\text {st }}$ century social movements. I integrated Dixon with Fraser, as well as with concepts from Black feminism (hooks and Crenshaw), queer theory (Duggan; Eng, Halberstam \& Munoz), and poststructuralist social movement theories (Broad, Gamson, Seidman).

\section{Evaluation of Trustworthiness}

\section{Challenges.}

According to Hsieh and Shannon (2005), using a deductive approach to qualitative content analysis presents some challenges. Using theory means that researchers will approach the data with "an informed but, nonetheless, strong bias" (Hsieh \& Shannon, 2005, p.1283). Approaching my work from a stance of critical inquiry, I recognize that I bring an agenda and bias to my work. This bias includes frustration and anger at many of the GRM organizations, and my agenda includes promoting the work of the queer liberation organizations. Consequently, researchers engaged in deductive analysis might be more likely to find evidence that supports their theory than evidence that contradicts it (Hsieh \& Shannon, 2005). In addition, interview participants may get cues about how to answer questions in a way that pleases the interviewers. These 
limitations are related to the question of trustworthiness (Lincoln \& Guba, 1985). For this reason, I planned for how I would address questions of trustworthiness.

Lincoln and Guba (1985) argued that qualitative research is inherently subjective and requires that the researcher demonstrate the trustworthiness of the research process and findings. They maintained that trustworthiness is established when findings reflect (as much as possible) whatever was described by the participants. Lather (1991) claimed that an epistemological approach of critical inquiry assumes that most knowledge is socially constructed by and for the dominant in society. Although as leaders in the movement, my participants have more power and privilege than their organizations' members, they are each part of multiple subordinated identity categories. Consequently, my participants are not the dominant in society, and it is even more urgent that my research reflects (as much as possible) what they described. In doing so, I can help to create oppositional knowledge, challenge the status quo and undertake social change (Lather, 1991). Toward this goal, my research project utilized several methods of achieving trustworthiness: a reflexive audit trail, peer debriefing, and member checking.

\section{Reflexive audit trail.}

A crucial component of establishing trustworthiness in qualitative research is considering how the researcher's social position impacts the research process (Lietz, Langer, \& Furman, 2006). Reflexivity is the recognition that actions, values, and decisions of the researcher will affect the context of the research and the experience it is trying to explain. Instead of pretending to be objective, researchers clearly state their own sociocultural positions. Engaging in reflexivity requires an understanding that all knowledge is affected by the social conditions in which it is produced and by the social 
locations and lives of both the researcher and the researched (Mann \& Kelley, 1997). Reflexivity requires deconstructing who we are and the ways in which our beliefs, lives, experiences, and social identity intersect with those of the people we are researching (MacBeth, 2001). Reflexivity is a process that occurs throughout the research, rather than at one point in the analysis (Lietz, Langer, \& Furman, 2006).

In addition, to increase the trustworthiness of the study, the researcher engaged in qualitative content analysis must also demonstrate a link between the results and the data (Elo \& Kynga, 2007). This is why the analytic process must be described when reporting the results. Lietz, Langer, and Furman (2006) recommended that qualitative researchers keep an audit trail that clearly describes all the steps taken throughout the data analysis process. An audit trail can be an essential component of establishing rigor in qualitative work because it describes all of the research procedures. It allows a researcher the freedom to make uncommon research decisions while also requiring that all decisions, and the reasons for them, be recorded throughout the process. In addition, an audit trail helps a qualitative project to be open for critique by the research community as the research procedures are fully described. The ability to critique research is an essential part of the research process. Whether it is quantitative or qualitative inquiry, critical analysis is a part of the research tradition. Audit trails allow for critical thinking to occur in qualitative inquiry (Lietz, Langer, \& Furman, 2006).

In order to engage in the process of reflexivity and keep track of my decisions, I kept a reflexive audit trail. It serves as an ongoing record of decisions I made at the different stages of this project, describing my feelings and reasons for making decisions. In this way, I engaged in reflexivity while also documenting my decision making process. 
This serves as a record that is available for review, allowing others to understand the research choices I made, and how my own identities and values impacted those decisions.

\section{Peer debriefing.}

Dialogue among researchers can help increase trustworthiness, leading many qualitative researchers to recommend peer debriefing. Peer debriefing involves discussions with colleagues who are not working on the project, but have experience with the issue, population, or research methods (Lincoln \& Guba, 1985). Peer debriefing allows a researcher to consult with colleagues outside of the research in order to minimize or be more accountable to the effects of bias or reactivity (Lietz, Langer \& Furman, 2006). By engaging in peer debriefing, a researcher can uncover assumptions and biases that might otherwise remain implicit in the study (Lincoln \& Guba, 1985). For qualitative content analysis, Elo and Kynga (2007) recommended talking to other researchers specifically about how codes are developed, defined and used. For all of these reasons, I engaged in ongoing conversations with trusted colleagues about my work as I proceeded.

I regularly engaged in peer debriefing with a group of fellow doctoral students throughout every stage of this process. These included Miranda Cunningham and Sandy Leotti, both of whom teach at PSU, and Thuan Duong, who is a research associate at the Center for Improvement of Child and Family Services, and has over 10 years experience in research. In particular, I consulted regularly with Thuan, seeking her advice on countless occasions about conducting interviews, developing codes, and engaging in analysis. 
I also consulted regularly with my dissertation committee Chair, Dr. Ben Anderson-Nathe. For eighteen months, we have held numerous consultations in person, over email, and by telephone, during which we discussed my research design, data collection, coding, and analysis processes. In addition, I got feedback last year from my entire dissertation committee about my research design, and will also be incorporating their comments and advice into the final product.

Additionally, I occasionally consulted with scholars with whom I have personal relationships. I debriefed with John D'Emilio (Professor, University of Illinois at Chicago) about issue area content, James DeFilippis (Associate Professor, Rutgers University, and my brother) about methods and issue area content, and Gitarani Mehrotra (Assistant Professor, PSU) and Hiram Perez (Assistant Professor, Vassar College) about theory and issue area content. Finally, I also engaged in peer debriefing with various community activists (Terry Boggis, Rodrigo Brandão, Yasmin Nair, Jessica Stern, Urvashi Vaid, etc.). I talked with them to build content knowledge, and to uncover assumptions and biases that might impact my analysis.

\section{Member checking.}

Member checking allows participants to appraise research data, interpretations, and findings, so they can corroborate or dispute the accuracy of the work, or complicate the analysis (Lincoln \& Guba, 1985). This is a significant tactic for establishing trustworthiness because it grants authority to the perspectives of the participants, thus managing the threat of bias (Lietz, Langer \& Furman, 2006).

Shortly after the initial interviews, I contacted most of the participants with clarifying questions to make sure I understood their answers. Months later, after I did my 
coding and my preliminary analysis, I sent my work to each of the people I interviewed. I sent each of them a 3-page summary of our interview, analyzing their organization's work, goals, and values. I asked them to discuss my analysis and let me know if I understood their words correctly. I also sent them 140 pages of material in which their interviews were directly quoted, in the event that they wanted to read that and give me feedback. Six of the interviewees have responded with feedback, one of them responded saying she was out of the country for a few months and would offer feedback when she

returned, and the eighth participant has not responded. I incorporated into the next round of my analysis the feedback I received from the six participants, and it was used throughout the findings and analysis sections.

\section{Researcher positionality.}

I came to this project as a social work researcher, a teacher, and a student eager to learn more about a subject that has interested me for decades. I also brought to this research my identity as a queer activist community organizer informed by years of feminist, Marxist, and anti-racist politics. These politics informed my choices of research methods and topic.

I also knew that my research would be informed by my sociocultural identities. As the middle-class, gay, gender-conforming, light-skinned, biracial son of two immigrants, I have seen the world through a lens of intersectionality since long before I ever heard that word. I brought to this research these experiences and the understanding that my multiple identities (both those in dominant social locations and those in subordinate positions) inform how I see the world and how I would make sense of my research. I also brought the recognition that, by virtue of my position in the academy, I 
hold more power than do most of the people I interviewed. My research has the potential to impact how scholars, students, and funders understand my participants' work, and consequently it can impact my participants' ability to do their work effectively. I held committed to holding myself accountable for the role my privilege and power played in my work. I used my reflexive audit trail to wrestle with the ways in which my various identities, may be impacting the research project.

My interest in this topic is shaped by almost 20 years of social work practice as a gay man working with LGBT people whose very lives give lie to the dominant social narrative of gay affluence. Among other work, for five years I was the director of one non-profit (SAGE/Queens) that worked with LGBT senior citizens, and for six years I was the founding director of another non-profit (Queers for Economic Justice) that worked with low-income and homeless LGBT adults (most of whom were people of color and/or gender nonconforming). During my work, I was in a constant state of frustration with the national gay rights movement because of the ways that they ignored these communities and because of what I felt was its myopic focus on issues of concern to White, affluent gay men and lesbians. I was also aware of the often-overlooked work of a few dozen other multi-issue queer liberation groups that centralized these same communities. Additionally, I saw how frequently these multi-issue groups worked together. These experiences absolutely informed my research agenda and my desire to do this project.

This work experience proved beneficial to my ability to do this project. I am very familiar with the world I investigated. Indeed, I worked at one of the organizations included in the study and for years I collaborated regularly with some of the others. As a 
result, it was very easy to get the participants to agree to be interviewed. I have friendships with three of them, I am an acquaintance of two others, and the remaining three knew of my work. I believe they all trust me and I believe that this allowed them to speak relatively candidly with me. However, this role as both insider (as an activist who worked with the participants in the past) and outsider (my work with them was the past, and I am now located in the academy) also provided challenges for me as a researcher.

Scholars often position themselves as either 'insiders' or 'outsiders' in their research (Bonner \& Tolhurst, 2002; Merriam, et al., 2001). Outsider-researchers study groups of which they are not a part, whereas insider-researchers study a group to which they belong, entering their study as an insider or 'native' (Bonner \& Tolhurst, 2002; Hewitt-Taylor, 2002; Kanuha, 2000). There are advantages and disadvantages of each approach.

Outsider-researchers are often accused of "parachuting" into communities, taking what they need and then vanishing (Breen, 2007; Gerrard, 1995). Nevertheless, outsiders can and do sensitively engage in research with communities of which they are not a part (Bishop, 2006). Advantages of being an insider-researcher include a greater understanding of the group and its culture, an easier interaction with the members of the group, and greater "relational intimacy" with the group (Bonner \& Tolhurst, 2002; Breen, 2007). However, there are accompanying disadvantages. These disadvantages include the fact that the researcher's prior experience and knowledge and greater intimacy with the group can lead to inadvertently making inaccurate assumptions (Breen, 2007; DeLyser, 2001; Gerrish, 1997; Hewitt-Taylor, 2002). In addition, familiarity can lead to relevant issues going 
unaddressed fully. This is because, in sharing a body of knowledge, the interviewer and interviewee communicate in incomplete thoughts (Breen, 2007; Kanuha, 2000).

In recent years, however, scholars have been questioning the insider-outside binary. They address the complexities involved in either role, and claim that the boundaries between the two roles are not so simply delineated (Merriam, et al., 2001). Some contend that the role of the researcher exists on a continuum between 'complete participant/ member researcher' and 'complete observer' (Breen, 2007; Ellis \& Bochner, 2000; Kearns, 2000). They argue that researchers are rarely entirely an insider or an outsider, and that research is a continuum, rather than an either/or dichotomy (Breen, 2007; Hodkinson, 2005). Dwyer \& Buckle (2009) describe "the space between" in which researchers exist as both insider and outsider rather than either one or the other. It is in this role, as both insider and outsider, that I situate myself in this research project. In order to negotiate the dual roles, I must reflexively examine positionality, power, and representation (Merriam, et al., 2001)

Although as part of my epistemological stance I do not claim objectivity, I still had to be diligent in attending to any pre-conceived notions I might have had regarding my research questions. I had to pay attention that I did not assume I knew what was being said simply because of my experiences with the issues or because I presumed a shorthand in our language. This was not always easy. For instance, during a few of the interviews the participant trailed off midsentence, never completing their thoughts before moving on to another point. In those moments, I did not stop them and ask them to complete their sentences because I instinctively, unthinkingly, presumed I understood what they were saying and how their sentences would have ended. It was only later, while analyzing the 
transcripts, that I realized they never actually made the points I assumed they were making. I had to account for this in my analysis and could not simply make assumptions about how they would have finished their thoughts, regardless of how strongly I felt that my assumptions were probably accurate.

In addition, there were times during the analysis process where I found an answer particularly surprising. In those moments, I had to reflexively investigate my response because being surprised implies that I had preconceived notions of what my interview participants were going to say. I struggled to balance my pre-existing knowledge of their work (which was useful in crafting my interview questions) with the need to remain open and curious about my findings.

More frequently, I found myself taking notice of the answers that felt especially resonant. Because I am familiar with this world, and was engaging in deductive analysis, there were some answers that I anticipated hearing. However, I had to pay attention to those anticipated answers to make sure that I was investigating what was actually said and trying to understand what the participant meant by it, rather than what I assumed was meant by such an answer.

For instance, two people I interviewed (SRLP's Reina Gossett and ALP's Cara Page) gave answers that required constant unpacking and reconsidering. Because I had worked closely with both organizations and knew both activists personally, I thought I understood them clearly upon initially hearing their answers. However, after consideration and examination, I realized they were not really making the points I had initially thought they were. Their words were more guarded and diplomatic than they have been in the past when we have discussed related topics over cocktails. But in the 
context of these interviews, I did not initially notice how carefully they were choosing their words. Because they have spoken more openly with me in the past, I was instinctively ascribing to them meanings that were not actually reflected in the specific words used in these interviews. I found myself tripping over my insider/outsider status. As a result, I had to stop at several points in the analysis to make sure I was analyzing what they actually said to me in these interviews last year, and not what they said to me more freely in a bar two years earlier when we discussed similar issues. I wrote a lot about this in my reflexive audit trail.

Another issue I wrote about in that journal was social desirability bias. Social desirability is one of the most common sources of bias affecting the validity of experimental and survey research findings (Nederhof, 1985). The term describes the tendency of research participants to deny or downplay socially undesirable traits or feelings, and to say the things he/she believes will please the researcher.

Although during my interviews, I was attentive to this concern, I did not believe that this would be a particular problem with these interview participants. I knew that I was asking people to talk about issues and ideas that they have discussed many times before. Because much of what they were discussing is based upon pre-existing organizational positions or commonly used rhetoric, it was less likely than usual that these interviewees would be influenced to answer questions in a way that pleased the interviewer. I assumed that only certain questions that they have not discussed before (e.g., "Do you think a new social movement is developing?") might lend themselves to social desirability bias. I believed that for the majority of my questions, however, organizational values, programs, and rhetoric would inform their answers. 
After conducting the interviews and completing my analysis, I still believe that for most of the interview participants, social desirability bias did not play a particularly large factor in their answers. However, there was one notable exception. One of the participants (someone I had met previously, but do not have a personal relationship with) is younger than I am and newer to this work than many of the interviewees. He has treated me, on several occasions, as a respected elder (which was both flattering and depressing, but that's another story). At several times during the interview, I got the distinct impression that he was choosing his words in a way he thought would meet with my approval. I have tried, as best I can, to factor this in to my analysis, but it is difficult to do. On the one hand, I recognize that social desirability bias is a real phenomenon, but on the other hand I know that he has agency and I respect his ability to speak for himself. It feels paternalistic to imply that I know that "he did not really mean that" and arrogant to assume he was trying to win my respect. For these reasons, I wanted to take him at his word, and analyze his responses on face value. Yet, there were several occasions where I had to consider the possibility of social desirability bias, and factor that into my analysis. I believe I was able to understand and characterize him fairly because when I engaged in member checking months later, in order to try to achieve clarity regarding my interpretations, he supported the way I represented his answers.

\section{Ethical Considerations}

For the interviews, I spoke with people who are very accustomed to speaking about these issues. Indeed, they are paid or volunteer activists who speak about these topics frequently as part of their work. For this reason, I felt comfortable asking them to speak on the record and believe the potential for emotional harm is minimal. There is, 
however, the potential for professional harm because several of the participants spoke unflatteringly about powerful organizations. I reminded them of this before the interviews began and took consideration to minimize this risk during the interviews (by asking general questions, rather than asking them to name specific people or organizations), but I also trust my participants' ability to gauge those risks better than I can.

Nevertheless, I attempted to minimize harm and engage in ethical research by member checking my findings with participants before I publish them. This not only allowed participants to give feedback that I used in my analysis, but also permitted them to decide if they wanted to exclude particular stories, information or details from the study that, in hindsight, they wish they had not shared. When I engaged in member checking, I told the participants that I would remove (or make anonymous) any quotes that they felt put them at harm.

In addition, in order to minimize the potential for harm to participants, I obtained Institutional Review Board (IRB) approval. All guidelines provided by the IRB at Portland State University were followed. I obtained IRB approval for the interviews, but I did not need their approval for information that is publicly available, such as mission statements and audiovideo documents posted on YouTube. I had this confirmed by Reva M. Chapman (IRB Administrator, Office of Research Integrity, Portland State University) and M. Cathleen Gal (Research Integrity Coordinator, Research \& Strategic Partnerships). Because mission statements and public speeches are deliberately and carefully crafted for public consumption, I did not feel any obligation to go above the requirements set by PSU's IRB and seek organizational approval to use their mission statements and speeches. However, I included my analysis of the mission statements and 
speeches with my analysis of the interviews when I engaged in member checking. In this way, they were able to contribute to and respond to my analysis of all their words.

I obtained participants' consent prior to each interview being conducted. The reason for the study and the research process were explained to potential participants both verbally and in writing. I explicitly stated to the participants in advance of the interviews that the information they provided will not be confidential, and I reminded them of this immediately before the interview. An informed consent form describing any potential risks and benefits was provided to each potential participant. I informed them that they could withdraw their consent and terminate the interview at any time. I also explained how information collected in the interviews would be used, how the data would be stored, and how the participant could remove their information from the study if they should change their mind about participating after the interview has taken place.

Each participant was provided with contact information for the researcher and the IRB in the event that they had concerns or questions during or after the research process.

\section{Conclusion}

To investigate the possibility that a separate queer liberation movement exists, I studied eight groups. This research project utilized deductive qualitative content analysis to investigate three questions for each organization. I drew from social movement theories to create coding categories in advance, which I then employed in a deductive analysis of 24 texts, engaging in thematic analysis within these categories. I turn now to my first research question: What does analyzing these organizations through SM theories reveal about the claim held by many that these organizations are the left-wing of the GR Movement? 


\section{Chapter 6: Research Question One}

\section{Introduction and Overview}

In this chapter, I answer my first research question: "What does analyzing these organizations through social movement theories reveal about the claim held by many that these organizations are the left-wing of the gay rights movement?" This question explores whether the eight organizations in my study are part of the gay rights movement (GRM), part of the progressive wing of the movement, or if they are separate from the GRM.

Social movement theorist William Gamson (1990) conceptualized "challenging groups" as defined by three "targets" of their actions. These three defining targets are the group's target of benefits (beneficiaries of action), target of mobilization (constituents engaged in the action), and target of influence (antagonists against whom the action is directed). Gamson's “targets framework" anchored this research question and guided my analysis.

Gamson's framework appears simple on the surface but its application is slightly complicated. The targets framework defines individual groups or organizations; Gamson himself did not refer to entire social movements. In order to examine the GRM, I researched the equality organizations that comprise the GRM, identified their primary targets, and used those targets as representative of the targets of the GRM overall. In doing so, I expanded Gamson's targets framework: if each organization has a primary target of $X$, then when those organizations collectively form a social movement, that movement must also have a primary target of $\mathrm{X}$.

I focused on the primary targets of the GRM. The GRM is huge, with many organizations that have additional secondary targets. However, I used as my gauge those 
targets that have been documented as primary for the GRM. These primary targets became a yardstick against which I compared the targets of the eight organizations in my study. Similarly, I prioritized the organizations' primary targets, although as with the GRM organizations mentioned above, some of these groups have secondary targets. I did address those secondary targets in my analysis, but I concentrated on the primary targets of each organization when making comparisons to the GRM. Table 6.1 summarizes the primary targets of the GRM, based on a summary of the literature covered in previous chapters.

Using their mission statements, interviews, and online videos, I explored whether the eight organizations in this study share the same targets as the GRM. I begin this chapter by examining my findings regarding their targets of mobilization and benefits, and comparing them to the targets of mobilization and benefits of the GRM. Next, I explore my findings concerning the targets of influence of the groups in my study and compare them to the GRM organizations' targets of influence. Finally, I offer my assessment of which organizations are part of the GRM and a discussion of relevant findings and questions that emerged from the analysis. 
Table 6.1

Targets of the GRM

\begin{tabular}{|c|c|}
\hline & $\begin{array}{l}\text { MAINSTREAM GAY RIGHTS MOVEMENT } \\
\text { Analyzed Using Framework Developed by Gamson (1990) } \\
\text { For "Identifying Challenging Groups" }\end{array}$ \\
\hline $\begin{array}{c}\text { TARGET } \\
\text { CONCEPT }\end{array}$ & TARGETS \\
\hline \multirow[t]{2}{*}{$\begin{array}{l}\text { Targets } \\
\text { Of } \\
\text { Influence }\end{array}$} & $\begin{array}{l}\text { Elected officials (via lobbying) } \\
\text { Those officials that are well positioned to affect policies relevant to their } \\
\text { limited agenda of single-issue campaigns on Marriage, Military, Anti- } \\
\text { Discrimination Laws, Hate Crime Legislation, Youth/Education. } \\
\text { (Bowen, 2012; Burke \& Bernstein, 2014; Cohen, 1999; D’Emilio, 2000; } \\
\text { Farrow, 2012; Gamson, 2001; Jones-Yelvington, 2008b; McMichael \& } \\
\text { Wallace, 1999; Movement Advancement Project, 2007; Movement } \\
\text { Advancement Project, 2012; Mahfuz \& Farrow, 2012; Shepard, 2001; } \\
\text { Southerners On New Ground, 2012; Vaid, 2012; Walsh, 1998.) }\end{array}$ \\
\hline & $\begin{array}{l}\text { The Judicial System (via litigation) } \\
\text { Those courts and judges that are well positioned to affect policies relevant to } \\
\text { their limited agenda of single-issue campaigns on Marriage, Military, Anti- } \\
\text { Discrimination Laws, Hate Crime Legislation, Youth/Education. } \\
\text { (Bowen, 2012; Carpenter, 2014; Cohen, 1999; Farrow, 2012; Jones- } \\
\text { Yelvington, 2008b; McMichael \& Wallace, 1999; Movement Advancement } \\
\text { Project, 2007; Mahfuz \& Farrow, 2012; Rosenblum, 1994; Shepard, 2001; } \\
\text { Southerners On New Ground, 2012; Vaid, 2012) }\end{array}$ \\
\hline \multirow[t]{2}{*}{$\begin{array}{l}\text { Target of } \\
\text { Mobilization }\end{array}$} & $\begin{array}{l}\text { Leadership: Almost entirely White, majority male, mostly professional class. } \\
\text { (Boykin, 2000; Carter, 1999; D’Emilio, 2000; Vaid, 2012) }\end{array}$ \\
\hline & $\begin{array}{l}\text { Constituency: All LGBT people, but predominantly white and middle-class } \\
\text { gays and lesbians. } \\
\text { (Carter, 1999; Movement Advancement Project, 2010; TransGriot, 2007; } \\
\text { Vaid, 1995; Vaid, 2012) }\end{array}$ \\
\hline $\begin{array}{l}\text { Target of } \\
\text { Benefits }\end{array}$ & $\begin{array}{l}\text { Mostly White middle-class and wealthy gay and lesbian American citizens. } \\
\text { (Carter, 1999; Conrad, 2010; Duggan, 2003; Hermosillo, 2013, Hutchinson, } \\
\text { 2001; Movement Advancement Project, 2010; TransGriot, 2007; Vaid, 2012) }\end{array}$ \\
\hline
\end{tabular}




\section{Targets of Mobilization and Targets of Benefits}

\section{Introduction and overview.}

Gamson (1990) defines the targets of mobilization as "those individuals or groups whose resources and energy the group seeks in carrying out its efforts at change" (p. 15). These are the group's constituency, the people whose readiness to engage in collective action the group seeks to increase. Gamson also argues that challenging groups must have targets of benefits, also called beneficiaries. These are "those individuals or groups whom the challenging group hopes will be affected positively by the changes that it seeks from its antagonist" (p. 16).

As part of determining if the groups in this study are part of the GRM, I examined whether they shared the same targets of mobilization and targets of benefits. As documented in previous chapters, the GRM's stated constituency is all LGBT people, but in practice, it is predominantly white and middle-class gays and lesbians. This applies to the leadership mobilizing the movement (Boykin, 2000; Carter, 1999; D’Emilio, 2000; Vaid, 2012) as well as the constituency being mobilized (Carter, 1999; Movement Advancement Project, 2010; TransGriot, 2007; Vaid, 1995; Vaid, 2012). Similarly, the beneficiaries of the GRM (its target of benefits) are mostly white, middle-class gays and lesbians (Carter, 1999; Conrad, 2010; Duggan, 2003; Hermosillo, 2013, Hutchinson, 2001; Movement Advancement Project, 2010; TransGriot, 2007; Vaid, 2012).

As I examined my findings, I decided to combine my analysis of targets or benefits with my analysis of targets of mobilization. Some social movement organizations' targets of benefits differ from their targets of mobilization. Gamson (1990) offers examples of such groups: anti-war organizations (whose work would not benefit its 
constituency any more than anyone else) and slavery abolition groups (whose constituency were nonslaves and whose beneficiaries were slaves). However, many groups' beneficiaries and constituents are identical. Gamson offers The Steelworkers Organizing Committee as an example, since both its constituents and beneficiaries were steelworkers. This is also true of most identity-based movements that have emerged since the 1960s. Based upon a review of the literature (cited above), the GRM belongs to this category, because both its targets of mobilization and its targets of beneficiaries are white, middle-class gays and lesbians.

As I analyzed the mission statements, interviews, and online videos, I found that this is also true for the eight queer liberation organizations in this study. All have chosen targets of mobilization that mirror their targets of benefits. For example, The Sylvia Rivera Law Project (SRLP) referenced its beneficiaries in the following way:

How can we create structural change so that the lives of transgender people of color and low income people, and people with disabilities, people with HIV/AIDS, who are incarcerated, who are homeless are not just materially better but people feel safe in their bodies, safe inhabiting space?

- Reina Gossett, SRLP Director of Membership

They not only provide services for these communities (the targets of their benefits), but they also mobilize them and develop leadership from within those communities (the targets of their mobilization):

We work through a collective structure built on the idea that our work should be by and for our community... It is critical that transgender, intersex, and gender variant people and people of color, especially lowincome people, youth, and people with disabilities, take leadership in our work.

- Sylvia Rivera Law Project, Mission Statement 
Each of SRLP's projects concentrates on a different issue, so each project mobilizes corresponding community members to guide the work, such as the Medicaid users who lead their efforts around Medicaid, or the Prison Advisory Committee, comprised of 70 people who are currently incarcerated.

And often those are the very people, whether they are incarcerated or whether they are low income; the very people who are navigating an issue are historically pushed out of social movements. So we think it's really important to not replicate that and to have people be central to the movement if it's an issue that they are facing.

- $\quad$ Reina Gossett, SRLP Director of Membership

SRLP is offered merely as one example; all eight organizations are clear that their beneficiaries and their constituents are the same. Consequently, the rest of this section examines Targets of Benefits and Targets of Mobilization simultaneously.

The eight organizations in this study share with each other many of the same constituencies and beneficiaries. In addition, some also have individual targets that are not shared by all the others. This chapter explores the major similarities and differences in the targets of these organizations, summarized in Table 6.2.

I then provide a more detailed exploration of these eight organizations' targets of benefits and mobilization. I break down their targets into different demographic characteristics (e.g., sexual orientation and gender identity, race and immigration status, economic status, geographic location) and explore the ways in which these targets are shared or different amongst the eight groups. Finally, I compare these targets of benefits and mobilization to those of the GRM. 
Table 6.2

Overview of Each Organization's Targets of Benefits and Mobilization

\begin{tabular}{|c|c|}
\hline Organization & Targets of Benefits and Mobilization \\
\hline $\begin{array}{l}\text { Affinity } \\
\text { Community } \\
\text { Services } \\
\text { (Affinity) } \\
\end{array}$ & Black LGBTQ people and queer youth \\
\hline Allgo & Queer people of color \\
\hline $\begin{array}{l}\text { Audre Lorde } \\
\text { Project (ALP) }\end{array}$ & $\begin{array}{l}\text { Lesbian, gay, bisexual, two spirit, trans and gender } \\
\text { nonconforming people of color, and other social justice } \\
\text { organizations }\end{array}$ \\
\hline $\begin{array}{l}\text { Center for } \\
\text { Artistic } \\
\text { Revolution } \\
\text { (CAR) }\end{array}$ & $\begin{array}{l}\text { All LGBTQ/SGL people, and other marginalized } \\
\text { populations, with a particular emphasis on youth }\end{array}$ \\
\hline $\begin{array}{l}\text { National Queer } \\
\text { Asian Pacific } \\
\text { Islander } \\
\text { Alliance } \\
\text { (NQAPIA) }\end{array}$ & AAPI LGBT people and organizations \\
\hline $\begin{array}{l}\text { Queers for } \\
\text { Economic } \\
\text { Justice }(\mathrm{QEJ})\end{array}$ & $\begin{array}{l}\text { Low-income queer people, and progressive queer } \\
\text { activists and organizations. }\end{array}$ \\
\hline $\begin{array}{l}\text { Southerners on } \\
\text { New Ground } \\
(\mathrm{SONG})\end{array}$ & $\begin{array}{l}\text { LGBTQ people who are rural, people of color, } \\
\text { immigrants, working class and/or poor, and social } \\
\text { justice organizations. }\end{array}$ \\
\hline $\begin{array}{l}\text { Sylvia Rivera } \\
\text { Law Project } \\
\text { (SRLP) }\end{array}$ & $\begin{array}{l}\text { Transgender, transsexual, intersex and other gender } \\
\text { nonconforming people, focusing on people of color, } \\
\text { poor people, immigrants, and people with disabilities }\end{array}$ \\
\hline
\end{tabular}

Sexual orientation and gender identity.

The question of sexual orientation might appear to be self-evident for the groups in a study such as this, but it does warrant examining the different ways they conceptualize the people they mobilize with and on behalf of. All the organizations use the word "queer" when discussing their communities. The significance of this identity category will be examined throughout my analysis. In addition, although they use 
different language to do so, six of the eight organizations explicitly say they work with LGBTQ (lesbian, gay, bisexual, transgender, and queer) communities. The others have different targets.

allgo and QEJ refer to working with queer communities, and they use this word ("queer") throughout their messaging. They use it as an umbrella term to encompass working with a range of sexual identity categories, as well as gender nonconforming people. Affinity, NQAPIA, and SONG identify their communities as LGBTQ, and sometimes spell out specific subpopulations (e.g., differentiating sexual orientation from gender identity), and sometimes they use the acronym LGBTQ. ALP is more specific in their mission statement, explaining that they are focused on working with "lesbian, gay, bisexual, two spirit, trans and gender nonconforming " people. They use the corresponding acronym LGBTSTGNC throughout their work, which appears to be a deliberate attempt to name their commitment to, and focus on, specific communities. They also frequently refer to queer people. Both Trishala Deb and Cara Page used the phrase "queer and trans people," suggesting that ALP sees queer as a signifier for sexual orientation identities but not for gender identity.

With regard to sexual orientation, CAR and SRLP locate themselves and their communities differently from the other six organizations in this study. CAR's mission statement says that CAR is "a LGBTQ/SGL centric" organization. It is the only organization to use the phrase "same-gender loving" (SGL), a term that is used because they want to include people who might not identify with the LGBT labels. In addition, the use of the word "centric" is intentional. In my interview with Randi Romo, she said 
“We're LGBTQ-centric, but not exclusively so.” CAR includes heterosexual allies among their targets of constituency and beneficiaries.

SRLP, on the other hand, mobilizes and benefits "transgender, transsexual, intersex and other gender nonconforming people." As such, it centers gender identity rather than sexual orientation. In fact, sexual orientation almost never came up in any of the data from SRLP. Homo-, hetero-, pan-, bi-, or asexual people are included as targets of their work, as are "queer" people, so long as they are transgender, transsexual, intersex, or otherwise gender nonconforming . SRLP is the only organization that centers gender as the primary organizing identity. All their programs, outreach, organizing, and legal support work are for transgender and gender nonconforming people. Still, although SRLP is the only trans-specific organization, all seven other organizations also focus on transgender people as targets of mobilization and benefits. In addition, seven organizations specifically reference working with women.

ALP prioritizes the mobilization of women and people who are transgender, Two Spirit, or gender nonconforming . Not only do they have organizing projects focused on these populations, but also their staff has been led entirely by women and/or people who are transgender or gender nonconforming. Affinity and SONG were each founded by queer women and continue to have leadership by women. They also focus on women and transgender communities as their constituency and beneficiaries. QEJ's mission statement states that they are an organization comprised of "people of diverse marginalized sexual and gender identities" and their work focused both on women and transgender communities. allgo began as a gay and lesbian organization, but deliberately expanded from that to become a queer organization, inclusive of transgender people. 
And so when we say queer, we use that as an umbrella term to include all sexual orientation identity performance as well as gender identity. So it includes certainly trans, folks who identify as trans or as gender queer as well.

- Rose Pulliam, allgo Co-Director

Neither CAR nor NQAPIA frame their work in a way that addresses women or transgender people distinctly, but both work on transgender issues and have transgender members.

\section{Race and immigration.}

allgo, Affinity, ALP, and NQAPIA all identify as people of color organizations. They see their targets of benefits and mobilization as queer people of color.

More than any of the organizations I researched, Affinity is deliberately consistent and specific in their messaging about for whom they work. The same sentence ("Affinity Community Services is a social justice organization that works with and on behalf of Black LGBTQ communities, queer youth, and allies") was found in their mission statement, the transcript of their online video, and in my interview with Director, Kim L. Hunt. While six of the other organizations are multi-racial, Affinity targets only Black queer people. Hunt makes this explicit: "Traditionally it has been black queer women that's who really got Affinity off the ground... Our people are Black people. Black LGBT people, in particular."

Similarly, NQAPIA's targets for mobilization and benefits center a specific racial category: LGBTQ Asian American, South Asian, Southeast Asian and Pacific Islander organizations and the communities they serve who are not served by mainstream LBGT organizations. 
On the other hand, allgo and ALP do not focus on any specific racial category; they work with communities of color in general. However, since allgo opened almost 30 years ago, its constituency and membership has evolved. It began in 1985 as a gay and lesbian Latino organization and later shifted focus from Latino to all people of color.

So allgo began basically because there were a group of queer Latino artists who were working to do advocacy, primarily. And when they went to organizations that were doing LGBTQ organizing they were told, 'just don't bring that Latino stuff in here.' And when they did stuff where they were organizing with Latino organizations they were told, 'just don't bring that queer stuff in here.' So they decided that they would create a space where they could bring all of who they were. And so they started allgo. ...And then when the black queer people of color organizations went defunct due to funding, they opened up their work to include African Americans and other people of color... .allgo embraced queer people of color in all their forms.

- Rose Pulliam, allgo Co-Director

In ALP's work with LGBTSTGNC people, it focuses on the mobilization of people of color (POC). Their mission statement specifically spells out different racial groups: "POC African/Black/Caribbean, Arab, Asian and Pacific Islander, Latina/o, and Native/Indigenous descent." Consequently, they work inside many different racial justice movements and communities to target them for mobilization and for benefits.

While allgo and ALP are multi-racial groups working with different communities of color, the other four organizations in my study (CAR, QEJ, SONG, SRLP) identify as multiracial in a way that is deliberately inclusive of White people. Thus, these four organizations differ from the others in that they do not identify as people of color organizations.

QEJ and SONG were founded as multi-racial organizations that targeted all progressive queer people, bringing together people of multiple identities who shared 
similar values. Both organizations have had people of color and white people in shared leadership positions. Both groups have run programs and engaged in campaigns that mobilize and benefit diverse POC communities, but also mobilize and benefit (lowincome, immigrant, or rural) white communities.

SRLP's work with transgender people prioritizes working with people of color, as well as (low-income) white people. They focus on transgender people of color as some of their primary constituency and beneficiaries; this focus was articulated over and over again.

CAR presented a unique case among the organizations' targets. Like QEJ, SONG, and SRLP, CAR was founded as a deliberately multi-racial organization. It works with and for people in Arkansas from multiple social locations.

Our commitment to intersectional work means that CAR strives to build intentional bridges of understanding and collaboration between diverse communities.

- Center for Artistic Revolution, Mission Statement

CAR, however, has not particularly made racial justice issues the center of their work (as will be evident in the next section about Targets of Influence). This has implications for the targets of benefits and mobilization, because the other organizations prioritize racial justice issue because they directly impact their own communities. Consequently, I asked the director for clarification.

(Interviewer: Are you saying your group is immigrants, and people of color, and women?) R.R.: Yeah, our group is all of those peoples... Our organization is very diverse. It's not more people of color and its not more white, and its not more women. It's pretty broad in who is in our organization. And trans community, very definitely represented.

- Randi Romo, CAR Executive Director

Despite Romo's assertion of whom the organization represents, I still had a difficult time 
trying to understand whom specifically CAR mobilizes. Interestingly, the audiovideo clip did not address mobilization, and the mission statement and interview offered internally conflicting perspectives. Clearly the organization has a broader agenda than single-issue gay politics and is concerned with racial and economic justice issues. Frequently (such as in the quotes above) they discuss those issues in the first person, as concerns that impact them personally, as people of color and low-income people. But other times these same concerns are positioned as external issues CAR takes on because they want to be good allies, as illustrated by this excerpt from their mission statement: "Justice isn't about 'just us', it's about justice for all people and their communities.” Romo told me how CAR organizes conversations among its membership about a variety of issues, and specifically cited racial justice, immigration, and reproductive justice. In doing so, she clearly positioned CAR as an ally in relationship to the communities impacted by those issues.

And so it's having these conversations around the intersections of injustices... And so it really allows us to thread these conversations and this analysis together to help people to kind of take off the horse blinders and to be better advocates and allies for others who are in struggle for something that you might not feel is your issue but that you recognize that it is un-just and that it does connect to your issue. Because definitely one of the things that we see here is that the folks that go after one group, that's the same group that's going after the rest of them.

- Randi Romo, CAR Executive Director

Approaching these issues as "allies" implies that CAR's membership does not share the same social identities of those with whom they wish to ally. While certainly many organizations straddle insider and outsider status with regards to the issues they work on, none of the other seven organizations in this study position themselves in that way. The other seven groups are clearer that their work mobilizes and benefits the people who are directly impacted by it. 
All eight organizations referenced their work with and for LGBTQ immigrants.

ALP, NQAPIA, QEJ, and SONG prioritized the creation of specific programs or campaigns focused on LGBTQ immigrants. They have mobilized LGBTQ immigrants and engaged with the immigrant rights movement to benefit LGBTQ immigrants.

These four organizations have also worked inside the GRM to influence the conversation about immigration policy. In spite of partnership with the GRM, they see this as distinct from the GRM's work on immigration, because that work, despite purporting to be about immigrants, has primarily focused on bi-national couples. These organizations, however, contend that the issue of bi-national couples, really focuses on American citizens, and their legal right to keep their foreign-born partners in the country.

The mainstream LGBT political scheme adopted and focused on binational couples early on and the locus and the sole lens through which to look at immigration reform. So looking at other ways in which immigrants who are LGBT are affected by the broken system, even in terms of just specific provisions like the one-year deadline to apply for asylum, (legal rights for bi-national couples are) not helpful... You know, we have stories of people who are queer in our communities who are citizens but their sister is about to be deported because the laws around deportation and the policies around judicial discretion are fucked up. And so you can't tell her, 'oh well, you're queer but you're a citizen so you're fine.' You know, you can't tell her the immigration system isn't broken when it ripped her sister apart from her.

- Ben de Guzman, NQAPIA Co-Director

By focusing on the needs of LGBTQ immigrants (rather than on the needs of American citizens who are dating immigrants), these organizations have centered LGBT immigrants among their targets of benefits. The related organizing work they do with those communities makes them also targets of mobilization.

\section{Class and economic status.}

While all eight organizations referenced working with and for low-income people, 
four (ALP, QEJ, SONG, and SRLP) prioritized low-income people as primary targets of benefits and mobilization. All four not only provide services for these communities (the targets of their benefits), but also mobilize and develop leadership from within those communities (the targets of their mobilization).

Of the groups in this study, QEJ focused on class and poverty most centrally; their primary constituents and beneficiaries were low-income queer people. This included people on public assistance and homeless adults, populations that are not usually targeted by the equality organizations.

I see the number of people that walk in our office every single day who we have to give a metro card to get back to the shelter because they don't have enough money to take a subway ride both ways. Who have no food, who have no clothes.

- Amber Hollibaugh, Former QEJ Executive Director

They also used the homeless shelters and welfare offices as sites from which to organize, and they worked extensively on the policies of those systems, centering low-income people as targets of both benefits and mobilization.

Although ALP, SONG, and SRLP do not centralize class in the same way as QEJ, they nevertheless target low-income LGBTQ people in every aspect of their work. ALP works extensively with people getting public assistance, such as Medicaid and TANF, and much of SONG's work is in rural communities with poor and working class people. SRLP prioritizes work with transgender people, a population disproportionately living in poverty (Badgett, Lau, Sears, \& Ho, 2007; San Francisco Bay Guardian \& the Transgender Law Center, 2006). Consequently they work extensively on campaigns that benefit and mobilize low-income people. They have a particular focus on mobilizing and serving transgender people who are incarcerated, who are disproportionately poor, and 
thus serve and organize low-income people in this way:

People who are currently incarcerated are going to know what are the most pressing issues to advocate for and organize around when it comes to the PIC. And often those are the very people, whether they are incarcerated or whether they are low income; the very people who are navigating an issue are historically pushed out of social movements. So we think it's really important to not replicate that and to have people be central to the movement if it's an issue that they are facing.

- $\quad$ Reina Gossett, SRLP Director of Membership

\section{Unshared targets.}

Thus far, I have focused on those targets of benefits and mobilization shared by most or all the queer liberation organizations. However, some targets are unique to certain groups in this study. For instance, in their early years, allgo and CAR focused on artists involved in political work. Although in recent years this has shifted, and their memberships grew to include many non-artist activists, many artists remain in the allgo and CAR communities. The other six organizations have never targeted artists in this way. Affinity is alone in having a program that targets senior citizens, while SRLP works with many people who have disabilities. Different groups in this study have still other targets. However, since most of these unique targets are not central to the organizations' work, they are not relevant to this analysis. This section will only focus on those unique targets of primary importance to the individual organizations.

\section{Geographic scope.}

The most obvious difference in targets among these organizations pertains to the issue of geography. Although some of these organizations engage in national coalition building or advocacy, their primary work (in the form of direct services or community organizing) is based in their different geographic communities. Some of these 
organizations limit their communities to their city limits. Affinity identifies its constituents and beneficiaries as black queer people living in Chicago, and ALP and QEJ both focus on queer people living in New York City. Many other organizations define their communities as statewide: allgo benefits and mobilizes queer people of color in Texas, while CAR works with LGBTQ/SGL people in Arkansas. SONG takes an even more expansive stance about their geographic scope, which spans an entire region; SONG is located in several southern states, and is focused on working with southerners. They exist in a region with much geographic isolation, and SONG's work often focuses on reducing isolation for LGBTQ southerners. NQAPIA, the only self-identified national organization, is a federation representing different Asian LGBTQ groups located in multiple cities.

Finally, SRLP is alone in this study in that it does not clearly identify its geographic focus. Located in NYC, it devotes significant resources to its work with transgender and gender nonconforming New Yorkers. However, it never claims to be a NYC-specific organization and much of its work is national in focus. Although by not identifying their geographic focus, they are unique in this study, they also illustrate a common dynamic among several other organizations. Although ALP, QEJ, and SONG state clear geographic targets of their primary work, the reality is that much of their work is national in focus. Their targets are more expansive than merely the queer people in their local communities. Their coalition building, their policy work, and their targeting of organizations in different social movements serve to complicate their geographic focus. This warrants closer examination. 


\section{Targeting other groups.}

ALP, QEJ, NQAPIA, and SONG target both individuals and groups. They provide support to organizations, and facilitate coalitions, in addition to their work organizing and supporting individuals. In targeting other organizations as well individuals, ALP, NQAPIA, QEJ, and SONG differ from the other organizations in this study.

ALP organizes LGBTSTGNC POC across social justice movements. They bring together activists from immigrant rights, racial justice, and economic justice movements into their work, and they send their members out to be involved in those movements.

QEJ also engaged in a lot of coalition building of organizations and bringing together individual activists from different movements to work together. It did this in different ways. First, it targeted other progressive queer groups (including most of the groups in this study) in its effort to create a coalition called "Building a Queer Left." QEJ also worked to bring progressive queer groups together with progressive non-queer groups.

My strategy for doing the "Building a Queer Left" work was, knowing that there were these networks of progressive left grassroots queer organizations around the country, and there was also queer folks who were working in progressive non queer organizations. And so part of what I was trying to do was build a strategy that would connect those things... You know, so "Building a Queer Left" was a movement building strategy to figure out how can we begin to leverage all these people we know through our own networks around the country that we've connected with over the years to really try to leverage power in some way and try to move the needle on the equality frame to really push a more - a social justice agenda.

- Kenyon Farrow, Former QEJ Executive Director

SONG's co-director Paulina Helm-Hernandez articulated that the organization's 
role has been "sometimes facilitative, sometimes directive, sometimes very much in coalition and alliance"; the organization targets other groups to help build collaborations or coalitions among them. In addition, her co-director Caitlin Breedlove described how they also provide technical support to "very small, pretty isolated groups doing intersectional work in the South" and have a travelling organizing school that helps build organizing skills in small communities in the South.

In addition, NQAPIA also targets other organizations, but from a different structural position than ALP, QEJ, or SONG. NQAPIA is a federation of many organizations, which is unique among the groups in this study. It is an independent nonprofit organization, representing different Asian LGBTQ groups located in multiple cities. According to its co-director, "our unit of analysis is our organizations. I think that that is where we are trying to spark movement.” ALP, NQAPIA, QEJ, and SONG make social justice organizations their target of mobilization and benefits, although they do it different ways. In this way, they share targets that are distinct from both the other four organizations and the organizations in the GRM.

\section{Youth.}

Finally, CAR has one primary group of constituents and beneficiaries that differs from the other seven organizations, but is shared with the GRM. Central to CAR's agenda is working with and for LGBTQ youth (unique in this way, although while Affinity works with queer youth, they target queer youth of color, a distinction that is not shared by CAR). For almost a decade, CAR has run the only LGBTQ youth program in Arkansas, which offers "social justice/life skills." CAR also assists students who want to establish a Gay-Straight Alliance (GSA) on their campuses. Citing advocacy efforts with 
youth, CAR's director reported taking their youth program leadership representatives to Arkansas Citizens First Congress: "sometimes they would be there as full voting congress members. Sometimes they were there as advisory." Similarly, The equality organizations have prioritized working with LGBT youth and building GSAs in schools, and consequently CAR shares this target of mobilization and benefits.

\section{Conclusion.}

Queer theory interrogates the concept of "normal.” By centralizing questions of gender identity, race, immigration status, and economic class, these eight organizations challenge the default assumptions of the GRM, which positions white, middle-class, gay and lesbian American citizens as their "normal" (Cohen, 1999; Hennessy, 2002). As illustrated by the mission statement for SRLP, these groups' work is clearly rooted in an intersectional understanding of queer lives:

Our agenda focuses on those in our community who face multiple vectors of state and institutional violence: people of color, incarcerated people, people with disabilities, people with HIV/AIDS, immigrants, homeless people, youth, and people trying to access public benefits.

- Sylvia Rivera Law Project, Mission Statement

As a result of such a deliberate intersectional approach, they work with populations that are largely absent from the GRM.

And the first time I (worked with QEJ), I expected there to be the usual suspects of activism that I was kind of already familiar with. And I was really surprised that there were about 25 or so queer and trans folks from the shelter system in NYC who were there, and I was just impressed that there was an actual organization that was working with that base of folks who often don't show up in a lot of organizing or activism spaces.

- Kenyon Farrow, Former QEJ Executive Director 
This intersectional lens determines the constituents and beneficiaries of these organizations. They do not see themselves as mobilizing and benefiting the same targets as the organizations in the mainstream gay rights movement do.

So to me there's a difference (between Affinity and the equality organizations), and the difference has to do with being more intersectional in the approach to the work and looking at the multiple identities that people bring to an issue. And looking beyond just the LGBT component of who folks are. And I don't want to say that Equality Illinois isn't mindful of that, but what they work on is not reflective of that and their hiring is not reflective of that and who they reach out to is not reflective of that intersectional approach.

- Kim L. Hunt, Affinity Executive Director

Queer theory contests the concept that gender or sexuality is part of an essential self, and instead posits that gender, sexual behavior, and sexual identity are social constructs (Butler, 2006; Rich, 1980; Warner, 1993). How these identities are constructed, and how discourse is created around those constructs, confers and maintains power. The eight organizations have a variety of terms to describe the sexual and gender identities of their constituents, but one identity label they all used in their descriptions of their targets of mobilization and benefits was the word "queer." Warner (1993) examined the way the word queer can be used to discuss anything categorized outside of hegemonic notions of "normal." While the equality organizations pay lip service to "LGBT" communities, as I documented in earlier chapters, the "normal" for the GRM is primarily limited to gay or lesbian. The constructs utilized by these eight organizations, regarding the sexual and gender identities of their constituencies and beneficiaries, destabilize the social identity categories (of gay and lesbian) that function as the default focus of the GRM. In defying the normal construction of identity categories in GRM activism, these eight groups can present a challenge to the GRM's hegemonic hold on the public imagination of LGBT 
communities. And, with regards to sexuality and gender, they clearly have different targets of mobilization and benefits than does the GRM.

Butler (1993) argued for subverting and destabilizing sexual and gender identity categorizing altogether, and prescribed utilizing a variety of sexual, racial, class, and gender differences in politics. Eng, Halberstam, and Muñoz (2005) built on Butler's critique of gender and sexual identity categories, advocating the use of queer theory to study more than just White male sexuality. They contend it must be also applied to gender, race, and nationality, and the normal/abnormal categorizations that exist within those constructs.

Using such a lens here illuminates how these queer liberation organizations disturb the GRM's dominant concepts of normality with regards to race and nationality. Where GRM situates white citizens as its "normal" and selects corresponding targets of benefits and mobilization, the organizations in this study explicitly focus on LGBTQ people of color and immigrants. In doing so, they subvert the GRM's default of race and nation.

All of those (GRM) groups are predominantly white. Their perspectives don't appropriately include communities of color perspectives... The commonality that I would attribute between the equality federations groups and the national LGBT groups is based on their focus, or their lack of sufficient focus on the unique needs of LGBT people of color... We look at ourselves as providing a more intersectional analysis and lifting up people of color and immigrants.

- Ben de Guzman, NQAPIA Co-Director

The result of this "lifting up people of color and immigrants" is that, regarding race and nation, the groups in this study demonstrate different targets of benefits and mobilization than those of the GRM.

Feminist scholar Rosemary Hennessy (2002) uses queer theory to analyze the 
impact of labor, capitalism, and commodification upon sexual identities. She argues that sexual identity is often understood through gender, race, and nationality, but these identities have themselves already been shaped by capitalism. She posits that capitalism creates "the work we do, the food we eat, our mobility in the world, how we know, who and how we love" (p. 36), and consequently critiques hegemonic constructions of queer identities for failing to incorporate a class lens. The groups in this study incorporate exactly this lens that Hennessy prescribes, even as they recognize that the GRM fails to do so.

It's very difficult to find an LGBT organization (like QEJ) where you engage with the hard issues, you really take on issues like economic justice, you take on issues like HIV status, and you take on the question of shelter work and homelessness. And you say, 'come here, come think with us, come help build a very different alignment of priorities in an LGBTQ imagination. Come and say that economic justice is interwoven and unremoveable from a queer identity.'

- Amber Hollibaugh, Former QEJ Executive Director

When Fraser (1999) applied Butler's theory of performativity to scrutinize public signifiers of difference, she argued that, by virtue of their class, some people are excluded from representation in queer activism. This is certainly true of the equality organizations. However, the queer liberation organizations in this study present very different faces to represent their work. Low-income people are represented by and represent these organizations.

As has been demonstrated, these groups clearly challenge the default identity categories (of white, middle-class, gay and lesbian citizen) centralized the GRM. To a certain degree, this is consistent with queer theory's call for the destabilization of social identity categories (Gamson, 1995; 2009; Seidman, 1993). However, they still categorize 
their populations. These categories are more expansive and nuanced than those framed by the GRM, but they are still categories nevertheless. This is an important complication, and will be explored in Chapter Nine.

It is, however, less complicated to compare the targets of the groups in this study to those of the GRM. My analysis of Q1 leads to the conclusion that the queer liberation groups do not share the same primary targets of mobilization and targets of benefits as the organizations in the GRM. The queer liberation groups have prioritized mobilizing and benefiting queer people who are low-income, transgender, and/or people of color, who constitute different targets than the white, middle-class LGBT people who are the primary targets of the GRM. This issue is explored further in Chapters Eight and Nine.

\section{Targets of Influence}

\section{Introduction and overview.}

Gamson (1990) defines a target of influence as "that set of individuals, groups, or social institutions that must alter their decisions or policies in order for a challenging group to correct a situation to which it objects" (p. 14). They can also be called the group's antagonists. The organizations in the GRM have two primary targets of influence: elected officials and the judicial system. These organizations attempt to influence elected officials through lobbying efforts (D'Emilio, 2000; Farrow, 2012; Gamson, 2001; Movement Advancement Project, 2012; Vaid, 2012; Walsh, 1998). They target the judicial system in the form of litigation (Carpenter, 2014; Farrow, 2012; Rosenblum, 1994; Vaid, 2012).

The policy issues about which the equality organizations attempt to influence these actors have been single-issue in nature, lacking an intersectional perspective or 
agenda (Cohen, 1999; Jones-Yelvington, 2008b; Mahfuz \& Farrow, 2012; McMichael \& Wallace, 1999; Shepard, 2001; Southerners On New Ground, 2012). They object to the exclusion of LGBT people from existing legal, social, and political structures. Their agenda has been focused primarily on gaining inclusion into those structures. Specifically, they have focused on access to family protections (e.g., marriage and adoption), inclusion of sexual orientation in hate crime and civil rights/anti-discrimination laws (e.g., employment protection and access to the military), and support for youth/education (e.g., safe schools, GSAs). The majority of their resources have been spent on those issues (Bowen, 2012; Funders for LGBTQ Issues, 2012; Movement Advancement Project, 2007). Consequently, when equality organizations target elected officials and judges, they focus only on those judges well positioned to influence these concerns.

I used these targets of influence by the equality organizations in the GRM as the yardstick against which I compared the queer liberation organizations' targets of influence. In order to determine if the groups in my study are part of the GRM, I examined their primary antagonists, exploring whether they are elected officials and judicial systems well positioned to shape policy about family protections, hate crime laws, civil rights/anti-discrimination laws, and youth/education. My examination of these eight groups finds that one shares the same targets of influence as the GRM, while seven do not. The rest of this chapter will explore those targets in depth, summarized in Table 6.3. 
Table 6.3

Comparison of Targets of Influence

\begin{tabular}{|c|c|c|c|c|c|c|c|c|}
\hline & $\begin{array}{c}\text { Criminal } \\
\text { Justice system } \\
\text { (besides the } \\
\text { creation of } \\
\text { hate crime } \\
\text { legislation) }\end{array}$ & $\begin{array}{c}\text { Hate Crime } \\
\text { Legislation } \\
\text { (elected } \\
\text { officials and } \\
\text { judicial courts } \\
\text { well positioned } \\
\text { to shape these } \\
\text { policies) }\end{array}$ & $\begin{array}{c}\text { Immigra- } \\
\text { tion } \\
\text { system }\end{array}$ & $\begin{array}{c}\text { Social } \\
\text { Services } \\
\text { and Public } \\
\text { Assistance }\end{array}$ & $\begin{array}{c}\text { Other } \\
\text { Social } \\
\text { Justice } \\
\text { Groups }\end{array}$ & $\begin{array}{c}\text { Marriage } \\
\text { Equality } \\
\text { (elected } \\
\text { officials and } \\
\text { judicial courts } \\
\text { well } \\
\text { positioned to } \\
\text { shape these } \\
\text { policies) } \\
\end{array}$ & $\begin{array}{c}\text { Youth/ } \\
\text { Education } \\
\text { (elected } \\
\text { officials and } \\
\text { judicial courts } \\
\text { well } \\
\text { positioned to } \\
\text { shape these } \\
\text { policies) } \\
\end{array}$ & $\begin{array}{l}\text { Civil Rights/Anti- } \\
\text { Discrimination } \\
\text { Laws } \\
\text { (elected officials } \\
\text { and judicial courts } \\
\text { well positioned to } \\
\text { shape these } \\
\text { policies) }\end{array}$ \\
\hline $\begin{array}{c}\text { Equality } \\
\text { Groups in } \\
\text { GRM } \\
\end{array}$ & & Q & & & & प & प & Q \\
\hline Affinity & & & प & प & प & & & \\
\hline Allgo & प & & प & 0 & प & & & \\
\hline ALP & Q & & प & 0 & प & & & \\
\hline CAR & & & & & Q & $\square$ & प & प \\
\hline NQAPIA & & & $\square$ & 0 & 0 & & & \\
\hline QEJ & 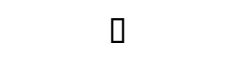 & & प & 0 & प & & & \\
\hline SONG & प & & प & 0 & प & & & \\
\hline SRLP & 0 & & प & 0 & 0 & & & \\
\hline
\end{tabular}




\section{Broad range of targets.}

Before I explore the specific targets of influence of the organizations I studied, it is important to frame them by bringing attention to a theme that emerged from my data. The targets of influence for these queer liberations are very broad and diverse, in marked contrast to the equality organizations' very specific targets. Both collectively and individually, these organizations identify a wide range of antagonists. Each utilizes an intersectional analysis of their communities' needs, and views their targets of benefits as impacted by a multiplicity of systems, structures, and institutions. To address these numerous needs, they have identified numerous targets of influence.

Any social justice organization's specific choice of antagonists will be informed by their long-term goals and vision for the future (Rangan, 2004). Upon review of their mission statements, it is immediately evident that these organizations do not seek to simply gain access to existing institutions. Instead, they seek to entirely revamp multiple aspects of American life. The long-term goals and visions articulated in their mission statements are both sweeping and imprecise, as indicated in the direct quotes highlighted in Table 6.4: 
Table 6.4

Values and Goals

\begin{tabular}{|l|l|}
\hline Organization & Excerpts from Mission Statements \\
\hline $\begin{array}{l}\text { Affinity Community } \\
\text { Services }\end{array}$ & $\begin{array}{l}\text { "Affinity Community Services works for social justice, freedom, and } \\
\text { human rights." }\end{array}$ \\
\hline Allgo & $\begin{array}{l}\text { "envisions a just and equitable society that celebrates and nurtures } \\
\text { vibrant people of color queer cultures... (and seeks to) radically } \\
\text { transform systems and policies toward a collective liberation." }\end{array}$ \\
\hline Audre Lorde Project & $\begin{array}{l}\text { "We work for community wellness and progressive social and } \\
\text { economic justice." }\end{array}$ \\
\hline $\begin{array}{l}\text { Center for Artistic } \\
\text { Revolution }\end{array}$ & $\begin{array}{l}\text { "CAR's work includes working to end discrimination... Securing } \\
\text { legal protections for our lives and our families." }\end{array}$ \\
\hline $\begin{array}{l}\text { National Queer Asian } \\
\text { Alliance }\end{array}$ & $\begin{array}{l}\text { "NQAPIA seeks to... challenge homophobia, racism, and anti- } \\
\text { immigrant bias." }\end{array}$ \\
\hline $\begin{array}{l}\text { Queers for Economic } \\
\text { Justice }\end{array}$ & $\begin{array}{l}\text { "Our goal is to challenge and change the systems that create poverty } \\
\text { and economic injustice in our communities, and to promote an } \\
\text { economic system that embraces sexual and gender diversity" }\end{array}$ \\
\hline $\begin{array}{l}\text { Southerners on New } \\
\text { Ground }\end{array}$ & $\begin{array}{l}\text { "SONG envisions a sustainable South that embodies the best of its } \\
\text { freedom traditions and works towards the transformation of our } \\
\text { economic, social, spiritual, and political relationships." }\end{array}$ \\
\hline $\begin{array}{l}\text { The Sylvia Rivera } \\
\text { Law Project }\end{array}$ & $\begin{array}{l}\text { "(SRLP) works to guarantee that all people are free to self-determine } \\
\text { their gender identity and expression, regardless of income or race, } \\
\text { and without facing harassment, discrimination, or violence." }\end{array}$ \\
\hline
\end{tabular}

These are lofty goals, indicating that most of the organizations aim for more than mere inclusion and legal equality. Only two of these quotes, from CAR and from SRLP, suggest a primary focus on ending legal discrimination under the law and, even then, the quote from SRLP, supported by the remaining text of its mission statement, also has implications for more far-reaching goals. Meanwhile, the mission statements of the other six organizations very clearly point to agendas that require a major overhaul of American political and legal systems, and culture.

However, just because their long-term goals and vision are so sweeping does not mean that these organizations have not also identified specific antagonists. The following 
sections examine the specific targets they have chosen to influence. Table 6.5

summarizes each organization's targets in broad strokes.

Table 6.5

Targets of Influence

\begin{tabular}{|l|l|}
\hline Organization & $\begin{array}{l}\text { Primary Targets of Influence } \\
\text { (People or institutions that can impact the following issue areas) }\end{array}$ \\
\hline Affinity & Community violence, marriage equality, and immigration reform. \\
\hline allgo & Reproductive justice, sexual freedom, immigration, and anti-violence. \\
\hline ALP & $\begin{array}{l}\text { The criminal justice system, immigration policy, the medical } \\
\text { establishment, and the welfare system. And, more broadly, the state. }\end{array}$ \\
\hline CAR & The state's civil rights law and with the state's educational system. \\
\hline NQAPIA & The immigration system. \\
\hline QEJ & $\begin{array}{l}\text { Economic policies and systems, including the welfare, homeless shelter, } \\
\text { and immigration systems. }\end{array}$ \\
\hline SONG & $\begin{array}{l}\text { Southern political life (including the criminal justice system and social } \\
\text { service systems), with particular focus on the immigration system }\end{array}$ \\
\hline SRLP & The prison, medical, and welfare systems. \\
\hline
\end{tabular}

These eight organizations often advocate for access to and inclusion in the systems they target. For most, however, access and inclusion is a short-term goal; their long-term goals are bigger. Regardless of which institutions these groups are trying to influence, the majority of these organizations articulated positions similar to those of allgo Co-Director Rose Pulliam, who argued that allgo is "trying to work and influence the institutions as a whole." Almost all the interview participants explained that their concerns are greater than merely gaining access for LGBT people to social institutions. In their views, access to a system that treats people poorly is no victory. This is true for most of these organizations, regardless of which system they challenge, or whom, specifically, they target. The rest of this chapter explores in depth these organizations' 
specific targets. While reading about these targets, it is important to situate them within the sweeping long-term goals articulated by most of the organizations. For most of these groups, the context for any of their specific targets is their larger vision, best articulated in SRLP's mission statement: "We can't just work to reform the system. The system itself is the problem."

\section{Elected officials.}

The organizations in the GRM have used lobbying as one, if not the primary, strategy to move forward their agenda. Consequently, their principal targets of influence include elected officials. However, their targets are limited to those politicians who are well positioned to make changes in policy related to marriage/family, hate crime legislation, civil rights/anti-discrimination protections, and education (see Table 6.1). In my analysis of these eight queer liberation organizations, I examined whether they too made these same types of elected officials the targets of their influence.

All the organizations in my study do target elected officials and government agencies as part of their work. However, much of that work takes the form of organizing and protesting against government agencies, rather than lobbying elected officials. (This distinction is important, and will be addressed in depth later.) When I narrow the focus to lobbying elected officials, only three organizations in my study (Affinity, CAR, and NQAPIA) regularly engage in these efforts. The other five organizations do not prioritize lobbying elected officials and, thus, do not share this target with the equality organizations. 
Affinity, CAR, and NQAPIA described lobbying elected officials as a regular part of their work. To determine if they shared the same target of influence as the GRM, I examined whether they lobby the same types of elected officials as the equality organizations (those well positioned to impact policy on marriage/family, hate crimes, civil rights/anti-discrimination, or youth/education). Among the three, CAR was most invested in seeking legislative remedies for the issues they prioritize, focused primarily on work with the Arkansas Citizens First Congress, a coalition of many social justice organizations.

We are pushing for the creation of a civil rights commission for the state of Arkansas ... we also want to add the words to the states civil rights law: sexual orientation and gender identity... And so we are now working on our strategy for initiating a legislative request in 2015 to add those words... And so then we are able to have a conversation about what it means to live in a state and to worry about your job, worry about where you can go in public, and not having any legal protections if you are discriminated against.

- Randi Romo, CAR Executive Director

Although CAR works on other, non-LGBT, issues, this quote illustrates the priority given to LGBT inclusion in the Arkansas civil rights laws. In prioritizing civil rights laws and targeting influential lawmakers in this regard, CAR's agenda and target of influence align with the GRM's. In addition, by making non-partisan electoral lobbying a central strategy of that work and therefore targeting politicians who can create civil rights legislation, CAR shares the same antagonists as the equality organizations. Affinity has only recently begun to prioritize lobby visits to elected officials as one of their strategies. They have worked on issues such as marriage, and have targeted elected 
officials well positioned to impact that issue. However, their approach to lobbying is very different from the single-issue focus of the equality organizations.

We are trying to influence legislators... We have been very intentional about increasing those relationships to include in our work more intersectional issues. We work with legislators from that angle, helping them see the LGBT impact of some of the legislation they are promoting, and the impact on communities of color. And I think we are making our needs more visible as folks with multiple identities whose lives are impacted by the work that they do.

- Kim L. Hunt, Affinity Executive Director

This intersectional agenda requires Affinity to target a broader range of elected officials than those targeted by the equality organizations. For instance, Affinity has targeted politicians working on issues as varied as homelessness and public transportation, issues unaddressed by the GRM. Consequently, although they share some common antagonists with the equality organizations, they differ substantially in scope and focus.

NQAPIA is the final organization that focuses on lobbying elected officials. Not only does NQAPIA currently engage in these efforts, they have also recently committed to increasing the resources devoted to this kind of targeting of government officials:

Our strategic plan is moving us in a direction that is focusing more solidly around member political engagement. In previous years we had a focus on bringing folks to DC because we have wanted to bring them to our summits where we do capacity building and trainings and networking amongst ourselves. This year our advocacy work is really around amplifying their voices more directly and connecting them more directly with policymakers. So this year we brought some of our partners to DC to a special roundtable with the Deputy Secretary of Homeland Security. So it's kind of moving them more directly on that spectrum of movement building.

- Ben de Guzman, NQAPIA Co-Director 
de Guzman's articulation of lobbying as an example of movement building is worth noting here. As I will explain later, this is in contrast to other queer liberation organizations' assertion that, although lobbying has its place in social justice work, it does not constitute movement building.

Like Affinity, NQAPIA also approaches lobbying intersectionally:

In terms of doing advocacy work, we focus as a national entity around national policy makers. We engage both the API and the LGBT congressional caucuses. We work through two lenses. Through the lens of Asian American and Pacific Islander advocacy. As well as engaging policy makers shoulder to shoulder with national LGBT groups. We get invited to both of those tables.

- Ben de Guzman, NQAPIA Co-Director

By working on these two fronts, they are both similar to and different from the GRM. Although NQAPIA focuses on elected officials as targets of influence (including congress, the White House and federal agencies), they lobby a broader range of elected officials than do the equality organizations. One of their targets of influence are those elected officials who work on LGBT civil rights and family recognition policy, who are also a target of the equality organizations. However, they also target elected officials working on immigration policy, who are not a primary target of the GRM. Consequently, although there are some important similarities, their points of distinction from the GRM's targets of influence are significant.

In summary, five organizations (allgo, ALP, QEJ, SONG, and SRLP) do not prioritize lobbying any elected officials as a central part of their work; they clearly focus on different targets than the equality organizations. Two organizations (Affinity and NQAPIA) prioritize lobbying elected officials, but in a broader range of policy areas than 
those targeted by the equality organizations. So although they share some common antagonists with the equality organizations, their targets differ more than they overlap. Only CAR shares this same target of influence with the GRM organizations.

\section{Judicial system.}

As documented in previous chapters, the organizations in the GRM have also used litigation as one of their primary strategies in their work (Carpenter, 2014; Rosenblum, 1994; Vaid, 2012), clearly making the judicial system their targets of influence. However, as discussed earlier in this chapter, their lawsuits are limited to focusing on those courts (e.g. special federal courts) well positioned to impact policy on marriage (e.g., United States v. Windsor, 2013), hate crime legislation (e.g., People v. DeLee, 2013), civil rights/anti-discrimination protections (e.g., Boy Scouts of America v Dale, 2000), and education (e.g., Couch v. Wayne Local School District, 2012). Contrasting the GRM, seven of the organizations in my study do not engage in any direct litigation. They do not target the judicial system as part of their work, and thus, do not share this target with the GRM organizations.

Only SRLP engages in litigation as part of its work. Litigation is only one part of its legal work, and because SRLP engages in so many other efforts, it cannot be said that litigation of any kind is its primary strategy (SRLP Mission Statement, n/d). Nevertheless, I wanted to explore whether, when it does engage in litigation, it shared the same target of influence as the GRM. I examined whether they target the same types of courts as the GRM (those well positioned to impact policy on marriage/family, hate crimes, civil rights/anti-discrimination, or youth/education). 
SRLP's legal work is focused primarily on the prison system, the medical system, and the immigration system. Sometimes the work on those issues involves civil rights/anti-discrimination cases, and in these cases, SRLP targets the same courts as the equality organizations. However, because they prioritize prison, medical, and immigrant issues, most of their work focuses on judicial issues that are not the primary focus of the equality organizations. SRLP's work requires focusing on a wider variety of courts than do the equality organizations. Accordingly, I cannot claim that SRLP shares the same target of influence as the GRM organizations. Thus, none of the eight groups in this study share this target of influence with the GRM.

\section{Criminal justice.}

The equality organizations have worked on criminal justice issues. The GRM focuses on obtaining access to the protection of a criminal system, and (as previously discussed) their work has been almost entirely limited to the pursuit of legislation to enhance criminal penalties for hate crimes (Kohn, 2001; Mogul, Ritchie, \& Whitlock, 2011; Whitlock \& Kamel, 2001). Organizations in the GRM have made their targets those government officials and entities who were well positioned to add sexual orientation (and sometimes gender identity) to the list of classes covered by existing hate crime laws, or to create new hate crime legislation. They also targeted the media to tell stories of violence against LGBT people and create public support for hate crime legislation.

The criminal justice system is a major target of influence among the organizations in this study, but they have a different focus. Gamson (1990) talked not only about 
individuals or groups as antagonists but also entire social institutions. The organizations in this study see the entire criminal justice system as a target of influence. Five groups (allgo, ALP, QEJ, SONG, and SRLP) referenced their criminal justice work, and three of those (allgo, ALP, and SRLP) have devoted substantial resources towards influencing the criminal justice system. They work to influence different aspects of the criminal justice system and also to end violence against their communities. Part of their work responds to the surveillance and harassment of low-income neighborhoods and communities of color by police. They work to challenge the targeting by police of their communities.

I think the biggest take away from the work I've done at the Sylvia River Law Project for the last 10 years is the significance of different forms of criminalization in the lives of poor people. And the ways that that criminalization is highly ritualized, highly gendered; so both in terms of who gets arrested and what the police think looks unusual and which neighborhoods they spend time patrolling.

- Dean Spade, SRLP Founding Director

We are inside of a coalition of communities united for police reform that's trying to actually change police accountability in NYC... (We are) resisting against increasing policing targeting... it was really about moving against a right wing agenda that further marginalized our communities and policed our bodies... struggling with city government on where policing is, and how the increase of policing is certainly connected to the racial and economic injustices of our communities.

- Cara Page, ALP Executive Director

These quotes reflect an intersectional understanding of queer people's lives. In the analysis put forward by these organizations, sexual orientation and gender identity are factors in the policing of these organizations' communities, but so too are race and class.

In addition to working on the issue of police surveillance and targeting, these organizations focus on how LGBT people are treated when they are incarcerated. Several 
organizations engage in advocacy work to change policies within prisons. Some provide direct services to incarcerated or formerly incarcerated people.

We are looking at the policies for trans and queer gender queer folk in Texas jails. And there's an adult version of that and there's a juvenile version of that. We've done some research around both the policies and the practices... And we've done some training, particularly with the Juvenile Justice System, (and we hope) to do some additional training for the adult jail population, particularly about being trans sensitive if nothing else, and certainly some trans justice.

- Rose Pulliam, allgo Co-Director

This type of work brings with a different set of targets than does the GRM's criminal justice work in pursuit of hate crime legislation. In fact, most of these organizations stand in direct opposition to the GRM with regard to hate crime legislation. They recognize that hate crimes against LGBT people are a huge problem. In fact, allgo and ALP have programs that specifically address violence against their communities. However, they do not believe that hate crime legislation will end this violence. They do not believe that laws prevent violence.

A lot of us are saying, 'actually this strategy doesn't really work.' It definitely doesn't prevent violence against us. Nobody has ever argued that when people are thinking about who to beat up or kill tonight, they look thru some book and they say, 'oh there's a higher penalty if it I do it for that reason.' That's not how violence works, there's no argument that it prevents our deaths or our beatings.

- Dean Spade, SRLP Founding Director

QEJ's Kenyon Farrow agreed with Spade's assessment, claiming, "having queers under the federal hate crimes protection laws will not actually decrease homophobia or homophobic violence, not without shifting the culture and the dynamics of violence in the 
country." Several other leaders expressed their similar belief that the solution to hate crimes involves cultural change, not criminalization.

In addition to claiming that hate crime legislation fails to prevent violence, these organizations opposed it due to their social justice values. Because of their intersectional analysis, they see the criminal justice system as fundamentally racist and classist.

We're the most imprisoning nation in the world. We have five percent of the world's population and twenty-five percent of the world's prisoners. And people in our prisons are primarily people of color and poor people in prison for crimes related to poverty. Inside those prisons, there is outrageous racial and gender violence - in all of them. In the women's prisons and in the men's prisons.

- Dean Spade, SRLP Founding Director

Consequently, they are deeply critical of using enhanced criminal penalties as a solution to the problem of hate crimes. Staff members from allgo, ALP, QEJ, SONG, and SRLP, all expressed perspectives similar to Spade's. They understand that their positions are very different from those of the GRM.

Certainly an equality frame presumes that we are still relying on mechanisms of state because there are some pieces around equality that still use the Prison Industrial Complex and the Military Industrial Complex as setting standard. And we are not a part of that frame. For us, our strategy, our political strategies are about pushing up and resisting against those systems that are policing our bodies and controlling our bodies.

- Cara Page, ALP Executive Director

In 2009, three organizations (ALP, QEJ, and SRLP) took a public stand against the addition of hate crimes legislation to New York's Gender Employment NonDiscrimination Act (GENDA). GENDA would have added transgender people to the classes of people covered by hate crime laws, and it was supported by many GRM 
organizations. Yet ALP, QEJ, and SRLP (and two other NYC LGBT organizations)

opposed it because they resisted further empowering the criminal justice system. All these organizations prioritize the needs of people of color, poor people, and transgender people. Yet because of their opposition to hate crime legislation, white transgender activists attacked them in the gay press, calling them transphobic. This accusation came from white activists who did not share the same intersectional analysis as these queer liberation organizations.

You have (GRM organizations) advocating for stronger hate crime legislation at the same time that we are beginning to see other social movements, and communities of color, in particular, really rejecting the use of criminalization as a strategy for solving a whole range of problems. So when you are working on a single-issue strategy, you then just dismiss the impacts on other sorts of bodies that you don't imagine as part of your identity, or have any relationship to.

- Kenyon Farrow, Former QEJ Executive Director

These activists believe that their communities experience more violence at the hands

of the carceral state than they do from homophobic strangers on the street.

Consequently, they argue that hate crime legislation helps to strengthen a system that should instead be disempowered, if not completely abolished.

(Hate crime legislation) enhances the punishing power of the system that is actually the main perpetrator of violence in the lives of SRLP clients. The most common perpetrator of violence is the police or corrections officers or immigration officers. So what does it mean to add power to that system, providing no relief to us? That system has been desiring growth very intensely for at least the last forty years and that growth has been motivated by profit because prisons are privatized. So the real reason this system wants to pass hate crimes laws is not because it's gonna save our lives but just because the system wants to grow in any direction.

- Dean Spade, SRLP Founding Director

These critiques of hate crime legislation demonstrate the use of this intersectional 
lens. Spade illuminated connections between the prison system, corporate America, and the immigration system, while Farrow looked at the prison system with regards to its impact on people of color as much as its impact on LGBT people. Implicit in Farrow's comments is the additional understanding that these are not mutually exclusive communities.

Rather than embracing the GRM's push for hate crime legislation, most of the organizations in my study openly oppose these efforts and consequently seek to influence significantly different targets. According to QEJ's Kenyon Farrow, these organizations “are moving against stopping prisons or policing strategies." Further, several queer liberation groups talk openly with their members about what it means to be safe, when you cannot count on the police to protect you:

One of the things that we're seeing right now in our community is actually this is a huge, splintering issue - this issue of policing and how people are also framing safety. For some people, safety is just not getting harassed by the police every time you walk out of the gay club.

- Paulina Helm-Hernandez, SONG Co-Director

Some of the groups are finding ways to create safety in their communities that do not rely upon the police or the criminal justice system. Below, Cara Page describes a project of ALP's “Safe Outside the System” Collective, which challenges hate and police violence by using community based strategies rather than relying on the police. The particular project she describes, the "Safe Neighborhood Campaign," seeks to build safe spaces within Brooklyn. These Safe Spaces are public spaces that visibly identify as willing to open their doors to community members fleeing from violence, and whose staffs have been trained on homophobia, transphobia, and how to prevent violence 
without relying on law enforcement.

So our strategy is about saying, yes, there are hate crimes, so what are we doing inside of our communities with allies, with families, with other queer and trans people of color? What are we identifying as strategies that define safety for us, and help us reimagine how oppression has divided us and created a narrative of hatred between us? So how are we building relationships to each other that are not defined by state but are instead defined by our livelihood, our survival, our cultural and political existence?

In the above quote, Page makes clear that in ALP's approach to criminal justice the targets of influence are community members, rather than the state. ALP is working to transform relationships in local communities, and build safety by training neighbors to take care of each other, rather than to fear each other.

Another strategy is how are we building with allies. How are we not assuming that the state or criminal system or military is defining safety and will save us from each other, but how are we looking eye to eye, in the words of Audre Lorde, and asking of ourselves and each other 'who am I willing to be for your safety? Who are you willing to be for mine?' So hate crimes legislation, beyond relying on the state, also defines safety as being 'us versus them'.

Rather than empowering the state to further criminalize their communities, Page sees

those communities as potential allies to be targeted for collaboration and support.

And we are really pursuing a strategy of redefining safety in central Brooklyn. And saying a space of predominantly (straight) Caribbean and African immigrant communities, and African American communities, and newer communities coming in - as people of color, where are we building safety that's not defined by police? And how are we thinking about hatred and oppression and violence around how we are going to transform that amongst ourselves?

So while the GRM targets the criminal justice system for the creation of more laws (hate crime legislation), these queer liberation organizations have, instead, targeted other 
entities as sites in which to create safety, while simultaneously targeting the criminal justice system to decrease its power. In fact, prison abolition lurks in the background of much of the queer liberation organizations' work. Although the day-to-day work of some of these organizations involves providing direct legal services for individual prisoners, class action suits, or sensitivity training for prison staff, their long-term goals appear to be creating safety outside of the criminal justice system while also pursuing prison abolition. Some of the interviewees implied this, while others stated it outright, such as SRLP's Reina Gossett: “A lot of my energy goes into a movement to abolish the prison industrial complex." These goals, and their accompanying antagonists, are clearly different from those of the GRM.

\section{Immigration.}

Legislators and judges who influence immigration policy are a major target of influence among these organizations. In addition, these groups view the entire immigration system as a target of influence. Because Gamson (1990) argued that entire social institutions could be antagonists, I look here at how these groups target the overall immigration system.

All eight organizations I studied referenced their work with immigrant populations, and seven (Affinity, allgo, ALP, NQAPIA, QEJ, SONG, and SRLP) have devoted substantial resources towards influencing immigration policy.

A lot of SONG's work in the last couple of years has also been focused explicitly around immigration because it's been one of the pretty defining fronts of struggle in our region at this time... We have a huge and growing immigrant community in the south - a lot of undocumented folks in our 
community very much working very low wage jobs, working in the very informal economies that have no benefits, no safety net built into them.

- Paulina Helm-Hernandez, SONG Co-Director

In order to influence the debates about immigration reform, one target of influence is the immigrant rights movement. They work inside immigrant rights coalitions, attempting to influence them and make them more inclusive of LGBT people and families. ALP, for instance, has assumed a stance of radicalizing the existing immigrant justice movement to include concerns related to sexuality and gender:

The understanding of how queer and trans people of color are centrally located inside of immigrant justice is a newer...in the past decade has really elevated to a different level, especially in the global south. And to me, it's taken a movement that we have always been inside of but we are now radicalizing... We are now transforming that movement by bringing that queer and trans lens. By looking at gender violence. By looking at sexuality and politicalizing the role of what that means in terms of body, and sovereignty, and state. And taking the immigrant justice movement to another level.

- Cara Page, ALP Executive Director

These organizations also work inside the LGBT movement to influence the conversation about immigration policy. These groups have made the GRM itself a target of influence. They challenge the GRM's work on immigration, because they view that work as principally focused on American citizens and their right to keep their foreignborn partner in the country.

We really spent a lot of time engaging [GRM groups] to make sure that the LGBT movement knew that immigration was not just about bi-national couples, that there are all these other ways in which LGBT folks who have immigrants in their families or who are immigrants themselves are affected and have a stake.

- Ben de Guzman, NQAPIA Co-Director

This highlights the difference between a single-issue analysis, such as the equality 
organizations' exclusive focus on sexual orientation (e.g., immigration policy as experienced by a white American citizen who is gay or lesbian), and the intersectional analysis offered by these queer liberation groups, which simultaneously focuses on sexual orientation, immigration status, and race (e.g., immigration policy as experienced by an LGBT immigrant of color).

In addition to influencing LGBT organizations to take a broader view of which LGBT people are impacted by immigration policies, the organizations in my study also work to bring to the equality organizations an understanding of immigration policy that is more thoroughly grounded in this intersectional analysis. They push the GRM to fight for comprehensive immigration. In addition, and more interestingly, they also require the GRM to make connections between immigration and other social movements, such as the gay rights movement, yes, but also to the struggles of Palestinians, Indigenous Americans, Black Americans, and people with disabilities. They make these interconnections and parallels explicit in their work.

We see (comprehensive immigration reform) as a step in our longer goal to actually transform the idea of citizenship, to talk about indigenous sovereignty and the role of indigenous communities, in defining that conversation. Of the pushing back of the white nativist movement that assumes that only white people have claim to the US, only white people have claim to legitimate citizenship in this country... We think our people need and have demanded citizenship as one of the main ways to also be able to honor the reality of most undocumented communities being reduced only to labor. This assumption that we're disposable, and as long as you can stand up and work and produce, then you can be here. In the shadows, but you can be here. And as long as you don't become a person with disabilities, as long as you're not queers, as long as all of these other things, because then (it's) thank you for your labor and good day.

- Paulina Helm-Hernandez, SONG Co-Director 
SONG is trying to influence the GRM, by pushing the equality organizations to consider that analysis and incorporate it into their work. Other organizations are similarly invested in targeting the GRM, and their own communities, by pushing them to develop a more complicated analysis of immigration policies. They do this while simultaneously targeting the immigration itself. Between 2006-2008, ALP and QEJ each issued various white papers about immigration, using an intersectional lens to address numerous aspects of immigration policy. To use just one issue as an example, ALP and QEJ each argued that guestworker programs result in the exploitation of guest workers while simultaneously undercutting the U.S. labor movement. Such an analysis explicitly draws connections between immigration policy and economic policy. Additionally, it does so while implicitly situating all workers, (LGBT people and heterosexual cisgendered people, citizen and noncitizen) in solidarity with each other. This argument is clearly rooted in an intersectional framework. Additionally, by targeting the government's guestworker proposals, the queer liberation organizations have set vastly different targets for themselves than have the equality organizations. This is because they engage the issue from a very different perspective.

We are actually even interrogating this assumption that 'citizen' should equal 'safety'. Why are we assuming that, when we've seen that in this country... (pauses)... well, you know, I've learned so much from the generosity of southern black communities about what black citizenship actually looks like, and about this automatic assumption that citizenship is going to be the only thing that we need as a movement. The assumption that with this demand only, that it's going to fix everything else, right? Versus actually transforming what we actually mean by that, and what we are actually saying to each other about who we are willing to protect and why.

- Paulina Helm-Hernandez, SONG Co-Director 
If one of the primary goals of the immigrant rights movement is the creation of paths to citizenship, then Helm-Hernandez's interrogation of citizenship poses a profound challenge to that movement. SONG's target of influence here is the immigrant rights movement and the GRM, as well as the general public, attempting to complicate their analyses.

The need to target the GRM's stake in immigration is great. Aside from its work on bi-national couples, it has largely remained silent on immigration policy. In 2007 , organizations from across the country worked for a year to identify a platform of issues impacting LGBT immigrants (DasGupta, 2012). Fifty immigrant rights and LGBT organizations eventually signed it and used it in their advocacy work. Most of the LGBT groups who signed on were small, local organizations - the majority of the national LGBT organizations refused to sign on or address these issues in their work (DasGupta, 2012).

The organizations in the GRM movement offer no real critique of their own about immigration policy beyond the issue of bi-national couples, and their only antagonists in immigration policy are those legislators who are well positioned to protect bi-national couples (DasGupta, 2012). The GRM, therefore, does not share the complicated web of antagonists implied by the analysis of SONG's Helm-Hernandez:

Part of our work has been to do political education with the LGBT community about understanding what does immigration even mean? What actually are the root causes of immigration? What are some of the most common misconceptions - not just about who comes here and (the narrative that says) 'everybody wants to come to the US'. But the fact that immigration is a global issue, that people are migrating all over the world 
all the time. ...(The United States is) one of the major players of driving people out of, you know, exiling people out of their own countries by destroying their economies... And to examine how citizenship, historically, has always been used to define our proximity to privilege. And so for us it's been really important to do that level of political education with our communities.

Her targets of influence in the above quote are still the equality organizations, but also LGBT communities more broadly. The groups in this study target their own communities, seeking to educate them about immigration policy and influence them to get involved in immigration work.

The organizations in my study take an approach to USA immigration policy that avoids single-issue analysis and, instead, looks for solutions that address the complexities of immigration policy. They work to influence the entire immigration system and expand the current parameters of the immigration debate. Consequently, they seek to influence a different group of targets than those pursued by the GRM. The following excerpts from a speech given by ALP's Trishala Deb at the 2007 US Social Forum illustrates how multifaceted are the targets of these organizations.

We are in a critical moment within the broader struggle for the rights of migrants in the United States and in the world. I am speaking of the mounting costs of a very small sector of wealthy people accumulating unimaginable resources off the backs of the majority of the world. Every year, over 175 million people migrate around the world in search of a sustainable existence... As people in the United States, we must accept that the transnational economy that some people benefit from is completely dependent on the suppression of economic autonomy throughout the global south.

This is a much more complicated critique of immigration policy than has been offered by the GRM. ALP and the other queer liberation organizations seek to expand the 
national dialogue beyond merely the questions of guestworkers and fences, and to put those questions in the larger context of links between immigration and capitalism. Deb is identifying neoliberalism itself as an antagonist. In her speech, Deb goes on to delineate different pieces of neoliberal policies that impact immigration:

We must understand that the War on Terrorism is a war abroad and at home, and that when we say our people are being unfairly incarcerated for the benefit of a few, we mean an American prison population which is largely citizens of color, the detention industry, and the illegal incarceration of prisoners of war. When we talk about the War at Home we mean the militarization of the border and the use of local police officers and immigration enforcement agents... We must make the connections between the detention industry and the prison industrial complex, war profiteering and disaster profiteering.

Several of these queer liberation organizations share this analysis that examines who profits from current immigration policies. Here Deb included among her targets the criminal justice system, ICE, and the military. However, her targets also include her listeners. Like SONG, ALP attempts to influence its communities through the public offerings of these analyses. This analysis is meant to serve as a call to action, influencing Deb's listeners to take action.

We can build local coalitions and national strategies which will consolidate our collective understanding and power to say to anyone in Washington: we will not go through another mass registration program which results in the loss of the most vulnerable among us, we will not accept... another guestworker policy, we will not consent to billions of our money spent to incarcerate entire families, including children, on top of the trillions of dollars in profit being used to kill our families abroad... We will not consent to surveillance drones used on our southern borders, the way they are used to patrol the wall in Palestine; we are not temporary, disposable, or alien.

The analyses put forward by these queer liberation groups require engaging a 
vastly different set of targets than does an analysis (such as the GRM's) limited to seeking access for gay and lesbian American citizens to marry their foreign-born partners. For the groups in this study, the entire immigration system is the target. In these ways, these queer liberation groups are markedly different from the mainstream LGBT movement, which has devoted few resources towards influencing immigration policy, redirecting those resources almost exclusively to target policies about bi-national couples.

\section{Social services and public assistance.}

Government programs that provide public benefits and health services are also major antagonists for the queer liberation groups. Six organizations (Affinity, allgo, ALP, NQAPIA, QEJ, SONG, and SRLP) referenced working on issues such as poverty, TANF, homelessness, Medicaid, and HIV. Four (allgo, ALP, QEJ, and SRLP) have devoted substantial resources towards influencing public benefits and healthcare systems. They target these systems because the intersectional analysis they employ recognizes that, in contrast to the GRM's dominant narrative, LGBT people are not all affluent white people who can afford to privatize their own health:

The work that I do now is really based on the idea that issues of the economy are profoundly affected by how you live out sexual orientation and gender identity. That we're impacted by all the intersections of our identities and how those then are reflected in what our choices are... If you're poor, if you're transgender, if you're a person of color, if you're HIV positive, and you're homeless, the ability to be safely somewhere... is unlikely. And QEJ works in a lot in places like shelter systems, when in a traditional LGBT analysis, you would never know that there are queer people that are homeless. You would never know that there are low income people who are LGBTQ and that we're actually the majority of who shares that identity, not a minority.

- Amber Hollibaugh, Former QEJ Executive Director 
Building on this recognition, QEJ targeted New York City's Department of Homeless

Services and effectively engaged in efforts to influence their policies and their practices.

And at QEJ, we have done a lot of organizing and advocacy in the shelter systems and with the welfare system. Jay's shelter project runs support groups in the shelters (the only nonreligious organization in the city, gay or straight, that has access to the shelters), and runs monthly "Know Your Rights" trainings, and does advocacy. Jay spent two years leading a successful campaign to get the City to change its policy around transgender homeless shelter residents, and now people can self-select which shelters they want to be in. This was a real victory. And Joseph worked for three years to get the city's shelter system to allow domestic partners access to the shelters for homeless families. And he won. Before that, you needed to be married. So the shelter project has accomplished a lot.

- Kenyon Farrow, Former QEJ Executive Director

ALP, QEJ, and SRLP have worked together to influence the NYC welfare system, striving to eliminate barriers to TANF for transgender people, and to do so they targeted the Human Resource Administration (HRA):

The Human Resources Administration in NYC is notorious for being really a hostile place for trans and gender non conforming people who are accessing welfare at a time when job discrimination for trans people is incredibly notorious and really prevalent here in the city and they need services in order to survive. So we had a great grassroots campaign and collaboration with a number of organizations including QEJ targeting the city and targeting this agency, the Human Resources Administration.

- Reina Gossett, SRLP Director of Membership

These same organizations also targeted the HRA, as well as Medicaid and other healthcare systems, around discrimination against transgender people in healthcare. SRLP has filed a class action lawsuit, and worked with ALP to organize a related grassroots organizing campaign, against a New York State Medicaid policy that denies health care to transgender people. They see this campaign as related to their other targets 
of influence.

Healthcare is similar to other policies that exist in New York State and in NYC where we are targeting policy makers. For example, the mayor has the power to change NYC's birth certificate policy. Currently, the birth certificate policy requires trans and nonconforming people to have a certain kind of surgery that they may or may not want and that most often cannot afford. So that's another policy that we work on.

- $\quad$ Reina Gossett, SRLP Director of Membership

Other groups in this study have also worked on health issues. For instance, health systems have always been among allgo's targets of influence, as indicated by its mission statement: "allgo works toward its vision through ... promoting health within a wellness model." Initially, this meant targeting the Department of Health with work on HIV/AIDS and sexual freedom. allgo was "the first openly gay and lesbian organization that got funding from ... the Texas Department of Health" and during the AIDS crisis was threatened to be defunded by that department due to Texas law criminalizing gay and lesbian sexual activity. The organization activated its resources in its defense: "So we had our attorneys lined up, ready to take it on" (online video about allgo's origins). allgo's work has expanded to include other sexual health issues, including reproductive justice. By making the connections between HIV rates among communities of color and queer people (and also recognizing that these are not mutually exclusive categories), and by making connections between healthcare, HIV, and reproductive justice, allgo demonstrates another example of work grounded in an intersectional analysis.

The GRM has not prioritized targeting the welfare and health systems. By working on issues such as TANF, homelessness, Medicaid, and healthcare, these seven organizations (only CAR gave no indication of working on social service systems) have 
identified targets of influence that are not shared by the GRM organizations.

\section{Other social justice organizations.}

All eight organizations referenced how they target and attempt to influence other social justice organizations based on their belief that other organizations have excluded the issues of concern to queer people of color. In all eight interviews, staff discussed the lack of an intersectional analysis by other social justice organizations, and how that required intervention.

The groups in my study target non-LGBT social justice organizations that are part of "other" movements. They raise issues impacting LGBT people and push other movements to address them. For example, NQAPIA pushes Asian American immigrant advocacy groups to make sure that LGBT issues are included in their work, and Affinity works to influence NAACP, the Urban League, and NOW, to be inclusive of LGBT people. All eight of the organizations have done this kind of work.

We try to educate our constituency about the issue and bring them on to be connected with the organizations who are doing that work so that there is a queer people of color presence there... There's an organization in the community who are doing some anti-racism work... We need some people involved in this. We don't know whether it's going to be messed up or not but we need queer people of color there. They are going somewhere. We need to know where they are going. We need our people to influence where they are going and how they go.

- Rose Pulliam, allgo Co-Director

SONG alone has conducted trainings for over 100 Southern and national racial and economic justice organizations to help them combat homophobia and transphobia.

The queer liberation organizations influence these other social movements, but they also do parallel work within the GRM. At the same time that they push racial and 
economic justice organizations to address LGBT issues, they also target LGBT

organizations and push them to expand their focus to include issues of racial and economic justice. Affinity, for instance, "was founded by a group of black LGBT people who wanted to bring visibility to black people within the LGBT community and LGBT people within the black community" (Kim L. Hunt, Affinity Executive Director). Similarly, QEJ's mission involves a call to "work to broaden the discourse, vision and agenda within both queer and economic justice organizations." allgo co-director Rose Pulliam offered a clear example of how this work unfolds in Texas:

We do work with other social justice organizations or players. And this is what we call our leverage work. So for example, when racial justice organizations in Texas are doing work we try to influence their work to ensure a queer people of color perspective. And certainly hope it doesn't do harm to queer people of color. It's at the intersections. We do the same thing with mainstream LGBTQ organizations, with reproductive justice organizations, so our leverage work is to influence the work of those folks who are doing social justice work.

- Rose Pulliam, allgo Co-Director

In fact, the statewide and national equality organizations in the GRM are a central target of influence for many queer liberation organizations; interview participants made numerous references to how the equality organizations were too white and middle-class in both composition and agenda.

Frankly, these (GRM) organizations are very white. They may have a handful of people of color connected to them or involved but more often than not the people of color in them are not necessarily connected to people of color communities. And sometimes even when they are, they are also frustrated with the agendas. Particularly about the differing agendas of these organizations.

- Rose Pulliam, allgo Co-Director

Because of this, the organizations I studied are committed to influencing the equality 
organizations. They work to influence the GRM to expand their agenda to incorporate racial and economic justice issues. NQAPIA co-director Ben de Guzman articulated efforts to "engage LGBT movements around racial issues... we engage our LGBT partners...the HRCs and the Taskforces of the world to make sure that they are working through an analysis of race and ethnicity."

These organizations target the equality organizations in different ways. Sometimes it involves working in coalition with them; sometimes it involves organizing against them. Some of these efforts have been successful at influencing them, as indicated by SRLP's victories with the Empire State Pride Agenda (a GRM organization that transgender activists have protested against for not serving transgender communities):

These groups we once protested are now working to foreground issues that are affecting trans and gender nonconforming people. So for instance, ESPA has recently started working on healthcare and repealing the regulations in NY State that denies trans and gender nonconforming people access to Medicaid.

- $\quad$ Reina Gossett, SRLP Director of Membership

Their influence on these targets can be seen in a story shared with me by QEJ's Kenyon Farrow, describing some of the byproducts of QEJ's monthly “Building a Queer Left" teleconference meetings (where QEJ brought together organizations from across the country for monthly teleconferences about topics that QEJ chose and organized). After QEJ spent years trying to influence the national GRM organizations, they finally began responding when Obama was elected. Farrow explained that newly appointed White House officials were contacting the larger GRM groups, asking for information about 
issues (related to HUD, Medicaid, identification papers, drug policy, etc.) that the GRM

organizations had never worked on. Consequently, GRM groups such as HRC, NGLTF and the Equality Federation started joining the monthly teleconferences to learn about these issues from the queer liberation groups.

Under Bush, we spiraled into a real serious global financial crisis, and the equality organizations had no analysis around that. And no real answer. So they back themselves into a wall around marriage while the whole rest of the world is talking about subprime mortgages and bundling being sold all over the globe and then causing a crisis in Greece and all these other things. They just had no real answer for it; they had no analysis to offer. And so, what was interesting about that particular moment was that it then forced them to engage with us to get as much information out of the other queer left organizations as possible because they just had no idea how to deal with some of these other issues that had become, not just the national, but, like, the global conversation.

- Kenyon Farrow, former QEJ Executive Director

However, the attempts to influence the GRM organizations are not always this successful. Numerous organizations described their frustration with being ignored by the equality organizations. For instance, allgo's Rose Pulliam said that staff members of the local equality group “don’t want to work us unless they have to. Unless they are absolutely required to." This is because allgo often tries to intervene when the GRM group "is moving towards something downright harmful” to allgo's communities. allgo attempts to influence them, but the GRM group is usually not receptive.

We are a thorn in their side most of the time. And that's the truth. And they see us as inconsequential. So they also see us as people they don't have to work with. We are a pain in the ass and they don't really have to deal with us... It reminds me of those cartoons where you have the person ding something and then there is their conscience over to the side talking to them that they mostly ignore. There is a way in which I think we serve that role to some degree to that larger movement. And they ban us away. 
Like, 'don't talk to me, get away from me. You know, you're spoiling my high' or something.

- Rose Pulliam, allgo Co-Director

In addition to targeting equality organizations, these groups discussed how they

have targeted each other. QEJ's “Building a Queer Left” project was one venue where

queer liberation organizations came together to influence each other.

So, for example, you had organizations that were working around various kinds of issues around criminalization. ALP in NYC started this "Safe Outside the System" project to work to try to build some strategies to reduce violence against queer and trans folks in BedStuy, Brooklyn, without bringing in the police. Working with local businesses and then doing training with folks as a way to sort of do that. And then at the same time, ALP found out about (the organization) Women with a Vision in New Orleans. And they exchanged strategies. Because Women with a Vision does both services and organizing and advocacy for women, particularly from an HIV frame, but also was organizing against the ways in which women, including trans women, doing sex work were being criminalized in New Orleans. So those kinds of relationships got developed through "Building a Queer Left"; this is just one example of how groups learned from each other.

- Kenyon Farrow, former QEJ Executive Director

The Astraea Foundation's Movement Building grant program also supported these groups in their efforts to network with and impact each other's work. For instance, Kim L. Hunt described to me how Affinity has spent the last four years prioritizing immigration work because of what they learned from the other Astraea Movement Building grantees doing that work. Affinity started with a participatory research project examining Black American and immigrant views and attitudes towards each other. As they continued to develop their immigration expertise, in part with the help of the other Astraea grantees, they have expanded their immigration work. 
Although some GRM organizations work with each other in various coalitions (e.g., The Equality Federation), very few of them have prioritized working inside of other social movements. And those that have done so have not prioritized that work. By targeting other social justice organizations (from other movements, from the GRM, and each other), the groups in this study have clear targets of influence that are not shared by the groups in the GRM.

\section{Marriage.}

Securing access to legal marriage has been the clear priority of the GRM for the past 15 years. Consequently, they have targeted the media and those elected officials and judicial systems that are well positioned to impact marriage laws. Pursuing these targets has utilized more of the GRM's resources than has the pursuit any other target (Bowen, 2012; Funders for LGBTQ Issues, 2012; Movement Advancement Project, 2007). For this reason, it is significant that none of the queer liberation groups have prioritized work on "marriage equality" campaigns.

The eight organizations had different relationships to the GRM's work on marriage. While Affinity, CAR, and NQAPIA have actively supported marriage campaigns, none of these organizations dedicated significant resources towards that work; it was not a priority. Meanwhile, the other five organizations did no work to support marriage equality campaigns. ALP and QEJ actively opposed the GRM's marriage equality work. allgo, SONG, and SRLP have done no work on marriage one way or another. 
The reasons for these different relationships to the marriage campaigns are complicated but significant. They are particularly pertinent to my other two research questions and will be explored in depth in the next chapter. What is most relevant to this research question is the fact that none of the eight organizations made "marriage equality" a priority; they clearly do not share this target of influence with the GRM.

\section{Conclusion.}

As detailed in previous chapters, the agenda of the GRM has been constructed in a way that primarily benefits white, middle class gays and lesbians. The equality organizations' only objection to the way our social, political, and legal systems are structured is the exclusion from them of gays and lesbians (Duggan, 2003; Gore, Jones, Kang, 2001, Rosenblum, 1994; Schulman, 2012; Seidman, 1993; Shepard, 2001). Cohen (1999) argued that this is because the GRM lacks an intersectional understanding that because of multiple subordinated identities and social locations, different queer people suffer from different degrees of oppression. As evident among the queer liberation organizations, such an intersectional lens would result in a very different political agenda.

The groups studied in this project clearly employ this intersectional analysis. Although these organizations share an understanding of queer lives and issues that is more expansive than the GRM's, they enact that understanding in different ways. Some share many targets of influence (immigration, criminal justice, and social services systems), but sometimes these targets are not shared by all (e.g., reproductive health, antiviolence, youth). My analysis of these eight organizations leads me to find that one (CAR) shares the same targets of influence as the organizations in the GRM, while seven 
do not.

To varying degrees, Affinity, allgo, ALP, NQAPIA, QEJ, SONG, and SRLP share the same targets of influence (e.g., the criminal justice system, the immigration system, social service agencies, and other social justice groups). The GRM does not share these targets. In addition, the GRM's targets of influence (those elected officials, judicial system, well positioned to shape policy about family protections, hate crime laws, civil rights/anti-discrimination laws, and youth/education) are not targets prioritized by Affinity, allgo, ALP, NQAPIA, QEJ, SONG, and SRLP. In addition, often these organizations actively opposed the GRM's work on these issues.

CAR, on the other hand, falls in a different category. Although CAR shares some of the same targets of influence as the other queer liberation groups in this study, it has not prioritized those targets. None are central to CAR's work, appearing instead to be secondary targets. On the other hand, they do share some of the same primary targets of influence as the GRM. Their focus on civil rights/anti-discrimination laws and their work with LGBTQ youth are in line with the agenda of the GRM organizations. I find that CAR, alone among the groups in this study, shares targets of influence with the GRM.

\section{Summary and Discussion}

\section{Answering research question \#1.}

To determine whether these organizations are, as some have suggested (Applied Research Center, 2010; Applied Research Center, 2012; Funders for Lesbian and Gay Issues, 2005), part of the GRM, I compared their targets of benefits, mobilization, and 
influence, as conceptualized by Gamson (1990), to the primary targets of the equality

organizations in the GRM. Table 6.6 provides a summary of these targets.

Table 6.6

Overview of Comparison of All Targets

\begin{tabular}{|c|c|c|}
\hline & $\begin{array}{c}\text { Primary Targets of } \\
\text { Benefits and } \\
\text { Mobilization } \\
\end{array}$ & Primary Targets of Influence \\
\hline $\begin{array}{l}\text { Equality } \\
\text { Organizations } \\
\text { in the GRM }\end{array}$ & $\begin{array}{l}\text { All LGBT people, but } \\
\text { predominantly white and } \\
\text { middle-class gays and } \\
\text { lesbians. }\end{array}$ & $\begin{array}{l}\text { Elected officials (via lobbying) } \\
\text { Judicial System (via litigation) } \\
\text { (those that are well positioned to affect } \\
\text { policies relevant to Marriage/Family } \\
\text { Protections, Civil Rights/Anti- } \\
\text { Discrimination Laws, Hate Crime } \\
\text { Legislation, Youth/Education) }\end{array}$ \\
\hline $\begin{array}{l}\text { Affinity } \\
\text { Community } \\
\text { Services }\end{array}$ & Black LGBTQ people. & $\begin{array}{l}\text { Politicians and government social services } \\
\text { agencies, community institutions, and } \\
\text { social justice organizations }\end{array}$ \\
\hline allgo & Queer people of color. & $\begin{array}{l}\text { Health, criminal justice, and immigration } \\
\text { systems, as well as other social justice } \\
\text { organizations. }\end{array}$ \\
\hline $\begin{array}{l}\text { Audre Lorde } \\
\text { Project }\end{array}$ & $\begin{array}{l}\text { LGBTSTGNC People of } \\
\text { color. }\end{array}$ & $\begin{array}{l}\text { Immigration, criminal justice, medical, and } \\
\text { welfare systems, and the state more broadly }\end{array}$ \\
\hline $\begin{array}{l}\text { Center for } \\
\text { Artistic } \\
\text { Revolution }\end{array}$ & $\begin{array}{l}\text { All LGBTQ/SGL people, } \\
\text { and other marginalized } \\
\text { populations, with a particular } \\
\text { emphasis on youth. }\end{array}$ & $\begin{array}{l}\text { The education system, and elected officials } \\
\text { who are well positioned to create LGBT } \\
\text { civil rights legislation. }\end{array}$ \\
\hline $\begin{array}{l}\text { National } \\
\text { Queer Asian } \\
\text { Pacific } \\
\text { Islander } \\
\text { Alliance }\end{array}$ & $\begin{array}{l}\text { API LGBT organizations } \\
\text { and the API people served } \\
\text { by those organizations. }\end{array}$ & $\begin{array}{l}\text { Politicians and government agencies } \\
\text { (primarily those that are well positioned to } \\
\text { affect policies relevant to immigration and } \\
\text { racial justice issues), and other social } \\
\text { justice organizations. }\end{array}$ \\
\hline $\begin{array}{l}\text { Queers for } \\
\text { Economic } \\
\text { Justice }\end{array}$ & $\begin{array}{l}\text { Low-income queer people, } \\
\text { and progressive queer } \\
\text { activists and organizations. }\end{array}$ & $\begin{array}{l}\text { Economic policies and systems -- } \\
\text { particularly the homeless shelter, welfare, } \\
\text { and immigration systems. }\end{array}$ \\
\hline $\begin{array}{l}\text { Southerners } \\
\text { on New } \\
\text { Ground }\end{array}$ & $\begin{array}{l}\text { LGBTQ southerners and } \\
\text { organizations, who are } \\
\text { people of color, immigrants, } \\
\text { working class or poor, } \\
\text { and/or rural. }\end{array}$ & $\begin{array}{l}\text { Immigration system, criminal justice } \\
\text { system, social service systems, and other } \\
\text { social justice organizations. }\end{array}$ \\
\hline
\end{tabular}




\begin{tabular}{|l|l|l|}
\hline Sylvia Rivera & $\begin{array}{l}\text { Transgender, transsexual, } \\
\text { intersex and other gender } \\
\text { nonconforming people, } \\
\text { focusing on people of color, } \\
\text { poor people, immigrants, } \\
\text { and people with disabilities. }\end{array}$ & \\
\hline
\end{tabular}

In summary, given the vast differences between their targets of benefits, mobilization, and influence and those of the GRM, seven of these groups (Affinity, allgo, ALP, NQAPIA, QEJ, SONG, and SRLP) are not part of the GRM. Only CAR shares the necessary targets of benefits, mobilization, and influence with the equality organizations to be considered part of the GRM.

\section{Discussion.}

\section{Overview.}

The seven organizations outside the GRM are very clear about how they differ from the equality organizations. They find the agenda of the GRM too limited in its scope, too focused on seeking inclusion into systems that benefit only those LGBT people whose racial, class and gender identities allow for them to be served once the sole problem of homophobia is remedied. Interconnected issues of racial and economic justice, or xenophobia or transphobia, are ignored.

These critiques parallel Duggan's (2002) theory of homonormativity, which she applies to the GRM's role in enacting the sexual politics of neoliberalism. In this case, homonormativity characterizes the organizations in the GRM as having abandoned any claim of addressing social justice issues beyond homophobia, focusing instead on equality with its promise of inclusion into broken systems. While this analysis describes 
the GRM, it does not apply to the organizations in my study, which have chosen broader agendas, driven by a more sweeping vision of social justice.

The groups in this study utilize the intersectional lens prescribed by Rosenbaum (1994) when he deployed queer theory to call upon LGBT advocates to focus on the multiplicity of LGBT identities, so can better address the different ways queer women, people of color, poor people, transgender people, and others face discrimination and structural barriers. This intersectional lens is obvious in the discourse employed by these organizations' staff as they discussed their work on immigration, criminal justice or poverty, as well in the language of these groups' mission statements. This finding, how the work of these groups is informed by intersectional analysis, emerged throughout all of the data. Their analyses address capitalism, imperialism, racism, and transphobia at least as frequently as homophobia. Consequently, their targets of benefits, mobilization, and influence (illustrated in Table 6.6) are vastly different from those targets of the equality organizations in the GRM. The single-issue lens of homophobia applied by the GRM results in targets that allow for legal equality and access for (primarily white, middleclass) gays and lesbians, whereas the intersectional lens of the queer liberation groups results in targets that would result in larger structural transformations benefitting queer people of color, poor people, and transgender people.

\section{Co-option.}

Another finding from this study was a complete surprise to me. When I worked in "the movement," my colleagues at different organizations often voiced frustration about how the equality organizations failed to work on racial and economic justice issues, or to 
address the issues facing transgender communities. Unsurprisingly, they also surfaced throughout data collection. However, participants raised a new, related concern that I had not anticipated. In the years since I left work in this community, many of these groups became concerned that when the fight for marriage is over, more equality groups would start to do racial and economic justice work or work on transgender issues, refocusing their targets of benefit and influence to those areas they had historically ignored. The people I interviewed expressed apprehension that, in order to justify their continued existence, the equality organizations would look for issues to work on. The concern comes, in part, from the anticipation that when they do it, the equality organizations will have the political clout and resources to take the work away from the groups in my study, and that they will do the work badly:

It's my belief that once marriage is conquered, and it will be, then that movement goes off and I don't know what they are going to be doing because marriage is mostly the final frontier. And our work will still just be beginning. And those folks who are in that LGBTQ movement may go off internationally to do things or not, but I don't have a lot of confidence that that movement will know how to do a very good job of taking on some of the additional issues that our movement is highlighting.

- Rose Pulliam, allgo Co-Director

Most interviewees expressed similar sentiments. They claimed that the GRM organizations lack an intersectional analysis and consequently they do not understand how to do the kind of work that is needed by the communities represented by the organizations in this study.

The queer liberation groups also fear the equality organizations will co-opt their work. Affinity's Kim L. Hunt said that she has spoken with staff from many 
organizations ("the smaller ones, that have worked from an intersectional approach"), who share this concern. They fear that when the marriage battles are finally done, the equality groups "will begin to swallow up the work of the smaller organizations who have been on the ground doing this more intersectional work for years. Maybe I'm just paranoid."

Given how many other organizational representatives told me that the GRM has already started co-opting their work, it does not appear that Hunt is paranoid. They have already been used by the equality organizations without being given credit. Ben de Guzman explained how some equality groups have taken sole credit for projects that were really partnerships with NQAPIA: "They talk about the work they have done in communities of color but it's actually through partnership with us. They're pointing to their diversity grids or goals, but it's actually the work that we've done with them." Other interviewees shared similar stories with me of not being given credit for collaborations.

In addition, participants shared stories of having their ideas taken, watered down, and misrepresented, by GRM organizations. For instance, ALP's Cara Page described how numerous organizations serving queer people of color have seen their work "coopted and consumed by larger centrist organizations" that then use their greater resources to package and publicize "watered down" versions of these ideas to a larger audience. Page explained how this made groups like ALP more cautious about their engagement with the GRM:

ALP centers our political education work as our strategy - and to have mainstream organizations ask us for our resources and our thinking as thought partners, and to then not be responsible in how they uprooted that 
information, took it out of context, and put it back out to the public... that really implies a dangerous road that we are walking. 1) A lack of accountability; but then 2) how do we maintain transparency and truth telling in our work if we can't even share our thoughts?

These groups are already strategizing about how to deal with this issue in their work with the equality organizations. Several raised the question of transparency, claiming that the only way they will continue to partner with GRM organizations in a post-marriage campaign world is if more rigorous systems of transparency are formalized from the onset.

Some interview participants felt that many of the organizations in the GRM did not know how to be supportive of their work. The equality groups either ignore certain issues or they claim leadership over them; they do not know how to play a supportive role. The groups in this study were worried that this dynamic would increase post-marriage, whereas what they need is more support. For instance, SRLP's Reina Gossett described how the equality groups have ignored transgender issues for decades, while smaller queer and trans groups have done that work in the shadows with fewer resources. As a result of that work, transgender issues have recently become much more visible, and the heightened media spotlight has led some of the GRM to increase, or begin, their efforts on transgender issues. Gossett believes that those efforts should be in a supportive role, rather than trying to take leadership: "They really need to support people who have been doing this work long before it ever made the cover of Time." The only way some of the groups in this study will work with the GRM organizations in the future is if those equality groups offer support and "some kind of humility and acknowledgement that you 
are new to the game and new to understanding that certain lives matter." Other interview participants also mentioned the need for the GRM to exhibit humility by offering support rather than leadership. This issue was framed as related to the previously mentioned concerns about competence, transparency, and the watering down of their ideas.

Finally, this "watering down" of their more radical ideas requires a brief analysis. It is consistent with critiques that have been made for years about the equality organizations. The GRM has been accused of silencing radical queer voices for decades by presenting more conservative alternatives that are aligned with dominant values (Duggan \& Kim, 2005; Sycamore, 2004; Warner, 1999, 2000). Social movement literature discusses how this is common in most movements. Many social movement organizations often attempt to distance themselves from more radical organizations (Downey \& Rohlinger, 2008; Haines, 1995) because they want to highlight how the goals of the movement are consistent with societal values, principally by stressing dominant values that align with the desired social change (Klandermans, 1988; Snow \& Benford, 1992). These theorists characterize this as typical within movements, which complicates my assertion that these organizations are outside of the GRM. However, these "watering down" dynamics are not the basis for my claim. I am not arguing that this issue proves that the groups in my study are separate from the GRM. Rather, its relevance is in the way they characterize it, and the ways that those characterizations highlight how these organizations situate themselves outside the GRM.

Situating themselves outside the movement.

On its own merits, that issue (the co-option of these organizations' work by the 
GRM) is interesting. However, what makes it particularly relevant to this first research question is not the issue itself, but how these organizations articulated it. When this issue came up, the interviewees used language that shed light on how they understood their work in relationship to the GRM. They frequently situated their own organizations as outside of the gay rights movement, or framed it as having their work co-opted by outsiders.

For instance, people often addressed how the equality organizations in the GRM have sometimes used the groups in my study as a way of doing outreach into communities of color. As they made this point, the interviewees consistently referred to a distinction between communities; the speakers viewed communities of color as "our communities," and the equality organizations were situated as outside of those communities.

For many, including Ben de Guzman of NQAPIA, "some of the groups in the equality movement have looked at us like their entry point into communities of color, into our communities." Others echoed this sentiment. Rose Pulliam described how allgo has a collegial relationship with the local equality organization, but only works with that group "occasionally, when they need brown or black faces." Pulliam explained that the GRM organization also contacts them to speak publicly as queer people of color when it is tactically strategic.

(They call us) if there's something politically that they do not want, that's too messy for them. If there is an incidence that has intersectional repercussions, they usually try to defer to us. So for example, a few years ago they had folks of Mexican Heritage on the radio saying things about queer people. They asked us to say something about it because they are 
concerned about being in trouble about the racial stuff. Or, you know, if black folk are saying something homophobic or whatever, they want us to respond to it.

This dynamic illustrates how the equality group represents white people, while allgo is situated in communities of color. It also implies that allgo and the equality group each know that the other shares this understanding; it is how both organizations see the situation. According to Pulliam, allgo is fine with this arrangement, in part because "we don't think they do a good job with our communities." That phrase "our communities" came up again and again in the interviews, usually in opposition to "their communities" (the communities represented by the GRM).

This construction of different communities often led to language that implied different movements. For instance, when I asked Affinity's Kim L. Hunt whom they were trying to influence, her answer included the following:

We are also trying to influence the organizations in the mainstream LGBT movement to (work) with organizations that are smaller and have a great deal of influence and history with our communities, with communities of color. Influencing those mainstream organizations, too, in terms of sharing resources instead of coming to us as an outreach arm when they get grants.

Often the speakers situated their own organizations as outside the mainstream movement. The above quotes by de Guzman and Hunt refer to equality organizations as not merely different types of organizations, but as actually belonging to a different social movement.

All interview participants utilized this us/them language at different points during our conversations. Sometimes the distinction they referenced was in regards to categorizing the different types of organizations ("equality organizations" versus "queer liberation organizations"). This was to be expected, since it is widely understood that 
there are different types of organizations in the GRM. Indeed, that very same conceptualization of these differences is what sparked this study. It is significant, however, that often the interviewees made larger distinctions. Although they sometimes referred to "the equality organizations," other times they referred to "the equality movement" or "the mainstream movement." When they used these phrases, they situated themselves and their organizations as outside the equality/mainstream movement. For instance, in Rose Pulliam's statement that “once marriage is conquered, and it will be, that movement goes off and I don't know what they are going to be doing" her use of the phrases "that movement" and "they" imply that she is not part of the GRM.

This can be seen in other, related, findings that emerged from the data. For instance, several participants described their apprehension about how the members of their community will be treated by the equality organizations as those groups take up the work currently done by the queer liberation organizations. They voiced concern that the equality organizations will start to serve queer people of color and transgender people in a way that is marginalizing and exoticizing. Cara Page and Rose Pulliam illustrate this in the following two quotes:

And now seeing the mainstream movement ...in many ways I think codifying, sort of pulling trans and gender nonconforming people of color in but still as a secondary thought in many ways... I think we are at a particular place in our movements for that movement to learn how to honor leadership without objectifying, exploiting, or exoticizing our leaders. And it's happening to people of color, it's happening to two spirit, it happening to the trans and gender nonconforming people. Like, not identifying their role in our movements, our role, this whole time. And doing some weird elevation of some and not everyone.

- Cara Page, ALP Executive Director 
I don't think that they are particularly willing to think about queerness in all its beauty, in all its glory. I get disturbed by the way that movement is exoticizing and determining what's appropriately trans and what's not. Almost creating this splinter between...I can't even describe it or talk about it. So that there is appropriate trans-ness and inappropriate transness somehow.

- $\quad$ Rose Pulliam, allgo Co-Director

These quotes not only illustrate concern over the equality organizations' treatment of certain populations, they also point to how those equality organizations comprise a movement to which the speakers do not belong. When the speakers refer to how "mainstream movement" or "that movement" treats people of color or transgender people, they frame their language in an "us and them" dichotomy that implies that the speakers see themselves as situated outside of the equality organizations' movement.

This is a complicated dynamic, because sometimes the interview participants identify themselves as part of the GRM, sometimes they identify themselves as outside of it, and sometimes they identify as both inside and outside of it. This tension is addressed in depth in Chapter Nine.

\section{Their own answers to this research question.}

The criteria I used for determining if these eight organizations are part of the GRM movement is based upon social movement theory, not the opinions of the organizations themselves. Nevertheless, I still wondered what the leadership of these organizations thought about this question. At the end of each interview, I asked them directly if they thought their organization was part of the GRM. Their answers were diverse. Some said yes, some said no, some said yes and no. 
Three said yes, they thought their organizations were part of the same social movement as the equality organizations. Randi Romo of CAR answered simply and clearly. Although Romo did not use Gamson's language of "targets of influence," she nevertheless based her answer on the fact that CAR shared the GRM's targets:

Yes, I do believe that we are. I mean, we are very focused on this issue about adding the words to include orientation and gender identity (to the state civil rights law) so that LGBT communities are protected under the law. We have not been a part of the marriage stuff that has happened here but we have supported it in providing information and news about it... I definitely think that we are in alignment with that and with our alignment around Safe Schools. Yeah. I would say yeah.

- Randi Romo, CAR Executive Director

SRLP's Reina Gossett also said yes, but for very different reasons. She told a very long story outlining the historical tensions at the beginning of the American gay rights movement between the more conservative and the more radical factions. They had very different goals and tactics, and were frequently at odds. Gossett situated the current tensions between the equality organizations and the queer liberation groups as directly descended from that history. In doing so, she made the case that the organizations in my study are still part of the GRM, existing as the modern version of the radical left wing. Similarly, ALP's Cara Page saw the work of the queer liberation organizations as bringing back the radical roots of the GRM.

When I think about whether or not we are a part of current social movements in this country or even globally, I think we are. And I want to say, I'm sure there are different political opinions of this, but I do feel like groups like ALP, SONG, SRLP, and Esperanza (Peace and Justice Center), and QEJ's legacy continue to radicalize, if you will. And I use that term cautiously because I don't know always what radicalism means but what I do know is that our existence and our being is radical [laughs]. You know, that we have even gotten this far. And that we are re...I use the term re- 
memory. We are a part of a political legacy and memory that is so far and wide and deep inside of these movements, but I would stretch to say that it has been forgotten. So we are pushing back on memory saying, this is not it, we are not heading for status quo, we are not heading for equality, we are going for something much deeper and much wider because we have, this is what we deserve, and what we are a part of. And that our collective liberation, our collective power, and our collective love for one another has to re-imagine our movements at a much more deeper and wider level. And that it is our role, not to create another movement but to really widen and deepen what we are already inside of.

- Cara Page, ALP Executive Director

Both Gossett and Page situate the queer liberation organizations as part of a lineage with the historic tensions between radical and moderate factions in the GRM. They are arguing that the GRM's history must be rewritten, to acknowledge its often forgotten radical roots. They also contend that the tensions between current the queer liberation groups and the equality groups are reflective of the history of the GRM. In this way, they see their organizations as part of a complex, multi-faceted movement riddled with tensions, rather than as part of a separate movement. In this framework, they see their work as a continuation of those forgotten radical roots.

Many others share this conceptualization of the queer liberation groups as the modern left wing of the GRM (Applied Research Center, 2010; Applied Research Center, 2012; Funders for Lesbian and Gay Issues, 2005). Gamson (1990) is one of numerous social movement scholars who contend that it is common for movements to have more radical groups exist in tension with more moderate ones. Downey and Rohlinger (2008) refer to this as the existence of different players "widely spread across the political possibilities frontier" (p. 23). Social movement theorists claim that organizational diversity and tensions within a movement can lead to a reintegration that brings with it a 
healthy variety of tactics that can be deployed in different circumstances (McCammon, 2003). These movements benefit from having a variety of tactical approaches (Armstrong, 2002; Olzak \& Ryo, 2004). These perspectives would suggest that Gossett and Page are correct when they claim that their organizations are the radical wing of the GRM. Indeed, I suspect that many would agree with them, and characterize this as a normal part of social movements.

However, many social movement theorists contend that sometimes such differences are not reconcilable. Tarrow (1998) claims that polarization is often characteristic of a social movement in decline, rather than one that will reintegrate. Others have documented how sometimes polarization and factionalism leads to neither reintegration nor decline, but instead in the creation of a different social movement (Tarrow, 1990). In the mid-1960s, the civil rights movement experienced major tensions between the moderate groups (NAACP and SCLC) and the Black Power groups. Although some historians view this as a case of internal disagreements within a movement (Branch, 2006), others contend that the Black Power groups emerged as their own social movement (Berger, 1967, McAdam, 1982).

These different theoretical perspectives allow for at least two readings of Gossett and Page's descriptions of the historical disagreements within the GRM. They could be understood as typical of tensions found within social movements or as the antecedents of the split into a new movement. I designed this study precisely because I do not believe that the historical disagreements described in my interviews with Gossett and Page are sufficient criteria for determining whether or not these groups are part of the GRM. 
The other interviewees did not share Gossett's and Page's opinion. They described their organizations as distinct from the GRM. They offered a variety of reasons for their answers. Affinity's Director Kim L. Hunt, for instance, expressed that she thought Affinity worked on too many issues, and was part of too many social movements, to be considered part of the GRM. She found it difficult to align Affinity with any social movement.

I would have to say that it is becoming less and less true that we see (any one social movement) as our home... But it's just so hard to separate all of these different identities to claim one movement to work in... I can't really say anymore that we are just an LGBT organization. And when you look at where some of our funding is beginning to come from, it is not just LGBT. There's race stuff. There's gender stuff. There's poverty stuff. There's health stuff. Yeah. It's hard to be situated in one place. Which I think makes it messy, too, for communicating. I mean to work and getting those reports just right for funders and others who want to see you situated. I mean, one of our last grants was from an entity that funds reproductive justice work because that's a more expansive movement than many people think it is. Yeah. It's getting tougher.

- $\quad$ Kim L. Hunt, Affinity Executive Director

In my interviews with staff from QEJ and SONG, neither Kenyon Farrow nor Paulina Helm-Hernandez answered the question directly. They did not explicitly say they were distinct from the GRM, but when asked whom they were building a social movement with, they repeatedly omitted mention of the equality organizations and spoke at length about building a social movement with queer liberation organizations. For instance, when Hernandez-Helm was discussing the recent announcement of QEJ's closing, she said:

So much of the love connection (between SONG and) QEJ has been rooted around our shared commitment around racial and economic justice with a particularly analysis and understanding of what economic justice 
actually looks like in our lifetime and what our communities are actually experiencing and what it looks like for queer folks to be part of a transformative economic justice movement.

Hernandez-Helm went on to talk other organizations with which SONG is aligned. These included some of the groups in this study (e.g., ALP, SRLP), and some that are not (including the Esperanza Peace and Justice Center, an Astraea grantee that was eligible to be in the study), but she did not mention a single equality based organization.

You know there are so many amazing organizations we consider to be sort of like our queer left sister organizations, where there is quite a bit of political commitment to not just to keep up with each other's work but to deeply try to understand each other's strategies, tactics, the general trajectory of our work, so we can learn from each other. And so that we can also have the kind of robust networks and coalitions that we need... We definitely see them as our similar closest organizations because we have learned so much from them and because we continually have sought to bring our work even in closer alignment.

Farrow made statements similar to those by Helm-Hernandez, and while quotes like these do not prove that they see themselves as outside of the GRM, it certainly seems likely.

When I asked NQAPIA's Ben de Guzman if he thought the Astraea grantees were part of the GRM or if they were building a new social movement, he changed his answer several times. Initially he considering saying that they were part of a new movement:

You know, there is a part of me that would love nothing more than to own the uniqueness of the moment that we have together as movement building grantees and, you know, fuck everything we've done before. This is something new. And people of color and economic justice and this intersectionality lens is not the norm for the movement. Part of me would love nothing more than to say yes, yes, yes (we are creating a new movement). 
But as he continued to think about it, de Guzman questioned that: "I think that... and this is probably a dumb answer, or at least one that may not be satisfying to you, but I am not sure that I am willing to say that it is either/or." He said that perhaps these groups were part of the GRM and also creating a new movement. However, then he considered whether that was possible, because perhaps the Astraea grantees were too different from the GRM to be part of that movement: "I think that in some ways the vision that animates our groups is radically different than what animates the mainstream LGBT movement. In some ways I do think those visions are very radically different.” De Guzman explained that the GRM's fight for equality was just the minimum of what needs to be done. He referred to fighting for equality as "the floor" and the Astraea grantees' fight for justice as "the ceiling." However, after making that argument, he then questioned his own framework by saying, "they are fighting for the floor and we are fighting for the ceiling, but I think that it's maybe a semantic difference that lets people attach meaning." He then changed his mind again, saying once more that the Astraea grantees were building a new movement while also being part of the GRM. However, he finally landed on a position, deciding that NQAPIA is not part of the mainstream movement:

I think that because our groups are committed to a more intersectional analysis and think that we have to engage other movements in more fundamental ways, I think I am more inclined to fall on the side of we are different (from the GRM). We are different. It is sort of a different animal. I think that if I had to choose, I think I would choose... I think we are different. With that said, I am also trained not to access binaries. [laughs].

It is clear that even though de Guzman answered that the queer liberation organizations are not in the GRM, he was torn. It appears that he really wanted to claim 
that these groups both did and did not belong to the GRM, but perhaps felt that he could not. This may be due to social desirability bias. As I discussed in Chapter 5, I attempted to be attentive to this (in this case, by not offering my own opinion about this question), but I suspect I did not do so sufficiently. I am left with the impression that de Guzman believes that the Astraea groups are part of the GRM while simultaneously building a new social movement.

He was not alone in this opinion. When I asked Rose Pulliam from allgo if they belong in the GRM or comprise a new movement, she replied by saying both. However, she did not change her mind the way de Guzman did; she stood by her answer that it was possible to be both.

I think I believe both things, actually... There is a way in which I think we serve (as the conscience) to some degree to that large movement... But I also believe we are profoundly different... I don't think we are the same. It's my prayer that (GRM) folks figure something out. I think privilege in that movement is too prevalent. And that when (marriage is legal and) privilege has its full privilege, it will go off and enjoy its privilege, as opposed to doing the work. And so I see our work as different and there are pieces of that movement that we are connected to, that resonate with us, that they need us for. And then we have a whole other piece of work to do. A whole other movement. So that's my yes and no answer.

- $\quad$ Rose Pulliam, allgo Co-Director

This "yes and no" answer illustrates the complicated relationships these organizations have with the GRM. NQAPIA and allgo understand that their work locates them in the GRM in some ways, but in other ways they see how they do not fit. Page and Gossett from ALP and SRLP, despite identifying as part of the GRM, articulated how their organizations serve functions that separate them from the majority of that movement. This is also evident in the previous section when I explored their concerns about having 
their work co-opted. Their "us/them" language in those sections potentially contradict, and definitely complicate, their "we are part of the GRM" answers to this question, and evidence the complex relationship of these organizations to the GRM. Even as the leadership from Affinity, QEJ, and SONG located their organizations as outside of the GRM, they also discussed their relationships within that movement. Only Romo offered an unambiguous response when she identified CAR as clearly part of the GRM. (And CAR is also the only organization that meets the criteria I developed, based on Gamson's work, to determine if these organizations are part of the GRM.) The complexities that informed the answers of the other participants similarly informed the rest of the data when I determined that those seven organizations were not part of the GRM. Because I am usually social movement definitions, not dependent upon the participants' answers, I still maintain that these organizations are not part of the GRM. However, their complicated answers are still significant, and are central to the framework I developed (presented in Chapter Nine) for understanding these organizations.

\section{Next steps.}

Having determined that seven of the organizations are not part of the GRM, while one is, my next research question explores what this means about the organizations. Are the seven organizations a separate social movement? Are they a coalition? Are they autonomous organizations acting independently? And what of CAR? How can social movement theory explain its relationship to the GRM? These questions are explored in the next chapter, as I answer my second research question: "What does analyzing these 
organizations through social movement theories reveal about their relationship to one another?" 


\section{Chapter 7: Research Question Two}

\section{Introduction and Overview}

In this chapter, I answer my second research question: "What does analyzing these organizations through social movement theories reveal about their relationship to one another?" My first research question revealed that seven of these eight organizations are distinct from the GRM. Knowing that, however, offers little in terms of insight into what these organizations are or do. My second research question investigated how these seven organizations function. Are these seven organizations merely independent challenging groups isolated from other organizations and movements? Are they a coalition? Or have they have formed their own social movement?

First I explore whether these seven groups have common purposes and a collective identity (hallmarks of social movements), as defined by shared identities, values, goals and grievances. I demonstrate that they share identities as radical, intersectional organizations, share values of justice and liberation, as well as a commitment to community organizing and movement building, share goals of racial and economic justice, and share grievances with the GRM.

Then I explore whether they engage in collective action and structured organization (the other criteria for comprising a social movement). First I examine whether they individually engage in intra-agency structure and collective action, and then analyze whether and how they collectively engage in interagency structure and collective action.After exploring and analyzing my findings from my second research question, this 
chapter concludes by setting up these findings in relationship to my third and final research question.

My analysis explored whether they were autonomous organizations (independent of any social movement or other organizations), if they functioned together as a coalition, or if they constitute a new social movement.

Christiansen (2009) observed that a social movement is neither a stable, powerful body such as a political party, nor a transitory and unorganized entity, such as a mass trend or fad. Rather, a social movement is somewhere in between (Freeman \& Johnson, 1999). Consistent with the working definition I developed in Chapter Two, De la Porta and Dani (2006) maintain that social movements have certain characteristics: groups in social movements engage in battles with clearly identified adversaries; are connected by solid informal networks; and share a clear collective identity. I used the following as my working definition of a social movement: A social movement is a group of people engaged in collective work, consisting of structured activities and organizations, with common goals, grievances, values and purposes. Consequently, in my research I looked for three criteria to determine if these seven organizations constitute a social movement: common purpose and collective identity; collective action; and structure and organization.

\section{Common Purposes and Collective Identity}

\section{Introduction.}

In determining whether these seven groups comprise a distinct social movement, I looked for common purposes and collective identity. McAdam, et al. (2001) explained that all social movements form a collective identity based upon claims, values, and 
grievances shared by the movement's participants. Diani and Bison (2004) distinguished between a social movement and a coalition. They argued that a social movement requires creating and recognizing a connectedness, and brings "a sense of common purpose and shared commitment to a cause, which enables single activists and organizations to regard themselves as inextricably linked to other actors, not necessarily identical but surely compatible, in a broader collective mobilization" (p. 284). Similarly, Tarrow (1998) argued that similar goals and social solidarities drive social movements to engage in collective action.

Consequently, I examined whether these organizations shared similar claims, values, grievances, goals and social solidarities that form a "common purpose and collective identity." My analysis demonstrates that these seven organizations do indeed share common values, solidarities, goals, and grievances. The following section presents my findings and my analysis of those findings simultaneously, rather than dividing them into different sections. Although there were many commonalities, I focus here on those the values, goals, solidarities, and grievances that emerged most saliently from the data.

\section{Shared identity: Intersectional.}

In answering my first research question, I repeatedly invoked black feminism's intersectionality framework to analyze how it applies to these organizations' constituents and beneficiaries, as well as to the issues they emphasize. However, it is important to explore how these organizations invoke that rhetoric themselves, particularly in terms of its role in their shared identity or solidarity. These organizations use the language of intersectionality frequently; nearly every data source included references to 
intersectionality, in mission statements, online videos, and the language the staff used during interviews. Intersectionality is not merely a framework that they use to center their work, as I claimed in Q1; it is so central to how they talk about their work and their organizations, that I contend it is also a shared identity among these groups. They identify as "intersectional organizations." For this reason, it requires additional examination here in Q2.

Most interview participants volunteered their definitions of intersectionality to make sure I understood how they were using the term. Ben deGuzman introduces intersectionality on an individual level and then moves to its policy implications, while Cara Page centers the notion in terms of political and cultural definition:

I think it has a very specific meaning, like, referring to the fact that people have different types of discrimination when they are at the intersection, and the discrimination that they face becomes synergistically higher. So a queer immigrant not only faces worker exploitation because she could be fired for being who she is as someone queer, but if she is also undocumented, she doesn't have access to worker protections that citizens have. So, I think that the intersectional nature of our work means making sure that the policy recommendations that those movements make do not compromise another part of our movement.

- Ben de Guzman, NQAPIA Co-Director

The core value of the Audre Lorde Project is about centering intersections. So what that means is we are holding the nexus - economic, racial, disability justice, language justice - different elements that define who we are both politically and culturally.

- Cara Page, ALP Executive Director

An intersectionality framework informs why these groups do their work and why they were founded. Most of the origin stories of these groups include sections describing the founders' frustration with other organizations' lack of an intersectional approach in 
their work. These organizations were born out of a desire to create a place that centers the intersections of their communities' identities. For instance, Caitlin Breedlove explained that SONG was started by White and Black lesbians in 1993 to do intersectional work, after they were frustrated with White gay activists who refused to engage in work focused on NAFTA, which they did not deem a gay issue. Similarly, Dean Spade described how he named SRLP after Sylvia Rivera, a low-income transgender woman of color, to honor the intersectional lens she demanded of White gay activists, who, in turn, pushed her out of the GRM. Most of the other organizations had similar origin stories. The term "intersectional" was usually explicitly invoked in the telling of those stories, indicating that an intersectional framework is a deliberate part of the groups' identities, from their foundings.

In addition to informing why these organizations do their work, an intersectionality framework influences how they do their work. For example, as they approach their antagonists, they do not isolate homophobia or transphobia as the only issue to combat.

So as an organization we believe that all forms of violence and oppression are inextricably linked to each other. So it's really important to end transphobic discrimination at the Human Resources Administration, at the welfare office. But it's also really important to say, are welfare benefits enough for any people to survive in NYC? How can we change that on a structural level?

- $\quad$ Reina Gossett, SRLP Director of Membership

This intersectional framework also factors into their decisions regarding what populations of people they will work with to build community. Who they reach out to is determined by the desire to work along the intersections of different identities and oppressions. For instance, when Paulina Helm-Hernandez told me how SONG's work 
often focuses on finding "strategic opportunities to build more intersectionality inside of our movement" she offered the following example:

(We) engage and grapple with what it means to be in a multi-racial community, to be in a region that has always pitted, particularly, black and brown folks against each other - to actually be willing to sort of turn that contradiction around to say what is our willingness to actually organize and build together? What's our shared destiny as communities?

- Paulina Helm-Hernandez, SONG Co-Director

It similarly factors into the choices these groups make regarding partner organizations.

Decisions about outside collaborations are determined by the desire to prioritize working with groups that share the value they place upon intersectionality. SRLP's Reina Gossett said this explicitly: "All of the organizations we work with have an intersectional theory of change that seeks to change hearts and minds, behaviors, and have systemic change. I should say with an eye towards liberation." This desire to work with other intersectional organizations signals an important social solidarity. All seven organizations have identified other groups (including the other Astraea Movement Building grantees and others) social solidarity as among those who share this value and with whom they choose to work.

(The people we want to work with are) whoever wants to pay attention to both the intersections of the issues and the intersections of oppression and how we experience it. Whoever is willing at some point to talk about poverty and the impacts of poverty and how that intersects with queerness. To talk about race and how that intersects. I don't know always know who that is. I certainly believe it is some of the organizations who are part of the (Astraea) movements building work.

- $\quad$ Rose Pulliam, allgo Co-Director

This implies that these organizations have embraced what McAdam, et al. (2001) refers to as a shared collective identity, one of the defining characteristics of a social movement. 
It is clear that one collective identity among these organizations is "intersectional groups." Intersectionality is not usually understood to be an identity, but for these groups it is. "Intersectional group" is the language they each use to describe and name themselves. It also the language they use to describe and name each other.

Diani and Bison (2004) theorized that one of the definitions of a social movement is the existence of a collective identity that creates a connectedness between actors and also publicly recognizes that connectedness. By identifying themselves and each other as intersectional organizations, these seven groups share such a collective identity and connectedness. They also share another collective identity, and I turn now to an exploration of this.

\section{Shared values: Radical justice and liberation vs. equality and rights.}

As has been well documented, the defining value of the gay rights movement is “equality” (Conrad, 2009; Duggan, 2003; Farrow, 2012; Hutchinson, 2001; Vaid, 1995). It is also evident in how they brand themselves that "equality" is their primary unifying value and vision. For instance, state-based LGBT advocacy organizations all belong to the "Equality Federation," the campaign for same-sex marriage rights is referred to as "marriage equality," and HRC (the largest LGBT organization) uses the equal sign as its ubiquitous logo. The GRM's utilization of equality rhetoric and its pursuit of equal rights are indisputable.

Consequently, it is significant that the groups in this study do not share this value. They do not embrace equality as their primary value or goal. Five do not even bring up the word equality in their mission statements. Although Affinity and ALP briefly 
mentioned equality as one of their goals, it is listed amidst other values and goals (justice, liberation, etc.) and is not centralized as the dominant value that drives their work.

Instead, these organizations characterize their work as the pursuit of justice and liberation. Most described themselves as "liberation organizations," and all seven described themselves as "social justice organizations." Some also label themselves and these goals and values "radical." Consequently, I will now explore those different concepts, and what each means to these seven groups.

Of the seven organizations examined here, five (allgo, ALP, QEJ, SONG, and SRLP) have mission statements that cite liberation as a value or a goal. In my interviews, when asked to describe the values that drive the work of their group, staff members from those five groups explicitly claimed "liberation" as a primary, defining value. Staff from a sixth organization, Affinity, also claimed to be in pursuit of liberation. Staff from the final organization, NQAPIA, used the word briefly, claiming the organization seeks liberation for its communities, but did not indicate that it was at the heart of their organizational values.

When I asked Affinity's Kim L. Hunt to describe the values that drive the organization's work, she stated: "For a long time now, the LGBT movement has been using the word equality. But it started out being more a discussion about liberation. I kind of hate to use the word equality. I think liberation better describes Affinity." Affinity, allgo, ALP, QEJ, SONG, and SRLP appear to similarly embrace "liberation" as their operating framework, regardless of the particulars of their work. For instance, the goal of liberation anchors SRLP's specific efforts with transgender people. However, the 
liberation framework links SRLP to different claims made by the other groups whose focus is not specifically transgender and gender nonconforming people, but who cite liberation as their primary goal and value. In addition, these organizations use the term in fairly similar ways. My interview participants often define liberation as people's ability people to self-determine their own lives and identities.

Liberation is the word that probably most resonates. And that's that liberation within and the other liberation. Liberation within those who we serve, this notion of liberation for them. And then marching towards that liberation without, for others. Liberation within our greater community and the culture. And that means having the freedom without penalty to express who we are and to ultimately be ourselves. So that they are both living their lives in a way that is a challenge to the system, and also being healthy as they are doing it.

- Rose Pulliam, allgo Co-Director

They refer to liberation as the freedom of everyone, not just certain individuals, to make their own choices. Central to that value is a sense of obligation to liberate each other, which underlies part of the organizations' resistance to the equality movement. This notion of collective responsibility is what separates it from, say, the value of freedom centralized by a libertarian:

I use the word liberation pretty deliberately. Instead of using equality, because, well... you know, I actually really understand and have a lot of empathy and sympathy for people wanting to be in loving relationships that they feel validated and supported in, collectively. But I think that when we have explicitly, more deliberately focused on the framework of liberation, we say that that is actually not good enough. And that one individual family, one individual couple, really can't transform the conditions of our community that are at the core of our survival.

- Paulina Helm-Hernandez, SONG Co-Director

These activists see not only their own groups as liberation organizations, but also see each other's organizations similarly. ALP, for instance, works locally in NYC with QEJ 
and SRLP, and across the country with others "that we know share a political liberatory frame":

Right now, we are working predominantly with other queer and trans people of color organizations that also follow the principal of liberation and work inside of economic and racial justice and how we queer those politics together.

- Cara Page, ALP Executive Director

Affinity, allgo, ALP, QEJ, SONG, and SRLP clearly share this view of their own work and each other's work. They also cited additional liberation organizations (not included in this study) with whom they partner. This is significant because it illustrates the shared values and social solidarities identified by Tarrow (1998) and McAdam (2001) as central characteristics of a social movement. It also aligns with the description of social movements by Snow and Soule (2010) as collectivities acting for the purpose of challenging extant systems of authority in the society in which they are embedded.

There is even clearer consensus about "justice," which was repeatedly referenced by all seven organizations (rather than just six, as with "liberation"). The word can be found in every piece of data from each organization, often multiple times. Sometimes the organizations named justice as a value, often in the phrase "social justice." Most of the mission statements referred to the groups as social justice organizations, and in all seven of the interviews the staff referred to their organizations that way. Other times the word justice was used when describing a goal as the pursuit of "racial justice" or "economic justice," two phrases used frequently to describe the organizations' work. Some of the activists discussed the tactics used in pursuit of justice and how they differ from those tactics used in pursuit of equality. This issue (the relationship between values and tactics) 
is explored in a later section. All the interviews included discussions about the differences between justice-focused and equality-focused organizations. Still, in spite of all these references, it is important to note that "justice" was never specifically defined on its own terms. While its meaning can be inferred from how it was used, justice as a theoretical construct was never specifically defined by anyone independent of comparisons to "equality" or of descriptions of their work.

Perhaps a flaw in my execution of the interview questions accounts for this; I did not think to solicit a concise definition from each participant. However, this still does not explain why an organizing principle so central to these groups is not explicitly defined in their mission statements or online videos. It is possible that the groups assume that word and concept are self-evident. Although I question whether this is a reasonable assumption to make of the general public, it does seem clear from the rhetoric employed by the interview participants that their organizations share a similar understanding of the concept of justice. Certainly their comparisons of "justice" versus "equality" appear to be grounded in shared understandings of those two concepts. They often referenced "justice" as being in direct opposition to "equality." For that reason, it is necessary to explore their analyses of the "equality" framework and how their organizations situate themselves in relationship to it.

Not only do these organizations embrace the values of justice and liberation instead of equality, these values are positioned in an adversarial relationship to equality. These activists are deeply critical of the equality framework. Justice is not merely portrayed as different from equality, but it is characterized as oppositional. In every 
interview, organizational leaders disputed the notion that their organizations primarily sought "equal rights," and each offered extensive and thoughtful criticisms of the concept of "equality." Many shared the same grievances.

Participants expressed their belief that equal rights were important, but not sufficient. Some of them thought that equality was a good starting place, but believe that the fight should be bigger, seeking the broader goals implied by justice:

Those (GRM) groups look at equality as the standard around which success can be measured. And I think we look at equality as the floor and not the ceiling. At the very minimum our community should be treated equally. But to think about justice, to think about liberation, and to think about autonomy for individuals to be able to live their lives in ways that work best for them, that is what our social justice vision is about.

- Ben de Guzman, NQAPIA Co-Director

Others argued that equality is the wrong gauge. They contend that equality can be achieved without receiving any material gains, and it is those material goals that must be pursued:

(You can) look at the last forty or fifty years in the United States and say, "wow, there's been so much work to declare us all equal in law, to say that racism and ableism and sexism are illegal." And yet you've seen the actual conditions of racialized violence, and of the growing apparatuses of criminalization, worsen. You've seen the wealth gap worsen. You've seen women still having enormous paid wage gap. You've seen the attacks on reproductive health worsen.

- Dean Spade, SRLP Founding Director

These activists argue that in order to have meaning in people's lives, in order to obtain and sustain these material changes, equality needs to be accompanied by larger transformations in culture. Without a larger transformation, the rights will not be durable:

We all know that anything that can be legislated can be undone by a million tiny cuts in funding, or changes and rolls back in legislation. Just 
look at what's happened with abortion rights or voting rights. And so you can win equal rights one day and then have it become completely irrelevant.

- Kenyon Farrow, QEJ former Executive Director

Many also offered cultural objections to the equality framework. They critiqued the implicit assumptions embedded in an equality framework when they each asked, “equal to whom?" For some, equality implied "sameness" and the need to conform to dominant social norms. They reject this call to assimilate.

(We at allgo have) this notion that "who is it we are supposed to be equal to?" And what does that say when we are supposed to be like whatever group of people we are talking about. We don't want to be like them. We want to maintain all of our difference in all of its glory. All of the multiple differences in all its glory. And for all of us to be liberated. To be those people we are without penalty. So we would almost never use equality in that way.

- Rose Pulliam, allgo Co-Director

In my experience, in some ways when you focus only on the equality framework, what you are saying is that 'we want to be equal too.' And my question is always, 'we want to be equal to what?' To straight married people? That's what we want to be equal to? We want to be equal to heterosexual or heteronormative norms of what it means to be married?

- Paulina Helm-Hernandez, SONG Co-Director

This rejection of assimilation is the rejection of what Duggan (2003) called the homonormativity of dominant gay and lesbian culture and politics. Homonormativity, Duggan argued, does not contest heterosexist structures and values but instead maintains and seeks access to them. Pulliam and Helm-Hernandez clearly break with the dominant gay and lesbian culture when they question and reject this homonormativity. They are not alone. Others similarly reject the GRM's homonormativity when they ask their own versions of "equal to whom?" by interrogating the actual systems into which equality is 
being sought or granted. Affinity’s Kim L. Hunt said, “To fight for equality you have to have an underlying assumption of: equal to what? And the system that you are trying to be equal in, is it a just system to begin with? And it's not." Farrow and Pulliam expanded upon this same sentiment:

There is also the question of "Are we talking about getting rights to help with assimilation into systems that are violent and destructive and problematic?" The equality framework is the most egregious (framework) of them all. It's an uncritical framework that presumes that it is possible to be politically or legally equal, and I don't think that it is. Not under capitalism... I think it is the least critical of them all because it takes the world as it is, and just demands access into it.

- Kenyon Farrow, QEJ former Executive Director

We don't talk about equality really. Or when we talk about equality, we say fair isn't equal and equal isn't fair. That framing is problematic for us because there is no legal system in the world that is going to make us equal.

- $\quad$ Rose Pulliam, allgo Co-Director

Most participants shared some version of this idea that the systems are flawed, rendering equal access to them not a victory. Instead, they argue, we should be looking for solutions that lead to larger structural transformations. They see victory as defined not by achieving equal rights, but by the improvement in the material conditions of people's lives.

Certain kinds of visible inclusion practices don't result in material gains... So you've got to ask: what is it about legal equality frameworks that don't deliver the goods on the ground? I want us to move away from a conversation that's solely about whether we can get the law to say good things about us, to (instead discussing) "how do we actually resolve material conditions?"

- Dean Spade, SRLP Founding Director 
To me the question of "justice" demands a critical look past assimilation and past policy gains to how do people actually live in certain conditions? Do these conditions promote their emotional, economic, spiritual, physical well-being? And as we are thinking about whatever equal rights we are trying to achieve, who gets lost? Who gets thrown under the bus, directly or indirectly? I think a "justice" framework requires that kind of dynamic and constant tension in conversation because there isn't a pot at the end of the rainbow that's ever won. Hopefully it leads to some kind of movement where there is an actual transformation in society in terms of wealth and how people's actual living conditions and material well-being actually looks and feels. But until then, I think the justice framework demands a certain kind of ongoing critical engagement. It does not mean 'oh you won some policy and now we can all go home' which is what I think the 'rights' framework often does.

- Kenyon Farrow, QEJ former Executive Director

These comments about "equality" present a clearer understanding of how these groups conceptualize "justice." For Hunt, Farrow, Pulliam, and Spade, justice is about altering the situations of people's day-to-day lives in concrete ways, "the goods on the ground" as Spade phrases it. It is about changing macro systems to improve the material conditions of the people who interact with them. It is also, according to Farrow, an ongoing process that requires constant attention and effort to keep realizing, rather than the few one-time-and-then-it's-legal victories needed to change a policy in the pursuit of equal rights. Additionally, Hunt's simple question ("And the system that you are trying to be equal in, is it a just system to begin with?"), which requires the interrogation of the political, legal, and cultural systems which structure American life, is central to this vision of justice. The data illustrates that these organizations have a shared (or at least very similar) understanding of justice: the creation or redesign of basic American structures and systems so they provide equitable resources to all and fundamentally alter and improve the material conditions of those currently most marginalized and vulnerable. 
The equality framework does not merely ignore the larger structural and material changes demanded by these activists, it actually hinders it. Several of the activists interviewed shared with me stories of how their work has been criticized and hindered by gay and lesbian activists or organizations who claimed that fighting for anything other than single-issue equality campaigns detracts energy and resources away from "the cause."

And one of the things that we have also seen has been a lot of push back and backlash, from folks in the LGBT community saying, "Why are you working on immigration? This is not a queer issue. This is not at all related to LGBT equality."

- Paulina Helm-Hernandez, SONG Co-Director

The equality framework is viewed by the participants in this study as the narrowing of what used to be a much more expansive vision in the LGBT movement. Duggan described homonormativity as the "sexual politics of neoliberalism" and the people I interviewed expressed dismay that 30 years of neoliberal policies have constricted the ability of activists to imagine or dream. The groups identify themselves as different from the current GRM politics that, confined in their aspirations to seeking claims of equality, have shed the liberationist goals of earlier years. They repeatedly characterized themselves as more aligned with what once was understood as a larger fight for justice and liberation and the creation of a new world, rather than what has now shrunk to a movement seeking equal rights and inclusion.

Being respectful of the extraordinary (equality) work that has happened in the last 35 years is not the same thing as it reflecting my values. I'm not sorry that we can now enter the military, and I'm not sorry that we can marry. But frankly, I come from a moment in time with a radical vision that never made marriage or the military my criteria of success. I didn't want us to have wars, I didn't want us to have armies, and I did not want to register my relationship with the state. So are those rights victories? 
They are. Were those policies discriminatory? Yes they were. Were they my idea of what it was we were trying to build as a liberation movement for queer people? No, it wasn't at all.

- Amber Hollibaugh, Former QEJ Executive Director

When Hollibaugh says, "I come from a moment in time and with a radical vision that never made marriage or the military my criteria of success," she simultaneously situates herself as different from the GRM and connects her work to a lineage with the more radical groups formed in the 1960s seeking larger social change. Others in this study similarly defined themselves both in opposition to current politics and in alignment with prior radical goals.

Significantly, they do not believe they are taking up this mantle alone. They understand each other's organizations to share these same radical values and goals that connect them all to the gay liberation groups of the New Left.

(The types of groups in this study) are actually the people who are carrying on the legacy of what happened at Stonewall and pushing back against the idea that a non-discrimination bill is the way to create the most amounts of freedom for LGBT, queer, and trans people. - Reina Gossett, SRLP Director of Membership

We are a part of a political legacy and memory that is so far and wide and deep inside of these movements, but it has been forgotten. So we are pushing back on memory saying, this is not, we are not heading for status quo, we are not heading for equality, we are going for something much deeper and much wider because we have, this is what we deserve and what we are a part of.

- Cara Page, ALP Executive Director

They see these goals and values as shared not only by each other, but also by organizations that are not included in this study. They situate their work, and the work of the other Astraea grantees, as representative of a broader re-emergence of radical politics 
among many newer organizations. They use the word "radical" frequently to describe these renewed political orientations.

It also just kind of happened that QEJ, ALP, SONG, FIERCE, etc., a range of these progressive organizations all kind of sprung up around the same time, more or less within five years of each other, that were kind of radical queer organizations that were in some respects responding to what was happening in terms of 'gay and lesbian rights' work.

- Kenyon Farrow, QEJ former Executive Director

We are building with other radical and transformative organizers in the larger movement - not just necessarily queer but also racial justice, immigrant, economic justice, those movements that are really looking to make a systemic change on how we are moving our lives and our safety.

- Cara Page, ALP Executive Director

Although most of the organizations in this study used the word "radical," their definitions of radical, while never contradictory, were not always identical. For Affinity, the mere composition of their membership is itself "radical."

When Affinity was created, and when some of these other organizations were created, it was a radical move, clearly. It was a radical move to create spaces where queer and trans people of color and other marginalized groups under the rainbow could find space and build community and identify the nuances of these larger issues, and identify for themselves the issues that were important to them and impacting their day to day lives. That was clearly a radical move. I think there is still some radicalness around that. Even to talk about race and gender identity within the LGBT community is still a little bit risqué because you alienate those equality groups - the national organizations - that are not, don't feel to me like they are ready to have that discussion still.

- Kim L. Hunt, Affinity Executive Director

In this analysis, allowing queer and trans people of color to build their own community and establish their own agenda (rather than having it decided by white gays and lesbians), is radical. Other organizations used the word radical as a way of distinguishing between reforming systems and transforming them. For instance, the mission statements of both 
allgo and QEJ describe as "radical" the transformation of macro systems and policies that will be required in order to achieve their goals of liberation and justice.

Numerous scholars have observed that the equality organizations' neoliberal politics resulted in a homonormative movement that it doesn't even bother to fake an interest in combating racial or economic injustice (e.g., Duggan, 2002, 2003; Richardson, 2005; Vieira, 2013). By building their organizations around the values of radical liberation and justice, these seven groups clearly distinguish themselves from the politics of homonormativity embodied by the equality organizations. More importantly, for this study, these shared values contribute to the solidification of a collective identity. These groups unanimously share the value of justice, and to a large extent, liberation; they share grievances about the equality framework, and they share social solidarity as radical organizations. These facts, along with their shared identities as intersectional organizations, establish the common values and collective identity that is central to the definition of a social movement.

In addition to shared values, organizations in a social movement must share common goals. The next section explores other emergent themes related to the question of these organizations' common goals.

\section{Shared goals: Racial, economic, and "Trickle-Up" social justice.}

These seven organizations state that they pursue programmatic work anchored by and reflective of the values described above. Their programmatic work covers a range of issues, some of which are unique to each individual organization. However they share a focus on immigration, criminal justice, and health and social services. These shared aims 
are significant because they demonstrate similar goals, one of the hallmarks of a social movement. These targets and goals, though covering a broad range of specific issues, are reflective of certain shared priorities. These organizations' programmatic work (on immigration, criminal justice, and social services, as well the other unique work they each do that is not shared by all the groups) is reflective of the way they prioritize racial justice and economic justice.

In addition to those shared goals that have already been described, these groups pursue other goals informed by this shared commitment to racial and economic justice. Many work for community wellness and health. Several focus on community safety and anti-violence. Most discuss fighting for sexual freedom. All discuss the ways in which they celebrate and affirm all identities and fight for self-determination. The common thread among all these goals is that each issue is presented through an analysis explicitly linked to racial and economic justice. All of their work reflects a common race and class analysis, which I explore in the following paragraphs.

The price of a recession is that we're killed on the streets, we're not let into shelters, our children have no health insurance. Those are the price of this kind of economy out of control. And that's a queer issue. It's a primary issue if you live with almost no work, if you live in a place where there's no labor movement that recognizes you as an LGBT person or defends you in your work site. That doesn't talk about workplace harassment. Those are our issues and those are not less LGBT than marriage and "don't ask, don't tell."

- Amber Hollibaugh, Former QEJ Executive Director

My data contains numerous references, such as this one by Hollibaugh, to the economy and to racial injustice. These organizations prioritize these kinds of issues not out of the desire to be good allies who show solidarity to other social movements, but 
because these are the issues their members wrestle with. Each of the activists I

interviewed believes that this commitment to racial and economic justice distinguishes them from the GRM:

It was so painful to me even coming out of the receptions (at a GRM conference) and to go into one of the bathrooms and to be like "Wow, people just really don't give a shit. People really just pee on the floor, leave their trash everywhere." And it's because somebody brown that looks like my grandmother is going to have to come here and clean it behind you. And that's what we are looking at. And that's the reality. And there is no class analysis incubator in these organizations to help these people think about these things. If we are really honest, they're like "its so great to be gay"... but then let's pretend that nobody is going to have to clean up after us. Let's pretend like that's not happening because we don't have to see them. They are hotel workers. And they're somehow so different from us. And I think (the agenda) is so symbolic of that as well. - Paulina Helm-Hernandez, SONG Co-Director

Helm-Hernandez not only voices her frustration with the GRM, but also illustrates how race and class analyses result in a particular focus of concern. In this quote, HelmHernandez's concern is focused on the brown, elderly hotel worker (presumably an immigrant) who must clean up the mess. Her concern focuses more on her than on the (presumably white and affluent) gay activists whose celebration caused the mess. HelmHernandez has centered her focus on the least powerful person in this story. This choice to focus on the least powerful is shared by all seven organizations in all of their work.

Those who face the most severe consequences of violence and discrimination should be the priority of movements against discrimination... (Our goal is) to participate in the larger movement for racial, social, and economic justice that includes gender liberation and prioritizes the issues of those most affected by the systems of oppression under which we live.

- Sylvia Rivera Law Project, Mission Statement 
It's very difficult to find an organization like QEJ where you engage with the hard issues, you really take on issues like economic justice, you take on issues like HIV status, and you take on the question of shelter work and homelessness. And you say, "Come here, come think with us, come help build a very different alignment of priorities in an LGBTQ imagination."

- Amber Hollibaugh, Former QEJ Executive Director

Audre Lorde may have famously said, "there is no hierarchy of oppressions" but these seven organizations clearly believe in a hierarchy of the oppressed. They believe that people who experience a multitude of oppressions must be prioritized over those who experience fewer forms of oppression. Understanding this is crucial to understanding these groups.

SRLP founder Dean Spade described this as "trickle-up social justice." Spade argues that for too long, social movements have engaged in the reverse: "trickle-down justice." They prioritize the most privileged of their movement, and assume that advances made on their behalf would benefit all of their constituents.

One of the ways of thinking about social change is: let's get the few most charismatic people, the people who the most look like what society already thinks are good people, and have a few really spectacular cases, maybe some New York Times article about them, and people will think we're good and like us and perhaps we will make an advance for everyone. It turns out that doesn't really work.

- Dean Spade, SRLP Founding Director

Spade argues that this has failed because the solutions that benefit the most privileged segment of a marginalized group often end up not helping those below them. Worse, these solutions frequently stigmatize further those people on the bottom. Spade maintains that the reverse strategy is needed. By prioritizing the needs of those at the bottom of the economic or social ladder, resulting solutions will benefit everyone above them. 
And so the idea of trickle-up social justice is that we should actually ethically start with those who are facing the worse conditions, who are most losing their lives: those people in prisons and immigration facilities and experiencing poverty and homelessness. We should start by figuring out how to solve the problem for them and inevitably, that will solve the problem for everyone. But it's not the reverse. And so that's part of the idea - that's really a critique of the gay and lesbian rights framework that has really taken up the strategy of choosing a few charismatic, white couples and having that be the image of what an anti-homophobic framework is. And that really hasn't worked out for people on the bottom.

- Dean Spade, SRLP Founding Director

Organizations provided numerous examples of how they deliberately employed this "trickle-up social justice" framework, whether or not they used Spade's specific phrase. Interview participants repeatedly referenced how they prioritized the needs of the most marginalized queer people over those of their more privileged peers. Some of them stated this philosophy outright, such as ALP's Cara Page: “We are creating a liberation movement that is centering people of color and trans and queer leadership... taking the most marginalized and centering our relationship to systems of state that are controlling our bodies and lives." Others conveyed the same values in sarcastic quips, such as SONG's Paulina Helm-Hernandez's "I have not heard a particularly transformative idea of how if we win same sex marriage, the most vulnerable people in our community will be lifted up as well."

This decision to pursue racial and economic justice as a part of their "trickle-up social justice" framework constitutes a shared value and similar goal, both of which are markers of a social movement. It also represents a shared grievance, with the GRM for its focus on the most privileged, another indicator of belonging to the same movement. 


\section{Shared grievance: Marriage.}

Marriage in the $21^{\text {st }}$ Century has been, far and away, the main priority of the GRM organizations. When I compared the targets of influence in my first research question, I noted that although their positions on marriage varied, none of the organizations in my study have prioritized marriage equality work. This is an important commonality among them and an important distinction from the GRM organizations. However, the issue of marriage is significant to this study beyond the issue of targets of influence. All of these groups have critiques about how the marriage campaigns have unfolded. In fact, marriage came up consistently throughout all of my interviews. Even when the questions I asked had nothing to do with marriage, inevitably the interviewee would end up referencing their frustrations with the GRM's focus on marriage. These critiques are so significant that I contend they comprise a shared grievance, and are thus relevant to the issue of collective identity.

Affinity and NQAPIA were the only two groups that supported the marriage campaigns in their communities. It was not a high priority for either of those organizations, and they did minimal work on it. Ben de Guzman barely referenced marriage in my interview with him about NQAPIA's work. And when he did, he voiced frustration with the parallels he saw between the emphasis on marriage in the LGBT movement and the emphasis on bi-national couples in LGBT immigration work. Affinity also publicly insisted that the GRM organizations not prioritize marriage equality over other issues impacting the communities they serve, such as poverty. Indeed, they supported marriage based more on their concerns about poverty than on civil rights. 
For us, it wasn't just about the sanctity of marriage to be involved in this battle. It was really more about being a vehicle of economic security for vulnerable families. Because right now marriage is still the most resilient vehicle we have for recognizing families and for making sure that there are benefits and rights that come to surviving partners, for example, children in homes where the couple is married, and that kind of thing. So that was more what it was about for Affinity.

- Kim L. Hunt, Affinity Executive Director

While Affinity and NQAPIA supported, however limitedly, the GRM's marriage equality campaigns, ALP and QEJ actively challenged these campaigns. Fifteen years ago, ALP was the first LGBT organization to release a public statement that looked critically at the goal of marriage, and in 2006 QEJ convened leaders from across the country for a weekend of drafting a statement criticizing the marriage campaigns, which hundreds of activists and scholars signed onto and released widely.

I think that the baseline was that everyone (who drafted the document) was certainly concerned that this had become the crown jewel of movement issues for LGBT folks and so that was the lynch pin there. And then there were people who felt that way, and people who had more of a radical feminist perspective on the history of marriage and capital and subjugation of women, and others who critiqued the neoliberal agenda that marriage served, and others who were concerned that marriage failed to protect most queer families, you know, those kinds of issues. So the document really took a lot of the ideas that we all discussed that weekend... And hundreds of people signed it and it had a major impact. People to this day quote it or cite it as a kind of grounding for a different way forward.

- Kenyon Farrow, QEJ former Executive Director

Both ALP and QEJ supported access to marriage as a matter of fairness but questioned attaching economic privileges to marriage in the first place. Both organizations questioned the need for relationships to be defined by the government, and discussed the many ways that queer people build families in structures other than non- 
conjugal couples. They urged the GRM to focus on securing protections for all families and strengthening the social safety net, instead of counting on marriage to provide benefits for families.

In the years following the release of those two documents, the organizations continued to interrogate and push the marriage equality work of the GRM. In addition, both ALP and QEJ framed their public grievances with the marriage equality campaigns through explicitly intersectional lenses. Their analysis of marriage is rooted in their work with, and understandings of, a range of other social justice movements, including the civil rights movement, the immigrant rights movement, and the women's movement. For instance, ALP's Trishala Deb filtered her critique of marriage through the lens of being a queer immigrant: "As LGBTST immigrants, we can see through the myth of the nuclear family - that we survive through extended families and families of choice, LGBTST and heterosexual immigrants alike." QEJ's Kenyon Farrow made related comments when he unfavorably compared the marriage campaigns to the civil rights movement:

A lot of times, gay marriage advocates will say about "Loving vs. Virginia," the case that ended the ban on interracial marriages, stuff like "well that was won by the civil rights movement and therefore we have the right to fight for our own kind of marriages." But "Loving vs. Virginia" was actually a secondary byproduct of this larger structure around racial injustice and inequality. It wasn't like the civil rights movement took that up as the main issue. It came out of everything else that had been happening. And I feel like the LGBT movement has gotten it backwards. Instead of, like in the civil rights movement, marriage falling under this big umbrella of everything else that is fought for, instead now it's that everything else should fall under this umbrella of marriage. Now every issue facing queer people has been reduced to being about same-sex partners. And I think that's ridiculous.

As a result of these analyses, ALP and QEJ worked to influence the GRM, with whom it 
had clear grievances about marriage.

For the remaining organizations, allgo, SONG, and SRLP, marriage has not been part of their programmatic work one way or another. These groups understand that some of their members care about the right to get married, and the organizations support that right. But they have not focused their organizational work on securing it. In fact, the websites for these three organizations do not even mention marriage. However, the organizations' leaders offered critiques of the marriage equality campaigns. And while they have shared these analyses publicly, they have not invested resources in targeting the GRM about them.

One common thread of these organizations' critiques is questioning the GRM's assumption that marriage is enough. They argue that marriage might be nice, but it will not provide the liberation or justice needed to resolve their daily struggles to survive.

It's complicated for me because I am married. Very happily married. And I am also really aware that while I may be very happily married, my marriage isn't going to liberate anybody. My marriage isn't going to lift anybody out of poverty. My marriage isn't going to stop somebody from being killed and raped in the streets. My marriage isn't going to automatically give healthcare and wellness care to our entire community who do not have access to it.

- Paulina Helm-Hernandez, SONG Co-Director

Our work is on behalf of and with the most disenfranchised. Our issues are muddy. And the issues for the equality groups are generally fairly clean. And what I mean by that is you get marriage, we get it on the books, and for you, the job is done. And for us, that's half an answer... And when we talk about 'marriage equality', that framing is in some ways really objectionable for folks from allgo's perspective because it doesn't include an intersectional analysis. Frankly, we talk about marriage equality as a last frontier for middle class, rich, gay, white men. They get marriage equality, maybe they will be equal. But it won't make us equal. So that 
framing of equality at this stage, in particular, is troubling and problematic for us.

- Rose Pulliam, allgo Co-Director

This issue raised by Pulliam, questioning who benefits from marriage, was also raised by many of the organizations. They argue that it was white, affluent gays and lesbians who made marriage laws the primary goal for the GRM.

And because, okay some of us can now get married but what does that mean for our livelihood? Because many of us are still getting murdered as trans women of color, from Harlem to Baltimore to the global south. Many of us are homeless. Many of us are unemployed. What about our communities?

- Cara Page, ALP Executive Director

Most of these people pushing for marriage actually already have health insurance, they have lawyers, they have all of those things, they are not the people in our country who are hurting financially. They have most of their basic needs met. They just want moral approval.

- Kenyon Farrow, QEJ former Executive Director

Comments like these lay bare important class and race tensions between LGBT organizations. This grievance is shared by all seven organizations and connects them in an important way. Beyond demonstrating a shared grievance, and thus evidencing another benchmark of social movements, it also offers another example of how the value of "trickle-up social justice" is shared by these organizations. For these groups, marriage is not an issue that provides liberation for all, because it does not benefit anyone but the most privileged.

We have to have a willingness to not be so defensive about marriage because of our own relationships, because of our own personal connection to it, and actually crack open the question that nobody should actually have to be married to have benefits. Nobody should have to be married to be validated. Nobody should have to be married in order to have a dignified death... We have to have a shared stake in each other's survival, 
and see the limitations of saying that the backbone of the collective safety net will be through couple-hood only.

- Paulina Helm-Hernandez, SONG Co-Director

Others argued that this focus on couple-hood has been executed in a way that not only

excludes other family forms, but also actually publicly denigrates them.

It's happening at a particular moment when most people aren't even getting married. And rather than shifting the conversation to how unmarried people should be able to make determinations about their families, how women and single mothers need protection, they just picked up that gay people should be allowed to get married. Which is sort of counter-intuitive. And the argument for gay marriage presumes all of this stuff that is really conservative and right-wing about the moralistic notions about marriage... That movement, despite what it says about wanting the $1,000+$ legal rights that come with marriage, what it really is about is that marriage gives kind of a moral absolution of their relationships.

- Kenyon Farrow, QEJ former Executive Director

Finally, many groups discussed how the marriage equality campaign has impacted

them specifically, as social justice organizations. The most consistently voiced comments described how the issue of gay marriage has diverted funds from other social justice work and from their organizations.

Well the gay marriage fight, it's just sucked a lot of resources out of other kinds of work. There are just some foundations that that's just what they are going to fund. If you're not talking marriage, you're not getting any money.

- Kenyon Farrow, QEJ former Executive Director

Farrow is not alone; all of my interview participants talked about how hard it is to raise money from LGBT foundations because those foundations have prioritized marriage. LGBT funders do not value work about immigration or welfare. Consequently, the groups in my study often have difficulty even applying for grants because the funding 
dockets of LGBT foundations often do not cover the type of work being done by these groups.

Because of my relationship to QEJ, and the fact that the announcement of its closing happened around the time I was conducting interviews, several people cited QEJ's closing as an illustration of their point about resources that were diverted to marriage.

You know was really interesting to be at this expensive (GRM) conference while at the same time one of our most beloved sister organizations, QEJ, is also closing its doors. To me it is so symbolic of the political moment that we are in and the priorities. Because one of the realities is that QEJ has always been the main organization to ask "what about our folks in poverty? Where are they at in this leadership?" It's been really hard to watch this idea of "DOMA was repealed and so now we can get married, we are all a little bit freer," and at the same time QEJ is closing its doors because it wasn't able to secure the funding that it needed to survive. And that wasn't by lack of trying or lack of resiliency. But literally because the LGBT funding sector decided that their work was not priority.

- Paulina Helm-Hernandez, SONG Co-Director

Helm-Hernandez was very clear in her belief that the focus on marriage is the reason that other issues have been ignored and defunded. She clearly shares the grievances of others:

It has just been, not just crushing and heartbreaking on a personal level because I care deeply about QEJ. But also, as a movement person, what it actually signifies is that there's enough money to make this glossy marriage stuff, but there's no money to sustain work by organizations that are critical to lifting our LGBT folks out of poverty, that are critical in shaping the story about what is really happening in our communities. The contradiction is huge to me. At this conference, I got handed, I don't even know, like, ten different graphs and maps about progress we are making on marriage. And nowhere in that equation does it even acknowledge that in order for this to happen and be the only priority, at what expense did it come? And to me, the closing of QEJ, that's the expense. That's the cost of focusing only on a narrow demand of same sex marriage. And what other costs are coming next? 
In addition to the issue of funding, participants raised numerous comments about how the marriage campaigns have impeded their work in other ways. Gay marriage has shifted the cultural landscape, shaping and narrowing the public imagination of LGBT lives and issues.

What it's also done that's been a challenge is that it has created this narrative for straight people, that "oh, the gays just want marriage"... And so they don't reach out to us to build coalitions on other issues; issues that we actually care about. So queer organizations that are doing other kinds of social justice work, they then also have to educate people who would be their allies, because marriage has just sucked up all of the air out of the room.

- Kenyon Farrow, QEJ former Executive Director

ALP's Cara Page explained that the dynamic described above by Farrow is not

limited to straight allies. She discussed how the role of the queer liberation groups now is to work together to remind LGBT communities of a whole host of issues rendered

invisible by marriage, and to broaden the agenda and imagination of activists:

We are doing a lot of damage control because marriage equality created this massive misunderstanding of what queer and trans liberation is. And unfortunately, those of us that were talking about poverty, homelessness, the medical industrial complex, just got rolled in this tidal wave. Marriage became the priority. It completely de-funded our resources and diffused our movement in a very dangerous way. Now we are left to pick up the pieces and re-guide and re-direct people and remind them where we were heading. We lost, what, ten years maybe? We are accelerating our work around immigrant rights and justice because we're behind. But we had to pull people back onto the train and say, "this is the freedom ride we are taking." Marriage took us way off course. But now it's time for us to change and transform and again radicalize the work. And we're still dealing with what we have lost. We are watching QEJ close because the marriage equality movement took us in a different direction and completely diffused the impact that many of us cumulatively were building. So we are trying to re-build the brick and mortar while we know the foundation was already laid. We are just trying to re-build it quickly so that we can keep going. 
Marriage has become part of a homonormative politics of distraction. These politics, which seek access to heterosexist structures (Duggan, 2002), have moved LGBT activism away from a radical agenda. This radical agenda, rooted in the values of the New Left gay liberationists, and shared by the organizations in this study, is the "very different alignment of priorities in an LGBTQ imagination” that QEJ's Hollibaugh referenced. ALP's Page argues that the prioritization of marriage, and the homonormative agenda it represents, has dampened the creative and imaginative possibilities of queer activism. And she is clear about her desire, shared by others in this study, to redirect focus away from the distractions of marriage and back towards this different, more radical, vision.

As the last several pages illustrate, the same-sex marriage campaigns have had tremendous impact on all the organizations in this study for multiple reasons. Obviously, it illustrates a shared grievance among the organizations; they each discussed it at great length, expressing tremendous rage and frustration. This is important because shared grievances are a hallmark of social movements. This issue helps solidify among these organizations the social solidarities that define a social movement. In addition, for the very reasons explained in those grievances, the issue of same-sex marriage proved to be a huge wedge between many LGBT organizations. Longstanding tensions in the movement and disagreements dating back to the 1950s about values, goals, priorities, and tactics, were highlighted and exacerbated by same-sex marriage. If indeed a new social movement has been created, gay marriage may very well have been responsible for it. 
Marriage is a perfect illustration of the politics of equality and access. These seven organizations see those equality politics (represented by the marriage campaigns), as standing in stark contrast to their own politics of justice and liberation. The following quote by SONG's Helm-Hernandez beautifully articulates how her organization's liberation-centered politics and values differ from those represented by the marriage campaigns.

In L.A., some of the women's prisons were making tactical choices to allow lesbian couples to actually be in the same cell, together. It was explicitly because it actually decreased complaining or organizing against prison conditions by folks who were incarcerated, because they went from being individuals inside of a prison where they were actually collectively worried about what was happening, but when they allowed people to bunk together, people became more like, "I'm good. Me and my partner are good." And like, "We're so worried about each other's safety in such a hostile environment that forget everybody else." And I just think it's such an interesting parallel. A homophobic, patriarchal institution like the prison system, that comes out of the legacy of slavery and policing and surveillance, is saying "You and your lover can stay together so that you are actually more worried about her safety than anybody else's safety here." That's one reason why I struggle with marriage and the equality framework it represents, because it continuously calls us to a smaller "we" versus the broader "we."

This story by Helm-Hernandez vividly illustrates Duggan's (2002) argument that the politics of homonormativity privilege domesticity and privacy over engaging in radical social change or even critiquing heteronormativity.

\section{Shared value: Organizing and movement building.}

As these groups engage in radical social change, they prioritize mobilizing community members and building a base of activists. All seven groups discussed how much they value grassroots work and community organizing. They recognize how direct 
services and advocacy are important and can help individual people, but they do not think that larger change can result from direct services, as SRLP's Reina Gossett stated directly: "We think that legal services and legal strategies are important and have their place but are not necessarily the central way to change policy, to changes structures, to change people's behaviors and their hearts and minds." Similarly, ALP's Cara Page explained ALP did not start out prioritizing community organizing, but evolved from providing direct services into an organizing center "because we inherently felt that until we are organizing and changing the systems, we can't rely on the systems to provide for our communities." Consequently, these groups see grassroots organizing and movement building as fundamental to their work, and most state this in their mission statements. They do not believe that even policy wins (i.e., successfully changing laws or government policies) are sufficient social change.

For (GRM groups), policy wins are goal completed. And for us, policy wins are not goal completed because even with policy wins, given the oppression that folks at the intersections experience, how those policy wins will be implemented on behalf of a trans sex worker is very different than how those policy wins will be implemented on behalf of your white gay lawyer.

- Rose Pulliam, allgo Co-Director

Pulliam's quote reflects an understanding of policy (and the limitations of policy wins) shared by all the organizations. They believe that policy wins alone are not enough because what is needed is material changes in people's lives. They do not believe that policy produces these changes, but they do believe that such changes can be accomplished through social movements. 
Those promises of legal equality don't actually deliver what we need. And to actually get what we need, it's really grassroots struggle that's been what's ever won anything meaningful in terms of material change in the US. And so I think that question of how can we turn our attention away from just trying get our names on hate crimes laws or our names on antidiscrimination laws that aren't going to deliver the goods, towards actually building meaningful strategies for dismantling criminal and imprisonment regimes, for getting rid of the violent border regimes that we have, and for actually readdressing poverty.

- Dean Spade, SRLP Founding Director

Nevertheless, most of these organizations have done some degree of lobbying. As noted in the previous chapter, Affinity and NQAPIA prioritize lobbying and advocacy work. NQAPIA even sees lobbying as a form of movement building. Although it is alone in that position, the other six organizations do share with NAQPIA an understanding that advocacy and lobbying in pursuit of policy victories is not mutually exclusive from movement building. This is a relatively recent understanding. QEJ's Kenyon Farrow shared how, in his work coordinating the "Building A Queer Left" teleconferences, he deliberately tried to address the resistance to policy work that has historically existed in some of the movement-building organizations.

Part of what I was trying to do was build a strategy that would connect (policy and movement-building)... because they are just strategies and not necessarily mutually exclusive. So one of the things I developed were doing these monthly calls where we would have larger national institutions that were focused more on the public policy end and also folks who were doing the organizing on the ground. I wanted to have people be able to talk to each other about their work and get past this kind of "Oh if you are doing policy then you can't be engaged or you are somehow anti a movement- building grassroots base building strategy," but to think about them as complimentary. There is some value for people who are working on policy in DC or NY to understand the work that people are doing on the ground; and also for the grassroots organizations to understand what is actually happening nationally... So it became a way to kind of unite these 
kind of ideological factions, to actually start talking to each other and think strategically on how to build together.

Farrow also explained that he sees policy advocacy as a potential bridge into movement building. He argued that movement-building organizations could then engage people who become engaged in activism about a particular policy. Through political education and trainings about community organizing skills, people who were once only excited about a specific issue can become involved in broader social justice organizing. Other activists shared similar perspectives during our interviews.

The activists I interviewed believe that the way to achieve policies that benefit queer people who are people of color, immigrants, transgender people, and/or lowincome is to organize them when they come in for services, build power through base building, and then connect advocacy to those community organizing efforts. They believe that their communities should be involved in each of those stages, as illustrated by ALP's Mission Statement: "Services and organizing efforts are most successful when they involve the communities served." All seven organizations provide services, and they share ALP's approach to service provision. They do this because they believe it will be effective, and because it reflects their values:

In terms of doing organizing and advocacy, justice comes out of a philosophy that people who are most affected by issues should be engaged in helping shift how those issues get framed, and what the actual solutions are... It is working with them to figure out what are the issues they want to work on. And it's about then building that base and connecting them to other folks who are like them... And using that as a strategy to then build power. And your goal could be a policy win, right? There's nothing wrong about that.

- Kenyon Farrow, QEJ former Executive Director 
It is important, however, to understand that these organizations do not merely view community organizing as a strategy to achieve better policy change. They actually believe movement building is more important than policy advocacy; building a base builds power.

(I ask) the mainstream LGBT movement, "Are we committed to building power that would make actual, transformative change, or are we going to just be focused on individual policy change that would affect the most privileged people in our community?"

- Caitlin Breedlove, SONG Co-Director

They believe that campaigns focused on specific policies are not enough to build a movement. Building a movement requires long-term investment in community members. It requires that community members develop a collective identity as part of something bigger than just themselves or just a single campaign. To do this, community members have to believe that they are leaders with ownership of the organization. This sense of community must continue beyond advocacy on any specific policy.

I often hear our members saying, "You know in every part of my life, there is no justice. I feel like I have almost no control. This organization is a place where I have justice in my life, I can count on it, and I know what we're doing in SONG, I know what we're working on, I know what our agreements are, I know what I'm struggling with and it's what keeps me grounded." That's what makes people stay in organizing for life. And that's what we miss in mainstream LGBT politics (where) the focus has been policy wins, they've been very singular.

- Caitlin Breedlove, SONG Co-Director

These long-term engagements create relationships that are deeper than those created during advocacy on a specific policy or lobbying about a specific bill. Community power is developed through sustained engagement with groups over the long haul, and persevering in that commitment despite policy losses or personal differences. 
I think in order to really think about organizing, we have to go to that question of "Why groups?" and think about what's possible as a group that's not possible when we're an email list, that's not possible when we're a social network. Like what's possible when we're actually taking on issues, campaigns, and projects and actually working them through. So I think the other part that comes up is that being part of a group is a little more fragile sometimes. Conflict comes up; campaigns can be heartbreaking because we lose a lot. Coming from a region where we've consistently lost every mainstream LGBT policy battle, and yet continue to be an organizing family that feels more committed than ever to launch a movement, I can tell you that losing isn't the worst thing in the world. We still have each other, which is the most important thing. So I think that's really a very visceral difference between mainstream LGBT politics and what (the Astraea Movement Building grantees) got going on.

- Caitlin Breedlove, SONG Co-Director

The organizations in my study value movement building and have committed to it, despite resistance from the GRM. These groups argue that not only do the GRM organizations fail to do the work of organizing communities themselves, but they also fail to support it when others employ this strategy. The national LGBT advocacy groups frequently show up temporarily in local communities to work on a policy battle and disregard, or undermine, the organizing that has been taking place there. The statewide equality groups fail to recognize community leadership that is not institutionalized, and will often only deal with the Executive Directors of the groups in my study, rather than with volunteer leaders that have been mobilized.

In addition, the LGBT funders demand advocacy policy wins without supporting the long-term base building that these organizations see as central to doing that advocacy work.

And I think when we think about what gets funded in terms of LGBT work, it's often that the funders don't understand the value of the work that it takes to even get to a place where a base is ready to do policy work. 
That work can take years of developing a base ... That's a hard deliverable to sell... (Base building) doesn't have value for a lot of funders or people who think in particular terms about what 'wins' are. - Kenyon Farrow, QEJ former Executive Director

Our mission statement and our values still rotate and center around our member groups and building their capacity, but funders are not supporting leadership development and capacity building right now. They are focused on policy outcomes, they are focused on 'the win', they are focused on legislative stuff... You know, one of our local partners has this great Tshirt campaign: 'Our community is our campaign'. You know, because funders are like, 'well, what's your campaign, what are you pushing for?' And our groups say, 'making sure our communities are vibrant', 'making sure that they live in places where there is food justice'.

- Ben de Guzman, NQAPIA Co-Director

So the groups in this study face a doubly-uphill battle for funding from LGBT

foundations; in addition to focusing on issues that fall outside of funders' focus on marriage, these groups also engage in long-term organizing when funders are prioritizing specific advocacy campaigns and policy wins.

Nevertheless, these seven organizations share this commitment to the goal of community organizing. They each place a similar value on movement building. This shared goal and value unites them in a collective identity as movement building organizations.

\section{Conclusion: Common Purposes and Collective Identity}

This collective identity as movement building organizations exists alongside their other collective identities as intersectional organizations and as radical liberation and justice organizations. The shared emphasis on community organizing is one more value and practice these seven organizations hold dear, along with additional values of the pursuit of racial and economic justice issues and their commitment to "trickle-up social 
justice.” These seven groups also share grievances (e.g., marriage) as well as programmatic priorities (e.g., immigration, criminal justice, social services, selfdetermination, safety, wellness and sexual freedom). Because of these common identities, goals, grievances, and values, it is clear that these seven groups share the requisite common purposes (Diani \& Bison, 2004) of a social movement.

\section{Collective Action and Organization}

This next section explores my second and third criteria for social movements. Because these two criteria are so interconnected, I explore both at the same time.

The second criterion in my definition of a social movement is collective action. Social movements organize people to work collectively (as opposed to individuals engaged in lone acts of protests, or litigants working individually). Dani and Bison (2004) argued that a social movement's collective action must challenge the behavior or legitimacy of specific political or social actors, not of single individuals. Nor can they be focused on problems caused by non-human causes (such as a natural disaster). Social movement theorists such as Gamson (1990), Snow and Soule (2010), and Tarrow (1998) described collective action as an essential component of a social movement. Collective action can take many forms, including direct action (marches, rallies, and boycotts) as well as political education (public forums, activist trainings, know-your-rights trainings). Consequently, I investigated whether each of these organizations engaged in "collective action."

According to Diani and Bison (2004), in order to be considered a social movement, it is not enough for each of these groups to engage in collective action with 
their own constituents; they must also engage in jointly organized collective actions and engage in long-term partnerships that go beyond a single campaign. For this reason, I also explored whether these groups participated in inter-agency collective action.

"Structure and organization" is the third criterion of a social movement. I investigated whether these seven organizations and their collective actions have structure and organization. Social movement theorists (Snow \& Soule, 2010; McAdam, et al., 2001) maintain that social movements are engaged in organized activities. These activities can be varied (e.g., coordinated protests, the creation of an organization, or networking of different groups) but they must be deliberately planned and organized. Because of this, I investigated whether these groups have built structured organizations and activities. As with collective action, the criteria of structure and organization must be met by the individual organizations as well as between the organizations working together.

To determine whether these seven organizations meet the two criteria described above, I first investigated them individually, and then studied them again collectively. In other words, I first examined (briefly) whether each group had built its own intra-agency structured organizations and activities, and if it engaged in collective action as part of its own intra-agency programmatic work. Then I explored whether the seven groups built any interagency structures, linking their organizations, and whether they engaged in collective action together. 


\section{Intra-agency structure and collective action.}

These seven organizations have clearly developed their own individual structures and activities. They are each incorporated as 501(c)3 organizations. They each have their own Board of Directors. They have paid staff (although most of them have small staffs). They have volunteer leaders. They have fundraising campaigns. They have mission statements. They run programs (which are addressed throughout this paper). Each organization has built a structure and runs organized activities. In these ways, the organizations meet the criteria of organized structure.

I have already demonstrated how each group values community organizing and movement building. This section will investigate how those shared values, which contributed to their collective identity, translate into actual practice at each of the organizations. That practice is what constitutes evidence of collective action.

These seven groups engage in public education, where their own communities can be transformed by learning organizing skills or participating in political education. Every one of these organizations described how they attempt to educate and influence their own communities. allgo uses arts programs to initiate political conversations within the community. Affinity and SONG have targeted community institutions, such as schools, to educate their community members located there, and have also organized community discussions about political issues. The public education activities of these seven groups are in keeping with Dani and Bison's (2004) claim that a social movement must engage in collective action that challenges the behavior or legitimacy of particular political actors.

Most of the organizations described how they provide trainings for their 
communities. NQAPIA organizes summits to provide trainings, and networking for its member organizations. ALP, QEJ, and SRLP each held "Know Your Rights" trainings about a range of issues, such homeless shelter policies, Medicaid, TANF, and police brutality. Affinity, QEJ, and SONG each ran their own activist schools that provided classes on activism and social justice issues to community members. They believe that providing tools and political education to individual activists is an important part of building power in their bases. NQAPIA and SONG provide technical assistance and capacity building to activist organizations in their communities. They believe that movement building requires developing the capacity of organizations as well as individuals.

In addition to public education and training, many of the organizations engage in leadership development and then recruit organizational leaders from within their communities. Staff from allgo, ALP, QEJ, SONG, and SRLP) discussed at great length the ways in which their communities own these organizations. People with lived experiences of the issues on which the organizations work make decisions about programs and campaigns. They lead much of the work.

All these activities (the public education forums, the community organizing classes, the leadership development) are tools for getting communities involved in protests and organizing campaigns. McAdam, Tarrow, and Tilly (2001) would categorize these activities as "repertoires of contention," which are ways social movements engage people in collective action. Each organization gets its respective communities engaged in these repertoires of contention. 
Some of these organizations are clear that their collective action efforts primarily take the form of direct action and resistance. They position themselves as organizers and agitators who mobilize people to protest unjust institutions or policies.

And part of SONG's work is just to, oftentimes, just fan the flames, to see what solutions are going to be brought to bear. We have to be willing to escalate in our collective action, to be willing to say 'if Obama isn't willing to stop deportations, are we willing to do it? Are we willing to actually intervene on federal facilities?' And what actually happens when people are transformed by direct action?

- Paulina Helm-Hernandez, SONG Co-Director

Likewise, Cara Page described how ALP's work has “always been centered around resistance," explaining that they have been engaged in movement building that challenges the criminal justice and medical systems. She stated, "Our work has been against state... anything that is resisting, and redefining how we are creating communal infrastructure that's about our lived experience and about engaging in our collective well being and safety.

For ALP, QEJ, SRLP, and SONG, collective action has often taken the form of rallies, marches, and protests. Their training with members is intended to prepare those members for these kinds of direct action on their various social justice campaigns. Tarrow (1998) articulates these collective actions as quintessential components of a social movement.

We build into our general work, and membership and leadership development work with our member leaders, this idea that you can learn all of the right words, you can learn all of the right analysis and that is not good enough. That the trainings themselves are not organizing. That organizing actually has to be on the streets. It has to be in coalition in our communities. It has to have relationship to direct action. Yes, it has to have a relationship to reflection and analysis. But it can't just be that we 
are going to be so politicized to the point where we are mentally liberated but nothing has actually shifted.

- Paulina Helm-Hernandez, SONG Co-Director

Still, the nature of that collective action is different among the groups. For instance, NQAPIA differs from the others in that they are a federation, comprised of multiple organizations across the country. Thus, NQAPIA does not mobilize communities directly. Rather, the groups in NQAPIA's coalition each organize their own communities. NQAPIA then mobilizes the federation's member organizations to work together in collective action. In addition, the different API organizations that belong to NQAPIA engage in collective action in a variety of ways. Some do direct action and others hold educational social groups.

We do have groups that build community through social activities but strive to do more than just social stuff. Like awareness or educational forums or, you know, those kinds of things. (API LGBT) groups are in different 'spaces' right now. Like some of them are hard-core activists who work on economic justice and do that kind of movement building work. And some of them care about these issues but they are more interested in building community, and they have better potlucks than they do marches. And (in NQAPIA) we are trying to create a culture in which our (member) organizations are the ones that more closely hold values around movement building and become more committed. We look at it as sort of a continuum between the potluck and the rally. So we look at our work as moving people along that spectrum.

- Ben de Guzman, NQAPIA Co-Director

Likewise, Affinity's collective action does not always involve direct action. Often it involves social events or public events to highlight a political issue. Sometimes their collective action tactics separate them from the other Astraea Movement Building grantees: 
We didn't call the work that we were doing base building. We called it, you know, just educating our constituents, or having community forums... The outcomes were similar but we weren't using the tools that everybody else seemed to be using... For us having an event that seemed social and we had discussions around a particular issue and everyone participated, that was a success for us. It wasn't a direct action campaign... It looks different in different places.

- Kim L. Hunt, Affinity Executive Director

Nevertheless, Affinity still engages in collective action and describes its work as movement building. They have not prioritized direct action, but their collective action takes the form of building and educating their base, mobilizing them to work with other organizations on community violence, immigration reform, health and wellness, and other issues. Similarly, allgo engages its constituents in collective action by educating them and connecting them to organizations that are working on various campaigns. They conceptualize this work as mobilizing and building coalitions and networks, which are forms of collective action.

Each organization engages in collective action on a variety of issues. As documented previously, immigration is one of the issues they share. All seven organizations have mobilized their communities to work on different immigration campaigns. For instance, NQAPIA's member organizations have worked to push GRM organizations to work on comprehensive immigration reform, whereas SONG was one of the leaders of a grassroots coalition in GA that successfully organized against HB 87, which made "harboring of illegal aliens" punishable by law. Other issues about which these seven groups have separately mobilized their constituents include welfare rights, Medicaid, community violence, and homeless shelter policies. 
Engaging in collective action not only moves forward those campaigns, but also

transforms the activists involved, in ways that merit discussion. In discussing SONG's

work on the "Not One More Deportation" campaign, Paulina Helm-Hernandez

powerfully described how collective action could be transformative in this way.

It's one thing to talk about shutting down detention centers, it's an entirely different thing when you are facing federal agents saying, "We are no longer willing to allow facilities like this to hide the pain and suffering of our communities. We know that our people are in there. And we want them to know that we are also out here willing to do what we need to do." It was even transformative for me and I've been part of direct actions, I've been part of organizing direct actions, mass mobilizations, all kinds of different things.

She described how overcoming the fear that exists about these kinds of direct actions can bind activists together, and builds a community that can be mobilized in the future.

It was a huge transformative moment around dismantling our own fear and dismantling this idea that there is this invisible line that we are not supposed to cross when it comes to the government. And then once you cross over that line, what you find out is, well, you find out that everybody doesn't come with you. You definitely find that out. [Laughs]. But you also find out that the people whose time has come to step up are so collectively transformed by that willingness to move together. They are in a different place collectively after that. After that, you are in this together for the long haul.

Because of their "trickle-up social justice" approach, the people mobilized into collective action by these organizations are often the most vulnerable in society. This approach can be transformative not just for those being mobilized, but also for those who witness it. For instance, SRLP's Reina Gossett told a story about how, long before she worked at SRLP, she saw how QEJ mobilized homeless people at a march, and the way this motivated her to volunteer. 
QEJ was actively involved in supporting the lives of homeless low income LGBTQ people in NY. As a person who was formerly homeless and was navigating poverty as a young person, that floored me. It was really amazing. It was really groundbreaking work. The first time I met the folks at QEJ was at the first "Trans Day of Action" march, which was happening in the village at a time when affluent residents were really organizing against having LGBT people, specifically low-income people and people of color, in that neighborhood. And I was just floored that QEJ had organized all of these shelter residents to come to the protest. I was amazed. I was so excited. I wanted to learn how I could be more involved.

- Reina Gossett, SRLP Director of Membership

However, one of the concerns involved in mobilizing vulnerable populations for collective action is that they may be severely punished for their actions. When middleclass citizens attend a protest, they have certain resources available to them to help in the event that they are arrested. But when homeless people or undocumented immigrants participate in direct action, they face potentially steeper risks. This is one of the many reasons why so many organizations working with these communities provide direct services but do not engage in collective action. For all the organizations in this study, however, engaging in collective action is a priority. And for some, that collective action often takes the form of direct action. With the vulnerable communities themselves taking leadership, they decide for themselves whether and how to manage the risks involved. And these decisions can result in profound experiences that cement their commitment to social justice work, and alter their sense of what is possible.

We were having all of these conversations after our folks were arrested and released and a lot of the undocumented folks who were part of that action and part of the planning of it, just being like, "That was my worst fear for 25 years. My worst fear was to face down an ICE agent for 25 years, and then I did it and it happened, and I realized that we can actually do this. Not only can we challenge it but we actually can take them down." Now can you imagine if we did that with our city halls? Can you imagine 
if we did that with our school board? Can you imagine if we did that with other institutions that we also see as some of the main antagonists, who have limited the access of our communities? Then what do we do? I think that it then actually changes the conversation about, strategy and tactics, and about our overall willingness to be able to do that as a movement as well.

- Paulina Helm-Hernandez, SONG Co-Director

In this way, one collective action (confronting ICE agents) opens up the imagination and possibility of subsequent collective actions. These activists understand that each individual action is connected to a long-term vision of greater actions in the future.

They also understand how participation in these collective actions open up the imaginations of community members, transforming their sense of what is possible. In this way, the organizations are redirecting their members back from the distraction of the GRM's homonormative agenda.

For all seven of these organizations, collective action is a big part of their work. Their collective actions take different shapes, including political education, leadership development, coalition building, and direct action. Regardless of the different forms it may take, the commitment by all seven organizations to collective action is clear.

The examples of collective action provided thus far have focused on those intraagency actions organized by individual organizations. According to Diani and Bison (2004), in order to be considered a social movement, these groups must also engage in collective actions that are organized by the organizations jointly. I turn my attention now to examining how these seven organizations have worked together. 


\section{Interagency structure and collective action.}

And so we have been very grateful and lucky to be in close relationship with amazing organizations over the years, that we also have a lot of love for and definitely a lot of political alignment with, like QEJ, like The Audre Lorde Project, the Sylvia Rivera Law Project, organizations like Streetwise and Safe, organizations like, in our own region like the Esperanaza Center in San Antonio. You know there are so many amazing organizations we consider to be sort of like our queer left sister organizations, if you will, where there is quite a bit of political commitment and not just to keep up with each others work but to deeply try to understand the strategies, tactics, the general trajectory of our work so we can learn from each other. And so that we can also have the kind of robust networks and coalitions that we also need.

- Paulina Helm-Hernandez, SONG Co-Director

Helm-Hernandez and several other participants illustrated how these organizations have built relationships with each other, even referring to the other Astraea grantees as "sister organizations." In addition to maintaining relationships with each other, the groups have engaged in numerous examples of interagency collective action, including campaigns, trainings, and coalitions/networks. During these interagency collective actions, they established formal relationships and developed infrastructure. The following section explores those efforts, investigating if and how they meet the criterion of joint collective action required to constitute a social movement.

The formal relationships between some of these organizations began at the Creating Change conference. Since the 1980s, Creating Change, organized by the National Gay and Lesbian Task Force (NGLTF), has been the largest national LGBT conference of activists and advocates in the world. Every year thousands of activists from across the country spend five days networking and attending workshops, plenary discussions and all-day Institutes on a variety of specialized topics. Most of the 
organizations in this study had presented on panels together over the years at this

conference, solidifying their informal relationships. However, in 2005 ALP, QEJ, and

SONG were presented with the opportunity to work formally together for several years to shape a key component of the conference. NGLTF offered to fund them (and two other groups, The First Nations Two Spirit Collective and The Disability Justice Collective) to work together to plan and facilitate its "Racial Justice" Institutes. The five groups had already worked together on other projects (including at previous Creating Change conferences), but this offered the chance to work together more intensively. QEJ's Kenyon Farrow described this process:

We had already been sort of using Creating Change strategically to build relationships with some of those other organizations... there have just been moments where a real alignment and political strategy would come together at this conference. But then in 2005 there was an opportunity to reimagine and really shape the Racial Justice Institutes... They wanted us to fix those institutes, and help activists develop some real critical thinking around racial justice... we saw it as an opportunity to move our politics even more broadly. And so working in that way together for several years, helped develop stronger relationships... So I think that became a real place to build some shared analysis and build a shared strategy for how we would use the institutes to really develop more political leadership in the mainstream movement with a different kind of racial and economic lens in terms of thinking about, you know, work among people of color and also white folks.

- Kenyon Farrow, QEJ former Executive Director

This project strengthened the working relationship between ALP, QEJ, and SONG. As they continued to work together on this for several years, they also worked together in other ways.

As discussed previously, in 2006, the Astraea Lesbian Foundation for Justice initiated a multi-year grant-making program called "U.S. Movement Building" Grants. 
Over four years, Astraea awarded $\$ 150,000$ each to twelve organizations for several years of support in their movement building work. In addition to receiving the funding, these twelve organizations participated in strategic retreats where grantees could discuss their experiences, share strategies, and build skills to increase their organizational capacity and advance their movement-building work. They developed a network of ongoing communication that existed for several years. This network influenced some of the organizations in significant ways. As the Astraea grantee organizations worked together in this coalition, eventually different groups partnered on numerous projects together. For instance, from 2006-2007, some of these groups worked together with the Barnard Center for Research on Women in a coalition ("Desiring Change") to address the role of desire and sexuality in social justice work. They also often presented together on panels at conferences. As they worked together, some of their collaborations became more routine, and involved laying the groundwork for longer-term infrastructure among the organizations. Three particular projects warrant discussion: Transforming Justice, the US Social Forum, and "Building A Queer Left."

In 2006, SRLP worked with several organizations across the country (including fellow Astraea Movement Building grantees) to create the Transforming Justice coalition, an effort focused on transgender imprisonment issues and prison abolition work. This coalition worked together for several years. Part of their work included organizing a 2007 conference in San Francisco, where members of organizations from 14 states, including ALP, QEJ, and SONG, joined SRLP for two days of planning and strategizing. 
In 2007, QEJ and SONG worked together to plan an all-day gathering at the U.S. Social Form in Atlanta, GA. Born out of the World Social Forum, the U.S. Social Forum brings together social justice activists in the United States, to build unity and ties between different social movements. QEJ and SONG organized an all-day meeting that convened 45 queer liberation organizations from 18 states. Among the 45 participating organizations were ALP and SRLP (as well as three other Astraea Movement Building grantees that are not included in this study). These 45 queer liberation organizations shared a broad vision of social justice and sought to strategize about how these queer liberation groups could work together in ongoing basis to build their own social movement. That discussion resulted in the creation of the "Building A Queer Left" coalition.

As a result of that 2007 USSF convening, QEJ sought and obtained funding to launch its "Building a Queer Left" project. This effort brought together many of these organizations on a regular basis for teleconference calls to plan strategies, exchange technical assistance, and build a queer liberation social movement. That work brought together dozens of organizations across the country and lasted for two years, until the project folded due to lack of funding.

Throughout these different projects, the groups continued to work together through the network developed with Astraea. This is another example of their interagency collective action, as well as interagency structure. Astraea provided the infrastructure and funding for this network for several years, but when the grant program ended, the groups transitioned to a new format. 
In 2010, all twelve Astraea Movement Building grantees came together, with The First Nations Two Spirit Collective and The Disability Justice Collective, to form the Roots Coalition, for which SONG served as the fiscal sponsor. SONG's Paulina HelmHernandez explained that they were "trying to bring together a lot of LGBT groups and collectives that are working explicitly at the intersections of LGBTQ organizing, gender and sexual liberation, and racial and economic justice." The following excerpt from the mission statement of the Roots Coalition situates the member groups as located in multiple social movements, centers queer and transgender people of color, connects to the "trickle-up social justice" framework, and describes their central value as being one of liberation:

The mission of the ROOTS Coalition is to create a national network of Queer and Trans People of Color (QTPOC) led organizations and collectives engaged in cutting edge multi-issue organizing across progressive movements... The vision of the ROOTS Coalition is one that is motivated by a collective yearning to build organizing efforts and infrastructure that supports QTPOC communities and the pressing economic and political issues we are facing. In this political moment, there is a deep hunger for a national body that represents a liberation agenda: one that is led by those who are most affected by inequity and injustice. (Roots Coalition, $\mathrm{n} / \mathrm{d}$ )

Their work focused on three areas: organizing convenings to strategize, developing a "rapid response" system for mobilizing together quickly, and a "Community Schools

Project" that offered leadership development and political education to build community.

They also focused on developing structure for their work together.

What brought us together as a coalition is the fact that we are all interested in alternative visions of what it looks like to build strong infrastructure for our communities. We see two specific needs: one, to build infrastructure and create new and inventive ways to build our own communities; and two, 
on a resistance level, to challenge neoliberalism, particularly how it affects our communities.

- Caitlin Breedlove, SONG Co-Director

McAdam, Tarrow and Tilly (2001) maintained that one of the characteristics of a social movement is that the challenging groups must have "forms of organization" which offer structure to engage in mobilization efforts. The Roots Coalition was created as exactly such a form of organization and allowed the members to engage in mobilizing projects. For example, three years after the first U.S. Social Forum gathering, QEJ and SONG again convened organizations at the 2010 U.S. Social Forum. Working with the other groups in the Roots Coalition, they developed a policy platform to present at the conference in Detroit, MI. This platform identified pressing issues for LGBT people, ranging from health care to employment, and was adopted by all 15,000 activists at the closing ceremony of the conference.

The Roots Coalition worked together for three years. SONG's Paulina HelmHernandez told me the staff from the different organizations bonded socially and learned from each other professionally. She said that she sees those groups "as our similar closest organizations because we have learned so much from their work and because we also continually have sought to bring our work even in closer alignment around our shared understanding about the different work that people are doing."

In 2013, the Roots Coalition lost its funding, so the formal coalition no longer exists. Since the loss of funding, some of the groups (Affinity, allgo, NQAPIA) no longer partner with the other organizations as frequently as they once did. For instance, Affinity 
has not worked on any ongoing projects with any of the other organizations in this study since the end of the Roots Coalition.

We were very much involved in the Roots Coalition. We were on the leadership team a couple years ago... For many of the organizations, their work is like ours, it's very local. So outside of the national Roots Coalition, there hasn't been any work on our end to partner with the other organizations.

- Kim L. Hunt, Affinity Executive Director

These three organizations do, however, maintain informal relationships with the other groups, consulting with each other for advice, and contend that if the resources existed, they would continue to do more formal collaborations.

Certainly, we were part of the movement building work and so we were part of Roots. And we maintain relationships, not so much as doing work with folks but certainly relationships that are mutually beneficial. So those relationships are generally great...you know, when we had the movement building grant and some funds that would help bring us together we actually were able to work together. Without that funding it is more informal. We know what other people are doing on a national basis. We talk together. But the active work that we are doing together is certainly not as organized or profound. And I think it's just a matter of resources. It's too hard. We don't have the resources to do it.

- Rose Pulliam, allgo Co-Director

All seven groups continue to purse these informal relationships and support each other's work from across the country. For instance, last year when SONG organized a march in Washington DC, protesting the deportations of undocumented immigrants, all of the other Roots Coalition organizations officially endorsed the march, publicly encouraged their members to participate, and engaged in efforts to publicize the event.

Although Affinity, allgo, and NQAPIA are not currently in formal partnerships with organizations from the Astraea Movement-Building grants, the other four 
organizations continued to work together with Astraea grantees after the Roots Coalition folded. Often this takes the form of local work, shaped by geography. ALP, QEJ, and SRLP are located in NYC, where they worked together frequently. As documented previously, they have partnered on campaigns about the city's shelter system, Medicaid, and access to TANF. Several years ago, they made a collective decision (along with fellow Astraea grantee and Roots Coalition member FIERCE) to move into the same building together to facilitate easier and more frequent partnership. Each organization rented out a separate floor, and they named the building The Miss Major-Jay Toole Building, in honor of two elders central in the founding of two of the Astraea movement building organizations. In doing so, these organizations demonstrate the partnership and collective identities that Diani and Bison (2004) argued must "go beyond specific campaigns and initiatives" (p. 284) in order to comprise a social movement.

The Miss Major-Jay Toole building has become in many ways the epicenter of queer liberatory work... My hope is we will keep moving as a body no matter where we are. Even if we have to put up a tent city. My hope is that we are still going to move together politically.

- Cara Page, ALP Executive Director

Another queer liberation organization, Streetwise and Safe, subsequently moved in to the building. Until QEJ closed, all five organizations worked together frequently and the surviving four still do.

The organizations in the building... are not looking for necessarily equality or rights for the communities they represent but are looking to create systemic change on behalf of people of color, people with disabilities, people who are incarcerated or who are dealing with police violence, people who need access to healthcare... Those are the primary organizations that we partner with along a whole host of issues. Whether it's coming together to do "Know Your Rights" training about navigating 
police encounters with Streetwise and Safe. Or the campaign that we have been running with ALP's Trans Justice around access to safe and affordable healthcare for trans and gender nonconforming people. Or doing skill shares with FIERCE and talking queer and trans history and also what it means to create spaces for safety where people have access to what they need. Those are all organizations that we really value our partnerships with.

- $\quad$ Reina Gossett, SRLP Director of Membership

Meanwhile, SONG continues to partner with other queer liberation organizations in the south, including informal work with Affinity on immigration related strategy conference calls. In addition, SONG worked with the Applied Research Center to coordinate the Better Together Program. This project convened eleven organizations (including CAR), spanning ten southern states, for an extensive enterprise that combined media, research, and leadership development to advance racial justice and LGBT liberation. For several years, the groups focused on doing research and strengthening their organizational relationships. This illustrates SONG's general commitment to interagency collective action and movement building. Consequently, it gives me reason to believe SONG staff when they declare their intention of finding ways of continuing to work with the other QLM groups in the future.

\section{Conclusion: Structure and collective action.}

Investigating the second and third criteria (structure and collective action) offers no simple verdict about whether these seven organizations meet these criteria. Each organization has its own intra-agency structure, and each group engages in collective action with its own community members. These criteria for a social movement have been 
met. However, the questions of interagency structure and interagency collective action are harder to assess.

At the moment, since the seven organizations have no formal interagency infrastructure and are not engaged in formal partnerships that involve collective action among all seven groups, one could argue that they do not meet the structure/collective action criteria required of a social movement. However, such an assessment would be simplistic and inaccurate. These organizations clearly want to develop structure to support organized interagency work. Between the Astraea network, the "Building a Queer Left" project, and the Roots Coalition, they have repeatedly attempted to build permanent infrastructure as a social movement. They have stated that when they have resources, they will rebuild that infrastructure. In addition, they have previously organized numerous campaigns where they engaged in interagency collective action, some continue to do so, and by all accounts, they hope to continue doing so in the future. For this reason, I contend that they do meet the criteria for structure and organized activities (McAdam, et al., 2001; Snow \& Soule, 2010), as well as for collective action (Gamson, 1990; Snow \& Soule, 2010; Tarrow, 1998). Consequently, I contend that these seven groups do comprise a social movement, which I am calling the Queer Liberation Movement.

\section{Discussion}

At the onset of this project, I defined a social movement as a group of people with common goals, grievances, values and purposes, engaged in collective work, consisting of structured activities and organizations. With that benchmark, the evidence indicates 
that these seven organizations do comprise a coalescing social movement. They definitely share the same values, goals, grievances, and social solidarities that indicate common purposes. They have independently created intra-agency structures and activities and mobilized their respective communities in collective action. And while they currently lack interagency structure to coordinate their social movement activities and collective action, they have devoted substantial efforts and resources in the past to developing that infrastructure, and hope to do so again.

This is not to say that all seven organizations meet the criteria in identical ways. It is easy to argue that ALP, QEJ, SONG, and SRLP engaged in interagency activities. It is more difficult to make that same argument for Affinity, allgo, and NQAPIA, because since the closing of the Roots Coalition, they have not sustained the same level of partnerships with other organizations. However, their past partnerships, their stated desire to engage in future partnerships, as well as their continued shared common purposes, place them in this movement, albeit less actively than ALP, QEJ, SONG, and SRLP were at the time of these interviews.

Because the organizations relate to this social movement with differing degrees of strength, and because the current infrastructure between the organizations does not exist formally, I contend that the movement is in an early stage of coalescence. Some social movement scholars believe that many movements go through stages of development (Blumer, 1969; Christiansen, 2009). The first stage is emergence, during which social movement organizations and their members serve as agitators who raise consciousness about the issues with which they are discontented. I believe the Queer Liberation 
Movement is beyond this stage. The second stage is coalescence, the third is bureaucratization/formalization, and the fourth is decline. It is in the second stage, coalescence, where I situate this movement.

In the coalescence stage, the individual agitators become aware of each other and begin to coordinate their work. This stage is characterized by a more clearly defined sense of discontent (regarding their particular grievances) among the participants. Hopper (1950), states that at this stage "Discontent is no longer uncoordinated and individual; it tends to become focalized and collective" (p. 273). He argues that participants of the preceding stage become aware of each other, leadership emerges, and strategies for success are developed. It is during this stage that the movement grows beyond discontented individual actors, and becomes organized and strategic (Christiansen, 2009). This stage appears to be the closest fit for the Queer Liberation Movement.

The developmental stage of this new social movement can also be understood by drawing on Freeman's (1999) elements involved in the formation of a new social movement. She contends that new social movements develop when they have preexisting communications networks, a series of crises that galvanize people, and/or bonding efforts. Freeman's first element is the growth of a preexisting communications network that is co-optable to the ideas of a new movement. She draws on Pinard (1971) to define "cooptable" as sharing an ideology or interests congruent to a new movement, or acting as mobilizing agents. The organizations in this study clearly have developed such a network. Because these groups already possess this essential element, in order to further develop into a social movement, they require at least one of two more elements. These other 
elements are a series of crises that galvanize people from that network into action, and/or engaging in organizing efforts to weld the groups together into a movement. My study indicates that these organizations have been engaged in efforts to weld the groups together. That work is not completed yet, but it has begun. Consequently, I argue that these organizations are in the early stages of building a social movement.

It is important to note that I do not believe this social movement is limited to these organizations. Interview participants made constant notable references to partnerships with three other organizations: the Esperanza Peace and Justice Center (in San Antonio, TX), FIERCE (in New York, NY), and the Transgender, Gender Variant and Intersex Justice Project (Oakland, CA). Participants argued that these groups shared common purposes and goals, as well as activities and structures with the organizations I studied. These frequent references are notable because these organizations also received the Astraea Movement Building grant and were eligible for inclusion in this study. They were not included only because I worked with the first eight Astraea organizations that responded to my request. It is possible that if had I included these three organizations in the study I might have an even stronger basis on which to claim that these groups comprise a social movement. Additionally, participants mentioned other organizations, not part of the Astraea project, that share common purposes, activities, and collective action. These groups (e.g., The Transgender Law Center, Streetwise and Safe, The First Nations Two Spirit Collective, The Disability Justice Collective, BreakOUT!, Freedom Center for Social Justice, and the Young Women's Empowerment Project) are a possible focus of future research investigating whether and how they relate to this queer liberation 
movement.

The activists I interviewed expressed differing perspectives about the question of a new social movement. Some stated that they were part of a new movement, while others situated themselves as part of multiple movements. And still others, as I discussed in the conclusion to my analysis of my first research question, maintained that they were part of a radical wing of the GRM. These participants did not directly address the question of whether a new social movement exists, but by situating themselves in the GRM, they implicitly indicate that they do not identify as part of any new movement. Even allgo's Rose Pulliam, who did not see allgo as part of the GRM, does not think that a new social movement has been created yet. However, her words convey optimism about the potential:

No. I don't (think we are a social movement). And I don't know how it will happen. I think the Roots Coalition has done the best that it can with the resources it has.... And we're spread too thin, both geographically and regarding resources. Much of our time and energy is scrambling to do those things that our members need us to do on a local level. And then scrapping for the money to really do the rest of the movement building work that we know we need to do... I think because we work at the intersections, it is very difficult for us to carve out this nickel wide niche to get us started. For all of the organizations, the needs of people in our different localities are so different and so unique that even then it was very difficult finding our commonality in terms of strategy, it was really hard for us. But I happen to believe it's still going to happen. That part of the work, the creating of the relationships between organizations, there is still this connection. Right? One of the first steps.

So although some of the groups here do not, themselves, claim to be part of a new social movement, they do recognize a strong and significant connection. Noted social movement theorist Sidney Tarrow (1998) explained, "what underlies the most successful 
(social movements) is the role of the informal connective tissue operating within and between formal movement organizations" (p. 137). That informal connective tissue between the organizations in my study is illustrated over and over again throughout the data. These organizations do not merely share common goals and collective actions; their staffs also have deep informal relationships with each other. The activists I interviewed frequently discussed how much they "loved" the other activists or organizations in this study. More importantly, they each see their organization's individual success as intimately connected to the success of the other organizations in this study. For example, numerous people referenced the closing of QEJ, discussing how they mourned and how it made it them more keenly aware of their stake in each other's survival.

But the moment that QEJ had to close its doors, we held a moment of grief and had to acknowledge how we may have participated and not have foreseen the future so that we could adapt more quickly to taking in our own and making sure that - or questioning what can we do differently so that no one is closing their physical doors... How are we moving together to make sure we have each other's backs in a very real political way, but also in a very survival way, that we move like we need each other? Because the equality or the mainstream movement, that's not what they are doing. They are moving to identify their own charge... agenda, and you know, a funding empire. We need to move like we are about loving, and living, and building for each other. That's distinctly different from these larger 'rights' organizations.

- Cara Page, Audre Lorde Project Executive Director

The connective tissue among these organizations is significant enough, coupled with the other criteria I examined, to claim that they comprise a social movement. I make this claim, even with their current lack of interagency infrastructure, and even though not all of the groups see themselves in the same way I do. Their organizations' collective identities and common purposes, their focus on collective action, their demonstrated 
commitment to building interagency structure together, and their clear connection to each other, indicate that they are a social movement, rather than a coalition. Diani and Bison (2004) argued that one criteria of a social movement is when organizations recognize a connectedness that inextricably links them to other compatible organizations. I close this chapter with a quote from SONG's Paulina Helm-Hernandez, illustrating the importance of the informal relationships that still exist among these organizations, and how strongly these organizations see themselves as compatible and linked:

One of the things we always consider, because we are a movement building organization, is who we are aligned with and who we choose to partner with in our work. And even with folks that it might not be the right time or opportunity to partner together, we see part of our survival as connected to their survival. To the survival of groups in the Roots Coalition. And so we try to lift up their work. We try to give as much love, and also light to their work. Including inside our membership so people understand that a lot of the risk that SONG is taking isn't being taken alone and that part of our work as movement building organizations is to provide political cover for each other. And to be able to say when are the times to co-lead something together versus when there's times to actually just flank each other, and say we are not in the lead of this, you guys clearly are, you are the experts, there's enough political trust for you all to be able to do that and our role is to support you and to give you the backing that you need and to say, yes, you are not crazy for doing this, no, you are not alone in this risk that you are taking. 


\section{Chapter 8: Research Question Three}

\section{Introduction and Overview}

In this chapter, I answer my third research question: "What does a social movement analysis reveal about these organizations, collectively and individually?" Having found in Q2 that seven of the organizations do constitute a social movement, I now examine them collectively as the Queer Liberation Movement (QLM). In addition, as per my research question, I also look at them individually, making connections between how each organization operates on its own and how they each function as part of the QLM.

It is clear that something new is happening with these organizations. The QLM is not only markedly different from the GRM, it is also different in important ways from other identity-based social movements that have emerged in the last five decades. First, it shares much of the same radical politics as the grassroots queer groups of the New Left, and pursues both recognition-based goals and redistributive goals, but does so within the 501(c)3 model that emerged in the GRM in the 1980s and 1990s. Yet the institutions that are being built by the QLM are different from traditional non-profits, and can be better understood as counterinstitutions. In addition, it is identity-based and also complicates narrow constructions of identity, while working inside multiple social movements. All of these important dynamics warrant explanation and examination, as they suggest that this is a new form of queer activism, unseen before. These issues are explored in this chapter, except for the question of collective identity, which is explored in the next. 
This chapter is divided into two parts. First, I look at the QLM through the lens of different social movement theories that I had identified in my proposal as significant. In the second part of this chapter I use Dixon's (2014) model of “Another Politics" as a framework for understanding some key aspects of how the QLM works.

In my research design, I identified certain social movement theories as most prominent and potentially relevant, and incorporated them into my categorization matrix. These theories were perspectival dualism (Fraser, 1995; Fraser \& Honneth, 2003), resource mobilization (McCarthy \& Zaid, 1977), disruptive power (Piven \& Cloward, 1979), and political process (McAdam, 1982). However, after collecting my data and engaging in my analysis, I came to realize that these theories were insufficient for understanding the QLM. Each of those theories can be used to understand the movement to a certain extent, but only in limited ways. In addition, those limited ways in which these theories apply to the QLM don't really move existing theoretical knowledge forward. Consequently, I merely provide a brief overview of these four theories and how they inform an understanding of the QLM, and then move on to a new framework, developed by activist Chris Dixon in his 2014 book Another Politics, which I think fills in some of the gaps and moves existing theories forward.

\section{Significant Existing Social Movement Theories}

In this section I explore four different theories that I had identified as potentially useful before undergoing my research. These theories are perspectival dualism (Fraser, 1995; Fraser \& Honneth, 2003), resource mobilization (McCarthy \& Zaid, 1977), disruptive power (Piven \& Cloward, 1979), and political process (McAdam, 1982). 
Prominent social movement scholars advocate using multiple theories to understand any one social movement, since such an approach highlights how different theories can complement and contradict each other (McAdam, McCarthy, \& Zald, 1996). Similarly, I think these four theories each contribute to a partial understanding of the QLM, even as they contradict and complement each other.

\section{Perspectival dualism.}

In this section, I explore how the QLM can be understood through Nancy Fraser's theory of perspectival dualism (Fraser, 1995; Fraser \& Honneth, 2003). I contend that as the QLM fights multiple forms of oppression, it is engaging in the practice of perspective dualism.

Critical theorist Nancy Fraser is one of the few to question the recognition/redistribution binary that exists in most of the social movement literature. She conceptualizes the redistribution movements as concerned with "injuries" caused by economic exploitation and deprivation, and the recognition movements as focused on "insults" caused by cultural domination and disrespect. She explains that these very different understandings of injustice have led to the two distinct paradigms for remedy and redress (redistribution versus cultural change). However, she insists that any specific example of injustice will almost certainly contain elements of both economic and cultural harms. Consequently, Fraser theorizes about the potential of social movements to focus on both socialist redistributive efforts and deconstructionist recognition-based claims. She also explores how even those movements primarily based on recognition can still potentially support (as well as potentially undermine) a politics of redistribution. Fraser 
questions the standard conception of redistributive movements as inherently distinct and oppositional from recognition movements (Smith, 2001). Rather, she proposes "a 'twodimensional' conception of justice that encompasses claims of both types" without having one trump the other (Fraser \& Honneth, 2003, p. 3). This framework of "perspectival dualism" offers an analysis of both class inequity and status hierarchy.

Fraser's framework remains largely theoretical. She analyzed several movements, the GRM among them, to see if they align with her theory. She did not look at the queer liberation organizations in this study and instead uses the national equality organizations to define the movement (Fraser, 1995). She heuristically categorizes the GRM as specifically focused on recognition-based goals, arguing that her model does not describe them because they are not focused on redistribution. I contend that although she is right in her assessment of the GRM, her theory is misapplied because she did not consider the types of organizations in this study; her theory does describe the Queer Liberation Movement. By struggling against multiple forms of oppression in multiple systems, the QLM also engages in redistributive and recognition-based efforts, hallmarks of Fraser's perspectival dualism.

The GRM is rightfully understood as similar to other identity-based movements focused on recognition. The distinction between recognition-based social movements and redistribution-based movements exists, in part, because recognition-based movements often seek cultural validation rather than material benefits. For instance, the famous "Prop 8" battle in California (over a 2008 ballot initiative that banned gay marriages in the state) was fought over largely symbolic issues. California's domestic partnership 
system was one of the most comprehensive in the country, and already provided most of the material benefits and protections of legal marriage (Farrow, 2008). The (well-funded) battle lines in Prop 8 were drawn over the social significance of marriage and the desire of marriage activists to obtain (and marriage opponents to withhold) the cultural validation that comes with the word "marriage."

Despite their critiques of the GRM for its exclusive focus on recognition and access, the groups in the QLM have also pursued legal recognition and access as part of their work. Although they are critical of the equality framework for putting all of its focus on equal rights and access, the QLM groups do nevertheless pursue recognition-based goals as part of their work. Examples of the QLM's recognition/access work include: allgo providing transgender sensitivity trainings to Texas jails; ALP and SRLP fighting with NYC's Human Resource Administration and Medicaid to recognize and serve transgender people; Affinity and NQAPIA working on local marriage equality campaigns; and QEJ's campaign to get NYC's homeless shelter system to recognize domestic partnerships and allow domestic partners to access the family shelters.

The QLM groups do not seek these rights in order to secure cultural validation like the recognition-based movements. Instead, they are very clear that these recognitionbased efforts to obtain rights also provided material benefits (housing, welfare benefits, healthcare) to their constituents. In order to obtain these benefits, the groups need legal recognition for their communities.

Even the marriage work done by Affinity and NQAPIA was framed as an economic, rather than cultural, goal. Affinity's Kim L. Hunt made this explicit: "For us as 
an organization, it wasn't about the sanctity of marriage to be involved in this battle. It was really more about being a vehicle of economic security for vulnerable families." Fraser's theory of perspectival dualism suggests that issues of injustice often contain elements of both economic and cultural harms. The QLM illustrates this in its choice of recognition targets that provide economic benefits.

The QLM often frames concerns to highlight both the economic and cultural issues at stake. This is evident when SONG's Paulina Helm-Hernandez discusses poverty in the South:

(Poverty has) always been a reality. We know that economic access has been used as a tool for white supremacy. We know that blocking economic access, blocking access to education, blocking access to better paying job, has been a way to also keep communities of color and poor people continuously in this sort of invisibility, and also to just neutralize them politically. We know that the south has a long history of redistricting that is continuously, strategically, very well planned out, sort of like a design. We know that so much of the economic infrastructure of the south has been shaped by the design of the right wing and by the design of white supremacists in the U.S.

In this quote, Hernandez-Helm clearly links what Fraser calls distribution-based "injuries" (economic exploitation and deprivation) to recognition-based "insults" (racial and cultural domination and disrespect). In doing so, Hernandez-Helm illustrates how the QLM sees these different forms of domination and oppression as interconnected and mutually reinforcing. This can be seen also in the following quote from SRLP's Dean Spade:

The economic crisis has had huge impacts on our clients. Already (the trans people of color) we work with are criminalized and highly poor and homeless. But cuts to existing programs and benefit systems going back to 
the nineties have made a major impact on transgender people's ability to get the basic needs met, to get housing.

This analysis is shared by all seven organizations; they see identity as interconnected with economic security. As a result of that shared analysis, all the QLM organizations connect those goals that focus on recognition with their redistributive goals. Examples are plenty: all seven organizations focus on poverty issues, and SONG's Paulina Helm-Hernandez, QEJ's Amber Hollibaugh, and Affinity's Kim L. Hunt talked about the role of class and classism in the lives of their non-poor queer constituents; NQAPIA’s Ben de Guzman, SRLP's Reina Gossett, SONG's Paulina Helm-Hernandez, and ALP's Cara Page critiqued the state for creating structural barriers and violence for poor queer people of color; ALP's Trishala Deb discussed the role of neoliberal policies in shaping immigration's impact on queer people, and SRLP's Dean Spade discussed those same economic policies when looking at the criminal justice system's impact on transgender people; and SRLP's Reina Gossett and Dean Spade, and QEJ's Kenyon Farrow discussed improving the material conditions in queer people's lives.

It can also be seen when allgo's Rose Pulliam told me this story about how transgender people are simultaneously impacted by the GRM's transphobia and the American labor market:

We sat down with the folks from national HRC. They were talking about this "cutting edge program" that they were doing somewhere in the southeast where they were teaching transgender women how to dress and put make up on so that they could be presentable so that they could get jobs. And we said to them, "Wow, so trans women need to transform themselves to meet this idea, so that they can be more perfect women or something? How about they are okay the way they are?" and they said, "Well they need jobs." Absolutely they need jobs. But there is something 
wrong with this picture... We said, "Your idea of helping them is to teach them how to dress the way you think women ought to dress. They are women already. How about directing your substantial resources towards changing corporate America instead of changing trans women?" We often have to challenge what they think are good ideas with the reality of the lives of the people who are at the intersections, people who are living in poverty.

Pulliam focuses on both identity-based recognition claims ("they are women already") and economic redistribution goals ("change corporate America instead"). Throughout the study, issues of identity (recognition) are interwoven with issues of economics (redistribution).

The focus on both recognition and redistribution is perhaps inevitable when the QLM has such an expansive agenda, focused on the social safety net, family recognition, transgender rights, anti-violence, and the immigration, criminal justice, and healthcare systems. Such a broad agenda is bound to include both redistributive and recognition claims. Thus, I was not surprised by my results that found Fraser's theory was enacted by the QLM. However, I was surprised by my findings when they indicated that other significant social movement theories, theories that I had expected to be able to draw upon in order to understand these organizations, did not prove to be as useful. I turn now to explore these other theories.

\section{Resource mobilization theory.}

Resource mobilization theory, widely used by scholars, is perhaps the most influential social movement theory. Focused on organization and resources, not culture or identity, it characterizes social movements as focused on building formal organizations 
and increasing resources that mobilize constituents (Buechler, 1995; McCarthy \& Zaid, 1977; Morris, 1984).

All the QLM organizations concentrate on mobilizing resources to increase their groups' strength. They build programs and activities within their organizations, and these are the exact types of formal organizational structures centered in resource mobilization theory (McCarthy \& Zaid, 1977). All the interviews and mission statements made references to formal services, programs, and campaigns. These activities require economic resources to pay for them; Volunteer labor helps move these programs forward, but alone it is not sufficient.

We really want to engage more with the jail policies around trans people but it requires the resources that we don't currently have to do that... And how much we get accomplished generally really does depend on how much our resources are. When we have few resources our progress is really slow but we continue to work on them.

- Rose Pulliam, allgo Co-Director

The individual organizations clearly need these resources but, in addition, so too does the larger queer liberation movement of which they are a part. For instance, several participants discussed how the Roots Coalition's work was substantially scaled back when it lost funding.

Their primary method of mobilizing resources comes from foundations. They all pursue funding from foundations to support their work and their organizational structure. Several people discussed how difficult it is for these queer liberation groups to get foundation support, particularly from LGBT foundations, which have prioritized a different set of issues. Consequently, the philanthropic support for the queer liberation 
groups often comes from non-LGBT foundations. These groups have been particularly hit hard by the marriage campaigns, which have diverted resources that might otherwise have been leveraged by these organizations. A discussion of how these groups mobilize resources would be incomplete without referencing the impact of the marriage campaigns.

Because of GRM funders' emphasis on advocacy work, it is difficult to obtain funding for capacity building or community organizing. Private foundations often define success by policy "wins" rather than by mobilizing or base building efforts. At the same time, government grants do not often fund the work of challenging the government. Public dollars are much easier to obtain when non-profits instead provide direct services. For instance, Rose Pulliam described allgo's struggles to leverage resources since it stopped providing HIV services. The direct services had enabled allgo to obtain government grants that promptly disappeared when allgo chose to refocus its work away from HIV services.

These fundraising struggles are relevant here because for most non-profit organizations the importance of mobilizing resources cannot be understated. The stakes are clear: if they fail to do so, they may close. Many of the interviewees referenced partner organizations that had closed due to their inability to mobilize sufficient resources. For instance, Rose Pulliam discussed how allgo absorbed many of the members of Ebony Connection, a black queer organization, when Ebony could not raise the funds to remain open. And for organizations whose values and goals do not align with those of the mainstream movement (what Dixon, 2014, calls counterinstitutions), the available resources are limited. To illustrate this point, several people mentioned QEJ's closure. 
QEJ was one of the few organizations that centered LGBT people living in poverty, and for it to close, to me the message that I get is that kind of work is not valued. Work that is about economic justice or economic violence, work that is done by people who are living in poverty, is not to be valued. I think if it was valued there would have been more resources for it. There would have been more support for QEJ.

- Reina Gossett, SRLP Director of Membership

These organizations' staff members recognize the precarious state of their own organizations' financial health, and discussed it with me freely. Their counterinstitutions are less likely to obtain government or corporate support, precisely because they challenge the dominant institutions that are supported by (or run by) the state and corporate America. Yet because of the structure of their organizations and the nature of the non-profit system, they persist in their work and in their fundraising for that work. They recognize that they need to mobilize resources in order to operate. However, they also know that they do not need as many resources as other, larger, organizations. They have made strategic choices that include the decision to remain small. Cara Page illustrated this: "ALP is not building an empire. We work with organizations that are not building empires."

Resource mobilization theory posits that social movements must build large bureaucratic institutions in order to succeed. So although in many ways resource mobilization theory is applicable to the social movement formed by these groups, in this specific way the theory does not align. These organizations do not believe that their survival depends on building larger institutions. In fact, in some ways, their smaller size makes it easier to survive; they are able to function without amassing the large resources often assumed to be essential for social movements (McCarthy \& Zaid, 1977). For 
instance, while discussing some of her hopes for future work, allgo's Rose Pulliam said, "I think some things will have to change. And that's not necessarily to say that we just have to get additional resources to do it, because we have been known to do almost everything we want to do without resources."

Resource mobilization theory also argues that members of social movements do not, on their own, possess sufficient power to implement the changes they seek. Consequently, movements must influence powerful elites to accept and support their ideas (Buechler, 1995; McCarthy \& Zaid, 1977; Morris, 1984). Referencing back to Gamson (1990) and these organizations' targets of influence, some of the QLM groups shared the target of elected officials and government agencies or institutions. McCarthy and Zaid (1977) considered government figures the quintessential "elites" that social movements need to influence. Ben de Guzman explained how NQAPIA has prioritized influencing these elites: "In terms of doing advocacy work as well, we focus as a national entity around national policy makers. We engage both the API and the LGBT congressional caucuses. We work with the White House. We work with federal agencies.” Similarly, Affinity's Kim L. Hunt described why this kind of work was important to Affinity, "We've taken it on (lobbying) as another strategy for work. Because it gets us in front of the influencers and decision makers, which ultimately helps because we want the world changed." The strategy of these groups to bring about the radical change they envision requires influencing the political arena.

And so we just celebrated our 20-year anniversary this past year and so we are finally hitting that grown and sexy stride in terms of... how we are thinking about building collective power to build the kind of political 
majorities we really need. Not just in our region but in the rest of the country to actually be able to... think about long term trajectory political interventions that we can make that can bring us closer to the sort of idea of beloved community.

- Paulina Helm-Hernandez, SONG Co-Director

In addition, the groups sometimes try to leverage support from other elites, including the GRM. In Q1, I discussed how the QLM groups try to influence the GRM agenda to be more inclusive of racial and economic justice issues. However, they also target the GRM to get from them tangible support and resources. Hunt described how Affinity tries to influence "those mainstream organizations, in terms of sharing resources, instead of coming to us as an outreach arm when they get grants. [Laughs]. And writing us into the proposal." Hunt's desire to be written into grant proposals reflects these groups' need to accumulate resources of their own.

Resource mobilization theory contends that groups focus on amassing substantial resources from elites, but though the QLM works to influence elites and build resources, it does not prioritize this work as its primary goal, nor does it seek to amass the amount of resources that other social movements have sought. These groups live within the contradiction of needing to mobilize resources from entities they are simultaneously organizing against and building alternatives to. They have done some work to influence elites that increase their resources, but have also found ways to function with few resources. Consequently, resource mobilization theory provides only limited utility for understanding the QLM. Piven and Cloward (1979) offered a relevant challenge to resource mobilization theory, so I turn now to an examination of disruptive power theory. 


\section{Disruptive power theory.}

Social movement scholars Piven and Cloward (1979) positioned their "disruptive power" analysis in direct contradiction to the prevailing resource mobilization theory. While they agree with the basic premise of resource mobilization theory that oppressed people lack the resources to make the changes they want to see, Piven and Cloward prescribe a different solution. Whereas resource mobilization theory calls social movements to mobilize great resources, Piven and Cloward argue that movements instead build strength in their ability to withdraw - withdrawing production, withdrawing payment, withdrawing participation, withdrawing compliance. Piven and Cloward believe that poor people have power (for brief periods in times in particular historical circumstances), which is exerted by their withdrawal from participation in regular life.

The QLM organizations embrace the tactics prescribed by Piven and Cloward. Most engage in protests and other forms of direct action. They have organized against numerous government agencies about a range of issues, including picketing welfare offices, blocking access to immigration detention centers, organizing against Medicaid offices, and protesting policing policies such as NYC's "Stop and Frisk."

Additionally, Piven and Cloward (1979) argue that elites react to rebellion and disruption but do not make changes in response to pressure from institutions. Consequently, Piven and Cloward argue that building large institutions is a mistake. They contend that building large bureaucratic membership institutions actually undermines success, because these institutions are too difficult to manage, cannot succeed, and distract momentum and resources away from engaging in activities that actually can 
succeed. Piven and Cloward argue that social movements are successful when they focus on mobilizing, but not when they organize communities into structures. They fault organizers for failing do what they actually can do (engage in disruptive direct action and mass protests), when they instead try to do what they can't do (build influential institutions).

In this regard, the queer liberation movement is engaging in strategies that Piven and Cloward would regard as unlikely to succeed. Although these QLM organizations clearly focus on mobilizing their constituents for direct action, which Piven and Cloward would support, they also engage in institution (or counterinstitution) building, which Piven and Cloward oppose. The QLM may place a lower priority on building institutions than do some other social movements, but nevertheless they do prioritize it to a certain extent. In doing so, they challenge Piven and Cloward's prescription for successful social movements. It remains to be seen if the QLM can defy Piven and Cloward's prognosis by succeeding.

Piven and Cloward (1979) offer another central argument: social movements fail when they seek government acceptance of their ideas (a marker of success in resource mobilization theory). They believe that government acceptance is never full, and partial acceptance results in changes in the political climate and dampened constituent motivation. Such acceptance also often leads to the co-option and institutionalizing of issues, rather than to the continued disruption needed to make changes.

In this regard, the queer liberation movement complicates Piven and Cloward's theoretical framework. On the one hand, these organizations do engage in lobbying 
efforts aimed to get elected officials and government agencies to accept the demands of the organizations. This tactic runs counter to Piven and Cloward's prescription for how social movements should work. On the other hand, the queer liberation organizations do not employ lobbying as their only strategy and they do not see government acceptance as their goal. For example SRLP's Dean Spade argues that LGBT should stop prioritizing whether the law says "good things" about queer people, and focus more on changing the material conditions of people's lives. The reforms sought by the QLM are only steppingstones towards a larger vision of societal transformation. For instance, even though SRLP has met with government officials about changing policies that govern the treatment of incarcerated transgender people, their real goal is prison abolition.

As discussed in previous chapters, these larger visions separate the queer liberation groups from the GRM, whose goals are limited to reform. In our interview, Reina Gossett addressed this distinction: "It's important for those more equality based organizations to shift away from thinking that LGBT access into the military or access into institutions like marriage are the most pressing ones of our time.” In previous sections, I addressed how comments like that reflect the differing agendas of the GRM and these groups. However, that there is additional significance to Gossett's sentiments, or the related sentiments conveyed here by allgo's Rose Pulliam: "We sometimes find that policy wins can be more problematic than they are good because they create an illusion that you've made progress when in fact the real lived lives of people are not changed significantly." Comments like these reflect QLM groups' frequent skepticism, if not outright opposition, to government acceptance that results in the institutionalization 
of issues. Their opposition to hate crime legislation and their critiques of marriage equality serve as examples of how these organizations work to avoid government cooption and institutionalization of their concerns. As ALP's Cara Page said, “we are always struggling with state.”

Piven and Cloward's theory of disruptive power explains aspects of the QLM, but it does not explain it fully. By engaging in protests and disruption, the QLM enacts a central tenant of Piven and Cloward's theory, but by also building institutions, the QLM complicates that theory. Similarly, the QLM engages in lobbying with political elites (which contradicts Piven and Cloward) while simultaneously resisting government acceptance and co-option (which aligns with Piven and Cloward). Consequently, the disruptive power theory has limited utility for understanding how the QLM operates, and must be supplemented by other theoretical frameworks in order to explain the QLM.

\section{Political process model.}

McAdam (1982) developed the "political process" model as an alternative to resource mobilization. This model describes how dynamics both inside and outside a social movement contribute to protest and insurrection. McAdam posits that social movements develop as a result of certain political opportunities, indigenous organizational power, and shared understandings of the problem (called "insurgent consciousness"). He argues that social, political, and economic contexts create political opportunities that are seized by groups of disgruntled people, who share a collective sense of injustice, and are organized (formally or informally) to work together to achieve their goals. 
Aspects of this model certainly apply to the QLM. Clearly, these organizations are united by shared understandings of problems, and prioritize building indigenous organizational power. They do so to a certain degree through resource mobilization, discussed earlier in this chapter, and through their base-building work, described elsewhere. In these regards, the political process model helps to understand the QLM.

However, a central tenet of the political process model is the idea that social movements develop in response to particular political opportunities caused by certain historical moments. Tarrow (1998) defined political opportunities as "consistent - but not necessarily formal or permanent - dimensions of the political struggle that encourage people to engage in contentious politics" (pp. 19-20).

These seven organizations have developed over the course of twenty years (the oldest is allgo, founded in 1985, and the newest is NQAPIA, founded in 2005), and have been working together closely in the past decade. During these three decades, neoliberal policies have increasingly shaped American life, dramatically shaping the issues these organizations care most about - the social safety net, poverty, the criminal justice system, immigration policies, healthcare access, and marriage politics. These are the very issues that these organizations have focused on; indeed, these organizations were created to address those concerns. So if thirty years of national policy can be considered a historical moment, then this social movement can be understood as having emerged in response to a political opportunity.

However, the political process theory put forth by McAdam, Tarrow, and others does not frame "political opportunity" so broadly. Instead, they refer to specific moments 
where the existing political system is vulnerable to a challenge and where activists take advantage of that opportunity to advance social change.

Because thirty years is too long to be considered a specific historical moment, the emergence of this social movement cannot be linked to any one specific relevant political opportunity or historical event. While some of the activists included in this study described how they have found opportune times (such as President Obama's first election or the Occupy movement) to push for specific changes, these occasions did not birth the movement, nor were they the primary focus of these organizations' work. Rather, the organizations were born in response to the more general political trends of the past few decades.

Downey and Rohlinger (2008) described how groups could lay the foundation for change by serving as incubators for direct action that happens in the future. Such an analysis provides a useful supplement to the political process model when examining the QLM. Generally, the movement has not responded to specific historical moments. Rather, these organizations see themselves as engaged in work over the long haul. Audre Lorde (1984) famously said, "Revolution is not a one-time event. It is becoming always vigilant for the smallest opportunity to make genuine change" (pp. 140-141). This quote is featured on ALP's website and reflects the perspective of the other groups in the queer liberation movement. The QLM groups are working to be ready for specific opportunities, but they are invested in long-term, consistent efforts at social change. They are building bases equipped to work together for years. SONG's Caitlin Breedlove explains the 
difference between focusing on a particular moment and building a movement that will fight for years:

Campaigns can be heartbreaking because we lose a lot. But I think that what's left, coming from a region where we've consistently lost every mainstream LGBT policy battle and yet continue to be an organizing family that feels more committed than ever to launch a movement, is that losing isn't the worst thing in the world. We still have each other, which is the most important thing.

The political process model has served as a useful framework for understanding the class-based organizations that emerged in the first half of the $20^{\text {th }}$ century. Those groups engaged in large actions and were usually short-lived (Armstrong, 2002, Piven \& Cloward, 1979). However, this model does not address the advent, since the 1960s, of identity-based organizations built for long-term work. Many have noted that political opportunities are too often unproductively reified as static moments and objective structures (Downey \& Rohlinger, 2008). For these reasons, this model offers little to a deep understanding of the mechanisms of the QLM.

\section{Conclusion.}

None of the four prominent social movement theories explored here offer a complete understanding of the QLM. Only Fraser's theory of perspectival dualism (Fraser, 1995; Fraser \& Honneth, 2003) aligns completely with the QLM. However this theory addresses the goals of social movements without focusing extensively on the behavior of social movements. (It also fails to address the role of identity, which will be discussed in the next chapter.) 
The other three theories, which focus on how social movements function, offer only limited utility for understanding the QLM. The theories of resource mobilization (McCarthy \& Zaid, 1977), disruptive power (Piven \& Cloward, 1979), and political process (McAdam, 1982) each explain aspects of the QLM, and prove useful for understanding how certain dynamics of the QLM reflect other social movement patterns. However, the QLM complicates all three of those theories in different ways, thus limiting the ability of any of those theories to fully explain the QLM. The QLM engages in protests and disruption, but is too focused on building institutions to be explained by Piven and Cloward (1979). However these institutions are not large, bureaucratic organizations, and are not entirely dependent upon the support of elites, so resource mobilization (McCarthy \& Zaid, 1977) fails to completely explain the QLM. And the political process model (McAdam, 1982) fails to address organizations built for longterm cultural change.

I have demonstrated that some of the canonical social movement theories have a degree of utility in explaining the QLM, but do not completely explain this social movement. I believe that the reason none of these theories provides satisfactory understanding of the QLM is because the QLM represents a new form of social movement. I turn now to a model developed by activist Chris Dixon (2014) that describes this new form of social movement that has emerged in the $21^{\text {st }}$ century. Dixon's new framework helps to fill in some of these gaps, explaining how some contemporary social movements are building counterinstitutions to do long-term protest work without amassing huge resources or depending entirely upon the support of elites. As such, it 
helps paints a fuller picture of the QLM than could be developed with just the dominant social movement theories.

\section{Another Politics}

\section{Introduction and overview.}

In the following section, I explore four themes I have identified that make the QLM different from the identity-based social movements that emerged in the second half of the $20^{\text {th }}$ century. These themes are: (1) pursuing radical politics; (2) building institutions; (3) how these institutions operate; and (4) strategic approaches to long-term vision. Other themes, related to questions of collective identity and engagement with other social movements, are explored in depth in the next chapter. To anchor these four themes, I use a framework called "Another Politics," developed by activist-scholar Chris Dixon. Dixon does not provide a sufficient theoretical for understanding the QLM, particularly because he does not substantially address the role of collective identity, and so in my next chapter I develop a theoretical frame of my own. However, Dixon offers a partial framework for understanding the QLM, and that framework is useful and relevant enough to address in-depth here.

Dixon's book Another Politics (2014) describes $21^{\text {st }}$ century social movements, based upon interviews with hundreds of activists in the USA and Canada. These activists are involved in many different social movements, including prison abolition, immigration, global justice, anti-violence, reproductive justice, Indigenous sovereignty, workers' centers, environmental justice, and anti-poverty. They critique the non-profit world, the political party system, and white anti-organization anarchist groups. They work at 
organizations seeking to build different kinds of anti-authoritarian, anti-capitalist social movements, including well known national groups (such as Critical Resistance, No One is Illegal, INCITE! Women of Color Against Violence, and the Occupy movement) and at small, local groups with less national recognition.

Dixon (2014) argues that these organizations are building $21^{\text {st }}$ century social movements that differ from preceding movements. He refers to this new form of social movements as Another Politics, describing a new form of activism aligned with antiauthoritarian, anti-capitalist, and anti-oppression politics. These new social movements are led by groups that he argues are developing a substantive link between the work of "against," which fight ruling institutions, and the work of "beyond," which develops liberatory alternatives to those institutions. Dixon contends that groups aligned with Another Politics engage in four core principles: (1) struggling against all forms of domination, exploitation, and oppression; (2) developing new social relations and forms of social organization in the process of struggle; (3) linking struggles for improvements in the lives of ordinary people to long-term transformative visions; and (4) organizing that is grassroots and bottom-up. He argues that these four principles are not entirely new; "When it comes to social movements, hardly anything ever is" (p. 7). But he believes that the synthesis of these four principles marks an important and powerful new social movement form.

Dixon is not alone in noticing recent developments in $21^{\text {st }}$ century social movements (Crass, 2013; Farro, 2014; Khatib, Killjoy, \& McGuire, 2012; LaMarche, 2014; Lustiger-Thaler, 2014; Touraine, 2014). Some have observed that recent years have 
seen many progressive organizations working outside of the "silos" that have characterized the left of the last 30 years, and standing in solidarity with other movements (Kriegman, 2006; LaMarche, 2014).

Activist Chris Crass (2013) also writes about contemporary social movements and shares Dixon's analysis. Both Crass and Dixon see contemporary movements for economic justice, immigrant rights, environmentalism, global justice, prison abolition, reproductive justice, and racial justice as interconnected, situated within a larger movement for collective liberation, and less siloed off from each other than the social movements of the 1980s and 1990s. While Crass' work is focused on interviews and his personal reflections about these new politics, Dixon uses many of the same ideas to develop a descriptive framework for understanding $21^{\text {st }}$ century social movements. Because he structures his work as a framework, Dixon's book can easily be used to examine the QLM. Dixon's book was published during my data collection and analysis. As I read it, I was struck by how many similarities I saw between the new social movements in his study and the social movement groups I was researching. Initially, I was not convinced of his model's applicability to the QLM, because Dixon turns much of his attention to anarchist groups, which the QLM are not. However, his study is not limited to anarchist groups, and his model includes groups operating through a variety of legacies of resistance and a range of political orientations. Dixon described these social movements as utilizing a synthetic approach: "they draw on a variety of influences and traditions... to stay critical, avoid dogmatism, and find what actually works... this synthetic approach is an eagerness to learn from diverse traditions and movements even 
while being critical of them" (p. 58). The range of political orientations included in this synthetic approach signaled to me that it might also apply to the QLM.

Upon closer examination of his model, I realized that it could certainly describe the QLM, although Dixon does not focus on queer groups. Dixon's study of $21^{\text {st }}$ century social movements makes clear that although the queer liberation movement is a new kind of LGBT social movement, it does have commonalities with other contemporary movements; the QLM, though new, is not unique. The dynamics I see in the QLM are reflected in other (non-queer-specific) social movements emerging in the $21^{\text {st }}$ century. This chapter situates the QLM in the context of this significant change.

Although Dixon makes occasional connections to various theoretical frameworks and ideologies such as Black feminism and Marxism, he does not explore those connections in tremendous depth. Additionally, his work is largely descriptive, with almost no focus on social movement theory. In this chapter, I take his descriptive framework and situate the queer liberation movement (largely unexplored in his book) within it.

\section{The work of "against."}

Dixon contends that Another politics involve creating links between the work of "against," which fight ruling institutions, and the work of "beyond," which develops liberatory alternatives to those institutions. This section focuses on the radical politics of the QLM, which situate it against many ruling structures, values, and institutions of American life. 
One of the most important ways in which the QLM differs from the GRM and other identity-based social movements of the $20^{\text {th }}$ century is its pursuit of an expansive and radical political agenda. Most identity-based social movements function in pursuit of recognition within and equal access to social institutions and laws. The QLM's agenda is much broader than that. Dixon's framework of another politics makes clear that this is common for many of the social movements that have emerged in the $21^{\text {st }}$ century. Dixon describes them as "struggling against all forms of domination, exploitation, and oppression," characterizing this as a central principle of another politics. In this section I will explain the core concepts of this principle (the "four antis") and explore how the QLM enacts them. I will then return to Nancy Fraser's theory of perspectival dualism, explaining how this theory fits within Dixon's principle as a conceptual tool for understanding the QLM.

The QLM, like the other groups that share another politics, works to resist multiple forms of oppression. Rather than focusing on the single-issue politics that define the GRM and other identity-based social movements, many $21^{\text {st }}$ century social movements engage in multi-issue work against numerous forms of domination. Whatever social justice issue any individual group prioritizes is connected to other forms of oppression.

The "synthetic approach" described earlier makes possible the merging of a variety of political beliefs and goals that form another politics. Dixon explains that this convergence is centered on the politics of four "antis": (1) anti-authoritarian politics; (2) anti-capitalist politics; (3) anti-oppression politics; and (4) anti-imperialist politics. 
Merging these four "antis" results in social movements that work against multiple forms of domination, exploitation, and oppression. These politics are summarized in Table 8.1. The QLM shares those four politics and, thus, Dixon's framework provides a useful model for understanding the QLM.

Table 8.1

The four "antis" of the QLM's politics, as delineated using Dixon (2014)

Core principle: Struggling against all forms of domination, exploitation, and oppression.

\begin{tabular}{|l|l|l|l|}
\hline $\begin{array}{c}\text { Anti \#1: } \\
\begin{array}{c}\text { Anti-Authoritarian } \\
\text { Politics }\end{array}\end{array}$ & \multicolumn{1}{|c|}{$\begin{array}{c}\text { Anti \#2: } \\
\text { Anti-Capitalist } \\
\text { Politics }\end{array}$} & $\begin{array}{c}\text { Anti \#3: } \\
\text { Anti-Oppression } \\
\text { Politics }\end{array}$ & $\begin{array}{c}\text { Anti \#4: } \\
\text { Anti-Imperialist } \\
\text { Politics }\end{array}$ \\
\hline Rejection of the State & $\begin{array}{l}\text { Opposing capitalist } \\
\text { relations }\end{array}$ & $\begin{array}{l}\text { Sees power relations } \\
\text { as fundamentally } \\
\text { intertwined }\end{array}$ & $\begin{array}{l}\text { Opposing } \\
\text { imperialism }\end{array}$ \\
\hline $\begin{array}{l}\text { Critique of } \\
\text { Vanguardism }\end{array}$ & $\begin{array}{l}\text { Avoiding replicating } \\
\text { power relations in } \\
\text { movements and in } \\
\text { day-to-day lives }\end{array}$ & $\begin{array}{l}\text { Decolonization } \\
\text { framework }\end{array}$ \\
\hline & & $\begin{array}{l}\text { Transforming systems } \\
\text { of domination and } \\
\text { shifting society's } \\
\text { power relations }\end{array}$ & \\
\hline & & & \\
\hline
\end{tabular}

\section{Anti \#1: Anti-authoritarian politics.}

The first "anti" is anti-authoritarian politics, which oppose the social relations of hierarchy and domination found "in states, wars, borders, workplaces, prisons, schools, neighborhoods, families, and other sites" (Dixon, 2014, p. 64). Those engaged in antiauthoritarian politics include anarchists, unsurprisingly, but also prison abolitionists, antiracist feminists, activists involved in indigenous struggles, and others. Anti-authoritarian politics shares three central features: rejection of the state, non-hierarchical organizing, and critique of vanguardism. I will briefly explore each of those features and how they 
apply to the QLM.

\section{Rejection of state.}

Dixon describes how rejection of the state is a common trait among social movements sharing another politics. Some groups reject the most repressive aspects of the state, while others reject the state altogether. All social movements sharing another politics share a commitment to mobilization to resist oppressive government policies.

As indicated by their focus on targeting criminal justice and immigration systems,

the QLM shares this feature. "The most exciting strategies I see around the country," said SRLP's Dean Spade “are strategies to stop the expansion of criminalization and immigration enforcement." They do not merely seek reform of these systems, they work toward prison abolition and a complete overhaul of the immigration system. The QLM organizations see both state-run institutions as oppressive to the basic fabric of society, as illustrated by the following quote from ALP's Trishala Deb, while speaking at the 2007

\section{US Social Forum:}

We can see through the myth of democracy - that U.S. citizens and immigrants alike had no choice and no power in determining the outcome of at least the last two presidential elections, and the prison industrial complex insures that many working class and poor people of color will never be entitled to participate in this imaginary democracy.

Additionally, the QLM's work on other issues (beyond criminal justice and immigration) is informed by similar critiques of the state. Many of the groups have organized against different laws requiring people to register with the state by getting official identification (e.g., the Real ID Act), because of their impact on homeless people, transgender people, and immigrants. 
Similarly, when QEJ's Amber Hollibaugh described how access to the military or marriage were never on her agenda for queer activism, part of her vision included a clear critique of the state: “I didn't want us to have wars, I didn't want us to have armies, and I did not want to register my relationship with the state." This lack of trust in the state was evident in many of her comments.

This creates an interesting tension, because QEJ has also worked to strengthen the social safety net (e.g., TANF), and that activism is, in itself, a form of expanding, and thus empowering, the state. Other groups in the QLM similarly challenge state oppression while simultaneously strengthening aspects of the state that they view as beneficial. They differ from their anarchist peers, who are opposed to the state altogether. Rather, they are opposed to the ways in which the state subordinates and oppresses certain communities. At no point, however, do these activities that strengthen aspects of the state negate the QLM organizations' critique. These organizations remain deeply critical of and resistant to state power, as illustrated by SONG's Paulina Helm-Hernandez: "There is so much violence in our communities that trickles all the way down from violence from the state, violence from institutions that shape our lives." Many of these activists shared this analysis of how LGBT communities suffer violence at the hands of the state. Their opposition to hate crime legislation, for example, is rooted in this analysis:

It enhances the punishing power of the system that is actually the main perpetrator of violence against us. In the lives of SRLP clients, the most common perpetrator of violence is the police or corrections officers or immigration officers. So what does it mean to add power to that system which is providing no relief to us?

- Dean Spade, SRLP Founding Director 
These groups often identify the state as their target. For example, ALP's Cara Page characterized all of ALP's work as a rejection of the state: "we know the state is not preserving our need to exist... our work has always been centered around resistance to the state." The Roots Coalition (to which all of the QLM belonged) issued "Queer and Trans Peoples Resolution for the Safe Self-Determination of Our People” (Roots Coalition, 2010) which made clear how they view the state as antagonist, when they declared their desire to:

build a national movement of our people to fight the state sponsored destruction of our communities: We do hereby establish our interdependence to one another to ensure our peoples' Safe SelfDetermination; to abolish the state privileging of marriage or certain kinds of heteronormative families, kinships and communities...

While their complicated relationship with the state (strengthening some aspects of government while also critiquing and rejecting its reach and abuses) clearly separates the QLM from anarchist groups who share another politics, it aligns the QLM with some of the other another politics movements who clearly share this aspect of anti-authoritarian politics.

\section{Critique of vanguardism.}

Another central feature of anti-authoritarian politics is a critique of vanguardism, which Dixon (2014) defines as organizations directing a social movement, based on their own political priorities, by trying to "enlighten" others through raising community members' political consciousness. Movements sharing another politics characterize this approach as paternalistic, elitist, and antithetical to movement building, insisting that “oppressed people don’t need to be told how to win their own liberation" (p. 66). 
To a certain extent, the groups in the QLM do engage in political education with their constituents, running classes, trainings, public forums, and schools, for community members. Sometimes these events focus on raising political awareness. For example, Affinity, QEJ, and SONG have organized public forums to raise awareness about political issues and potential solutions, and allgo uses arts programs to facilitate political conversations. In pursuing these activities, the QLM is not aligned with the principles of another politics.

However, the vast majority of the QLM's community education efforts do not focus on political consciousness-raising but instead on teaching social movement history (e.g., in Affinity's program for young scholars), explaining how the law works (e.g., in "Know Your Rights" trainings organized by ALP, QEJ, and SRLP), building organizational capacity (e.g., in NQAPIA's and SONG's technical assistance work with community groups), and/or teaching tools and tactics for activism (e.g., in activist schools run by Affinity, QEJ, and SONG). These forms of public education focus more on skill building than the type of dogmatic political consciousness raising eschewed by groups sharing another politics (Dixon, 2014, p. 66). According to Dixon, “people don’t join movements because we tell them how to think, but because we suggest how they can participate" (p. 60) suggesting that, by prioritizing skill-building activities over political consciousness-raising, the QLM are in line with, not opposed to, the stance on vanguardism held by groups sharing another politics.

\section{Anti \#2: Anti-capitalist politics.}

The second of another politics" "four antis" is anti-capitalist politics. Dixon 
(2014) explains that anti-capitalism opposes capitalist social relations. In doing so, some organizers drew on established theoretical frameworks, from Marxism to anarchism, but others formed anti-capitalist politics from struggles "against borders, prisons, environmental destruction, militarism, poverty, the mainstreaming of queer politics, university restructuring, animal exploitation, and cuts to public services" as well as from engagement in union organizing campaigns, workers' centers, Indigenous land struggles, and labor solidarity work (p. 67). Dixon claims that these shared politics are clearly a response to over 30 years of battling neoliberalism. He contends that although not everyone engaging in another politics has participated in overtly anti-capitalist struggles, they have all been influenced by those struggles against neoliberal policies.

The QLM shares this critique of neoliberal policies and frequently critiques capitalism. When SRLP's Dean Spade discussed the issues facing transgender communities, he very directly situates them inside American capitalism: "Those kinds of really material, harmful conditions that are shortening our lives... are being exploited and increased by neoliberal austerity measures.” Similarly, QEJ's Amber Hollibaugh describes her activism as operating in a capitalist context that informs her work:

I feel really actually quite terrified about the world as it now exists. The kind of economic, the kind of sucking the world dry for a dollar, seems to me to be even worse - though it was hard for me to imagine 30 years ago that it could get worse. And the idea that 'bling and profit over human beings' is really more and more a credible idea, people don't even examine it with any kind of question, I find really terrifying.

This critique of capitalism informs the approach taken by the QLM organizations. For instance, the decision to prioritize movement building over electoral politics comes 
from an understanding of the limitations of electoral politics in our current economic system. This is evident when QEJ's Kenyon Farrow, ALP's Cara Page, and allgo's Rose Pulliam each insisted that anti-discrimination laws would not make their communities equal under capitalism. Instead, they seek broader transformations in society. Still, not all the QLM groups overtly presented anti-capitalist politics. Some (Affinity and NQAPIA) never explicitly mentioned capitalism or neoliberal policies. However, even these organizations articulate the impact of poverty and cuts to public services upon their communities, and they engage in related work. These findings suggest that they are generally aligned with the QLM's critique of capitalism, in practice if not in language.

Finally, all seven organizations belonged to the Roots Coalition, an incubator of this Queer Liberation Movement. According SONG's Caitlin Breedlove, one of the primary reasons that the Roots Coalition was formed was "to challenge neoliberalism, particularly how it affects our communities." Although the seven organizations may implement it in different ways, the movement to which they all belong clearly holds anticapitalist politics.

\section{Anti \#3: Anti-oppression politics.}

The third "anti" is anti-oppression politics. This term reflects an array of politics and practices "aimed at confronting and transforming intersecting systems of exploitation and oppression" (Dixon, 2014, p. 71), including racism, patriarchy, heterosexism, capitalism, and ableism. Dixon argues that contemporary social movement activists' understanding of anti-oppression examines how those different systems shape and mediate each other. This understanding has been informed by different kinds of activism 
and politics, including anti-colonial, anti-war, socialist, feminist, Black Power, disability justice, global justice, and others. However, the most significant influence has been antiracist feminism. For another politics activism, "anti-oppression politics is an effort to carry radical women of color feminist ideas into a set of principles and practices" (p. 72). Intersectionality is often explicitly named as a guiding principle, and movements sharing another politics understand power relations to be fundamentally intertwined.

Prior to this chapter, I devoted a lot of space to addressing how the QLM employs the black feminist framework of intersectionality, and the next two chapters explore how U.S. Third World feminist ideas inform the work of the QLM. Those sections about black feminism and U.S. Third World feminism make it abundantly clear how the QLM enact anti-oppressive politics. Consequently, I will not address this issue in this section. I return to only one example here, from Trishala Deb's immigration policy speech that I analyzed in Chapter 6. In that speech, Deb included critiques of capitalism, neoliberalism, the criminal justice system, ICE, heterosexism, and the military. She presented each of those systems as intertwined, functioning in concert to oppress queer immigrants. It exemplifies how all of the organizations in the QLM hold anti-oppressive politics.

\section{Anti \#4: Anti-imperialist politics.}

The final "anti" central to another politics is anti-imperialist politics. Dixon defines imperialism as the ways in which countries in the global north dominate countries in the global south economically, politically, culturally, and/or militarily. It also includes the colonialization and oppression of Indigenous peoples in the Americas. "Antiimperialism as it is developing in another politics opposes imperialism and the 
colonialism that it rests upon" (Dixon, 2014, p. 75). These $21^{\text {st }}$ century social movements see themselves as aligned with Indigenous peoples across the globe that have resisted colonialism for centuries. They see current battles (including Mexican Zapatistas, Palestinians struggling with Israeli occupation, American wars of occupation in Afghanistan and Iraq, and American Indigenous struggles for sovereignty) as part of a lineage connected to movements in Latin America, Asia, and Africa during $19^{\text {th }}$ and $20^{\text {th }}$ centuries that defeated formal European colonialism.

Movements sharing another politics grapple with the ideas of solidarity and "being a Zapatista where you are" which these movements understand to be remedies for the inclination of radicals to become focused on distant struggles in ways that prevent them from seeing similar battles at home. In this understanding, suggested by Zapatista representative Subcomandante Marcos, solidarity requires recognizing and building connections between far away struggles against imperialism and those taking place locally (Dixon, 2014).

The groups in the QLM do not focus on international work and do not prioritize their work battling imperialism, yet anti-imperialist politics run throughout much of their work. When ALP, QEJ, and SONG discuss their immigration work, they constantly frame it through an explicitly anti-imperialist lens, in which they take public stands against imperialist US foreign policy and also make connections to Indigenous sovereignty movements in the United States. This can be seen in the following quote from my interview with SONG's Paulina Helm-Hernandez, when she discussed SONG's approach to immigration reform: 
(We want) to actually transform the idea of citizenship, to talk about indigenous sovereignty and the role of indigenous communities, in defining that conversation. Of the pushing back of the white nativist movement that assumes that only white people have claim to the US, only white people have claim to legitimate citizenship in this country.

They also situate immigration policy as part of a global economy that benefits the global north at the expense of the global south, and consequently they advocate for immigration reforms that are designed based upon this understanding. This is clear in the following quote from ALP's Trishala Deb:

As people in the United States, we must accept that the transnational economy that some people benefit from is completely dependent on the suppression of economic autonomy throughout the global south... What we will do is build a movement with our Indigenous comrades, with all people of color struggling for liberation, with all LGBTST and gender nonconforming people, and with our people at home- wherever that is, for justice, self determination, an end to imperialism...

The QLM organizations enact their anti-imperialist politics in different ways. Over the years, several of the QLM organizations (ALP, QEJ, SONG, SLRP) have been actively engaged in various anti-war campaigns.

Although none of the groups in this study are specifically Indigenous organizations, two QLM groups (ALP and SONG) are inclusive of many Indigenous members, and the organizations have been actively involved in struggles for sovereignty by Indigenous peoples in the USA, prioritizing the leadership of Two Spirit activists. In addition, the Roots Coalition, of which all the groups in this study were members, was co-founded by The First Nations Two Spirit Collective, a national group of activists that has partnered with all of the organizations in this study at various points.

At the 2007 US Social Forum, conversations about imperialism and colonialism 
were central to the all-day "Building A Queer Left” convening organized by QEJ and SONG, and attended by ALP and SRLP. Dozens of queer organizations spent the day situating their work within an anti-imperialist framework. Three years later, at the 2010 US Social Forum, the Roots Coalition (including the seven QLM organizations studied here) drafted a resolution (signed by 15,000 LGBT people at the Forum) that declared their intention "to secure our political and cultural liberation that has been denied for over 500 years of colonization and oppression, resulting in the silencing and erasure of our peoples" (Roots Coalition, 2010).

Despite this language from the Roots Coalition (to which all of the QLM groups belong), it is important to note that not all the QLM groups have individually engaged in explicit anti-imperialist politics. Affinity and NQAPIA do not appear to utilize this framework in their activities, although when I interviewed Kim L. Hunt and Ben de Guzman, I failed to ask specifically if they do. I did not ask anyone about antiimperialism specifically, but it was brought up organically by my other interviewees or in the other data from those organizations. This again situates Affinity and NQAPIA slightly differently within the QLM, as I will explore in Chapter 10.

However, all the QLM groups enact anti-imperialist politics in the way they indirectly utilize what Dixon calls a "decolonization framework" shared by another politics organizations. This framework includes a commitment to self-determination for everyone, in the US and abroad. Self-determination aligns within these politics because it rejects "power-over" and emphasizes people's ability to build their own power and solve their own problems. This analysis also connects the "colonial present" of settler states to 
the imperialist relations that they create (Dixon, 2014, p. 79). Self-determination is a central value for the QLM. It is explicitly named in the mission statements of several of the organizations and came up numerous times during my interviews. So although only some QLM groups explicitly name anti-imperialist politics, this decolonization framework is implicitly utilized by all of the groups, by virtue of the premium they place on self-determination.

\section{The synthesis of all four "antis."}

Dixon (2014) documents how the framework of another politics brings together the four "antis" of anti-authoritarian, anti-capitalist, anti-oppression, and anti-imperialist politics. The synthesis of these four "antis" leads to the first principle of another politics as "struggling against all forms of domination, exploitation and oppression." Dixon argues that all the $21^{\text {st }}$ century social movements in his study share this principle.

Because of the question of vanguardism, Dixon's model does not entirely apply to the QLM. However, the vast majority of his framework does apply to the QLM, and consequently I find it useful as a way of categorizing and understanding the politics of the QLM, and situating them in a broader context of $21^{\text {st }}$ century social movements.

I contend that, by fighting on multiple fronts, the QLM can be categorized as being aligned with the another politics principle of struggling against all forms of domination, exploitation, and oppression. The QLM sees liberation as connected to issues of racial justice, gender liberation, and economic justice. This situates them as connected to the lineage of the radical queer groups that emerged as part of the New Left in the 1960s. The Gay Liberation movement engaged in redistributive politics, combined with 
identity politics (Armstrong, 2002). It was connected with the politics of the New Left, and it viewed gay liberation as inextricably linked with structural societal transformation (but also embraced identity politics values of pride and visibility), and pursued these goals with smaller, ephemeral groups. Similarly, the subsequent Gay Power Movement identified first as revolutionaries, and second as gay. This was a product of the socialist ideals of the New Left. Gay Power activists argued that gay freedom could not be achieved without freedom for workers, women, and Blacks. They aligned with revolutionary projects of the left, and aimed to overthrow capitalism to create a liberated society (Armstrong, 2002, p. 91).

By representing low-income queer and trans communities of color, the modern QLM works with people who face multiple forms of domination, exploitation, and oppression:

A lot of the issues that we have found to be a common thread across the board have been issues of criminalization against our folks; issues of racial and economic justice... the vast majority of our people actually are facing pretty severe survival issues. Pretty explicit survival issues such as, dealing with poverty; dealing with lack of access to healthcare; we have a huge and growing immigrant community in the south - a lot of undocumented folks in our community very much working very low wage jobs, working in the very informal economies that have no benefits, no safety net built into them; a lot of violence.

- Paulina Helm-Hernandez, SONG Co-Director

Because their communities face so many different issues, the QLM deliberately works to combat these many different forms of domination, exploitation, and oppression. All the interview participants echoed SRLP's Reina Gossett's points:

We are looking at how we can create structural change so that the lives of people of color and low income people, and people with disabilities, 
people with HIV/AIDS, who are incarcerated, who are homeless are not just materially better but people feel safe in their bodies, safe inhabiting space. So that people are not having to navigate police violence or violence from the state in terms of incarceration or detention centers. I think all of those issues are really inextricably linked. So we have to think about how can we create our work and how can we have an impact that addresses all of them.

The another politics principle of struggling against all forms of domination, exploitation, and oppression is a useful way of understanding the politics of the QLM, and how the QLM reflects the politics of current social movements.

I return now to Fraser's (1995) theory of perspectival dualism, because by holding politics that are anti-authoritarian, anti-capitalist, anti-oppressive, and anti-imperialist, it is logical that the QLM's broad agenda encapsulates both claims of redistribution and recognition.

To illustrate how Dixon and Fraser can be brought together to understand the QLM, I developed Table 8.2. This table takes three of the Queer Liberation Movement's main targets of influence (the criminal justice system, the immigration system, and social service systems) and integrates both Dixon's another politics framework and Fraser's perspectival dualism theory. 
Table 8.2

QLM's Targets of Influence, Delineated using Dixon (2014) and Fraser (1995)

(Redistribution Goals are in regular blue font. Recognition Goals are in green font, in italics.)

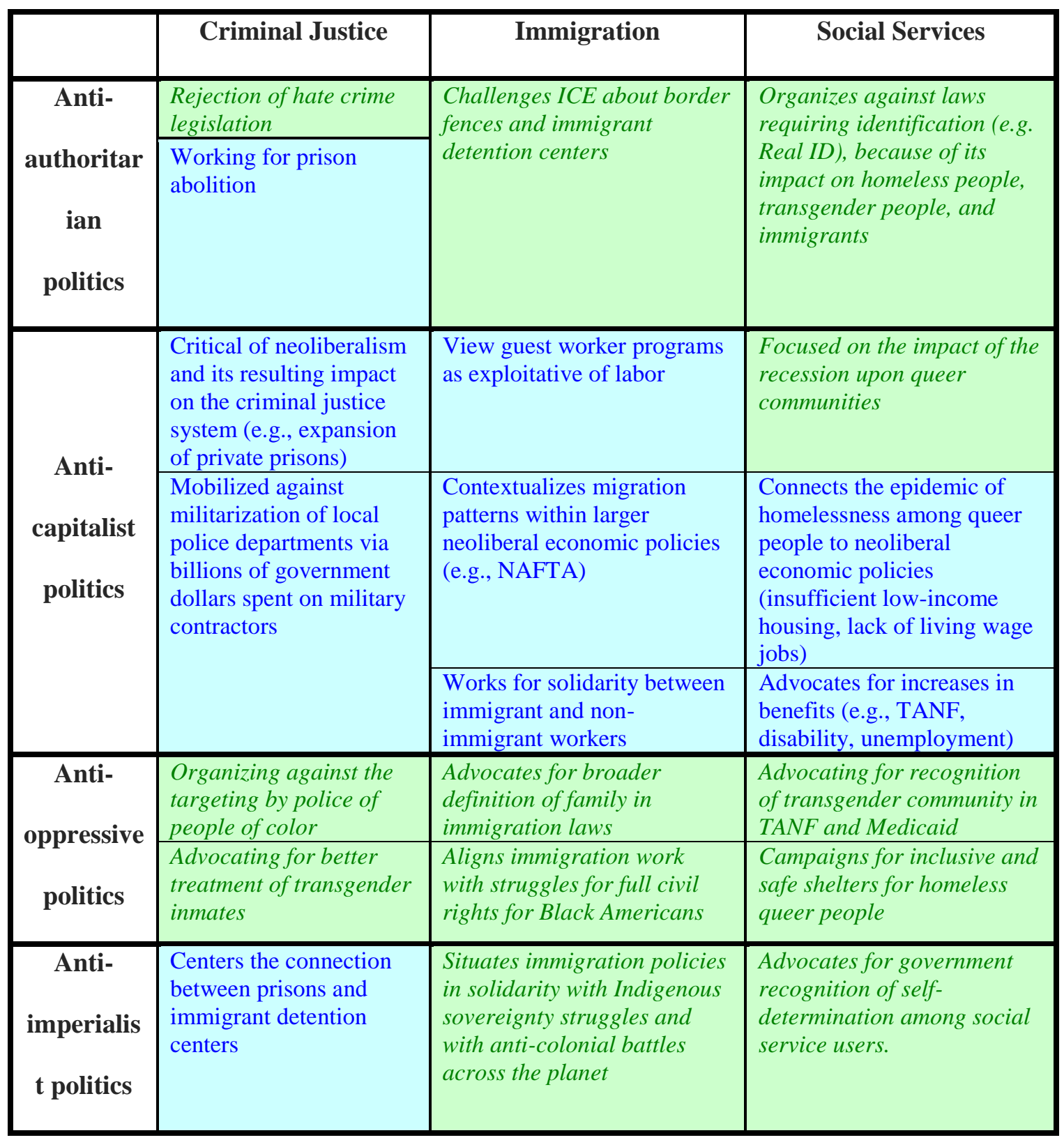

These specific targets of influence, which are categorized here within Dixon's four antis, also reflect the QLM's broader goals of racial and economic justice. Table 8.2 
illustrates how the QLM's broad goals of racial and economic justice are aligned with those of the other $21^{\text {st }}$ century social movements that Dixon studied. This suggests that the QLM is reflective of a new form of social movement.

This table illustrates how for each of those targets, there are both redistributive and recognition-based goals. Perspectival dualism (Fraser, 1995) claims that most forms of injustice contain elements of both economic and cultural harms, and this table demonstrates how the QLM chooses targets that address both distribution-based "injuries" and recognition-based "insults." The academic literature does not offer examples of the Fraser's theory in action, but the QLM offers an example of at least one social movement that enacts perspectival dualism. Dixon's description of a new $21^{\text {st }}$ century model of social movements suggest that the QLM is not alone in its pursuit of both redistributive and recognition-based goals. Indeed, it seems possible that, by struggling against multiple forms of domination, exploitation, and oppression, all of the movements Dixon addressed might constitute examples of Fraser's theory, but such an analysis is beyond the scope of this research project. What this research does demonstrate, however, is how Dixon and Fraser are compatible frameworks for understanding at least one social movement: the QLM.

\section{The work of "beyond."}

Dixon contends that another politics involve creating links between the work of "against," which fight ruling institutions, and the work of "beyond," which develops liberatory alternatives to those institutions. After focusing thus far on the "four antis," 
which described what the QLM is against, this section focuses on the way the QLM builds alternatives to dominant structures, values, and institutions.

Another core principle of another politics is "developing new social relations and forms of social organization in the process of struggle." This involves developing liberatory alternatives to the way the world is currently structured, linked to the long-term vision of the world activists want (p. 126). One of the central ways that this is done is by building the infrastructure of a new society (building 'counter power'), a concept that I explore now.

\section{Prefigurative politics.}

In developing new social relations and forms of social organization, many activists are dedicated to "prefigurative politics" (Dixon, 2014). This refers to activists' efforts to establish the world they aspire to create through the methods they use to fight in this world. The world to which the QLM aspires is reflected, in part, in Table 8.2. The QLM's politics of "the four antis," and its pursuit of both economic and cultural goals, reflect the racial and economic justice agenda of the QLM as well as its vision of how the world could be. Prefigurative politics are the methods used to pursue this vision. Examples of these efforts include using deliberately democratic means of decision making, building institutions through which people can self-organize, and prioritizing listening and trust building (Dixon, p. 83). These examples represent a shared commitment among new social movements to the idea that "how we get ourselves to a transformed society (the means) is importantly related to what that transformed society will be (the ends). The means prefigure the ends" (Dixon, p. 83-84). 
These new forms of social relations and organizations manifest feminist theoretical constructs of social movements (e.g., Jakobsen, 2005). For instance, Native feminist anti-violence activist and scholar Andrea Smith described how social movements must work against existing models while simultaneously creating their own:

On the one hand, it is necessary to engage in oppositional politics to corporate and state power by taking power. Yet, if we only engage in the politics of taking power, we will have a tendency to replicate the hierarchical structures in our movements. So it is also important to "make power" by creating those structures within our organizations, movements and communities that model the world we are trying to create (Smith, 2005, p. 151).

Groups sharing another politics enact these theoretical arguments using a variety of prefigurative practices, including building and running counterinstitutions, and creating more egalitarian modes of interacting within movement contexts. The following sections examine these prefigurative models of another politics, and explore how the QLM enacts them. I begin with the building of counterinstitutions.

\section{Building counterinstitutions and infrastructure of a new society.}

Dixon (2014) describes how social movements sharing another politics create counterinstitutions that both address the needs of their communities and destabilize the dominant models, citing examples of food co-ops, free community health clinics, and land trusts. These counterinstitutions provide essential necessities for communities without depending upon or empowering the oppressive systems in which those services and goods are typically provided. In fact, they often aspire to drain support from those institutions. They also bolster broader movements and offer opportunities for people to practice democratic ways of working together. This model reflects the critiques made of 
identity-based social movements for seeking individual rights (and the corresponding access granted into existing institutions) at the expense of imagining larger structural change. For instance, feminist scholar Janet Jakobsen stated "Freedom need not be defined only by an increase in individualism; freedom could also be constituted through alternative social formations" (Jakobsen, 2005, p. 298).

Some of the QLM groups engage in the building of similar counterinstitutions, reflecting the values and politics of the QLM. This can be seen when SRLP's Dean Spade was discussing "a critical and discerning trans politics," one shared by the QLM, and declared that these politics require rejecting "invitations to inclusion in systems, arrangements and institutions that are deadly and monstrous." He argued that groups like those in the QLM already practice those politics:

We are already doing work to help each other survive these conditions. We are already doing work to dismantle the systems that shorten our lives. And we are doing work to build alternatives to the systems that exist. To build a world that we actually want.

There are numerous examples of this in the QLM organizations. For instance, Caitlin Breedlove described how SONG works with queer people of color living and farming in the rural south who have developed organizing centers and workers centers. These people survived the recession by living off the land collectively while developing organizing centers:

(There is) fierce and incredible organizing that comes from some of those communities, who are just like "we are rural people of color who are creating local economies, what do you know about it?" They are really thinking about that. And those are queer projects. We have clusters of members that insisted, "We want an organizing center." ... They are talking about straight up organizing centers where there are cottage industries coming out of that space, 
there are gardens in the back, there's youth political education happening in the evenings, there's childcare, there's support for sex workers. What they are talking about is totally different economies for taking care of each other."

These farming-organizing collectives are not officially part of SONG's non-profit structure, but are being created by SONG members, with support from SONG's infrastructure. Some of the other QLM organizations are building counterinstitutions within their more typical 501(c)3 structures. For instance, the Audre Lorde Project has a program called "Safe Outside the System" (SOS) that combats violence by using community-based strategies, rather than relying on the police. As described in Chapter Six, one of the projects that developed out of SOS is the "Safe Neighborhood Campaign," which has worked with local businesses and community organizations to build safe spaces in Brooklyn. Despite being organized from within a traditional 501(c)3 structure, this program is a perfect example of building counterinstitutions that serve the community without relying on existing models.

At the same time, QEJ's Jay Toole has spent the past several years, prior to and since QEJ's closure, working to create a homeless shelter specifically for LGBT homeless adults. This shelter ("Jay's House") is scheduled to open in the next year, and although it will work with the city, and thus participate in the system, it will nevertheless be a different model of a shelter than exists anywhere in the country. "Jay's House" will not only be the first LGBT-specific adult shelter in the country, it will also provide LGBT-centered services while connecting residents to queer activism.

To a lesser degree, the QLM organizations themselves are counterinstitutions. Although all seven groups utilize a 501(c)3 structure, they have built their institutions 
differently from most non-profits. I contend that even the QLM groups not mentioned above are essentially counterinstitutions by virtue of what they do and how they run. Dixon (2014) discusses the importance of building organizations that can struggle with dominant institutions or the state for legitimacy (p. 138). All seven QLM groups engage in exactly those struggles, whether with dominant institutions (such as the largest national LGBT organizations) or with the state.

\section{Tensions of working within a non-profit structure.}

Although the politics of the QLM can be understood as connected to the lineage of the radical queer groups that emerged as part of the New Left in the 1960s, it differs from them significantly in the way it has built institutions. In this regard, the QLM is much more aligned with the GRM and other social movements which, in the 1980s and 1990s, greatly expanded the use of the 501(c)3 non-profit structure. The relationship between radical politics and the non-profit structure merits examination.

Skepticism about institution building is not limited to Piven and Cloward (1979), particularly when the institutions are 501(c)3 non-profit organizations; a rich body of literature critiques the role of non-profits in social movements. As I discussed in Chapter 4, numerous critiques exist about the rise over the past four decades of non-profits in social movements (McCarthy, Britt, \& Wolfson, 1991; INCITE!, 2007; Kivel, 2007; Rodriguez, 2007). In addition to these general critiques of non-profits, other critiques relate specifically about the role of non-profits in the GRM (Caterine, 2014; Chasin, 2000; Cohen, 1999; Gamson, 2000; Halperin \& Traub, 2009; Hussain, 1997; Mananzala \& Spade, 2008; Nair, 2013, Sender, 2004; Vaid, 1995). These critiques primarily center 
on the idea that the non-profits depend upon funding sources (government and wealthy donors) that will support moderate reform but will never lead to true transformation, and that the organizational structure of non-profits, modeled on corporate America, is too hierarchical and elitist. Consequently, they argue that social justice non-profits provide services but do not lead to social change.

Because of the many critiques that exist of the non-profit model, many $21^{\text {st }}$ century activist groups described by Dixon (2014) have chosen not to form 501(c)3s and instead to function as unfunded volunteer-driven groups. Similarly, dozens of unfunded grassroots queer groups have also emerged in the past two decades, many of them radical groups and/or people of color organizations (Conrad, 2009b; Drucker, 2015; Espinoza, 2008). Some share characteristics that might position them within the QLM, but could not be included in this research project because I used the Astraea Foundation grantees as my eligibility criteria. (As groups that did not incorporate as 501(c)3 organizations, they cannot receive grants, and thus were ineligible to apply for the Astraea grant, and ineligible for this study.) Some groups explained their reasons for not forming non-profits, and cited concerns that are similar to those listed above. Some of the another politics organizations described by Dixon (2014) share with the QLM groups a commitment to using the structures of their organizations as a means of community accountability. I turn now to examine how the QLM struggle with both the limitations and the potential of nonprofit structure.

Dixon (2014) claims that the organizations built by activists with another politics incorporate new social relations that result in new models of institution building. The new 
models always bump against the dominant social order. He describes this tension as an important contradiction, "on the one hand, developing entirely liberatory social relations is never fully possible in a context of domination; on the other hand, developing such social relations is crucial to building visionary movements capable of transforming the world" (p. 83). This contradiction can be seen in the QLM groups. For instance, when I asked Kim L. Hunt about the values that undergird Affinity’s work, she indicated that they aspire to liberation, but the non-profit structure makes her question whether that is possible:

But I'm not so sure that we are always fighting for liberation because there's such messiness in that, and it's hard to put that in a box. And especially when you have this ongoing tension between the goals of your work and what's acceptable in how you do the work... And by that I mean, having staff, having all of those structures that are required in order to have a sustainable organization, means that at some point, inside your doors liberation can only go so far. Because you may or may not have a sustainable organization if you fight for liberation within those organizations or allow for in quotation marks liberation within the organization in the same way that you are pushing for it outside of your organization. So that dichotomy always is troublesome and thought provoking for me. Because I think we are fighting for liberation outside. But there are still these structures that we have inside that don't jive so well with that.

Interview participants said they think about these kinds of questions frequently. They are aware of the structural limitations of non-profits. They were not defensive about the critiques made of institutions; in fact they share those critiques. For instance, QEJ's Kenyon Farrow addressed how a 501(c)3 organization, dependent upon foundation funding, struggles to retain connection to its own values and goals:

It's always the challenge, even with our progressive funders, there is always the aspect of your pitching and kind of spinning your work to suit 
the funder. And that's just the reality of the situation, even with funders who are your allies, there is some level of which where you always have them in your head when you are trying to conceive of the work that needs to be done. If you are in charge of fundraising, or in some programmatic position of power, then that is something you have to think about, right? So then the work that we are able to do and the work that needs to be done, and what's even possible to do, becomes mitigated by sometimes intentional and sometimes unintentional centering around how we think we will get it funded.

Similarly, Affinity’s Kim L. Hunt discussed how the non-profit structure has affected the organization's politics and goals: "I think there is a level of mainstreamness and conservatism that has come with being institutions and 501c3's that has tamped down some of that radicalness.” She further stated that some of the QLM groups began with more revolutionary goals that, over the years, proved unsustainable in the non-profit structure: "There is an element of who we are in our work that is...not radical. And not pushing the envelope in the same way that our organizations may have pushed the envelope in their early days."

Because activists at these QLM organizations have spent so much time considering the strengths and limitations of the non-profit model, when I asked how they negotiate these tensions, they had language readily available. For instance, Cara Page talked at great length about how ALP handles the "borders" created by the non-profit structure. Here is just one of many examples:

We are moving people. We are moving across borders or wanting to undefine what borders are. The non-profit industrial complex has created borders. Geographical, political, financial borders. And so we are at a particular place where we always have to challenge ourselves to not fall into living inside of those borders or default to working inside of those borders. 
Most participants said that their groups' founders were aware of these pitfalls when they started the organizations. These were not lessons learned the hard way, after it was too late. Rather, most of the organizations were created by people who understood the challenges of non-profit structure from the beginning but, after weighing the pros and cons, decided to do it anyway. SONG's Paulina Helm-Hernandez explains how, even with the limitations of a non-profit structure, aspects of that structure enable their movement building work to grow:

It's not to say that the non-profit sector is the end-all-be-all of where all movement and liberation work needs to be incubated, but we know that it's an important mechanism in being able to not just secure funding but to bring a lot of that work to scale in a way that is supportive, that is more formalized, that is about also raising the visibility of it in a different way, or that is actually trying to formalize ways that leadership development is happening. So there is some things that are...that have to be incubated in organizations so they can grow to scale.

Despite their choices to operate within the non-profit structure, the QLM groups acknowledge that radical queer activism is not limited to non-profits. Participants discussed unfunded groups with which they partner, admire, or where they volunteer. They also discussed their own activism as not limited to the 501(c)3 arena. Others talked about the importance of not identifying the QLM's work as located only within the walls of their non-profits. This came up in several activists' discussion of QEJ's closure. For instance, SONG's Paulina Helm-Hernandez said, "We are not saying that QEJ's work is dead or the work is going away, because it's not. We know that the people who built that organization are movement people and will continue to be a part of the movement." ALP's Cara Page took this point further, when she talked about the dangers of only 
engaging in non-profit work:

And, again, if we want to go beyond borders and walls, my hope is we will keep moving as a body no matter where we are. Whether or not we have to put up a tent city, I hope that (the QLM groups) are still going to move together politically.... there is something to be said for a metamorphosis of how we are going to do our work. Because if we are literally thinking that closing the non-profit doors means the work of the organization or that community has stopped, we are in trouble. So really the question is: How are we accountable to elevating the legacy of QEJ while we keep doing our work around economic justice and freedom? And if we are not doing that then there's no reason to exist. If we are not really building the memory and still doing the work regardless of the 501c3 status.

These QLM groups have given a lot of thought to these issues, which reflects a similar thoughtfulness across the modern social movements utilizing the another politics framework. Dixon (2014) argues that the particular form of institution being built is not as important as is how the institution building is done. "The question is how selfconscious these organizations are about what they're trying to do and who they're trying to work with. What are the ways that their form helps or hinders that?” (p. 200). The QLM groups are clearly self-conscious about how their form helps and hinders their work. For instance, over the years, Affinity has embraced a concept called "critical justice."

Kim L. Hunt described that concept and how they use it to think about how they work within their 501(c)3 structure:

And that's the idea of really examining how you do your work and being aware if you are guilty of creating the same hierarchies and structures that we fight against in our social justice work. So that there is a constant critical look at how we do what we do. And we don't always do that well. But we try to examine. It's really hard. Especially when you've become a part of the non-profit industrial complex. There are just some things that come with that. We fight it at other places and then we create it in our organizations and in our work. And it's a constant battle. 
Hunt clearly recognizes how Affinity sometimes fails to live up to its own values, yet the organization continues to try. Most participants expressed similar sentiments regarding the contradictions within which they operate, which Dixon (2014) describes as common among another politics groups. He also contends that living with these contradictions is both inevitable and necessary: "We can't bring a new world into being as long as current systems call the shots. And yet we can't bring a new world into being unless popular movements can envision and create something new here and now" (pp. 83-84). I turn now to an exploration of the specific and concrete ways these QLM groups try "to envision and create something new here and now.

\section{How these institutions operate.}

\section{New ways of relating within organizations.}

Dixon (2014) posits that another politics organizations engage in a prefigurative practice that involves building counterinstitutions as well as creating more egalitarian modes of interacting within movement contexts. I have examined the creation of these institutions, and in this section I explore how these groups create new modes of interacting within those institutions. Part of their commitment to anti-oppressive politics is a commitment to "confronting the ways in which people replicate power relations in movements and in day-to-day lives" (Dixon, 2014, p. 74). Another politics organizations do this by creating intentional structures that shift power relations in the organizations. The prefigurative models of another politics involve new ways of relating within organizations, including organizing with horizontal orientation, affective organizing, transforming power relations, and organizing that is grassroots and bottom-up. I will 
examine each of these concepts individually.

\section{Non-hierarchical organizing.}

According to Dixon (2014), some $21^{\text {st }}$ century social movements reject corporate hierarchies and have developed alternative ways to lead their organizations and movements, which he refers to as non-hierarchical organizing, or organizing with horizontal orientation. He describes how another politics organizations engage in "horizontalism," taken from the Spanish "horizontalidad." This orientation aspires to direct democracy, self-management, and autonomy, rather than representative democracy or the empowerment of leaders. Horizontalism seeks to build collective power, and create more participatory and freer spaces for all (Dixon, 2014; Sitrin, 2012). A central part of this practice is non-hierarchal decision-making, such as collective leadership structures or consensus decision-making.

All seven QLM organizations engage in this practice, in a variety of ways, including (for most) consensus-based decision making. Sometimes this happens at the board level, sometimes at the staff level, and/or sometimes among volunteers. Another way the QLM groups engage in this practice is by shared leadership structures. NQAPIA, QEJ, and SONG each have a Co-Director model (rather than an Executive Director model); NQAPIA and SONG have each had Co-Directors since the organizations were founded, and QEJ started using a Co-Director model in 2012 (after nine years of using the Executive Director model). allgo and SRLP each function as a collective. Rose Pulliam explained that allgo is designed "so that each of the staff positions are all titled Director. And they all work as kind of a collective, so that no single person has authority 
over the other ones. People just work together." This model illustrates the participatory leadership representative of horizontalism. Similarly, Reina Gossett explained that SRLP is "a non-hierarchical organizations. We are run as a collective. There is no 'The Boss.' We are all Directors at the organization, all of the staff." SRLP's Mission Statement explains why they made this decision: "the working environment of an organization shapes the work, and for this reason we strive to create an environment that is nonhierarchical in structure and operates by consensus."

Only Affinity and ALP have Executive Directors. However, neither follows the typical Executive Director model. ALP's Executive Director has a discrete set of responsibilities and cannot make unilateral decisions about everything. ALP has a variety of Working Groups that guide their work (e.g., "Membership," "The SOS Collective," "TransJustice"), and the leaders of those Working Groups help develop organizational policy on various issues and help implement programs. Affinity's commitment to "critical justice" requires that the Director consult with community members who run their ongoing programs and groups. The community members have tremendous power to run the groups or programs as they want, consulting only with Affinity's Executive Director or Board of Directors if they need to increase their budgets or want to commit the organization to joining an ongoing coalition. Consequently, Affinity and ALP share important similarities with the other QRL organizations in the ways in which they practice horizontal leadership.

\section{Affective organizing.}

According to Dixon (2014), affective organizing is another new way of relating 
within organizations, and it is typical of the prefigurative models of another politics. Affective organizing involves building healthy relationships of genuine care, embracing the whole person, and "being nice." Affective organizing requires spending time building personal relationships with each other, rather than creating the functional or transactional relationships typically found in the non-profit model.

Affective organizing takes many forms; in the QLM it manifests in a variety of ways. For instance, when staff members of QEJ and SONG critiqued the GRM's organizing strategy (showing up to knock on doors in a town where there is a ballot initiative, and then leaving town when the campaign is over) they discussed how real movement building requires creating long-term infrastructure built on ongoing relationships. On the other hand, Affinity focuses on its members' emotional health of its members, as indicated in its Mission Statement: "Healthy shared leadership that does not expect martyrdom, but embraces reflection, succession, and rejuvenation." This concern with healthy leadership and healthy relationships illustrates Dixon's concept of affective organizing.

Other QLM groups are similarly concerned with the emotional connections between their members. ALP's Cara Page believes queer activists of color must constantly push themselves to build relationships with each other and make sure they leave no one out. She argued for ongoing reflection: "we constantly have to keep leaning in and asking of each other, how can we do this in an even more transformative, loving way?" Several other groups also talked about the role of love in their work. NQAPIA's online promotional video ends with a voiceover, heard over photos of NQAPIA activists: 
Believe in the infinite possibilities of love... Walk together, stand beside each other in your safety. Chant together. Swim hard together in the changing weather. Bond your spirits into peacefulness. Dream together. Love each other. Live together. Be together. Believe in love, if it's the only thing you believe in.

Not all the groups use this rhetoric, but it is clearly consistent with other organizations' commitment to creating relationships among community members that are more than merely official or transactional.

In different ways, all the QLM groups address this idea of creating deep relationships within the membership. Paulina Helm-Hernandez from SONG talked about poverty and complained about the same-sex marriage campaigns. Embedded in that topic, just in passing, she linked her concerns to this notion of relationship:

There's this idea that same sex marriage is going to lift everybody out of poverty. And what we are seeing is that it's actually not true. There are more and more people we know that are relying on the collective safety net of our communities... More and more people are slipping farther and deeper into poverty and more and more of our folks are relying on each other to be able to just barely survive, so what does it actually mean that we are placing all of our energy on marriage as this idea of a singular way of validating and creating family. That's actually not reflective of how most people are surviving. That's not reflective of how most people are actually living who are in poverty. And it's not reflective of what people have historically had to do in order to survive, which is to collectivize.

Here Helm-Hernandez indirectly references the importance of relationship building within social movement spaces. The development and maintenance of deep personal relationships is not only central to survival in our personal lives, but also in movement work. Helm-Hernandez describes how those collective personal relationships impact SONG's organizational priorities (e.g., towards poverty or marriage). In addition, both she and Caitlin Breedlove made numerous references to how organizing at SONG 
facilitates the interpersonal relationships that help community members survive and how those same interpersonal relationships then help SONG grow by creating a dedicated membership.

During the interviews, I did not think to ask about how the organizations put their rhetoric to work. This analysis focused on how my interviews revealed these activists' philosophical commitment to affective organizing, but did address how this commitment was put into practice. Future research may explore how it is operationalized.

\section{Transforming power relations.}

In Dixon's framework of another politics, prefigurative practice requires an additional new way of relating within organizations: transforming power relations. Transforming power relations involves deliberate plans to avoid replicating the dynamics of power found in general society, where some groups hold domination over other groups. Prefigurative practice intentionally builds consciousness and creates organizational structures that challenge power and privilege.

The QLM organizations address this issue repeatedly in their work. It shows up overtly on their websites and their mission statements. For instance, SRLP's Mission Statement says that SRLP works "to build a non-hierarchical collective organization that internally practices what we're struggling for by developing the leadership of low-income transgender, intersex, and gender nonconforming people of color.” Similarly, QEJ's Mission Statement stated that one reason they were created is "because although poor queers have always been a part of both the gay rights and economic justice movements, they have been, and continue to be, largely invisible in both movements." These 
organizations have made transformation of power relations part of their very reason for existence. They recognize how their constituencies have been oppressed and ignored by larger society, and they work to make sure their organizations operate differently.

ALP's Cara Page told me how The Miss Major-Jay Toole Building (home of several of the QLM organizations) was named to honor two low-income, gender nonconforming elder activists, not only because of their significant individual work, but also because low-income people, gender nonconforming people, and elders are too often ignored. Similarly, SRLP's Reina Gossett said:

A lot of times our elders are not honored. A lot of times the people who helped create the possibilities for this work are treated as disposable... So we named the building after these two people because they have an extraordinary legacy. And also because we want to prefigure how we treat people who have done incredible work but are often not considered valuable.

One way the QLM groups transform power relations is by making sure that people in subordinated positions in the outside world take leadership within the organizations. Participants talked extensively about how and why they prioritize the leadership of marginalized people:

We believe that the people who are navigating these issues are the experts on these issues and are really powerful and capable of changing these issues. So that's who we imagine we are most accountable to... Often those are the very people, whether they are incarcerated or whether they are low income; the very people who are navigating an issue are historically pushed out of social movements. So we think it's really important to not replicate that and to have people be central to the movement if it's an issue that they are facing.

- Reina Gossett, SRLP Director of Membership 
Gossett was not the only person to talk about how social movements "push out" certain groups. Others raised this issue, sometimes specifically referring to the GRM. An example of this comes from SONG's Paulina Helm-Hernandez, when she described how SONG and other QLM groups have been involved in "working against the continued attack and undermining and pushing out of LGBT people of color leadership, particularly trans people of color leadership being pushed out of the main LGBT movement." It is no surprise, then, that the overwhelming majority of leaders at these seven organizations (staff, board, and key volunteers) are people of color, transgender, and/or low-income.

All the organizations shared a commitment to this ideal, and each group knows this to be true of the others. For instance, when SRLP's Reina Gossett talked about QEJ's closing, she said, “QEJ was not just talking about issues of poverty. It was being led by and centered people who were currently living in poverty." The shared commitment to this principle is one reason these seven groups were drawn to each other.

The QLM organizations also attempt to transform power relations through their personnel policies. For instance, QEJ had an equal pay structure, because salary hierarchies usually reinforce class stratification by rewarding people whose economic privileges have provided them with access to the qualifications needed for those higher paying jobs. QEJ's founders believed that in social movement spaces, white people often work as directors and in development, and in those positions get paid more than the people of color who often work in the lower-paying positions of community organizers and support staff. So QEJ created a policy wherein all staff would be hired at the same base salary rate, regardless of position or title. (Part-time staff was pro-rated at the same 
salary as full-time staff.) Other QLM groups have similar or related policies, such as unlimited sick days, or community involvement in hiring decisions.

During the interviews, I did not think to ask follow up questions about how these approaches to personnel policies play out in the organization, or how other (nonleadership) staff experience them. As with the issue, above, of affective organizing, future research may explore if and how these personnel policies are transformative in other areas of the organizations.

\section{Organizing that is grassroots and bottom-up.}

Dixon (2014) identified another core principle of some $21^{\text {st }}$ century social movements as the prioritization of grassroots organizing, which involves developing relationships in the community that connect people to long-term struggles. This is carried out through democratic processes and collectives, where leadership is developed from below (the grassroots). Some of these themes were discussed in the previous section but there are other important aspects of this that merit consideration.

Most of the groups in the QLM have deliberately built their organizations to elevate the leadership of community members, especially those most disempowered in general society. Only NQAPIA did not address this issue; while I asked no specific question about this, all six other QLM organizations offered examples of how they elevate leadership from below. SRLP's Prison Advisory Committee (comprised of 70 incarcerated people) guides the organization's work, and a larger collective membership structure leads the organization. SRLP's “Collective Member Handbook” (Sylvia Rivera Law Project, 2009b) makes explicit their commitment to leadership from the bottom: 
"SRLP's commitment to maintaining a collective body that is diverse, our commitment to developing new leadership and under-heard voices in our community... may sometimes result in a determination that an applicant is not suitable for membership at this time." Other QLM organizations have similar advisory structures. For instance, a Welfare Project Director staffed QEJ's “Welfare Organizing Project” and worked together closely with a group of volunteer members on public assistance (the "Welfare Warriors") to lead that project.

ALP's Mission Statement explains the underlying values that inform the decisions to function in these ways: "Understanding that services and organizing efforts are most successful when they involve the communities served, ALP is committed to creating and supporting decision-making/organizational structures that are representative of our communities." As noted earlier in this chapter, ALP has a variety of Working Groups who help lead the organization. Volunteer community members lead these Working Groups, and help develop organizational policy on various issues and help implement programs.

Some QLM organizations have leadership from below at their highest level of authority: the Board of Directors. The typical non-profit model often involves having wealthy Board members, because they are assumed to be able to help with fundraising (McLaughlin, 2014). The QLM groups differ from this model in their commitment to having community members on their Boards of Directors. For instance, QEJ was committed to having a multi-classed Board of Directors and always had homeless shelter residents serving as members of their Board. 
Affinity also works to build leadership from within its constituents. Kim L. Hunt told me that one of Affinity's core values is the belief that community members should lead: "Individuals don't need to really look for a leader. Everybody is capable of having a leadership role. Everybody is capable of being a change agent." She explained that Affinity is intended to be an organizing space and that the organization functions as "a vehicle for folks to use to do that work to change the world or just build community. So that's the thing that underlies the work that we do." Hunt's quote illustrates what Dixon (2014) described as the commitment among another politics groups to "building institutions through which people can self-organize to meet popular needs" (Dixon, p. 84). In this model, the organizations exist to provide infrastructure for projects that are determined and led by community members. Caitlin Breedlove described how SONG, which always utilized that model, has moved even further in that direction:

We see the usefulness of still being a non-profit, but we are trying to shrink the non-profit while we grow the organization. And the main mechanism we use for that is membership... The staff become more and more just the coordinators and the administrative side of the organization to help boost member-led work.

She went on to talk about how the typical non-profit model limits leadership to those, like her, in paid positions. Breedlove believes that this model is antithetical to movement building.

There's literally just too few people at work in non-profits. And where do people enter movements now? What are the entry points? What one of five jobs in a non-profit can you work? Or you are in academia. What are the other places that people can enter? And it's not a movement if there are not opportunities for new leaders to be coming in. Building a movement is about constant leadership development. 
This quote is reflective of what Dixon (2014) called "the Ella Baker thing - the role of the leader is to make more leaders" (p. 188). This idea is central to Dixon's model of another politics and it is similarly central to the QLM. Most of the organizations in the QLM engage in deliberate and comprehensive leadership development efforts. This model of constantly building new leaders, who direct the organization in participatory modes of governance, is closely aligned with Dixon's model of another politics.

\section{Strategic approaches to long-term vision.}

Dixon (2014) describes the practice of many $21^{\text {st }}$ century social movements of linking struggles for improvements in the lives of ordinary people to long-term transformative visions. This principle is put into practice through engagements with reform struggles ("staying grounded in day-to-day realities while pushing at and pointing beyond what is possible," p. 126) and keeping the day-to-day work connected to a longterm vision. As I explore how the QLM engages in this practice, I will incorporate Dixon's another politics framework.

\section{The importance of reform.}

Dixon's contends that radical organizers often tend to create obstacles for themselves that impede their work. These obstacles include focusing on radical principles (rather than being strategic and making concrete plans), fetishizing particular tactics (such as direct action or large mobilizations), and engaging in crisis mode organizing (responding to problems rather than leading with a vision). Another politics groups seek to overcome these three obstacles to radical work by engaging in movement building (rather than just activism). Rather than just concentrating on big mobilizations, just 
responding to crisises, or setting out to destroy the state in principle, these organizations build a long-term movement for transformation. This sometimes involves planting the smaller seeds of reform that will make it possible for future activists to engage in more radical transformation.

Clearly the groups in the QLM pursue smaller reforms while building a movement for larger change. Although they definitely engage in direct action, they do not pursue this action to the exclusion of other tactics. As discussed in Chapter 7, the QLM engages in activist trainings and leadership development. NQAPIA and SONG organize summits to provide trainings for other organizations; ALP, QEJ, and SRLP each organize "Know Your Rights" trainings for their members; and Affinity, QEJ, and SONG have each run their own activist schools that provided classes about organizing skills and social justice history to community members. All of the groups participate in lobbying and policy work but believe these efforts alone are insufficient for radical transformation. When I interviewed Astraea's Katherine Acey about the movement-building grant program, she addressed this issue:

Take, for example, NYC grantees like ALP and QEJ. What did they do? They provided support groups, they provided some services... They did organizing, direct action, but they also worked with other groups to change policy in the city of New York, as it affected people of color and trans people, the different policies in the shelters. So it's not like these people of color groups are only about militant direct action or only about policy or only about only about services - there's a broad range of tools that they use.

Acey cited this diversity of tactics as one reasons these organizations received the grant: they knew how to be strategic. The groups in the QLM enact another politics when they 
situate lobbying, leadership development, and direct action as different tools to be used strategically to move forward their radical vision.

Dixon (2014) explains that this practice is also employed when groups examine how regular people, who may identify as neither radical nor activists, navigate oppressive systems: migrants coming into the country illegally, employees stealing from their jobs to supplement low wages, queers creating alternative communities, youth of color using hip hop or graffiti to claim urban space, and others. Dixon describes how some $21^{\text {st }}$ century social movements learn from these groups and connect their work to these "small" acts of every day resistance. "Where there is oppression and exploitation, there is frequently resistance" (p. 118). The framework of another politics links these immediate resistance strategies to long-term vision and build on it.

The QLM groups engage in this practice of taking individual acts of resistance and building activism from them. Caitlin Breedlove discussed SONG members who live by farming the land collectively and running organizing centers on the farms. Kim L. Hunt described how Affinity's work with individual survivors of intimate partner violence has led to the organization thinking more broadly about violence as a public health issue. Likewise, QEJ examined the individual survival strategies devised by different LGBT residents of the homeless shelter system, and used these strategies to inform QEJ's community organizing in the shelters. Rose Pulliam described how allgo used the work of its artist members to link their cultural work to their organizing work.

Dixon explains that one result of fixating on principles over concrete plans is that some activists "often spend a lot of time and energy debating whether particular 
individuals, activities, or organizations are sufficiently 'radical' without asking basic questions about how they seek to move us toward actually winning” (p. 131). Groups enacting another politics recognize how reform and day-to-day work are connected to long-term radical vision. Toward that end, organizations sharing another politics often combine service provision and community organizing. The provision of services usually raises the question (Kivel, 2007) of whether non-profits engage in service provision rather than (or to prevent) real social change. Groups who enact the principles of another politics deliberately structure their work to preclude them from such critiques. They are intentional about linking services to organizing. Borrowing from the Black Panthers' concept of "Survival Programs Pending Revolution," these organizations offer services or goods that their communities desperately need, but link those programs to their social justice work. They use those programs to recruit members for organizing campaigns. As they do so, they conceptualize community members as partners, not clients, and attempt to reinvent the idea of serving the people. The QLM then can be described in Dixon's words: "Although there is a lot of diversity among them, these groups share an ability to bring together needs-based work and struggles for justice while moving away from the client/service model" (Dixon, p. 142).

The QLM groups utilize these strategies. They provide services their communities need and use those services as recruitment tools, connecting community members to organizing campaigns. This requires starting at a basic level of providing safe spaces for community members to come together; building community is one way they get people involved in the movement. Kim L. Hunt discussed how Affinity "creat[es] safe space and 
building community for Black LGBT folks" that can then be used as a site for mobilization. QEJ ran support groups in homeless shelters and monthly "Know Your Rights" trainings for people on public assistance, and both of those programs were also used as organizing recruitment tools. Astraea's Katherine Acey said this was standard for all of the Movement Building grantees:

Different groups definitely provided that kind of social networking and community events, or provided services, but it wasn't limited to that. Those programs were part of their strategy to bring people together in community. Let's have fun, let's celebrate, or come get these services, but then let's have people recognize that they can be actors in their own lives to make change.

Most participants discussed how their organizations engage in these kinds of strategies, providing examples of community events, direct services, or public policy advocacy as methods to connect people to longer-term movement building. ALP's Cara Page put it succinctly when she said, "We are always advocating for our communities and struggling with state."

\section{The importance of vision.}

Dixon (2014) shows how the another politics groups struggle to do the day-to-day work of running programs and keeping their institutions afloat while balancing that with the work of remaining involved in social movements and staying connected to their longterm visions. "In all of their activities, such institutions must navigate the treacherous tides of capitalism and other ruling systems. Without movements to hold and orient them, counterinstitutions are much more susceptible to pressures to become either more subcultural or more professional" (p. 148). In order to avoid becoming merely 
professionalized service providers (and thus become part of the problem addressed by so many of the critics of non-profits), these groups focus on their vision for long-term change. This requires being deliberate, rather than reactive, and understanding how every decision they make and activity they organize is connected to their long-term vision.

Here again, the QLM shares this strategy with the groups in Dixon's study. Some articulated their commitment to this goal when they were first founded, as evidenced by SONG's Mission Statement:

SONG is visionary, not reactionary. SONG organizes for hope, not in response to fear. We build, connect, and sustain a kind of organizing... that amplifies hopes and dreams of transformation to a better world. We organize to build the world we really want to live in.

These groups adhere to their visions by thinking about how current actions impact future work, including work in the distant future. SRLP's Dean Spade insisted that activists must ask themselves "In 50 years, are we going to be glad we did this?" and explains, “There's this thing about capitalism that makes us only want to look two-three minutes ahead, so I think it's really interesting and important to politically allow ourselves to ask these questions." For similar reasons, these organizations look backward, as well as forward, to connect to their vision.

QEJ's Amber Hollibaugh explained how assessing the past helps her to understand how the current world measures up to her long-term vision:

I think we are in a very different place than we were 35 years ago. Whether it's a place that I really feel has done what I hoped would happen, that's not in place yet. I feel really actually quite terrified about the world as it now exists. The kind of economic policies, the kind of sucking the world dry for a dollar, seems to me to be even worse - though it was hard for me to imagine 30 years ago that it could get worse... So while I think 
there have been amazing and unforeseen changes in the United States in the last 35 or 40 years, it's not what I had hoped each of those avenues would be. The Civil Rights movement has not led to a society that is free of racism. The Women's Liberation movement has not led, ultimately, to women's freedom, though it has fundamentally shifted the way that gender is understood. And the kind of possibility of LGBTQ rights, the kind of idea of queer liberation is now a very contested terrain. Do we now fight for the kind of passionate belief that I have about sexuality, about the importance of the erotic? Of people actually getting to fulfill desire and not be punished because they have it? No, we're nowhere near that. We're dealing with an AIDS epidemic that continues out of control globally and in this country. No. This is not the movement that I am fighting to create.

Hollibaugh illustrates how these activists recognize the progress made by reform while measuring it against their vision of how the world should be and the work that still remains. Similarly, the way in which some of the QLM groups discussed the difference between equality and justice illustrates how they measure their current situation against their long-term vision. For example, when NQAPIA's Ben de Guzman talked about equality as "the floor" and justice as "the ceiling" he was taking the current state of LGBT activist success and comparing it to his understanding of the work still to be done. Dixon (2014) explained that another politics requires constantly engaging in such comparisons, while considering "How can our activities tangibly build toward future revolutionary transformation on a large scale?" (Dixon, p. 110). SRLP's Reina Gossett discussed this issue with me. She said, "We think that legal services and legal strategies are important and have their place" but insisted that, on their own, they are not the way to make long-term changes. She explained that the day-to-day activities of SRLP must always have a concrete connection to their bigger goals, and consequently "how we try to shift policies is aligned with our services, which is aligned with our visions and values." 
Historically, many activist organizations have concentrated on fighting smaller battles that feel winnable, rather than taking on larger fights that are less certain to succeed. Dixon (2014) understands the reasons behind choosing winnable battles. Concrete wins are crucial, "they help sustain people in struggle and demonstrate in practical terms what we can achieve when we fight together for what we want" (p. 132). However, he contends that the $21^{\text {st }}$ century social movements aligned with his another politics framework do not entirely share that strategy. They take on battles they think they may win, but in doing so they are also "avoiding confinement to what seems possible" (p. 132). They choose winnable battles that move forward a larger agenda clearly articulated within the context of the smaller winnable battle, so activists understand this smaller battle as a stepping-stone. The QLM organizations are aligned with this view. This is illustrated on the website for the Roots Coalition: "We want to engage in concrete, winnable struggles that positively affect the daily lives of our constituents and offer potential victories that build our collective political power." SRLP's Dean Spade spoke explicitly about the importance of remaining connected to long-term vision when considering options that might achieve immediate victories:

We have to do an analysis that includes measuring these options against our vision. For instance, what is your vision about family structure, and should it determine whether or not you have health insurance? Or whether we can immigrate? Asking ourselves questions about our actual vision of how we want that to look, so we can know whether or not we are going there, and what is it we are taking an incremental step towards.

QEJ's Amber Hollibaugh also addressed this issue directly:

I think social change work is some of the most extraordinary dreaming that any of us have the possibility of doing. In some ways, the challenge of 
staying political is to stay a dreamer at the same time. Everyone's always told about politics that you have to be practical. But I actually think that's not true. I think you actually have to hold to a dream and then understand what you can execute and what you can move forward. But you never give up the dream.

Hollibaugh advocates pursuing revolutionary goals in increments, when the political opportunity presents itself. Dixon (2014) contends that revolutionary goals are rarely winnable in any immediate sense, but at the same time, achieving immediate goals can help to make revolutionary goals appear more winnable. Another politics activists ask, "How can we do this work in a way that opens up the imaginative terrain?" (p. 132). Winning smaller reforms help open up the imagination. As Hollibaugh continues, she illustrates this when discussing how fighting for economic improvement in the lives of her communities helps allow those communities to dream bigger.

There is no way to imagine a world that is that kind of compelling, if you also don't imagine a world where profit doesn't determine whether or not you can afford to live, you can afford to eat, you can afford to take the subway, you can afford to actually have children. If you can't do anything but fight for every single solitary thing, every single solitary day, then the privilege of dreaming becomes something that only a few people have.

In this framework, making limited but concrete improvements in the lives of poor people can help facilitate their engagement in longer-term movement building. The opportunities to make immediate short-term gains by the groups in the QLM help move them closer to their long-term vision of liberation. This strategy is clearly aligned with Dixon's framework of another politics. 


\section{Conclusion}

The queer liberation movement is a new kind of LGBT social movement, engaging in queer activism that has not been seen before. The another politics framework developed by Dixon (2014) links the QLM, itself a new form of LGBT social movement, to a new wave of social movements that have appeared in the $21^{\text {st }}$ century. Dixon describes the emergence in the past two decades of a new model of multi-issue social movements, wherein activists build concrete connections between what they are working against and what they are building towards. Dixon's framework fills in some of the gaps that exist when only examining the QLM through the lens of canonical social movement theories such as resource mobilization (McCarthy \& Zaid, 1977), disruptive power (Piven \& Cloward, 1979), and political process (McAdam, 1982). The framework of another politics demonstrates how some contemporary social movements are building counterinstitutions to without amassing huge resources or depending entirely upon the support of elites, and relying instead on building its strength from the grassroots.

This chapter presented the utility of another politics as an overarching framework for contextualizing the QLM and positioning it with other emerging social movements, and in doing so, attests to the need for more nuanced social movement theory than the established canon has previously offered.

As I used Dixon to explain the QLM, I also explored how the QLM is situated vis-à-vis the body of literature critiquing modern social movements for being too dependent upon the 501(c)3 structure. The QLM is engaged with these concerns and is actively building organizations that mitigate the limitations of this model. It remains to be 
seen if the QLM (or other another politics movements) can successfully overcome the confines of the non-profit structure, but it is clear that it is thoughtfully wrestling with the contradictions of doing liberation work within this setting.

Because the QLM is focused on building small counterinstitutions that pursue short-term reforms while building a social movement for long-term transformation, it complicates each of the social movement theories that I had expected might apply to the QLM organizations. The QLM groups are too focused on building institutions to be fully explained by Piven and Cloward's disruptive power theory (1979), but also not focused enough on building large, bureaucratic institutions to be explained satisfactorily by resource mobilization theory (McCarthy \& Zaid, 1977). Similarly, the QLM institutions are too focused on long-term struggles to be entirely understood by an application of the political process model (McAdam, 1982). It is significant that none of these three prominent social movement theories can easily describe what is transpiring in the QLM. This lack of a fit suggests that this social movement is a new model, requiring new theoretical understandings, the beginning of which Dixon helps to inform. The QLM illustrates both the utility and limitations of predominant social movement theories for understanding the new social movement form that Dixon describes.

The QLM enacts Fraser's theory of perspectival dualism (Fraser, 1995; Fraser \& Honneth, 2003), which has always been a largely theoretical and aspirational model, because she doesn't present many examples of the theory in action. This, too, indicates that the QLM is an example of a new kind of social movement. This theory, while applicable, does not capture all of the dynamics of the QLM and how it actually functions. 
In addition, Fraser's conceptualization of the recognition/redistribution dynamic is dependent upon static definitions of identity, which does not accurately describe the QLM. I explore this dynamic in the next chapter, where I develop a theoretical frame that provides a more relevant and interesting analysis of the QLM than any of these four social movement theories.

Using Dixon's framework helps explain how the QLM is not merely substantially different from the GRM, but has more in common with the new social movements that have emerged in the $21^{\text {st }}$ century than it does with the other identitybased social movements that have emerged in the $20^{\text {th }}$ century. Thus far, I have demonstrated some of those differences, including how it pursues radical politics similar to those of the liberationist groups of the New Left (while operating within the non-profit model that emerged in the GRM in the 1980s and 1990s), and how those politics contain both recognition-based and redistributive goals.

However, the QLM differs from the GRM and other identity-based social movements an additional significant way: it is identity-based, but it also complicates many questions of identity. This results in a complex engagement with other social movements. In the next two chapters, I offer an examination of these issues, and the ways in which they provide an opportunity to build upon existing theories and develop a new theoretical framework for understanding the QLM. 


\section{Chapter 9: Deconstructing and Reconstructing Identity Categories}

\section{Introduction}

You say my name is ambivalence? Think of me as Shiva, a many-armed and legged body with one foot on brown soil, one on white, one in straight society, one in the gay world, the man's world, the women's, one limb in the literary world, another in the working class, the socialist, and the occult worlds. A sort of spider woman hanging by one thin strand of web. Who, me, confused? Ambivalent? Not so. Only your labels split me.

- Gloria Anzaldúa (Moraga \& Anzaldúa, 1981, p. 205)

In this quote, Anzaldúa resists the labels that seek to shrink her identity into one that can be categorized easily. The identity categories Anzaldúa rejects are not complex enough to capture the multiple worlds of which she is a part. In this chapter, I examine the queer liberation movement as one built in some ways upon a collective identity, yet which, like Anzaldúa, defies simple categorization.

The question of identity has been important in the study of social movements; the major social movements of the last 50 years have been identity-based. The GRM, and LGBT activism in general, has been particularly organized around identity categories.

The concepts of collective identity and identity categories are not only significant concepts in social movement theory generally, but they are also central to understanding $20^{\text {th }}$ century LGBT activism. In the previous chapter I show how Dixon's (2014) another politics framework describes certain $21^{\text {st }}$ century social movements and contributed to my understanding of the QLM. However, Dixon does not address the issue of identity categories, nor does he examine the role of collective identity in these social movements. Consequently, Dixon's framework must be complemented in order to arrive at a complete understanding of the QLM. 
This chapter deals with questions and ideas about collective identity in the QLM that emerged during my analysis. It presents a discussion about my findings from the entire study, addressing theoretical issues of identity that emerged inductively from the data and investigating questions I wish I had incorporated into my research design (and which I may return to in future research).

Throughout this chapter, I draw from a variety of theoretical traditions, including social movement theories (collective identity and identity deployment), feminisms (Black feminism and U.S. Third World feminism ${ }^{3}$ ) and post-structuralist theories (postcolonialism and queer theory), to explore questions of collective identity in the queer liberation movement.

I begin this chapter by looking at some of the concrete ways that the QLM organizes around identity. I demonstrate how identity categories figure prominently in how the QLM conceives of itself, and how its collective identity shapes its work.

The second section examines the QLM through different theoretical lenses about collective identity and identity categories in activism and social movements. By bringing together a range of identity theories I explore how the QLM utilizes and challenges static concepts of identity. I use social movement theories to explain how collective identity is necessary for creating cohesive groups that can organize; I employ queer theory to clarify

\footnotetext{
${ }^{3}$ I use the term "U.S. Third World feminism" (as an umbrella term to refer to a cohort of American women of color feminists) because of its convenience and common usage. However, I struggle with how the term collapses the multiplicity of identities and traditions of these feminists into a simple collective identity, one that erases the very complexities of identities that is the focus of this chapter.
} 
how the QLM destabilizes the dominant identity categories around which other movements organize; and I apply U.S. Third World feminism to explain how the QLM instead uses more expansive, intersectional, identity categories. Using poststructuralist theories, I demonstrate that the QLM simultaneously tears down and builds up identity categories.

\section{Reliance on Identity}

\section{Introduction.}

As briefly discussed in Chapter Seven, SRLP's founding director Dean Spade describes the QLM's approach to its work as “trickle-up social justice.” In this section, I return to an investigation of that practice and contextualize it to inform the theoretical questions of identity I explore later in this chapter. This section focuses on how the QLM prioritizes certain identities. I put Spade's trickle-up social justice approach in conversation with Black feminist theorizing, specifically focusing on bell hooks' concept of "margin to center" to demonstrate how identity categories figure prominently in the QLM's agenda, work, and leadership structures. In doing so, I illustrate how the way the QLM conceives of its collective identity shapes how it conceives of its work.

\section{Impossible people.}

A precursor to Spade's "trickle-up social justice” framework is his idea of “impossible people.” Spade describes transgender people as impossible people, who society says cannot exist. The gender binary is so prevalent throughout society that countless systems exclude or reject the very existence of transgender identity. He quotes fellow transgender scholar Paisley Currah: "When trans people walk up to an institution, 
it's like the computers break down and the walls fall down, it's like they can't understand us, they are just like 'you can't exist!"' Spade shares this quote as an example of how social structures and policies indicate trans people cannot or should not be possible. "We are being told that we are impossible people, we are told that constantly by every single person that can talk" (Barnard Center for Research on Women, 2009b). Precisely because society ignores or rejects them, these impossible people are a central focus of the work of the QLM. Other groups prioritized by the QLM are similarly impossible people, whose very existence is denied by dominant society. Homeless gay White men, or incarcerated Black lesbians, or undocumented Latino queers are similarly centralized by the QLM. Their statuses, as people without homes, full civil rights, or legal identities, make them similarly impossible people. The QLM's choice to centralize these types of impossible people reflects what Spade would later refer to as a commitment to "trickle-up social justice."

\section{Trickle-up social justice.}

As noted in Chapter Seven, activists in the QLM believe that people who experience the greatest oppressions must be prioritized over the most privileged. In doing so, people with more privileges will also benefit from work that benefits those who are less privileged. Using Gamson's (1990) framework, the QLM's target of benefits are the most oppressed among LGBT people. This philosophy, attributed originally to Spade, is shared by all the QLM organizations. SRLP's mission statement affirms the QLM commitment to this principle: "We believe that justice does not trickle down, and that 
those who face the most severe consequences of violence and discrimination should be the priority of movements against discrimination."

\section{Employing the trickle-up framework.}

As presented in Chapter Seven, all the QLM organizations use this framework.

The decision to focus on the needs of the most marginalized not only informs the organizations' agendas, it also impacts how they work in pursuit of those agendas. For instance, several of the groups must schedule organizing meetings at times that allow their low-income members to attend and sometimes have to provide them with money to be able to attend.

Day in and day out, you see the number of queer people that walk in our office every single day who we have to give a metro card to get back to the shelter because they don't have enough money to take a ride in both ways.

- Amber Hollibaugh, Former QEJ Executive Director

Oftentimes even for SONG, it's hard to, in places like Alabama, like rural Virginia, in places like small town Georgia, it's hard to talk about what it means to organize when people are like "I don't have $\$ 2.50$ to get on the bus to get to a meeting. I just don't have it." Or "I would love to come but I'm working two jobs and by the time you all wrap up I won't even be off work by then. Like, I'll be off work at midnight or two o'clock in the morning."

- Paulina Helm-Hernandez, SONG Co-Director

Some QLM organizations do outreach at locations like homeless shelters or welfare offices, which are not usually understood to be recruitment sites for LGBT organizing. Some have provided community members with cellphones so they have technology needed to participate in community organizing campaigns or serve on the Board of Directors. Other groups provide childcare at their events so low-income parents can 
participate. Most do outreach in multiple languages. In all cases, the organizations' work with people from multiple subordinated identity categories demands multiple strategies for including them.

In addition, these organizations have to be thoughtful and selective about what campaigns they will support, because of their focus on trickle-up social justice. For example, in the last chapter, I examined how the QLM attempts to make incremental change, working on winnable battles that move forward a larger vision of liberation. However, these activists simultaneously critique how that strategy is often utilized by social movements. They know that too often when social movements have chosen "winnable" battles, the most vulnerable communities have been discarded, as illustrated by this quote from SRLP's Spade:

There is a question that maybe comes for people around whether inclusion is an incremental step on the way to something else. This is something that has often been said about trans people: "We will come back for you later, we swear." Like when the sexual orientation act passed in 2002 here in New York State, and they decided that they could leave us for later. So those ideas about whether something is an incremental step are more or less believable in different contexts (Barnard Center for Research on Women; 2009).

People with multiple subordinated identities are often deliberately omitted in order to make that battle more winnable. QEJ's Kenyon Farrow, SRLP's Reina Gossett, SONG's Paulina Helm-Hernandez, ALP's Cara Page, and allgo's Rose Pulliam each expressed some version of that same sentiment. Spade explained that this is the reason that a trickleup approach is necessary; without it, the most oppressed people are either abandoned or harmed: 
We have to ask ourselves, does this (tactic) divide our community by leaving out vulnerable people? That's probably the first thing to ask. Is this incremental step conveniently eliminating the people that are easiest to eliminate in our community? And does this incremental step invite backlashes that will harm the most vulnerable? Because that's who backlashes always harm. Even though a lot of the rights that people have been fighting for only benefit the very few at the top, they usually harm the people who are at the bottom (Barnard Center for Research on Women; 2009).

\section{Fluid definitions of the most oppressed.}

Organizations that focus on the needs of their most marginalized community members raise the question of whom that is, specifically. When they combat so many different forms of oppression and target so many different systems for change, how do these groups decide who is the most marginalized? How do they conceptualize the identity/identities of the people whose needs they prioritize? The following quote by Spade offers some clues:

Social justice doesn't trickle down. And so we should center the experiences of the most vulnerable first. That's how we should determine our agenda. So if we deal with the problems that the rich are having with the economic crisis, there is no reason to believe that dealing with those problems will address the issues of the poor. We can make sure that they have their bonuses back, and we still know that the real hit of this crisis is still going to be felt by the people with the lowest income. Similarly, if we address the problem that white gay people who want to marry an immigrant have, you won't necessarily have addressed the problems of two undocumented queer people who aren't partnered with a citizen. Although if you address the problems of undocumented queer people, you will address the problems of somebody who wants to marry an immigrant. And if you address the issues of professional white lesbians and their parental rights, you won't solve the problem of low-income mothers of color or imprisoned mothers who the child welfare system targets for separation from their families. But if you do the reverse, if we really upended the child welfare system, and made it about reunification of families and communities, then inevitably, that would have beneficial effects on rich, white gay people who want to make sure that they have 
parental rights. So it does trickle-up, but it doesn't trickle down (Barnard Center for Research on Women, 2013).

In this quote, Spade conceptualizes the identities of the communities he prioritizes. By referencing low-income people, undocumented queers, people of color, and imprisoned people, Spade prioritizes a number of people. He does not just hold up one identity category as the most oppressed. The targets of benefits (Gamson, 1990) are defined merely in opposition to those with greater privilege (bonus-receiving rich people, White gay citizens who are dating immigrants, or lesbian professionals who are mothers), and not by any specific single identity category of their own. His approach of trickle-up social justice is thus flexible enough to accommodate a variety of different identity categories.

The other organizations in the QLM also share similarly fluid definitions of the most marginalized people. Sometimes those identities are deliberately broad and encompassing of many different identity categories, such as in this quote from SONG's Paulina HelmHernandez:

There are more and more people we know that are relying on the collective safety net of our communities, that are relying more and more on street economies, that are relying more and more on underground economies, both as undocumented people, but also as gender nonconforming people who don't have identification that matches their gender identity.

Other times, however, specific identity categories are named as the most oppressed in particular contexts and recognized as the focus of a particular campaign. For instance, describing a story about controversy in immigration activism, NQAPIA's Ben de 
Guzman stated clearly what type of person was the most oppressed within the immigration system:

The bi-national couples' provision, while important, should not be articulated as one gay journalist put it, "Oh the immigrants threw us under the bus." You know, when, in fact, undocumented immigrants can't even drive a fucking bus. So those policy debates look very different when you have that kind of analysis.

In this story, he maintained that undocumented straight immigrants were more vulnerable than gay American citizens. However, at different times, de Guzman positioned other identity categories as the priority in other arenas of NQAPIA's work, such as when he explained that transgender immigrants have even greater needs than gay immigrants. In this way, NQAPIA illustrates how the QLM fluidly uses the trickle-up social justice approach to prioritize a range of identity categories.

\section{Leadership that trickles-up from below.}

Trickle-up social justice is compatible with the practices of groups sharing another politics. While the trickle-up social justice approach centers the needs of the most oppressed community members when organizations determine their agendas, Dixon's idea of "leadership from below" (as discussed in the last chapter) involves community members guiding the work of the organization. These two frameworks are connected by their shared commitment to the practice of organizations taking their lead from community members. The QLM enacts both approaches in its organizing efforts. It does this by prioritizing the issues of concern to queer people in multiple subordinated identity categories and simultaneously creating structures for those same people to lead the organizations. 
Although these practices differ from other current LGBT activism, they are similar to activism that arose from the New Left, which centered people from multiple subordinated identity categories. The QLM sees itself aligned with that legacy. For instance, when SRLP's Reina Gossett was discussing how the QLM chooses its priorities, she invoked two iconic, low-income, transgender activists of color from the 1970s: "Sylvia Rivera and Marsha P. Johnson said that the way to change homophobia and trans phobia is to support the lives of people who are most affected by that." Similarly, SONG's Paulina Helm-Hernandez discussed how the QLM organizations see themselves as connected to the legacy of the Stonewall Riots, led by low-income trans people of color:

One of the powerful things about legacy is that once you invoke legacy you actually have to be accountable to it. It's not good enough to name, like, Stonewall as a buzzword without actually talking about who was in the lead of that? Who was it that was actually so enraged by the condition of what's happening in our communities, and saw that there was no other option but to rebel, when a lot of people were in hiding and were completely unwilling? And so when we look at that, who has, historically, been those folks? And who are the people who have always stepped to the line and have encouraged the rest of us to step to that line as well?

Helm-Hernandez characterizes the QLM as taking its lead from the most oppressed members of LGBT communities, by prioritizing the issues most important to them (trickle-up social justice) and following their lead on those issues (leadership from below).

\section{From margin to center.}

Dean Spade may have coined the term trickle-up social justice, but the underlying concept is based upon Black feminist ideas that are over 30 years old. bell hooks (2000) claimed the problems of White feminists were legitimate problems that did warrant 
redress, but she argued that these problems were not the most important issues facing the majority of women, and White feminists had ignored the problems of most women. She explained that not everyone is oppressed equally, and those women who were the least oppressed had created the second wave feminist agenda. "Being oppressed means the absence of choices... Many women in this society do have choices" (p. 5).

Years later, this same argument is reflected in Dean Spade's trickle-up approach, when he critiques social movements that prioritize the most privileged segments of oppressed groups, focusing on "the few most charismatic people, the people who the most look like what society already thinks are good people" and building legal cases or advocacy campaigns around them. Both Spade and hooks contend that it is a mistake to have the most privileged members of an oppressed group drive that group's agenda.

This argument is taken further when hooks (2000) posited that for feminism to be useful to all women, it must focus on the diversity of women's political and social realities, "especially the women whose social conditions have been least written about, studied, or changed by political movements" (p. 27). This sentiment is centralized in the trickle-up social justice approach. hooks claimed that the least powerful women must be centralized if feminism is to help everyone, and this is exactly the same point made by Spade about social movements, and employed by the QLM. This is illustrated on the website of the Roots Coalition (n/d), which specifically invokes hooks when the coalition states: "We will create models and actions that truly encompass the intersections of race, ethnicity, culture, gender, sexuality, disability, age, immigration status and class leaving 
no one at the margins" (emphasis added). In this way, hooks' margin to center can be understood as the theoretical container for Spade's approach and for the QLM's work.

hooks also claimed that the strategies, critiques, and agendas created by Black women from their place on the margins must be centralized by feminism, in order to abolish all forms of domination and oppression. This principle is put into practice by the QLM, when it centralizes the leadership of people with multiple subordinated identities and prioritizes their issues. The QLM looks to the people whose knowledge about oppressive systems came from living under those systems. SRLP's Reina Gossett illustrates this when she discussed why a group of low-income queer people of color developed the focus and strategies of one of the anti-poverty projects that she staffed:

"Those are the folks who know the best, who can say these are the questions we should focus on, and these are the ones that we shouldn't."

\section{Conclusion: From practice to theory.}

The QLM enacts Spade's trickle-up approach, informed by hooks' concept of margin to center and aligned with Dixon's another politics. hooks and Spade (as well as Dixon) advocate centralizing people from multiple subordinated identity categories. By examining Spade and hooks, I have demonstrated that identity categories figure prominently in how these organizations choose their issues and structure their leadership. The next section explores the theoretical significance of these identity categories, analyzing how different disciplines of theoretical inquiry understand the role of identity categories in social movements. 


\section{Deconstructing Identity}

\section{Introduction.}

This section explores different theories addressing collective identity and identity categories in activism and social movements, and applies these theoretical constructs to the QLM. I begin by examining the prominent social movement concept of collective identity and identify the collective identity of the QLM. I then explore how U.S. Third World feminism posed a challenge to static concepts of identity, and then look at how social movements have deployed their collective identities in pursuit of strategic essentialism or strategic differences. Throughout, I use these theories to understand the role of collective identity in the QLM. Next, I discuss postmodern understandings of LGBT identities, examine the unrealized potential of queer politics, apply poststructuralist theories to the collective identity of the QLM, and explore how the QLM engages in the simultaneous deconstruction and reconstruction of identity categories. These discussions inform the final section of this chapter, which uses these issues to develop a theoretical framework for understanding the QLM.

\section{Collective identity.}

"Collective identity" is a significant concept in social movement literature, which explains how social movements generate long-term commitment and unity between activists. It supplements theories about how collective actions come about and how individuals acquire the motivation to act, and it describes the process by which individuals realize their commonalities and consequently decide to act together (Melucci, 1989). This concept has gained tremendous importance in the social movement literature 
- so much so that it is often used as one of the criteria in determining whether acts of activism constitute a social movement. Indeed, I used it as a criterion in my second research question.

A collective identity is one which organizers use, or create, to build solidarity and support around an idea (Goodwin \& Jasper, 2009). These identities are categorized as either formed by pre-existing membership in a group based on identity (e.g., the disability rights movement) or by creating an actual membership (e.g., labor unions). Collective identities promote inclusiveness among actors who may share limited identification and social and political experiences (della Porta, 2005). Taylor and Whittier (1999) define collective identity as "the shared definition of a group that derives from members' common interests, experiences and solidarity" (p. 170). In defining collective identity, Snow (2001) said, “its essence resides in a shared sense of 'one-ness' or 'we-ness' anchored in real or imagined shared attributes and experiences among those who comprise the collectivity" (p. 3). Snow links that "shared we" to collective agency, explaining that groups sharing collective identity also share a belief in their ability to take action together. In doing so, these groups form what Taylor and Whittier (1992) call a "social movement community."

I have argued that the QLM groups had similar identities as intersectional, radical, social justice and liberation organizations. However, in order to examine collective identity in the QLM overall, I must identify a collective identity possessed by the movement as a whole (rather than as individual organizations that share similar identities). Although individual activists or organizations have their own language for describing the 
identities of the QLM (e.g., Dean Spade's term “impossible people”), I focus on language used by all of the actors in the QLM to describe the identities of the people in their movement. Determining such an identity was not difficult. The groups themselves often reference the Roots Coalition as a proxy for their collective work, and the Coalition explicitly claims such a collective identity. Its mission statement identifies them repeatedly as "queer and trans people of color" groups. Interestingly, despite the fact that two of the organizations (QEJ and SONG) are multi-racial groups that include White members, when all the groups work together as the QLM they identify themselves as people of color groups. By this identification, the groups are enacting a collecting identity.

This construction of a queer and trans people of color (POC) identity is central to my analysis. This chapter explores this identity construction through different theoretical frameworks, beginning with an examination of how U.S. Third World feminists impacted notions of collective identity and how this applies to the QLM.

\section{U.S. Third World feminism.}

The QLM's collective identity as queer and trans people of color challenges the GRM in much the same way feminists of color challenged second-wave feminists. Just as U.S. Third World feminists sought to complicate reductionist feminist constructions that hegemonized the experiences of white, middle-class women, so too does the QLM work to destabilize the dominant conception of gay and lesbian identity as the terrain of white and middle-class bodies. This was clear throughout the data, such as when Kim L. Hunt described how Affinity was always "looking at the multiple identities that people bring to an issue. And looking beyond just the LGBT component of who folks are." One of the 
QLM's goals is challenging the centrality in LGBT activism of the experiences of white, middle-class gays and lesbians.

In addition, U.S. Third World feminists sought to bring together people of various identities "on the bottom" with whom they have connections (Moraga \& Anzaldúa, 1981), and the QLM similarly works to organize people based upon the marginalized status of their identity categories. The QLM embodies the sentiments from Audre Lorde's famous 1984 speech about Malcolm X:

You do not have to be me in order for us to fight alongside each other. I do not have to be you to recognize that our wars are the same. What we must do is commit ourselves to some future that can include each other and to work toward that future with the particular strengths of our individual identities. And in order to do this, we must allow each other our differences at the same time as we recognize our sameness (Lorde, 1984, p. 142).

This sentiment was shared by all of the activists in my study. Examples include when SRLP's Reina Gossett discussed working with non-queer people on public assistance, when Kenyon Farrow explained how QEJ's organizing work in the shelters was inclusive of heterosexual homeless people, and when NQAPIA's Ben de Guzman described partnering with non-queer immigrant organizations. Although the QLM uses identity categories as the basis for organizing, it does not follow in the footsteps of other identitybased movements that limit their scope to those people with matching identity categories. Rather, the QLM shares with U.S. Third World feminists the understanding that people of all marginalized identities must work together collaboratively. In this way, both movements challenge binary constructions of identity politics that rely on uni- 
dimensional identity categories to determine eligibility for collaboration ("we are the same, so you are in / we are different, so you are out").

Both the QLM and U.S. Third World feminism are comprised of people whose very identities challenge binary categorization. Critical and cultural theorist Chela Sandoval (2000) explained that U.S. Third World feminists exist in the gaps created by binary identity categories, residing "in the interstices between normalized social categories," by virtue of being gendered, raced, sexed, and classed "between and among" the lines that exist between men and White women (p. 45). The result is that women of color comprise a conceptual third, divergent, and supplementary gender category.

Chicana cultural theorist Gloria E. Anzaldúa $(1987,1991)$ used the term "new mestiza" to explore people who embody identities that do not conform to binary conceptions of identity categories. New mestizas claim multiple racial, cultural, sexual, and political identities in one word. A mestiza reject the absolutist and essentialist identity category labels required by the patriarchal society dominant in Western Society, and is aware of how her contradictory and interlocking identities provides her with "new angles of vision" to challenge society. It is an identity that resists single identity categories, and thus is a paradox that situates the person as belonging in many spaces and not belonging anywhere (Anzaldúa, 1987). While Anzaldúa theorized about the new mestiza, other U.S. Third World feminists were writing about "the third woman" (Alarcon, 1981), "woman warriors” (Kingston, 1976), “sister outsiders” (Lorde, 1984), "la Güera” (Moraga, 1981), and other women of color who embodied multiple identities (Sandoval, 2000). According to Anzaldúa (1987), women like these live in "the Borderlands," between cultures, 
straddled by invisible borders that exist between many groups normally delineated by binaries (e.g., men/woman, Mexicans/Americans, heterosexuals/homosexuals). People living in the Borderlands live in and between multiple worlds.

The QLM organizations are comprised of people who similarly construct their identities as situated in multiple worlds. For example, ALP's Cara Page often used the language of borders: "We are moving across borders or wanting to undefine what borders are." The identities of queer and trans people of color require navigating at least four worlds (navigating two cultures demarcated by sexual orientation: the queer world and the mainstream straight world, and at least two worlds delineated by race: their individual racial identity(ies) and dominant White culture). In addition, most straddle additional worlds. For instance, queer immigrants of color must navigate at least two additional cultures: those determined by nationality (the U.S. and their country of origin). Similarly, transgender people of color must also be fluent in the languages of two genders (the gender world they were assigned at birth, and the gender world where they identify). Similar analysis might even be extended to queer prisoners or homeless people (who, it could be argued, must navigate mainstream society as well as the worlds of prisons or homeless shelters).

Consequently, Anzaldúa's concepts apply to the QLM, as it is comprised of activists that can be metaphorically understood to be living in a different kind of borderlands, between various social movements. This is a departure from many other identity based social movements, which organize around uni-dimensional identities. U.S. Third World feminism complicated previously essentialized identity categories, and the 
QLM continues that practice. The next section examines how other identity-based movements have deliberately constructed and deployed their identities in less complex ways, and explores whether those frameworks might also apply to the QLM.

\section{Strategic essentialism and strategic differences.}

In the 1970s, gay and lesbian groups began to identify themselves as a legitimate minority group, positioning themselves as having a quasi-“ethnic” status (Altman, 1973; Armstrong, 2002; Bernstein, 2005; Epstein, 1998; Phelan, 1997). Accordingly, they increased their demands for the same rights and protections as other minority groups. In the process, gays and lesbians began to publicly present themselves in ways that made generalizations about the unique and inherent traits that comprise sexual orientation, such as being born with a fixed attraction to people of the same sex, common experience of homophobia, and shared cultural worlds, as demonstrated by queer spaces (Altman, 1973; Epstein, 1998). They also utilized a strategy of "coming out" to raise visibility and build community cohesion. This strategy contributed to the notion that gay and lesbian are fixed, generalizable identity categories, because coming out defines people in rigid ways, and effectively serves as a declaration of "this is who I am, forever" that does not allow room for an understanding of sexuality as either complicated or fluid (Phelan, 1997; Savin-Williams, 2005). Similar fixed constructions of identity continue today, in arguments made by gay and lesbian activists claiming they were "born this way" (Morningstar, 2014) and in analogous contentions made in transgender activism (Reed, 2013). 
This quasi-ethnicity framework, which makes generalizations about the inherent traits that comprise sexual orientation or gender identity, constitutes an essentialized identity category (Epstein, 1998; Gamson, 1995; Phelan, 1997; Savin-Williams, 2005; Seidman, 1993). There is, however, disagreement over whether it is problematic for social movements to employ essentialized identity categories. Some have argued that all identity groups engage in strategic essentialism in order to achieve a collective identity. Strategic essentialism, introduced by literary critic and theorist Gayatri Chakravorty Spivak (Ray, 2009; Spivak, 1988; Spivak, 1990), is a significant postcolonial concept describing a tactic that ethnic groups, nationalities, or minority groups may use to present themselves. Although any given group may have tremendous differences (of ideologies and politics, as well as in demographics or other traits), they may sometimes find it useful to form a provisional solidarity in order to engage in social action. Strategic essentialism describes how groups may temporarily essentialize themselves in order to present their collective identity in a simplified way that helps them reach specific objectives.

Spivak (1988) argued that universalizing discourse could be useful, provided that the limits of such discourse are understood. She contended that minority groups could engage in transactional strategies that temporarily adhere to essentialist notions in order to achieve their aims. Spivak simultaneously critiqued and endorsed the usefulness of that essentialism. Her critiques are important, in part, because she articulated particular concern for how White American feminism employed similar strategic essentialism at the expense of an "other" woman (Ray, 2009). 
In such an analysis, the QLM can be understood as engaging, to a certain degree, in strategic essentialism. By organizing around queer and trans POC identities, the QLM does not, to the casual observer, allow internal differences of geography, race, class, or gender identities, to distract from their public identity. For instance, the fact that some individual groups organize around a specific racial identity (NQAPIA is Asian, Affinity is Black, etc.) is subsumed in the movement's larger umbrella identity as POC. In addition, QEJ and SONG are not POC-specific organizations (they are multi-racial groups that are inclusive of white people), yet when working with QLM groups all of the organizations collectively identify as POC. In this way, POC becomes a strategically essentialized identity, which it can use for purposes of funding, advocacy, research, etc. Indeed, even organizing around a singular racial identity (e.g., Affinity is a Black organization) is to engage in strategic essentializing (e.g., of Blackness). Consequently, collapsing all differences among and between various racial groups into an identity of POC, the QLM made a strategic choice to essentialize its respective identities and characteristics.

However, the QLM simultaneously shares Spivak's critiques of such essentializing. Spivak (1988) cautioned about the limits of universalizing discourse, criticizing how American White feminists had failed to recognize those limits. Likewise, the QLM criticizes how the GRM has failed to recognize the limits of universalizing discourse. That critique informs the way in which the QLM groups engage in the deployment of their own identity categories. Although they engage in strategic essentialism, they simultaneously speak openly about the many differences among their 
constituents within their individual organizations as well as the differences among the GRM organizations. This was clear throughout my interviews, such as when Kim L. Hunt discussed the conversations Affinity's Black membership had about engaging in the QLM's immigration work (which, on the surface, could be argued did not directly affect Black American citizens), or when Ben de Guzman told me about the differences among the different API communities that comprise NQAPIA. These organizations utilize strategically essentialized identities while concurrently deconstructing those essentialized identities.

Sociologist Mary Bernstein (1997) built upon on Spivak's strategic essentialism theory, proposing "identity deployment" theory to explain how gay rights activists portray their identities in different ways at different times. Identity deployment explains how gay activists often choose to strategically minimize their differences from the dominant society, in order to emphasize similarities to the majority of Americans who are heterosexual. Bernstein offered case studies of gay activists who have chosen to highlight these similarities, and explained how this theory applies to other social movements.

Bernstein did not appear to share Spivak's concern about the limits to the utility of universalizing discourse. She was dismissive of criticisms of essentialism, whether those critiques focus on strategic essentialism or essentialism more broadly (Bernstein, 2005). She argued that identity categories are too difficult to challenge, and implied that activists should not be burdened with such expectations. She posited that essentialized constructions of identity are deployed because the dominant culture places value on these essentialized identities and devalues others (Bernstein \& Taylor, 2005). For this reason, 
the GRM has deployed an essentialized identity of gays and lesbians that is white, middle class, and gender conforming, because these identities are valued by the dominant culture. In this theory, organizing around such an essentialized identity is savvy, strategic activism.

Bernstein focused her analysis on the equality organizations and did not examine the QLM groups. However, an application of her theory to the QLM would find that these organizations are unlikely to succeed. She contends that the GRM has succeeded because it deployed its identities to highlight similarities to White, middle-class Americans (identities that are most valued in our society). The QLM rejects this practice. For example, the phrase "impossible people," defies the logic of identity deployment. The term "queer" similarly rejects identity deployment. Either term ("impossible people" or "queer") marks an identity group, and an argument can be made that these are essentialized identities. However, Bernstein would argue that these are not "strategic deployed" identities. The labels of "impossible" or "queer" automatically situate people as different from, rather than similar to, dominant mainstream society. The goal of identity deployment is to simplify identities in order to highlight similarities to, rather than differences from, dominant society. Consequently, the QLM while sometimes engaging in strategic essentialism (as Spivak defines it) works at other times to combat it (as Bernstein's identity deployment conceptualizes it). By refusing to deploy this identity construction (in part, because they cannot) the QLM will be unable to help the dominant feel solidarity with the communities represented by the QLM. Indeed, by enacting Spade's "trickle-up social justice" approach and centering the most marginalized of their 
communities, the QLM engage in exactly the opposite practice from what Bernstein indicated is necessary for success.

Sociologist Elizabeth Armstrong $(2002 ; 2002 b)$ developed a theoretical framework to describe the GRM that avoids the entire question of essentialized identities, and in doing so indirectly perpetuates them. She argued that gay activism owes its success to the movement's strategic diversity. She contended that gays and lesbians understand their "ethnic" status as distinct from other ethnic identities because sexual orientation is a category that encompasses people from multiple backgrounds, who come to this identity later in life than they do their other ethnic identities. Consequently, gays and lesbians have claimed to celebrate diversity in two ways: insisting that American society celebrate sexual differences between groups, and as a claim that the gay and lesbian community itself is internally diverse. Armstrong described how many organizers in the San Francisco gay rights organizations of the 1970s referred to a wide array of groups, focused on many different interests but united in their gay identity, as "unity in diversity." Armstrong used that term to develop her "unity in diversity" theory to explain the success of the GRM over the subsequent decades. In this model, people took various identities or interests (e.g., religion, sports, professions, etc.) and combined them with their gay identities to form what she calls "Gay+1" identity groups (e.g., gay Jews, gay football players, gay doctors). Consequently, a wide range of gay people with many identities could find commonality, mobilizing large numbers. In her theory, it is this strategic diversity, rather than any strategic essentialism, that has contributed to the success of the movement. 
However, Armstrong's theory does not take into account some of the basic hallmarks of diversity: race, class, and gender. By those measures, the San Francisco groups were not remotely diverse (as she acknowledges elsewhere, but does not incorporate into her theory), nor are the subsequent GRM groups. I argue that this failure to examine race, class, or gender renders Armstrong's theory of unity in diversity in gay activism, at best, limited in applicability or, at worst, spurious. It also perpetuates a different form of essentialism that limits gayness within the bounds of white, middleclass people.

Interestingly, however, I now find unity in diversity useful. An application of Armstrong's theory to the QLM (rather than to the GRM) offers a more optimistic prognosis than did the application of Bernstein's theory. Whereas Bernstein's theory of strategic identity deployment portends failure for the QLM, Armstrong's unity in diversity theory implies that the QLM has the potential to achieve even greater success than that of the GRM. By constructing an identity as queer and trans people of color, embodying a broader conception of diversity (one that signals a diversity of identity categories marked by race, class, and gender) than does the GRM, the QLM has the potential to bring together a wider range of people, comprising even more identity categories. Organizing across race, class, and gender, as well as across interests and professions creates the potential of mobilizing a large constituency.

Armstrong's and Bernstein's theories offer different characterizations of the diversity of LGBT identities. Gender and sexuality scholar Jane Ward (2008) contends that these theoretical inconsistencies (about the question of diversity among LGBT 
identities) are deliberate. She argues that gay and lesbian activists only embrace diversity of race, class, gender, or sexuality, when it is "predictable, profitable, rational, or respectable" and actively work to suppress diversity when it is "unpredictable, unprofessional, messy, or defiant" (p. 2). This argument provides a potential explanation of how Armstrong could have omitted race, class, and gender. In addition, although Ward and Bernstein both claim that gays and lesbians suppress identity differences, Ward diverges from Bernstein significantly because Ward is deeply critical of this dynamic, whereas Bernstein appears to admire it.

Ward and others describe the political strategy of the GRM in the past thirty years as one of suppression of gay and lesbian difference. This strategy distances "gay" from “abnormal” and, specifically, from "queer." Instead, it positions gay as "just like you," claiming that the only difference between heterosexuals and gays/lesbians is the small question of sexual orientation, and consequently gays and lesbians deserve the rights extended by the state (Anderson-Nathe, 2015; Ryan, 2009; Ward, 2008; Warner, 2000). The GRM engages in what Phelan (2001) calls “a flight from strangeness," politically and socially distancing themselves from bisexual, transgender, and queer people (Gamson, 1995; Phelan, 2001; Ryan, 2009).

Ward argues that gay activists employ "instrumental conceptualizations of difference, privileging those forms of difference that have the most currency in a neoliberal world and stifling difference that can't be easily represented, professionalized, or commodified" (2008, p. 2). The staff members at the QLM organizations share this analysis. For example, SRLP's Spade discussed incremental steps taken by the GRM: "I 
think we also have to ask ourselves, does this divide our community by leaving out vulnerable people? Is this incremental step conveniently eliminating the people that are easiest to eliminate in our community?" Spade's concern over the disposability of certain queer people mirrors Ward's analysis. Ward argued that gay organizations engage in the rhetoric of diversity in order to improve their public image and "accrue liberal capital" that will help them secure corporate funding and public legitimacy. The result is that these organizations seek functional and readily quantifiable forms of difference, "creating the most room for those who embody predictable and fundable kinds of diversity, adversity, or transgression" (2008, p. 6). ${ }^{4}$

The QLM, however, has embraced, centralized, and highlighted its constituents' diversity. Or rather, it trumpets its racial, gender, and class diversity; it remains to be seen how it will handle what allgo's Pulliam called "queerness in all its beauty, in all its glory"

\footnotetext{
${ }^{4}$ This theoretical argument explains GRM behavior that appeared to puzzle two of my interview participants. ALP's Cara Page and allgo's Rose Pulliam both shared thoughts with me about their discomfort with the GRM's selective embrace of diversity. Page claimed the GRM was "codifying, sort of pulling trans and gender nonconforming people of color in, but still as a secondary thought in many ways." She continued, "I think we are at a particular place in our movements for that movement to learn how to honor leadership without objectifying, exploiting, or exoticizing our leaders." She argued that it was happening to people of color, to Two Spirit people, and to trans and gender nonconforming people. She maintained the GRM was ignoring the contributions of those communities, "not identifying their role in our movements, our role, this whole time. And doing some weird elevation of some and not everyone." Similarly, Pulliam argued that the equality organizations are not willing "to think about queerness in all its beauty, in all its glory. I get disturbed by the way that movement is exoticizing and determining what's appropriately trans." She claimed that the GRM is "Almost creating this splinter between...I can't even describe it or talk about it. So that there is appropriate trans-ness and inappropriate transness somehow." Both Page and Pulliam appeared to be struggling to explain this dynamic, searching for their words and acknowledging their inability to capture the dynamic clearly. Ward's analysis, of how LGBT organizations embrace only the diversity that offers capital in neoliberal America, serves as a theoretical container for contextualizing and understanding Page and Pulliam's comments.
} 
with regards to sexuality. Although the QLM is comprised of people claiming numerous sexual and gender identities, these identities are still quasi-ethnic in their construction. They describe who people are sexually, not what they do sexually; sexuality is constructed as an identity, not a behavior. The diversity of sexual behavior within the QLM's communities (from monogamous "vanilla" sexual relationships, to people who practice BDSM or engage in non-monogamy) is not highlighted nearly as visibly as the diversity of identity categories. Ward's analysis may thus apply to the QLM, with regard to how it strategically downplays difference, at least within the arena of sexual behavior. Nevertheless, the QLM is markedly different from the GRM with regards to other features of diversity (race, class, gender, nation), in that it refuses to suppress those differences. In that important respect, neither Bernstein's nor Ward's theories about strategic suppression of difference apply to the QLM.

Sociologist Maura Ryan (2009) put Bernstein and Ward in conversation with postmodern theories, arguing that LGBT activism sometimes celebrates difference and sometimes suppresses difference. She drew on Joshua Gamson's (1995) description of "ethnic/essentialist politics" and "deconstructionist politics" to explain how LGBT activism handles difference. Ethnic/essentialist politics insist that clearly defined identity categories and collective identity are required in order for social movements to succeed, and thus difference within a given identity category must be suppressed. Deconstructionist politics, however, celebrates difference by contending that defined categories are obstacles to success, and thus celebrates differences. Gamson's work drew from queer theory and other poststructural theories in this framing. Because postmodern 
thought has much to say about the role of collective identity in activism, I turn now to an examination of it.

\section{Applying poststructuralist theories to the QLM.}

Many poststructuralist scholars have addressed the issue of essentialized identities within social movements, and some have turned their focus specifically to the context of the LGBT movement (Alarcón, 1990; Gamson, 1995, 2009; Seidman, 1993). Norma Alarcón (1990) addressed how the postmodern subject is decentralized, with multiple historically situated constructed identities, but in order to pursue liberation must engage in provisional solidarities through social movements. Consequently, "one may recognize the endless production of differences to destabilize group or collective identities, on the one hand, and the need for group solidarities to overcome oppression through an understanding of the mechanisms at work, on the other" (p. 376). Similarly, Gamson (1995; 2009) examined the relationship between poststructuralism and essentialized constructs of identity and what this said about the relationship between postmodernism and the new social movements. He focused on the question of queer and other sexual identities in social movements, questioning how social movements use gay and lesbian as identity categories at the same time queer theory is deconstructing those same identities (Gamson, 1995).

In some ways, the QLM enacts this destabilization of sexual and gender identities from within. They claim a multitude of sexual and gender identities, expanded beyond the default fixed categories of gay and lesbian. Queer theory contends that gender and sexual identity are social constructs and rejects a single authoritative account of 
experience. These QLM organizations have similarly constructed sexual and gender identities that destabilize the notion of a single authoritative experience. These groups identify themselves - individually and as a collective movement - at different times, as "LGBT," "LGBTQ," "lesbian, gay, bisexual, Two Spirit, trans and gender nonconforming (LGBTSTGNC)," "sexual minorities," "queer," "queer and trans," "gender variant," and "transgender, transsexual, intersex and other gender nonconforming people." Staff members from most of these groups explained how they deploy those terms deliberately, as a more accurate characterization of their members than would be using "gay and lesbian" as a default. In addition, each organization used more than one of these phrases to describe their constituents. The Roots Coalition's "official language" (the language found on its website, and in its mission statement) is "Queer and Trans People." The significance given to the terms queer and trans is particularly meaningful. Both words are not merely umbrella terms that subsume a variety of other identity categories; they also challenge hegemonic notions of normal. Consequently, the QLM organizations' use of these different terms appears to be both deliberate and fluid. The mere act of signifying themselves contests the notion of fixed authoritative identity categories.

Queer theory depicts gender and sexual identity as social constructs and demands they be deconstructed. However, what can be deconstructed can also be reconstructed. Gamson (2009) considered whether social movements should continue to use fixed categories (e.g., gay and lesbian) or whether to emphasize the subversion of categories (queer). Whereas deploying the term queer deconstructs collective categories, forming a 
collective identity around "queer" inherently builds this category up. Gamson has also articulated how these tensions relate to the larger question facing all identity-based social movements: "Fixed identity categories are both the basis for oppression and the basis for political power" (1995, p. 383). He argued that critiquing essentialized identities is important because in reality, the categories are fluid. However, he also maintained that without boundaries, there are no groups, no solidarity and thus, no social movement.

This analysis, an elaboration of Spivak's theory of strategic essentialism, is shared by the QLM. The queer liberation movement has constructed (or reconstructed) its own identity categories. Although the extensive list of sexual and gender identity categories used by the QLM certainly complicate the essentialized categories commonly used, they are still categories. As such, they do not enact queer theory to its full potential to completely subvert the concept of identity categories. Nevertheless, they do challenge the idea of an authoritative gay or lesbian identity.

Seidman (1993) also theorized about the relationship between poststructuralism and identity constructions. His examination of how queer theory deconstructs rigid sexual identity categories led him to employ a Black feminist intersectional analysis. Like Cohen (1997), he makes an impassioned call for less essentialized (by race and class) notions of gayness and a more intersectional approach to LGBT organizing.

The queer liberation movement uses this intersectional analysis to address identity categories of race and class. Their intersectional approach directly contradicts the default assumptions of race and class that Cohen (1997) and Seidman (1993) argue informed the 
creation and priorities of the GRM. This can be seen, again, in the following quote, where Amber Hollibaugh described one of the ways that QEJ conceptualizes liberation:

If you're a person with resources who is LGBT you may have some problems with (homophobia) but frankly, you'll probably have an apartment. If you're poor, if you're transgender, if you're a person of color, if you're HIV positive, if you're homeless, the ability to act on desire, the ability to be safely somewhere to make love with anybody you want to make love with, is unlikely.... And QEJ works on the notion that says the economy is not removed from the way you live out your private life. If you struggle with issues of documentation, issues of your health care, issues of whether or not you'll be punished for being open about who you are, if you can be employed or not employed, how you can get an apartment or not get an apartment, then those things affect how it is that you feel free or not free.

- Amber Hollibaugh, Former QEJ Executive Director

Here Hollibaugh breaks down the fixed, one dimensional identity category of gay or lesbian that is employed by the GRM, and which is critiqued by Cohen and Seidman. She delineates how queer people belong to numerous identity categories. This includes her intersectional recognition that an affluent LGBT person may simultaneously be impacted by homophobia yet still have class privilege.

The other QLM groups similarly complicate normal racial categories and construct a multi-dimensional understanding of race. This construct goes beyond the typical "White People/People of Color" binary (that implicitly situates all people of color as one unified group), when allgo or Affinity address tensions between queer Latinos and queer Blacks. It complicates the standard "White = affluent" narrative when QEJ and SONG work with White people who are homeless or the rural poor. It complicates the normal view of "Asians" as a monolithic group, when NQAPIA distinguishes between the different racial and ethnic identities that comprise the term API. It engages in a 
similar process about "Blacks" when, in the following quote, a staff member from SONG points out class distinctions and tensions among queer Black people:

Now we get to have gay Black Pride celebrations in Atlanta that are focused on the beauty of our community and its great, but at the expense of the invisibility of a lot of rural poor people that don't have access, can't get there, won't be allowed in even if they show up.

- Paulina Hernandez-Helm, SONG Co-Director

By recognizing the multiplicity of identities embodied by queer people, the QLM employs complicated and intersectional constructions of identity categories. Indeed, the trickle-up social justice framework employed by the QLM is based upon this intersectional analysis. This also adheres exactly to the prescription offered by Cohen and Seidman, when they called for using queer theory to destabilize uni-dimensional identity categories.

Eng, Halberstam, and Muñoz (2005) and Perez (2005) shared these criticisms of how queer theory is not employed to its full potential. They echoed Cohen (1997) and Seidman (1993)'s demands to use queer theory to destabilize hegemonic concepts of normality with regards to gender, sexuality, race, and gender, and extended those calls to also include nationality.

The QLM unsettles the categories of nationality in ways that are similar to their deconstruction of sexual and gender identities. It deconstructs the normal "American citizen/Immigrant" binary categories of nation when ALP and SONG participate in the Tribal Sovereignty Movement. It does so again when ALP, NQAPIA, and SONG choose to interrogate the meaning of citizenship as part of their immigration work. And again when ALP, QEJ, SONG and SRLP discuss Mexican immigration to the U.S., situating it 
in the larger contexts of neoliberalism and global migration patterns. In these and other ways, the queer liberation movement unsettles hegemonic categories of nation.

By framing the constructs of gender and sexual identity, race, class, and nation in these complicated ways, the queer liberation movement enacts the calls made by Cohen (1997), Eng, Halberstam, and Muñoz (2005), Gamson (1995; 2009), Perez (2005), and Seidman (1993) to employ queer theory to deconstruct those identity categories. This process can be seen clearly in the following excerpt from the statement drafted by the Roots Coalition, and signed on to by 15,000 people at the 2010 US Social Forum:

Our identities are not our possessions; we do not own them, and we are more than any one label. However, our embodied existences are under attack and we do know that it is our duty to fight for specific and concrete human rights and overall system transformation, and we utilize this framework as we move towards Safe Self Determination (Roots Coalition, 2010).

Even as these QLM groups recognize that they challenge hegemonic notions of normal, with regard to gender, sexuality, race, class, and nation, they also know that they have built their individual organizations, and their collective social movement, around identity categories. These categories create group cohesion, even as the organizations actively work to avoid simplistic, essentialized identity categories. Such a delicate balancing act is rife with contradictions, yet it is not a wholly contradictory theoretical frame.

Sociologist K.L. Broad (2002) examined the processes of identity in transgender social movement activism, looking at how collective identity is both deconstructed (by challenging dichotomous male and female gender scripts) and constructed (as transgender). She argues that transgender politics are not centered exclusively on either 
the identity politics of the GRM, or the destabilizing politics of queer theory. Just as Gamson (2009) considered the complications of utilizing queer theory to destabilize collective categories despite knowing that forming a collective identity inherently builds the categories up, Broad (2002) makes a similar argument about transgender activism. She posits that transgender politics and activism are shaped by the simultaneity of both constructions and deconstructions of identity. Both Gamson's and Broad's ideas can be extended to describe the queer liberation movement. By simultaneously breaking down some categories of identity while building up others, the QLM groups engage in similar social movement processes of collective identity.

Cohen (1997) argued that movement building must be constructed not around identity, but around shared marginal status within the dominant power systems. This idea is embodied by the QLM. Solidarity among different subordinated groups was illustrated when Reina Gossett discussed how it is not enough for SRLP to work to end transphobic discrimination at welfare offices, they also must work to raise welfare payments for all poor people. It can also be seen in QEJ's campaign to allow domestic partners to access NYC's family shelter system. QEJ sided against an equality organization that wanted to accept the City's offer to make exceptions just for same-sex couples, and insisted that the city allow homeless heterosexual couples the same right. These examples illustrate how the QLM's identity is based upon solidarity among disempowered groups at least as much as it is upon sexual identity categories. As such, it does not merely complicate identity categories - it actually challenges the very concept of identity-based organizing. 


\section{Conclusion.}

This examination of identity categories and collective identity supplements Dixon's another politics framework, providing another way to understand the queer liberation movement. The QLM complicates social movement theories about identity (collective identity, identity deployment, unity through diversity) because it enacts aspects of each of these frameworks but fails to fit neatly within any of them. Consequently, existing social movement theories offer useful but limited models for understanding the QLM.

In some ways, the QLM embodies the synthesis of Black feminism and queer theory. It enacts important constructs (e.g., intersectionality and margin to center) from Black feminism which require combatting oppression of multiple identity categories and working with people from similarly marginalized identity groups. It does this while simultaneously enacting queer theory's call to deconstruct those identity categories. Deploying identity categories as sites from which to organize, while simultaneously expanding and destabilizing those very categories, is a significant feature of the QLM. To fully capture how the QLM works, this dynamic is important to understand. In addition, it is also significant to the study of social movements more broadly because it is so uncommon in social movements, which largely organize around static, often essentialized, constructions of identity.

For that reason, it was important to incorporate U.S. Third World feminism, which provides a rare and important theoretical precedent to the QLM. It shares with Black feminism the prioritization of people of marginalized identities while also 
engaging in queer theory's challenge to identity categories. Anzaldúa's (1987) concepts

of mestiza and borderlands are particularly applicable to understanding how the QLM navigates issues of identity.

However, U.S. Third World feminism did not build a typical social movement. Although these feminist scholars of color were also activists involved in many social movements, they did not construct a distinct social movement of their own, at least not one that meets the traditional definitions of a social movement that are used in this paper. ${ }^{5}$ Consequently, it is possible that the QLM may be the first American social movement to embody the ideas and politics of U.S. Third World feminism. Regardless of whether or not that supposition bears out, the QLM does at least represent the rare praxis of U.S. Third World feminism.

The QLM's work of deconstructing and reconstructing marginalized identities gives rise to some interesting complications. In the next section I explore how this complicated relationship to identity has resulted in the QLM groups forming a similarly

${ }^{5}$ Although some scholars (notably Sandoval, 2000) refer to U.S. Third World feminism as a social movement, there is not evidence that they developed the requisite infrastructure and organizations to comprise a traditional social movement. Rather, U.S. Third World feminism largely took the forms of theorizing, discourse, and political analysis, which have been significant and influential. Third World feminists have been involved in many local activist campaigns around the world (Herr, 2014), and in the U.S. there were some small Third World feminist organizations built (e.g., the Combahee River Collective). However, the level of institution building and infrastructure development among U.S. Third World feminists has not risen to the level of a distinct social movement of its own, as defined by social movement theorists. Rather, in the U.S.A. the extensive and significant activism of these feminists of color has largely been conducted in multiple other social movements (the civil rights movement, the Chicano movement, gay rights, etc.), which they have worked to transform with their political analysis. In addition, they have engaged in individual acts of resistance and activism, having sometimes been seen as "urban guerrillas" (Hurtado, 1989) engaged in "guerrilla warfare" (Moraga \& Anzaldúa, 1981). 
complicated movement that engages in a parallel process of deconstruction and reconstruction of social movement models as well as identity categories. 


\section{Chapter 10: Deconstructing and Reconstructing Social Movement Models}

I would have to say that it is becoming less and less true that we see (any one social movement) as our home... It's just so hard to separate all of these different identities to claim one movement to work in... I can't really say anymore that we are just an LGBT organization... It's hard to be situated in one place. Which I think makes it messy.

- Kim L. Hunt, Affinity Executive Director

I just think when you're trying to make change, when you're talking about movement building, what you're really talking about is very messy. So I don't think it's linear... So that's kind of the beauty and the challenge of having multiple identities but also having intersectional politics. You have many places where you need to be but also you have to make those choices about how you're going to position yourself.

- Katherine Acey, former Executive Director, Astraea Foundation

\section{Introduction}

Hunt's and Acey's references to "messiness" have preoccupied my thoughts throughout this research. In their attempts to explain the social movements in which the QLM organizations are involved, each of them drew clear connections to the multiple identities of the activists who lead these organizations. The connection made by Acey and Hunt, between multiple identities and multiple social movements, is key to understanding the QLM and represents an important development in the evolution of American social movements. This chapter offers a framework for exploring this development in social movements and how it is related to the issue of identity.

In this chapter, I present a theoretical "four domain" framework to understand the QLM, which builds off those discussions of identity. I developed this framework because, as previous chapters illustrate, many different theoretical frameworks have partial applicability to the QLM, but none fully explain this social movement. Bringing different 
theories and frameworks together in different combinations offers a more comprehensive understanding of this movement.

This chapter builds off of the previous chapter's examination of collective identity in the QLM. It explains how, because of this complicated relationship to identity, the QLM has created a unique social movement. By representing communities that are part of so many identity groups, and working on the corresponding multiplicity of issues that impact them, the QLM is inside of and outside of many different social movements. The QLM occupies an “outsider/within” identity (Collins, 2008) in connection to a variety of social movements, in which they are simultaneously inside and outside. In addition, the QLM groups serve as bridge between these movements, while also comprising their own social movement.

Consequently, I label the QLM a "post-structuralist social movement" that deconstructs social movements while also reconstructing them, existing in four domains simultaneously: (1) outside multiple social movements; (2) inside, between, and among those same social movements; (3) as a bridge connecting multiple movements; and (4) as its own movement. This four-domain structure of the QLM is a new social movement form that defies dominant models of identity-based social movements. Figure 10.1 illustrates the four domains of the QLM. 
Figure 10.1

Four domains of the Queer Liberation Movement

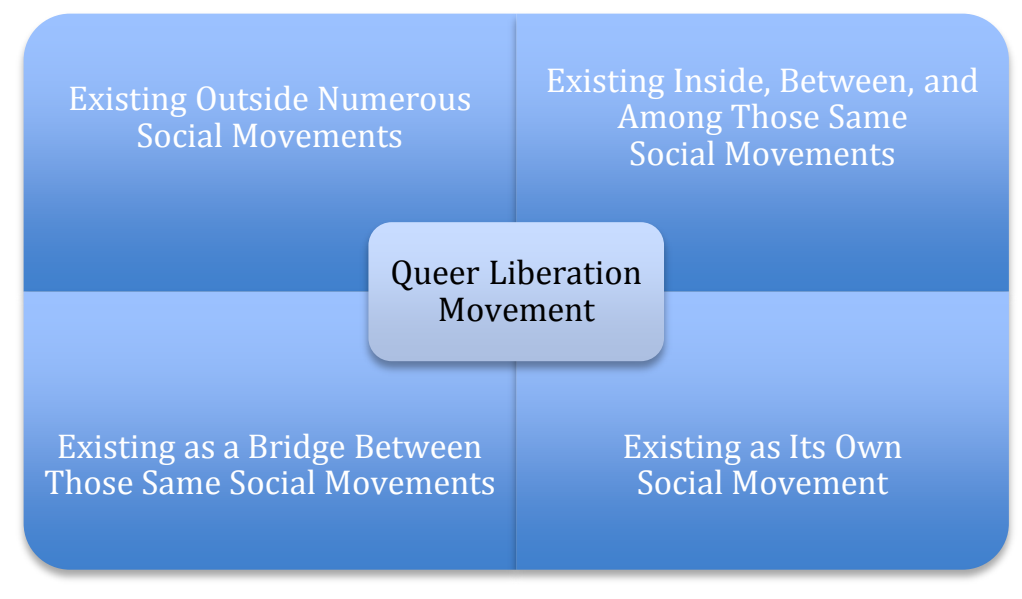

In the previous chapter, I used queer theory to explain how the QLM destabilized hegemonic identity categories, and black feminism as a context for understanding the more expansive, intersectional, identity categories used by the QLM. The queer liberation organizations construct (or reconstruct) their own identity categories. Here I contend that the QLM have engaged in a parallel process whereby they similarly deconstruct social movement categories while simultaneously reconstructing their own "post-structural" social movement.

This parallel process involves deconstructing the hegemonic identity-based models of social movements that have dominated the past half-century and rebuilding an intersectional movement situated in as many social movements as the activists are in identity categories. Because of the multiplicity of identities embodied in the QLM, and the corresponding multiplicity of issues that impact them, the QLM is located inside multiple social movements. For instance, while the QLM groups function in many ways as part of the GRM (and some say they belong to it), there are significant and defining 
ways in which they are not part of the GRM, and cannot be considered part of that movement. Consequently, they occupy what African-American feminist theorist Patricia Hill Collins (2008) called an "outsider/within” identity regarding the GRM.

In addition, the QLM organizations maintain a similar “outsider/within” status with a variety of other social movements, including the immigrant rights movement, the prison abolition movement, the reproductive justice movement, and the anti-poverty movement. The QLM organizations work in partnership with them around shared goals, based on belonging to certain shared identity categories, while also targeting those other social movements, pushing them to address issues that impact different aspects of their identities. I cannot accurately call them "other" social movements, because in many ways the QLM groups are part of each. Yet they are also not purely inside, as they function outside the bounds of those movements. They are simultaneously inside and outside these movements. In addition, the QLM groups comprise their own social movement, which brings those other social movements together in coalitions that are rare for identity-based movements. The result is a post-structural social movement that exists in four domains simultaneously. This four-domain structure of the QLM challenges dominant models of social movements.

Gamson $(1995,2009)$ and Broad (2002) argued that queer and transgender activisms have deployed identity in a unique way - simultaneously tearing down and building up identity categories. The QLM extends this process beyond identity categories used by social movements, to destabilize and expand the very structure of social movements themselves into this four-domain model. Similar to their deconstruction and 
reconstruction of these identities they have deconstructed identity-based movements and constructed a social movement that exists simultaneously outside and inside of multiple identity-based social movements. In this sense, the QLM can be termed a poststructuralist social movement. Just as post-structuralists view binaries as social constructs that must be challenged in order to destabilize the power of dominant groups (Scott, 1988), the QLM approaches the siloed model of modern social movements as a false binary that must be challenged. It breaks the binary categories and borders of social movements by existing in these four domains simultaneously. Paralleling how it deconstructs and reconstructs the theoretical concept of identity, the QLM deconstructs and reconstructs the concept of a social movement. This parallel process involves destabilizing the siloed identity-based social movement model utilized by identity-based movements and reconstructing an intersectional movement with these four domains. The result is a social movement not bound by the category of LGBT or even queer, and interconnected with many other movements. It is its own queer social movement, yet it is also part of other non-queer social movements.

The post-structuralist four domains of the QLM reflect many of the theories and frameworks (e.g., Black feminism, U.S. Third World feminism, homonormativity, queer theory, another politics, perspectival dualism) with which I have been working. I center Anzaldúa’s (1987) post-structuralist concepts of mestiza and borderlands. Her insights provide me with a framework in which I can bring these different theories together into a cohesive explanation for the post-structuralist social movement that is the QLM. I take 
the idea of the mestiza, usually understood individually, and apply it to the QLM, which I argue exists in its own version of Anzaldúa's borderlands.

\section{Domain 1: Existing Outside Other Social Movements}

To separate from my culture (as from my family) I had to feel competent enough on the outside and secure enough inside to live life on my own.

- Gloria Anzaldúa (1987, p. 21)

The QLM resists any one home or location. The QLM organizations are commonly understood as part of the GRM, albeit the progressive wing or radical edge of it (Applied Research Center, 2010; Applied Research Center, 2012; Funders for Lesbian and Gay Issues, 2005). From a certain viewpoint, this assumption is understandable because of how both movements are, to varying degrees, built around sexual orientation and gender identity categories. However, this study makes clear that the QLM is not part of the GRM; such an understanding is too simplistic and, by social movement definitions, not accurate. Similarly, despite its work on prison abolition, immigrant rights, antipoverty, and reproductive justice, it would not be accurate to say that the QLM's primary home is in any of those movements either. Because the QLM rejects single-issue politics, there is no one movement where the QLM is primarily based, and no one political space that it calls its main home.

In addition, because it is comprised of "impossible people," the QLM is often not fully welcomed completely by other social movements. The QLM's refusal to engage in strategic essentialism or identity deployment means that other social movements do not often know how to work with them. SRLP's Dean Spade described how QLM constituents are often viewed by other movements as "politically unviable" colleagues, 
whose impossible identities made it too hard for activists in other social movements to view them as persuasive allies. Other participants voiced similar sentiments.

Consequently, the QLM is welcomed into other social movements in ways that are limited and inconsistent.

This lack of a political home contributes to the messiness described by Acey and Hunt. Similarly, allgo's Rose Pulliam called it "muddy," while SRLP's Reina Gossett, SONG's Paulina Helm-Hernandez, and ALP's Cara Page named it “complicated.” For decades, most social movements created clearly defined (or "siloed") political homes. The QLM's lack of one marks it in stark contrast to other movements and causes the "mess."

However, even if this comprises a new type of social movement structure, poststructuralists have theorized about this messiness for years. Anzaldúa (1987) stated that mestiza "can't hold concepts or ideas in rigid boundaries" (p. 79), reflecting Sandoval's (2000) argument that U.S. Third World feminism "shattered the construction of any one ideology as the single most correct site where truth can be represented" (p. 58). In this way, the QLM built on the politics of U.S. Third World feminism, functioning as the social movement equivalent of a mestiza who is unable to live within rigid conceptual boundaries. The QLM cannot be categorized within any one ideology, reflecting what Anzaldúa envisioned as "a collapse of the systems of categorization through the mestiza and queer consciousness created by them" (Raiskin, 1994, p. 159).

Similarly, queer theory prefigured the QLM's resistance to any one political home. Discussing LGBT activism, Eng, Halberstam, and Muñoz (2005) observed, “Queer has 
no fixed referent" and argued that consequently a queer epistemology serves "as a continuous deconstruction of the tenets of positivism at the heart of identity politics" (p. 3). By rejecting the identity politics of the GRM, the QLM is situated outside of that movement and lacks a single-issue referent where it can locate itself or its politics. Indeed, QLM leaders frequently discussed their politics in ways that defined them in opposition to those of the GRM rather than aligned with those of any one other movement. Fuss (1991) used queer theory to reveal how the creation of meaning is dependent upon oppositional constructs: "the denotation of any term is always dependent on what is exterior to it (heterosexuality, for example, typically defines itself in critical opposition to that which it is not: homosexuality)" (p. 1). The QLM is similarly defined, in part, by a rejection of homonormative GRM politics, and that rejection situates the QLM as outside of the GRM.

By not becoming absorbed into any one social movement, the QLM maintains a position of difference. Remaining outside of social movements, even as it works with them, highlights how the QLM is different from those movements. Butler (2004) argued that a framework of difference brings to fore the political and cultural realities of domination, refusing to elide them (p. 210). By existing outside of numerous social movements, the QLM implicitly calls attention to how these movements don't completely serve their queer communities.

\section{Domain 2: Existing Inside, Between, and Among Other Social Movements}

The mixture of bloods and affinities, rather than confusing, or unbalancing me, has forced me to achieve a kind of equilibrium. Both cultures deny me 
a place in their universe. Between them and among others, I build my own universe.

- Gloria Anzaldúa (Moraga \& Anzaldúa, 1981, p 209)

While the QLM operates outside many social movements, not claiming any of them as its home, it also simultaneously exists inside those same social movements. This is clear in the mission statement of the Roots Coalition, which explicitly situates the member groups as located in multiple social movements: "The mission of the ROOTS Coalition is to create a national network of Queer and Trans People of Color (QTPOC) led organizations and collectives engaged in cutting edge multi-issue organizing across progressive movements" (Roots Coalition, $\mathrm{n} / \mathrm{d}$ ). It is the social movement equivalent of the individuals Anzaldúa (1981) describes as weaving "between and among" different worlds defined by oppositional identities and ideologies.

Anzaldúa described individuals, but this analysis also extends to organizations themselves. The QLM organizations are each part of numerous social movements. They identify as existing inside numerous social movements (e.g., the immigrant rights, prison abolition, and welfare rights movements) by virtue of working on related issues, partnering with related organizations, and organizing around related identities. For instance, I asked Rose Pulliam if she saw allgo as located within any of the social movements that she had specifically mentioned in our interview (the GRM, anti-racism, immigrant rights, and reproductive rights), and she responded, "I think we are located in all of them." Pulliam went on to explain the complicated nature of allgo's existence within those movements: 
We found ways to be in leadership in some of those movements. In some cases allgo is the leading force. And in others what we do is bring people to the table where there are other organizations that are the primary impetus for the organizing, but we bring people to that table because it's our movement too. And sometimes we are on the banner as one of the five organizations that are making this happen and sometimes we are not. And some of that is strategic on our part. And some of it is not strategic. But even when they don't see us as part of that movement, oftentimes, we are actively recruiting our membership to be involved anyway.

QEJ's Kenyon Farrow, ALP's Cara Page, and NQAPIA's Ben de Guzman each also discussed the complicated ways in which their organizations sometimes served as leaders in multiple movements, and sometimes as outsiders in those same movements.

By existing between and among, inside and outside, multiple social movements, the QLM also embodies queer theory's call to destabilize rigid constructions of identity. By refusing to align with just one identity-based social movement, while simultaneously existing within multiple such movements, the QLM implicitly highlights the limitations of such identity categories. In doing so, it enacts Gamson’s (1995) “deconstructionist politics," which positions clearly defined categories as obstacles to success.

The need to engage with so many movements reflects the far-reaching agenda of the QLM, which comes from the particular identities of the QLM's members. Because these groups' identities are subordinated by numerous systems of oppression, the movement combats those numerous systems. Both hooks (2000) and Anzaldúa (1987) described how people living on the margins or in the borderlands have a unique perspective that allows them to see the interconnectedness of systems of oppression. This perspective leads the activists in this study to see their issues as "muddy," because there are so many different systems to combat, rather than "clean" issues, which can be 
resolved by one particular form of change. hooks (1994) explained that marginalized people need to understand "the interlocking, interdependent nature of systems of domination and recognize specific ways each system is maintained" (p. 244), and numerous feminists of color have made similar arguments for decades. It is because of this analysis that the QLM pursue an agenda of another politics (Dixon, 2014), which requires addressing all forms of exploitation, domination, oppression.

This analysis merits additional mention here because it demonstrates that these expansive politics are the result of how the identities of QLM activists connect them to multiple social movements. The QLM brings to the center those people living on the margins, making participation in so many different social movements necessary.

This is illustrated in a speech given by SRLP's Dean Spade. Spade begins by describing the political agenda of the communities with which the QLM works. He said he hears demands from community members "that really exceed recognition and inclusion and visibility" and described how these demands, which are based upon the needs of people who are oppressed by numerous systems, are radical:

These concepts, even just entertaining these concepts, like a country without prisons, entertaining concepts like that, or a country without immigration enforcement, those concepts require us to drastically reconsider the nation and citizenship itself. And these demands are inherently spaces of impossibility (Barnard Center for Research on Women, 2009b).

Spade understands that many view a political agenda as radical as this one to be impossible to achieve. Spade then goes on to say how it makes sense to him that these "impossible" demands are being made by "impossible people" such as transgender 
communities. He claims that impossible people develop their impossible agenda as a result of surviving impossible circumstances. To Spade, because of their ability to survive the unsurvivable, and their existence as impossible people, they make the impossible possible: "I think that there is a space of possibility that exists in part because we are not yet included or recognized."

However, to make such impossible demands possible, multiple battles must be fought. No one social justice movement can address these "impossible" demands. Such a restructuring of society requires the engagement of multiple social justice efforts and movements. Describing the QLM's work, Astraea's Katherine Acey recognized this: “It's messy, it's multiple identities and multiple agendas within the social justice and feminist framework, (in) the queer movement, racial justice movement, immigrant movement, all intersecting. You know, that's the messy part.” In addition, participants also stated that many of those social movements are siloed, and are generally not inclusive of queer issues, or other "nonrelated" issues. As such, the QLM groups also see themselves as outside of those movements, often charged with "queering them up." In this way, they take on the "outsider/within" identity (Collins, 2008).

A similar "outsider/within" dynamic exists between the QLM groups and the GRM. Although Gamson’s (1990) “targets” framework situates the QLM groups as outside of the GRM, they are still involved in the GRM in many ways. Some QLM groups work closely with GRM groups and some participants even identified themselves as part of the GRM. Even those QLM groups who neither work with the GRM nor identify as part of it must still contend with it on a daily basis, as they seek to reframe 
hegemonic understanding of issues and redirect dominant strategies. The GRM occupies a large psychic space in the organizational lives of the QLM, who must constantly situate their work in relationship to that of the GRM. The QLM are situated on the border of the GRM, in some ways living inside it (e.g., as they work in coalitions with GRM organizations) even while in most ways they are outside it (e.g., as they pursue a different agenda).

Political scientist Shane Phelan (2010b) contends that U.S. queers are "strangers," not quite the enemy (since they enjoy some of the rights of citizenship), but not quite citizens either. U.S. queers are ambiguous figures that live on the border between "us" and "them," with American society ambivalent about allowing them full citizenship, and queer people themselves ambivalent about becoming part of the "mainstream." Phelan's framework can be analogously applied to the QLM's relationship to the GRM. According to my interview participants, both the QLM and the GRM are ambivalent about the place of the QLM groups within the GRM, with both movements unsure about what space the QLM groups occupy in the GRM. Further research might explore how GRM leaders themselves characterize their relationship to the QLM, but my interview participants were clear that they felt that the GRM sometimes welcomed them and sometimes excluded them.

Consequently, the QLM groups live both in multiple political lands and between multiple political lands. The QLM is a social movement that exists in the "crossroads" between races, nations, languages, genders, sexualities, and cultures (Anzaldúa, 1987). 
Because the QLM lacks any one political home and, instead, operates within and between so many social movements, it is able to pursue its expansive, multi-issue agenda.

This broad agenda is what makes the QLM a concrete enactment of Fraser's (1995) perspectival dualism, bringing to life her theoretical imagining of a social movement that pursues both economic redistribution and identity-based claims of recognition, without reducing either type to the other. Fraser's framework is embodied by the QLM when it travels inside and outside multiple social movements, pursuing multiple agendas, just as Anzaldúa's mestiza travels between and among cultures. The mestiza refuses to reify cultural nationalism, without entirely forsaking nation, and offers connections to class-based movements, without becoming so subsumed by class politics that it erases questions of cultural, racial, and sexual identities (Anzaldúa, 1987; Phelan, 1994). Because the mestiza never identifies with merely one aspect of her multiple selves, "the mestiza cannot be captured in the oppositions that are presented as inevitable: class or nation, sex or race, or any other reified opposition” (Phelan, 1994, p. 75). The QLM, in rejecting those binaries in its pursuit of both redistributive and recognition claims, enacts both Fraser's and Anzaldúa's frameworks.

Eng, Halberstam, and Muñoz (2005) argue that queer epistemology can reconceptualize intersectionality as more than merely the consideration of oppressions based on race, sexuality, and class, but also as an understanding of how these factors can exist simultaneously, yet be distributed unpredictably. They reference cultural critic Tavia Nyong'o (2005) who describes such intersections as "a meeting of two streets, and in a landscape long given over to automotivity, it is a place of particular hazard for the 
pedestrian" (p. 31). A queer politics that rigorously enacts queer theory must engage in praxis that fully interrogates identity categories and how their intersections create hazardous conditions for those traveling within them. The QLM is the pedestrian navigating these hazardous streets as it travels between and among different worlds.

Similarly, the QLM engages in what Argentine philosopher Maria Lugones (1987) refers to as "world travel" between and among "worlds of meaning." This travel is "required by the logic of oppression," and is flexible and roaming, but focused (p. 77). The QLM demonstrates similar flexibility and focus as it "travels" from one social movement to another. This lack of a political home is significant, because it stands in stark contrast to 40 years of siloed social movements that built homes based on particular identities or interests.

\section{Domain 3: Existing as a Bridge that Connects Multiple Movements}

Caminante no hay puentes, se hace puentes al andar. (Voyager there are no bridges, one makes them as one walks).

- Gloria Anzaldúa (Moraga \& Anzaldúa, 1981)

While simultaneously operating outside and inside multiple social movements, the QLM also brings those movements together. It works in partnerships with multiple movements that are rare for identity-based movements, which traditionally operate in separate "silos." (Kriegman, 2006; LaMarche, 2014). These partnerships exist inside various social movements, and sometimes take the form of participation in coalitions with many organizations, and sometimes in alliances with individual organizations. Table 10.1 lists some of these coalitions and partnerships. 
Table 10.1

Coalitions and Alliances Across Movements In Which the QLM Participates

\begin{tabular}{|c|c|c|c|c|}
\hline $\begin{array}{c}\text { Criminal } \\
\text { Justice / } \\
\text { Prison } \\
\text { Abolition }\end{array}$ & $\begin{array}{l}\text { Health Care / } \\
\text { Social Services }\end{array}$ & Immigrant Rights & $\begin{array}{c}\text { LGBT } \\
\text { Equality }\end{array}$ & $\begin{array}{l}\text { Racial } \\
\text { Justice }\end{array}$ \\
\hline $\begin{array}{l}\text { Communities } \\
\text { United for } \\
\text { Police Reform, } \\
\text { Critical } \\
\text { Resistance, } \\
\text { Drug Policy } \\
\text { Alliance, } \\
\text { Ferguson } \\
\text { Action, } \\
\text { Jail Action } \\
\text { Coalition, } \\
\text { LGBT } \\
\text { Coalition on } \\
\text { Police } \\
\text { Profiling, } \\
\text { Texas After } \\
\text { Violence } \\
\text { Transforming } \\
\text { Justice }\end{array}$ & $\begin{array}{l}\text { AIDS Foundation of } \\
\text { Chicago, } \\
\text { Federation for } \\
\text { Protestant Welfare } \\
\text { Agencies, } \\
\text { Howard Brown, } \\
\text { NARAL Texas, } \\
\text { NYS Medicaid } \\
\text { Coalition, } \\
\text { Queer Economic } \\
\text { Justice Network, } \\
\text { SPARK } \\
\text { Reproductive Justice } \\
\text { NOW, } \\
\text { Welfare Rights } \\
\text { Initiative, } \\
\text { Women with a } \\
\text { Vision }\end{array}$ & $\begin{array}{l}\text { Austin Immigrant } \\
\text { Rights Coalition, } \\
\text { NYC Anti-Violence } \\
\text { Advocates Against } \\
\text { Deportation, } \\
\text { Border Network for } \\
\text { Human Rights, } \\
\text { Georgia Immigrant } \\
\text { \& Refugee Rights, } \\
\text { Georgia Latino and } \\
\text { Human Rights, } \\
\text { NYC Immigrant } \\
\text { Communities in } \\
\text { Action, } \\
\text { LGBT Immigration } \\
\text { Working Group, } \\
\text { We Are Georgia } \\
\text { Campaign }\end{array}$ & $\begin{array}{l}\text { Equality } \\
\text { Federation, } \\
\text { LGBT National } \\
\text { Policy } \\
\text { Roundtable, } \\
\text { NYS LGBT } \\
\text { Health and } \\
\text { Human Services } \\
\text { Network }\end{array}$ & $\begin{array}{l}\text { Better } \\
\text { Together } \\
\text { Coalition, } \\
\text { INCITE!, } \\
\text { National } \\
\text { Counsel of } \\
\text { Asian Pacific } \\
\text { Americans, } \\
\text { National } \\
\text { Association for } \\
\text { the } \\
\text { Advancement } \\
\text { of Colored } \\
\text { People, } \\
\text { Project South, } \\
\text { Race Forward, } \\
\text { SisterSong, } \\
\text { United African } \\
\text { Organization }\end{array}$ \\
\hline
\end{tabular}

However, in addition to participating in these coalitions and alliances located within various specific social movements, the QLM also convenes numerous social movements to work together on a range of issues across movements. The QLM used the "Better Together" network (a series of convenings among diverse social justice groups), the "Building A Queer Left" coalition (a series of monthly teleconferences), and the U.S. Social Forum (national gatherings in 2007 and 2010) to bring together multiple social movements, including the affordable housing, disability rights, economic justice, indigenous sovereignty, immigrant rights, LGBT equality, prison abolition, racial justice, reproductive justice, welfare rights, universal healthcare, and youth empowerment 
movements. They came together to build relationships and work towards broad-based progressive transformation for multiple communities and peoples.

By uniting and joining these different social movements, the QLM continues to make manifest the social movement equivalent of Anzaldúa's concept of the individual mestiza, who connects different people to each other: "I am an act of kneading, of uniting, and joining" (Anzaldúa, 1987, pg. 81). Indeed, by bringing together different marginalized communities, the QLM enacts some of the central politics of U.S. Third World feminism which sought to unite different communities that were located "on the bottom” (Moraga \& Anzaldúa, 1981), “to fight alongside each other” (Lorde, 1984, p. 142). By bridging movements, the QLM serves as the social movement equivalent of what Moraga and Anzaldúa (1981) famously referred to as "this bridge called my back." In that landmark collection of writings by feminists of color, Merle Woo (1981) described U.S. Third World feminist politics and theories as a new paradigm for resistance, one "created in a community, bonded not by color, sex or class, but by love and the common goal for the liberation of mind, heart, and spirit" (p. 147).

This prioritizing of common goals, rather than shared identities, is a significant aspect of the QLM. Because it brings together multiple social movements (partly due to its position inside and between them), the QLM expands its focus from collective identity to also including working with people who have shared interests. In doing so, it enacts the calls put forward by many feminist and queer theorists. For instance, Cohen (1997) argued that social movements must stop organizing around identity and, instead, mobilize people with shared marginal status within the dominant power systems. The QLM brings 
together numerous such people and employs a "unity through diversity" that is much more diverse than the gay rights groups being studied by Armstrong (2002).

Feminist scholar Janet Jakobsen (2005) built upon Cohen’s argument, claiming, "A shift is needed, but not just from identity to shared interests. Rather, our movements need to shift from identities and interests to alternative affinities, different values, and reconstructed interests" (p. 304). When the QLM organizes across movements, it enacts Jakobsen's call, organizing around a different set of affinities, values, and reconstructed interests, as evidenced in my discussion, in Chapter Eight, of Dixon's "another politics." Not only does the QLM's coalition work reflect a core principle of another politics ("Struggling against all forms of domination, exploitation and oppression"), it also represents the types of affinities, values, and reconstructed interests Jakobsen prescribes. The QLM's coalition work brings together many movements to work together on multiple fronts, reflecting the interconnection of all forms of oppression. By bring together many marginalized communities and enacting another politics by working against numerous systems of oppression, the QLM makes manifest the politics of U.S. Third World feminists like the Combahee River Collective (1981): "We realize the liberation of all oppressed peoples necessitates the destruction of the political-economic systems of capitalism and imperialism, as well as patriarchy" (p. 213). Building bridges between social movements is an important feature of the QLM, and it is particularly notable given its rarity among $20^{\text {th }}$ century social movements. 


\section{Domain 4: Existing as Its Own Social Movement}

For a people who are neither Spanish nor live in a country in which Spanish is the first language; for a people who live in a country in which English is the reigning tongue but who are not Anglo; for a people who cannot entirely identify with either standard (formal, Castillian) Spanish nor standard English, what recourse is left to them but to create their own language? A language which they can connect their identity to, one capable of communicating the realities and values true to themselves.

- Gloria Anzaldúa (1987, p. 55)

The final of the QLM's four domains is its status as its own movement. In the interviews I conducted, activists communicated to me the realities of their work and the values they hold. This research shows that these organizations comprise their own, distinct social movement. This movement serves as a political home for these organizations, a place where they share (to varying degrees) values, goals, strategies, and constituents (e.g., the QLM centers queer and transgender people of color, connects to the "trickle-up social justice" framework, pursues liberation, etc.).

In this fourth domain, the QLM engages in more typical behaviors that have been theorized by social movement theorists. For instance, the QLM organizations have built institutions, as described by resource mobilization theory (McCarthy \& Zald, 1977).

These include counter institutions, as conceptualized by another politics (Dixon, 2014).

The institutions built by the QLM represent the synthesis of radical politics (linked to the legacy of the politics of gay liberation and U.S. Third World feminism) and the nonprofit structure (utilized by the GRM and other social movements of the past forty years). Chapters Seven and Eight provide more details about how this social movement functions. 
In addition, in this domain, the QLM organizes most clearly around its (complicated, deconstructed, and reconstructed) collective identity. This chapter has documented how that shared identity can be examined through the lens of numerous identity theories. These included collective identity, intersectionality, trickle-up social justice/margin-to-center, strategic essentialism, queer theory, identity deployment, and unity in diversity. Regardless of which lens is used, it is in this domain of its own movement that the QLM most centralizes the identity categories it has constructed.

The activists in this movement have enacted Anzaldúa's concept of developing their own language together. When the activists in this study talk extensively about liberation and justice (rather than equality), about community organizing and movement building (rather than direct services or policy wins), expansive definitions of family (rather than couples), and about impossible people and trickle-up social justice (rather than white, middle-class, gays and lesbians) they are communicating in "a language which they can connect their identity to, one capable of communicating the realities and values true to themselves."

\section{Conclusion}

Many different theoretical frameworks have partial applicability to the QLM, but none fully explain this social movement. Bringing the theories and frameworks together in different combinations offers a more comprehensive understanding of this movement. Because none of these frameworks on its own describes the QLM, I developed the fourdomain framework for understanding this post-structuralist social movement. This fourdomain framework explains how the queer liberation organizations deconstruct social 
movement categories and reconstruct the model of a social movement. The QLM does this by simultaneously existing outside of multiple social movements, inside/between/among those same social movements, as a bridge that connects movements, and as its own movement. This four-domain structure of the QLM challenges and destabilizes the dominant existing models for understanding of social movements, in a process that is informed by and parallels how they construct (or reconstruct) their own identity categories.

It is possible that the framework presented in this chapter has implications for other social movements beyond the QLM. After decades of siloed identity-based social movements, recent years have seen increasing solidarity between different progressive social movements (Kriegman, 2006; LaMarche, 2014). In addition, as discussed in Chapter Eight, some of these different social movements have been taking a new form (Crass, 2013; Dixon, 2014; Farro, 2014; Khatib, Killjoy, \& McGuire, 2012; LustigerThaler, 2014; Touraine, 2014). Further research is necessary to determine the degree to which the QLM reflects these changes in social movements, and whether the framework offered here can be applied to other movements. 


\section{Chapter 11: Contributions, Limitations, and Future Research}

My work provides a basis for claiming that a new social movement, the queer liberation movement, has developed distinct from the mainstream gay rights movement. This research also demonstrates how the QLM is a new form of a social movement. These are two significant contributions to the study of social movements. However there are also important limitations to this project and many opportunities for future research. In this chapter, I examine the contributions and limitations of this study, as well as opportunities for future research.

\section{Limitations and Future Research}

\section{Limitations of Gamson.}

As I engaged in my analysis, I became aware of the limitations involved in my choice to use Gamson's (1990) framework of three targets (Targets of Influence, Targets of Benefits, and Targets of Mobilization) to answer my first research question ("What does analyzing these organizations through social movement theories reveal about the claim held by many that these organizations are the left-wing of the gay rights movement?"). I compared the targets of GRM organizations to the targets of these queer liberation organizations. I chose to use Gamson because his work is regarded as canonical in social movement literature. However, Gamson was writing about the targets of "challenging groups" (i.e., individual organizations), not the targets of entire social movements. In order to use his framework for my study, I had to adapt it so that it would apply to social movements. In retrospect, choosing a different set of criteria that did not 
require adaption might have made for a cleaner, perhaps more persuasive, claim that seven groups in my study are not part of the GRM.

\section{Limitations regarding the composition of the QLM.}

This dissertation demonstrates that seven organizations are part of a queer liberation movement, but is limited because it does not examine the composition of the QLM beyond the groups in my study. This section explores the potential for future research about this issue.

First, however, it is worth looking briefly at how two organizations in this study have a different relationship to the QLM than the other organizations. Although Affinity and NQAPIA share many central features with the other groups in the QLM, their political analysis and agenda are less radical than the other organizations. This became to clear when I realized they were the only two groups who did not situate their progressive, intersectional analysis within a discourse that looked critically at capitalism or imperialism. This also was clear from their (limited) support of the marriage campaigns. Affinity and NQAPIA are also two of the three organizations (along with allgo) that are least connected to the other groups since the Roots Coalition lost its funding. I remain confident in my findings that Affinity and NQAPIA have been a part of the QLM.

However, for the reasons listed above, I have questions about whether and to what extent they will continue to be part of the QLM in the future. This issue may be worth examining in follow-up research.

This also raises the related larger question about the current and future composition of the QLM. As noted already, since the Roots Coalition lost its funding, 
Affinity, allgo and NQAPIA no longer have the resources to actively collaborate with the other organizations as frequently as they once did. In addition, QEJ has closed since I began this study, and my research determined that CAR is not part of the QLM. The result of these various facts is that, of the eight groups in my study, I am essentially claiming that only three groups are currently actively engaged in work together as a social movement: ALP, SONG, and SRLP. Future research may focus on following up with the six existing groups that are currently part of the QLM (all eight groups in this study, minus CAR and QEJ) to see how they continue to work together. However, it is likely that other organizations, not included in this study, may be part of the QLM.

In particular, the organizations in this study have worked very closely with three other Astraea Movement-Building grantees, which were eligible for inclusion in this study: the Esperanza Peace and Justice Center (San Antonio, TX), FIERCE (New York, NY), and the TGIJ (Transgender, Gender Variant and Intersex Justice) Project (Oakland, CA). My interview participants made numerous references to partnerships with these three organizations, and those collaborations appear to remain strong even after the Roots Coalition lost its funding.

Furthermore, three additional groups were part of the Roots Coalition who may also be part of the QLM: the Disability Justice Collective (national), the First Nations Two Spirit Collective (national), and the Queer Women of Color Media Arts Project (San Francisco, CA). My interview participants mentioned their post-Roots Coalition relationships with these groups but did not discuss them as frequently or in as much depth as they discussed their relationships with Esperanza, FIERCE and TGIJ Project. 
Consequently, I am interested in investigating further the state of the QLM's partnerships with the Disability Justice Collective, the First Nations Two Spirit Collective, and the Queer Women of Color Media Arts Project.

Two other organizations, not part of the Roots Coalition, have also worked closely with QLM groups: the Transgender Law Center (San Francisco, CA), which recently announced a new long-term partnership with SONG, and Streetwise and Safe (New York, NY) which shares the Miss Major-Jay Toole Building with ALP, FIERCE, and SRLP. Finally, several interview participants referenced working with six other organizations, though I do not know how frequently. These groups are BreakOUT! (New Orleans, LA), Familia: Trans Queer Liberation Movement (Los Angeles, CA), the Freedom Center for Social Justice (Charlotte, NC), GLOBE: the LGBTQ Justice Organization of Make the Road By Walking (Brooklyn, New York), SPARK (Atlanta, GA), Trans Women of Color Collective (Washington, DC).

My research gives me reason to believe that it is possible that any or all of the fourteen non-profit organizations named above may be part of the QLM. I am interested in conducting future research to explore whether this is true.

There are dozens of queer organizations across the country that are involved in multi-issue work. Appendix D lists some of them. Future research may explore which of them might also be part of the QLM.

When designing this study, I did not include unfunded groups that operate outside of the non-profit structure. This is a significant limitation of this research. As mentioned earlier, many unfunded grassroots queer groups have also emerged in the $21^{\text {st }}$ century, 
and many are people of color organizations (Conrad, 2009b; Drucker, 2015; Espinoza, 2008). Because they are unfunded, they differ from the groups in this study. However, their political agendas imply that they may share certain features of the QLM, as well as with the other $21^{\text {st }}$ century social movements described by Dixon (2014). These politics inform their decisions not to create non-profit organizations. For instance, the radical queer group Against Equality (based out of Chicago, IL), has stated:

As an anti-capitalist collective, we are quite skeptical of the non-profit model employed by multi-million dollar organizations like the Human Rights Campaign and the National Gay and Lesbian Task Force... Though foregoing non-profit status and fiscal sponsors has rendered us ineligible for grants, it allows us to be more directly accountable to our community instead of to funders. We've deliberately eschewed a non-profit structure, preferring to operate as a collective. Not being beholden to a board or conventional funders has meant that we've struggled financially, but that also keeps us focused on our work, not endless grant writing, fundraising and board development (Conrad, Chavez, Nair, \& Loeffler, 2014, p. 6).

I include this quote, because it raises questions I may want to explore in future research. While it is clear that the structures of unfunded groups like Against Equality enable them to avoid being "beholden to a board or conventional funders," it is less clear how exactly they, or other unfunded groups, are "directly accountable to their community." In what ways are such groups accountable to their communities? Is it not possible that being an "anti-capitalist collective" merely gives groups the freedom to do whatever they want, without being accountable to anyone? (This question if of particular interest given how the groups in this study have tried to incorporate community leadership into their nonprofit structures.) How does being an unfunded collective also impact their ability and desire to work with groups that have been built as 501(c)3 
organizations? Future research must explore the unfunded queer groups who share certain features of the QLM and investigate whether and how these groups are part of the QLM.

\section{Other limitations.}

Throughout my analysis, I discovered other limitations that highlight additional areas of potential future research. These areas of future research include returning to my participants to collect additional data, conducting interviews with leaders in the GRM, members of the QLM, and groups in other social movements. Numerous questions emerged during my analysis for which I did not have answers in my data. During my interviews I did not think to ask certain follow-up questions that became much more interesting to me later during my thinking and writing.

In designing this project, I did not think to focus on the issue of funding sources. I did not ask the interview participants about their budgets and how they get their funding. Particularly given the numerous points in the preceding chapters where questions related to funding, the politics of funding, and the implications of those politics emerged, having asked these questions and others would have been instructive. Moving forward, it will be informative to explore where and how the QLM organizations are funded and compare these funding dynamics to other social movements, particularly the GRM. Every political issue is connected to money, and comparisons to the larger, more lucratively funded equality organizations could inform my analysis. Comparison of funding between QLM and marriage equality groups would underscore the degree of disparity and power that exists between them. In addition, other funding related questions arose during my analysis. How do funders understand the work of QLM groups and how do the QLM 
groups attempt to influence funders? Some activists made references to these issues, but I did not think to ask follow-up questions that teased out more comprehensive information. How are funders responding to organizations that engage in multi-issue work? This is an important question when so many funders have discreet funding streams that support particular "silos" of work. How do organizations that are engaging in what Dixon (2014) called "new ways of relating" address their unconventional structures (e.g., collective leadership, affective organizing) when talking with funders? This would be an interesting focus of future research because the critiques of the nonprofit industrial complex are not limited to internal structural limitations; funding sources often create and exacerbate the dynamics that are assessed by critics of nonprofits.

Another question that arose for me during my analysis pertains to Dixon's (2014) idea of affective organizing, addressed in Chapter Eight. Although my interview participants discussed their philosophical commitment to the concepts of affective organizing, I would like to learn more about how some of the organizations operationalize these ideas. In what ways does their work enact their commitment to affective organizing? How is this principle made concrete?

Similarly, in the same chapter I addressed how the QLM is committed to transforming power relations, and offered some examples of how they do this (e.g., through the prioritization of leadership of marginalized people, and with progressive personnel policies). Future research may look at the impact of those decisions in other areas of the organization. How are the culture and environment of these organizations 
impacted if the staff members are truly equals in the work being conceived and done? What are the larger impacts on the movement as a whole?

I also did not interview leaders in the GRM. Interview participants described how they felt simultaneously welcomed and excluded by the GRM. Further research may investigate leaders in the GRM, exploring how they understand their relationship to the QLM. Do they share the assessment offered by my participants? Do they view the QLM as partners in a larger multi-faceted movement, or as "pains in the ass" in the words of allgo's Rose Pulliam (whose quote captured sentiments shared by other interview participants), or do they simply view them as distinct from the GRM?

In addition, this study is limited by its focus on leadership. In future research, I want to conduct interviews with members of the QLM organizations. While this dissertation focused on the QLM leadership, future interviews with the membership (rather than the leadership) can serve the dual purposes of deepening knowledge about the QLM while also challenging my hierarchal focus on leadership.

Finally, this study only begins to explore the relationship between the QLM and other social movements. Future research might examine how the QLM works with progressive, queer-inclusive, but not queer-specific organizations. Many progressive groups across the country are not explicitly queer, but actively include queer issues in their work (e.g., Highlander Center, INCITE, Generation Five, SisterSong, Women with A Vision, etc.). The QLM organizations sometimes work with these organizations, but those organizations were beyond the scope of this dissertation. I want to understand the nature of those relationships, and how those groups might be understood in relationship 
to the QLM as a social movement (rather than to the individual QLM organizations). Are they allies, or should they be considered part of the QLM?

\section{Other Future Research}

\section{History.}

As I prepared my proposal for this project, I conducted an extensive literature review that informed Chapter Three ("A Brief History of the Gay Rights Movement In the United States ") and Chapter Four ("The $21^{\text {st }}$ Century"). In doing so, I discovered important gaps in existing scholarship. Although much has been written about the historical tensions within the GRM that existed between the radical factions (those seeking broad structural transformation) and the assimilationist factions (those seeking equality and inclusion), I found no comprehensive history of the radical queer left. Rather, most scholars have focused on particular radical groups or moments, or else they have merely referenced the tensions as part of their work documenting the rise of the mainstream gay rights movement, without concentrating primarily on the radical factions. I had to cobble together my history sections from dozens of sources that each addressed only a small aspect of radical queer organizing. Very little work focuses, specifically and comprehensively, on the history of radical queer organizing (including the gay liberation groups of the 1960s, the queer politics of the 1990s, and the QLM in the $21^{\text {st }}$ century).

In particular, there is a lack of scholarship focused on the history of organizing by

queer people of color. Finding information about the $20^{\text {th }}$ century activism and organizing of queer people of color was a challenge. 
I am very interested in contributing to this scholarship. I would like to focus on the history of radical organizing by queer people of color and situate my findings about the QLM in that history. As noted elsewhere, I see the emergence of the QLM as connected to critiques of the GRM, but I also understand it to be an outgrowth of past radical activism of queer people of color. I intend to contribute to a deeper understanding of this historical activism as I write about the emergence of the QLM.

\section{Research about indigenous activism.}

In recent years, a body of scholarship has emerged about the critiques issued by queer and Two Spirit scholars and activists that position their focus as different from other forms of LGBT activism (Driskell, 2010; Driskill, Finely, Gilley, \& Morgensen, 2011; Morgensen, 2010 \& 2011; Simpson \& Smith, 2014; Smith, 2005 \& 2010). These Indigenous scholars critique US settler colonialism as well as many queer organizations' perpetuation of it. Certain forms of Two Spirit and Indigenous queer organizing look different from that of the QLM.

Although this study does not focus on any groups that are specifically Indigenous, ALP and SONG are inclusive of Indigenous members, and those organizations have been involved in struggles for sovereignty by Indigenous peoples in the USA. Cara Page mentioned how, as part of that sovereignty work, ALP prioritizes the leadership of Two Spirit activists. In addition, The First Nations Two Spirit Collective, a national group of activists, was one of the co-founders of the Roots Coalition and has partnered with all of the groups in this study.

My interview questions did not focus on sovereignty work, nor did they 
specifically explore the leadership of Two Spirit and queer Indigenous activists. Future research may examine how theorizing by queer Native scholars such as Qwo-Li Driskell (2010, 2011), Scott L. Morgensen (2010 \& 2011) and Andrea Smith (2005 \& 2010) might apply to the QLM. It may also explore how groups in the QLM engage in sovereignty work, and how Two Spirit activists are involved in that work.

\section{Research about other social movements.}

I am interested in doing further research about whether the QLM is representative of other $21^{\text {st }}$ century social movements. It is conceivable that the four-domain framework presented in the last chapter has implications for other social movements beyond the QLM. The siloed identity-based social movements of the past have been changing in recent years, with increasing solidarity between different progressive social movements (Kriegman, 2006; LaMarche, 2014). In addition, as discussed in Chapter Eight, some $21^{\text {st }}$ century social movements have been taking a new form (Crass, 2013; Dixon, 2014; Farro, 2014; Khatib, Killjoy, \& McGuire, 2012; Lustiger-Thaler, 2014; Touraine, 2014). I intend to engage in further research to ascertain whether and how the QLM reflects these changes in social movements.

I have seen tensions in other social movements that mirror those in LGBT activism. Certain factions of various social movements appear to be questioning longstanding goals of inclusion and rights, and arguing that broader system change is needed. These discussions are happening in various social movements, including those working on reproductive health (abortion rights vs. broader reproductive justice), criminal justice (prison reform vs. abolition), disability rights (individual access vs. structural remedies), 
immigration (immigrant rights vs. comprehensive immigration reform). These debates parallel debates within the GRM that preceded and informed the emergence of the QLM. I am curious about whether these other movements might be on a similar trajectory, or if these internal disputes are merely the types of debates that are typical of social movements (Mansbridge, 2009; Snow \& Soule, 2010).

\section{Contributions and Scholarship from this Dissertation}

This section focuses on potential scholarship that can come from this research project. This dissertation provides me with opportunities to use my findings to contribute to academic scholarship in various fields (e.g., social movement literature, queer studies, and social work). I am not yet sure if I want use this research to publish a series of individual journal articles or if I want to turn it into a book ${ }^{6}$. Below I summarize the findings from this research that have the potential to contribute to scholarly literature.

\section{The existence of the QLM.}

I intend to publish first about the central contribution of this research: the existence of a separate Queer Liberation Movement. My work provides a grounded foundation from which to argue that according to social movement theory, such a movement - distinct from the GRM - $\underline{\text { does }}$ exist. This makes important contributions both to social movement literature and to queer studies. Although well-documented critiques about the GRM exist, only a handful of scholarly articles address the work of

\footnotetext{
${ }^{6}$ For tenure and promotion purposes, a series of journal articles makes the most sense. However, a book allows for greater cohesion and comprehensiveness. These are questions I will have to weigh as I move forward, but for this chapter, I consider both options "scholarship and future research."
} 
organizations born in response to those critiques, and no scholarship addresses the fact that a new social movement has developed. I intend to explore how these organizations have developed into a distinct movement, with constituents, goals, targets, and strategies that are uniquely its own.

After publishing that a QLM has emerged, I intend to build off that work, to explore further this new social movement. In particular, I will write about the "four domain" framework I developed in the previous chapter. While the emergence of the QLM as a distinct movement is significant on its own, of similar significance is the fact that it represents a new post-structuralist model of social movement. I will examine how it exists simultaneously inside and outside of other social movements, as a bridge between them, and as its own movement. In addition, I will publish about the issues of collective identity (explored in Chapter Nine) that have informed the creation of this new social movement model.

In addition to these central overarching findings, I will also explore some of the more specific issues that emerged from my research. These issues, focused on specific dynamics of the QLM, are briefly summarized below.

\section{Organizing versus lobbying.}

The organizations in this study prioritize movement building but do not oppose advocacy or policy work. They engage in policy work but disagree with the GRM's tactic of measuring successful social change by successfully changing laws. These organizations believe that material change in people's lives cannot be achieved by

policies alone. They contend that movement building is more important than policy 
advocacy, and that building a base builds power. They remain committed to this principle despite how it limits their funding options (because LGBT funders are more interested in advocacy wins). This issue came up throughout my interviews, and I have enough data to analyze and publish about the tensions these groups experience regarding organizing versus lobbying.

\section{Trickle-up social justice.}

The QLM is an important social movement model because of its focus on the issues of queer people who experience multiple forms of oppression, from multiple systems. It prioritizes the issues of concern to queer people in multiple subordinated identity categories and simultaneously creates structures for those same people to lead the organizations. By putting into practice hooks' (2000) concept of margin to center, the QLM is distinct from many other identity-based movements. I have more data about this issue than was included in the dissertation, and I intend to explore this issue further in my writing.

\section{Marriage politics.}

This research contributes to a body of literature that looks critically at the samesex marriage movement, including my own emerging scholarship (DeFilippis, 2012a; DeFilippis, 2015; DeFilippis, Anderson-Nathe, \& Panichelli, 2015). In addition to supporting the existing critiques, future publications based on this dissertation can move the literature forward by providing concrete examples of how the marriage equality campaigns have impacted the funding of those LGBT organizations not working on 
marriage. I expect to publish about interview participants' discussion of how funding has been diverted away from the issues they work on and redirected to marriage campaigns.

In addition, I situate this research in a larger context of marriage politics in the United States. Many activists and scholars have examined how gay activism, and the marriage campaigns more specifically, serve a neoliberal agenda (DeFilippis, AndersonNathe, \& Panichelli, 2015; Dobbs, 2012; Duggan, 2002; Farrow, 2011b; Nair, 2013b; Ryan, 2009; Ward, 2008). My dissertation moves that conversation forward by showing how the QLM differs from such activism. I expect to publish about how this movement actively works to challenge neoliberal policies, and contribute to the larger discourse about marriage politics.

\section{Co-option of racial justice work.}

As noted previously, I was surprised to learn of the QLM leaders' concern about having their work co-opted by the GRM. They contend that as marriage victories pile up, the GRM is starting to think about the work it will take on next. My interview participants shared stories about how the GRM has begun to co-opt the racial justice work the QLM groups have been working on for the past 30 years. They also claim that the GRM organizations have subsequently watered down the QLM's racial justice analysis and agenda, shifting focus from structural critiques to anti-discrimination concerns. My data provides me with enough material to publish about these themes.

\section{Perspectival dualism.}

In previous decades, social movement scholars have documented the shift

between the redistributive agenda of the early $20^{\text {th }}$ century class-based social movements 
and the demands for access and recognition put forward by the identity-based movements of the 1960s New Left (Bernstein \& Taylor, 2005; Polletta \& Jasper, 2001; Taylor \& Whittier, 1999). Very little has been written about the emergence in the $21^{\text {st }}$ century of social movements that embrace both frameworks. While the mainstream gay rights movement can clearly be characterized as a typical identity-based social movement, my research demonstrates that the QLM is not. Although centered around identity claims, albeit complicated ones, the QLM goals are redistributive as well as recognition-based. Perspectival dualism (Fraser, 1995; 2003) theorizes about the potential of social movements to be both redistribution-based and recognition-based. Because Fraser limited her LGBT focus to the equality organizations, she did not see LGBT activism as pursuing both redistribution and recognition goals. My study expands Fraser's theoretical framework by illustrating how the QLM complicates the widespread binary understanding of social movements as either redistributive or recognition based. I intend to publish about how the QLM brings Fraser's theoretical construct into practice, thus contributing to the body of knowledge about social movements.

\section{Implications for philanthropy.}

In the $21^{\text {st }}$ century, there has been major increase in foundation funding of LGBT organizations; $86 \%$ of all philanthropic support ever given to LGBT organizations has been since 2000 (Funders for LGBTQ Issues, 2012). During this same period, marriage campaigns have dominated the work of the GRM and have received $\$ 72.5$ million from foundations, while LGBT people of color organizations have been underfunded (Funders for LGBTQ Issues, 2012). The QLM organizations believe that they have lost funding 
due to funders' focus on marriage work. However, I expect that gay marriage will become legal across the country in the next few years. In addition, many of the major policy issues prioritized by the mainstream gay rights movement have already been achieved, including its efforts regarding gays in the military, hate crime legislation, and anti-discrimination laws. When the marriage campaigns are over, what will happen to the increased funding that foundations have been giving to GRM organizations in recent years?

I am concerned that once the limited agenda of the GRM has been accomplished, foundations that have supported this work will cease or decrease their funding of LGBT issues. Yet, many other issues also impact LGBT people, including economic issues, housing, immigration, health care and the social safety net, and criminal justice. These issues are being addressed by the QLM, a movement comprised of underfunded, small organizations.

I hope that my work contributes to philanthropic organizations' understanding of other LGBT funding options and helps catalyze philanthropic support to these other organizations. By documenting that these groups constitute a separate movement, they can be considered an underserved population/movement. As long as they are viewed as part of the GRM, funders may believe that this movement is already being served by their existing support of "gay rights" organizations. When the GRM achieves its limited set of goals within the next decade, I want the QLM groups to be considered separate from that "victory." If they are understood to be seeking different goals for different constituents, it will be easier to make the case that their agenda has not yet succeeded. I will convert my 
findings into a report that can be disseminated to funders, with the help of colleagues at Funders for Lesbian and Gay Issues.

\section{Implications for Social Work}

My research has significant implications for the social work profession. The following section examines how my work can contribute to both social work education and social work practice.

\section{Implications for social work education.}

I identify three primary implications for social work education: challenging essentialized identities, social justice versus equality, and elevating the importance of macro-level work. The following sections explore how my research addresses those issues.

\section{Challenging essentialized identities.}

Based upon my experience teaching in three cities in three different social work programs and talking with faculty at additional universities across the country, I contend that social work education frequently embraces an essentialized notion of LGBT identity. Although some textbooks view sexuality through an intersectional lens (e.g. Kumashiro, 2001), these are rare. The various schools of social work where I have been employed have used textbooks (Adams, et al., 2010; Collins \& Andersen, 2007; Stombler, et al., 2010) that too often presume homophobia and structural heterosexism are the only obstacles facing LGBT communities. The result positions gayness as by default White and middle-class. 
Similarly, many instructors who teach "social justice" courses (or comparable classes) structure their curriculum so that each week the class focuses on a different "ism" (e.g., racism, classism, homophobia, and religious oppression). While I understand the functional appeal of such a framework, the lack of an intersectional lens frequently results in the perpetuation of uni-dimensional identities for all the oppressed groups being studied. Although individual instructors may, and often do, complicate such essentialized discourse, there is little structural requirement or curricular support for doing so (Jani, Pierce, Ortiz \& Sowbel, 2011). If social work is to successfully serve LGBT people, it is vital that it begin recognizing the multiplicity of obstacles facing them. It can do this by utilizing more regularly the intersectional analysis employed by the queer liberation organizations I researched.

In addition, when intersectionality is addressed in social justice/diversity/antioppression classes within the social work curriculum, it often remains abstract. Students learn about the intersection of identities, and how that leads to a multitude of oppressions, but are rarely provided with examples of how to combat these oppressions from an intersectional approach.

By focusing on organizations doing intersectional, multi-issue work that are led by people with multiple subordinated identities, this project demonstrates that LGBT lives are, in fact, much more complicated than existing uni-dimensional notions have captured. It also provides real-world examples of how theorizing about intersectional identities can be put into practice, and these examples hold significant value for social work students interested both in organizing/community work and direct micro practice. I 
expect to publish articles from this dissertation that contribute to an understanding of how social work can study and conceptualize LGBT people through an intersectional lens.

\section{Social justice versus equality.}

My commitment to the field of social work exists because of the field's commitment to the language of social justice. I am proud that the profession centralizes this concept, despite my belief that it often fails to live up to this commitment. By prioritizing social justice, social work implicitly demonstrates the limitations of mere equality. My interview participants offered explicit and persuasive critiques of the equality framework and their work offers clear examples of how a dedication to social justice becomes enacted in practice. I believe my work supports social work's commitment to social justice and can be used in social justice classes to illustrate the concept.

\section{Elevating the importance of macro-level work.}

In addition, this study demonstrates the need for social work education to provide increased focus on macro-level social change work. According to the NASW Code of Ethics (2008) "social workers should promote the general welfare of society, from local to global levels, and the development of people, their communities, and their environments" (6.01). Yet in my personal experience, social work education too often presumes that that students' areas of practice are in the micro or mezzo levels. Research classes rarely address macro-level research methods and practice classes often presume that students' work will focus on micro or mezzo-level social problems exclusively through programmatic interventions at social service institutions. I believe that social 
work education is not focused enough on the needs of students interested in community organizing campaigns, public policy, or social movements. Many social work programs are ill equipped to address the academic interests of students interested in studying any social problem that is addressed outside of institutional/programmatic settings. In order to prepare students for the full range of social change opportunities, social work programs must increase their focus on macro work. They must incorporate the study of social movements and develop the community organizing skills of social work students.

\section{Implications for social work practice.}

I identify three primary implications for social work practice: engaging in multiissue work, serving all LGBT families, and highlighting unaddressed needs of LGBT people. The following sections explore how my research addresses those issues.

\section{Engaging in multi-issue work.}

Social workers must understand that the form of $21^{\text {st }}$ century social movements is different from those of latter decades of the $20^{\text {th }}$ century, when movements were largely organized around narrowly constructed collective identity categories, working in "silos" towards single-issue goals. The intersectional understanding of identities has resulted in intersectional social movements, working on broad agendas encompassing many different targets. Consequently, social work practitioners must learn to work in multi-faceted movements. The result of this new form of multi-faceted social movements means that single-identity issues are being downplayed and replaced by intersectional analysis and action. Rather than focusing primarily on work with specific populations, social workers must also strengthen their ability to work on specific policies (e.g. immigration) or 
systems (e.g. the criminal justice system) that impact a variety of populations, as well as populations whose intersectional identities mean that they are impacted in a variety of ways. Further thinking is needed about the specific implications of this, but it might require a shift from focusing on specific populations to, instead, focusing on skills and methods of work that address policies and systems. I will definitely be publishing articles that address this important new social change dynamic and contribute to an emerging analysis and understanding (e.g., Dixon, 2014) of this new social movement model.

\section{Serving all LGBT families}

The activists in my study offered extensive critiques of the gay marriage movement which support numerous critiques offered by scholars for over a decade. These critiques offer lessons for social workers.

Social workers must engage with the issue of gay marriage in more complicated ways than it has been thus far. We must situate the issue of gay marriage within broader marriage politics and understand its relationship to neoliberal policies and goals, and to actively resist the dismantling of government programs in favor of privatized caregiving through increasingly narrow "legitimate" family forms (DeFilippis, Anderson-Nathe, Panichelli, 2015; Duggan, 2003; Nair, 2013b).

In addition, this paper explains how queer families are frequently constructed outside of the hegemonic family dynamic of two adults in a conjugal relationship. Consequently, making marriage the vehicle through which we disperse protections, rights and benefits perpetuates rather than diminishes discrimination against most LGBT people. Social workers must fight to resist making marriage mandatory in order for a family to be 
recognized and protected as "legitimate" and must work to expand, rather than eliminate, other forms of family recognition (e.g., domestic partnerships, civil unions, reciprocal beneficiaries) so that multiple family formations are protected.

\section{Highlighting unaddressed needs of LGBT people.}

The literature reviewed in Chapter Four (“The Twenty-First Century") describes a range of issues impacting LGBT communities, and my research explores how the QLM is addressing those issues. These issues (poverty, criminal justice, immigration, etc.) are rarely addressed as queer issues by the social work profession.

The question of queer poverty offers a useful example. The literature review makes clear that LGBT communities face disproportionately high levels of economic inequality. LGBT people access need-based public benefits (food stamps, public assistance, and housing assistance) and health-related public benefits (Medicaid, Social Security Disability, and HIV/AIDS Service Administration benefits) more frequently than do non-LGBT people. Social workers regularly interact with these public benefits systems and need to understand the ways in which they impact LGBT people. In addition,

poverty among LGBT people consistently manifests in ways that are both similar to and different from those experienced by other poor people, and the dismantling of welfare and the public safety net has uniquely impacted low-income LGBT people. Therefore, it is important that social workers understand LGBT families when working within social welfare institutions.

The field of social work must begin to incorporate the impact of poverty into its micro-level work with LGBT adults and their families. Likewise, macro-level 
practitioners must address structural economic inequality as they simultaneously pursue their existing civil rights agenda. The social work profession must recognize that LGBT poverty is a widespread problem. Yet there is a severe shortage of services, supports or policy change efforts targeted towards low-income LGBT people. This must change. Similarly, social workers must also begin to address how the criminal justice system, immigration policies, healthcare programs, and other systems impact LGBT communities. By documenting how the QLM is addressing these policies and systems, my research illustrates how these issues are "queer issues." Social workers must begin to address them as such. 


\section{References}

Adam, B.D. (1998). Theorizing homophobia. Sexualities, 1(4), 387-404.

Adam, B.D. (1987). The rise of a gay and lesbian movement. Boston, MA: Twayne Publishers.

Adams, M., Blumenfeld, W.J., Castañeda, C., Hackman, H. W., Peters, M. L., \& Zúñiga, X. (Eds.). (2010). Readings for diversity and social justice. New York, NY: Routledge.

Alarcón, N. (1990). Chicana feminism: In the tracks of 'the' native woman. Cultural Studies, 4(3), 248-256.

Alarcón, N. (1981). Hay que inventarnos/We must invent ourselves. Third Woman: Of Latinas in the Midwest, 1(1), 1-6.

Albelda, R., Badgett, M.V.L., Schneebaum, A., \& Gates, G. (2009). Poverty in the lesbian, gay and bisexual community. Retrieved from University of California Los Angeles School of Law, Williams Institute website: http://www.law.ucla.edu/williamsinstitute/pdf/LGBPovertyReport.pdf

Alexander, J. (1999). Beyond identity: Queer values and community. International Journal of Sexuality and Gender Studies, 4(4), 293-314.

Allday, E. (2013, June 22). Almost one-third of homeless in S.F. are gay. San Francisco Chronicle. Retrieved from http://www.sfchronicle.com/bayarea/article/almostone-third-of-homeless-in-S-F-are-gay-4615829.php?t=7406798fdc

Allegretto, S. A., \& Arthur, M. M. (2001). An empirical analysis of homosexual/ heterosexual male earnings differentials: Unmarried and unequal? Industrial and Labor Relations Review, 54, 631-646.

Altman, D. (1973). Homosexual: Oppression and liberation. New York, NY: New York University Press.

Alvesson, M., \& Karreman, D. (2000). Varieties of discourse: On the study of organizations through discourse analysis. Human Relations, 53(9), 1125-1149.

Ambrogi, D. (2013, April 19). Who does marriage leave behind? Washington Blade.

Retrieved from http://www.washingtonblade.com/2013/04/19/who-doesmarriage-leave-behind-getequal-opinio/

American Friends Service Committee and the National Youth Advocacy Coalition (2003). Is opposing the war an LGBT issue? Retrieved fromhttp://www.safeschoolscoalition.org/LGBTAntiWar.pdf

Amos, V., \& Parmar, P. (1984). Challenging imperial feminism. Feminist Review, 17, 319.

Anderson-Nathe, B. (2015). We are not just like everyone else. In Sickels, C. (Ed.), Untangling the knot: Queer voices on marriage, relationships \& identity (pp. 111). Portland, OR: Ooligan Press.

Anderson-Nathe, B., Hansen, K., Rotman, M. (2015). "Just hold on:" Investigating the discourse of "It Gets Better®." Unpublished manuscript, School of Social Work, Portland State University, Portland, Oregon. 
Anzaldúa, G. (1981). La prieta. In Moraga \& Anzaldúa (Eds.) This bridge called my back: Writings by radical women of color (pp. 198-209). New York, NY: Kitchen Table.

Anzaldúa, G. (1987). Borderlands: La Frontera. San Francisco, CA: Spinsters Aunt Lute. Anzaldúa, G. (1991). To (o) queer the writer-Loca, escritora y chicana. In Anzaldúa, G., \& Warland, B. (Eds.) InVersions: Writings by dykes, queers and lesbians. Vancouver, BC: Press Gang Publishers.

Anzaldua, G. (1997). La conciencia de la mestiza: Towards a new consciousness. In A.M. Garcia (Ed.), Chicana feminist thought: The basic historical writings (pp., 270274). New York, NY: Routledge.

Andrew, M. (2012, June 15). SEIU gives \$100K to Approve R-74. Seattle Gay News. Retrieved from www.sgn.org/sgnnews40_24/mobile/page1.cfm

Andriote, J.M. (2013, July 31). Marking a civil rights milestone, elitism is robbing LGBT movement of power to 'Make Good the Promise of America'. Huffington Post. Retrieved from http://www.huffingtonpost.com/johnmanuel-andriote/marking-acivil-rights-mi_b_3678674.html

Applied Research Center. (2010). Better together: Research findings on the relationship between racial justice organizations and LGBT communities. Retrieved from http://www.arc.org/content/view/2170/180./

Applied Research Center. (2012). Better together in action: Organizations working to integrate racial justice and LGBT issues. Retrieved from http://www.arcusfoundation.org/images/uploads/downloads/Better_Together_In_ Action_June_2012[3].pdf

Arend, E. D. (2005). The politics of invisibility: Homophobia and low-income HIVpositive women who have sex with women. Journal of Homosexuality, 49(1), $97-$ 122.

Arkles, G., Gehi, P., \& Redfield, E. (2010). The role of lawyers in trans liberation: Building a transformative movement for social change. Seattle Journal for Social Justice. 8(2), 579-641.

Armstrong, E.A. (2002a). Forging gay identities: Organizing sexuality in San Francisco, 1950-1994. Chicago, IL: University of Chicago Press.

Armstrong, E. A. (2002b). Crisis, collective creativity, and the generation of new organizational forms: The transformation of lesbian/gay organizations in San Francisco. Research in the Sociology of Organizations, 19, 361-395.

Armstrong, E. A., \& Bernstein, M. (2008). Culture, power, and institutions: A multiinstitutional politics approach to social movements. Sociological Theory, 26(1), 74-99.

Arnold, E. A., \& Bailey, M. M. (2009). Constructing home and family: How the ballroom community supports African American GLBTQ youth in the face of HIV/AIDS. Journal of Gay \& Lesbian Social Services, 21(2-3), 171-188.

Asian American Federation of New York (2004, March). Asian Pacific American samesex households: A census report on New York, San Francisco and Los Angeles. 
Retrieved from Asian American Federation of New York website:

http://www.aafny.org/cic/report/GLReport.pdf

Astraea Lesbian Foundation for Justice. (2011a). The movement building initiative celebrates six years of success. Retrieved from

http://www.astraeafoundation.org/news/216/60/The-Movement-Building-

Initiative-Celebrates-Six-Years-of-Success

Astraea Lesbian Foundation for Justice. (2011b). Investing in Astraea empowers movement building. Retrieved from http://crm.astraeafoundation.org/civicrm/mailing/view?reset=1\&id=25http://

Astraea Lesbian Foundation for Justice. (2010). Queers to the left, to the left. Retrieved from http://www.astraeafoundation.org/news/167/60/Queers-to-the-Left-to-theLeft

Astraea Lesbian Foundation for Justice (n.d.). U.S. Movement Building Grants 20072008. Retrieved from http://www.astraeafoundation.org/what-we-do/us-archive/us-movement-building-grants/us-movement-building-0708

Auchmuty, R. (2004). Same-sex marriage revived: Feminist critique and legal strategy. Feminism Psychology, 14(1), 101-126.

Audre Lorde Project. (2000, September). ALP position on marriage. Retrieved from Audre Lorde Project website: http://alp.org/whatwedo/statements/marriage

Audre Lorde Project (2003). Statement: Open letter to LGBTST communities opposing war. Retrieved from Audre Lorde Project website: http://alp.org/whatwedo/statements/antiwar

Audre Lorde Project (2010). The winning team: The Welfare Justice Campaign trains Human Resource Administration on policy to address discrimination against trans and gender nonconforming people. Retrieved from Audre Lorde Project website: http://alp.org/winning-team-welfare-justice-campaign-trains-humanresource-administration-policy-address-discrimina

Avicolli Mecca, T. (2002, June 6). Gay shame. Alter-Net. Retrieved from http://www.alternet.org/print/story/13327/gay_shame

Badgett, L.M.V. (1998). Income inflation: The myth of affluence among gay, lesbian, and bisexual Americans. Retrieved from National Gay and Lesbian Task Force Policy Institute website: http://www.thetaskforce.org/downloads/reports/reports/IncomeInflationMyth.pdf

Badgett, M. V. L. (1997). Beyond biased samples: Challenging the myths on the economic status of lesbians and gay men. In A. Gluckman \& B. Reed (Eds.), Homo Economics. Capitalism, Community, and Lesbian and Gay Life (pp. 65-71). New York, NY: Routledge.

Badgett, M.V.L., Durso, L.E., \& Schneebaum A. (2013). New patterns of poverty in the lesbian, gay, and bisexual community. Retrieved from University of California Los Angeles School of Law, The Williams Institute website: http://williamsinstitute.law.ucla.edu/wp-content/uploads/LGB-Poverty-UpdateJun-2013.pdf 
Badgett, M.V.L., Lau, H., Sears, B. \& Ho, D. (2007). Bias in the workplace: Consistent evidence of sexual orientation and gender identity discrimination. Retrieved from University of California Los Angeles School of Law, The Williams Institute website: http://williamsinstitute.law.ucla.edu/wp-content/uploads/Badgett-SearsLau-Ho-Bias-in-the-Workplace-Jun-2007.pdf

Bailey, M.M., Kandaswamy, P., \& Richardson, M.U. (2004). Is gay marriage racist? In M.B. Sycamore (Ed.). That's revolting!: Queer strategies for resisting assimilation (pp. 113-119). Berkeley, CA: Soft Skull Press.

Bamberg, M. (2004). Considering counter narratives. In M. Bamberg and M. Andrews (Eds.) Considering counter narratives: Narrating, resisting, making sense, (pp. 351-371). Amsterdam: John Benjamins.

Banks, J. A. (2002). Race, knowledge construction, and education in the USA: Lessons from history. Race, Ethnicity and Education, 5(1), 7-27.

Barnard Center for Research on Women (Producer). (2013). Dean Spade: Impossibility Now. Available from https://www.youtube.com/watch?v=OU8D343qpdE

Barnard Center for Research on Women (Producer). (2009). Dean Spade: Trickle-up social justice. Available from http://bcrw.barnard.edu/videos/dean-spade-trickleup-social-justice-excerpt/

Barnard Center for Research on Women (Producer). (2009b). Dean Spade: Impossible people. Available from https://www.youtube.com/watch?v=cT4VFEUi-XA

Battle, J., Cohen, C.J., Warren, D., Gergerson, G. \& Audam, S. (2002). Say it loud, I'm Black and I'm proud: Black pride survey 2000. New York, NY: The Policy Institute of the National Gay and Lesbian Task Force.

Beam, J. (Ed.) (1986). In the life: A Black gay anthology. Boston, MA: Alyson Publications.

Beam, J. (1991). Brother, can you spare some time? In E. Hemphill (Ed.). Brother to brother: New writings by Black gay men (pp. 195-198). Boston, MA: Alyson Publications.

Beauchamp, D., Skinner, J., Wiggins, P. (2003). LGBT persons in Chicago: Growing older -- a survey of needs and perceptions. Retrieved from Chicago Task Force on LGBT Aging website: http://www.centeronhalsted.org/programs/growing_older.pdf.

Beeler, J.A., Rawls, T.W., Herdt, G., \& Cohler, B.J. (1999). The needs of older lesbians and gay men in Chicago. Journal of Gay \& Lesbian Social Services, 9(1), 31-49.

Benford, R. D. (1993). Frame disputes within the nuclear disarmament movement. Social Forces, 71(3), 677-701.

Benford, R.D. and Snow, D.A. (2000). Framing processes and social movements: An overview and assessment. Annual Review of Sociology, 26(1), 611-639.

Berger, M. (1967). Equality by statute: The revolution in civil rights (Vol. 591). New York, NY: Doubleday.

Berger, R. M. (1977). An advocate model for intervention with homosexuals. Social Work, 22(4), 280-283.

Berger, R. M. (1984). Realities of gay and lesbian aging. Social Work, 29(1), 57-62. 
Bernstein, M. (2013). Perry and the LGTBQ movement. N.Y.U. Review of Law \& Social Change. Symposium Issue, 37(1). Retrieved from http://socialchangenyu.com/symposium/forthcoming-symposium-issue/

Bernstein, M. (2005). Identity politics. Annual Review of Sociology, 31, 47-74.

Bernstein, M. (2002). Identities and politics: Toward a historical understanding of the lesbian and gay movement. Social Science History, 26(3), 531-581.

Bernstein, M. (1997). Celebration and suppression: The strategic uses of identity by the lesbian and gay movement. The American Journal of Sociology, 103(3), 531-565.

Bernstein, M., \& Taylor, V. (2005). Identity politics. The Wiley-Blackwell Encyclopedia of Social and Political Movements. Hoboken, NJ: Wiley-Blackwell.

Berube, A. (1990). Coming out under fire: The history of gay men and women in world war two. New York, NY: Free Press.

Billies, M., Johnson, J., Murungi, K. \& Pugh, R. (2009). Naming our reality: Lowincome LGBT people documenting violence, discrimination and assertions of justice. Feminism \& Psychology 19(3), 375-380.

Birch, E. (1999). Former Executive Director of Human Rights Campaign. Public statement in New York City town meeting. April 14, 1999.

Bishop, B. (2006). How irresistible is the seagull imperative?: Countering the 'dead hand of academe'. Australian Community Psychologist, 18(2), 86-88.

Black, D., Gates, G., Sanders, S., \& Taylor, L. (2000). Demographics of the gay and lesbian population in the United States: Evidence from available systematic data sources. Demography, 37, 139-154.

Blasius, M., \& Phelan, S. (Eds.). (1997). We are everywhere: A historical sourcebook of gay and lesbian politics. New York, NY: Psychology Press.

Blum, R. (2012). Equality with power: Fighting for economic justice at work. A New Queer Agenda: The Scholar and The Feminist Online. 10(1-2). Retrieved from http://sfonline.barnard.edu/a-new-queer-agenda/equality-with-power-fighting-foreconomic-justice-at-work/0/

Blum, R., DeFilippis, J. \& Perrina, B.A. (2000). Why welfare is a queer issue. New York University Review of Law and Social Change, 26, 201-219.

Blumberg, R.L. (2009). The civil rights movement. In Goodwin, J., \& Jasper, J. M. (Eds.). The social movements reader: Cases and concepts Vol. 12 (pp. 15-23). Hoboken, NJ: John Wiley \& Sons.

Blumer, H. (1969). Collective behavior. In Lee A.M., (Ed.), Principles of sociology (3rd Ed.). New York, NY: Barnes and Noble Books.

Blumer, H. (1951). Collective behavior. New outline of the principles of sociology (pp. 166-222). New York, NY: Barnes and Noble Books.

Boggis, T. (2012). Still coming ashore: The LGBT community and the many meanings of family. A New Queer Agenda: The Scholar and The Feminist Online. 10(1-2).

Retrieved from http://sfonline.barnard.edu/a-new-queer-agenda/still-comingashore-the-lgbt-community-and-the-many-meanings-of-family/

Bohn, T. R. (1984). Homophobic violence: Implications for social work practice. Journal of Social Work \& Human Sexuality, 2(2-3), 91-112. 
Bond, L., Wheeler, D.P., Millett, G.A., LaPollo, A.B., Carson, L.F., \& Liau, A. (2009). Black men who have sex with men and the association of Down-Low identity with HIV risk behavior. American Journal of Public Health, 99 (Suppl. 1), 92-95.

Bonner, A., \& Tolhurst, G. (2002). Insider- outsider perspectives of participant observation. Nurse Researcher, 9(4), 7-19.

Boozer, M. (2013). A history of the gay movement in Washington, D.C. Retrieved from http://www.blacklightonline.com/gayhistory.html

Bowen, A. (2012). Forty years of LGBTQ philanthropy: 1970-2010. Retrieved from Funders for LGBTQ website: http://www.lgbtfunders.org/files/40years_lgbtqphilanthrophy.pdf

Bowen, D.J., Bradford, J.B., McMorrow, P., Powers, D., Linde, R., Murphy, B.C., Han, J., \& Ellis, J. (2004). Comparing women of differing sexual orientations using population-based sampling. Women \& Health, 40(3), 19-34.

Bower, L. (1997). Queer problems/Straight solutions: The limits of a politics of 'Official Recognition.' In Shane Phelan (Ed.), Playing with fire: Queer politics, queer theories (pp. 267-291). London, UK: Routledge.Boyd, N. A., \& Ramírez, H. N. R. (2012). Bodies of evidence: The practice of queer oral history. Oxford, UK: Oxford University Press.

Boyer, D. (2009, June 26). It's time to de-center the Center. IndyBay. Retrieved from http://www.indybay.org/newsitems/2009/06/26/18604014.php

Boykin, K. (2000). Where rhetoric meets reality: The role of black lesbians and gays in "queer" politics. In C.A. Rimmerman, K.D. Wald \& C. Wilcox (Eds.) The Politics of Gay Rights (pp. 79-96). Chicago, IL: The University of Chicago Press.

Branch, T. (2007). At Canaan's edge: America in the King years, 1965-68. New York, NY: Simon and Schuster.

Breen, L. J. (2007). The researcher 'in the middle': Negotiating the insider/outsider dichotomy. Australian Community Pyschologist, 19(1), 163-174.

Brinkley, S. (2009) The National Coalition of Black Lesbians and Gays: Making history. Retrieved from http://www.blacklightonline.com/ncblg_1.html

Broad, K. L. (2002). GLB+ T?: Gender/sexuality movements and transgender collective identity (de) constructions. International Journal of Sexuality and Gender Studies, 7(4), 241-264.

Brown, D. G., \& Lynn, D. B. (1966). Human sexual development: An outline of components and concepts. Journal of Marriage and the Family, 28(2), 155-162.

Brown, M. (2011, April). The sad, the mad and the bad: Co-existing discourses of girlhood. Child \& Youth Care Forum, 40(2), 107-120.

Burdge, B. (2007). Bending gender, ending gender: Theoretical foundations for social work practice with the transgender community. Social Work, 52(3): 243-250.

Burke, M. C., \& Bernstein, M. (2014). How the Right usurped the queer agenda: Frame co- optation in political discourse. Sociological Forum, 29(4), 830-850.

Burns, R. (2012, July 24). Beyond gay marriage: Is the LGBT movement walking down the aisle to nowhere? In These Times. Retrieved from http://inthesetimes.com/article/13466/beyond_gay_marriage/ 
Butler, J. (1990). Feminism and the subversion of identity. Gender trouble (pp. 1-25). London, UK: Routledge.

Butler, J. (1993). Imitation and gender insubordination. In H. Abelove, M.A. Barale, \& D.M. Halperin (Eds.) The lesbian and gay studies reader (pp. 307-320). New York, NY: Routledge.

Butler, J. (2004). Undoing gender. New York, NY: Psychology Press.

Cahill, S. \& Kim-Butler, B. (2006). Policy priorities for the LGBT community: Pride survey 2006. Retrieved from The National Gay and Lesbian Task Force Policy Institute website: http://www.thetaskforce.org/downloads/reports/reports/2006PrideSurvey.pdf

Cahill, S. R., \& Jones, K. T. (2001). Leaving our children behind: Welfare reform and the gay, lesbian, bisexual, and transgender community.. Retrieved from the Policy Institute of the National Gay and Lesbian Task Force website: http://www.ngltf.org/downloads/reports/reports/LeavingOurChildrenBehind.pdf

Cammett, A. (2009). Queer lockdown: Coming to terms with the ongoing criminalization of LGBTQ communities. Retrieved from the University of Nevada Las Vegas, William S. Boyd School of Law website: http://scholars.law.unlv.edu/cgi/viewcontent.cgi?article=1626\&context=facpub

Carby, H. (1982). White woman listen! Black feminism and the boundaries of sisterhood. In Ashcroft, Griffiths, \& Tiffin (Eds.). The Empire Writes Back: Theory and Practice in Postcolonial Literatures (pp. 61-86). Routledge.

Carpenter, L. (2014). Getting queer priorities straight: How direct legal services can democratize issue prioritization in the LGBT rights movement. University of Pennsylvania Journal of Law and Social Change, 17(2), 106-136. Retrieved from http://scholarship.law.upenn.edu/cgi/viewcontent.cgi?article $=1166 \&$ context=jlasc

Carter, D. (2004). Stonewall: The riots that sparked the gay revolution. New York, NY: St. Martin's Press.

Carter, M. (1999). The emperor's new clothes, or how not to run a movement. In K. Kleindienst, K. (Ed.) This is What Lesbian Looks Like, (pp. 62-69). Ithica, NY: Firebrand Books.

Castells, M. (1972). Urban renewal and social conflict in Paris. Social Science Information, 11(2), 93-124.

Castells, M. (2010). End of millennium: The information age: Economy, society, and culture| (Vol. 3). Malden, MA: Wiley-Blackwell.

Catanzaro, M. (1988). Using qualitative analytical techniques. In P. Woods \& M. Catanzaro (Eds.) Nursing research: Theory and practice, (pp. 437-456). New York, NY: C.V. Mosby Company.

Caterine, E. (June 22, 2014). How to break Pride: A guide for the LGBTQ movement. Youngist. Retrieved from http://www.youngist.org/how-to-breakpride/\#.U7BWUqjXdXZ

Catlett, B. S. (2004). Critiquing the case for marriage promotion: How the promarriage movement misrepresents domestic violence research. Violence against women, $10(11), 1226$. 
Centers for Disease Control and Prevention (2010). HIV and AIDS among gay and bisexual men: A CDC fact sheet. Retrieved from Center for Disease Control website: http://www.cdc.gov/nchhstp/newsroom/docs/FastFacts-MSMFINAL508COMP.pdf

Charles, V., \& Conron, K.; (2002). Double jeopardy: How racism and homophobia impact the health of Black and Latino Lesbian, Gay, Bisexual, and Transgender (LGBT) communities. Retrieved from Boston Public Health Commission, LGBT Health website: http://lgbthealth.webolutionary.com/downloads/research/BPHCLGBTLatinoBlac kHealthDispar.doc

Chafetz, J. S., Sampson, P., Beck, P., \& West, J. (1974). A study of homosexual women. Social Work, 19(6), 714-723.

Charles, V. \& Conron, K.; (2002). Double jeopardy: How racism and homophobia impact the health of black and latino lesbian, gay, bisexual, and transgender (LGBT) communities. Retrieved from Boston Public Health Commission, LGBT Health website: http://lgbthealth.webolutionary.com/downloads/research/BPHCLGBTLatinoBlac kHealthDispar.doc

Chasin, A. (2000). Selling out: The gay and lesbian movement goes to market. New York, NY: Palgrave Macmillan.

Chauncey, G. (1982). From sexual inversion to homosexuality: Medicine and the changing conceptualization of female deviance. Salmagundi, 58/59 (Fall 1982/Winter 1983), 114-146.

Chauncey, G. (1989). Christian brotherhood or sexual perversion? Homosexual identities and the construction of sexual boundaries in the World War I era. In Duberman, M., Vicinus, M., \& Chauncey, G. (Eds.) Hidden from History: Reclaiming the Gay \& Lesbian Past (pp. 294-317). New York, NY: Meridian Books.

Chauncey, G. (1994). Gay New York: Gender, urban culture, and the making of the gay male world 1890-1940. New York, NY: BasicBooks.

Cha' vez, K. R. (2010). Border (in)securities: Normative and differential belonging in LGBTQ and immigrant rights discourse. Communication and Critical/Cultural Studies 7(2), 136-155.Cheek, J. (2004). At the margins? Discourse analysis and qualitative research. Qualitative Health Research, 14(8), 1140-1150.

Chesters, G., \& Welsh, I. (2011). Social movements: the key concepts. New York, NY: Routledge.

Christian, R. \& Mukarji-Connolly, A. (2012). What's home got to do with it? Unsheltered queer youth. A New Queer Agenda: The Scholar and The Feminist Online. 10(1-2). Retrieved from http://sfonline.barnard.edu/a-new-queeragenda/whats-home-got-to-do-with-it-unsheltered-queer-youth/

Christiansen, J. (2009). Four stages of social movements. EBSCO Research Starters. Retrieved from http://www.ebscohost.com/uploads/imported/thisTopic-dbTopic1248.pdf 
Clark-Flory, T. (2011). Will marriage change gay love? Many have embraced the romantic values of the mainstream -- and dropped ideas about alternative lifestyles. Salon. Retrieved fromhttp://www.salon.com/2011/06/28/gay_marriage_23/

Clemens, E. S. \& Minkoff, D. C. (2004). Beyond the iron law: Rethinking the place of organizations in social movement research. In D.A. Snow, S.A. Soule \& H. Kriesi (Eds.) The Blackwell Companion to Social Movements (pp. 155-170). Malden, MA: Blackwell.

Clements-Nolle, K., Guzman, R., \& Katz, M. (2001). HIV prevalence, risk behaviors, health care use, and mental health status of transgender persons: implications for public health intervention. American Journal of Public Health. 91(6), 915-921.

Clendinen, D., \& Nagourney, A. (2001). Out for good: The struggle to build a gay rights movement in America. New York, NY: Simon and Schuster.

Cnaan, R.A., \& Boddie, S.C., (2002). Charitable Choice and faith-based welfare: A call for social work. Social Work, 47(3), 224-235.

Cohen, C. (1999). What is this movement doing to my politics? Social text, No. 61, Out front: Lesbians, gays, and the struggle for workplace rights, 111-118.

Cohen, C.J. (1997). Punks, bulldaggers, and welfare queens: The radical potential of queer politics? GLQ: A Journal of Lesbian and Gay Studies, 3(4), 437-465.

Collins, P.H. (1990). Black feminist thought in the matrix of domination. From Black feminist thought: Knowledge, consciousness, and the politics of empowerment (pp. 221-238). Boston, MA: Unwin Hyman.

Collins, P.H. (2000). Black feminist thought: Knowledge, consciousness and the politics of empowerment. New York: Routledge.

Collins, P. H., \& Andersen, M. (Eds.). (2007). Race, class and gender: An anthology. Belmont, CA: Thomson-Wadsworth Publishing.

Collins, P. H. (1998). Fighting words: Black women and the search for justice (Vol. 7). Minneapolis, MN: University of Minnesota Press.

Combahee River Collective, (1981). A black feminist statement. In C. Moraga \& G. Anzaldua (Eds.) This Bridge called My Back: Writings by Radical Women of Color, (pp. 210-219). New York, NY: Kitchen Table Press.

Communigayte: Agency for Gay Marketing and Advertising. (2013). Why gay marketing? Retrieved fromhttp://www.communigayte.com/about_us/why_gay_marketing.html

Conrad, R. (2009). Against equality, in Maine and everywhere. Bilerico Project. Retrieved fromhttp://www.bilerico.com/2009/11/against_equality_in_maine_and_everywhe re.php

Conrad, R. (2009b). Out of the closets and into the libraries. Retrieved from: http://www.faggotz.org/final_zine.pdf

Conrad, R. (Ed.) (2010). Against equality: Queer critiques of gay marriage. Chicago, IL: Against Equality Press. 
Conrad, R. (Ed.). (2012). We who feel differently. Retrieved from http://www.wewhofeeldifferently.info/journal.php?issue $=2$

Conrad, R., Chavez, K., Nair Y., \& Loeffler, D. (2014). Introduction. In Conrad, R. (Ed.) Against equality: Queer revolution, not mere inclusion. Oakland, CA: AK Press.

Coontz, S., \& Folbre, N. (2002, April). Marriage, poverty, and public policy. Paper presented at The 5th Annual Conference of the Council on Contemporary Families, New York, NY.

Covenant House Institute. (2009). Youth in crisis: Characteristics of homeless youth served by Covenant House New York. New York, NY: Covenant House Institute.

Crass, C. (2013). Towards collective liberation: Anti-racist organizing, feminist praxis, and movement building strategy. Oakland, CA: Pm Press.

Crenshaw, K. (1991). Mapping the margins: Intersectionality, identity politics, and violence against women of color. Stanford Law Review, 43(6), 1241-1299.

Crenshaw, K. (1989). Demarginalizing the intersection of race and sex: A Black feminist critique of antidiscrimination doctrine, feminist theory and antiracist politics. University of Chicago Legal Forum, 139-167

Crenshaw, K. W. (1997). Intersectionality and identity politics: Learning from violence against women of colour. In M. Stanley and V. Naryan (Eds.) Restructuring Feminist Political Theory: Feminist Perspectives (pp. 178-193). Cambridge, MA: Polity Press.

Crenshaw, K., Peller, G.,\& Thomas, K. (Eds.). (1996) Critical race theory: The key writings that formed the movement. New York, NY: The New Press.

Crimp, D., \& Rolston, A. (1990). AIDS demographics. Seattle, WA: Bay Press.

Cronin, A., \& King, A. (2010). Power, inequality and identification: Exploring diversity and intersectionality amongst older LGB adults. Sociology, 44(5), 876-892.

Currah, P. (2008). Stepping back, looking outward: Situating transgender activism and transgender studies - Kris Hayashi, Matt Richardson, and Susan Stryker frame the movement. Sexuality Research \& Social Policy, 5(1), 93-105.

Haraway, D. J. (1985). A manifesto for cyborgs: Science, technology, and socialist feminism in the 1980s (pp. 158-81). Australian Feminist Studies 2(4), 1-42.

D'Emilio, J. (1983). Sexual politics, sexual communities: The making of a homosexual minority in the United States, 1940-1970. Chicago, IL: University of Chicago Press.

D’Emilio, J. (1992). Making trouble: Essays on gay history, politics and the university. New York, NY: Routledge.

D'Emilio, J. (2000). Cycles of change, questions of strategy: The gay and lesbian movement after fifty years. In C.A. Rimmerman, K.D. Wald \& C. Wilcox (Eds.) The Politics of Gay Rights (pp. 31-53). Chicago, IL: The University of Chicago Press.

D'Emilio, J. (2006). The marriage fight is setting us back. Gay and Lesbian Review, 13(6), 10-11. 
D’Emilio, J. (2009). The gay liberation movement. In J. Goodwin \& J.J. Jasper (Eds.). The social movements reader: Cases and concepts (pp, 36-41). Malden, MA: Wiley-Blackwell Publishing.

D’Emilio, J. (2012) Creating change. A New Queer Agenda: The Scholar and The Feminist Online. 10(1-2). Retrieved from http://sfonline.barnard.edu/a-newqueer-agenda/creating-change/0/

D’Emilio, J. (2012). Capitalism and gay identity. In H. Abelove (Ed.). The lesbian and gay studies reader (pp. 467-476). New York, NY: Routledge.

Daley, A. (2010). Reflections on reflexivity and critical reflection as critical research practices. Affilia, 25(1), 68-82.

Dang, A. \& Frazer, S. (2005). Black same-sex households in the United States: A report from the 2000 Census ( $2^{\text {nd }}$ ed.). Retrieved from National Gay and Lesbian Task Force Policy Institute \& National Black Justice Coalition website: http://www.thetaskforce.org/downloads/reports/reports/2000BlackSameSexHouse holds.pdf

Dang. A. \& Hu, M. (2004). Asian Pacific American lesbian, gay, bisexual and transgender people: A community portrait - A report from New York's queer Asian Pacific Legacy Conference. Retrieved from National Gay and Lesbian Task Force Policy Institute: http://www.thetaskforce.org/docroot/downloads/reports/reports/APAstudy.pdf

DasGupta, D. (2012). Queering immigration: Perspectives on cross-movement organizing. A New Queer Agenda: The Scholar and The Feminist Online. 10(1-2). Retrieved from http://sfonline.barnard.edu/a-new-queer-agenda/queering-immigrationperspectives-on-cross-movement-organizing/0/

Davids, J. (2011). Proof positive of injustice: Queering the next generation of the AIDS movement. Unpublished manuscript.

Dececco, J.P., \& Bullough, V. L. (2014). Before stonewall: Activists for gay and lesbian rights in historical context. New York, NY: Routledge.

Decena, C.U. (2008). Profiles, compulsory disclosure, and ethical sexual citizenship in the contemporary USA. Sexualities 11(4): 397-413.

DeCrescenzo, T. A. (1979). Group work with gay adolescents. Social Work with Groups, 2(1), 35-44.

DeFilippis, J. (2001, February). Poor understanding. City Limits.

DeFilippis, J. (2012a). Introduction. A New Queer Agenda: The Scholar and The Feminist Online. 10(1-2). Retrieved from http://sfonline.barnard.edu/a-newqueer-agenda/introduction/0/

DeFilippis, J. (2012b). Common ground: The queerness of welfare policy. A New Queer Agenda: The Scholar and The Feminist Online. 10(1-2). Retrieved from http://sfonline.barnard.edu/a-new-queer-agenda/common-ground-the-queernessof-welfare-policy/0/

DeFilippis, J.N. (2015). Wedding bells are breaking up that old gang of mine. In C. Sickels (Ed.), Untangling the knot: Queer voices on marriage, relationships \& identity (pp. 123-140). Portland, OR: Ooligan Press. 
DeFilippis, J.N., Anderson-Nathe, B., \& Panichelli, M. (2015). Notes on the same-sex marriage movement: Concerns for feminist social workers. Affilia

Della Porta, D. (2005). Multiple belongings, tolerant identities, and the construction of 'another politics': Between the European social forum and the local social fora. In D. Della Porta \& S. Tarrow (Eds.), Transnational Protest \& Global Activism (pp. 175-202). Lanham, MD: Rowman \& Littlefield.

De la Porta, D. \& Diani, M. (2006). Social movements: An introduction (2nd Ed). Malden MA: Blackwell Publishing.

Deluca, K. M. (1999). Unruly arguments: The body rhetoric of earth first!, ACT UP, and Queer Nation. Argumentation and Advocacy, 36(1), 9-21.

DeLyser, D. (2001). "Do you really live here?" Thoughts on insider research. The Geographical Review, 91(1/2), 441-453.

Dennis, D. (1997). AIDS and the new medical gaze: bio-politics, AIDS, and homosexuality. Journal of homosexuality, 32(3-4), 169-184.

Dettmer, L. (2010). Beyond gay marriage. Retrieved from http://www.kpfa.org/archive/id/58061

Diani, M., \& Bison, I. (2004). Organizations, coalitions, and movements. Theory and Society, 33(3-4), 281-309.

Diaz, R.M., Ayala, G., Bein, E., Henne, J., \& Marin, B.V. (2001). The impact of homophobia, poverty, and racism on the mental health of gay and bisexual Latino men: Findings from 3 US cities. American Journal of Public Health, 91(6), 927932.

Dixon, C. (2014). Another politics: Talking across today's transformative movements. Oakland, CA: University of California Press.

Dobbs, B. (2012). Gay marriage is a conservative cause. The New York Times. Retrieved from http://www.nytimes.com/roomfordebate/2012/04/16/is-support-for-gayrights-still-controversial/gay-marriage-is-a-conservative-cause

Dolan, M., \& Garrison, J. (2013). Knowing gay person a key factor in rising support for gay marriage. Los Angeles Times. Retrieved from http://articles.latimes.com/2013/mar/26/local/la-me-gay-marriage-close-20130326

Donahue, J. (2011). Making it happen, mama: A conversation with Miss Major. In E. A. Stanley \& N. Smith (Eds.). Captive genders: Trans embodiment and the prison industrial complex (pp. 267-280). Edinburgh: AK Press.

Downe-Wamboldt, B. (1992) Content analysis: method, applications and issues. Health Care for Women International, 13(3), 313-321.

Downey, D. J., \& Rohlinger, D. A. (2008). Linking strategic choice with macroorganizational dynamics: Strategy and social movement articulation. Research in Social Movements, Conflicts and Change, 28, 3-38.

Drew, N. (2006). The seagull imperative. Australian Community Psychologist, 18(1), 4041.

Driskill, Q. L. (2010). Doubleweaving Two-Spirit Critiques: Building alliances between Native and Queer Studies. GLQ: A Journal of Lesbian and Gay Studies, 16(1-2), 69-92. 
Driskill, Q. L., Finely, C., Gilley, B.J., \& Morgensen, S.L. (Eds.). (2011). Queer Indigenous studies: Critical interventions in theory, politics, and literature. University of Arizona Press.

Drucker, P. (2015). Warped: Gay Normality and Queer Anti-Capitalism. Leiden, Netherlands: Brill.

Druss, R. G. (1967). Cases of suspected homosexuality seen at an army Mental Hygiene Consultation Service. Psychiatric Quarterly, 41(1), 62-70.

Duberman, M. (2009). Waiting to land: A (mostly) political memoir, 1985-2008. New York, NY: The New Press.

Duberman, M. B. (1994). Stonewall. New York, NY: Plume.

Duberman, M., Vicinus, M., \& Chauncey, G. (1989). Hidden from history: Reclaiming the gay \& lesbian past. New York, NY: Meridian Books.

Duggan, A. (2012). 'Nobody should ever feel the way that I felt': A portrait of Jay Toole and queer homelessness. A New Queer Agenda: The Scholar and The Feminist Online. 10(1-2). Retrieved from http://sfonline.barnard.edu/a-new-queeragenda/nobody-should-ever-feel-the-way-that-i-felt-a-portrait-of-jay-toole-andqueer-homelessness/0/

Duggan, L. (2002). The new homonormativity: The sexual politics of neoliberalism. In R. Castronovo \& D.D. Nelson (Editors) Materializing democracy: Toward a revitalized cultural politics (pp. 175-194). Durham, NC: Duke University Press Books.

Duggan, L. (2003). The twilight of equality: neoliberalism, cultural politics and the attack on democracy. Boston, MA: Beacon Press.

Duggan, L. (2004, March 15). Holy matrimony! The Nation, 16-18.

Duggan, L. (2012). Beyond marriage: Democracy, equality, and kinship for a new century. A New Queer Agenda: The Scholar and The Feminist Online. 10(1-2). Retrieved fromhttp://sfonline.barnard.edu/a-new-queer-agenda/beyond-marriagedemocracy-equality-and-kinship-for-a-new-century/0/

Duggan, L., \& Kim, R. (2005, July 18). Beyond gay marriage. The Nation, 24-27.

Dulaney, D. D., \& Kelly, J. (1982). Improving services to gay and lesbian clients. Social Work, 27(2), 178-183.

Dunkel, J., \& Hatfield, S. (1986). Countertransference issues in working with persons with AIDS. Social Work, 31(2), 114-117.

Dunn, M. and Moodie-Mills, A. (2012). The state of gay and transgender communities of color in 2012: The economic, educational, and health insecurities these communities are struggling with and how we can help them. Retrieved from The Center for American Progress website: http://www.americanprogress.org/issues/2012/04/lgbt_comm_of_color.html

Dwyer, S. C., \& Buckle, J. L. (2009). The space between: On being an insider-outsider in qualitative research. International journal of qualitative methods, 8(1), 54-63.

Edelman, M. (2001). Social movements: Changing paradigms and forms of politics. Annual Review of Anthropology, 30, 285-317. 
Edwards J. (2000). AIDS, race, and the rise and decline of a militant oppositional lesbian and gay politics in the U.S. New Political Science, 22(4), 485-506.

Egan, P.T., \& Sherrill, K. (2005). Marriage and the shifting priorities of a new generation of a lesbians and gays. PS: Political Science and Politics, 38(2), 229-232.

Eilperin, J. (2013). Gay marriage fight will cost tens of millions. The Washington Post. Retrieved from http://www.washingtonpost.com/blogs/thefix/wp/2013/07/01/how-much-will-the-gay-marriage-fight-cost-over-the-nextthree-years-tens-of-millions/

Ellis, C., \& Bochner, A. P. (2000). Autoethnography, personal narrative, reflexivity: Researcher as subject. In N. K. Denzin \& Y. S. Lincoln (Eds.), Handbook of qualitative research (2nd ed., pp. 733- 768). Thousand Oaks, CA: Sage.

Elmslie, B., \& Tebaldi, E. (2007). Sexual orientation and labor market discrimination. Journal of Labor Research, 28(3), 436-453.

Elo, S., \& Kyngäs, H. (2008). The qualitative content analysis process. Journal of advanced nursing, 62(1), 107-115.

Eng, D.L. (2010). The feeling of kinship: Queer liberation and the racialization of intimacy. Durham, NC: Duke University Press.

Eng, D. L. (2003). Transnational adoption and queer diasporas. Social Text, 21(3), 1-37.

Eng, D. L., Halberstam, J., \& Muñoz, J. E. (2005). Introduction: What's queer about queer studies now? Social Text 84-85, 23(3-4), 1-17.

Engel, S.M. (2001). The unfinished revolution: Social movement theory and the gay and lesbian movement. Cambridge: Cambridge University Press.

Epstein, S. (1998). Gay politics, ethnic identity: The limits of social constructionism. P. N. Nardi \& BE Schneider, eds., Social perspectives in lesbian and gay studies: A reader (New York: Routledge, 1998), 134-159.

Espinoza, R. (2008). Building communities: Autonomous LGBTQ people of color organization in the U.S. Retrieved from Funders for Lesbian and Gay Issues website: https://www.lgbtfunders.org/files/FLGI\%20LGBTQ_POCRprt-F.pdf

Essig, L. (2000, July 10). Same-sex marriage: I don't care if it is legal, I still think it's wrong

and I'm a lesbian. Salon. Retrieved from: http://www.salon.com/2000/07/10/marriage_10/

Ettelbrick, P.L., Bradford, J.B., \& Ellis, J. (2001). The 21st century family: Same-sex unmarried partners and the US census. New York, NY: National Gay and Lesbian Task Force, Policy Institute.

Faderman, L. (1981). Surpassing the love of men: Romantic friendship and love between women from the Renaissance to the present. New York, NY: Morrow.

Faderman, L., \& Timmons, S. (2006). Gay LA: A history of sexual outlaws, power politics, and lipstick lesbians. New York, NY: Basic Books.

Farro, A. L. (2014). A new era for collective movements: the subjectivization of collective action. In A.L. Farro \& H. Lustiger-Thaler (Eds.), Reimagining social movements: From collectives to individuals (pp. 15-34). Burlington, VT: Ashgate Publishing, Ltd. 
Farro, A. L., Lustiger-Thaler, H., \& Toscano, E. (Eds.). (2014). Reimagining social movements: from collectives to individuals. Burlington, VT: Ashgate Publishing, Ltd.

Farrow, K. (2005). Is gay marriage anti-black. Retrieved from http://kenyonfarrow.com/2005/06/14/is-gay-marriage-anti-black/

Farrow, K. (2008). Prop 8 1: A material or moral defeat? Retrieved from http://kenyonfarrow.com/2008/11/17/prop-8-a-material-or-moral-defeat/

Farrow, K. (2011a). In defense of Brontez - and the rest of us too proud or too trashy to go down without a fight. Retrieved from http://kenyonfarrow.com/2011/08/16/indefense-of-brontez/

Farrow, K. (2011b). Gay marriage in New York: Progressive victory or GOP roadmap? Alternet. Retrieved from http://www.alternet.org/story/151444/gay_marriage_in_new_york\%3A_progressi ve_victory_or_gop_roadmap

Farrow, K. (2011c). A military job is not economic justice. Huffington Post. Retrieved from http://www.huffingtonpost.com/kenyon-farrow/post_1732_b_824046.html

Farrow, K. (2012). Afterword: A future beyond equality. A New Queer Agenda: The Scholar and The Feminist Online. 10(1-2). Retrieved from http://sfonline.barnard.edu/a-new-queer-agenda/afterword-a-future-beyondequality/

Federal Bureau of Investigation. (2012). Hate crimes accounting: annual report released. Retrieved from the Federal Beueau of Investigation website: http://www.fbi.gov/news/stories/2012/december/annual-hate-crimes-reportreleased/annual-hate-crimes-report-released

Feinberg, L. (2002). LGBT Groups take stand against war. International Action Center. Retrieved from http://www.iacenter.org/Iraq/iraq_lgbt.html

Feinstein, R., Greenblatt, A., Hass, L., Kohn, S., \& Rana, J. (2001). Justice for all? A report on LGBT youth in the New York juvenile justice system. Retrieved from the Equity Project website: http://www.equityproject.org/pdfs/justiceforallreport.pdf

Fetto, J. (2012). A look at household income and discretionary spending of lesbian, gay and heterosexual Americans. Retrieved from Experian Marketing Services website: http://www.experian.com/blogs/marketing-forward/2012/07/20/sim-alook-at-household-income-and-discretionary-spend-of-lesbian-gay-andheterosexual-americans/

Fitzgerald, E. (2013). No golden years at the end of the rainbow: How a lifetime of discrimination compounds economic and health disparities for LGBT older adults. Retrieved from National Gay and Lesbian Task Force: http://www.ngltf.org/downloads/reports/reports/no_golden_years.pdf

Focault, M. (1990). The history of sexuality: An introduction. Volume 1. New York, NY: Vintage Books.

Fone, B.R.S. (1995). A road to stonewall: Male homosexuality and homophobia in English and American literature 1750-1969. New York, NY: Twayne Publishers. 
Fraser, M. (1999). Classing queer politics in competition. Theory, Culture \& Society, 16(2), 107-131.

Fraser, N. (1995). From redistribution to recognition? Dilemmas of justice in a 'postsocialist' age. New Left Review, 1, 68-68.

Fraser, N., \& Honneth, A. (2003). Redistribution or recognition?: A politicalphilosophical exchange. London: Verso.

Freedman, E.B. (1996). The prison lesbian: Race, class, and the construction of the aggressive female homosexual, 1915-1965. Feminist Studies, 22(2), 397-423.

Freeman, J. (1999). On the origins of social movements. In J. Freeman \& V. Johnson (Eds.) Waves of protest: Social movements since the Sixties, (pp. 7-24). Lanham, MD: Rowman \& Littlefield Publishers.

Freeman, J. \& Johnson, V. (1999) Waves of protest: Social movements since the sixties. Lanham, MD: Rowman \& Littlefield.

Freire, P. (1970). Pedagogy of the Oppressed. (M. B. Ramos, Trans). New York, NY: Continuum.

Funders for Lesbian and Gay Issues. (2005). Out for change: Racial and economic justice issues in lesbian, gay, bisexual and transgender communities. Retrieved from Funders for LGBTQ Issues website: http://www.lgbtfunders.org/files/LGBTREJ.pdf.

Funders for LGBTQ Issues (2012). Forty years of LGBTQ philanthropy: 1970 - 2010. Retrieved from Funders for LGBTQ Issues website: http://www.lgbtfunders.org/resources/pub.cfm?pubID=57

Furstenberg, A. L., \& Meltzer Olson, M. (1984). Social work and AIDS. Social work in health care, 9(4), 45-62.

Fuss, D. (1991). Inside/out. In D. Fuss (Ed.) Inside/out: Lesbian theories, gay theories, (pp. 1-10). New York, NY: Routledge.

Gabbay, S. G., \& Wahler, J. J. (2002). Lesbian aging: Review of a growing literature. Journal of Gay \& Lesbian Social Services, 14(3), 1-21.

Gaia, R. (2011). An un-queer time and place. Retrieved from http://rosagaia.wordpress.com/2011/12/23/an-un-queer-time-and-place-2/

Gallo, M. M. (2006). Different daughters: A history of the Daughters of Bilitis and the rise of the lesbian rights movement. New York, NY: Seal Press.

Gallo, M.M. (2012). Queer left histories: Achebe Powell and Martin Duberman on culture and politics. A New Queer Agenda: The Scholar and The Feminist Online. 10(1-2). Retrieved from http://sfonline.barnard.edu/a-new-queer-agenda/queerleft-histories-achebe-powell-and-martin-duberman-on-culture-and-politics/0/

Gambe, R., \& Getzel, G. S. (1989). Group work with gay men with AIDS. Social Casework, 70(3), 172-179..

Gamson, J. (1995). Must identity movements self-destruct? A queer dilemma. Social Problems, 42(3), 390-407.

Gamson, J. (2000, March 30). Whose Millennium March? The Nation. Retrieved from http://www.thenation.com/article/whose-millennium-march\# 
Gamson, J. (2004). The sociology of sexualities: Queer and beyond. Annual Review of Sociology, 30(1), 47-64.

Gamson, J. (2009). The dilemmas of identity politics. In J. Goodwin \& J.J. Jasper (Eds.) The social movements reader: Cases and concepts, (pp. 383-392). Malden, MA: Wiley-Blackwell Publishing.

Gamson, W. (1990). The strategy of social protest. Belmont, CA: Wadsworth Publishing Company.

Ganz, M. (2009). Why David sometimes wins: Leadership, organization, and strategy in the California farm worker movement. New York, NY: Oxford University Press.

Garber, E. (1983). 'T'ain't nobody's bizness': Homosexuality in 1920s' Harlem. In M. Smith (Ed.) Black men/White men. San Francisco, CA: Gay Sunshine Press.

Garber, E. (1989). A spectacle in color: The lesbian and gay subculture of jazz age Harlem. In M.B. Duberman, M. Vicinus, \& G. Chauncey (Eds.). Hidden from History: Reclaiming the Gay and Lesbian Past (pp. 318-331). New York, NY: Meridan.

Garber, L. (2013). Identity poetics: Race, class, and the lesbian-feminist roots of queer theory. New York, NY: Columbia University Press.

Gardiner, J. (1975). Women's domestic labor. New Left Review, I(89), 47-58.

Garraty, J.A. \& Foner, E. (Eds.). (1981). the reader's companion to american history. Boston, MA: Houghton Mifflin Company.

Garrity, Z. (2010). Discourse analysis, Foucault and social work research: Identifying some methodological complexities. Journal of Social Work, 10(2), 193-210.

Garza, C. M. (1995). Chicana lesbian identity and strategic essentialism: signifying self. Humanity \& Society, 19(2), 25-36.

Gates, G.J. (2003). Income of gay men lags behind that of men partnered with women. Retrieved from Urban Institute website: http://www.urban.org/publications/900631.html

Gates, G.J. (2013). LGBT Adult immigrants in the United States. Retrieved from University of California Los Angeles School of Law The Williams Institute website: http://williamsinstitute.law.ucla.edu/wpcontent/uploads/LGBTImmigrants-Gates-Mar-2013.pdf

Gates, G.J. (2014). Food insecurity and SNAP (food stamps) participation in LGBT communities. Retrieved from University of California School of Law, The Williams Institute website: http://williamsinstitute.law.ucla.edu/wpcontent/uploads/Food-Insecurity-in-LGBT-Communities.pdf

Gates, G.J. \& Ramos, C. (2008). Census snapshot: California's black LGB population. Retrieved from University of California School of Law, The Williams Institute website: http://williamsinstitute.law.ucla.edu/wp-content/uploads/Gates-RamosCA-Black-Snapshot-Report-Oct-2008.pdf

Gee, J. P. (2011). How to do discourse analysis: A toolkit. New York, NY: Taylor \& Francis.

Gergen, K. J. (1985). The social constructionist movement in modern psychology. American Psychologist, 40(3), 266. 
Gerrard, N. (1995). Some painful experiences of a white feminist therapist doing research with women of colour. In J. Adleman (Ed.), Racism in the lives of women (pp. 5564). Binghamton, NY: Harrington Park Press.

Gerrish, K. (1997). Being a 'marginal native': Dilemmas of the participant observer. Nurse Researcher, 5(1), 25-34.

Gilligan, H.T. (2011). What's the matter with gay marriage? Retrieved from http://thepublicintellectual.org/2011/07/14/what\%E2\%80\%99s-the-matter-withgay-marriage/

Gitlin, T. (1995). The twilight of common dreams: Why America is wracked by culture wars. New York, NY: Metropolitan Books.

GLAAD (2012). The 2012 network responsibility index: A comprehensive analysis of television's LGBT images. Retrieved from GLAAD website: http://www.glaad.org/files/GLAAD_2012_NRI.pdf

Gluckman, R. (2003). Ten reasons why militarism is bad for queer people. Different Takes, 21, 1-4. Retrieved from http://www.warresisters.org/files/10reasonsmilitarismbadqueer.pdf

Gochros, H. L. (1972). The sexually oppressed. Social Work, 17(2), 16-23.

Goldstein, R. (2003). The attack queers: Liberal society and the gay right. New York, NY: Verso Press.

Goldstone, J. A. (2001). Toward a fourth generation of revolutionary theory. Annual Review of Political Science, 4, 139-187.

Goodman, A. (2001, November 6). Gay human rights groups condemn anti-gay scrawls on a bomb about to be dropped on the Taliban- But what about dropping the bomb? Democracy Now. Retrieved from http://www.democracynow.org/2001/11/6/gay_human_rights_groups_condemn_a nti

Goodwin, J., \& Jasper, J. M. (1999). Caught in a winding, snarling vine: The structural bias of political process theory. Sociological Forum 14(1), 27-54.

Goodwin, J,. \& Jasper, J.J. (Eds.) (2009). The social movements reader: Cases and concepts. Malden, MA: Wiley-Blackwell Publishing.

Gore, D.F., Jones, T,. \& Kang, J.H. (2001). Organizing at the intersections: A roundtable discussion of police brutality through the lens of race, class, and sexual identities. In A. McArdle \& T. Erzen (Eds.) Zero tolerance: Quality of life and the new police brutality in New York City (pp. 251-269). New York, NY: New York University Press.

Gossett, C. (2011). Abolitionist imaginings: A conversation with Bo Brown, Reina Gossett, and Dylan Rodriquez. In E. A. Stanley \& N. Smith (Eds.). Captive genders: Trans embodiment and the prison industrial complex (pp. 323-342). Edinburgh: AK Press.

Gossett, C., Gossett, R., \& Lewis, A.J. (2012). Reclaiming our lineage: Organized queer, gender-nonconforming and transgender resistance to police violence. A New Queer Agenda: The Scholar and The Feminist Online. 10(1-2). Retrieved from http://sfonline.barnard.edu/a-new-queer-agenda/reclaiming-our-lineage- 
organized-queer-gender-nonconforming-and-transgender-resistance-to-policeviolence/\#sthash.Y68WOmTZ.dpuf

Gossett, R. (2012-2013). Jean O’Leary. ReinaGossett.com http://www.reinagossett.com/tag/jean-oleary/

Gould, K. H. (1987). Feminist principles and minority concerns: Contributions, problems, and solutions. Affilia, 2(3), 6-19.

Gramick, J. (1983). Homophobia: A new challenge. Social Work, 28(2), 137-141.

Grant, J.M., Mottet, L.A., \& Tanis, J. (2011). Injustice at every turn: A report of the national transgender discrimination survey. Retrieved from The National Gay and Lesbian Task Force website: http://www.thetaskforce.org/downloads/reports/reports/ntds_full.pdf

Grant, J.M., Mottet, L.A., \& Tanis, J. (2011). Injustice at every turn: A report of the national transgender discrimination survey. Retrieved from The National Gay and Lesbian Task Force website: http://www.thetaskforce.org/downloads/reports/reports/ntds_full.pdf

Gray, M.L. (2009). "Queer Nation is dead / long live Queer Nation": The politics and poetics of social movement media representation. Critical Studies in Media Communication, 26(3), 212-236.

Grbich, C. (2007). Qualitative Data Analysis: An Introduction. London: SAGE Publications.

Gringeri, C.E., Wahab, S., \& Anderson-Nathe, B. (2010). What makes it feminist? Mapping the landscape of feminist social work research. Affilia, 25(4), 390-405.

Grundy, J. \& Smith, M. (2007). Activist knowledges in queer politics. Economy and Society, 36(2,: 294-317.

Gumbs, A. P. (2007, November 1). Building a queer left. Left Turn. Retrieved from http://www.leftturn.org/building-queer-left

Haines, H. H. (1995). Black radicals and the civil rights mainstream, 1954-1970. Knoxville, TN: University of Tennessee Press.

Hammond, N. (2013). Illusions of safety: Policing hate crimes won't make us safer. Retrieved from The Bilerico Project website: http://www.bilerico.com/2013/06/illusions_of_safety_policing_hate_crimes_wont make.php

Haber, P. L. (1996). Identity and political process: Recent trends in the study of Latin American social movements. Latin American Research Review, 31(1), 171-188.

Halberstam, J. (1998). Female masculinity. Durham, NC: Duke University Press.

Haldi, A. (1999). AIDS, anger and activism: ACT UP as a social movement organization. In J. Freeman \& V. Johnson (Eds.). Waves of protest: Social movements since the sixties (pp. 135-150). Lanham, MD: Rowman \& Littlefield Publishers.

Hall, M. (1978). Lesbian families: Cultural and clinical issues. Social Work, 23(5), 380385.

Halley, J. E. (1993). Reasoning about sodomy: Act and identity in and after Bowers v. Hardwick. Virginia Law Review, 79(7), 1721-1780. 
Halperin, D. M., \& Traub, V. (Eds.). (2009). Gay shame. Chicago, IL: University of Chicago Press.

Hanisch, C. (1970, January 1). The personal is political. In S. Firestone \& A. Koedt (Eds.) Notes from the second year: Women's liberation: Major writings of the radical feminists (pp. 76-78). New York, NY: Radical Feminism.

Harding, S. (2002). Rethinking standpoint epistemology: What is-strong objectivity? In K. Brad Wray (Ed.) Knowledge and inquiry: Readings in epistemology (pp. 352384). Calgary: Broadview Press.

Hardisty, J. (2000). Mobilizing resentment: Conservative resurgence from the John Birch society to the promise keepers. Boston, MA: Beacon Press.

Hardisty, J., \& Gluckman, A. (1997). The hoax of "Special Rights": The right wing's attack on gay men and lesbians. In A. Gluckman \& B. Reed (Eds.) HomoeEconomics: Capitalism, community, and lesbian and gay life, (pp. 209222). New York, NY: Routledge.

Hanhardt, C.B. (2013). Safe space: gay neighborhood history and the politics of violence. Durham, NC: Duke University Press.

Harris Interactive Poll (May 19, 2008). Nearly One In Four Gay And Lesbian Adults

Lack Health Insurance. Retrieved from: http://www.harrisinteractive.com/NewsRoom/PressReleases/tabid/446/ctl/ReadCu stom\%20Default/mid/1506/ArticleId/335/Default.aspx

Harris, A.P. (2006). From Stonewall to the suburbs? Toward a political economy of sexuality. William \& Mary Bill of Rights Journal. 14(4), 1539-1582.

Harris, D. (2009). Black feminist politics from Kennedy to Clinton. New York, NY: Palgrave Macmillan.

Harrison, C., \& Young, L. (2005). Leadership discourse in action: A textual study of organizational change in a Government of Canada Department. Journal of Business and Technical Communication, 19(1), 42-77.

Hasenbush, A., Flores, A.R., Kastanis, A., Sears, B., \& Gates, G.J. (2014). The LGBT Divide: A Data Portrait of LGBT People in the Midwestern, Mountain \& Southern States. Retrieved from: http://williamsinstitute.law.ucla.edu/lgbtdivide/\#/economic-insecurity

Heller, P. (2009). Challenges facing LGBT asylum-seekers: The role of social work in correcting oppressive immigration processes. Journal of Gay \& Lesbian Social Services, 21(2-3), 294-308.

Hemphill, E. (Ed.). (1991). Brother to brother: New writings by Black gay men. Boston, MA: Alyson Publications.

Hennessy, R. (2002). Profit and pleasure: Sexual identities in late capitalism. New York, NY: Routledge.

Herek, G.M. (1984). Beyond "homophobia": A social psychological perspective on attitudes toward lesbians and gay men. Journal of Homosexuality, 10(1-2), 1-21.

Herek, G. M., Berrill, K., \& Berrill, K. T. (Eds.). (1992). Hate crimes: Confronting violence against lesbians and gay men. Thousand Oaks, CA: Sage. 
Hermosillo, M. (2013, March 29). Human Rights Campaign fails to advocate for minorities. Policy.Mic. Retrieved from

http://www.policymic.com/articles/31563/human-rights-campaign-fails-toadvocate-for-minorities/424007

Hernández, E. D. (2010). Postnationalism in Chicanalo literature and culture. Austin, TX: University of Texas Press.

Herr, R. S. (2014). Reclaiming third world feminism: Or why transnational feminism needs third world feminism. Meridians: feminism, race, transnationalism, 12(1), $1-30$.

Hesse-Biber, S. N. (2011). Feminist research: Exploring, interrogating, and transforming the interconnections of epistemology, methodology, and method. Handbook of feminist research: Theory and praxis (2nd ed., pp. 2-26) Thousand Oaks, CA: Sage.

Hesse-Biber, S. N., \& Leavy, P. (2004). Distinguishing qualitative research. Approaches to qualitative research: A reader on theory and practice (pp. 1-15). New York, NY: Oxford University Press.

Hesse-Biber, S. N., \& Piatelli, D. (2007). From theory to method and back again: The synergistic praxis of theory and method. In S. N. Hesse-Biber (Ed.), Handbook of feminist research: theory and praxis (pp. 143-154). Thousand Oaks, CA: Sage.

Hidalgo, H., Peterson, T. L., \& Woodman, N. J. (1985). Lesbian and gay issues: A resource manual for social workers. Silver Spring, MD: National Association of Social Workers.

Highleyman, L. (2002). Radical queers or queer radicals? Queer activism and the global justice movement. In B. Shepard \& R. Hayduk (Eds.) from ACT-UP to the WTO: urban protest and community building in the era of globalization (pp. 106-120) London: Verso Books.

Hirsh, E., Olson, G. A., \& Harding, S. (1995). Starting from marginalized lives: A conversation with Sandra Harding. JAC: A Journal of Composition Theory, 15(2), 193-225.

Hirshman, L. (2012). Victory: The triumphant gay revolution. New York, NY: Harper Books.

Hobson, B. (Ed.). (2003). Recognition struggles and social movements: contested identities, agency and power. Cambridge: Cambridge University Press.

Hodkinson, P. (2005). 'Insider research' in the study of youth cultures. Journal of Youth Studies, 8(2), 131-149.

Hollibaugh, A. (2012). 2, 4, 6, 8: Who says that your grandmother's straight. A New Queer Agenda: The Scholar and The Feminist Online, 10(1-2). Retrieved from http://sfonline.barnard.edu/a-new-queer-agenda/2-4-6-8-who-says-that-yourgrandmothers-straight/

Hollibaugh, A. (1996). Seducing women into a "lifestyle of vaginal fisting": Lesbian sex gets virtually dangerous. In Dangerous Bedfellows (Eds.), Policing public sex. (pp. 321-336). Boston, MA: South End Press. 
Hollibaugh, A., Jakobsen, J., \& Sameh, C. (2010). Desiring change. New Feminist Solutions(Vol. 7). Retrieved from http://bcrw.barnard.edu/publications/desiringchange/

hooks, b. (2000). Feminist theory: From margin to center. Chicago, IL: Pluto Press. hooks, b. (1994). Outlaw culture: Resisting representations. New York, NY: Routledge. hooks, b. (1981). Ain't i a woman: Black women and feminism. Boston, MA: South End Press.

Hopper, R. D. (1950). The revolutionary process: A frame of reference for the study of revolutionary movements. Social Forces 28(3), 270-280.

HoSang, D. (2006). Beyond policy: Ideology, race and the reimagining of youth. In S. Ginwright, P. Noguera \& J. Cammarota (Eds.), Beyond resistance! Youth activism and community change (pp. 3-20). New York, NY: Routledge.

Houston, S. (2001). Beyond social constructionism: Critical realism and social work. British Journal of Social Work, 31(6), 845-861.

Hsieh, H. F., \& Shannon, S. E. (2005). Three approaches to qualitative content analysis. Qualitative Health Research, 15(9), 1277-1288.

Hu, M. (2005). Selling us short: How social security privatization will affect lesbian, gay, bisexual, and transgender Americans. Retrieved from National Gay and Lesbian Task Force Policy Institute website: http://www.thetaskforce.org/downloads/reports/reports/SellingUsShort.pdf

Hudson, W. W., \& Ricketts, W. A. (1980). A strategy for the measurement of homophobia. Journal of Homosexuality, 5(4), 357-372.

Hughes, A. K., Harold, R. D., \& Boyer, J. M. (2011). Awareness of LGBT aging issues among aging services network providers. Journal of Gerontological Social Work, 54(7), 659-677.

Human Rights Campaign (2009). At the intersection: Race, sexual orientation and gender. Retrieved from http://www.hrc.org/files/documents/HRC_Equality_Forward_2009.pdf.

Human Rights Campaign (2013). Health insurance discrimination for transgender people. Retrieved from http://www.hrc.org/resources/entry/health-insurancediscrimination-for-transgender-people

Humphrey, J. C. (1999). Disabled people and the politics of difference. Disability \& Society, 14(2), 173-188.

Humphreys, G. E. (1983). Inclusion of content on homosexuality in the social work curriculum. Journal of Education for Social Work, 19(1), 55-60.

Hunter, J., \& Schaecher, R. (1987). Stresses on lesbian and gay adolescents in schools. Children \& Schools, 9(3), 180-190.

Hussain, P. (1997) Class action: Bringing economic diversity to the gay and lesbian movement. In A. Gluckman and B. Reed (Eds.), Homo Economics: Capitalism, Community, and Lesbian and Gay Life (pp. 65-71). New York, NY: Routledge.

Hutchinson, D L. (2001). Identity crisis: "Intersectionality," "multidimensionality" and the development of an adequate theory of subordination. Michigan Journal of Race \& Law, 6, 285-317. 
Hutchinson, D.L. (1999). Gay rights for gay whites: Race, sexual identity, and equal protection discourse. Cornell Law Review, 85, 1358-1391.

Hutchinson, D.L. (2004). Critical race histories: In and out. American University Law Review 53(6), 1187-1215.

Hurtado, A. (1989). Reflections on white feminism: A perspective from a woman of color. In S. Chan (Ed.), Social and Gender boundaries in the United States, (pp. 155186). Lewiston, NY: Edwin Mellen Press.

Icard, L. D. (1986). Black gay men and conflicting social identities: Sexual orientation versus racial identity. Journal of Social Work \& Human Sexuality, 4(1-2), 83-93.

Incite! Women of Color Against Violence. (2007). The revolution will not be funded: Beyond the non-profit industrial complex. Boston, MA: South End Press.

International Human Rights Funders Group. (2010). Retrieved from Astraea Lesbian Foundation for Justice website: https://www.ihrfg.org/funder-directory/astraealesbian-foundation-justice

International Lesbian, Gay, Bisexual, Transgender and Intersex Association (2007). State-sponsored Homophobia. Retrieved from: http://ilga.org/ilga/en/article/1058

Iverson, S. V. (2007). Camouflaging power and privilege: A critical race analysis of university diversity policies. Educational Administration Quarterly, 43(5), 586611.

Jacobs, K., \& Manzi, T. (2000). Evaluating the social constructionist paradigm in housing research. Housing, Theory and Society, 17(1), 35-42.

Jakobsen, J. R. (2005). Sex+ freedom= regulation why?. Social Text, 23(3-4 84-85), 285 308.

Jani, J. S., Pierce, D., Ortiz, L., \& Sowbel, L. (2011). Access to intersectionality, content to competence: Deconstructing social work education diversity standards. Journal of Social Work Education, 47(2), 283-301.

Jasper, J.M. (1997). Chapter two: The classical paradigms. The Art of Moral Protest: Culture, Biography and Creativity in Social Movements, (pp. 19-42). Chicago, IL: University of Chicago Press.

Jenness, V., Maxson, C. L., Matsuda, K. N., \& Sumner, J. M. (2007). Violence in California correctional facilities: An empirical examination of sexual assault. Retrieved from the National PREA Resource Center website: http://www.prearesourcecenter.org/sites/default/files/library/55preapresentationpreareportucijennessetal.pdf

Jiménez, I. (2010, March 8). Justice is sweet: Astraea's funding the fight for queer people of color. Feminist Teacher: Educating for Equity and Justice. Retrieved from: http://feministteacher.com/2010/03/08/justice-is-sweet-astraeas-funding-the-fightfor-queer-people-of-color/

Johnson, E. P. (2005). "Quare" studies, or (almost) everything I know about queer studies I learned from my grandmother. In E.P.P. Johnson \& M. G. Henderson. (Eds.). Black Queer Studies: A Critical Anthology (pp. 124-157). Durham, SC: Duke University Press Books. 
Johnson, E. P. (2008). Sweet tea: Black gay men of the south. Chapel Hill, NC: University of North Carolina Press.

Johnson, G.C. (2010, April 27). Divided we dance: Black gays get their own party started. Philadelphia Weekly. Retrieved fromhttp://www.philadelphiaweekly.com/newsand-opinion/cover-story/Divided-We-Dance-Black-Gays-Get-Their-Own-PartyStarted.html

Johnson, V. (1999). The strategic determinants of a countermovement: The emergence and impact of Operation Rescue blockades. In J. Freeman \& V. Johnson (Eds.) Waves of protest: Social movements since the sixties, (pp. 241-266). Lanham, MD: Rowman \& Littlefield Publishers.

Jones-Yelvington, T. (2008). A half-dozen things that we are: Collective identity in intersectional LGBT/Queer social movement organizations. Part 1. Theory in Action 1(1), 23-47.

Jones-Yelvington, T. (2008b). A half-dozen things that we are: Collective identity in intersectional LGBT/Queer social movement organizations. Part 2. Theory in Action 1(2), 83-105.

Juro, R. (2004). If not now, when? Live Journal. Retrieved from http://lostkidz.livejournal.com/53329.html

Kaid, L. L. (1989). Content analysis. In P. Emmert \& L. L. Barker (Eds.), Measurement of communication behavior (pp. 197-217). New York, NY: Longman.

Kandaswamy, P. (2008). State austerity and the racial politics of same-sex marriage in the US. Sexualities, 11(6), 706-725.

Kanuha, V. K. (2000). "Being" native versus "going native": Conducting social work research as an insider. Social Work, 45(5), 439-447.

Kantor, L. M. (2008). Abstinence-only policies and programs: An overview. Sexuality Research \& Social Policy, 5(3), 6-17.

Katz, J. N. (1985). Gay American history: Lesbians and gay men in the USA: A documentary. New York, NY: Harper \& Row.

Kaufman, M.J. \& Miles, K. (2009). Queer kids of queer parents against gay marriage: Resist the gay marriage agenda. Retrieved from http://queerkidssaynomarriage.wordpress.com/

Kearns, R. (2000). Being there: Research through observing and participating. In I. Hay (Ed.), Qualitative research methods in human geography (pp. 103-121). South Melbourne, Australia: Oxford University Press.

Kehoe, M. (1989). Lesbians over 60 speak for themselves. London: Compendium.

Kelley, R. D. (2012). Building a Progressive Movement in 2012. Souls, 14(1-2), 10-18.

Kelley, R. D. (1997). Identity Politics and Class Struggle. New Politics, 6(2), 84-96.

Kenagy, G., \& Hsieh, C.M (2005). Gender differences in social service needs of transgender people. Journal of Social Service Research, 31(3), 1-21.

Kenagy, G. (2005). Transgender health: Findings from two needs assessment studies in Philadelphia. Health \& Social Work, 30(1), 19-25.

Kennedy, E. L. (1993). Boots of leather, slippers of gold: The history of a lesbian community. New York, NY: Psychology Press. 
Khatib, K., Killjoy, M., \& McGuire, M. (Eds.). (2012). We are many: Reflections on movement strategy from occupation to liberation.Edinburgh: AK Press.

Kimmel, M. (1994). Masculinity as homophobia: Fear, shame and silence in the construction of gender identity. In H. Brod \& M. Kaufman (Eds.), Theorizing masculinities (pp. 119-141). Newbury Park, CA: Sage

Kingston, M. H. (1976). The woman warrior: Memoirs of a girlhood among ghosts. New York, NY: Vintage Books.

Kirby, D. B. (2008). The impact of abstinence and comprehensive sex and STD/HIV education programs on adolescent sexual behavior. Sexuality Research \& Social Policy, 5(3), 18-27.

Kiritsy, L. (2001, October 4). A call to action for gay and lesbian peace activists in U.S. Edge. Retrieved from http://www.edgeboston.com/index.php?ch=news\&sc=glbt\&sc3=\&id=56636\&pf= 1

Kitsuse, J. I. (1961). Societal reaction to deviant behavior: Problems of theory and method. Social Problems, 9(3), 247-256.

Kivel, P. (2007). Social service or social change. In Incite! Women of Color Against Violence (Eds). The revolution will not be funded: beyond the non-profit industrial complex. (pp. 129- 149). Boston, MA: South End Press.

Klages, M. (2006). Literary theory: A guide for the perplexed. London: A\&C Black.

Klandermans, B. (1988). The formation and mobilization of consensus. International Social Movement Research, 1, 173-196.

Kohn, S. (2001). Greasing the wheel: How the criminal justice system hurts gay, lesbian, bisexual and transgendered people and why hate crime laws won't save them.

Review of Law \& Social Change, 27, 257-280.

Kornhauser, W. (1959). Politics of Mass Society. California: Free Press.

Kondracki, N. L., Wellman, N. S., \& Amundson, D. R. (2002). Content analysis: Review of methods and their applications in nutrition education. Journal of Nutrition Education and Behavior, 34(4), 224-230.

Kreheley, J. (2009). How to close the LGBT health disparities gap: Disparities by race and ethnicity. Retrieved from Center for American Progress website: http://www.americanprogress.org/issues/2009/12/pdf/lgbt_health_disparities_race .pdf

Krehely, J., \& Hunt, J. (2011). Helping all of our homeless: Developing a gay-and transgender-inclusive federal plan to end homelessness. Retrieved from Center for American Progress website: http://www.americanprogress.org/issues/2011/01/pdf/lgbt_homelessness.pdf

Kriegman, O. (2006). Dawn of the cosmopolitan: The hope of a global citizens movement. GTI Paper Series. Retrieved from http://www.greattransition.org/archives/papers/Dawn\%20of\%20the\%20Cosmopol itan.pdf 
Krippendorff, K. (1969). Models of messages: three prototypes. In G. Gerbner, O.R. Holsti, K. Krippendorff, G.J. Paisly \& P.J. Stone (Eds.), The Analysis of Communication Content. New York, NY: Wiley.

Krisberg, K. (2001, November 16). Weighing war. New York Blade (p. 1)

Kumashiro, K. K. (Ed.). (2001). Troubling Intersections of Race and Sexuality: Queer Students of Color and Anti-Oppressive Education. London: Rowman \& Littlefield.

Kunzel, R. (2008). Lessons in being gay: Queer encounters in gay and lesbian prison activism. Radical History Review, 2008(100), 11-37.

Kuersten, A.K. (2003). Women and thelLaw: Leaders, cases, and documents. Santa Barbara, CA: ABC-CLIO.

Kumashiro, K. K. (2001). Troubling intersections of race and sexuality: Queer students of color and anti-oppressive education. London: Rowman \& Littlefield Pub Incorporated.

Lady Bunny (2010, November 18). Don't ask, don't go! Huffington Post. Retrieved from http://www.huffingtonpost.com/lady-bunny/dont-ask-dont-go_b_785596.html

LaMarche, G. (2014, August 13). How the left is revitalizing itself. The Nation. Retrieved from http://www.thenation.com/article/180987/how-left-revitalizing-itself

Lambda Legal Defense and Education Fund (2001). Youth at the margins: A report on the unmet needs of lesbian, gay, bisexual and transgender adolescents in foster care. Retrieved from Lambda Legal Defense and Education Fund website: http://www.lambdalegal.org/publications/youth-in-the-margins

Lather, P., \& Lather, P. A. (1991). Getting smart: Feminist research and pedagogy with/in the postmodern. New York, NY: Routledge.

Lavender \& Red Union (1976). The lavender \& red book: A gay liberation/socialist anthology. Retrieved from http://www.rainbowhistory.org/pdf/LARUreader.pdf

Lavers, M.K. (2012, November 30). Pro-Question group raises nearly \$6 million to defend Md. marriage law. Washington Blade. Retrieved from http://www.washingtonblade.com/2012/11/30/pro-question-group-raises-nearly-6million-to-defend-md-marriage-law/

Lehrner, A. (2008). Social change movements and the struggle over meaning-making: A case study of domestic violence narratives. American Journal of Community Psychology, 42(3-4), 220-234.

Lekus, I. (2006). The Long Sixties. OAH Magazine of History, 20(2), 32-38.

Lemisch, J. (1997). Angry white men on the left. New Politics, 6, 97-104.

Lesbians and Gays Against Intervention (1992). We like our queers out of uniform. Retrieved from http://faggotz.org/againstequality/We_Like_Our_Queers_Out_Of_Uniform.pdf

Levitsky, S. R. (2007). Niche activism: Constructing a unified movement identity in a heterogeneous organizational field. Mobilization: An International Quarterly, 12(3), 271-286.

Levy, A. (2009, March 2). Lesbian nation. The New Yorker. Retrieved from http://www.newyorker.com/magazine/2009/03/02/lesbian-nation

Levy, D. (1927). Notes on Psychotherapy. The Social Service Review, 1(1), 78-83. 
Libretti, T. (2004). Sexual outlaws and class struggle: Rethinking history and class consciousness from a queer perspective. College English, 67(2), 154-171.

Licata, S. J. (1981). The homosexual rights movement in the United States: A traditionally overlooked area of American history. Journal of Homosexuality, 6(12), 161-189.

Lietz, C. A., Langer, C. L., \& Furman, R. (2006). Establishing trustworthiness in qualitative research in social work implications from a study regarding spirituality. Qualitative Social Work, 5(4), 441-458.

Lin, A.J. (2008). The accuracy of condom information in three selected abstinence-only education curricula. Sexuality Research \& Social Policy, 5(3), 56-69.

Lincoln, Y. S., \& Guba, E. G. (1985) Naturalistic inquiry. Beverly Hills, CA: Sage.

Loiacano, D. K. (1989). Gay identity issues among Black Americans: Racism, homophobia, and the need for validation. Journal of Counseling \& Development, 68(1), 21-25.

Long, S. (2013, April 27). Bradley Manning, Bayard Rustin, and the perversion of Pride. A Paper Bird. Retrieved from http://paper-bird.net/2013/04/27/bradley-manningbayard-rustin-and-the-perversion-of-pride/

Long, S. (2014, June 28). Policing Pride. A Paper bird: Sex, rights and the world. Retrieved from: http://paper-bird.net/2014/06/28/policing-pride/

Lorde, A. (1984). Sister outsider. Berkeley, CA: Crossing Press.

Lugones, M. (1987). Playfulness, "world"- travelling, and loving perception. Hypatia, 2(2), 3-19.

Lustiger-Thaler, H. (2014). Occupying human values: Memory and the future of collective action. In A.L. Farro \& H. Lustiger-Thaler (Eds.), Reimagining Social Movements: From Collectives to Individuals. pp. 35-50. London: Ashgate Publishing, Ltd.

Macbeth, D. (2001). On "reflexivity" in qualitative research: Two readings, and a third. Qualitative Inquiry, 7(1), 35-68.

Macnair, R. H., Fowler, L., \& Harris, J. (2000). The diversity functions of organizations that confront oppression: The evolution of three social movements. Journal of Community Practice, 7(2), 71-88.

Magnus Collective (1976). Magnus: A Journal of Collective Faggotry, 1. Retrieved from http://rainbowhistory.omeka.net/items/show/4938153

Mahfuz, L. W., \& Farrow, K. (2012). Movement building. In P. Chamberlain (Ed.) Resisting the rainbow (section 5, pp. 8-15) Retrieved from http://www.politicalresearch.org/wpcontent/uploads/downloads/2012/12/Resisting-the-Rainbow-Full-Report.pdf

Mananzala, R. (2012). The FIERCE fight for power and the preservation of public space in the West Village. A New Queer Agenda: The Scholar and The Feminist Online. 10(1-2). Retrieved from http://sfonline.barnard.edu/a-new-queer-agenda/thefierce-fight-for-power-and-the-preservation-of-public-space-in-the-west-village/

Mananzala, R., \& Spade, D. (2008). The nonprofit industrial complex and trans resistance. Sexuality Research \& Social Policy. 5(1), 53-71. 
Mann, S. A., \& Kelley, L. R. (1997). Standing at the crossroads of modernist thought: Collins, Smith, and the new feminist epistemologies. Gender \& Society, 11(4), 391-408.

Mansbridge, J. J. (1986). Why we lost the ERA. Chicago, IL: University of Chicago Press. Mansbridge, J. J. (2009). Ideological purity in the women's movement. In Goodwin, J., \& Jasper, J. M. (Eds.). The social movements reader: cases and concepts (Vol. 12, pp. 161-166). New York, NY: John Wiley \& Sons.

MAP: LGBT Movement Advancement Project. (2012). 2012 National LGBT movement report. Retrieved from MAP website: http://www.lgbtmap.org/file/2012-nationallgbt-movement-report.pdf

MAP: LGBT Movement Advancement Project. (2010). Standard annual reporting: A financial and operating overview of the leading organizations of the LGBT movement. Retrieved from MAP website: http://www.lgbtmap.org/file/2010national-lgbt-movement-report.pdf

MAP: LGBT Movement Advancement Project. (2007). The Momentum Report - 2007 Edition. An Analysis of Key Indicators of LGBT Equality in the US. Retrieved from MAP website: http://www.lgbtmap.org/file/2007-momentum-report.pdf

MAP: LGBT Movement Advancement Project) \& SAGE (Services and Advocacy for GLTB Elders.) (2010). Improving the lives of LGBT older adults. Retrieved from American Progress website: http://www.americanprogress.org/issues/2010/04/pdf/lgbt_elders.pdf

Marcosson, S.A., (1995). The special rights canard in the debate over lesbian and gay civil rights. Journal of Ethics and Public Policy, 9(1), 137-183.

Marshall, M. N. (1996). Sampling for qualitative research. Family Practice, 13(6), 522526.

Matek, O. (1977). A methodology for teaching human sexuality to social work students. Journal of Education for Social Work, 13(3), 50-55.

Martinac, P. (2002, January 11). Past out: Lesbians left legacy of community service. The Washington Blade, p. 45.

Matzner, A. (2008). Settlement house movement. GLBTQ Social Sciences 2008, 1-3.

Mayring, P. (2000). Qualitative content analysis. Qualitative Social Research 1(2), 14385627. Retrieved from http://nbn-resolving.de/urn:nbn:de:0114-fqs0002204

McAdam, D. (1982). Political process and the development of black insurgency. Chicago, IL: University of Chicago Press.

McAdam, D., McCarthy, J. D., \& Zald, M. N. (Eds.). (1996). Comparative perspectives on social movements: Political opportunities, mobilizing structures, and cultural framings. Cambridge: Cambridge University Press.

McAdam, D., Tarrow, S., \& Tilly, C. (2001). Dynamics of contention. Cambridge: Cambridge University Press.

McCammon, H. J. (2003). "Out of the parlors and into the streets": The changing tactical repertoire of the US women's suffrage movements. Social Forces, 81(3), 787-818. 
McCarthy, J. D., Britt, D. W., \& Wolfson, M. (1991). The institutional channeling of social movements by the state in the United States. Research in Social Movements, Conflicts and Change, 13(2).

McCarthy, J. D., \& Zald, M. N. (1977). Resource mobilization and social movements: A partial theory. American Journal of Sociology, 82(6), 1212-1241.

McDermott, N. (2014). The myth of gay affluence. The Atlantic. Retrieved from http://www.theatlantic.com/business/archive/2014/03/the-myth-of-gayaffluence/284570/

McLaughlin, T. (2014, October 13). Board members. The NonProfit Times. Retrieved from: http://www.thenonprofittimes.com/news-articles/board-members/

McMichael, P. \& Wallace, C. (1999). Who is the 'we'? In K. Kleindienst (Ed.) This is what lesbian looks like, (pp. 152-165). Ithica, NY: Firebrand Books.

Mecca, T.A. (2004). It's all about class. In Sycamore, M.B. (ED.) That's revolting!: Queer strategies for resisting assimilation. Berkeley, CA: Soft Skull Press.

Mehrotra, G. (2010). Toward a continuum of intersectionality theorizing for feminist social work scholarship. Affilia, 25(4), 417-430.

Melucci, A. (1989) Nomad of the Present. Temple University Press.

Merriam, S. B., Johnson-Bailey, J., Lee, M. Y., Kee, Y., Ntseane, G., \& Muhamad, M. (2001). Power and positionality: Negotiating insider/outsider status within and across cultures. International Journal of Lifelong Education, 20(5), 405-416.

Meyer, D. S., \& Staggenborg, S. (1996). Movements, countermovements, and the structure of political opportunity. American Journal of Sociology, 1628-1660.

Miles, M. B., \& Huberman, A. M. (1994). Qualitative data analysis: An expanded sourcebook. Thousand Oaks, CA: Sage.

Miller, N. (1995). Out of the past: Gay and lesbian history from 1869 to the present. New York, NY: Vintage.

Minter, S., \& Daley, C. (2003). Trans realities: A legal needs assessment of San Francisco's transgender communities.. Retrieved from National Center for Lesbian Rights and the Transgender Law Center website: http://www.transgenderlawcenter.org/trans/pdfs/Trans\%20Realities\%20Final\%20 Final.pdf

Mogul, J. L., Ritchie, A. J., \& Whitlock, K. (2011). Queer (in)justice: The criminalization of LGBT people in the united states. Boston, MA: Beacon Press.

Mohanty, C. T. (1991). Cartographies of struggle: Third world women and the politics of feminism. In C. Talpade Mohanty, A. Russo, \& L. Torres (Eds), Third world women and the politics of feminism (pp. 1-47). Bloomington, IN: Indiana University Press.

Monro, S., \& Richardson, D. (2010). Theorizing intersectionality and sexuality. Basingstoke, England: Palgrave Macmillan.

Moodie-Mills, A.C. (2012). Jumping beyond the broom: Why black gay and transgender americans need more than marriage equality. Retrieved from Center for American Progress website: http://www.americanprogress.org/wpcontent/uploads/issues/2012/01/pdf/black_lgbt.pdf 
Moorehead, M. (2013, July 2). Trans action demands social justice. Worker's World.

Retrieved from http://www.workers.org/2013/07/02/trans-action-demands-socialjustice/

Moosa-Mitha, M. (2005). Situating anti-oppressive theories within critical and difference-centered perspectives. In L. Brown \& S. Strega (Eds.) Research as resistance (pp. 37-71), Toronto: Canadian Scholars Press.

Moraga, C. (1981). La güera. In C. Moraga \& G. Anzaldúa (eds.) This bridge called my back: Writings by radical women of color (pp. 27-34). New York, NY: Kitchen Table.

Moraga, C, \& Anzaldúa, G. (1981). This bridge called my back: Writings by radical women of color. New York, NY: Kitchen Table.

Mordhorst, M. (2008). From counterfactual history to counter-narrative history. Management \& Organizational History: $M \& O H, 3(1), 5-26$.

Morgan, T. (2002) From WHAM! to ACT UP. In B. Shepard \& R. Hayduk (Eds.) From ACT-UP to the WTO: Urban protest and community building in the era of globalization (pp. 141-149). London: Verso Books.

Morgensen, S.L. (2011). Spaces between us: Queer settler colonialism and indigenous decolonization. Minneapolis, MN: University of Minnesota Press.

Morgensen, S. L. (2010). Settle homonationalism: Theorizing settler colonialism within queer modernities. GLQ: A Journal of Lesbian and Gay Studies, 16(1-2), 105-131.

Morin, S. F., \& Garfinkle, E. M. (1978). Male homophobia. Journal of Social Issues, 34(1), 29-47.

Morningstar, A. (2014). Why "Born This Way" is a bad defense that we need to stop depending on. The Good Men Project. Retrieved from http://goodmenproject.com/featured-content/born-way-bad-defense-need-stopdepending/\#sthash.P7Fd2n4S.dpuf

Morris, A.D. (1984). The origins of the civil rights movement: Black communities organizing for change. New York, NY: The Free Press.

Morris, A.D. \& Staggenborg, S. (2007). Leadership in social movements. In D.A. Snow, S.A. Soule \& H. Kriesi (Eds.) The blackwell companion to social movements, (pp. 171-196). Malden, MA: Blackwell.

Motta, C. (2011). An interview with Kenyon Farrow. Retrieved from http://wewhofeeldifferently.info/interview.php?interview $=105$

Mottet, L., \& Ohle, J.M. (2003). Transitioning our shelters: A guide to making homeless shelters safe for transgender people. . Retrieved from National Gay and Lesbian Task Force Policy Institute and the National Coalition for the Homeless website:http://www.thetaskforce.org/downloads/reports/reports/TransitioningOur Shelters.pdf

Mumford, K. J. (1997). Interzones: Black/White Sex Districts in Chicago and New York in the Early Twentieth Century. New York, NY: Columbia University Press.

Mumford, K. J. (1996). Homosex changes: Race, cultural geography, and the emergence of the gay. American Quarterly, 48(3), 395-414. 
Nadal, K. L., Issa, M. A., Leon, J., Meterko, V., Wideman, M., \& Wong, Y. (2011). Sexual orientation microaggressions:"Death by a thousand cuts" for lesbian, gay, and bisexual youth. Journal of LGBT Youth, 8(3), 234-259.

Nair, Y. (2008, January 9). Queer immigration: Change the paradigms. Windy City Times. Retrieved from http://windycitymediagroup.com/gay/lesbian/news/ARTICLE.php?AID=17177

Nair, Y. (2009). Uniting American Families Act: Facts, fiction, money and emotions. Retrieved from http://queercents.com/2009/05/04/uniting-american-families-actfacts-fiction-and-emotions/

Nair, Y. (2010). DADT and the silence / Silencing of queer anti-war voices. Retrieved from The Bilerico Project website: http://www.bilerico.com/2010/02/dadt_and_the_silence_of_antiwar_queer_voices.php

Nair, Y. (2013). Gay marriage's economic underside. Retrieved from http://yasminnair.net/content/gay-marriages-economic-underside

Nair, Y. (2013b). Gay marriage IS a conservative cause. Retrieved from http://www.yasminnair.net/content/gay-marriage-conservative-cause

Nakagawa, S. (2013). Why I support same sex marriage as a civil right, but not as a strategy to achieve structural change. Retrieved from http://www.changelabinfo.com/2013/03/25/why-i-support-same-sex-marriage-asa-civil-right-but-not-as-a-strategy-to-achieve-structuralchange/\#.UVHmPhn1 cmm

Naples, N.A. (1998). Towards comparative analyses of women's political praxis: Explicating multiple dimensions of standpoint epistemology for feminist ethnography. Women and Politics, 20(1):29-54.

Nash, J. C. (2008). Re-thinking intersectionality. Feminist Review, 89(1), 1-15.

National Association of Social Workers (2008). Code of Ethics. Retrieved from: http://www.socialworkers.org/pubs/code/default.asp

National Black Justice Coalition, the National Gay and Lesbian Task Force, and the National Center for Transgender Equality. (2011). Injustice at every turn: A look at black respondents in the national transgender discrimination survey. Retrieved from http://www.thetaskforce.org/downloads/reports/reports/ntds_full.pdf.

National Center for Lesbian Rights (2006). Rights of Transgender Prisoners. San Francisco. Retrieved from the National Center for Lesbian Rights website http://www.nclrights.org/site/DocServer/RightsofTransgenderPrisoners.pdf?docI $\mathrm{D}=6381$

National Center for Lesbian Rights (NCLR) and the Transgender Law Center (2003). Trans realities: A legal needs assessment of San Francisco's transgender communities. Retrieved from the National Center for Lesbian Rights website:www.nclrights.org/site/DocServer/transrealities0803.pdf

National Coalition for LGBT Health (2004). An overview of U.S. trans health priorities: A Report by the Eliminating Disparities Working Group. Retrieved from: http://www.transgenderlaw.org/resources/transhealthaug04.pdf 
National Gay and Lesbian Task Force (2000). New study refutes myth of gay affluence and confirms breakthrough NGLTF and IGLSS research. Retrieved from http://thetaskforce.org/press/releases/pr296_052600

National Youth Advocacy Coalition. LGBTQ youth: National Health Survey Summary Report. Retrieved from National Youth Advocacy Coalition website: http://www.nyacyouth.org/docs/LGBQT_whitepaper.pdf

Nederhof, A. J. (1985). Methods of coping with social desirability bias: A review. European Journal of Social Psychology, 15(3), 263-280.

Nero, C. I. (2005). Why are gay ghettos white? Black queer studies: A critical anthology (pp. 228-248). Durham, NC: Duke University Press.

Newman, B. S. (1989). Including curriculum content on lesbian and gay issues. Journal of Social Work Education 25(3), 202-211.

Newton, E. (1984). The mythic mannish lesbian: Radclyffe Hall and the new woman. Signs, (4), 557-575.

Nieto, S. (2000). Affirming diversity: The sociopolitical context of multicultural education. New York, NY: Longman.

Noël, M. J. (2006). Progressive polyamory: Considering issues of diversity. Sexualities, $9(5), 602-620$.

Nopper, T. (2010). Why I oppose repealing DADT \& passage of the DREAM Act. We who feel differently. Retrieved from http://www.wewhofeeldifferently.info/journal.php?issue=2\#Tamara\%20K.\%20N opper

Nopper, T.K. (2012). Beyond the access narrative: Marriage politics, austerity, surveillance. The Feminist Wire. Retrieved from http://thefeministwire.com/2012/05/beyond-the-access-narrative-marriagepolitics-austerity-surveillance/

Nyong'o, T. (2005). Punk'd theory. Social Text, 23(3-4 84-85), 19-34.

Oaks, R.F., (1978). Things fearful to name: Sodomy and buggery in seventeenth-century New England. Journal of Social History, 12(2), 268-281.

Olson, M. (1965). The logic of collective action: public goods and the theory of groups. Boston, MA: Harvard University Press.

Osborne, D. (2002). Conversations and action: Iraq war, next steps divide Creating Change participants. Gay City News, 26(1),1.

Olzak, S., \& Ryo, E. (2007). Organizational diversity, vitality and outcomes in the civil rights movement. Social Forces, 85(4), 1561-1591.

Out Against the War Coalition (2002, December 11). "Boycott the NGLTF." Queers for Racial and Economic Justice Digest, (Digest \#736). Retrieved from http://groups.yahoo.com/group/QFREJ.

Padgett, D. (2008). Qualitative methods in social work research (Vol. 36). Thousand Oaks, CA: Sage.

Pendleton, E., \& Goldschmidt, J. (1998). Sex panic!- Make the connections: Defending sex venues is part of a larger struggle for freedom. Harvard Gay and Lesbian Review, 5, 30-32. 
Perez, H. (2005). You can have my brown body and eat it, too!. Social Text, 23(3-4 8485), 171-191.

Pettigrew, T. F. (1998). Intergroup contact theory. Annual Review of Psychology, 49(1), 65-85.

Pew Research Center (2013). A survey of LGBT Americans: Attitudes, experiences and values in changing times. Retrieved from Pew Research Center website: http://www.pewsocialtrends.org/2013/06/13/a-survey-of-lgbt-americans/

Phelan, S. (2010). Identity politics: Lesbian feminism and the limits of community. Philadelphia, PA: Temple University Press.

Phelan, S. (2010b). Sexual strangers: Gays, lesbians, and dilemmas of citizenship. Philadelphia, PA:Temple University Press.

Phelan, S. (Ed.). (1997). Playing with fire: Queer politics, queer theories. New York, NY: Psychology Press.

Phelan, S. (1994). Getting specific: Postmodern lesbian politics. Minneapolis, MN: University of Minnesota Press.

Phoenix, A., \& Pattynama, P. (2006). Intersectionality. European Journal of Women's Studies, 13, 187-192.

Pinard, M. (1971). The rise of a third party: A study in crisis politics. Englewood Cliffs, NJ: Prentice-Hall.

Pivon, F.F. \& Cloward, R.A. (1979). Poor people's movements: Why they succeed, how they fail. New York, NY: Vintage Books.

Plummer, K., \& Stein, A. (1994). I can't even think straight:"queer" theory and the missing sexual revolution in sociology. Sociological Theory, 12(2), 178-187.

Polikoff, N. (2009). Love makes a family...but only through marriage. Retrieved from The Bilerico Project website:http://www.bilerico.com/2009/04/love_makes_a_familybut_only_through marr.php

Polikoff, N. (2013). What marriage equality arguments portend for Domestic Partner employee benefits. NewYork University Review of Law \& Social Change, 37(1), 49-61. Retrieved from http://socialchangenyu.files.wordpress.com/2013/03/37-1polikoff.pdf

Polikoff, N.D. (2008). Beyond (straight and gay) marriage: Valuing all families under the law. Boston, MA: Beacon Press.

Polletta, F. (2009). It was like a fever: Storytelling in protest and politics. Chicago, IL: University of Chicago Press.

Polletta, F., \& Jasper, J. M. (2001). Collective identity and social movements. Annual Review of Sociology, 27, 283-305.

Polvere, L. (2011). Youth perspectives on restrictive mental health placement: Unearthing a counter narrative. Journal of Adolescent Research, 26(3), 318-343.

Potocky-Tripodi, M. (2003). Best practices for social work with refugees and immigrants. New York, NY: Columbia University Press.

Potter, S. J., \& Darty, T. E. (1981). Social work and the invisible minority: An exploration of lesbianism. Social Work, 26(3), 187-192. 
Preissle, J., \& Han, Y. (2012). Feminist research ethics. In S. N. Hesse-Biber (Ed.), Handbook of feminist research: Theory and praxis (pp. 583-605). Thousand Oaks, CA: Sage.

Presser, L. (2005). Negotiating power and narrative in research: Implications for feminist methodology. Journal of Women in Culture and Society, 30, 2067-2090.

Prokos, A. H. (2010). Poverty among cohabiting gay and lesbian, and married and cohabiting heterosexual families. Journal of Family Issues, 31(7), 934-959.

Puar, J. K. (2006). Mapping US homonormativities. Gender, Place and Culture, 13(1), 67-88.

Pulliam, R. M., \& Mott, M. (2010). allgo speaks: Reflections on intersectional organizing. Affilia, 25(4), 444-450.

Queers for Economic Justice (2006a). Beyond same-sex marriage: A new strategic vision for all our families \& relationships. Retrieved from http://beyondmarriage.org/full_statement.html.

Queers for Economic Justice (2006b). Queers and immigration: A vision statement. Retrieved from http://barnard.edu/sfonline/immigration/QEJ-ImmigrationVision.pdf

Queers for Economic Justice (2008). Poverty, public assistance, and privatization: the queer case for a new commitment to economic justice. Retrieved from http://q4ej.org/resources

Queers for Economic Justice (2010). Queer left at US Social Forum pledge a movement for 'Safe Self-Determination'. Retrieved from http://q4ej.org/queer-left-at-ussocial-forum-pledge-a-movement-for-safe-self-determination

Queers for Economic Justice (2010b). Act Queer! teleconference: Movement building in queer organizing. Retrieved from http://q4ej.org/act-queer-teleconferencemovement-building-in-queer-organizing

Queers for Economic Justice (2010c). Act Queer! Teleconference: Research in Queer Organizing. Retrieved from: http://q4ej.org/act-queer-teleconference-research-inqueer-organizing

Raible, J.W. (2010). LGBT parents \& transracial adoption. Retrieved from http://johnraible.wordpress.com/lgbt-parents-transracial-adoption/

Raiskin, J. (1994). Inverts and Hybrids: Lesbian Rewritings of Sexual and Racial Identities. In L. Doan (Ed.), The Lesbian Postmodern, (pp.156-72). New York, NY: Columbia University Press.

Ramírez, H. N. R. (2006). Borderlands, diasporas, and transnational crossings: Teaching LGBT Latina and Latino histories. OAH Magazine of History, 20(2), 39-42.

Ramos, C., \& Gates, G.J., (2008). Census snapshot: California's black LGB population. Retrieved from University of California Los Angeles School of Law, The Williams Institute website: http://escholarship.org/uc/item/98p6s7h0

Ramsey, F.; Hill, M.J.; Kellam, C. (2010). Black lesbians matter.. Retrieved from Zuna Institute website:

http://zunainstitute.org/2010/research/blm/blacklesbiansmatter.pdf. 
Ramsey, F., Hill, M. J., \& Kellam, C. (2010). Black lesbians matter. Retrieved from Zuna Institute website:

http://zunainstitute.org/2010/research/blm/blacklesbiansmatter.pdf.

Rangan, V. K. (2004). Lofty missions, down-to-earth plans. Harvard Business Review, 82(3), 112-119.

Rao, H. (1998). Caveat emptor: The construction of nonprofit consumer watchdog organizations 1. American Journal of Sociology, 103(4), 912-961.

Ray, N. (2006). LGBT youth: An epidemic of homelessness. Retrieved from the National Gay and Lesbian Task Force Policy Institute website: http://www.thetaskforce.org/downloads/HomelessYouth.pdf

Ray, S. (2009). Reading woman, reading essence: Whither gender?. Gayatri Chakravorty Spivak: In Other Words (pp. 107-138). London: Wiley-Blackwell.

Raymond, M. (2008). State refusal of federal funding for abstinence-only programs. Sexuality Research \& Social Policy, 5(3), 44-55.

Reck, J. (2009). Homeless gay and transgender youth of color in San Francisco: 'No one likes street kids - even in the Castro'. Journal of LGBT Youth, 6(2/3), 223-242.

Redman, L.F. (2010). Outing the invisible poor: Why economic justice and access to health care is an LGBT issue. Georgetown Journal on Poverty Law \& Policy, 17, 451-459.

Reed, N. (2013, March 9). Born this way (reprise): The new essentialism.

FreeThoughtBlogs. Retrieved from

http://freethoughtblogs.com/nataliereed/2013/03/09/born-this-way-reprise-thenew-essentialism/

Reid, C., \& Tom, A. (2006). Poor women's discourses of legitimacy, poverty, and health. Gender and Society, 20(3), 402-421.

Reineltl, C. (1994). Fostering Empowerment, Building Community: The Challenge for State-Funded Feminist Organizations. Human relations, 47(6), 685-705.

Reisch, M. \& Andres, J. (2002). The Road Not Taken: A History of Radical Social Work In The United States. New York: Routledge.

Rich, A. (1980). Compulsory heterosexuality and lesbian existence. Signs, 5(4), 631-660.

Richardson, D. (2005). Desiring sameness? The rise of a neoliberal politics of normalisation. Antipode, 37(3), 515-535.

Richardson, M. (1999). What you see is what you get: Building a movement toward liberation in the twenty-first century. In K. Kleindienst (Ed.) This is what lesbian looks like, (pp. 210-219). Ithica, NY: Firebrand Books.

Rimmerman, C. A. (2002). From identity to politics: The lesbian and gay movements in the United States. Philadelphia, PA: Temple University Press.

Risser, J. \& Shelton, A. (2002). Behavioral assessment of the transgender population. Houston, TX:. University of Texas School of Public Health.

Roberts, J.C. (1986). A light that failed. In J. Beam (Ed.) In the Life: A Black Gay Anthology, (pp. 62-67). Boston, MA: Alyson Publications.

Rohrer, M. (2013). Vanguard Revisited Online Exhibit: Introduction. Retrieved from: http://auralstories.blogspot.com/2013/07/vanguard-revisited-online-exhibit.html 
Robnett, B. (1997). How long? How long?: African-American women in the struggle for civil rights (p. 93). New York, NY: Oxford University Press.

Robson, R. (1997). To market, to market: Considering class in the context of lesbian legal theories and reforms. In S. Raffo (Ed.), Queerly classed: Gay men \& lesbians write about class. Boston, MA: South End Press.

Rodriguez, D. (2007). The political logic of the non-profit industrial complex. In Incite! Women of Color Against Violence (Eds.) The revolution will not be funded: beyond the non-profit industrial complex. (pp. 21-40). Boston, MA: South End Press.

Rodriguez, R.T. (2012). Making queer familia. In D.E. Hall \& A. Jagose (Eds.), The Routledge queer studies reader. New York, NY: Routledge.

Rolfe, G. (2006). Validity, trustworthiness and rigour: Quality and the idea of qualitative research. Journal of Advanced Nursing, 53(3), 304-310.

Roots Coalition. (n/d). About Roots. Retrieved from https://rootscoalition.wordpress.com/about-roots/

Roots Coalition (2010). Queer and trans peoples resolution for the safe selfdetermination of our people. Retrieved from the Roots Coalition website: https://rootscoalition.wordpress.com/resources/queer-and-trans-peoplesresolution-for-the-safe-self-determination-of-our-people/

Roque Ramírez, H. N. (2003). "That's my place!": Negotiating racial, sexual, and gender politics in San Francisco's Gay Latino Alliance, 1975-1983. Journal of the History of Sexuality, 12(2), 224-258.

Roque Ramírez, H. N. (2005). Latina/Latino Americans. GLBTQ. Retrieved fromhttp://www.glbtq.com/social-sciences/latina_latino_americans.html

Rosen, J. (1995). Public journalism: A case for public scholarship. Change, 27 (3), 34-38.

Rosenblum, D. (1994). Queer intersectionality and the failure of recent lesbian and gay victories. Law \& Sexuality: Review of Lesbian \& Gay Legal Issues, 4, 83-122.

Rosenblum, D. (1999). Trapped in Sing Sing: Transgendered prisoners caught in the gender binarism. Michigan Journal Of Gender \& Law, 6, 499-573.

Rosenfeld, D. (2009). Heteronormativity and homonormativity as practical and moral resources: The case of lesbian and gay elders. Gender \& Society, 23(5), 617-638.

Rubin, G. (2009). The "political economy" of sex. In E. Lewin (Ed.), Feminist anthropology: a reader (pp. 87-106). Malden, MA: Blackwell.

Ryan, M. (2009). “I will rock some glitter like you've never seen”: Burlesque, femme organizations, and the cultural politics of the femme movement. (Doctoral dissertation). Retrieved from: http://ufdcimages.uflib.ufl.edu/UF/E0/02/49/20/00001/ryan_m.pdf

Ryan, B. (1997). How much can I divide thee, let me count the ways: Identity politics in the women's movement. Humanity \& Society, 21(1), 67-83.

Samuels, G. M., \& Ross-Sheriff, F. (2008). Identity, oppression, and power: Feminisms and intersectionality theory. Affilia, 23(1), 5-9.

San Francisco Bay Guardian \& the Transgender Law Center (2006). Good jobs now!: A snapshot of the economic health of San Francisco's transgender communities, 
Retrieved from

http://www.transgenderlawcenter.org/pdf/Good\%20Jobs\%20NOW\%20report.pdf

San Francisco Lesbian and Gay History Project (1983). She even chewed tobacco:

Passing women in nineteenth-century America. In J. N. Katz (Ed.), Gay American history: Lesbians and gay men in the U.S.A. (pp. 209-280). New York, NY:

Thomas Y. Crowell.

Sanchez, G. (2002, June 28). A question of pride. Mother Jones. Retrieved from: http://www.motherjones.com/politics/2002/06/question-pride

Sandoval, C. (2000). US third world feminism: differential social movement. Methodology of the oppressed (pp. 40-63). Minneapolis, MN: University of Minnesota Press.

Santelli, J. (2006). Abstinence and abstinence-only education: A review of US policies and programs. Journal of Adolescent Health 38(1), 72-81.

Santos, A.C. (2012): Disclosed and willing: Towards A queer public sociology. Social Movement Studies: Journal of Social, Cultural and Political Protest, 11(2), 241254.

Savin-Williams, R. C. (2005). The new gay teen: Shunning labels today's youths are challenging fixed ideas about sexual identity. Gay and Lesbian Review, 12(6), 1619.

Schiffrin, D., Tannen, D., \& Hamilton, H. E. (Eds.). (2008). The handbook of discourse analysis. Hoboken, NJ: Wiley-Blackwell.

Scholl, D. (2009). Transgender community turns up heat on NYC welfare agency. AIDS Issues Update. Retrieved fromhttp://www.housingworks.org/blogs/detail/transgender-community-turns-upheat-on-nyc-welfare-agency/

Scott, J. W. (1988). Deconstructing equality-versus-difference: Or, the uses of poststructuralist theory for feminism. Feminist Studies, 14(1), 33-50.

Schulman, S. (2012). The gentrification of gay politics. In The Gentrification of the Mind: Witness to a Lost Imagination. (pp. 111-132). Berkeley, CA: University of California Press.

Schulman, S. (1994). My American history: Gay and lesbian life during the Reagan-Bush Years. New York, NY: Routledge.

Scott, J. W. (1988). Deconstructing equality-versus-difference: Or, the uses of poststructuralist theory for feminism. Feminist Studies 14(1), 33-50.

Scott, J. W. (1991). The evidence of experience. Critical Inquiry, 17(4), 773-797.

Sears, B., Gates, G.J., \& Lau, H. (2006). Race and ethnicity of same-sex couples in California: Data from Census 2000. Williams Institute. The Williams Project on Sexual Orientation Law and Public Policy UCLA School of Law.

Seidman, S. (1993). Identity and politics in a "postmodern" gay culture: Some historical and conceptual notes. In M. Warner (Ed.). Fear of a queer planet: Queer politics and social theory (pp. 105-122). Minneapolis, MN: University of Minnesota Press.

Seidman, S. (1997). Difference troubles: Queering social theory and sexual politics. Cambridge: Cambridge University Press. 
Seidman, S. (2003). The social construction of sexuality. New York, NY: Norton.

Seidman, S. (2009). Critique of compulsory heterosexuality. Sexuality Research \& Social Policy, 6(1), 18-28.

Seigel-Bernard, T. and Lieber, R. (2011, November 3). The high price of being a gay couple. The New York Times. Retrieved from http://www.nytimes.com/2009/10/03/your-oney/03money.html?pagewanted =all

Sen, R. (2003). Stir it up: Lessons in community organizing and advocacy (Vol. 16). Hoboken, NJ: John Wiley \& Sons.

Sen, N. \& Keleher, T. (2013). Better together in the south: Building movements across race, gender, and sexual orientation. Retrieved from http://www.arc.org/content/view/2369/

Sender, K. (2004). Business, not Politics: The making of the gay market. New York, NY: Columbia University Press.

Shepard, B. (2001). The queer/gay assimilationist split: The suits vs. the sluts. Monthly Review-New York, 53(1), 49-62.

Shepard, B. (2002). Culture jamming a SexPanic! In B. Shepard \& R. Hayduk (Eds.) From ACT UP to the WTO: Urban protest and community building in the era of globalization, (pp. 202-214). London: Verso.

Shepard, B. (2004). Sylvia and Sylvia's children: A battle for a queer public space. In M.B. Sycamore (Ed.), That's revolting!: Queer strategies for resisting assimilation (pp. 123-140). Berkeley, CA: Soft Skull Press.

Shepard, B. (2010). Play as world-making: From the Cockettes to the Germs, gay liberation to DIY community building. In D. Berger (Ed.). The hidden 1970s: Histories of radicalism (pp. 177-194). New Brunswick, NJ: Rutgers University Press.

Shepard, B., \& Hayduk, R. (2002) from ACT UP to the WTO: urban protest and community building in the era of globalization. London: Verso Books.

Shepard, B., \& Jackson, L. (2002) Jacks of color: An oral history. In B. Shepard \& R. Hayduk (Eds.) from ACT UP to the WTO: urban protest and community building in the era of globalization. (pp. 172-177) London: Verso Books.

Shepard, B. \& Schulman, S. (2002). The reproductive rights movement, ACT UP, and the Lesbian Avengers. In B. Shepard \& R. Hayduk (Eds.) from ACT UP to the WTO: urban protest and community building in the era of globalization (pp. 133-140). London: Verso Books.

Shilts, R. (1988). The mayor of Castro Street: The life and times of Harvey Milk. New York, NY: St. Martin's Press.

Shilts, R. (2000). And the band played on: Politics, people, and the AIDS epidemic. New York, NY: Stonewall Inn Editions.

Simon, W., \& Gagnon, J. H. (1967). Femininity in the lesbian community. Social Problems, 212-221.

Simpson, A., \& Smith, A. (Eds.). (2014). Theorizing native studies. Duke University Press.

Sinfield, A. (1998). Gay and after. London: Serpents Tail. 
Sitrin, M. (2012). Horizontalism and the Occupy movements. Dissent. Retrieved from http://www.dissentmagazine.org/article/horizontalism-and-the-occupymovements

Slagle, R. A. (1995). In defense of Queer Nation: From identity politics to a politics of difference. Western Journal of Communication, 59(2), 85-102.

Smith, A. (2005). Conquest: Sexual violence and American Indian genocide. Cambridge, MA: South End Press.

Smith, A. (2010). Queer theory and native studies: The Heteronormativity of Settler Colonialism. GLQ: A Journal of Lesbian and Gay Studies, 16(1-2), 41-68.

Smith, A. M. (2001). Missing poststructuralism, missing Foucault: Butler and Fraser on capitalism and the regulation of sexuality. Social Text, 19(2), 103-125.

Smith, A.M. (2001). The politicization of marriage in contemporary American public policy: The Defense of Marriage Act and the Personal Responsibility Act. Citizenship Studies, 5(3), 303-320.

Smith, B. (1999). Doing it from scratch: The challenge of black lesbian organizing. In K. Kleindienst (Ed.). This is what lesbian looks like (244-257). Ithica, NY: Firebrand Books.

Smith, B. (1993, July 5). Where's the revolution? The Nation. Retrieved from http://www.thenation.com/article/wheres-revolution

Smith, J.J., (2003, February 15). Shelters bar trans homeless. Southern Voice. Retrieved from http://www.southernvoice.com/alan- ta/index.php3?pub=atl

Smith, K.T. (1971). Homophobia: A tentative personality profile. Psychological Reports, 29 (3), 1091-1094.

Smith, L.A., McCaslin, R., Chang, J., Martinez, P., \& McGrew, P. (2010). Assessing the needs of older gay, lesbian, bisexual and transgender people: A service-learning and agency partnership approach. Journal of Gerontological Social Work, 53(5), 387-401.

Smith, M. (2007). Framing same-sex marriage in Canada and the United States: Goodridge, Halpern and the national boundaries of political discourse. Social \& Legal Studies, 16(1), 5-26.

Smith-Rosenberg, C. (1975). The female world of love and ritual: Relations between women in nineteenth-century America. Signs, 1, 1-29.

Smith-Rosenberg, C. (1989). Discourses of sexuality and subjectivity: The new woman, 1870-1936. In M. Duberman, M. Vicinus, \& G. Chauncey (Eds.), Hidden from history: Reclaiming the gay \& lesbian past. New York, NY: Meridian Books.

Snow, D. (2001). Collective identity and expressive forms. Center for the Study of Democracy. Irvine, CA: University of California, Irvine eScholarship Repository.

Snow, D. A., \& Benford, R. D. (1992). Master frames and cycles of protest. In A. D. Morris \& C. McClurg Mueller (Eds.), Frontiers in social movement theory (pp. 133-155). New Haven, CT: Yale University Press.

Snow, D. A., \& Benford, R. D. (1988). Ideology, frame resonance, and participant mobilization. International Social Movement Research, 1(1), 197-217. 
Snow, D. A., \& Soule, S. A. (2010). A primer on social movements. New York, NY: W.W. Norton.

Solis, H. (2011). A better understanding of employee benefits for an increasingly diverse american work force. . Retrieved from United States Department of Labor website: http://social.dol.gov/blog/a-better-understanding-of-employee-benefitsfor-an-increasingly-diverse-american-workforce/

Southerners on New Ground (2012). Our people are worth the risks: A southern queer agenda from the margins and the red states. A New Queer Agenda: The Scholar and The Feminist Online. 10(1-2). Retrieved from http://sfonline.barnard.edu/anew-queer-agenda/our-people-are-worth-the-risks-a-southern-queer-agenda-fromthe-margins-and-the-red-states/0/

Speer, S.A. (2002). What can conversation analysis contribute to feminist methodology? Putting reflexivity into practice. Discourse \& Society, 13, 783-803.

Spencer, C. (1995). Homosexuality in history. New York, NY: Harcourt Brace \& Company.

Spivak, G. C. (1990). The post-colonial critic: Interviews, strategies, dialogues. New York, NY: Psychology Press.

Spivak, G. C. (1988). Subaltern studies: Deconstructing historiography. In R. Guha \& G. C. Spivak (Eds.), Selected subaltern studies. London: Oxford University Press.

Staats, M. (2012). A very short summary of poststructuralist and queer feminist theory and practice. Retrieved from http://www.oakton.edu/user/2/hgraff/140PoststructuralFeminismS12.htm

Staller, K. M. (2012). Epistemological boot camp: The politics of science and what every qualitative researcher needs to know to survive in the academy. Qualitative Social Work, 12 (4), 395-413.

Stein, L. (2009). Social movement web use in theory and practice: a content analysis of US movement websites. New Media \& Society, 11(5), 749-771.

Stemler, S., \& Bebell, D. (1999, April). An empirical approach to understanding and analyzing the mission statements of selected educational institutions. Paper presented at The Annual Meeting of the New England Educational Research Organization, Portsmouth, NJ.

Stern, J. (2012). This is what pride looks like: Miss Major and the violence, poverty, and incarceration of low-income transgender women. A New Queer Agenda: The Scholar and The Feminist Online. 10(1-2). Retrieved from http://sfonline.barnard.edu/a-new-queer-agenda/this-is-what-pride-looks-likemiss-major-and-the-violence-poverty-and-incarceration-of-low-incometransgender-women/0/

Stombler, M., Baunach, D.M., Burgess, E.O., Donnelly, D., Simonds, W., \& Windsor, E.J. (Eds.). (2010). Sex matters: The sexuality and society reader. Boston, MA: Allyn \& Bacon.

Stone-Mediatore, S. (1998). Chandra Mohanty and the revaluing of "experience." Hypatia, 13(2), 116-133. 
Stryker, S. (2008). Transgender history, homonormativity, and disciplinarity. Radical History Review, 2008(100), 145-157.

Sullivan, A. (1996). Virtually normal: An argument about homosexuality. New York, NY: Vintage Books.

Sycamore, M.B. (2010). Get hitched or get ditched! The Skinny. Retrieved fromhttp://www.theskinny.co.uk/deviance/features/98386get_hitched_get_ditched

Sycamore, M.B. (2008, June 25). Down with legitimacy. San Francisco Bay Guardian. Retrieved from http://www.sfbg.com/2008/06/25/down-legitimacy

Sycamore, M.B. (Ed.). (2004). That's revolting!: Queer strategies for resisting assimilation. Berkeley, CA: Soft Skull Press.

Sylvia Rivera Law Project (2009). Statement on hate crime laws. Retrieved from http://www.blackandpink.org/prison-aboliton/statement-on-hate-crimeslegislation/

Sylvia Rivera Law Project (2009b). SRLP Collective member handbook. Retrieved from http://srlp.org/files/collective\%20handbook\%202009.pdf

Tanev, A. (2007). Community Health Survey, New York City Department of Health and Mental Hygiene. Unpublished raw data.

Taterka, M. (2014). Queers for Economic Justice closes its doors thanks to lack of economic justice. Autostraddle. Retrieved from

http://www.autostraddle.com/queers-for-economic-justice-closes-its-doorsthanks-to-lack-of-economic-justice-224520/

Tarrow, S. (1998). Power in movement: Social movements and contentious politics. New York, NY: Cambridge University Press.

Taylor, K. (2012, June 9). Black leaders and gay advocates march in step. New York Times. Retrieved from http://www.nytimes.com/2012/06/10/nyregion/blackleaders-and-gay-advocates-find-ways-to-march-in-step.html?_r=1

Taylor, V., \& Whittier, N.E. (1999). Collective identity in social movement communities: Lesbian feminist mobilization. In J. Freeman \& V. Johnson (Eds.). Waves of protest: Social movements since the Sixties (pp. 169-194). Lanham, MD: Rowman \& Littlefield Publishers.

Talley, A. (2014, June 23). 'Gay Pride is for White people'. Mused. Retrieved from http://www.musedmagonline.com/2014/06/gay-pride-white-people/

Thayer, A. (2002). The next war and why we should oppose it. Retrieved from Chicago Anti-Bashing Network Website: http://www.cabn.org/archives/2002/081802opposewar.html

The Rainbow Health Initiative, 2004. Minnesota Health Access Survey. Retrieved from: http://www.rainbowhealth.org/resources-for-you/research-and-publications/

The Welfare Warriors Research Collaborative (2010). A fabulous attitude: Low-income LGBTGNC people surviving \& thriving on love, shelter \& knowledge. New York, NY: Queers for Economic Justice. Retrieved from http://www.q4ej.org/Documents/afabulousattitudefinalreport.pdf 
Thrasher, S.W. (2013, April 30). Haaay to the chief: The military-industrial complex conquers the Homos. Gawker. Retrieved from http://gawker.com/haaay-to-thechief-the-military-industrial-complex-con-486133694

Tilcsik, A. (2011). Pride and prejudice: Employment discrimination against openly gay men in the United States. American Journal of Sociology, 117(2), 586-626.

Tilly, C. (1993). Social movements as historically specific clusters of political performances. Berkeley Journal of Sociology, 38, 1-30.

Tirado Gilligan, H. (2011). What's the matter with gay marriage? Retrieved fromhttp://thepublicintellectual.org/2011/07/14/what\%E2\%80\%99s-the-matterwith-gay-marriage/

Tomasky, M. (1996). Left for dead: The life, death, and possible resurrection of progressive politics in America. New York, NY: Free Press.

Tomkins, J. (2013). Against equality. Retrieved from https://www.facebook.com/groups/445317630245/permalink/

10152686673120246/?comment_id=10152687250500246\&offset=0\&total_comments=1 1

Touraine, A. (2014). Afterword: Globalization and the ar of gods. In A. D. Farro \& H. Lustiger-Thaler (Eds.), (2014). Reimagining social movements: From collectives to individuals (pp. 273-281). London: Ashgate Publishing, Ltd.

Transgender Law Center (2013). Recommendations for transgender health care. Retrieved from http://www.transgenderlaw.org/resources/tlchealth.htm

TransGriot (2007). Why the transgender community hates HRC. Retrieved from http://transgriot.blogspot.com/2007/10/why-transgender-community-hateshrc.html

United States Department of Health and Human Services (2010). Promoting responsible fatherhood home page. Retrieved from http://fatherhood.hhs.gov/

Vaid, U. (1995). Virtual equality: The mainstreaming of gay \& lesbian liberation. New York, NY: Anchor Books/Doubleday.

Vaid, U. (2012). Irresistible revolution: Confronting race, class and the assumptions of LGBT politics. New York, NY: Magnus Books.

Vaid, U. (2012b). Still ain't satisfied: The limits of equality. The American Prospect. Retrieved from http://prospect.org/article/still-aint-satisfied-limits-equality

Valocchi, S. (1999). The class-inflected nature of gay identity. Social Problems, 46(2), 207-224.

Van Deburg, W. L. (1992). New day in Babylon: The black power movement and American culture, 1965-1975. Chicago, IL: University of Chicago Press.

Vasquez, C. (1998). Endorsement of D'Amato equals betrayal. Gay Community News, 24, 14.

Vélez, V., Huber, L. P., Lopez, C. B., de la Luz, A., \& Solórzano, D. G. (2008). Battling for human rights and social justice: A Latina/o critical race media analysis of Latina/o student youth activism in the wake of 2006 anti-immigrant sentiment. Social Justice, 35(1), 7-27. 
Vieira, P.J. (2013). The sexual politics of austerity: Queer everyday life in neoliberal times. Retrieved from http://paulojorgevieira.wordpress.com/2013/03/20/thesexual-politics-of-austerity-queer-everyday-life-in-neoliberal-times/

Vogel, S. (2009). The scene of Harlem cabaret: Race, sexuality, performance. Chicago, IL: University of Chicago Press.

Walsh, E. (1998, October 23). Gay rights group stirs flap with D'Amato nod. Washington Post. Retrieved from http://www.washingtonpost.com/wpsrv/politics/campaigns/keyraces98/stories/ny102398.htm

Wang, Y. (2013, June). Five in one, on 24th: LGBTQ activism thrives. Chelsea Now. Retrieved from: http://chelseanow.com/2013/06/five-in-one-on-24th-lgbtqactivism-thrives/

Walters, S. D. (2003). All the rage: The story of gay visibility in America. Chicago, IL: University of Chicago Press.

Ward, J. (2008). Respectably queer: Diversity culture in LGBT activist organizations. Nashville, TN: Vanderbilt.

Warner, M. (2000). The trouble with normal: Sex, politics, and the ethics of queer life.Cambridge, MA: Harvard University Press.

Warner, M. (1999). Normal and normaller: Beyond gay marriage. GLQ: a Journal of Lesbian and Gay Studies, 5(2), 119-171.

Warner, M. (1993) Fear of a queer planet: queer politics and social theory. Minneapolis, MN: University of Minnesota Press.

Weber, R. P. (1990). Basic content analysis. Beverly Hills, CA: Sage.

Weiner-Mahfuz, L. (2010). Spill-over love: Building a just and multi-racial LGBT movement. Retrieved from Bilerico Project website: http://www.bilerico.com/2010/03/spill-over_love_building_a_just_and_multiracial_l.php

White, A. (2004, June 8). Reagan's AIDS legacy: Silence equals death. San Francisco Gate. Retrieved from http://www.sfgate.com/opinion/openforum/article/Reagans-AIDS-Legacy-Silence-equals-death-2751030.php

Whitlock, K., \& Kamel, R. (2001). In a time of broken bones: A call to dialogue on hate violence and the limitations of hate crimes legislation. Philadelphia, PA: American Friends Service Committee.

Whitman-Bradley, B., Lazare, S., \& Whitman-Bradley, C. (Eds.). (2011). About Face: Military Resisters Turn Against War. Oakland, CA: PM Press.

Wicks, L. K. (1977). Transsexualism: A social work approach. Health \& Social Work, 2(1), 179-193.

Wildemuth, B. M. (1993). Post-positivist research: Two examples of methodological pluralism. The Library Quarterly, 63(4), 450-468.

Wildermuth, J. (2009, February 3). Prop. 8 among costliest measures in history. The San Francisco Chronicle. Retrieved from http://www.sfgate.com/politics/article/Prop8-among-costliest-measures-in-history-3173589.php

Williams, W.L. (1992). The spirit and the flesh: Sexual diversity in American Indian culture. Boston, MA: Beacon Press. 
Wilson, J. (1973). Introduction to social movements. New York, NY: Basic Books.

Woo, M. (1981). Letter to ma. This bridge called my back: Writings by radical women of color, 140-147. New York, NY: Kitchen Table Press.

Wyllie de Echeverria, R. (n/d). The Roots Coalition: A queer lesson in movement building. Southerners on New Ground. Retrieved from http://rootscoalition.wordpress.com/about-roots/the-roots-coalition-a-queerlesson-in-movement-building/

Xavier, J.M. (2000). The Washington, DC. transgender needs assessment survey final report for phase two. Retrieved from Administration for HIV and AIDS of the District of Columbia Government website:

http://www.glaa.org/archive/2000/tgneedsassessment1112.shtml

Yar, M. (2001). Beyond Nancy Fraser's' perspectival dualism'. Economy and Society, 30(3), 288-303.

Zald, M. N., \& McCarthy, (1987). Organizational intellectuals and the criticism of society. In Zald, M. N., \& McCarthy, J. D. (Eds.). Social movements in an organizational society: Collected essays. (pp. 344-362). Piscataway, NJ: Transaction Publishers.

Zimmerman, B. (Ed.). (2000). Lesbian histories and cultures: An encyclopedia (Vol. 1). New York, NY: Taylor \& Francis. 


\section{Appendix A: Defining a Social Movement}

\begin{tabular}{|c|c|c|}
\hline Theorist & $\begin{array}{c}\text { Definition of a Social } \\
\text { Movement }\end{array}$ & Notes \\
\hline $\begin{array}{l}\text { Castells } \\
(2010)\end{array}$ & $\begin{array}{l}\text { A certain type of organization } \\
\text { of social practices, the logic of } \\
\text { whose development contradicts } \\
\text { the institutionally dominant } \\
\text { social logic. }\end{array}$ & $\begin{array}{l}\text { Avoided generalizing and over- } \\
\text { theorizing, and focused on the } \\
\text { specifics of each individual } \\
\text { movement. Social movements must } \\
\text { be understood on their own terms; } \\
\text { they are whatever they claim to be. }\end{array}$ \\
\hline $\begin{array}{l}\text { Diani \& Bison } \\
(2004)\end{array}$ & $\begin{array}{l}\text { The building and reproducing } \\
\text { of dense informal networks } \\
\text { between a multiplicity of } \\
\text { actors, sharing a collective } \\
\text { identity, and engaged in social } \\
\text { and/or political conflict. }\end{array}$ & $\begin{array}{l}\text { They are contrasted to coalitional } \\
\text { processes, where alliances to } \\
\text { achieve specific goals are not } \\
\text { backed by significant identity links, } \\
\text { and organizational processes, where } \\
\text { collective action takes place mostly } \\
\text { in reference to specific } \\
\text { organizations rather than broader, } \\
\text { looser networks }\end{array}$ \\
\hline $\begin{array}{l}\text { Gamson } \\
(1990)\end{array}$ & $\begin{array}{l}\text { Challenging groups capable of } \\
\text { taking action together }\end{array}$ & $\begin{array}{l}\text { Identifies challenging groups by } \\
\text { conceptualizing three distinct } \\
\text { targets for challenging groups: } \\
\text { (1) the target of influence, } \\
(2) \text { the target of mobilization } \\
(3) \text { the target of benefits. }\end{array}$ \\
\hline $\begin{array}{l}\text { McAdam, } \\
\text { Tarrow \& } \\
\text { Tilly (2001) }\end{array}$ & $\begin{array}{l}\text { In order to comprise a social } \\
\text { movement, challenging groups } \\
\text { must have a "classical social } \\
\text { movement agenda." }\end{array}$ & $\begin{array}{l}\text { A classical social movement agenda } \\
\text { has four components: } \\
\text { (1) "political opportunities" } \\
\text { (2) "forms of organization" } \\
\text { (3) "framing of grievances" } \\
\text { (4) "repertoires of contention" }\end{array}$ \\
\hline $\begin{array}{l}\text { Snow \& Soule } \\
(2010)\end{array}$ & $\begin{array}{l}\text { (1) challengers to (or } \\
\text { defenders of) structures or } \\
\text { systems of authority; } \\
\text { (2) collective actors; } \\
\text { (3) extra-institutional } \\
\text { challengers; } \\
\text { (4) engaged in organized } \\
\text { activities; } \\
\text { (5) existing with temporal } \\
\text { continuity. }\end{array}$ & $\begin{array}{l}\text { Also explained that all social } \\
\text { movements are collectivities acting } \\
\text { with some degree of organization } \\
\text { and continuity, partly outside } \\
\text { institutional or organizational } \\
\text { channels, for the purpose of } \\
\text { challenging extant systems of } \\
\text { authority, or resisting change in } \\
\text { such systems, in the organization, } \\
\text { society, culture or world system in } \\
\text { which they are embedded. }\end{array}$ \\
\hline
\end{tabular}




\begin{tabular}{|l|l|}
\hline Tarrow (1998) & $\begin{array}{l}\text { Collective challenges, based on } \\
\text { common purposes and social } \\
\text { solidarities, in sustained } \\
\text { interaction with elites, } \\
\text { opponents and authorities }\end{array}$ \\
\hline $\begin{array}{l}\text { Blumer } \\
(1969)\end{array}$ & $\begin{array}{l}\text { Contend that social movements go through stages of development: } \\
\text { (1) emergence } \\
\text { Hopper }\end{array}$ \\
$\begin{array}{l}\text { (1950) and } \text { Christiansen } \\
(2009)\end{array}$ & $\begin{array}{l}\text { (3) bureaucratization/formalization } \\
\text { (4) decline }\end{array}$ \\
\hline $\begin{array}{l}\text { Freeman } \\
(1999)\end{array}$ & $\begin{array}{l}\text { Contends that new social movements develop when they have } \\
\text { preexisting communications networks, a series of crises that galvanize } \\
\text { people, and/or bonding efforts. }\end{array}$ \\
\hline
\end{tabular}




\section{Appendix B: My Working Definition of a Social Movement}

I looked for three sets of criteria to determine if these organizations constitute a social movement. The first is the question of whether they are engaged in working collectively (as opposed to lobbyists or litigants working individually). Collective action, such as a mass protest or boycott, has been articulated as hallmark of social movements by social movement theorists (Gamson 1990; Snow \& Soule, 2010; Tarrow, 1998).

The second criterion I used is whether these groups and their collective actions have structure and organization. Social movement theorists (Snow \& Soule, 2010; McAdam, et al., 2001) maintain that social movements are engaged in organized activities. These activities can be varied (coordinated protests, the creation of an organization, networking of different groups) but they must be deliberately planned and organized.

The third criterion I looked for will be common purposes. Tarrow (1998) argued that the collective action of social movement is based upon similar goals and social solidarities, and McAdam, et al. (2001) made the same point when talking about how all social movements engage in the "framing of grievances" which legitimizes their claims, connects them to other claims, and forms a collective identity among the claimants.

For the above stated reasons, I used the following as my working definition of a social movement: A social movement is a group of people engaged in collective work, consisting of structured activities and organizations, with common goals, grievances, values and purposes. 
Appendix C: Major Social Movement Theories

\begin{tabular}{|c|c|}
\hline $\begin{array}{l}\text { THEORY / } \\
\text { FRAMEWORK }\end{array}$ & EXPLANATION \\
\hline \multicolumn{2}{|r|}{ Classic Social Movement Theories } \\
\hline $\begin{array}{l}\text { Collective } \\
\text { Behavior } \\
\text { Kornhauser, } 1959\end{array}$ & $\begin{array}{l}\text { Socially isolated people join social movements to end alienation } \\
\text { and anxiety and provide a sense of empowerment and belonging. } \\
\text { Social movements are psychological, rather than political, } \\
\text { responses to societal changes that are joined by unhealthy people. }\end{array}$ \\
\hline $\begin{array}{l}\text { Resource } \\
\text { Mobilization } \\
\text { McCarthy \& Zald, } \\
1977\end{array}$ & $\begin{array}{l}\text { Regards social movements as rational social institutions, created } \\
\text { with the goal of political action, engaged in instrumental action } \\
\text { through formal organization to secure resources and foster } \\
\text { mobilization. They focus on amassing resources (e.g. building } \\
\text { institutions) and leveraging support from elite third parties. }\end{array}$ \\
\hline $\begin{array}{l}\text { Disruptive Power } \\
\text { Piven and } \\
\text { Cloward, } 1979\end{array}$ & $\begin{array}{l}\text { Government acceptance often leads to the cooption and } \\
\text { institutionalizing of issues, rather than to continued disruption } \\
\text { and cooption. Organizers should focus on what they can do } \\
\text { (engage in disruptive mass protests), rather than focusing on what } \\
\text { they can't do (create change by building resources). }\end{array}$ \\
\hline $\begin{array}{l}\text { Political Process } \\
\text { McAdam, Tarrow } \\
\& \text { Tilly, } 2001\end{array}$ & $\begin{array}{l}\text { Describes insurgency as a product of both factors internal or } \\
\text { external to the movement. Focused on how political, economic } \\
\text { and social contexts create political opportunities that can be } \\
\text { exploited by social movements. }\end{array}$ \\
\hline \multicolumn{2}{|r|}{ Modern Social Movement Theories } \\
\hline $\begin{array}{l}\text { Collective } \\
\text { Identity } \\
\text { Goodwin \& Jasper, } \\
2009 \text { / } \\
\text { Interest Group } \\
\text { Armstrong, } 2002 \\
\end{array}$ & $\begin{array}{l}\text { Organizers use, or create, identity to build solidarity and support } \\
\text { around an idea with pre-existing membership in a group based on } \\
\text { identity or by creating an actual membership. Change occurs } \\
\text { when organizations represent large, united and homogeneous } \\
\text { groups of people to use legislative channels to successfully } \\
\text { influence public policy to end discrimination. }\end{array}$ \\
\hline $\begin{array}{l}\text { Framing } \\
\text { Benford \& Snow, } \\
2000\end{array}$ & $\begin{array}{l}\text { Social movements transmit beliefs, values and ideologies to the } \\
\text { public. Participants strategically engage in the production and } \\
\text { maintenance of meaning for their own constituents, their } \\
\text { antagonists, and observers. }\end{array}$ \\
\hline $\begin{array}{l}\text { Perspectival } \\
\text { Dualism } \\
\text { Fraser (1995), } \\
\text { Fraser \& Honneth, } \\
(2003) \text {. }\end{array}$ & $\begin{array}{l}\text { Class-based and Identity-based movements need not be mutually } \\
\text { exclusive. Integrates both the recognition perspective and the } \\
\text { distribution perspective in its analysis of current American } \\
\text { society's class inequity and status hierarchy. }\end{array}$ \\
\hline \multicolumn{2}{|r|}{ Theories About The Gay Rights Movement } \\
\hline $\begin{array}{l}\text { Identity } \\
\text { Deployment }\end{array}$ & $\begin{array}{l}\text { Activists frequently choose to strategically suppress their } \\
\text { differences from the dominant society, in order to highlight }\end{array}$ \\
\hline
\end{tabular}




\begin{tabular}{|l|l|}
\hline Bernstein, 1997 & similarities to the majority of Americans who are heterosexual. \\
\hline $\begin{array}{l}\text { Gay+1 / } \\
\text { Anity in Diversity }\end{array}$ & $\begin{array}{l}\text { A Gay+1 group combines gay identity with another interest to } \\
\text { create a new institutional form. The creation of this form let to a } \\
\text { wide array of groups, focused on many different interests but } \\
\text { united in their gay identity, represented a "unity in diversity." }\end{array}$ \\
\hline $\begin{array}{l}\text { Poststructuralism } \\
\text { and Social } \\
\text { Movements } \\
\text { Gamson, 1995; 2009; } \\
\text { Seidman, 1993. }\end{array}$ & $\begin{array}{l}\text { Poststructuralist theories challenge the essentialized identities } \\
\text { used in the social movement. Gamson questioned organizing } \\
\text { around identity categories (e.g. gay or lesbian) when queer theory } \\
\text { destabilizes such categories. Seidman employed an intersectional } \\
\text { analysis to question essentialized notions of gayness in LGBT } \\
\text { organizing. }\end{array}$ \\
\hline
\end{tabular}




\section{Appendix D: Intersectional Organizations Doing Multi-Issue Work}

1. Affinity Community Services (Chicago, IL)

2. allgo (Austin, TX)

3. Arizona Queer Undocumented Immigrant Project (Phoenix, AZ)

4. Astraea Lesbian Foundation for Justice (NYC, NY)

5. Audre Lorde Project (Brooklyn, NY)

6. Black and Pink (Boston, MA)

7. BreakOUT! (New Orleans, Louisiana)

8. Buried Seedz of Resistance (Denver, Colorado)

9. CAAAV: Organizing Asian Communities, (NYC, NY)

10. California Immigrant Youth Justice Alliance (Los Angeles, CA)

11. Catalyst Project (San Francisco CA)

12. Center for Artistic Revolution (Little Rock, Arkansas)

13. COLAGE, (San Francisco, CA)

14. Community United Against Violence (San Francisco CA)

15. The Disability Justice Collective (national)

16. El Centro Hispano (Durham, NC)

17. El/La Para Translatinas (San Francisco, CA)

18. Equality Utah (Salt Lake City, UT)

19. Esperanza Peace and Justice Center (San Antonio, TX)

20. Fairness Campaign (Louisville, KY)

21. Familia: Trans Queer Liberation Movement (Los Angeles, CA) 
22. The First Nations Two Spirit Collective (national)

23. FIERCE (New York, NY)

24. Freedom Center for Social Justice (Charlotte, North Carolina)

25. Freedom Inc. (Madison, WI)

26. Gender Just (Chicago, IL)

27. Gender Justice L.A. (Los Angeles, CA)

28. Generation Five (San Francisco, CA)

29. GLOBE: the LGBTQ Justice Organization of Make the Road By Walking (Brooklyn, New York)

30. GRIOT Circle (Brooklyn, NY)

31. Hearts on a Wire Collective (Philadelphia, PA)

32. Highlander Research and Education Center (New Market, TN)

33. Howard Brown Broadway Youth Center (Chicago, IL)

34. INCITE! Women of Color Against Violence (Chicago, IL)

35. Jacksonville Area Sexual Minority Youth Network (Jacksonville, FL)

36. Just Cause Oakland (Oakland, CA)

37. LELO (Seattle, WA)

38. Movement Strategy Center (Oakland, CA)

39. National Black Justice Coalition (Washington, DC)

40. National Coalition on LGBT Health (Washington, DC)

41. National Queer Asian Pacific Islander Alliance (Washington, DC) 
42. the Peter Cicchino Youth Project (New York, NY)

43. Power Inside (Baltimore, Maryland)

44. Pride at Work (national)

45. Project South: Institute for the Elimination of Poverty \& Genocide (Atlanta, GA)

46. Queer Women of Color Media Arts Project (San Francisco)

47. Reteaching Gender and Sexuality (Seattle, WA)

48. Rural Organizing Project, (Scappoose, OR)

49. Seattle Young People's Project (Seattle, WA)

50. SisterSong Women of Color Reproductive Health Collective (Atlanta, GA)

51. SOUL (School of Unity and Liberation), (Oakland, CA)

52. Southern Center for Human Rights (Atlanta, GA)

53. Southerners on New Ground (Atlanta, GA)

54. SPARK, Reproductive Justice NOW, (Atlanta, GA)

55. Sylvia Rivera Law Project (New York, NY)

56. Streetwise and Safe (New York, NY)

57. Trans Women of Color Collective (Washington, DC)

58. Transgender, Gender Variant and Intersex Justice Project (Oakland, CA)

59. the Transgender Law Center (San Francisco, CA)

60. Women With A Vision (New Orleans, LA)

61. Women's Prison Book Project (Minneapolis MO) 


\section{Appendix E: Organizations That Were Asked to Participate in this Study}

Affinity Community Services is a social justice organization in Chicago, IL, that works with and on behalf of Black LGBTQ communities, queer youth, and allies to identify emergent needs, create safe spaces, develop leaders, and bridge communities through collective analysis and action for social justice, freedom, and human rights. www.affinity95.org

allgo (Austin Latina Latino Lesbian and Gay Organization) is a statewide people of color organization located in Austin, TX. They are currently working in the areas of AntiViolence, Immigrant and Refugee Rights, Sexual Freedom, and Reproductive Justice. allgo works toward its vision through cultural arts, health and advocacy programming. www.allgo.org

The Audre Lorde Project is a Lesbian, Gay, Bisexual, Two Spirit, Trans and GenderNonconforming People of Color center for community organizing, focusing on the New York City area. They focus on mobilization, education and capacity-building. Their two biggest current projects are "Safe OUTside the System" (an anti-violence program devoted to challenging hate and police violence by using community based strategies rather than relying on the police) and "TransJustice" (mobilizing transgender people of color for access to jobs, housing, healthcare, education and safety from the police). www.alp.org

Center for Artistic Revolution is a statewide, grassroots community based organization, based in Little Rock, AR. It engages in progressive education, organizing skills, advocacy, and creative/cultural work and they currently have programs advocating for nontraditional families, queer youth, and transgender people.

www.artisticrevolution.org 
Esperanza Peace and Justice Center is a community organizing and arts center in San Antonio, TX. Through artistic creation and cultural expression, Esperanza brings together women, people of color, lesbians and gay men, the working class and poor for community building. www.esperanzacenter.org

FIERCE is a membership-based organization building the leadership of lesbian, gay, bisexual, transgender, and queer (LGBTQ) youth of color in New York City. Youth-led campaigns are focused on resisting the gentrification of the piers on the west side of NYC, decreasing police harassment and abuse and advocating for social services for LGBTQ youth of color.

www.fiercenyc.org

The National Queer Asian Pacific Islander Alliance is a Washington, DC-based federation of LGBTQ Asian American, South Asian, Southeast Asian and Pacific Islander organizations. NQAPIA seeks to build the capacity of local LGBT AAPI organizations, invigorate grassroots organizing, develop leadership, and challenge homophobia, racism, and anti-immigrant bias.

www.nqapia.org

Queer Women of Color Media Arts Project, based in San Francisco, CA, promotes the creation, exhibition and distribution of new films and videos that increase the visibility of queer women of color, their life stories, and the social justice issues of concern to them. www.qwocmap.org

Queers for Economic Justice was a multi-racial, multi-class organization in New York City. They engaged in local community organizing and advocacy with low-income and homeless LGBT people, to improve the welfare and shelter systems in New York. They 
also conducted public education campaigns nationally and build coalitions across the country on economic issues impacting LGBT people.

www.Q4EJ.org

(Note: QEJ closed last year. However, at the time of my research, they were continuing to wrap up some of their work. Given that staff, volunteers and board were still doing QEJrelated work, and given QEJ's relationships to these other organizations, I included QEJ in my study despite their imminent closure.)

Southerners on New Ground is based in Atlanta, GA but works in multiple states as a multi-issue southern justice movement in which poor and working class, immigrant, people of color, rural LGBTQ people take leadership. They work on strategic projects and campaigns developed in response to the current conditions in our communities. SONG builds this movement through leadership development, intersectional analysis, and organizing. www.southernersonnewground.org

Sylvia Rivera Law Project is based in New York, NY, and provides legal services for transgender, intersex or gender nonconforming people. It also engages in coalition building, public education and high impact litigation. It is a non-hierarchal collective. It works in juvenile detention, prisons, family court, health systems, HRA system, and homeless shelters.

www.srlp.org

\section{Transgender, Gender Variant and Intersex Justice Project is based in Oakland, CA} that works with incarcerated transgender people. Transgender people inside and outside prison organize to fight against imprisonment, police violence, racism, poverty, and societal pressures. www.tgijp.org 
Appendix F: Targets of the Mainstream Gay Rights Movement

\begin{tabular}{|c|c|c|}
\hline \multicolumn{3}{|c|}{$\begin{array}{l}\text { MAINSTREAM GAY RIGHTS MOVEMENT } \\
\text { Analyzed Using Framework Developed by Gamson (1990) } \\
\text { for "Identifying Challenging Groups" }\end{array}$} \\
\hline $\begin{array}{c}\text { TARGET } \\
\text { CONCEPT }\end{array}$ & TARGETS & SOURCES \\
\hline \multirow[t]{2}{*}{$\begin{array}{l}\text { Target of } \\
\text { Influence }\end{array}$} & $\begin{array}{l}\text { Elected officials (via lobbying) } \\
\text { (Those that are well positioned } \\
\text { to affect policies relevant to } \\
\text { their limited agenda of single- } \\
\text { issue campaigns on Marriage, } \\
\text { Military, Anti-Discrimination } \\
\text { Laws, Hate Crime Legislation, } \\
\text { Youth/Education) }\end{array}$ & $\begin{array}{l}\text { Bowen, 2012; Cohen, 1999; } \\
\text { D’Emilio, 2000; Farrow, 2012; } \\
\text { Funders for LGBTQ Issues, 2012; } \\
\text { Gamson, 2001; Jones-Yelvington, } \\
\text { 2008b; McMichael \& Wallace, } \\
\text { 1999; Movement Advancement } \\
\text { Project, 2007; Movement } \\
\text { Advancement Project, 2012; Mahfuz } \\
\text { \& Farrow, 2012; Shepard, 2001; } \\
\text { Southerners On New Ground, 2012; } \\
\text { Vaid, 2012; Walsh, 1998. }\end{array}$ \\
\hline & $\begin{array}{l}\text { The Judicial System (via } \\
\text { litigation) } \\
\text { (Those that are well positioned } \\
\text { to affect policies relevant to } \\
\text { their limited agenda of single- } \\
\text { issue campaigns on Marriage, } \\
\text { Military, Anti-Discrimination } \\
\text { Laws, Hate Crime Legislation, } \\
\text { Youth/Education) }\end{array}$ & $\begin{array}{l}\text { Bowen, 2012; Carpenter, 2014; } \\
\text { Cohen, 1999; Farrow, 2012; Funders } \\
\text { for LGBTQ Issues, 2012; Jones- } \\
\text { Yelvington, 2008b; McMichael \& } \\
\text { Wallace, 1999; Movement } \\
\text { Advancement Project, 2007; Mahfuz } \\
\text { \& Farrow, 2012; Rosenblum, 1994; } \\
\text { Shepard, 2001; Southerners On New } \\
\text { Ground, 2012; Vaid, } 2012\end{array}$ \\
\hline \multirow[t]{2}{*}{$\begin{array}{l}\text { Target of } \\
\text { Mobilization }\end{array}$} & $\begin{array}{l}\text { Leadership: Almost entirely } \\
\text { White, majority male, mostly } \\
\text { professional class. }\end{array}$ & $\begin{array}{l}\text { Boykin, 2000; Carter, 1999; } \\
\text { D’Emilio, 2000; Vaid, } 2012 .\end{array}$ \\
\hline & $\begin{array}{l}\text { Constituency: All LGBT people, } \\
\text { but predominantly white and } \\
\text { middle-class gays and lesbians. }\end{array}$ & $\begin{array}{l}\text { Carter, 1999; Movement } \\
\text { Advancement Project, 2010; } \\
\text { TransGriot, 2007; Vaid, 1995; Vaid, } \\
2012 .\end{array}$ \\
\hline $\begin{array}{l}\text { Target of } \\
\text { Benefits }\end{array}$ & $\begin{array}{l}\text { Mostly White middle-class and } \\
\text { wealthy gay and lesbian } \\
\text { American citizens. }\end{array}$ & $\begin{array}{l}\text { Carter, 1999; Conrad, 2010; } \\
\text { Duggan, 2003; Hermosillo, 2013, } \\
\text { Hutchinson, 2001; Movement } \\
\text { Advancement Project, 2010; } \\
\text { TransGriot, 2007; Vaid, 2012. }\end{array}$ \\
\hline
\end{tabular}




\section{Appendix G: Categorization Matrix}

Q1 - What does analyzing these organizations through social movement theories reveal about the
claim held by many that these organizations are the left wing of the GR Movement?

Q2- What does analyzing these organizations through social movement theories reveal about their relationship to one another?

\begin{tabular}{|c|c|c|c|c|}
\hline $\begin{array}{l}\text { Collective } \\
\text { Action }\end{array}$ & $\begin{array}{c}\text { Structure } \\
\text { and Organization }\end{array}$ & $\begin{array}{l}\text { Common Purposes } \\
\text { / Collective Identity }\end{array}$ & Coalitions & $\begin{array}{c}\text { Unaffili } \\
\text { ated }\end{array}$ \\
\hline $\begin{array}{l}\text { Quotes that } \\
\text { addressed } \\
\text { collective } \\
\text { action } \\
\text { organized by } \\
\text { the groups. }\end{array}$ & $\begin{array}{l}\text { Quotes that addressed } \\
\text { deliberately planned } \\
\text { and structured } \\
\text { activities. }\end{array}$ & $\begin{array}{l}\text { Quotes that } \\
\text { addressed their } \\
\text { values, goals, } \\
\text { grievances, or } \\
\text { identities. }\end{array}$ & $\begin{array}{l}\text { Quotes addressing the } \\
\text { coalitions each group is } \\
\text { in, or why they do } \\
\text { coalition work. }\end{array}$ & $\begin{array}{c}\text { Quotes } \\
\text { that } \\
\text { indicate } \\
\mathrm{d} \text { if the } \\
\text { organiz } \\
\text { ations } \\
\text { primaril } \\
\mathrm{y} \\
\text { worked } \\
\text { alone. }\end{array}$ \\
\hline
\end{tabular}

Q3 - What does a social movement analysis reveal about these organizations, collectively and individually?

\begin{tabular}{|c|c|c|c|c|c|}
\hline Disruption & Framing & Identity & Politics & Resources & $\begin{array}{l}\text { Recognition / } \\
\text { Redistribution }\end{array}$ \\
\hline $\begin{array}{c}\text { Quotes } \\
\text { related to } \\
\text { disruptive } \\
\text { power theory } \\
\text { by Piven \& } \\
\text { Cloward } \\
\text { (1979). }\end{array}$ & $\begin{array}{c}\text { Quotes } \\
\text { related to } \\
\text { Framing } \\
\text { theory } \\
\text { (Benford \& } \\
\text { Snow, 2000). }\end{array}$ & $\begin{array}{c}\text { Quotes } \\
\text { related to } \\
\text { Collective } \\
\text { Identity } \\
\text { (Goodwin \& } \\
\text { Jasper, 2009) } \\
\text { or Interest } \\
\text { Group } \\
\text { (Armstrong, } \\
\text { 2002). } \\
\end{array}$ & $\begin{array}{c}\text { Quotes } \\
\text { related to } \\
\text { Political } \\
\text { Process } \\
\text { theory } \\
\text { (McAdam, } \\
\text { Tarrow \& } \\
\text { Tilly, 2001). }\end{array}$ & $\begin{array}{c}\text { Quotes } \\
\text { related to } \\
\text { Resource } \\
\text { Mobilization } \\
\text { theory } \\
\text { (McCarthy \& } \\
\text { Zald, 1977). }\end{array}$ & $\begin{array}{l}\text { Quotes related } \\
\text { to the question } \\
\text { of whether this } \\
\text { social } \\
\text { movement is } \\
\text { focused on } \\
\text { recognition or } \\
\text { on } \\
\text { redistribution or } \\
\text { both. }\end{array}$ \\
\hline
\end{tabular}




\section{Appendix H: Interview Questions}

1. Please describe the work your organization does.

1a. What community(ies) does your organization represent, and who benefits from your work?

1b. What issue(s) does it work on, and what methods (programs, activities, etc.) does it use to work on them?

1c. Who, if anyone, is your organization trying to influence?

1d. Does your organization interact with any authorities or powerful entities (elected officials, government agencies, philanthropy, media, religion, criminal justice, etc.)? What is the nature of those interactions?

2. How does the organization run?

2a. What are the key staff/volunteer positions that currently exist?

2b. How are decisions made?

3. Please tell me about your organization's values and vision

3a. What prompted the creation of your organization?

$3 \mathrm{~b}$. What are the core values that drive your organization's work?

$3 \mathrm{c}$. Why does your organization do the work it does?

4. Please tell me about your organization's relationships to other organizations?

4a. Are there some organizations that your organization works closely with? If so, what are they?

4b. If yes: Why do you work closely with those groups, rather than other groups?

4c. What coalitions, if any, do you participate in? For how long have you been participating in it/them?

5. Please explain how your organization is similar to and/or different from the national LGBT organizations or the statewide equality organizations.

5a. Do you believe your organization shares the same goals as they have? How so, or how not so?

5b. Do you believe your organization engages in the same strategies as they do? How so, or how not so?

5c. Do you believe these organizations support your organization? How do, or don't, they?

6. Please talk to me about your organization's involvement in social movements.

6a. Does your organization engage in movement building, however you define that term? If so, how?

$6 \mathrm{~b}$. If so, who are you trying to mobilize?

6c. What movement, specifically, are you building people to be a part of?

$6 \mathrm{~d}$. Do you believe your organization is part of the same social movement as the largest national LGBT organizations or statewide equality organizations? Why or why not? 
6e. In addition, or instead, of belonging to that movement, do you think that your organization and the organizations with whom you work closely are a part of a different social movement? Please explain. 